\section{Pacific Northwest}

National Laboratory

Operated by Battelle for the

U.S. Department of Energy

\title{
Results of Performance Evaluation Testing of Electrical Leak-Detection Methods at the Hanford Site Mock Tank - FY 2002-2003
}
D. B. Barnett
G. W. Gee
W. D. Daily
M. D. Sweeney
J. B. Fink
M. D. Johnson
A. Ramirez
V. F. Medina
M. T. Levitt
D. P. Mendoza
A. Binley
B. G. Fritz
F. Khan
C. A. Baldyga

February 2003

Prepared for the U.S. Department of Energy under Contract DE-AC06-76RL01830 


\title{
DISCLAIMER
}

This report was prepared as an account of work sponsored by an agency of the United States Government. Reference herein to any specific commercial product, process, or service by trade name, trademark, manufacturer, or otherwise does not necessarily constitute or imply its endorsement, recommendation, or favoring by the United States Government or any agency thereof, or Battelle Memorial Institute. The views and opinions of authors expressed herein do not necessarily state or reflect those of the United States Government or any agency thereof.

\author{
PACIFIC NORTHWEST NATIONAL LABORATORY \\ operated by \\ BATTELLE \\ for the \\ UNITED STATES DEPARTMENT OF ENERGY \\ under Contract DE-AC06-76RL01830
}

This document was printed on recycled paper. 


\section{Results of Performance Evaluation Testing of Electrical Leak-Detection Methods at the Hanford Site Mock Tank - FY 2002-2003}
D. B. Barnett
W. D. Daily
G. W. Gee
J. B. Fink
M. D. Sweeney
A. Ramirez
M. D. Johnson
M. T. Levitt
V. F. Medina
A. Binley
D. P. Mendoza
C. A. Baldyga
B. G. Fritz
F. Khan

February 2003

Prepared for the U.S. Department of Energy

under Contract DE-AC06-76RL01830

Pacific Northwest National Laboratory

Richland, Washington 99352 


\section{Summary}

Pacific Northwest National Laboratory (PNNL) evaluated electrical geophysical methods for tankleak-detection performance parameters during a 110-day blind test staged at the Hanford Mock Tank Site in 2002. Thirteen releases of sodium thiosulfate solution (waste simulant) totaling $~ 53,000 \mathrm{~L}$ ( 14,000 gal) were injected into the soil beneath the Mock Tank to simulate a single-shell tank leak. The Performance Evaluation (PE) test was designed to determine the minimum leak volume that would trigger a detection response by the geophysical methods and how accurately the methods quantify the leak volumes, both with respect to background signal levels and signal levels from later periods, after leaking began (i.e., determining change in sensitivity of methods over time).

Extensive preparatory work to ready the Mock Tank for the PE test included installation of line electrical service, a limited access internet connection to the site to allow remote operation of the test, design and manufacture of a new data-collection system using beta-version software, and various structural modifications to the Mock Tank and electrode arrays. Irrigation water was periodically applied to the soil surface 5-m (16.4-ft) in a circular band from the outer edge of the Mock Tank to simulate the impact of "noise" from precipitation and flood (water-line leak) events on the electrical methods tested in FY 2002.

The methods evaluated during the PE test included Electrical Resistivity Tomography (ERT) with variations of the method termed the Point-Electrode Technique (PET) and the Long-Electrode Technique (LET). PET used eight vertical arrays of electrodes to perform tomographic (three-dimensional) inversion analysis of both the volume of a leak and its approximate location. LET used eight "fused" vertical arrays, simulating steel casings, to provide a two-dimensional tomograph of the leak. Data from both techniques were used to devise a statistical tool to provide a leak-no leak determination.

The second method, the High-Resolution-Resistivity Steel Casing Resistivity Technique (HRRSCRT), employed four variations of the technique to determine the most effective configurations of the measurement system. These sub-techniques involved different combinations of electrodes, including direct connection to the leaking solution (excitation of mass) to dynamically detect changes in the grounding characteristics of the tank due the presence or absence of leaking solution.

Results for the ERT-LET were mixed. This technique detected the onset of 12 leak periods; 10 leaks were detected on the same day as injection began; one leak was detected on the second day of injection, and one on the third day. Leaks were not detected continuously after commencement of each injection; however, this method accurately assigned a leak/no-leak condition in 65 of the 110 test days. This is believed to result from the establishment of a steady-state flow channel that produced no discernable resistivity changes until the steady-state condition was altered. While ERT-LET detection systems erred on 45 days, only one case was a false positive (leak condition declared when solution injection was not occurring). At its worst, the ERT-LET method was able to correctly differentiate between a leak-no leak situation nearly 93 percent of the time, compared to random estimates of 50 percent.. The ERT-LET method did not report volumes during the test. The ERT-PET method overestimated the actual volumes by more than a factor of two; however, calibration after the blind test tended to improve the volume estimates for ERT. 
Leak-detection results for the HRR-SCRT provided reasonable volume estimates (within 30 percent) of the solution injected into the subsurface as well as relatively accurate leak rates in realtime. Timeseries analysis of the normalized potential indicated that 9 of the 13 leak periods were clearly detectable with HRR-SCRT. The remaining 4 campaigns were not detected because of either major electrical interference during the disconnection of the sheet-piling or because the critical measuring electrode was not deployed; hence, these four campaigns were considered out of specifications for the HRR-SCRT method. Daily reports using moving and fixed-time window comparisons established for this PE test were found to yield an inferior analysis to the more realistic time-series analysis that considered periods longer than 1 day as was used during the 2001 study.

The success of the tests for both ERT-LET and HRR-SCRT methods depended on the exceptional performance of the geophysical monitoring equipment and the data-acquisition system. This system proved to be highly reliable. Out of 110 days, there were only four days of lost data (due to battery or electrical component failure). With the unique data-acquisition system, as designed and implemented by the research team, it was possible to monitor signal voltages, automatically connect electrodes, and make thousands of resistivity measurements in the course of a single day, all without the investigators being on site. Most of the monitoring during the 110-day testing period was conducted remotely from offices in Tucson, Arizona (HGI) and Livermore, Calif ornia (LLNL). PNNL support teams were available for onsite servicing and repairs when required. Reports were submitted on nearly a daily basis over the course of the testing. The results suggest that electrical methods have significant advantage (one to two orders of magnitude) over baseline monitoring methods for ex-tank leak detection, such as neutron or gamma logging. This is true not only because of increased sensitivity of electrical methods over baseline methods but because of continuity of measurements (data acquisition can be virtually continuous) as well as reduced operational costs (i.e., minimal manpower needs) and increased site safety. 


\section{Glossary}

\begin{tabular}{|c|c|}
\hline ADSL & Asynchronous Digital Signal Line \\
\hline AGI & Advanced Geosciences Inc. \\
\hline CAT & Category \\
\hline CDROM & Compact Disk Read Only Memory \\
\hline CH2M HILL & CH2M HILL Hanford Group \\
\hline DOE & U.S. Department of Energy \\
\hline ERT & Electrical Resistivity Tomography \\
\hline ERT-LET & Electrical Resistivity Tomography-Long Electrode Technique \\
\hline ERT-PET & Electrical Resistivity Tomography-Point Electrode Technique \\
\hline gph & Gallons per Hour \\
\hline GDP & Geophysical Data Processor \\
\hline HGI & HydroGEOPHYSICS, Inc. \\
\hline HLAN & Hanford Local Area Network \\
\hline HMS & Hanford Meteorological Station \\
\hline HRR-SCRT & High-Resolution-Resistivity Steel Casing Resistivity Technique \\
\hline IAEA & International Atomic Energy Agency \\
\hline ISDN & Integrated Services Digital Network \\
\hline LAN & Local Area Network \\
\hline LDMM & Leak Detection, Monitoring, and Mitigation \\
\hline LET & Long-Electrode Technique \\
\hline LLNL & Lawrence Livermore National Laboratory \\
\hline MS & Microsoft \\
\hline PE & Performance Evaluation \\
\hline PET & Point-Electrode Technique \\
\hline PID & Proportional IntegrałDifferential \\
\hline PNNL & Pacific Northwest National Laboratory \\
\hline PVC & polyvinyl chloride \\
\hline RCRA & Resource Conservation and Recovery Act \\
\hline SAFE & Subsurface AirFlow Extraction \\
\hline SST & Single-Shell Tank \\
\hline
\end{tabular}





\section{Acknowledgements}

The authors deeply appreciate all those who contributed to the extensive work of assembling the pieces of the project puzzle behind the scenes. Without their dedication, the critical schedule that the project demanded would not have been met.

Mike Bruun, PNNL, Chis Carlson and Bert Winschell, Fluor Hanford, and Ray Merriman, CH2M HILL Hanford Group (CH2M HILL), all did an outstanding job of ensuring that the installation of electrical service was timely. Marty Gardner, Bruce Markes, Scott Worley, Mike Dorsey, and Rory Steffler of Duratek Federal Services, provided their usual efficient services of drilling, well installation, and GPS surveys. Tom Mitchell and Kevin Bergstrom, CH2M HILL, performed the essential groundpenetrating radar survey and interpretations. Shirrell Brown, Dave Havens, and Terry Wentz of Lockheed Martin Services (LMSI) were responsible for installing the HLAN drop, which allowed remote access to the test. Construction of the steel wall was installed expeditiously under the direction of John Wright, Paul Dotson, and Joel Rivers, Fluor Federal Services. Skip Snyder and all those at Zonge Engineering made a fabulous contribution to the project by timely manufacture and delivery of a hybrid instrument assembly and software.

Fenton Khan, Chris Strickland, John Goreham, and Jason Keller, Pacific Northwest National Laboratory (PNNL), provided monitoring and data analysis for the neutron probe logging. Ray Clayton provided the irrigation system design and instrumentation. Donny Mendoza, Brad Fritz, Victor Medina, Bill Buchmiller, Walt Parks, Don Hartshorn, Kevin Heaton, Gary McAtee, William Robb, Karen WatersHusted, and TR Hensyel all provided exemplary field and laboratory support.

Many thanks are due Liz Rainey, Pat Wright, Sam Juracich, Ellen Prendergast, Mike Sackchewsky and Mike Stephenson, PNNL, for quick response in regulatory and safety planning for the project. Wayne Cosby, Lila Andor, and Rose Urbina, PNNL, provided technical review and text processing services. Wanda McCollom, Donna Feaster, and Rex Smyser, PNNL, provided much needed support for equipment and product deliveries and arranging for badges for site visitors. Excellent graphics work was supplied by Kathy Kachele, LMSI, and Dave Lanigan and Chris Newbill, PNNL. Jaralyn Carroll provided web and internet services. We thank Bruce Williams and Wayne Martin for review of the document.

Aleta Busselman, PNNL, did an outstanding job of tracking the complex costs, schedule, and deliverables for the project. We would have been lost without her. We also thank Julie Hughes, Lilly Burns, Janie Vickerman, Jean Brock, and Dianna Hannigan, PNNL, for careful and very timely attention to subcontracting issues.

The project benefited greatly from the sagely advice and program guidance of Joe Brothers, PNNL.

Thanks are extended to Mike Boger, Dan Baide, Jerry Cammann, and Warren Thompson, CH2M HILL, Fred Reich, Cogema, and Pete Gibbons and Paul Deichelbohrer, Numatec, for their guidance and support. We thank Wes Bratton, Joe Maresca, and Willie Dickerson, of Vista Engineering Technologies, for their partnership in this project. 
Finally, we thank the experts whose world-class knowledge is at the core of this project. Drs. Bill Daily and Abe Ramirez, Lawrence Livermore National Laboratory and Dr. Andrew Binley, Lancaster University, United Kingdom, and all their staff were responsible for the deployment of the Electrical Resistivity Tomography techniques. Dr. Jim Fink, Marc Levitt, and Chris Baldyga,

hydroGEOPHYISICS, Inc., designed and deployed the High Resolution Resistivity-Steel Casing Resistivity Technique methods. Both teams worked together to develop an effective hybrid datacollection system in time for the project. 


\section{Contents}

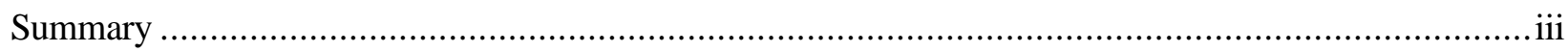

Glossary

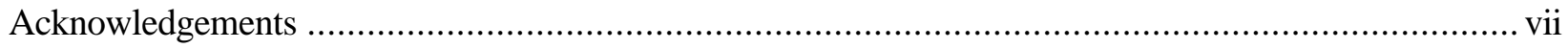

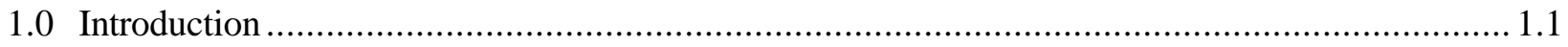

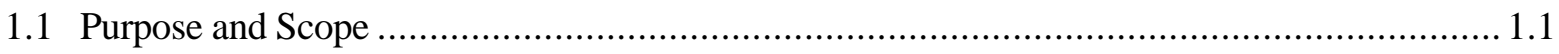

1.2 Problem Statement and Specific Objectives of the Test..................................................... 1.3

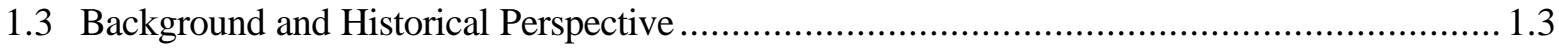

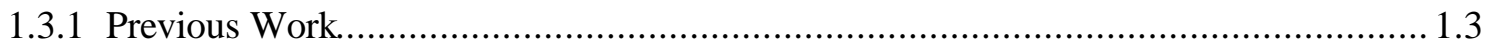

1.3.2 Related Documents...................................................................................... 1.4

1.3.3 Site Selection for FY 2002-2003 PE Testing ........................................................ 1.4

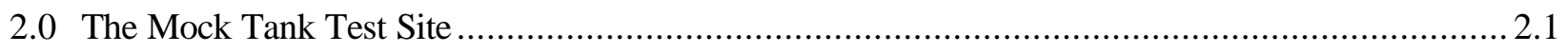

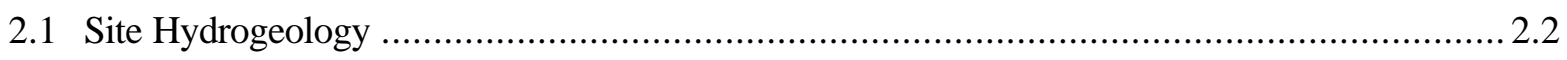

2.1.1 Comparison of the Mock Tank Site to 200-West Area Tank Farms ........................... 2.3

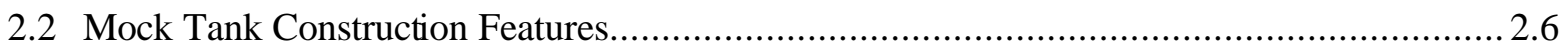

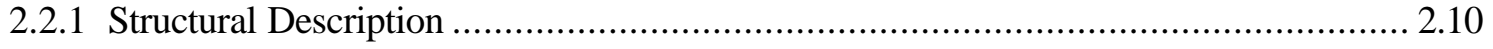

2.2.2 Electrical Service.......................................................................................... 2.10

2.2.3 Steel Wall 2.10

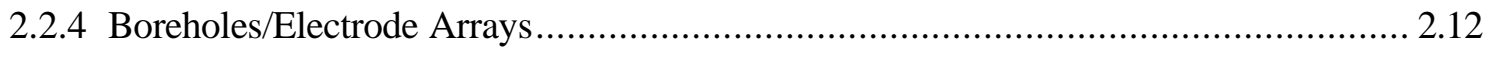

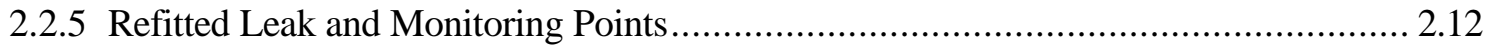

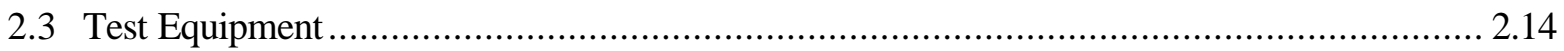

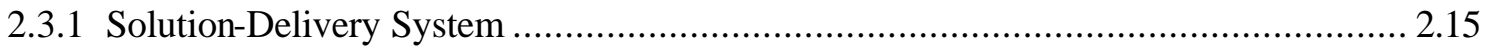

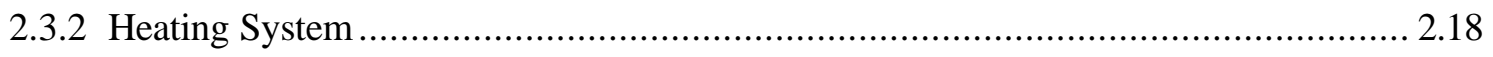

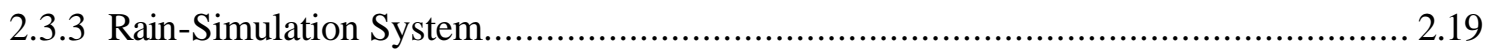

2.3.4 Solution-System and Site Data-Monitoring Equipment........................................ 2.21

2.3.5 Geophysical Data-Collection Systems ……………….......................................... 2.22

3.0 Summary of FY 2002-2003 PE Tests................................................................................. 3.1

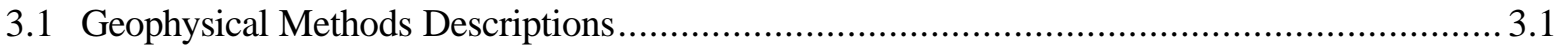

3.1.1 Electrical Resistance Tomography ………………............................................... 3.1

3.1.2 ERT Point-Electrode Tomography ………............................................................. 3.1

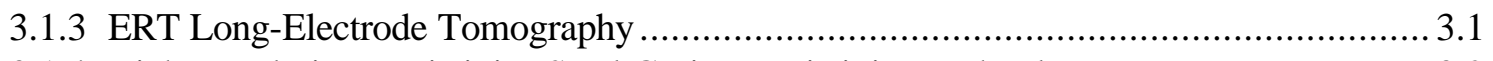

3.1.4 High-Resolution Resistivity-Steel Casing Resistivity Technology …........................... 3.2

3.2 Schedule and Implementation Plan.............................................................................. 3.2 


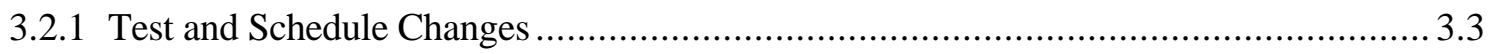

3.3 Scheduled Events and Data Acquisition .............................................................. 3.3

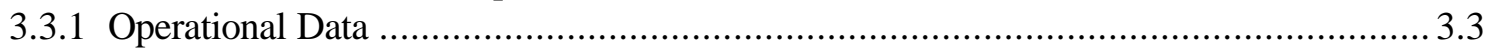

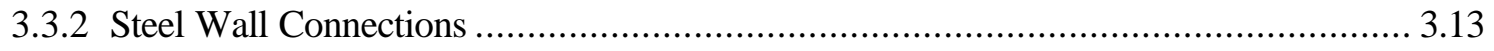

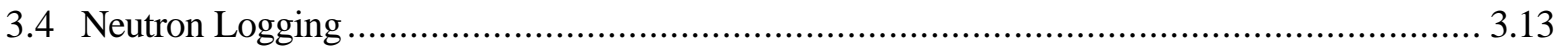

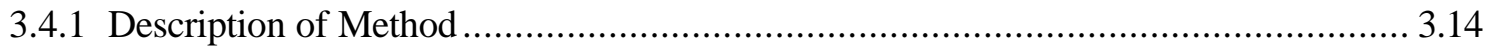

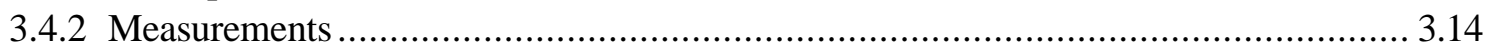

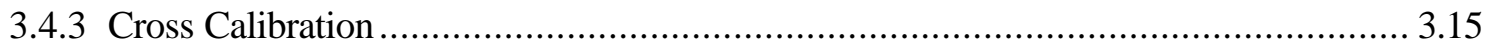

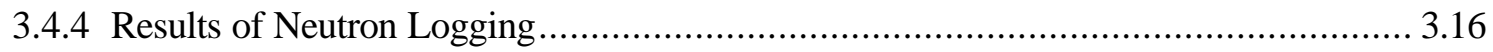

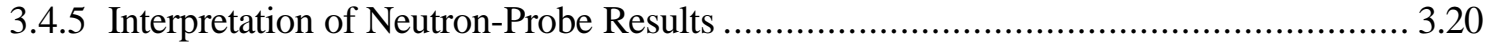

3.4.6 Results of Neutron Logging Inside the Mock Tank ......................................... 3.21

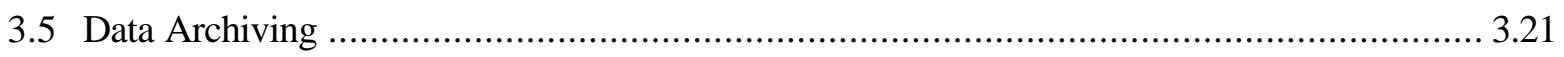

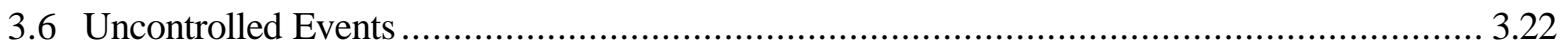

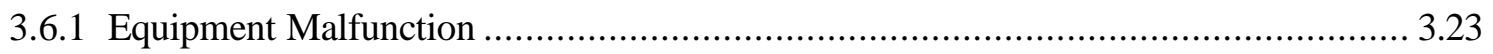

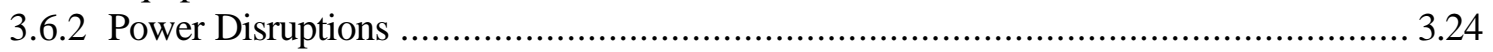

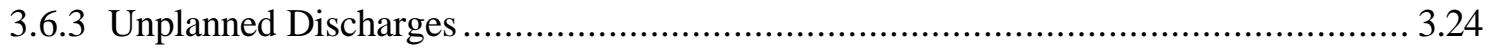

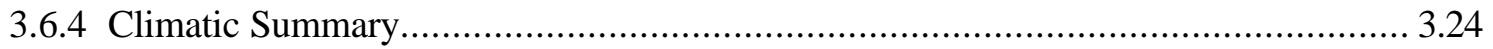

4.0 Summary of Results of Electrical Methods Leak Detection .................................................. 4.1

4.1 FY 2002 PE Data and Test Results ..................................................................... 4.1

4.1.1 Comparison of Actual Versus Detected Releases ........................................... 4.1

4.1.2 Comparison of Actual Versus Estimated Release Volumes...................................... 4.2

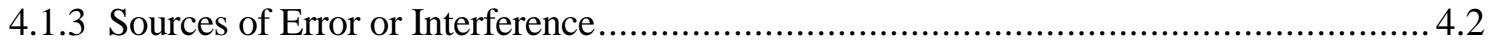

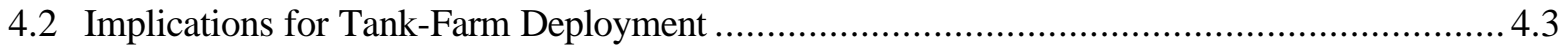

4.2.1 Flammable Gas and Electrical Connections ...................................................... 4.4

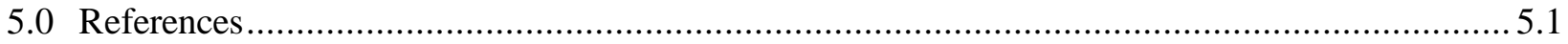




\section{Figures}

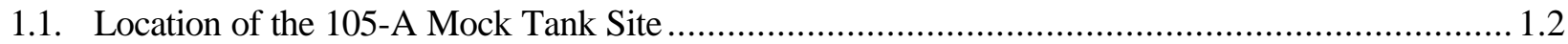

2.1. Oblique Aerial View of the Mock Tank Site from the Southeast.......................................... 2.1

2.2. Layout of the Mock Tank Site for the FY 2002-2003 PE Test ............................................2.2

2.3. Generalized Stratigraphic Cross Section of the Hanford 200-East Area................................. 2.4

2.4. Generalized Stratigraphic Cross Section of the Hanford 200-West Area Showing Locations of Tank Farms (after Williams et al. 2002) ....................................................... 2.5

2.5. View Looking West at the Mock Tank Just Prior to Test Start.............................................. 2.7

2.6. View Southwest of Mock Tank Site Showing the Solution Tank, Pump/Controller Housing, and Field Office at Left...................................................................................... 2.7

2.7. Schematic Cross Section of a Portion of the Mock Tank Structure......................................... 2.8

2.8. Installation of the Steel Sheet Wall at the Mock Tank .......................................................... 2.9

2.9. The Pole Installed at the 105-A Site, with the Three 13.8-kV Primaries Feeding Three 480-V Stepdown Transformers; the Integrated Services Digital Network (ISDN) Telephone Line Can Be Seen Beneath the Electrical Lines.............................................. 2.11

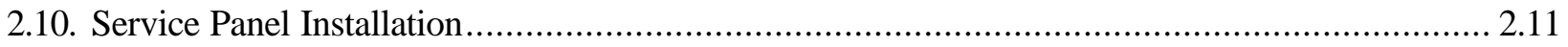

2.11. One of Four Steel Casings Used as Long Electrodes During the FY 2002-2003 Testing at the Mock Tank (center).

2.12. Locations of Permanent Electrodes and Interior Leak/Monitoring Ports at the Mock Tank 2.14

2.13. Solution Delivery System Components as Installed in the Housing Next to the Storage Tank.... 2.16

2.14. The Initial Solution Delivery System Used During the FY 2002-2003 PE Testing .................. 2.17

2.15. The Second-Generation Solution Delivery System …............................................... 2.17

2.16. The Solution-Delivery Line Leading from the Pump/Metering Housing to the Manifold Inside the Mock Tank

2.17. Sodium Thiosulfate Solution Storage Tank After Installation of Insulation Blanket

2.18. Layout of the Rain-Simulation System. The 9463 L (2500-gal) Tanks used for storing raw water are out of view to the right.

2.19. Pump and Controller Configuration for the Rain-Simulation System 2.20 
2.20. LabView Screen (during Metering Pump System Control Period

2.21. Interior of the Mock Tank Field Office Showing Instrumentation and Communication Systems . 2.24

3.1. Cumulative Volume Vs. Time: Target Volume vs. Actual............................................... 3.6

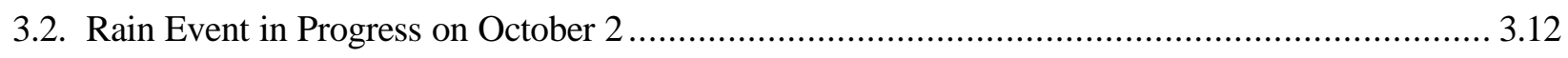

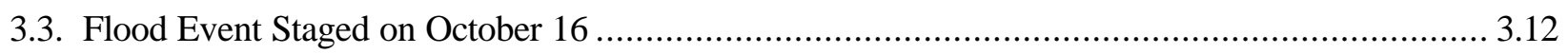

3.4. Plan View of the Mock Tank Monitoring-Well Layout Showing External Monitoring Points ..... 3.15

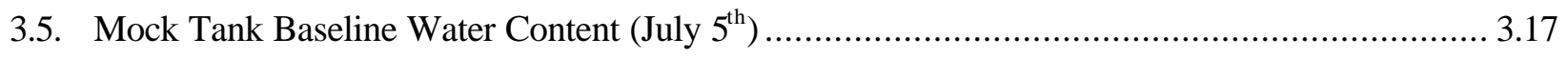

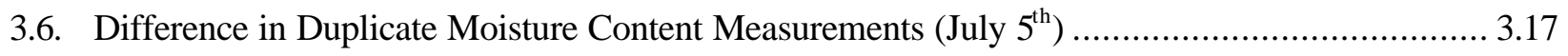

3.7. August $30^{\text {th }}$ Measured Moisture Content .................................................................. 3.18

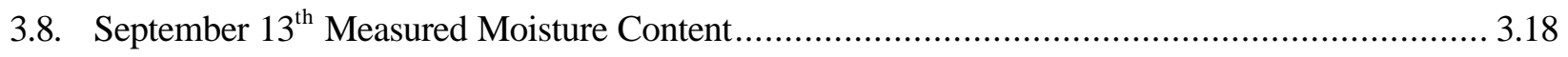

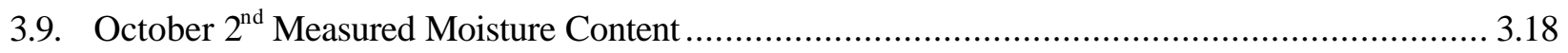

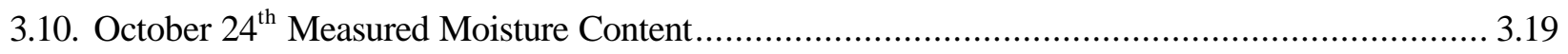

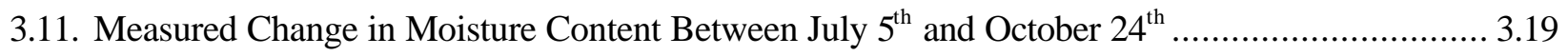

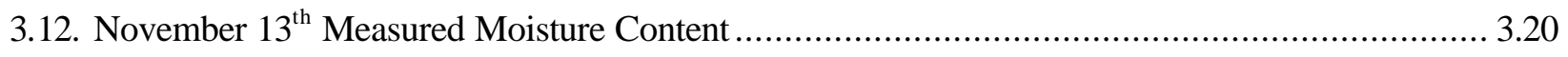

3.13. Measured Change in Moisture Content Between July $5^{\text {th }}$ and November $13^{\text {th }} \ldots \ldots \ldots \ldots \ldots \ldots \ldots \ldots . . . . . . . . .20$ 


\section{Tables}

2.1. Details of Electrical Service Installed at the Mock Tank .................................................... 2.10

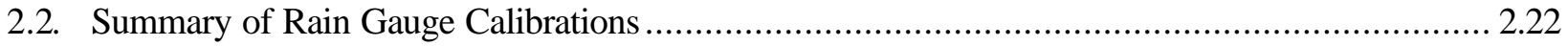

3.1. Summary of Flow Events and Their Basis of Flow Calibration and Calculation. $\mathrm{x}=$ meter

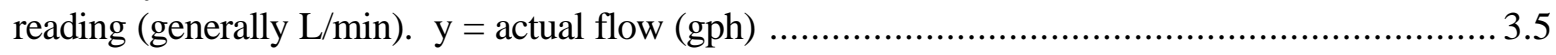

3.2. Summary of Flow Events: Goals vs. Flow Calculations ............................................... 3.6

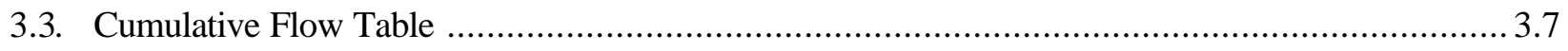

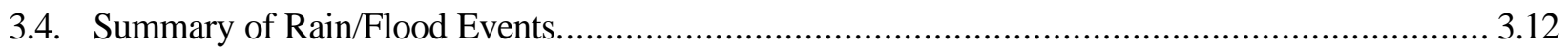

3.5. Neutron Probe Loggings Performed for the 2002 PE Test at the Mock Tank Site.................... 3.15

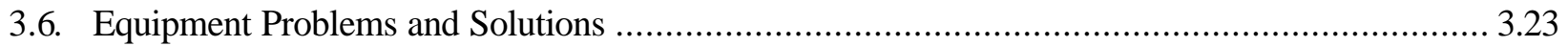

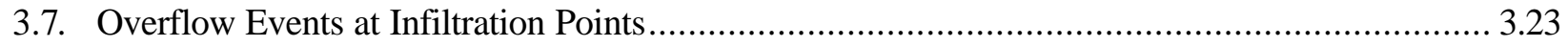

3.8. Synopsis of Climatic Parameters During the FY 2002-2003 PE Test..................................... 3.25

3.9. Natural Precipitation Events Recorded by the Rain Gauges............................................. 3.26 


\subsection{Introduction}

The Hanford Site in southeastern Washington State has 177 buried waste storage tanks with nearly 210M L (55M gal) of highly radioactive legacy waste from the Cold War years. Some 67 of these Single Shell Tanks (SSTs) are known or suspected as having leaked, possibly releasing an estimated 4M L (1M gal) of toxic fluids into the vadose zone (Gephart and Lundgren 1998). In addition, other less toxic waste fluids, in excess of 4 billion L (1 billion gal), have been discharged to ground at Hanford.

The M-45 series of milestones under the Hanford Federal Facility Agreement and Consent Order (Tri-Party Agreement; Ecology et al. 1998) requires the removal of wastes from SSTs and other miscellaneous underground tanks for storage in the double-shell tank system. Under the Tri-Party Agreement, CH2M HILL Hanford Group, Inc (CH2M HILL) is demonstrating several retrieval methods to dis lodge, mobilize, and remove the wastes. As additional assurance of protection of the vadose zone beneath the SSTs, tank wastes and tank conditions may be monitored during retrieval operations. Hence, significant effort is aimed at detecting, monitoring, and devising mitigation techniques for tank leakage. In addressing this effort, $\mathrm{CH} 2 \mathrm{M}$ HILL and their subcontractors have been evaluating a variety of potential in-tank and ex-tank (measurements conducted from outside a tank) technologies to support the development of a Leak Detection, Monitoring, and Mitigation (LDMM) system for use during wasteretrieval operations.

During FY 2001, six leak-detection methods (five geophysical and one geochemical) were tested at the Mock Tank for overall applicability and effectiveness. Of these, two primary methods were selected for further evaluation during an appraisal/elimination process completed in January 2002.

From mid July through early November 2002, Pacific Northwest National Laboratory (PNNL) and CH2M HILL and subcontractors evaluated performance parameters for two electrical geophysical methods for leak detection beneath buried tanks. The 109-day blind test involved a series of leaksimulant injections into the subsurface and continuous subsurface monitoring over the test period by electrical resistivity methods. This test is a follow-up to a broader evaluation of several geophysical methods conducted in FY 2001 (Barnett et al. 2002). As with the precursory tests conducted in FY 2001, the FY 2002-2003 Performance Evaluation (PE) test was conducted at the Hanford Site 105-A Mock Tank Facility (Figure 1.1).

\subsection{Purpose and Scope}

This document describes the preparation for and results of the PE testing conducted from July to November 2002. Also provided are summary results of each method (Electrical Resistivity Tomography [ERT] and the High-Resolution-Resistivity Steel Casing Resistivity Technique [HRR-SCRT]). Brief discussion is provided for comparison of the Mock Tank results and expectations for application in an SST tank-farm environment. Appendices to the document include the Test Implementation Plan for conducting the testing, which includes changes made during the course of the test. Other appendices are attached to document various activities and collected data and include the final technical reports from the principal investigators. 


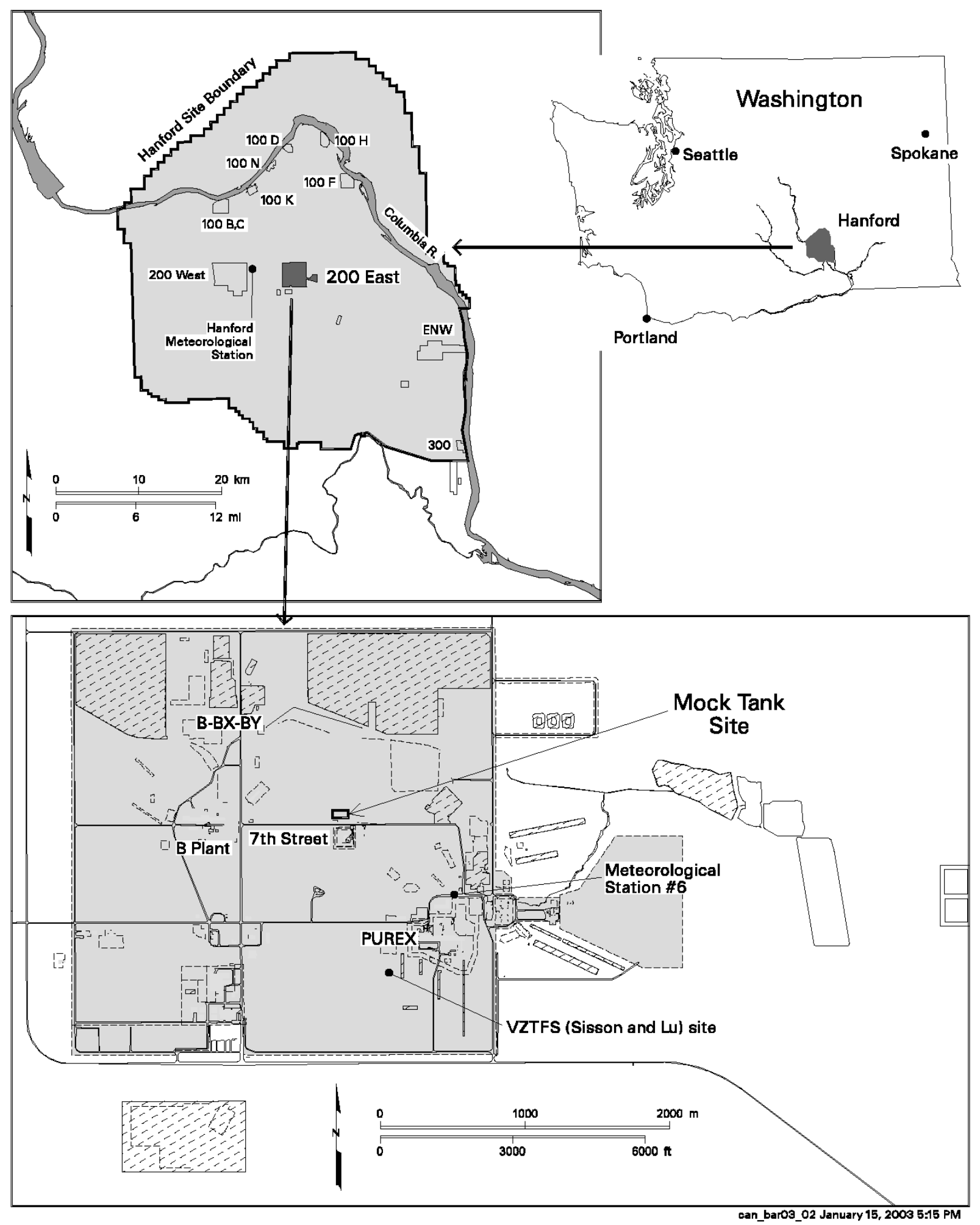

Figure 1.1. Location of the 105-A Mock Tank Site 
Principal investigators of the methods selected for the FY 2002-2003 evaluation were Lawrence Livermore National Laboratory (LLNL) using ERT and HydroGEOPHYSICS, Inc. (HGI) using HRRSCRT.

\subsection{Problem Statement and Specific Objectives of the Test}

In the event of leakage, hazardous and radioactive waste from Hanford Site SSTs entering the vadose zone may have access to pathways to groundwater that could lead to adverse effects upon human health and the environment. A program of detecting leaks and quantifying lost waste during SST retrieval operations is currently assumed to be an essential component of waste retrieval. Historically, monitoring for leakage has consisted of internal (inside the tank) and external methods (Boger 2002). The LDMM portion of the retrieval program has recognized that baseline technologies for external leak detection and monitoring (such as spectral-gamma logging of dry wells around the SSTs) lack resolution. Hence, several geophysical methods have been investigated for acceptable leak-detection capabilities. As a result of these investigations, two electrical-resistance methods of external leak detection, ERT and HRRSCRT, were selected for closer scrutiny. The specific objectives of the FY 2002-2003 PE Test were aimed at answering these questions:

- What is the minimum detectable volume of a leak?

- How accurate are volume or leak-rate estimations?

- What ranges of probabilities of detection and of false alarm can be expected?

- Can a leak be reported within a reasonable time frame?

- What is the effect of previous leakage in the soil on method sensitivity?

- Can the system(s) be deployed in an SST environment with minimal disturbance?

- What are the safety issues with deployment?

- Are the costs of deployment reasonable?

This report addresses most of these questions or provides a basis for further evaluation. Some analyses, such as statistical treatment of the data, are reserved for subsequent documents.

\subsection{Background and Historical Perspective}

\subsubsection{Previous Work}

The applications of electrical-resistivity geophysical methods at the Hanford Site belong to essentially two eras. During the mid-to-late 1970s, Boeing, Inc. and PNNL both deployed electricalresistivity systems in a tank farm and at other experimental sites. For undetermined reasons, this technology was not exploited (possibly because retrieval operations remained in a planning stage for several years). Renewed interest in geophysical leak-detection resulted in a series of ERT tests at the Mock Tank Site from 1994 to 1996. The Mock Tank Site has also been used to demonstrate other promising technologies for leak detection, such as cone-penetrometer deployment of electrode arrays and angle-hole drilling. Appendix A (p. A.7 to A.14) summarizes historical work at the site. 


\subsubsection{Related Documents}

Leading up to the FY 2002-2003 PE tests, several planning documents and reports were the basis for the testing parameters. These include the LDMM Ex-Tank Leak Detection Performance Evaluation Test Implementation Plan-FY 2002-2003 (Barnett et al. 2002, See Appendix A), Ex-Tank LDMM Performance Evaluation Test Specification (Bratton et al. 2002), and Test Plan for the Demonstration of Geophysical Techniques for Single-Shell Tank Leak Detection at the Hanford Mock Tank Site-Fiscal Year 2001 (Barnett et al. 2001). The Ex-Tank LDMM Technology Assessment and Down Selection Report (Bratton 2002) describes the process of elimination whereby the methods were chosen for FY 2002-2003 PE testing. A broad overview of the LDMM strategy and road map to deployment of the methods is described in Ex-Tank LDMM Performance Evaluation Strategy (Boger, 2002).

\subsubsection{Site Selection for FY 2002-2003 PE Testing}

Four alternative sites to the Mock Tank Site were considered during the initial selection process. The primary reason for considering alternate test locations was to identify a site with the most similarity with the Hanford SST tank-farm environment. Against this consideration, costs, schedule, accessibility, and logistics were compared for each candidate site. One offsite location (not on the Hanford Site) and three onsite potential testing areas were evaluated for the $2002 \mathrm{PE}$. The following synopses describe the main aspects of each and reasons for acceptance or rejection.

\subsubsection{California Site}

It was initially assumed that a specific California location had a buried structure that would simulate, to the best degree possible, the underground storage tanks in the Hanford tank farms. It was also assumed that the facility had adequate line power to support the deployment of the FY2002 geophysical technologies. The facility was deemed to be problematic, however, because of several considerations:

Permitting - The regulatory environment in California was unlikely to accommodate an expedited technology deployment that benefited Hanford testing. The regulators in Sacramento would have little or no vested interest in assuring that the technologies are deployed in the Hanford tank farms under the proposed schedule. In contrast, Washington State regulators have shown intense interest in these leakdetection methods and have historically made every effort to streamline the permitting process.

Client Access-One key success of the FY 2001 effort was the ability to provide access to the site for all concerned participants (CH2M HILL, Washington Department of Ecology, U.S. Department of Energy [DOE], PNNL, and contractors). A Hanford location provided the best venue for client-contractor interaction. It was also the best location for the stakeholders and regulators to view our progress.

Reestablish Infrastructure-The cost of drilling new wells alone would have made any relocation to California an expensive proposition. The question of whether these new wells could have been completed without continuous seals (an electricalinterference issue) was also unresolved, and it was difficult to assume that the regulatory environment would work to the advantage of the project (see above). If line power had not been available, the project would also have had to rely on mobile generators or have line power brought to the test site. Reliance on mobile generators might have involved additional regulatory burden as well (e.g., air-quality permitting). 
Schedule - The final schedule made it difficult to envision how construction activities, regulatory approval for various aspects of the testing, and mobilization could have been accomplished in the time frame allowed. Using the California site with additional scheduling difficulties would have also elevated travel time and manpower considerations.

Geology — The primary goal of the testing for FY 2001 was to simulate, as closely as possible, the environment inside Hanford tank farms. It was decided that a site in a dissimilar and uncharacterized geologic setting could not adequately reproduce the subsurface conditions of the Hanford Site. Climatic and hydrologic conditions also differ significantly.

\subsubsection{Rock Slinger Pit}

The Rock Slinger Pit is a structure in the 200 West Area that is located south of the U Plant. It is an unfinished facility constructed during the plutonium production era of Hanford's history. Again, several problems with construction at the Rock Slinger Pit were deemed too difficult to surmount in the time allowed.

Infrastructure-As with the California Site, new infrastructure would have to be constructed around the Rock Slinger structure. The site lacks established line power, the facility has little in common structurally with the underground tanks, and it carries an additional liability of excessive signal noise from rebar used in construction of the building foundation. The one positive attribute of the site was that it has a deep excavation on the north end that would have accommodated the construction of a two-thirds scale mock tank.

Regulatory-An established radio logical control area surrounds the upper portion of the facility. It is unknown what the source or extent of the radioactive contamination is, but it is unlikely that the site could be released for general use.

\subsubsection{Borrow Pit South of S Tank Farm}

The Borrow Pit on the south end of the S Tank Farm was also considered for the PE Test. It is nearest the tank farm where LDMM leak-detection methods are to be first deployed. The site was also removed from the list of candidate sites because of the following conditions:

Infrastructure-The site has been extensively excavated over a wide area encompassing the entire south fence line of the S Tank Farm. The area is wide enough to accommodate a full-scale mock tank as well as supporting infrastructure installations. Using this site would have required installing infrastructure including wells, electrode arrays, and a tank surrogate. The current well emplacements, two Resource Conservation and Recovery Act (RCRA) wells on the south end of the tank farm, were constructed using stainless steel casing. It was concluded that these wells could not serve a "dual use" role for the FY 2002 testing and the RCRA groundwater-monitoring project. Overall, construction costs and schedule considerations eliminated this site from the selection process. 
Regulatory-The proximity of the tank farm to the proposed test location carried the potential risk of encountering undocumented radioactive material or abandoned pipelines during excavation activities. While the risk was judged to be minimal, it was nonetheless a consideration in the site-selection process.

\subsubsection{Pump Test Pit}

The Pump Test Pit is located near the 200 East Area on Road 13, the main road between the 200 East and 200 West Areas.

Infrastructure - Of all of the proposed alternative sites (to the Mock Tank Site), the Pump Test Pit had the best available power and onsite laboratory facilities. Adequate line-power panels were found on both the north and south side of the test pit. The primary shortcomings of the site were the small diameter of the test pit itself and the presence of obstructions (e.g., observation decking, tank stand). The location was easily accessible and has a level grade. Installation of new wells and electrode arrays would have been required before the test pit could function as a test facility. It was questionable whether the diameter of the test pit was useful for testing, necessitating the construction of a mock tank at the site.

Regulatory-The high-levelwaste cross-site transfer line is located directly under the test pit site. Excavating the site to construct a mock tank structure (or drilling new wells and emplacing electrodes) would have been problematic.

\subsubsection{Cold Test Facility}

The Cold Test Facility is located at the intersection of Horn Rapids Lane and Kingsgate Way in north Richland, Washington. Prime advantages of this site are that the tank is full scale (23 $\mathrm{m} \mathrm{[75} \mathrm{ft]} \mathrm{diameter),}$ and line power is already installed. However, the simulant-injection points and the geophysical electrode arrays would need to be emplaced. Since this site was already nearing completion of construction activities, modifications to the facility would be difficult to implement. Other disadvantages of this site are that the tank bottom is on the ground surface, and that no near-surface electrical interference from piping or other subsurface infrastructure exists. The depth to groundwater is approximately $50 \mathrm{ft}$, limiting the soil depth that would be available for leak detection and increasing the probability that the groundwater would be affected by the leak-simulant solution. The Cold-Test Facility would be a shareduse site, requiring coordination with other activities that may have a higher priority. Since the PE testing is expected to run continuously for several months, the necessity of coordinating use of the site with other activities would preclude its use for this project.

\subsubsection{Sisson and Lu (Vadose Zone Transport Field Study) Site}

The Sisson and Lu Site in the 200 East-Area of the Hanford Site is well characterized, and the unsaturated flow of fluids in the subsurface is well understood. Numerous steetcased wells are installed at the site, and nine ERT point-electrode arrays are available. However, there is no tank-type structure at this site. A structure electrically simulating a tank could possibly be created using sheet piling, although it would lack a tank bottom. The existing wells could also be electrically connected to simulate a tank structure. How accurately this simulated structure would electrically simulate a full-scale steel tank is unknown and can only be evaluated by creating the structure and conducting additional tests. Hence, schedule constraints and the cost of additional construction are significant drawbacks to using this site. 


\subsubsection{Mock Tank Site}

Infrastructure-At the Mock Tank Site, ample well points and electrode arrays existed to conduct development work similar to the FY 2001 work scope. With the installation of one additional well, the FY 2002-2003 testing objectives could be fulfilled. Additional upgrades to the existing infrastructure such as electrical power-line extension, steel sheet-wall emplacement, and provision of communications links would be required at the other sites as well.

Geology_The Mock Tank Site has been extensively characterized using a variety of techniques, including drilling, surface geophysics, cone penetrometer sampling and instrumentation, and the various cross-well geophysical tests. No proposed alternative site has undergone the level of characterization effort as the Mock Tank Site.

Considering tight schedule requirements for the PE test, infrastructural components already in place, costs, hydrogeologic setting, and site accessibility to all parties, the Mock Tank was selected as the preeminent location. 


\subsection{The Mock Tank Test Site}

The 105-A Mock Tank (Mock Tank) is located in the 200-East Area of the Hanford Site (Figure 2.1 and Figure 2.2). The Mock Tank was constructed in 1994-1995 and previously used to test the applicability and effectiveness of an array of electricalresistivity sensors in providing tomographic imaging of simulated waste leaks beneath the tank. This remains the primary design goal of the facility; several infrastructural improvements have been made to the site to ele ctrically simulate SST tank-farm conditions, to allow numerous leak-simulation scenarios, and to allow testing of a wider variety of geophysical methods.

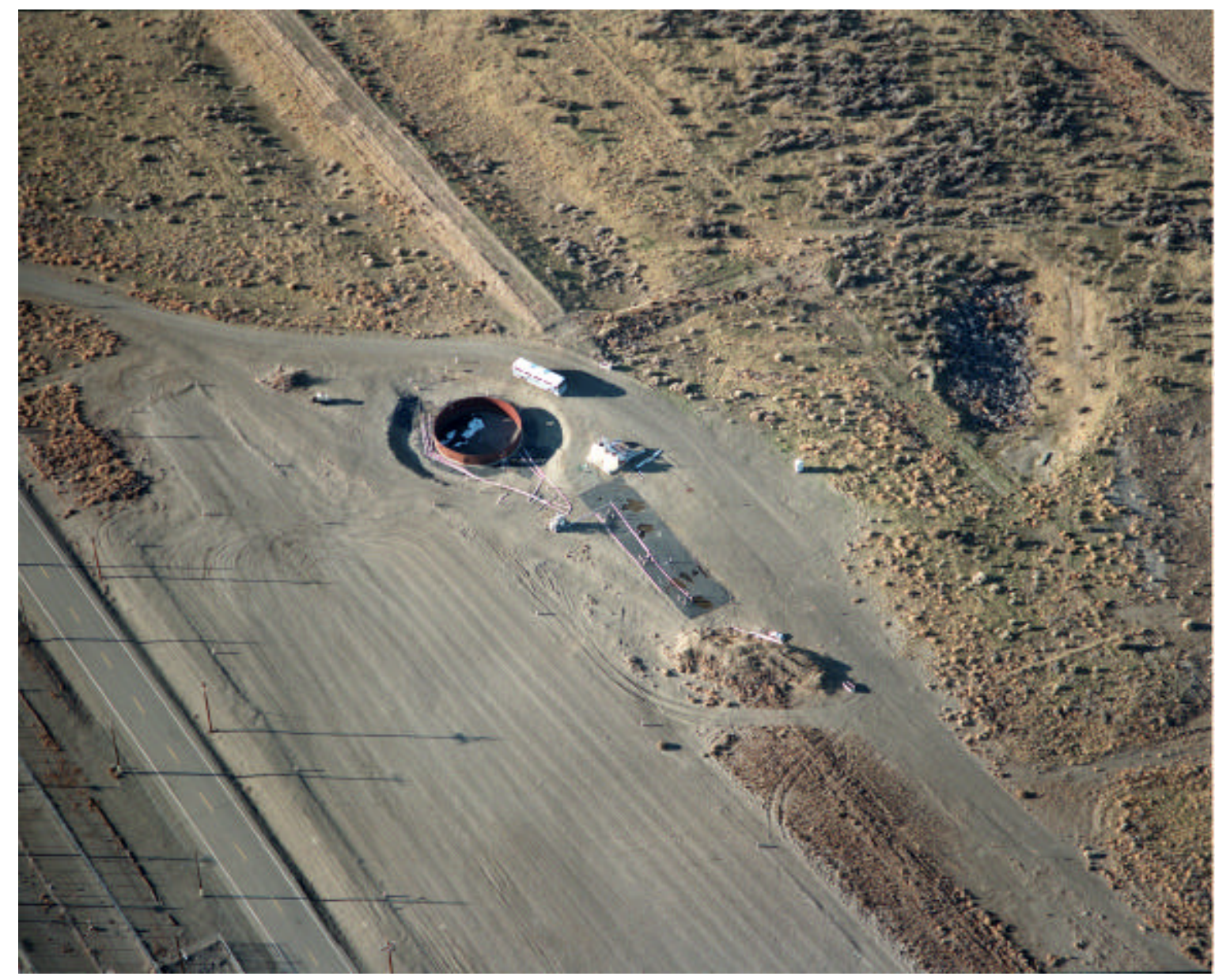

Figure 2.1. Oblique Aerial View of the Mock Tank Site from the Southeast. This photograph was taken in November 2001 before installing equipment for the FY 2002-2003 PE testing. The rectangular covering to the lower right of the tank is part of the Subsurface AirFlow Extraction (SAFE) testing apparatus de ployed concurrently with geophysical methods in 2001. Also visible are the bus used a mobile lab in 2001 and the permanent water-storage tanks (upper right and right of tank, respectively). 


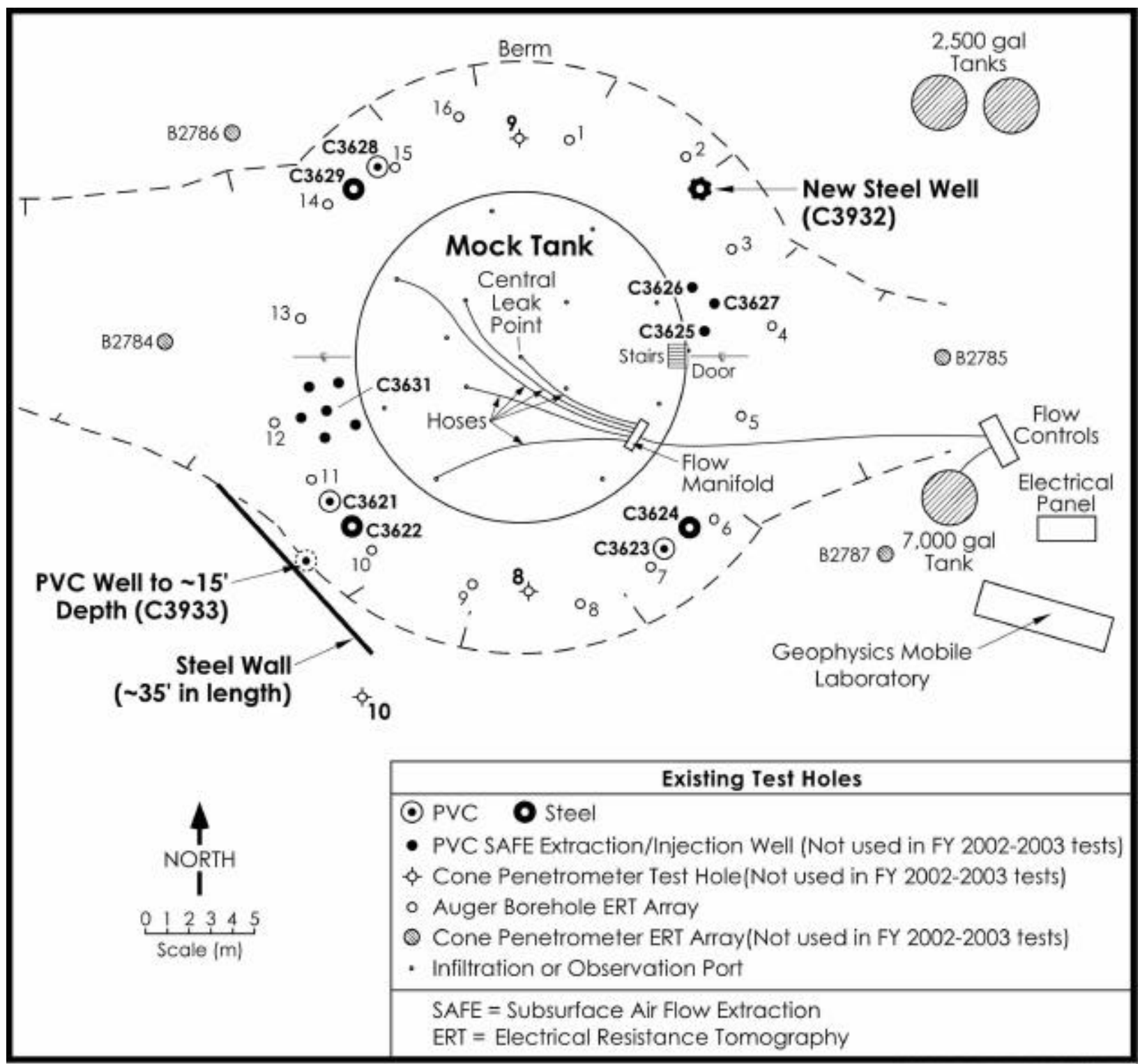

2003/DCL/Tank 105/003 (02/10)

Figure 2.2. Layout of the Mock Tank Site for the FY 2002-2003 PE Test. The locations of surface electrodes are shown in Appendix A, Figure 5.

\subsection{Site Hydrogeology}

Stratigraphy and geologic materials beneath a potentially leaking structure (such as a tank) are of paramount importance to the behavior and transport of liquids entering the subsurface environment. Hence, a summary contrasting vadose-zone stratigraphy between the Mock Tank site and other SST sites is appropriate here. A description of the stratigraphy and geology beneath the Mock Tank Site is provided in Appendix A (p. A.18) and by Barnett et al. (2002). 


\subsubsection{Comparison of the Mock Tank Site to 200-West Area Tank Farms}

The SST tank farms are located in two main areas of the Hanford Site; the 200-East Area and the 200West Area (Figure 1.1). Although some common features characterize the hydrogeologic setting of these two areas, such as a >61-m (>200-ft)-thick vadose zone, low precipitation, and a sedimentary section overlying basalt, there are also distinct differences that have significance to leak detection. Williams et al. (2000; 2002) describe the prominent stratigraphic features of both the 200-East and 200-West areas that, in part, determine recharge rates and fluid movement in the vadose zone.

Figure 2.3 is a generalized cross-section of sedimentary strata beneath the 200-East Area representative of the section at the Mock Tank Site (near Well E27-1). In this region, the Hanford

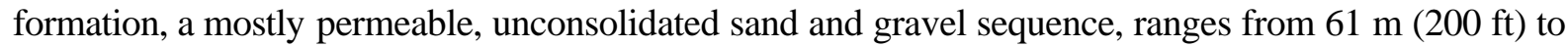
nearly $110 \mathrm{~m}(350 \mathrm{ft})$ thick. These sediments are characterized by little or no clast cementation and few fine-grained horizons; they are generally conductive to vertical fluid migration. Only one thin, finedgrained stratum is known in the subsurface beneath the Mock Tank (see Appendix A) that may slow the vertical migration of fluids.

Figure 2.4 illustrates the general, suprabasalt stratigraphy of the 200-West Area, showing the approximate locations of the tank farms. Of particular importance is the relatively thin Hanford formation sediments underlain, in most places, by the Plio-Pleistocene units, which constitute an inherently impermeable clayand-caliche-rich horizon up to $8 \mathrm{~m}$ (25 ft) thick in the region of the S-SX Tank Farm (DOE 1996; Williams et al. 2002). The Plio-Pleistocene units are significant in that they may locally constitute a perching horizon that could intercept downward-migrating effluent and result in la teral spreading of contaminants beneath the tanks. In some locales, fracturing, clastic dikes, scouring by late Pleistocene floods, or other discontinuities in the unit may allow downward migration. Below the Plio-Pleistocene units is the Ringold Formation, a variably cemented sand and gravel sequence that is significantly less permeable than the Hanford formation.

Differences in stratigraphy and lithologies between the Mock Tank Site and the 200-West Area tank farms may result in significantly different fluid migration patterns. Whereas effluent released into the vadose zone at the Mock Tank Site is seen to migrate mostly downward (See Section 3.44), with little lateral spreading, the behavior of a similar release in the 200-West Area may be more likely to encounter the intervening Plio-Pleistocene units and spread laterally at this level (Collard et al. 1996). In this sense, the Mock Tank Site is not representative of what may be encountered in the S-SX Tank Farms. This is a general comparison however, and site-by-site peculiarities, such as discontinuities, strata thicknesses, degree of cementation, will ultimately determine the migration rates and preferential patterns of any leaking effluent. 


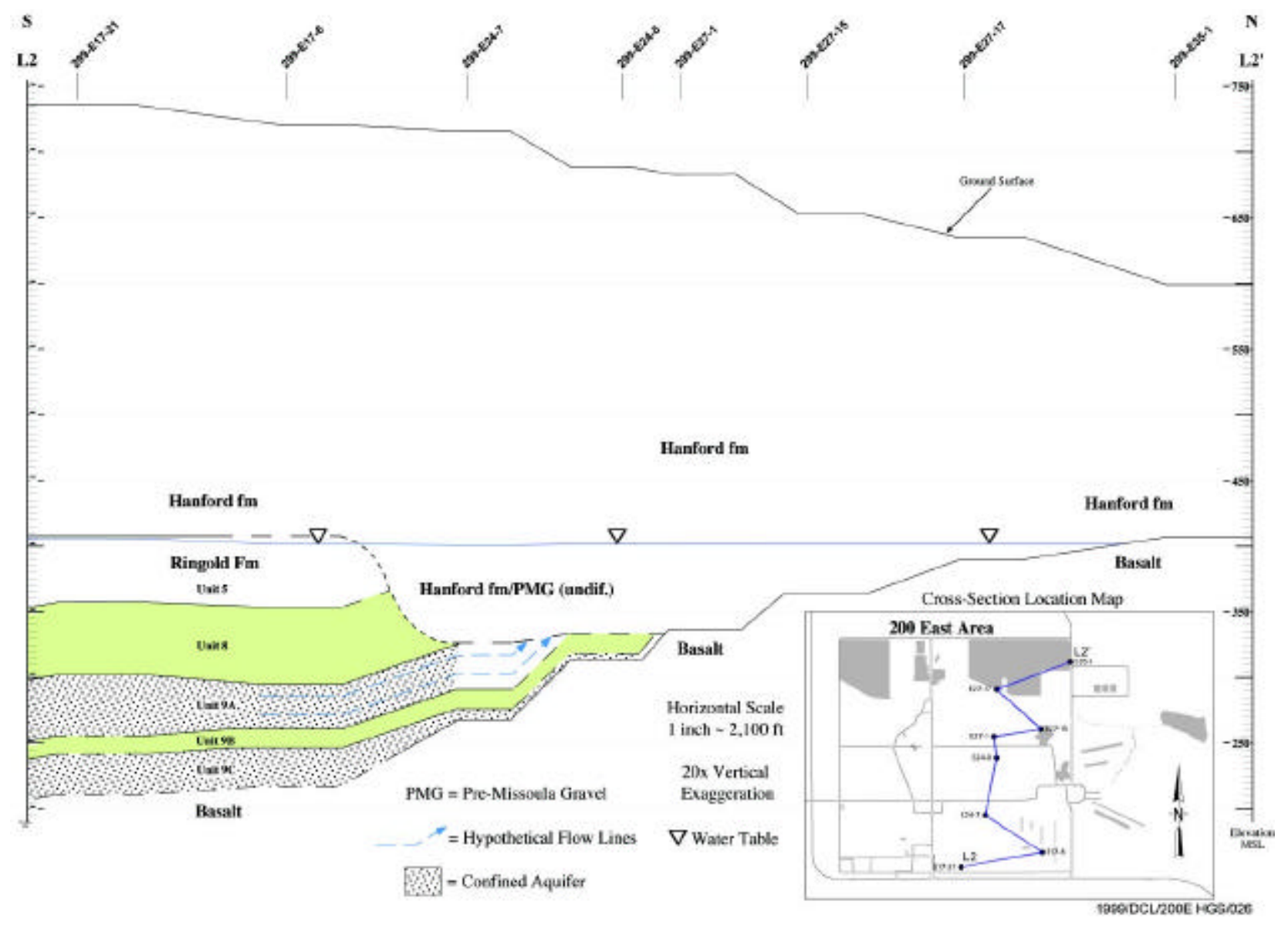

Figure 2.3. Generalized Stratigraphic Cross Section of the Hanford 200-East Area. The Mock Tank Site is near Well E27-1 (after Williams et al. 2000). 


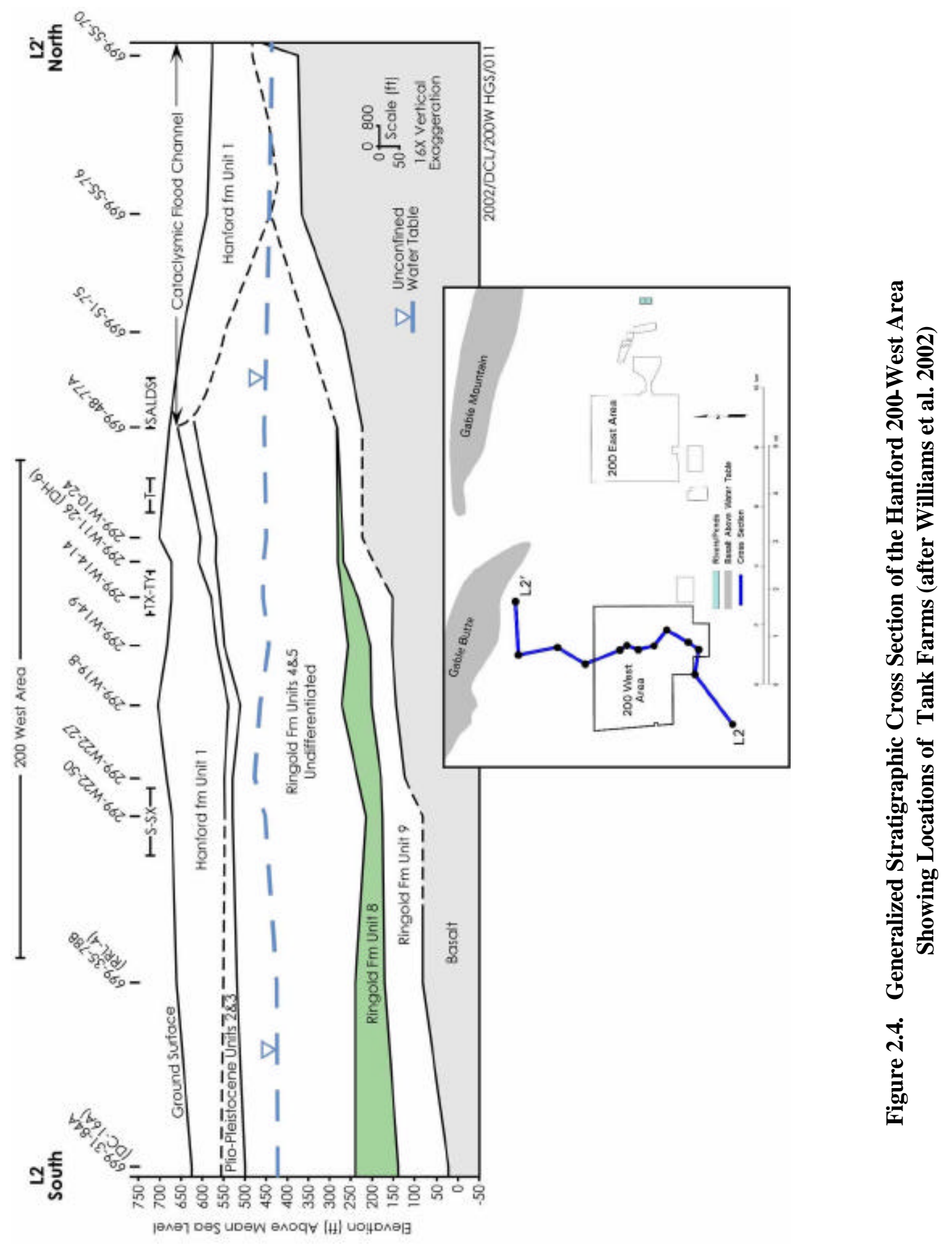




\subsection{Mock Tank Construction Features}

The 105-A Mock Tank (Figure 2.5 and 2.6) was built in 1994-1995 for the express purpose of testing ERT as a method of leak detection in the presence of a large steel tank. The history of construction and testing at the Mock Tank is summarized in Appendix A (p. A.7 to A.14) and by Barnett et al. (2002). Improvements to the site in preparation for the FY 2002-2003 PE Testing are described in this section.

Leak-detection studies at the Mock Tank have been conducted since 1995 (Ramirez et al. 1995, 1996; Narbutovskih et al. 1996a, 1996b). In FY 2001, the Mock Tank was used to test six leak-detection methods simultaneously. The additional infrastructure added in FY 2002 consisted of one new, shallow, steel-cased borehole, a steel sheet wall (to simulate an adjacent buried tank), mainline electrical power, a dual internet connection, and phone service. Also, several temporary systems were constructed (such as the solution-delivery and rain-simulation systems) and disassembled after the test. Figure 2.2 shows a layout of the Mock Tank Site as it appeared for the FY 2002-2003 testing. An example of one of the 16 electrode arrays, in relation to a partial profile of the Mock Tank, is shown in Figure 2.7, along with various features used for solution dispensing and electrical measurements.

The additional drilling and construction activities took place in May and June of 2002. Figure 2.8 shows the emplacement of the steel wall near the southwest edge of the Mock Tank. Steel panels were welded together and buried to $\sim 4.5-\mathrm{m}(\sim 15-\mathrm{ft})$ depth. The surface edge of the steel wall was alternately connected to and disconnected from the Mock Tank to evaluate the effects of a large conductive feature (such as an adjacent tank).

To provide cost savings and system enhancement, a hybrid data-collection and communication system was built to accommodate both HRR-SCRT and ERT measurements. The new system included internet connections for remote activation and data access, allowing the researchers to remain at their home offices (Tucson, Arizona and Livermore, California) while conducting the tests. Only initial site visits were necessary to perform set-up, with infrequent maintenance and repair performed by onsite PNNL staff. Other site improvements included installation of a line-based electrical supply to avoid test interruptions due to generator failure. 


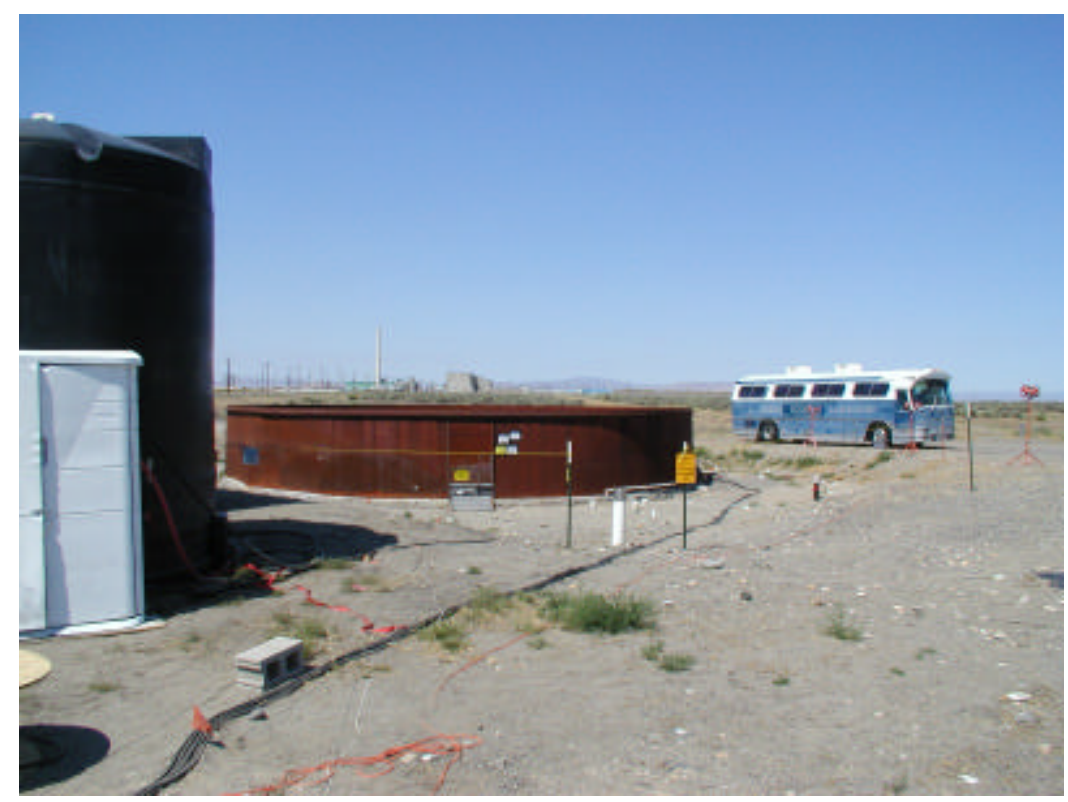

Figure 2.5. View Looking West at the Mock Tank Just Prior to Test Start. The 26,120 L (6,900gal) solution tank holding the leak simulant solution (sodium thiosulfate) and the pump/controller housing (white) is at far left. The Mobile Laboratory (bus) used in the FY 2001 tests is in the background.

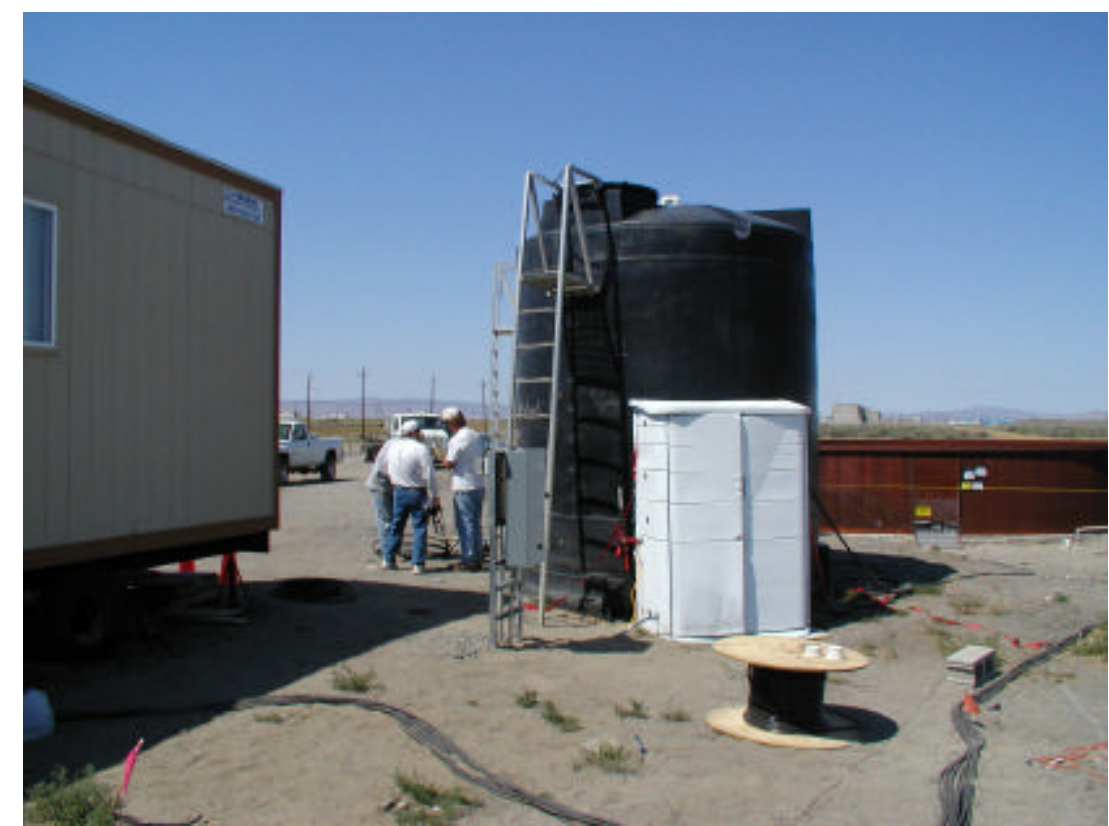

Figure 2.6. View Southwest of Mock Tank Site Showing the Solution Tank, Pump/Controller Housing, and Field Office at Left. The heavy cables seen at bottom contain bundles of individual leads to electrodes that are emplaced around the Mock Tank. 


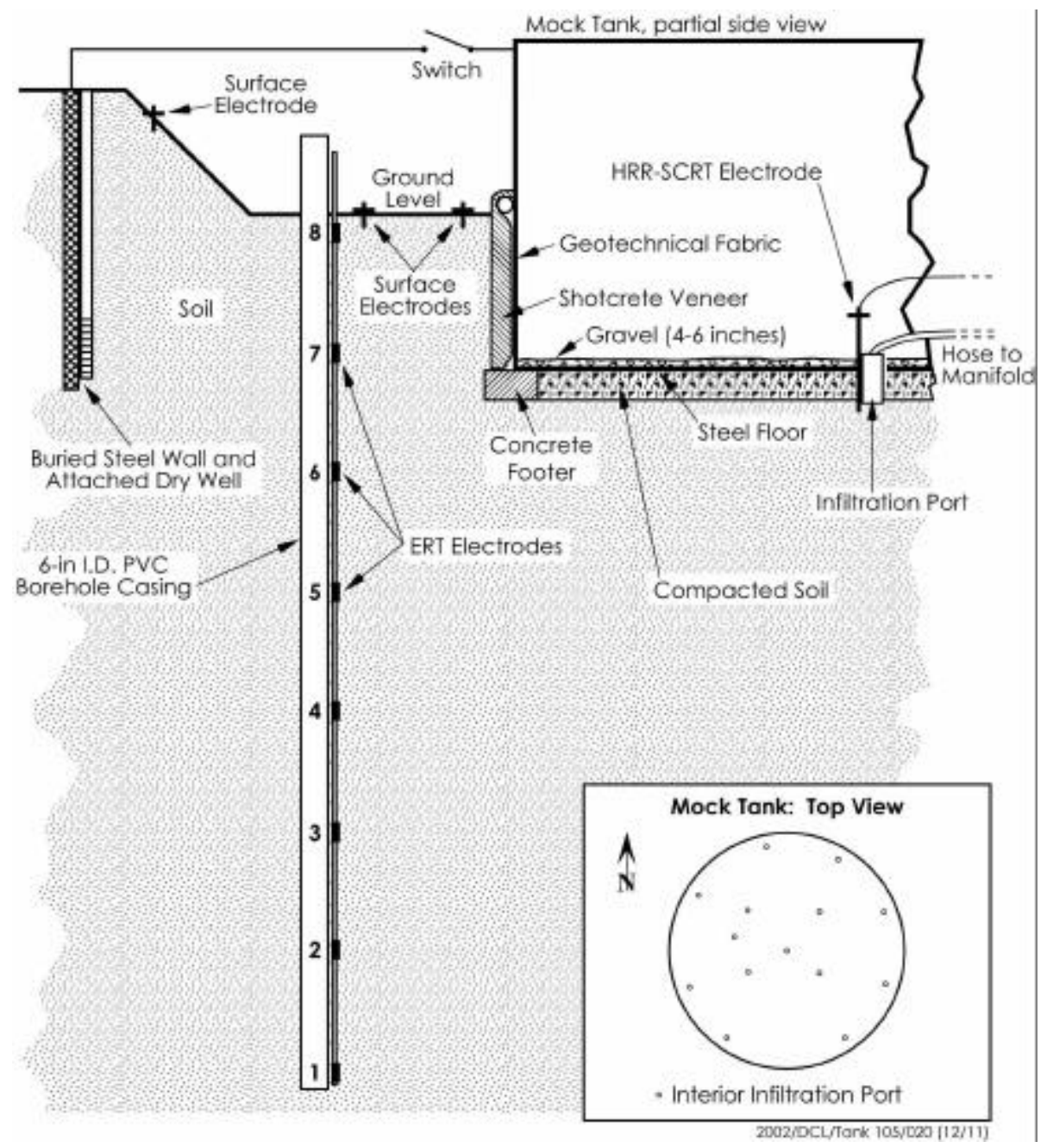

Figure 2.7. Schematic Cross Section of a Portion of the Mock Tank Structure. Also shown are the steel wall and dry well, one of 16 ERT arrays, and electrical connections. The inset shows the locations of access (monitoring) and infiltration ports inside the tank. 

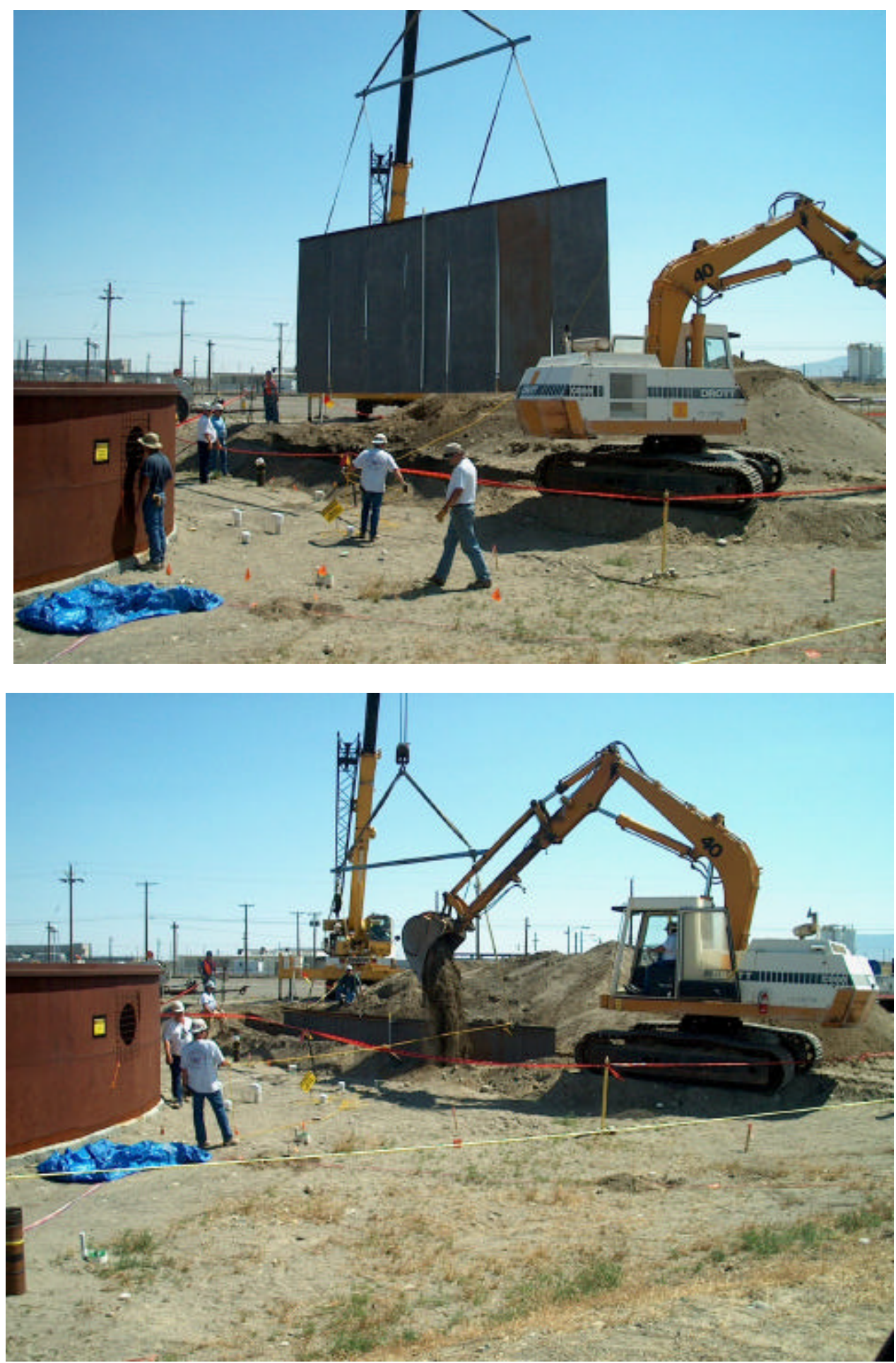

Figure 2.8. Installation of the Steel Sheet Wall at the Mock Tank. The PVC riser attached to the center of the wall for injecting water or waste surrogate near the wall was not used during the test. 


\subsubsection{Structural Description}

The Mock Tank was built in 1994-1995 to accommodate ERT deployment and tank-leak detection testing. A detailed description of the Mock Tank structure and construction process is provided by Barnett et al. (2002). The tank is essentially a steel ring with a tack-welded steel floor. The base of the ring (walls of the tank) rests on a concrete base. The steel floor and walls are underlain by compacted soil and gravel. Fourteen soil-access ports with steel-pipe risers were placed in the floor of the tank.

\subsubsection{Electrical Service}

The FY 2001 LDMM activities at the 105-A Mock-Tank Site employed a battery of diesel alternators to provide electrical power; this method of power generation proved cumbersome (e.g., refueling needs for multiple alternators under different loads with consequent differences in fuel consumption) and relatively unreliable. It was decided that the FY 2002-2003 LDMM PE activities would require extension of the existing electrical line from the Hot Semi-Works (a facility located south of the 105-A site) to provide a reliable power source for the duration of the test (approximately 110 days).

The 13.8-kV line from pole C8L6 (west of the Hot Semi-Works) was extended across $7^{\text {th }}$ Street using one span of three-phase primary wire to a pole emplaced east of the Mock Tank site (see Figure 2.2). Figure 2.9 and Figure 2.10 show main components of the electrical service at the Mock Tank Site. Table 2.1 details the electrical service provided.

Table 2.1. Details of Electrical Service Installed at the Mock Tank

\begin{tabular}{||c|c|c|c||}
\hline \hline No. Drops x Amps & Volts & Phase & Location \\
\hline $3 \times 50$ & 480 & 3 & Service panel; 1 drop extended to pump panel \\
\hline $1 \times 100$ & $120 / 240$ & 1 & Trailer \\
\hline $1 \times 50$ & $120 / 240$ & 1 & Pump panel \\
\hline $1 \times 20$ & 120 & 1 & Pump panel \\
\hline $1 \times 20$ & 120 & 1 & Outlets (outdoor) \\
\hline
\end{tabular}

\subsubsection{Steel Wall}

Electrical sensitivity modeling of the Mock Tank Site indicated early in test planning that adjacent and electrically-interconnected tank structures in the SST farms could influence resistivity measurements. A steel wall was installed below ground immediately southwest of the Mock Tank to determine the effect of inter-tank electrical properties on the proposed LDMM geophysical technologies.

Seven sections of 11-gauge steel were transported to the Mock Tank Site and assembled into a 4.5-m (15-ft) deep by 10.7-m (35-ft) long wall. One end of each section of steel sheeting was attached to a 0.64-cm (0.25-in.)-thick, $10.67-\mathrm{m}$ (35-ft) length of channel steel to provide electrical continuity and to aid in emplacement. The installation also included a 5-cm (2-in.)-diameter, 3.35-m (11-ft) section of PVC piping for the purpose of simulating a side leak from an adjacent tank structure, although this feature was not used during the FY 2002-2003 PE test. Figure 2.8 shows portions of the installation sequence of the steel wall. 


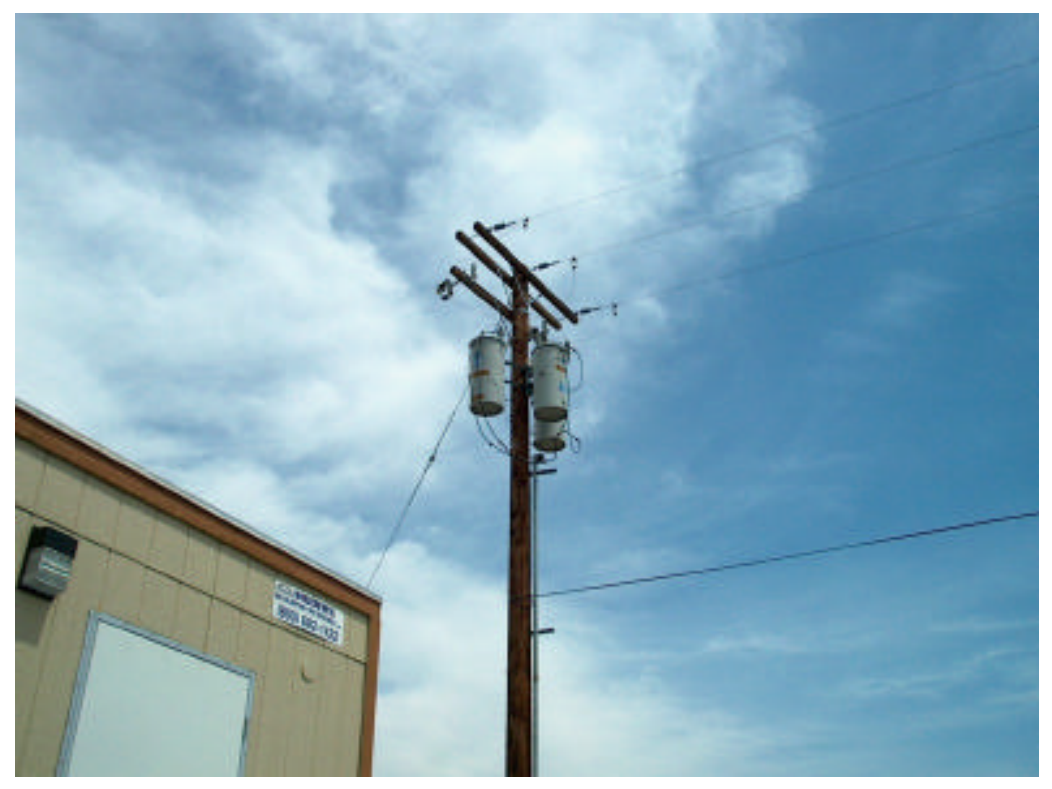

Figure 2.9. The Pole Installed at the 105-A Site, with the Three 13.8-kV Primaries Feeding Three 480-V Stepdown Transformers; the Integrated Services Digital Network (ISDN) Telephone Line Can Be Seen Beneath the Electrical Lines. The mobile field office is at lower left.

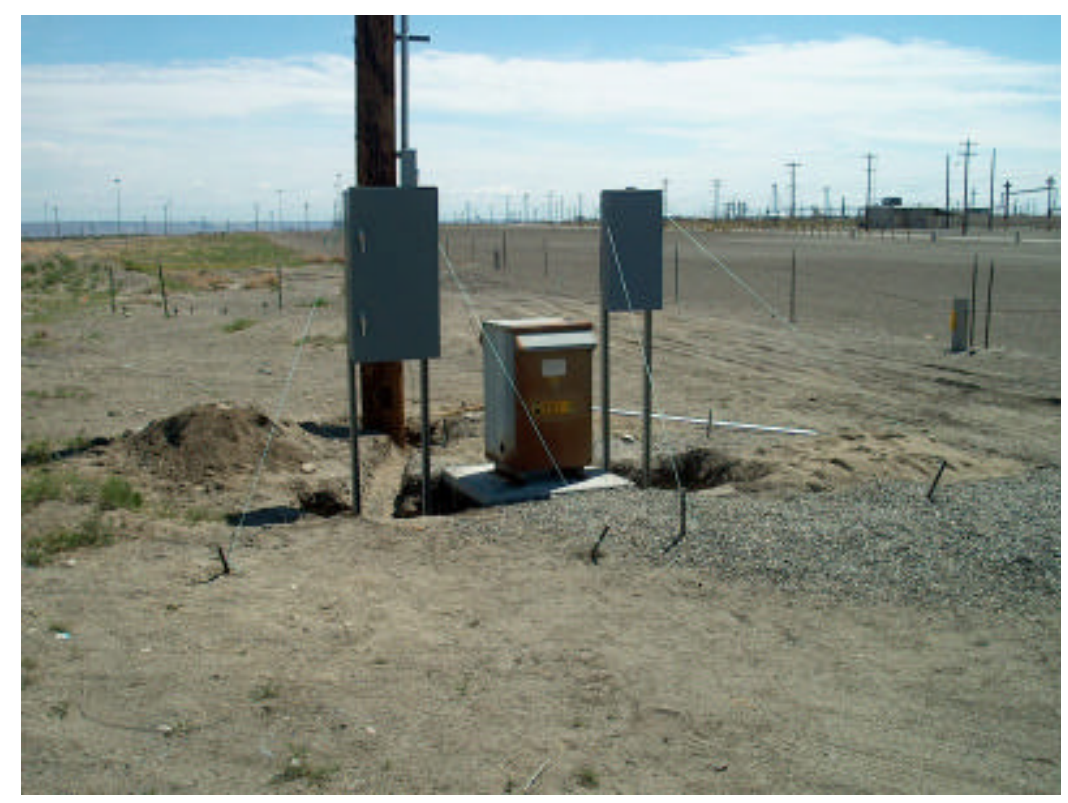

Figure 2.10. Service Panel Installation 


\subsubsection{Boreholes/Electrode Arrays}

The electrode infrastructure at the Mock Tank Site consists of sixteen ERT vertical electrode arrays mounted on 15-cm (6-in.)-diameter polyvinyl chloride (PVC) casings, four 15-cm (6-in.)-diameter steel cased wells functioning as dry-well electrodes, and fifty-one 0.6-m (2-ft)-long stainless steel stakes that form the surface array used in the HRR system (Appendix C).

The 16 vertical electrode arrays were installed in 1994 during the construction of the Mock Tank Site. They were initially used for point-electrode assessments of electrical resistivity tomography in a tankfarm setting. Each array consists of a 5- $\times 5$-cm $(2-\times 2$-in. $)$ stainless steel screen-mesh electrode with one 18-gauge braided wire leading to the surface. The PVC casing was used as an anchor on which to mount the eight individual electrodes. An additional section of 2.54-cm (1-in.)-diameter PVC pipe was attached to the array to inject water. Water was injected to assure proper bonding of the steel-mesh electrodes to the dry Hanford soil.

Three steel-cased wells were installed in FY2001 as part of the downselect testing that was a precursor to the PE testing of FY2002. The wells were used as "pseudo" dry wells or to mimic the construction of observation wells used for current baseline geophysical testing in the tank farms (e.g., neutron logging). These "long electrodes" are the preferred type of electrode infrastructure in the tank farms because of their current proximity to the tanks and the fact that they lessen the potential cost of deploying a leak-detection system. The casing is carbon steel and was transported in 3-m (10-ft) sections

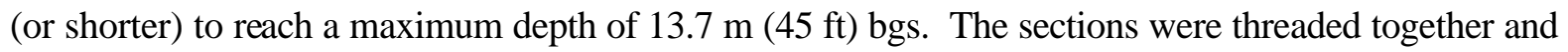
tightened above ground before being lowered into the auger flights situated in the excavated borehole drilled with an auger rig. A thin strip of the corrosion-inhibiting coating was removed from opposing sides of each flight on two of the three wells. The fourth well used in this test was installed in FY2002 to provide electrode coverage to four sides of the Mock Tank structure. The installation and materials were the same as the existing steel-cased wells and also had portions of the corrosion-inhibiting coating removed. Figure 2.11 shows one of the steelcased wells in relation to two of the ERT vertical arrays.

The surface array is composed of 51 stainless steel rods driven by hand into the top $0.6 \mathrm{~m}(2 \mathrm{ft})$ of surface sediment at the Mock Tank Site and at two remote locations approximately $762 \mathrm{~m}$ ( $2500 \mathrm{ft})$ from the center of the tank. These remote reference electrode locations are roughly orthogonal to each other through the center of the Mock Tank structure. Their purpose is to provide investigators with a reference electrode to complete a pole-to-pole resistance measurement, but with the electrode spatially removed from the Mock Tank structure to minimize contact-resistance errors affecting measurements at the test location. The remaining electrodes provide surface measurements of the potential distribution created as current is injected at the site during testing; these measurements allow mapping the potential fields created as site conditions change (e.g., when a solution is injected into the test area).

\subsubsection{Refitted Leak and Monitoring Points}

A set of 5-cm (2-in.) aluminum (neutron-transparent) casings were installed to a depth of

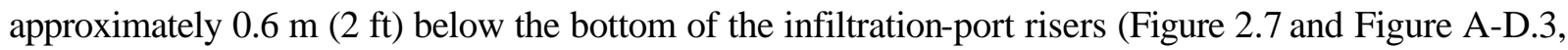
p. A.111) to facilitate neutron logging of the strata immediately below the tank floor. Gravel inside the existing ports was suctioned out to allow insertion of the aluminum tubes. This logging was performed to determine if leak solution was spreading out just under the steel floor of the tank and thus allow some 
inferences about the extent of connectivity of the tank with the leak solution. The locations and designations of the leak and monitoring ports inside the tank are shown in Figure 2.12.

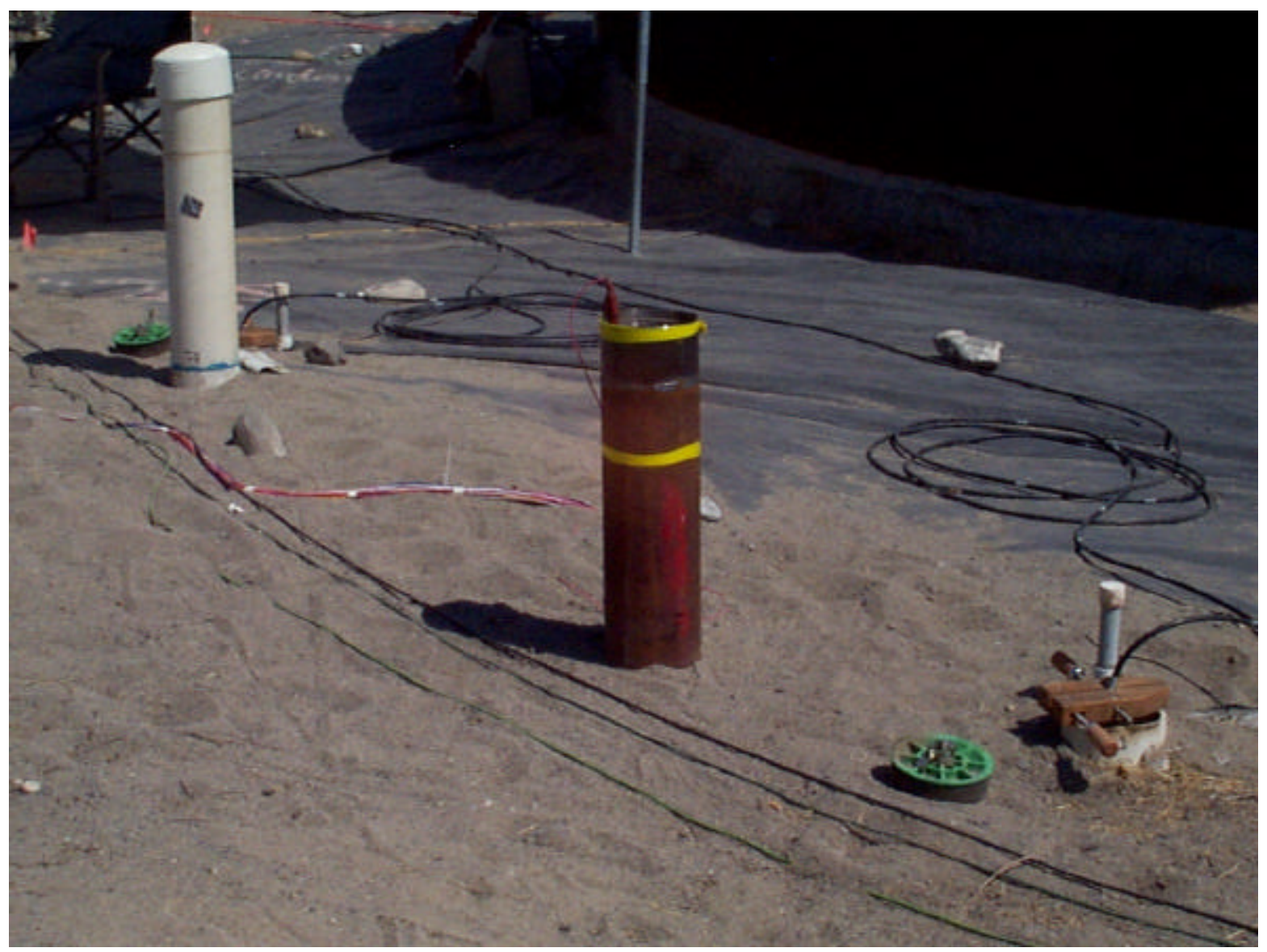

Figure 2.11. One of Four Steel Casings Used as Long Electrodes During the FY 2002-2003 Testing at the Mock Tank (center). To the lower right is 1 of the 16 ERT arrays around the tank. As indicated here, the caps of the 15-cm (6-in.) PVC casings with the arrays can be removed to allow access for accessory logging by neutron probe or other instruments. Eight of these arrays were used during the FY 2002-2003 testing. 


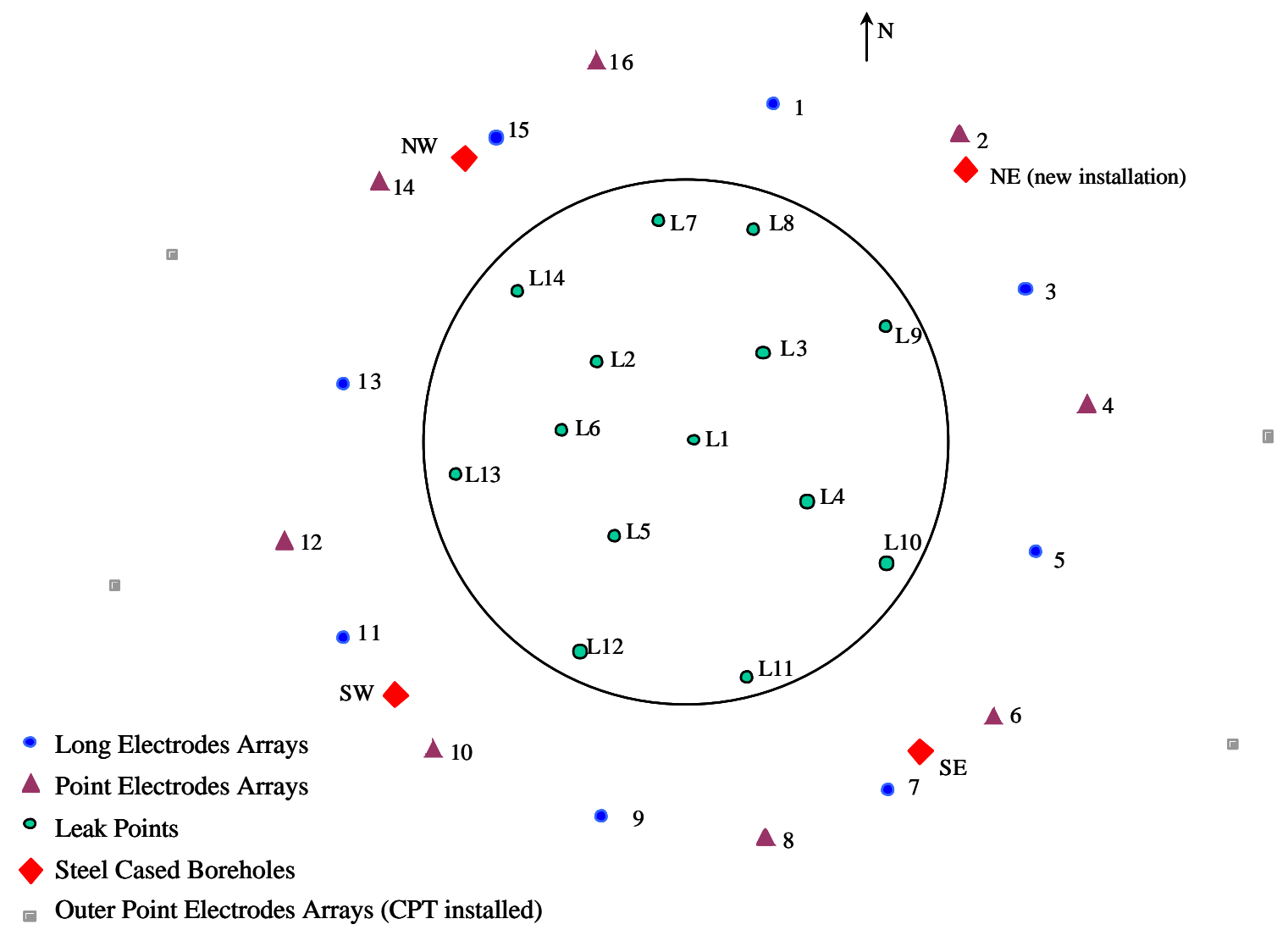

Figure 2.12. Locations of Permanent Electrodes and Interior Leak/Monitoring Ports at the Mock Tank

Attempts to inject solution at higher flowrates often resulted in filling and overflow of the infiltration port risers; the soil beneath infiltration ports was perforated using a pointed steel rod to a depth of

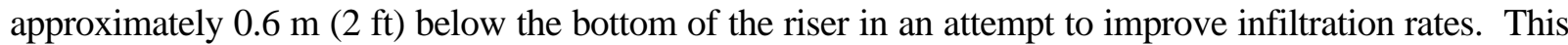
did not prove entirely effective in increasing infiltration rates to target levels; Wells L14 and L5 were augured out to a depth of approximately $0.3 \mathrm{~m}(1 \mathrm{ft})$ below the riser bottom and 5-cm (2-in.) PVC installed to facilitate infiltration.

\subsection{Test Equipment}

Following construction activities in May and June 2002 (Section 2.2), several components of equipment that would control test parameters were installed around the Mock Tank. These components controlled waste-simulant solution delivery to the infiltration ports and rain simulation around the outside perimeter of the tank; temperature and precipitation sensors and the HRR-SCRT electrodes were also emplaced. Data-logging computers for all sensors were located inside the field office. Below are descriptions of these systems. 


\subsubsection{Solution-Delivery System}

Approximately 53,000 L (14,000 gal) of $36 \mathrm{wt}$ percent sodium thiosulfate were prepared in three aliquots to simulate leaking waste beneath the Mock Tank. The solution was stored in a 26,120-L (6,900-gal) polypropylene tank approximately $3.66 \mathrm{~m}$ (12 ft) in height and $3 \mathrm{~m}(10 \mathrm{ft})$ in diameter with two butterfly valves located on the bottom of the tank. The solution delivery system components used are shown in Figure 2.13. Two solution delivery systems were used during the test. Both were fed from a constant-pressure loop recirculating the solution through these valves using a 50-gpm centrifugal pump (Finish-Thompson, model KC11) and a Plast-O-Matic RV-series back-pressure regulator. Strain-gaugetype pressure transducers (Omega, M2165/0395) were placed at the outlet of the sodium thiosulfate tank and immediately downstream of the centrifugal pump. An inline strainer was placed immediately upstream of the pump to protect it from large particles. Bourdon-type pressure gauges were located just downstream of the pump and at the solution-return inlet of the sodium thiosulfate tank.

Schematics for the two different systems are shown in Figure 2.14 and Figure 2.15. The first system employed a PID-type liquid turbine flow-controller (Alicat Scientific, TC-4.5LPM-D). Solution was fed to the controller from the constant-pressure recirculation loop. The Alicat controller provided flowrate control as well as the ability to track the quantity delivered. A pressure-relief valve was installed at the controller inlet to prevent overpressure damage. The controller delivered solution to a manifold of five delivery ports, each controlled with gate valves feeding into five separate risers inside the mock tank.

During the first leak-test period, the Alicat controller accuracy was verified with two confirmatory measurements: a liquid-flow sensor linked to a totalizer read out (Omega FLR 1000/DPF700) and a gravimetric analysis performed after the solution had passed through the flow controller and totalizer sensor (See Appendix A, Attachment I). A three-way valve was installed at the totalizer sensor outlet to obtain gravimetric samples.

The first flow-verification system was only used for this first leak-test period. Incompatibility of the flow sensor with the solution caused the sensor unit to deteriorate rapidly, causing a steady increase in totalizer error. Gravimetric analyses were performed daily during every leak-test period. All samples were weighed on a calibrated scale; solution density was measured as needed. Flowrates were calculated using the most recent density measurement.

A backup flow controller was used for a short period, but performed unreliably, possibly because of the HRR-SCRT energizing current that passed through the controller via the solution. A solution-delivery system using a different design basis was then installed.

This system employed two metering pumps (Fluid Metering, QD-2) with a variable output (3.8 to $68 \mathrm{~L} / \mathrm{hr}$ [1 to $18 \mathrm{gph}$ ). This system also used two measurements to verify correct solution delivery; a solution-compatible flow sensor (GF Signet 2507) connected to a flow transmitter (GF Signet 8550-1) and the gravimetric analysis as performed with the previous system. 

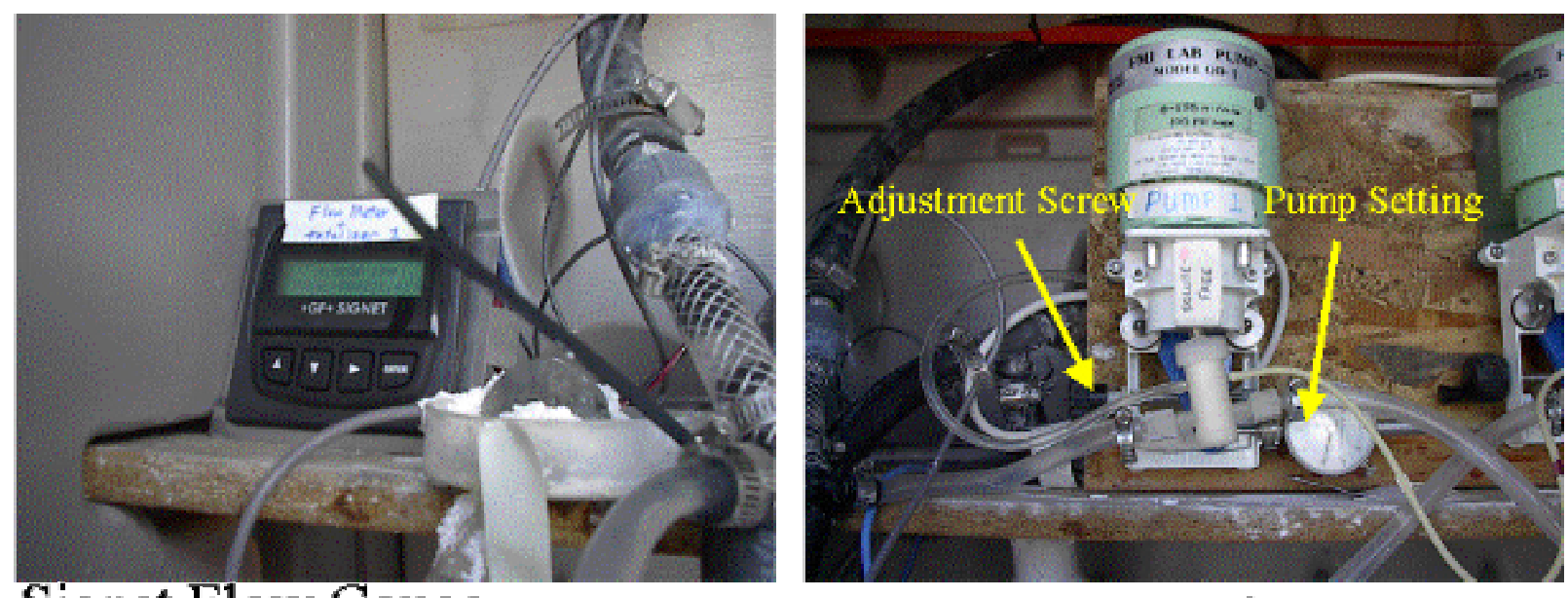

Signet Flow Gauge

\section{Metering Pump}

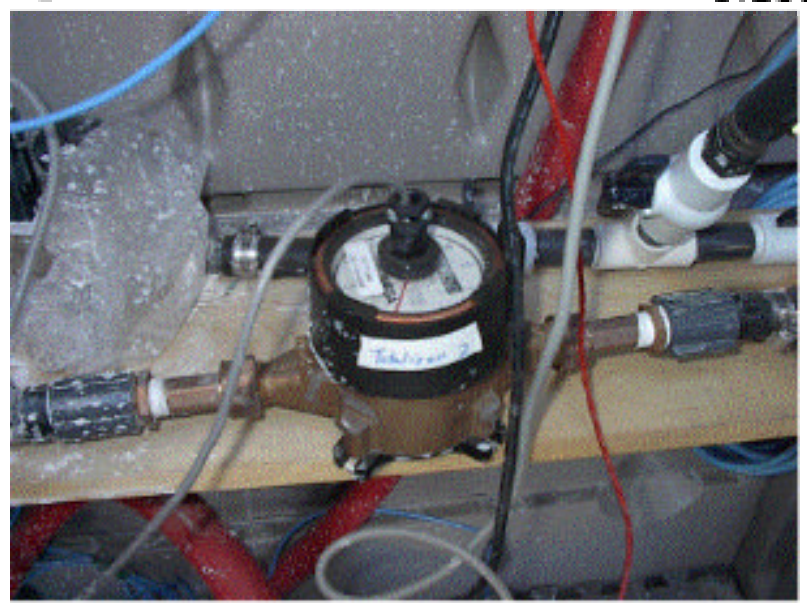

\section{Mechanical Totalizer}

Figure 2.13. Solution Delivery System Components as Installed in the Housing Next to the Storage Tank

Calibration curves were generated for this system at 19, 38, and $57 \mathrm{~L} / \mathrm{hr}(5,10$, and $15 \mathrm{gph})$ with each individual pump operating and at $76 \mathrm{~L} / \mathrm{hr}(20 \mathrm{gph})$ with both pumps operating. Set points for the desired leak rate were obtained using these curves.

Due to the incompatibilities of the solution with various system components, a flush line was installed. After each leak was terminated, river water was used to flush the delivery-system control/measurement components. The recirculation loop was isolated by closing a ball valve while the flush occurred. The flush water was collected through the gravimetric sample port for disposal. 


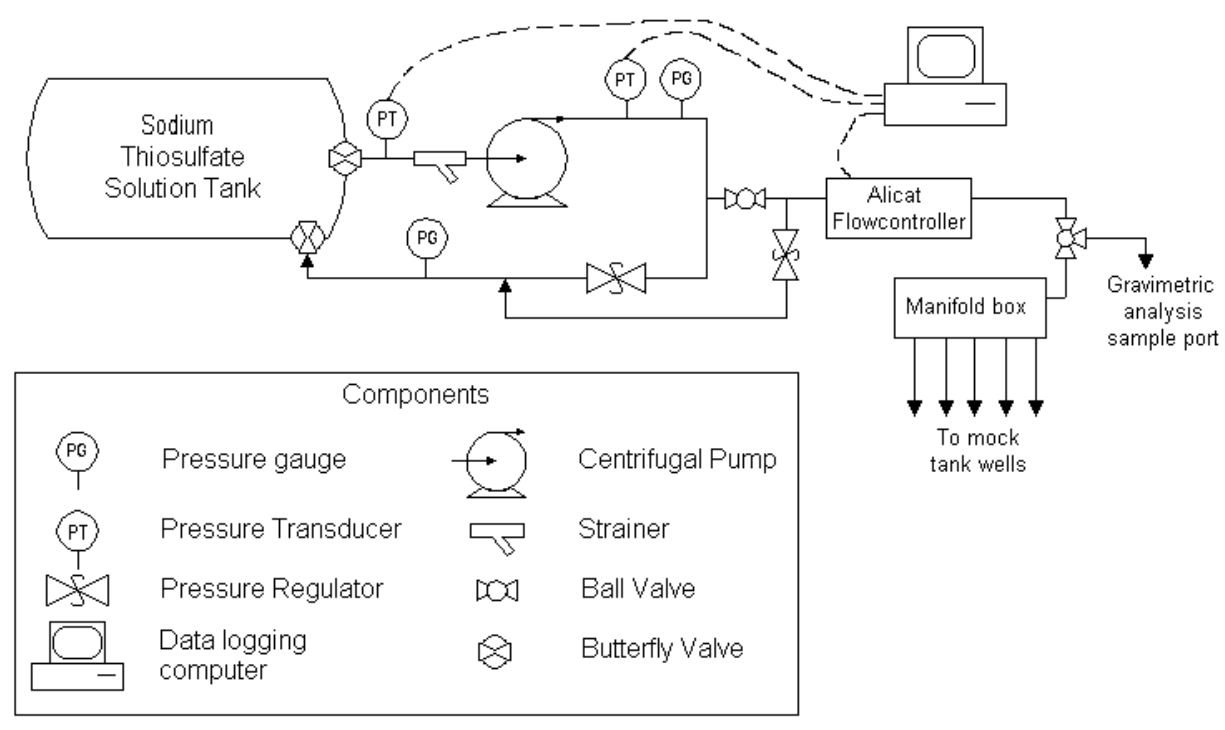

Figure 2.14. The Initial Solution Delivery System Used During the FY 2002-2003 PE Testing. This system used the Alicat PID flow controller, but an alternate system was devised after repeated malfunctions because of controller incompatibility with the mise-a-la-masse current.

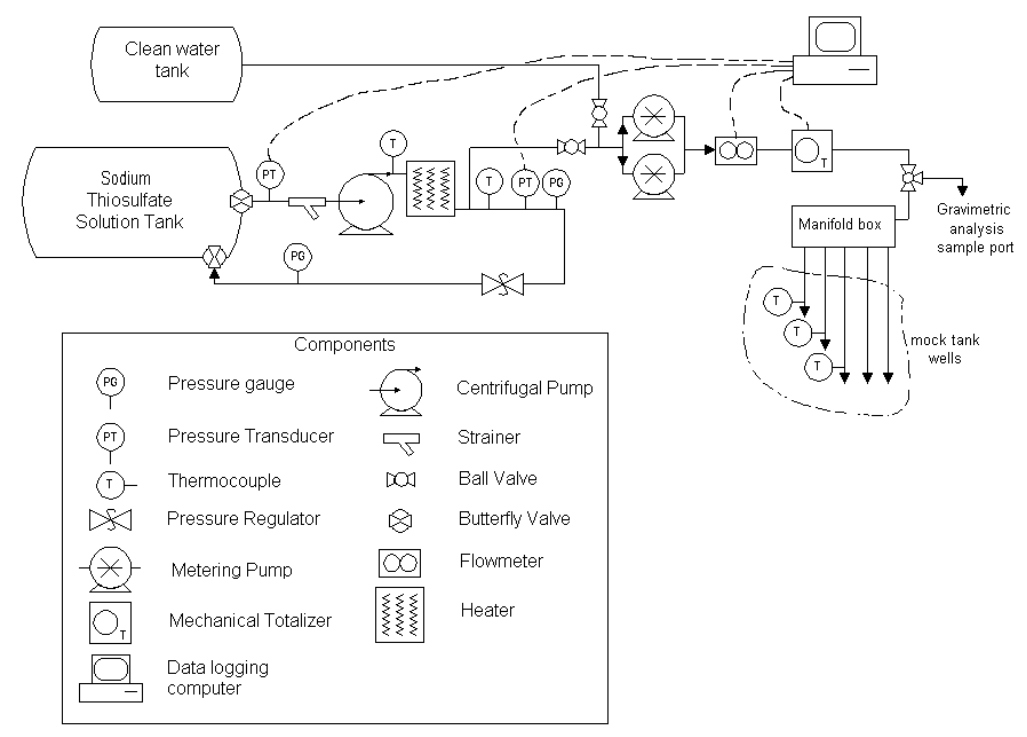

Figure 2.15. The Second-Generation Solution Delivery System. This system employed metering pumps instead of the PID controller; fresh-water tanks were connected to the system for flushing following solution-release periods. 


\subsubsection{Heating System}

A heating apparatus was designed for the solution delivery system in anticipation of colder weather as the test progressed into the fall. The solution delivery line was wrapped with insulation (see Figure 2.16). An inline water heater was plumbed into the recirculation loop at the centrifugal pump outlet, and the solution storage tank was insulated with a blanket of $0.64-\mathrm{cm}(0.25$-in.) foam insulation (Figure 2.17). These modifications maintained the tank solution temperature at $30^{\circ}$ to $35^{\circ} \mathrm{C}\left(86^{\circ}\right.$ to $\left.95^{\circ} \mathrm{F}\right)$. The solutiondelivery system was wrapped with heat tape and insulated with $1.9-\mathrm{cm}(0.75$-in.) pipe-foam insulation from the control components to each individual riser.

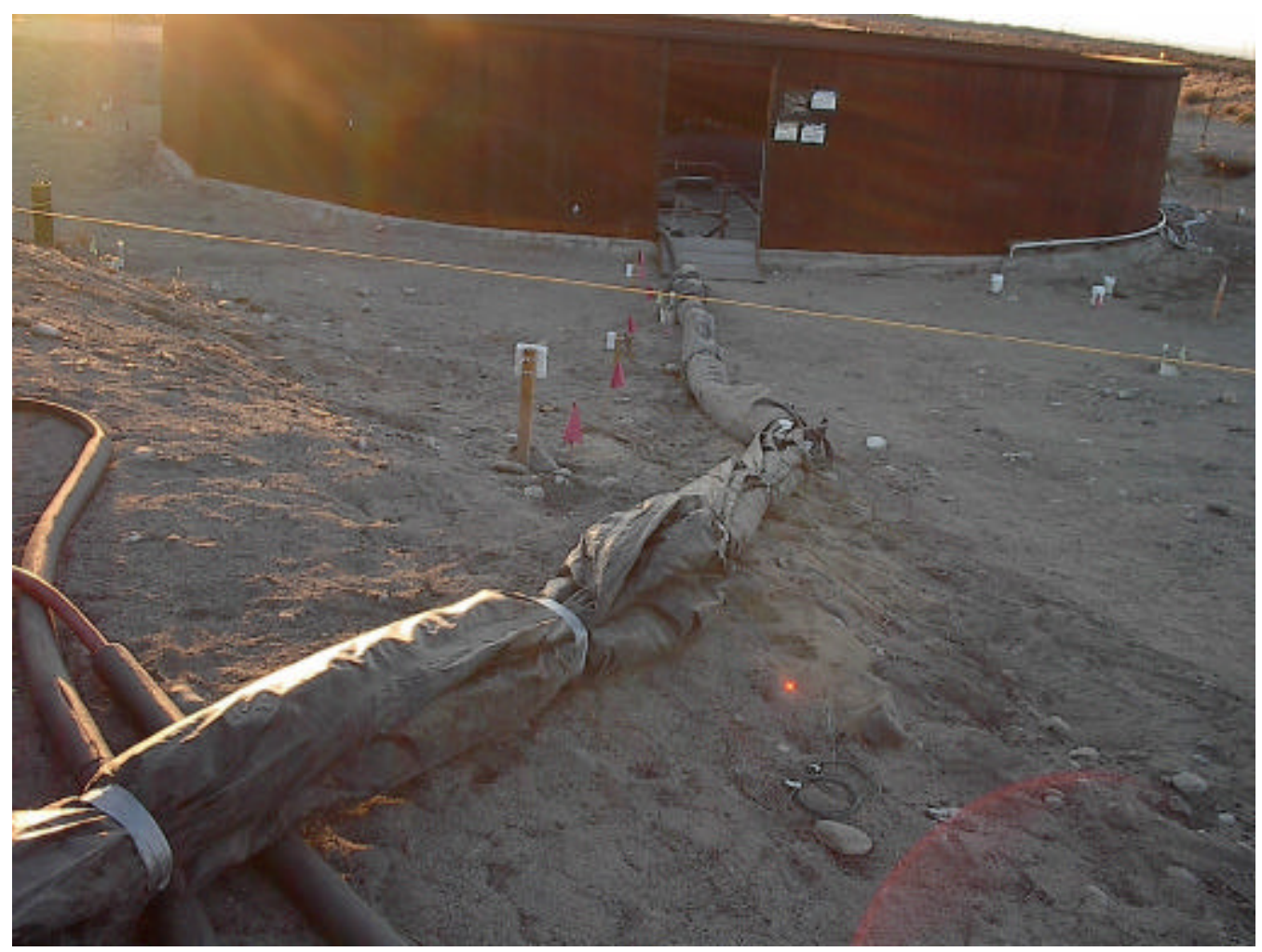

Figure 2.16. The Solution-Delivery Line Leading from the Pump/Metering Housing to the Manifold Inside the Mock Tank. This photograph shows the hose wrapped for cold weather to avoid crystallization/precipitation of the sodium thiosulfate solution. 


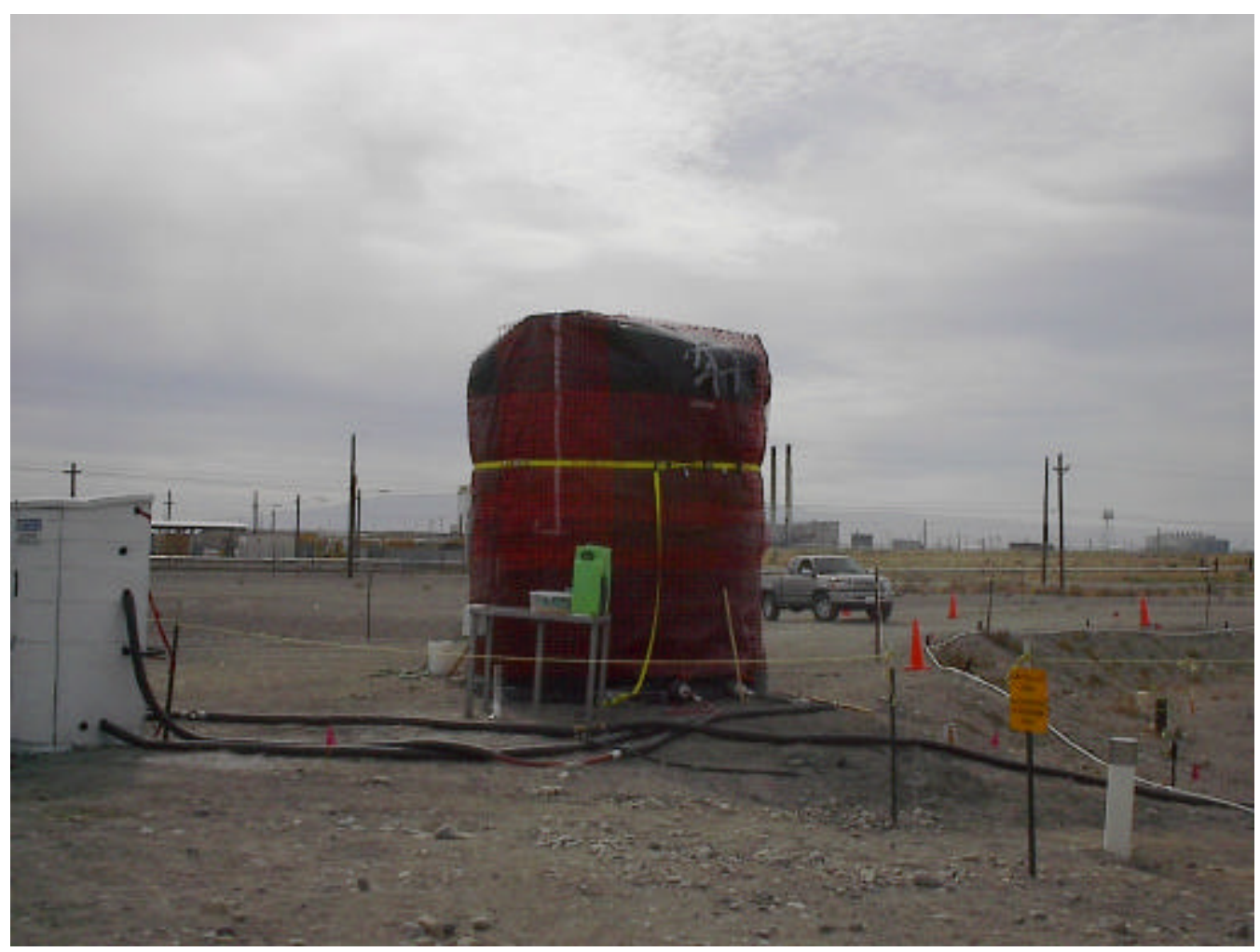

Figure 2.17. Sodium Thiosulfate Solution Storage Tank After Installation of Insulation Blanket

\subsubsection{Rain-Simulation System}

A sprinkler system was used to simulate rainfall at the site (Figure 2.18). Two 9463-L (2500-gal) tanks provided water to a pump-fed irrigation system consisting of two rings of sprinklers that were designed to provide even distribution of water across the area adjacent to the mock-tank structure. An $\mathrm{AgVision}^{\mathrm{TM}}$ irrigation controller controlled the flow to the sprinklers and recorded the cumulative flow (Figure 2.19).

The tops of point-electrodes and fused ERT arrays were intentionally exposed at the surface to allow any effects of precipitation (natural or controlled) to affect the sensor systems and thus to observe any related effects on electrical measurement systems. 


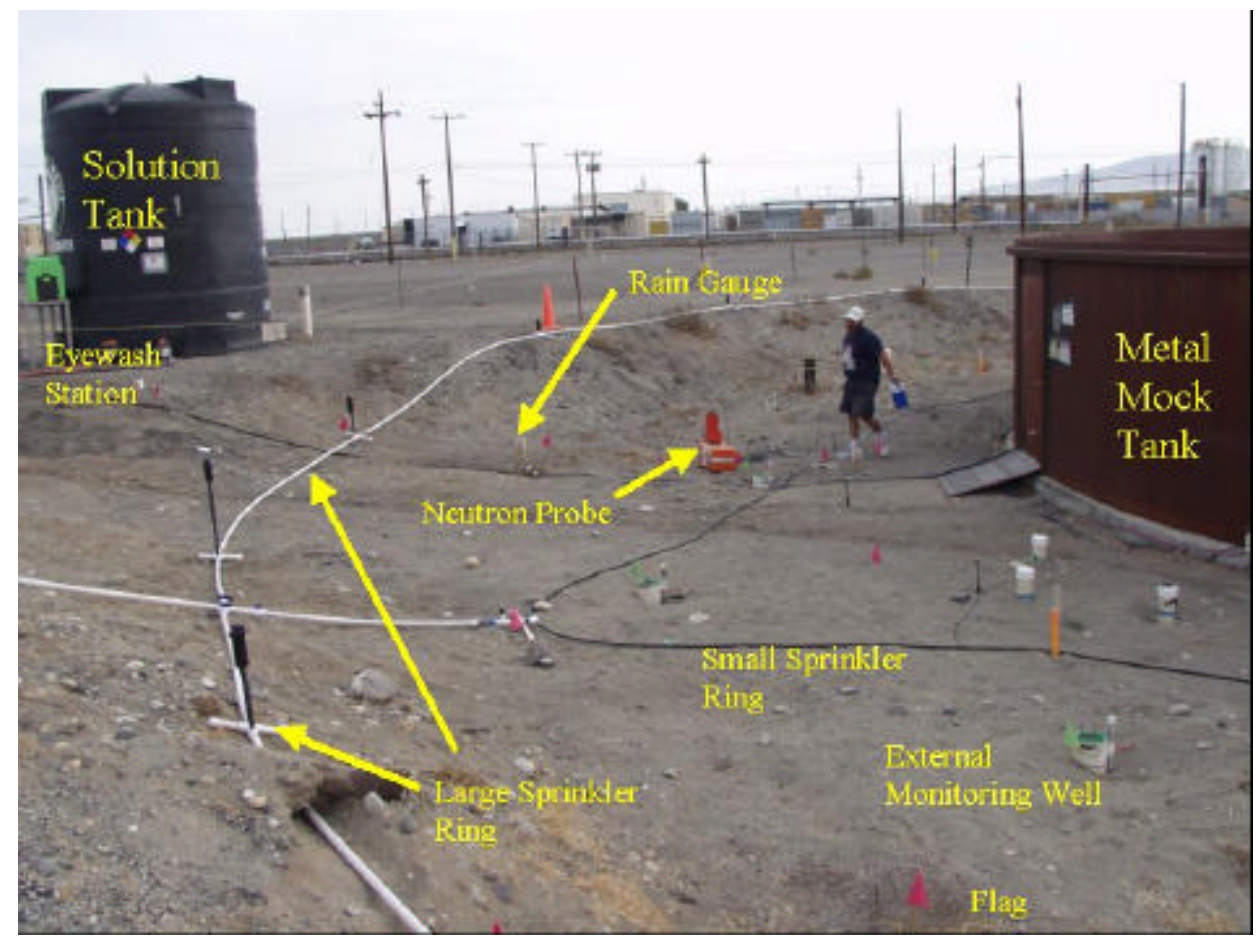

Figure 2.18. Layout of the Rain-Simulation System. The $9463 \mathrm{~L}$ (2500-gal) Tanks used for storing raw water are out of view to the right.

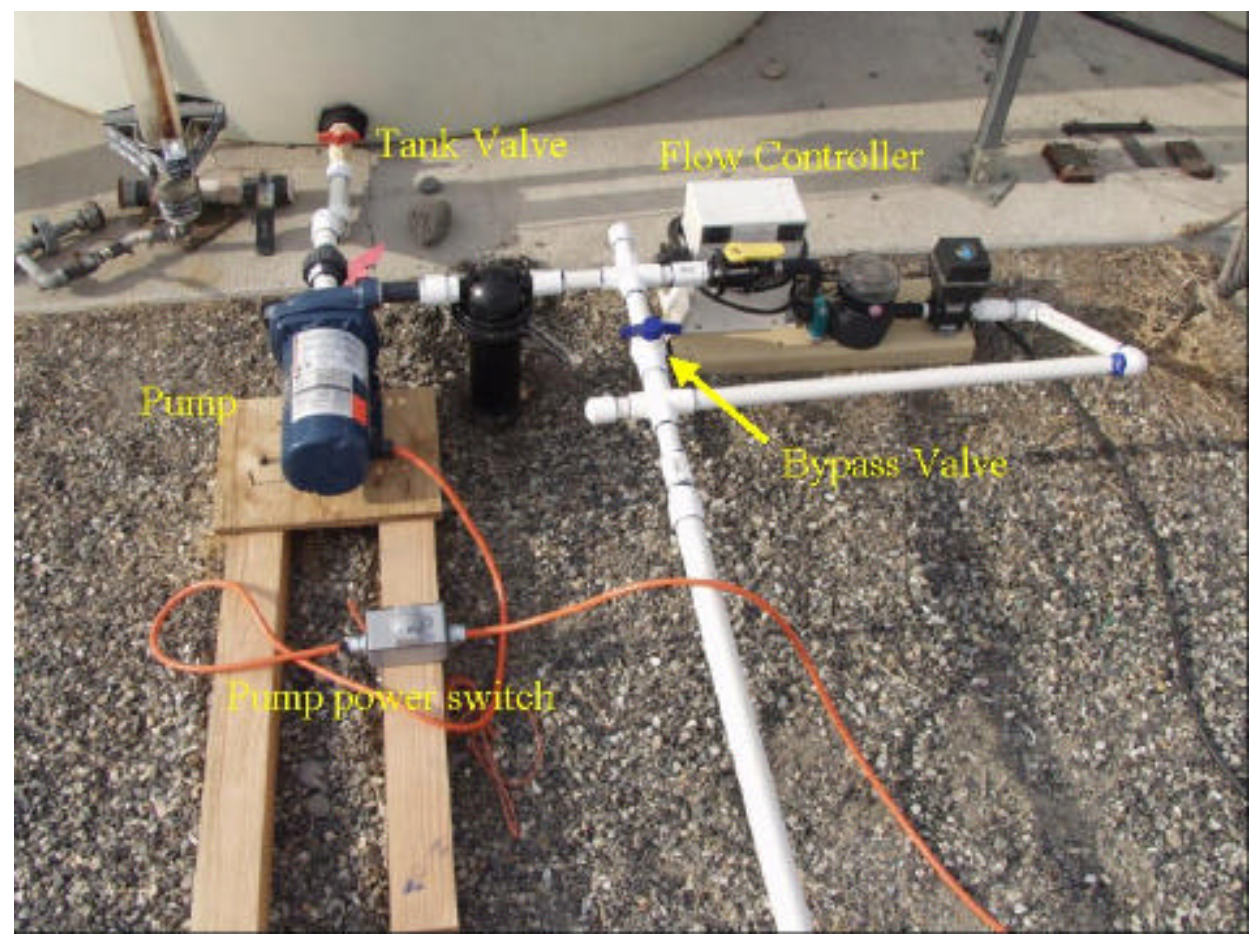

Figure 2.19. Pump and Controller Configuration for the Rain-Simulation System 


\subsubsection{Solution-System and Site Data-Monitoring Equipment}

LabView System. LabView, a controlling and data logging software by National Instruments (Austin, $\mathrm{TX}$ ), was chosen to manage and automatically log data collected during field activities. LabView is a graphicaldevelopment environment specifically designed for measurement and automation applications. Figure 2.20 is a picture of the LabView interface during the metering-pump system control period. The LabView program would collect data at user-defined intervals (generally $10 \mathrm{~min}$ ) and store them in Microsoft Excelcompatible data files. The interface included graphical readouts that provided data trends over an 8-hr period. LabView was used to control the solution delivery system and to continuously monitor the flow system and rain gauges. The LabView system was updated over the term of the project to reflect changes in solution delivery apparatus.

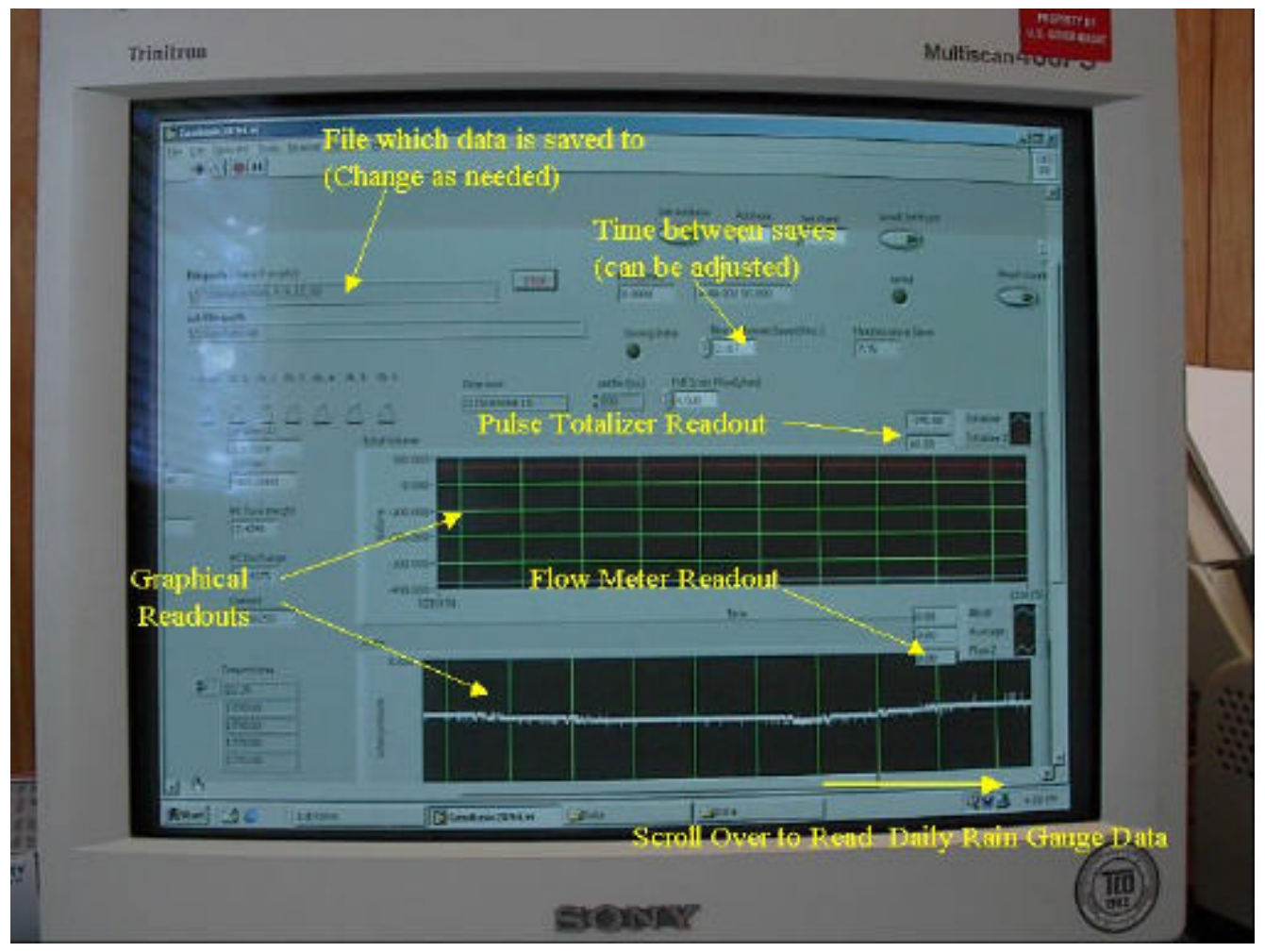

Figure 2.20. LabView Screen (during Metering Pump System Control Period

Alicat PID Controller. The Alicat flow controller and the Omega wheetbased flow totalizer were hooked up to the LabView system via pulse analog outputs. In addition, the LabView system also had inputs into the Alicat flow controller and to the power supply relay for the main solution pump. This enabled LabView to control the flowrate set point of the Alicat flow controller and toggle the recirculation pump on and off; these capabilities were not used for remote-operation purposes during the PE test series.

Metering Pump System. The Signet flow meter and the Omega pulse totalizer were attached to the LabView system by pulse analog outputs; data were collected at user-defined intervals (generally $10 \mathrm{~min}$ ) and stored in MS Excelcompatible data files. However, the LabView had no control capabilities for the metering pumps, which had to be set by a manual controlling screw. The totalizer readouts would reset after 1136-L (300-gal) increments, requiring these increments to be totaled in analytical spreadsheets. 
Rain Gauges. Rain gauges were attached to LabView via pulse-analog outputs. The program was designed to total the pulse outputs for each day and then reset the reading at midnight. This enabled calculation of natural and artificialrainfall. Table 2.2 summarizes the calibration of the rain gauge outputs.

Table 2.2. Summary of Rain Gauge Calibrations

\begin{tabular}{|lll|l||}
\hline \multicolumn{3}{|c|}{ Rain Gauge } & mm of Rain per Pulse \\
\hline North & 1.75 & $\mathrm{~m}$ & 1.040 \\
\hline North & $5.5 \quad \mathrm{~m}$ & 1.036 \\
\hline North & $10.75 \mathrm{~m}$ & 1.091 \\
\hline East & 1.75 & $\mathrm{~m}$ & 1.060 \\
\hline East & $5.5 \quad \mathrm{~m}$ & 1.080 \\
\hline East & $10.75 \mathrm{~m}$ & 1.000 \\
\hline South & $1.75 \mathrm{~m}$ & 1.000 \\
\hline South & $5.5 \mathrm{~m}$ & 0.980 \\
\hline South & $10.75 \mathrm{~m}$ & 1.000 \\
\hline West & $1.75 \mathrm{~m}$ & 1.100 \\
\hline West & $5.5 \quad \mathrm{~m}$ & 1.072 \\
\hline West & $10.75 \mathrm{~m}$ & 1.036 \\
\hline Trailer & 1.000 \\
\hline
\end{tabular}

\subsubsection{Geophysical Data-Collection Systems}

The electrical resistivity equipment used during testing at the Mock Tank Site in 2002 includes several standard items: a current transmitting device, a receiving instrument, a data-logging apparatus, signal multiplexing equipment, and ancillary equipment to minimize interferences from extraneous electrical sources (e.g., electrical grounding rods).

\subsubsection{Reasons for Selection of the Equipment}

Two systems were proposed for FY2002 testing. Each of the selected principal investigation teams was planning to use systems similar to those used in FY2001. The hydroGEOPHYSICS team had initially planned on using an Advanced Geosciences Inc. (AGI) Super Sting, which provides source current transmitting, potential measurement, multiplexing, and data-logging capabilities all in one unit. LLNL had included in their equipment plans the Zonge (GDP-series) system. The Zonge equipment has a separate transmitter, current power supply, data-acquisition unit (receiver/data logger), and multiplexer (see Appendix C, Figures C.5 and C.6).

The wiring and switching plans developed early in the FY2002 planning assumed a two-part acquisition-system approach. This approach broke down as it became apparent that the equipment necessary to switch two dissimilar testing systems between two differing surveying techniques was going to drive deployment costs to an unacceptable level. This approach was further complicated by the inability to network two systems and maintain network control of the solution-delivery system. The compromise system instead relied on the Zonge equipment connected with a simpler wiring scheme (See 
Appendix C). All electrodes were wired into one common harness and were multiplexed by three Zonge multiplexer units. The multiplexer outputs were fed to the Zonge GDP receiving unit that was under the common control of a desktop computer situated in the mobile laboratory.

\subsubsection{HLAN (Remote Communications and Control Capabilities)}

Operational continuity of geophysical testing at the Mock Tank Site required that either personnel be present in the mobile laboratory for the duration of testing or that some type of remote data link be established to facilitate equipment activation and data transfer. Due to the high cost associated with permanently manning the mobile laboratory and testing a proof-of-concept for tank-farm deployment, it was decided that a data and control link to the site would be installed.

Several types of network connectivity were considered for installation: wireless remote transmission links, two-way satellite networking, and Category 3 or 5 connections. Wireless transmission involved using a microwave repeater with a line-of-sight connection within the 200-East Area. The capabilities of a wireless network are well within the bandwidth requirements of the testing protocol (e.g., $>56 \mathrm{~Kb} / \mathrm{s}$ connection), but the maturity of the technology as deployed in the 200-East Area was not considered to be robust enough to meet the technical requirements of the test. Satellite systems also meet or exceed throughput requirements, but commercial vendors were unwilling to service a remote site for the timeframe established for this test. Affordable satellite systems were also unavailable because of their focus on the residential and small-business market.

The two remaining technologies, both with established service in the 200-East Area, relied on direct wire connection to the site. A Category 3 (CAT 3) or Category 5 (CAT 5) connection was evaluated due to the relatively inexpensive installation costs and the low total operational cost of providing the networking service. The first system to be considered was the standard Hanford Local Area Network (HLAN) connection that uses an industry standard CAT 5 wiring convention. The CAT 5 system is the most prevalent system used in inter- and intra-office networking via a local area network (LAN). The throughput, depending on intervening router and switch configurations, can reach $1 \mathrm{~Gb} / \mathrm{s}$. The difficulty in establishing this type of connection, however, is caused by the reliance of the HLAN on fiber-optic feed lines to the host site. A cooling system would have been necessary for maintaining a long-term presence for this type of network connection to the Mock Tank Site. Ultimately, it was decided that a CAT 3 arrangement, the type of connection normally associated with digital telephony, would be the proper networking technique for the test.

The CAT 3 network relied on digital telephone access that is readily available throughout the 200East Area. It uses the Asynchronous Digital Signal Line (ADSL) technology to provide network capability to the remote host. Two ADSL lines were installed to provide sufficient network bandwidth for the two remote computers that would occupy the site for the duration of the test. One additional benefit of the ADSL connection was that voice telephony would be provided concurrently to the digital access without interrupting the computer connection. Two ADSL modems were delivered to the site to provide the connection points for the two networked computers that formed the remote data acquisition and solution control for the test program. 


\subsubsection{Combining Data Collection Efforts for Both Electrical Methods}

Due to cost and schedule considerations, both groups of investigators agreed to a combined data acquisition system (Appendix C, Figure C.2 and Figure 2.21). The data were logged to a common computer that also provided remote access and control to the logging-equipment schedules (firing order for the transmitter and receiver). The common wiring system was easier to construct and maintain as well as troubleshoot.

The common system was not the optimal system for the hydroGEOPHYSICS team. There was a trade-off in accepting a common transmitter/power supply combination. The Zonge transmitter derives its power from an external source, in this case a Hewlett-Packard power supply owned by LLNL. The setting of 50 to 70 amps was greater than the current requirements of the HRR-SCRT system used in FY2001. The hydroGEOPHYSICS investigators recognized this limitation and were eventually assured that the higher currents would not negatively impact their results.

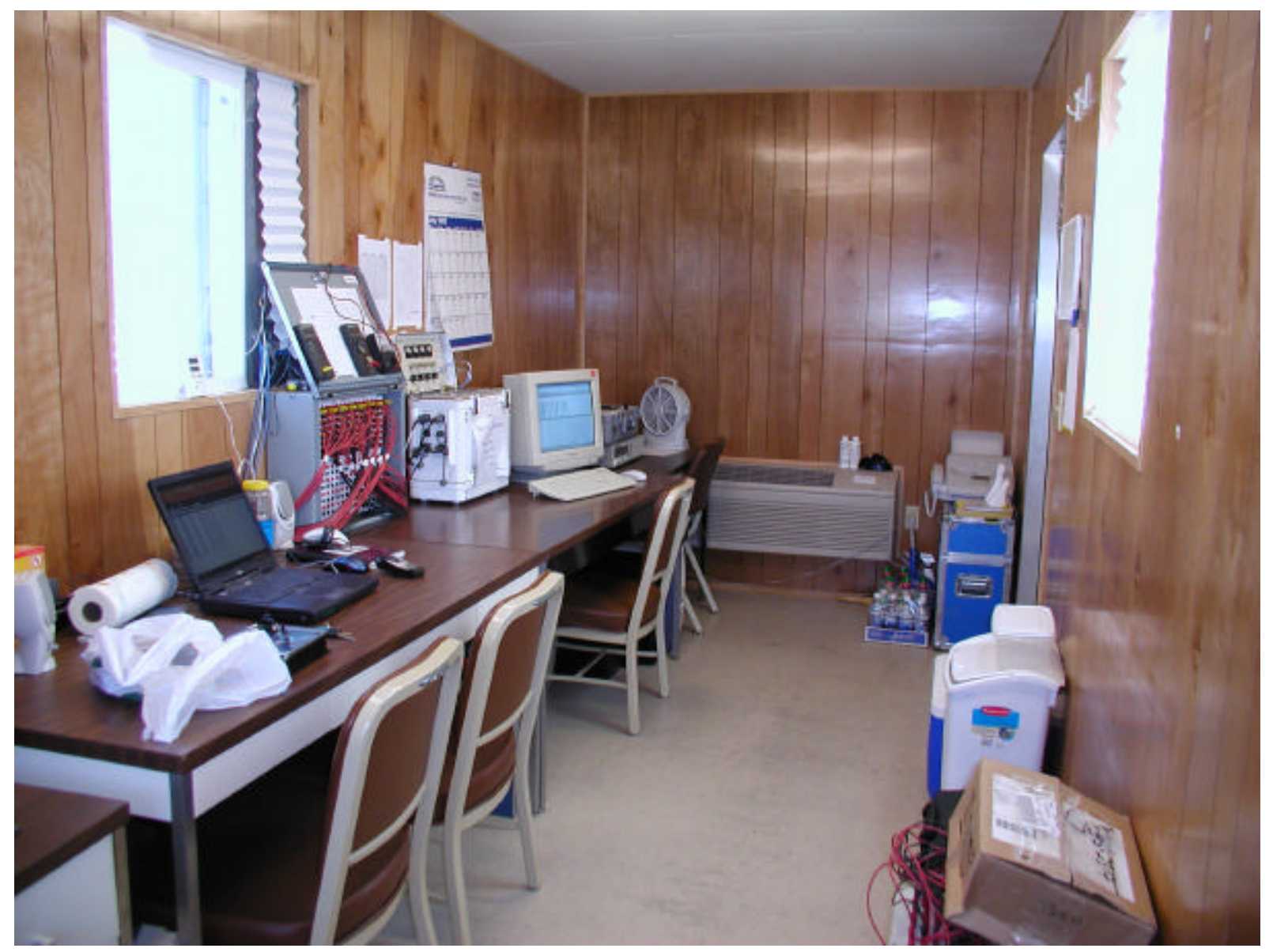

Figure 2.21. Interior of the Mock Tank Field Office Showing Instrumentation and Communication Systems. A CAT 3 internet link and phone lines enabled remote operation of equipment during the test. 


\subsection{Summary of FY 2002-2003 PE Tests}

\subsection{Geophysical Methods Descriptions}

The two electrical methods (ERT and HRR-SCRT) described in following sections were selected for testing from a group of nine different geophysical methods by a downselect panel in January, 2002. Details of the various methods and the downselection process are provided in Bratton (2002). Since the methods have not actually been deployed in a tank farm, it was decided that the PE tests be conducted at a clean site before testing and subsequent deployment in a tank farm. The experimental set up, test results, summary, and recommendations are provided in the sections that follow.

\subsubsection{Electrical Resistance Tomography}

The two electrical methods fielded by LLNL for this Test Series include a point-electrode design similar to resistivity surveys conducted at the Mock Tank Site in FY95 and FY00 as well as a method that uses steel well casings as electrodes (Barnett et al. 2002). The basis of these methods is the injection of current via a pair of electrodes into the subsurface near the target feature (dipole-dipole configuration). The resulting potential field is measured using another pair of electrodes. Successive measurements are gathered on other electrode pairs until all permutations of electrode receiver pairs have been exhausted, or until a predetermined lower threshold of electrode measurements has been gathered.

\subsubsection{ERT Point-Electrode Tomography}

The point electrode design (ERT-Point Electrode Tomography [PET]) is the method that produces apparent resistivity measurements that can be resolved into a three-dimensional resistivity plot. The electrodes in each of the vertical array strings are electrically isolated enough to produce geometrically discrete sampling for potential measurements. The density of the ele ctrodes, as well as their position in the subsurface with respect to the target, determines the resolution of this method. Electrode pairs are alternatively used as current sources and potential measurement points throughout one sampling cycle. A schedule read by the data-acquisition unit changes the arrangement of electrode charging and sampling points by remotely activating a multiplexing unit that handles both transmitted and received signals. As signals are passed through the target area, the potential field's distribution is mapped and recorded by the data-acquisition unit for further post-processing. As liquids or gasses pass through the target area, the effect they have on the electrical properties of the subsurface are preserved in the data as changes in the potential field.

\subsubsection{ERT Long-Electrode Tomography}

The second electrical method used by the LLNL researchers employed steel well casings as electrodes. The basis of this electrical-resistance survey is the same, but the spatial resolution of the method is less than that of ERT-PET. This method (ERT-Long Electrode Tomography [LET]) also uses two current and two potentialmeasuring electrodes to gather subsurface data. While ERT-PET data produce three-dimensional images from multiple ray paths, ERT-LET produces two-dimensional images using low-density potential field measurements. The method is still capable of generating a map of potential field distribution, but only as a horizontal slice of the target volume. 


\subsubsection{High-Resolution Resistivity-Steel Casing Resistivity Technology}

This method also uses the basis of current injection in the subsurface and the measurement of the potential fields that are produced. The significant differences between HRR-SCRT and the ERT methods include the use of linear surface arrays and a proprietary algorithm for calculating resistivity distribution. As with the ERT methods, the HRR-SCRT technique uses two electrodes to inject current into the subsurface around a target and then measures the resulting potential field with a second pair of electrodes. The electrodes that are comprised by the linear arrays provide a dense measurement grid at the surface. The tank and the steel well casings are alternatively used as both a source of current and as a potential field-measurement electrode. The use of a current electrode at the point of injection creates a mise-j-lamasse configuration where the test fluid is charged, and its effect on the subsurface resistivity distribution is tracked with the potential field measurements. The steel well casings also measure the change in resistivity distribution and can be used as a current source electrode. The linear surface arrays are used only to measure potential fields - their effect on the method is to provide additional horizontal distribution information and to provide depth correction/information.

HRR-SCRT collected eight different data sets during the Test Series, all using two-electrode polepole measurements in the following combinations :

- steel casings to injection system (with reciprocals)

- steel casings to surface electrodes (without reciprocals)

- steel casings to fused point arrays simulating a steel casing (with reciprocals)

- steel casing to steel casing (with reciprocals)

- fused arrays to injection system (with reciprocals)

- fused arrays to surface electrodes (without reciprocals)

- fused array to fused array (with reciprocals)

- injection system to surface electrodes (without reciprocals).

The data are post-processed by investigators using a proprietary algorithm. Plots of resistivity distribution in plan and profile view are produced as well as a time-series plot of normalized potential. The profile data have been corrected for topographic elevation, and the plots show the changes of resistivity in the target area in response to changes brought about by liquid or gas movements

\subsection{Schedule and Implementation Plan}

The general timeline of events, as planned, for FY 2002-2003 is presented in Appendix A, which is the test-implementation plan. The final version of the Implementation Plan (see Appendix A) includes the changes in procedure brought about through operational experience as well as changes in process equipment and instrumentation necessitated by equipment reliability and compatibility issues that arose during the conduct of the test. Changes to the schedule of the Test Series, or to the operational parameters of individual tests, are also included. 


\subsubsection{Test and Schedule Changes}

The Test Matrix was revised continually throughout the test, both to accommodate process-system capabilities as process equipment was changed out and to assure delivery of adequate solution flowrates at the tank leak ports (it was found some could not accept higher flowrates). See the final Implementation Plan (Appendix A) for details of test and schedule changes.

\subsection{Scheduled Events and Data Acquisition}

ERT collected two data sets; the first set was collected using the 56 point electrodes (ERT-PET) using 4-electrode measurements, with both the transmitter and receiver dipoles spanning three electrodes. This produced 1296 linearly independent measurements and their reciprocal pairs. The second data set acquired used the ERT-LET technique; eight steelcasing electrodes were sampled using 4-electrode measurements, with the transmitter and receiver electrodes both spanning one electrode. This produced 20 linearly independent measurements and their reciprocal pairs. Details of ERT data collection and analysis are included in Appendix D.

Data collected by the HRR-SCRT configurations were analyzed using four different methods and time windows of 2-hr, 6-hr, and 24-hr intervals. Details of data collection and analysis for HRR-SCRT methods are included in Appendix C.

\subsubsection{Operational Data}

Thirteen leak events, four simulated-rain events, and one flood event were carried out over the 110 days of the test series, beginning on July $22^{\text {nd }}$ and ending on November $8^{\text {th }}$. Data collection also occurred before and following the test period. These activities are detailed in the following sections.

\subsubsection{Solution-Release Data}

Flow data were calculated based on relationships between releases and various meter readings. Table 3.1 summarizes the basis of these calculations for each test. The first three flow events (B, D, and F) used an Alicat PID flow controller and an Omega totalizer. The Omega totalizer did not function reliably, and data from this device were not used. Total solution delivery was calculated during this period using the flowrate data from the Alicat controller. These data were adjusted by calibration factors to give the flowrate, and then the rate was integrated over time to give the cumulative volume

On September $5^{\text {th }}$, a new flow-control system was installed using metering pumps, a Signet flow meter, and a mechanical totalizer with pulse output. A calibration curve was developed for the Signet meter; it was determined that the pulse-output totalizer readings could be used without corrections.

The decision to use the pulse-totalizer data as the primary delivered-volume indicator for these injections was based on two considerations: integrating the flow-meter data may produce errors if the flow is unstable, and the pulse totalizer data generally agreed with periodic gravimetric measurements taken during the various tests better than the flow meter. 
However, it became necessary to use flow-meter calculations for two events (T and Y) later in the program. The pulse totalizer did not function at the 7.6-L/hr (2-gph) level; this flowrate was below its design parameters. A 7.6-L/hr (2-gph) flow event (event T) was conducted from October $21^{\text {st }}$ to October $25^{\text {th }}$. Flow-meter calculations were used for this event, and a special calibration curve was derived on October $17^{\text {th }}$. The pulse totalizer stopped functioning for flow event Y, making it necessary to use flowmeter data to calculate volume.

The final injection, Y, was targeted at $76 \mathrm{~L} / \mathrm{hr}(20 \mathrm{gph})$. As the injection began, it became clear the pulse totalizer was malfunctioning and that the Signet flow-meter calibration of September $6^{\text {th }}$ was no longer accurate. A new calibration curve was derived using gravimetric measurements conducted during the injection event.

Table 3.2 summarizes flow events during the PE test. There were 14 discharge events; only one discharge event did not meet the delivery goals, Event P. This event was 6.7 percent higher than the goal of $20 \mathrm{gph}$, which exceeded the 5-percent tolerance specified. Figure 3.1 shows actual cumulative flow versus the target delivery volume. As seen in Table 3.2 and the graph of Figure 3.1, the final delivery was within the 5-percent error bars, as were all but one release. Although some deviations occur, these usually resulted from variations in start times for the tests; the final delivery volumes were invariably within goals. 
Table 3.1. Summary of Flow Events and Their Basis of Flow Calibration and Calculation. $x=$ meter reading (generally $\mathrm{L} / \mathrm{min}$ ). $y=$ actual flow (gph). (Note: The set point was calculated using a quadratic fit, and then the linear ratio was applied.)

\begin{tabular}{|c|c|c|c|c|}
\hline $\begin{array}{c}\text { Flow ID } \\
\text { (dates) }\end{array}$ & $\begin{array}{l}\text { Flow } \\
\text { Meter }\end{array}$ & $\begin{array}{c}\text { Correction Factor for Flow Meter } \\
\text { (basis) }\end{array}$ & Totalizer & \begin{tabular}{|c|}
$\begin{array}{c}\text { Primary Basis of Flow } \\
\text { Calculation }\end{array}$ \\
\end{tabular} \\
\hline $\begin{array}{l}\mathrm{B} \\
(7 / 26-8 / 15)\end{array}$ & Alicat & $\begin{array}{l}\text { Quadratic Fit } \\
\mathrm{y}=3.7363 \times 3-6.2181 \times 2+20.683 \mathrm{x} \\
\text { (calibration conducted } 7 / 23 \& 24)\end{array}$ & Not operational & $\begin{array}{l}\text { Calculated from Alicat } \\
\text { meter }\end{array}$ \\
\hline $\begin{array}{l}\mathrm{D} \\
(8 / 21-8 / 23)\end{array}$ & Alicat & $\begin{array}{l}\text { Linear Fit } \\
y=16.736 x * \\
\text { (calibration conducted } 7 / 23 \& 24)\end{array}$ & Not operational & $\begin{array}{l}\text { Calculated from Alicat } \\
\text { meter }\end{array}$ \\
\hline $\begin{array}{l}\mathrm{F} \\
(8 / 27-8 / 29)\end{array}$ & Alicat & $\begin{array}{l}\text { Square Fit } \\
y=215 x 2-339.35 x+153.79 \text { (calibration } \\
\text { conducted } 8 / 27 \text { ) }\end{array}$ & Not operational & $\begin{array}{l}\text { Calculated from Alicat } \\
\text { meter }\end{array}$ \\
\hline I $(9 / 7-9 / 10)$ & Signet & $\begin{array}{l}\text { Linear Fit } \\
y=14.472 x \\
\text { (calibration conducted } 9 / 6 \& 7 \text { ) }\end{array}$ & Operational & Uncorrected totalizer \\
\hline$(9 / 10-9 / 12)$ & Signet & $\begin{array}{l}\text { Linear Fit } \\
y=14.472 x \\
\text { (calibration conducted } 9 / 6 \& 7 \text { ) }\end{array}$ & Operational & Uncorrected totalizer \\
\hline $\begin{array}{l}\mathrm{K} \\
(9 / 19-9 / 22)\end{array}$ & Signet & $\begin{array}{l}\text { Linear Fit } \\
y=14.472 x \\
\text { (calibration conducted } 9 / 6 \& 7 \text { ) }\end{array}$ & Operational & Uncorrected totalizer \\
\hline $\begin{array}{l}\mathrm{M} \\
(9 / 22-9 / 27)\end{array}$ & Signet & $\begin{array}{l}\text { Linear Fit } \\
y=14.472 x \\
\text { (calibration conducted } 9 / 6 \& 7 \text { ) }\end{array}$ & Operational & Uncorrected totalizer \\
\hline $\begin{array}{l}\mathrm{P} \\
(10 / 4-10 / 8)\end{array}$ & Signet & $\begin{array}{l}\text { Linear Fit } \\
y=14.472 x \\
(\text { calibration conducted } 9 / 6 \& 7 \text { ) }\end{array}$ & Operational & Uncorrected totalizer \\
\hline $\begin{array}{l}\mathrm{R} \\
(10 / 11-10 / 13)\end{array}$ & Signet & $\begin{array}{l}\text { Linear Fit } \\
y=14.472 x \\
\text { (calibration conducted } 9 / 6 \& 7 \text { ) }\end{array}$ & Operational & Uncorrected totalizer \\
\hline \begin{tabular}{|l|}
$\mathrm{T}$ \\
$(10 / 21-10 / 25)$
\end{tabular} & Signet & $\begin{array}{l}\text { Linear Fit } \\
y=16.099 x \\
\text { (calibration conducted } 10 / 17)\end{array}$ & $\begin{array}{l}\text { Not functional at } 2 \\
\text { gph }\end{array}$ & $\begin{array}{l}\text { Calculated from Signet } \\
\text { meter readings }\end{array}$ \\
\hline \begin{tabular}{|l|}
$\mathrm{V}$ \\
$(10 / 28-10 / 30)$
\end{tabular} & Signet & $\begin{array}{l}\text { Linear Fit } \\
y=14.472 x \\
(\text { calibration conducted } 9 / 6 \& 7 \text { ) }\end{array}$ & Operational & Uncorrected totalizer \\
\hline \begin{tabular}{|l|}
$\mathrm{W}$ \\
$(10 / 30-11 / 2)$
\end{tabular} & Signet & $\begin{array}{l}\text { Linear Fit } \\
y=14.472 x \\
\text { (calibration conducted } 9 / 6 \& 7 \text { ) }\end{array}$ & Operational & Uncorrected totalizer \\
\hline $\begin{array}{l}\mathrm{Y} \\
(11 / 5-11 / 7)\end{array}$ & Signet & $\begin{array}{l}\text { Linear Fit } \\
y=18.45 x \\
\text { (calibration based on gravimetric } \\
\text { measurements collected during test) }\end{array}$ & Not operational & $\begin{array}{l}\text { Calculated from Signet } \\
\text { meter readings }\end{array}$ \\
\hline
\end{tabular}


Table 3.2. Summary of Flow Events: Goals vs. Flow Calculations

\begin{tabular}{||l|c|c|c|c|c||}
\hline $\begin{array}{c}\text { Flow ID } \\
\text { (dates) }\end{array}$ & $\begin{array}{c}\text { Target Flow } \\
\text { (gph) }\end{array}$ & $\begin{array}{c}\text { Acceptable } \\
\text { Range (gph) }\end{array}$ & $\begin{array}{c}\text { Average Flow from } \\
\text { Flow Meter } \\
\text { (gph) }\end{array}$ & $\begin{array}{c}\text { Flow Calculated } \\
\text { from Totalizer } \\
\text { (gph) }\end{array}$ & $\begin{array}{c}\text { Ave. Gravimetric } \\
\text { Rate (gph) }\end{array}$ \\
\hline \hline \multicolumn{7}{|c||}{ Alicat Controlled } \\
\hline $\mathrm{B}(7 / 26-8 / 15)$ & 2 & 1.90 to 2.10 & $2.011 \pm 0.102$ & Not operational & $1.985 \pm 0.041$ \\
\hline $\mathrm{D}(8 / 21-8 / 23)$ & 20 & 19.0 to 21.0 & $20.094 \pm 0.073$ & Not operational & $20.100 \pm 0.198$ \\
\hline $\mathrm{F}(8 / 27-8 / 29)$ & 20 & 19.0 to 21.1 & $19.988 \pm 0.395$ & Not operational & $19.815 \pm 0.973$ \\
\hline \multicolumn{7}{|c||}{ Metering Pump Controlled } \\
\hline $\mathrm{I}(9 / 6-9 / 10)$ & 10 & 9.5 to 10.5 & $10.027 \pm 0.028$ & $9.774 \pm 0.028$ & $9.841 \pm 0.064$ \\
\hline $\mathrm{J}(9 / 10-9 / 12)$ & 20 & 19.0 to 21.0 & $18.668 \pm 0.114$ & $20.124 \pm 0.229$ & $20.279 \pm 0.104$ \\
\hline $\mathrm{L}(9 / 19-9 / 22)$ & 10 & 9.5 to 10.5 & $10.101 \pm 0.078$ & $9.797 \pm 0.123$ & $9.763 \pm 0.089$ \\
\hline $\mathrm{M}(9 / 22-9 / 27)$ & 10 & 9.5 to 10.5 & $10.197 \pm 0.067$ & $9.799 \pm 0.034$ & $9.729 \pm 0.162$ \\
\hline $\mathrm{P}(10 / 4-10 / 8)$ & 20 & 19.0 to 21.0 & $19.283 \pm 0.730$ & $21.322 \pm 1.759$ & $20.498 \pm 0.336$ \\
\hline $\mathrm{R}(10 / 11-10 / 15)$ & 20 & 19.0 to 21.0 & $18.778 \pm 0.088$ & $20.721 \pm 0.087$ & $20.428 \pm 0.069$ \\
\hline $\mathrm{T}(10 / 21-10 / 25)$ & 2 & 1.90 to 2.10 & $2.038 \pm 0.049$ & Not operational & $1.997 \pm 0.023$ \\
\hline $\mathrm{V}(10 / 28-10 / 30)$ & 10 & 9.5 to 10.5 & $10.291 \pm 0.055$ & $10.127 \pm 0.020$ & $10.188 \pm 0.078$ \\
\hline $\mathrm{W}(10 / 30-11 / 2)$ & 20 & 19.0 to 21.0 & $16.133 \pm 0.379$ & $19.975 \pm 0.261$ & $19.995 \pm 0.493$ \\
\hline Y (11/5-11/7) & 20 & 19.0 to 21.0 & $20.243 \pm 0.164$ & Not functional & $19.923 \pm 0.412$ \\
\hline Yellow indicates numbers used for performance assessment. \\
\hline
\end{tabular}

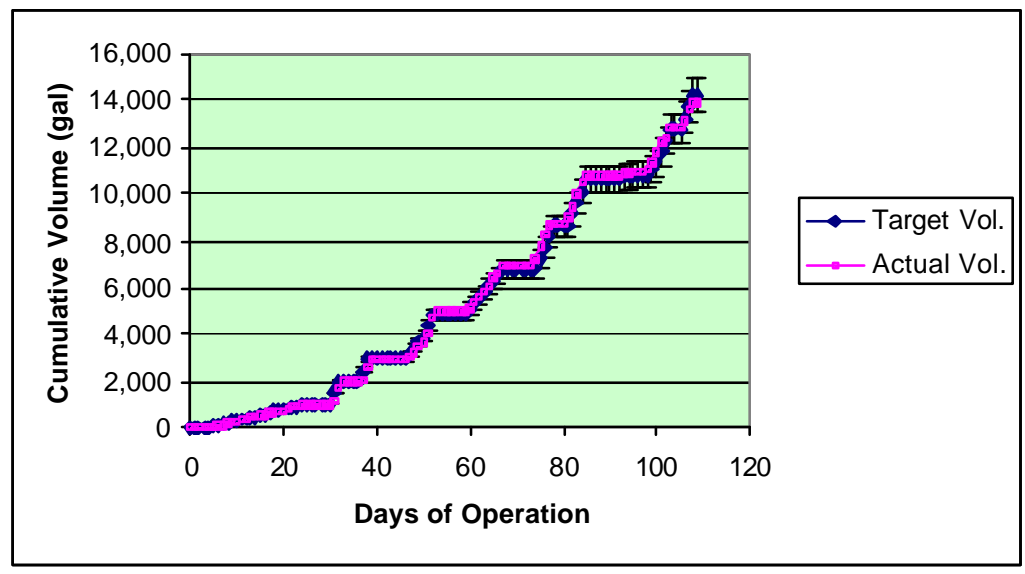

Figure 3.1. Cumulative Volume Vs. Time: Target Volume vs. Actual

Table 3.3 is a complete data table that contains daily measurements of solution releases during the project, cumulative flow, average flowrates during specific time periods, locations of leaks, and comments on other events. The flow-events schedule of October $10^{\text {th }}$ had a goal of $53,782 \mathrm{~L}(14,208$ gal). The final calculated delivery volume was $52,707 \mathrm{~L}(13,924)$ gal. This represents a deviation of $2 \%$, within the $5 \%$ designated in the test plan. 
Table 3.3. Cumulative Flow Table

\begin{tabular}{|c|c|c|c|c|c|c|c|c|c|}
\hline \multirow[b]{2}{*}{ Date } & \multirow[b]{2}{*}{ Day } & \multirow[b]{2}{*}{ ID } & \multicolumn{7}{|c|}{ Actual Injection } \\
\hline & & & Locale & $\begin{array}{c}\text { Time of } \\
\text { Test } \\
\text { Change }\end{array}$ & $\begin{array}{l}\text { Average } \\
\text { Rate gph }\end{array}$ & $\begin{array}{c}\text { Average Rate } \\
2300-2400 \\
\text { gph }\end{array}$ & $\begin{array}{c}\text { Average Rate } \\
1800 \text { - 2400 } \\
\text { gph }\end{array}$ & $\begin{array}{l}\text { Volume } \\
@ 2300 \mathrm{hr}\end{array}$ & Comments \\
\hline 22-Jul & 0 & A & L3 & $14: 00$ & & & & $\mathbf{0}$ & \\
\hline 23-Jul & 1 & A & L3 & & & & & $\mathbf{0}$ & \\
\hline 24-Jul & 2 & $\mathrm{~A}$ & L3 & & & & & $\mathbf{0}$ & \\
\hline 25-Jul & 3 & $\mathrm{~A}$ & L3 & & & & & $\mathbf{0}$ & \\
\hline 26-Jul & 4 & B & L1 & $8: 03$ & 2.00 & 1.995 & 1.995 & 30 & $\begin{array}{l}\text { LabView not active until 18:30 } \mathrm{pm} \text {. There was a one-hour } \\
\text { disruption in the flow from 17:00 to 18:00 }\end{array}$ \\
\hline 27-Jul & 5 & $\mathrm{~B}$ & L1 & & 2.00 & 1.950 & 1.992 & 77 & \\
\hline 28-Jul & 6 & $\mathrm{~B}$ & L1 & & 2.00 & 1.954 & 1.963 & 125 & \\
\hline 29-Jul & 7 & $\mathrm{~B}$ & L1 & & 2.00 & 2.015 & 2.016 & 173 & \\
\hline 30-Jul & 8 & $\mathrm{~B}$ & L1 & & 2.00 & 1.981 & 1.997 & 223 & \\
\hline 31-Jul & 9 & $\mathrm{~B}$ & L1 & & 2.00 & 1.981 & 2.008 & 269 & \\
\hline 1-Aug & 10 & $\mathrm{~B}$ & L1 & & 2.00 & 2.028 & 2.024 & 317 & \\
\hline 2-Aug & 11 & $\mathrm{~B}$ & L1 & & 2.00 & 1.981 & 1.981 & 365 & \\
\hline 3-Aug & 12 & $\mathrm{~B}$ & L1 & & 2.00 & 2.005 & 2.010 & 413 & \\
\hline 4-Aug & 13 & $\mathrm{~B}$ & L1 & & 2.00 & 2.001 & 2.001 & 461 & \\
\hline 5-Aug & 14 & $\mathrm{~B}$ & L1 & & 2.00 & 2.010 & 2.007 & 509 & \\
\hline 6-Aug & 15 & $\mathrm{~B}$ & L1 & & 2.00 & 1.992 & 2.006 & 557 & \\
\hline 7-Aug & 16 & $\mathrm{~B}$ & L1 & & 2.00 & 2.021 & 2.009 & 605 & \\
\hline 8-Aug & 17 & $\mathrm{~B}$ & L1 & & 2.00 & 2.013 & 2.011 & 654 & \\
\hline 9-Aug & 18 & $\mathrm{~B}$ & L1 & & 2.00 & 2.018 & 2.014 & 702 & \\
\hline 10-Aug & 19 & $\mathrm{~B}$ & L1 & & 2.00 & 2.038 & 2.025 & 750 & \\
\hline 11-Aug & 20 & $\mathrm{~B}$ & L1 & & 2.00 & 2.008 & 2.005 & 796 & \\
\hline 12-Aug & 21 & $\mathrm{~B}$ & L1 & & 2.00 & 2.013 & 2.015 & 845 & \\
\hline 13-Aug & 22 & $\mathrm{~B}$ & L1 & & 2.00 & 2.000 & 2.006 & 893 & \\
\hline 14-Aug & 23 & $\mathrm{~B}$ & L1 & & 2.00 & 1.989 & 2.002 & 941 & \\
\hline 15-Aug & 24 & B & L1 & & 2.00 & 2.026 & 2.068 & 990 & \\
\hline 16-Aug & 25 & $\mathrm{C}$ & L1 & $11: 00$ & 2.00 & & & 1014 & \\
\hline 17-Aug & 26 & $\mathrm{C}$ & L1 & & & & & 1014 & \\
\hline 18-Aug & 27 & $\mathrm{C}$ & L1 & & & & & 1014 & \\
\hline 19-Aug & 28 & $\mathrm{C}$ & L1 & & & & & 1014 & \\
\hline 20-Aug & 29 & $\mathrm{C}$ & $\mathrm{L} 1$ & & & & & 1014 & \\
\hline
\end{tabular}


Table 3.3. (contd)

\begin{tabular}{|c|c|c|c|c|c|c|c|c|c|}
\hline \multirow[b]{2}{*}{ Date } & \multirow[b]{2}{*}{ Day } & \multirow[b]{2}{*}{ ID } & \multicolumn{7}{|c|}{ Actual Injection } \\
\hline & & & Locale & $\begin{array}{c}\text { Time of } \\
\text { Test } \\
\text { Change }\end{array}$ & $\begin{array}{l}\text { Average } \\
\text { Rate gph }\end{array}$ & $\begin{array}{c}\text { Average Rate } \\
2300-2400 \\
\text { gph }\end{array}$ & $\begin{array}{c}\text { Average Rate } \\
1800 \text { - 2400 } \\
\text { gph }\end{array}$ & $\begin{array}{l}\text { Volume } \\
@ 2300 \mathrm{hr}\end{array}$ & Comments \\
\hline $21-$ Aug & 30 & $\bar{D}$ & L1 & $12: 13$ & 20.09 & 20.100 & 20.100 & 1221 & \\
\hline 22-Aug & 31 & $\mathrm{D}$ & L1 & & 20.09 & 20.100 & 20.100 & 1704 & \\
\hline 23-Aug & 32 & $E$ & L1 & $13: 08$ & 20.09 & & & 1985 & \\
\hline 24-Aug & 33 & $\mathrm{E}$ & $\overline{\mathrm{L} 1}$ & & & & & 1985 & \\
\hline 25-Aug & 34 & $E$ & L1 & & & & & 1985 & \\
\hline 26-Aug & 35 & $\mathrm{E}$ & L1 & & & & & 1985 & \\
\hline 27-Aug & 36 & $\mathrm{~F}$ & L3 & $17: 55$ & 19.99 & 20.010 & 20.010 & 2089 & \\
\hline 28-Aug & 37 & $\mathrm{~F}$ & L3 & & 19.99 & 20.010 & 20.010 & 2571 & \\
\hline 29-Aug & 38 & $\mathrm{G}$ & L3 & $17: 55$ & 19.99 & & & 2941 & \\
\hline 30-Aug & 39 & $\mathrm{G}$ & L3 & & & & & 2941 & Rain Event 406 gallons $14: 00$ to $14: 20$ \\
\hline 31-Aug & 40 & $\mathrm{G}$ & L3 & & & & & 2941 & \\
\hline $1-\mathrm{Sep}$ & 41 & $\mathrm{G}$ & L3 & & & & & 2941 & \\
\hline 2 -Sep & 42 & $\mathrm{H}$ & L10 & & & & & 2941 & \\
\hline 3-Sep & 43 & $\mathrm{H}$ & L10 & & & & & 2941 & \\
\hline 4-Sep & 44 & $\mathrm{H}$ & L10 & & & & & 2941 & \\
\hline 5-Sep & 45 & $\mathrm{H}$ & L10 & & & & & 2941 & \\
\hline 6-Sep & 46 & I & L10 & $14: 25$ & 9.77 & 9.70 & 9.69 & 3025 & \\
\hline 7-Sep & 47 & $\mathrm{I}$ & L10 & & 9.77 & 9.765 & 9.755 & 3259 & \\
\hline 8-Sep & 48 & $\mathrm{I}$ & L10 & & 9.77 & 9.757 & 9.757 & 3497 & \\
\hline 9-Sep & 49 & I & L10 & & 9.77 & 9.751 & 9.758 & 3726 & \\
\hline 10-Sep & 50 & $\mathrm{~J}$ & L10 & & 20.12 & 20.261 & 20.168 & 4052 & \\
\hline $11-\operatorname{Sep}$ & 51 & $\mathrm{~J}$ & L10 & & 20.12 & 20.177 & 20.176 & 4556 & Rain Event 725 gallons $14: 00$ to $14: 40$ \\
\hline 12-Sep & 52 & $\mathrm{~K}$ & $\overline{L 14}$ & $15: 00$ & 20.12 & & & 4870 & \\
\hline $13-$ Sep & 53 & $\mathrm{~K}$ & L14 & & & & & 4870 & \\
\hline 14-Sep & 54 & $\mathrm{~K}$ & L14 & & & & & 4870 & \\
\hline 15-Sep & 55 & $\mathrm{~K}$ & $\overline{L 14}$ & & & & & 4870 & \\
\hline 16-Sep & 56 & $\mathrm{~K}$ & L14 & & & & & 4870 & \\
\hline $17-$ Sep & 57 & $\mathrm{~K}$ & L14 & & & & & 4870 & \\
\hline 18-Sep & 58 & $\mathrm{~K}$ & L14 & & & & & 4870 & \\
\hline 19-Sep & 59 & $\mathrm{~L}$ & L14* & $10: 28$ & 9.80 & 9.787 & 9.780 & 4994 & *Flow switched from L14 to L7 to L2 \\
\hline $20-$ Sep & 60 & $\mathrm{~L}$ & L2 & & 9.80 & 9.674 & 9.652 & 5230 & \\
\hline
\end{tabular}


Table 3.3. (contd)

\begin{tabular}{|c|c|c|c|c|c|c|c|c|c|}
\hline \multirow[b]{2}{*}{ Date } & \multirow[b]{2}{*}{ Day } & \multirow[b]{2}{*}{ ID } & \multicolumn{7}{|c|}{ Actual Injection } \\
\hline & & & Locale & $\begin{array}{c}\text { Time of } \\
\text { Test } \\
\text { Change }\end{array}$ & $\begin{array}{l}\text { Average } \\
\text { Rate gph }\end{array}$ & $\begin{array}{c}\text { Average Rate } \\
2300-2400 \\
\text { gph }\end{array}$ & $\begin{array}{c}\text { Average Rate } \\
1800 \text { - 2400 } \\
\text { gph }\end{array}$ & $\begin{array}{l}\text { Volume } \\
@ 2300 \mathrm{hr}\end{array}$ & Comments \\
\hline 21-Sep & 61 & $\mathrm{~L}$ & $\mathrm{~L} 2$ & & 9.80 & 9.687 & 9.682 & 5467 & \\
\hline 22-Sep & 62 & $\mathrm{~L}$ & L14 & & 9.80 & 9.697 & 9.681 & 5700 & Flow returned to L14 \\
\hline 23-Sep & 63 & $\mathrm{M}$ & L14 & $13: 30$ & 9.80 & 9.75 & 9.70 & 5926 & \\
\hline 24-Sep & 64 & $\mathrm{M}$ & L14 & & 9.80 & 9.83 & 9.82 & 6199 & \\
\hline 25-Sep & 65 & $\mathrm{M}$ & L14 & & 9.80 & 9.83 & 9.84 & 6425 & \\
\hline 26-Sep & 66 & $\mathrm{M}$ & L14 & & 9.80 & 9.800 & 9.800 & 6659 & Natural Rain, Trace \\
\hline 27-Sep & 67 & $\mathrm{~N}$ & L10 & $13: 55$ & 9.80 & & & 6805 & \\
\hline 28-Sep & 68 & $\mathrm{~N}$ & L10 & & & & & 6805 & \\
\hline 29-Sep & 69 & $\mathrm{~N}$ & L10 & & & & & 6805 & Natural Rain, Trace \\
\hline 30-Sep & 70 & $\mathrm{O}$ & L10 & $11: 15$ & & & & 6805 & Rain Event 679 gallons $13: 00$ to $13: 25$ \\
\hline $1-\mathrm{Oct}$ & 71 & $\mathrm{O}$ & L10 & & & & & 6805 & \\
\hline 2-Oct & 72 & $\mathrm{O}$ & L10 & & & & & 6805 & Rain Event 722 gallons 14:02 to $15: 07$ \\
\hline 3 -Oct & 73 & $\mathrm{O}$ & L10 & & & & & 6805 & Natural Rain, 0.08 inches \\
\hline 4-Oct & 74 & $\mathrm{P}$ & L14 & $12: 15$ & 21.32 & 22.446 & 22.653 & 7047 & \\
\hline 5-Oct & 75 & $\mathrm{P}$ & L12* & & 21.32 & 22.234 & 22.311 & 7579 & *Flow switched to L12 \\
\hline 6-Oct & 76 & $\mathrm{P}$ & L12 & & 21.32 & 21.865 & 21.912 & 8079 & \\
\hline 7-Oct & 77 & $\mathrm{P}$ & $\mathrm{L} 12 *$ & & 21.32 & 21.444 & 21.463 & 8569 & *Flow switched from L12 to L14 to L5 \\
\hline 8 -Oct & 78 & $\mathrm{Q}$ & L5 & $12: 15$ & 21.32 & & & 8838 & \\
\hline 9-Oct & 79 & Q & L14 & & & & & 8838 & \\
\hline 10-Oct & 80 & Q & L14 & & & & & 8838 & \\
\hline $11-$ Oct & 81 & $\mathrm{R}$ & $\begin{array}{c}\text { L12 \& } \\
\text { L13 }\end{array}$ & $13: 00$ & 20.72 & 20.62 & 20.64 & 9044 & \\
\hline 12-Oct & 82 & $\mathrm{R}$ & $\begin{array}{l}\text { L5 \& } \\
\text { L13* }\end{array}$ & & 20.72 & 20.712 & 20.701 & 9542 & *L12 flow diverted to L5 \\
\hline 13-Oct & 83 & $\mathrm{R}$ & $\begin{array}{c}\text { L5 \& } \\
\text { L13 }\end{array}$ & & 20.72 & 20.680 & 20.670 & 10038 & \\
\hline $14-\mathrm{Oct}$ & 84 & $\mathrm{R}$ & $\begin{array}{c}\text { L5 \& } \\
\text { L13 }\end{array}$ & & 20.72 & 20.719 & 20.711 & 10537 & \\
\hline $15-\mathrm{Oct}$ & 85 & $\mathrm{~S}$ & L12 & $12: 15$ & 20.72 & & & 10821 & \\
\hline 16-Oct & 86 & $\mathrm{~S}$ & L12 & & & & & 10821 & Flood Event, 2000 gallons 13:30 to $18: 00$ \\
\hline $17-$ Oct & 87 & $\mathrm{~S}$ & L12 & & & & & 10821 & \\
\hline 18 -Oct & 88 & $\mathrm{~S}$ & L12 & & & & & 10821 & \\
\hline
\end{tabular}


Table 3.3. (contd)

\begin{tabular}{|c|c|c|c|c|c|c|c|c|c|}
\hline \multirow[b]{2}{*}{ Date } & \multirow[b]{2}{*}{ Day } & \multirow[b]{2}{*}{ ID } & \multicolumn{7}{|c|}{ Actual Injection } \\
\hline & & & Locale & $\begin{array}{c}\text { Time of } \\
\text { Test } \\
\text { Change }\end{array}$ & $\begin{array}{l}\text { Average } \\
\text { Rate gph }\end{array}$ & $\begin{array}{c}\text { Average Rate } \\
2300-2400 \\
\text { gph }\end{array}$ & $\begin{array}{c}\text { Average Rate } \\
1800-2400 \\
\text { gph }\end{array}$ & $\begin{array}{l}\text { Volume } \\
@ 2300 h r\end{array}$ & Comments \\
\hline 19-Oct & 89 & $\mathrm{~S}$ & L12 & & & & & 10821 & \\
\hline 20-Oct & 90 & $\mathrm{~S}$ & L12 & & & & & 10821 & \\
\hline 21-Oct & 91 & $\mathrm{~T}$ & L12 & $11: 05$ & 2.03 & 2.045 & 2.042 & 10845 & \\
\hline $22-$ Oct & 92 & $\mathrm{~T}$ & $\mathrm{~L} 12$ & & 2.03 & 1.980 & 1.995 & 10893 & \\
\hline $23-$ Oct & 93 & $\mathrm{~T}$ & L12 & & 2.03 & 2.035 & 2.037 & 11941 & \\
\hline 24-Oct & 94 & $\mathrm{~T}$ & L12 & & 2.03 & 2.077 & 2.067 & 10990 & \\
\hline 25 -Oct & 95 & $\mathrm{~T}$ & L12 & $17: 45$ & 2.03 & & & 11029 & \\
\hline 26-Oct & 96 & $\mathrm{U}$ & L12 & & & & & 11029 & \\
\hline $27-$-Oct & 97 & $\mathrm{U}$ & L12 & & & & & 11029 & \\
\hline 28 -Oct & 98 & $\mathrm{~V}$ & $\mathrm{~L} 1 *$ & $11: 45$ & 10.13 & 10.140 & 10.138 & 11140 & $\begin{array}{l}\text { Natural Rain, Trace. *Discharge started in L3, switched to } \\
\text { L1 after overflow }\end{array}$ \\
\hline $29-$-Oct & 99 & $\mathrm{~V}$ & L1 & & 10.13 & 10.130 & 10.129 & 11384 & Natural Rain, 0.04 inches \\
\hline $30-$-Oct & 100 & $\mathrm{~W}$ & L1 & $8: 10$ & 19.98 & 20.200 & 20.290 & 11773 & Sheet piling disconnected, $7: 50$ \\
\hline $31-$ Oct & 101 & $\mathrm{~W}$ & L1 & & 19.98 & 20.170 & 20.176 & 12257 & \\
\hline 1-Nov & 102 & $\mathrm{~W}$ & L1 & & 19.98 & 20.020 & 20.048 & 12733 & \\
\hline 2-Nov & 103 & $\mathrm{X}$ & L1 & $8: 00$ & 19.98 & & & 12906 & \\
\hline 3-Nov & 104 & $\mathrm{X}$ & L1 & & & & & 12886 & \\
\hline 4-Nov & 105 & $\mathrm{X}$ & L1 & & & & & 12886 & \\
\hline 5-Nov & 106 & $\mathrm{Y}$ & L1 & $10: 48$ & 20.24 & 20.310 & 20.220 & 13140 & Sheet piling reconnected, 9:40 \\
\hline 6-Nov & 107 & $\mathrm{Y}$ & L1 & & 20.24 & 20.250 & 20.250 & 13607 & \\
\hline 7-Nov & 108 & $\mathrm{Z}$ & L1 & $13: 48$ & 20.24 & & & 13924 & Natural Rain, 0.13 inches \\
\hline 8-Nov & 109 & $\mathrm{Z}$ & L1 & & & & & 13924 & Natural Rain, 0.03 inches \\
\hline
\end{tabular}


As a method of monitoring delivered volume, the solution height in the solution tank was measured periodically with a 4.6-m (15-ft) graduated rod. Measurements were taken every site visit. The outer

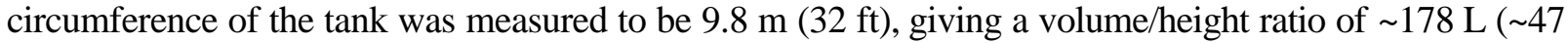
gal) per inch of solution level. The total tank volume measurements gave an estimated volume of 51,163 L (13,516 gal) discharged. Table B.2, Appendix B, summarizes these measurements.

Initial calculations using tank-height measurements indicated that this method was the least desirable for determining rate and volume released. The results were unstable and had a high level of deviation in comparison with other methods.

To quantify the deviation, a series of replicate measurements was performed on September $17^{\text {th }}$. Triplicate measurements were made in quick succession, and the standard deviations of the measurements were calculated. The first trial produced a standard deviation of $0.77 \mathrm{~cm}(0.31 \mathrm{in}$.), which corresponds to a volume of $56 \mathrm{~L}$ (14.8 gal). Over a 24-hr test at a flow of $75.7 \mathrm{~L} / \mathrm{hr}(20 \mathrm{gph})$, the cumulative deviation associated with the stick measurements from a single user (this assumes more uniformity than multiple users) could be as high as $6.25 \%$, which is higher than the operational goal. This error would increase in effect for lower flowrate tests. When three different users were allowed to measure the solution level, the standard deviation increased to $3.3 \mathrm{~cm}$ (1.3 in), which corresponded to a volume of $234 \mathrm{~L}$ (61.9 gal) and an error $(75.7 \mathrm{~L} / \mathrm{hr}[20 \mathrm{gph}$ ] for $24 \mathrm{hr}$ ) of up to $12.9 \%$. The deviations associated with the stick measurements were higher than the performance goal, which made it unsuitable for assessing leak performance. Therefore, the tank measurements were used more as a means to determine if unplanned leaks were occurring from the tank and to determine volumes of simulant solution needed to replenish the tank.

\subsubsection{Rain/Flood Events}

Four rain events and one "flood" event were staged during the course of the testing to determine the effects of natural or artificial hydrologic factors affecting performance of the electrical methods. Significant rainfall or ponding of water near SSTs are considered a possible source of noise that could affect the sensitivity of the methods.

Rain events (Figure 3.2) were recorded using the AgVision flow controller, as specified in the field procedures (See Appendix A.9 and Figure A.9-7). The water height was calculated by averaging raingauge data collected during the event.

In addition to simulated rain, a flood event was conducted from 13:00 to 18:00 on October $16^{\text {th }}$ (Table 3.4). This used the rain-delivery system with the sprinkler loops disconnected; water was delivered using five hoses with the goal of simulating a water spill or pooling of rainwater. The water was focused in the northeast corner of the tank's exterior. The total water delivery (7570 L [2000 gal]) for the flood event was measured using the volume markings on the tank. Ponding of water began within the first 30 min, resulting in a large pool within $1 \mathrm{hr}$ (Figure 3.3). The pool largely disappeared $1.5 \mathrm{hr}$ after termination of application. 
Table 3.4. Summary of Rain/Flood Events

\begin{tabular}{||c|c|c||}
\hline Date of Event & Gallons Delivered & Average Water Height (in) \\
\hline \hline \multicolumn{3}{|c||}{ Rain Events } \\
\hline $08 / 30 / 02$ & 406.1 & 0.043 \\
\hline $09 / 11 / 02$ & 725.0 & 0.065 \\
\hline $09 / 30 / 02$ & 678.9 & 0.064 \\
\hline $10 / 02 / 02$ & 722.1 & 0.061 \\
\hline \multicolumn{3}{|c||}{ Flood Event } \\
\hline $10 / 16 / 02$ & 2000 & $\begin{array}{l}\text { Not measured by rain gauges- } \\
\text { released over 5-hour period }\end{array}$ \\
\hline
\end{tabular}

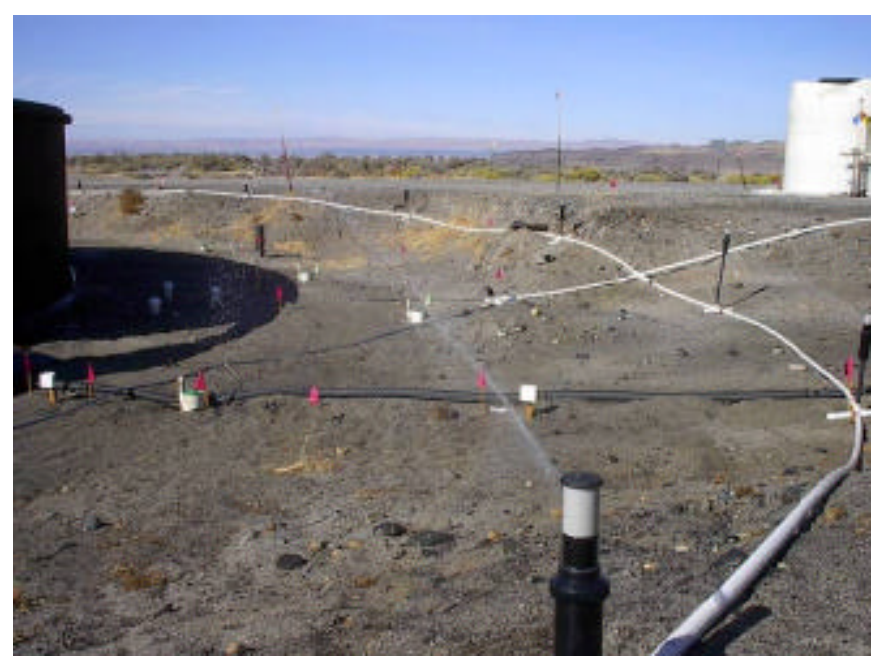

Figure 3.2. Rain Event in Progress on October 2

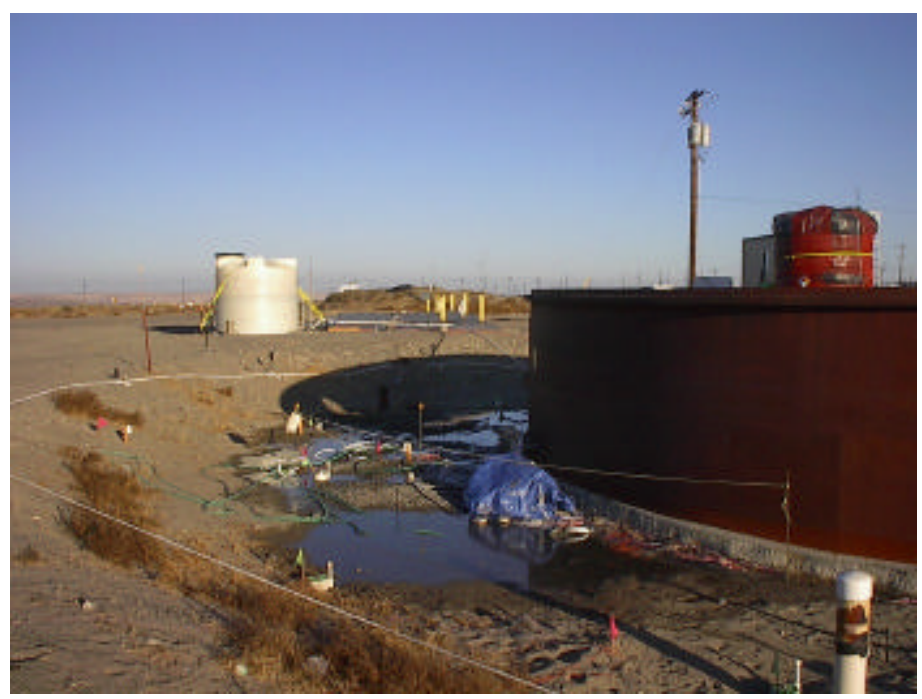

Figure 3.3. Flood Event Staged on October 16 


\subsubsection{Laboratory Data}

Laboratory analyses were limited to measurement of solution properties of the sodium thiosulfate waste simulant. Three analyses were performed after the delivery of each aliquot of solution; an additionalone was performed near the end of the test series. Appendix B (Table B.4) lists the results of the analyses. Concentrations of the solution ranged from $36.24 \mathrm{wt}$ percent calculated for the first aliquot in June to $38.13 \mathrm{wt}$ percent for the second September aliquot. Correspondingly, specific gravities ranged from 1.30 to 1.38 . Conductivities of the solution ranged between 74,000 and $90,000 \mu \mathrm{S} / \mathrm{cm}$.

\subsubsection{Other Field Data}

Gravimetric measurements were critical for measuring flow throughout the test period. The procedure, which is described in detail in the Field Methods Plan (Appendix A), involved timed filling of a container and using gravimetric measurements to measure the mass of the filled solution. Table 3.2 summarizes gravimetric measurements during the test.

\subsubsection{Daily Field Records}

Field activities were recorded during site preparation (following construction) in a field log book. During the testing, the log books were kept in a safe in the field office. A daily diary of significant events and data was also compiled. Table B.1, Appendix B, is a summary of the diary entries. Changes in test protocol occurred five times during the progress of the test. These changes are documented in Appendix A, Attachment E. Visitors to the site were briefed and relevant information entered on the sitesafety sign-in list.

\subsubsection{Steel Wall Connections}

The steel wall installed at the southwest corner of the Mock Tank was emplaced to simulate the electric-field effects of an adjacent tank or buried structure. In the SST farms, the tanks may be electrically linked by cascade lines or other common connecting equipment. Thus, the cable connection between the steel wall and the Mock Tank remained closed during the entire test, except for a 6-day period near the end of the test (October $31^{\text {st }}$ to November $5^{\text {th }}$ ). It was then reconnected for the final three days of the test. The purpose of this test was to observe the effects of interconnectivity between the Mock Tank and the buried steel wall, thus attempting to approximate the effects of changing conditions in an SST Farm.

\subsection{Neutron Logging}

During the simulated tank leaks, neutron logging was performed to measure moisture content around the periphery of the mock tank. The neutron logging served to monitor the movement of the simulated leaks and to confirm the measurements acquired from the various geophysical methods being tested at the site. 


\subsubsection{Description of Method}

The neutron probe indirectly measures moisture content by releasing high-energy neutrons from a small radioactive source and detecting the number of thermalized neutrons that are reflected back to the detector. When released into the soil, the high-energy neutrons are thermalized by collisions with other atoms, with the greatest energy loss being due to collisions with particles of similar mass, such as a hydrogen atom. Water comprises the majority of hydrogen atoms in the soil, allowing the number of thermalized neutrons detected to be related to the soil-moisture content through a calibration curve. Ideally, a calibration curve should exist for each neutron probe, soil type, and well casing material. A more thorough expla nation of the theory behind using the neutron probe to measure moisture content is given by Goodspeed (1981).

\subsubsection{Measurements}

Existing ERT wells were used as neutron-probe access tubes for the monitoring of moisture content. The ERT wells consist of PVC casing with ERT electrode arrays installed along the casing of the wells. Four steel wells located at the site, which also serve as transmitters for the HRR technology, were used for cross calibration of the neutron probes (described below). A plan view of the layout of ERT wells, steel cased wells, and the mock tank are shown in Figure 3.4.

Also logged during the PE test were five refitted soil-access ports inside the Mock Tank (Figure 2.1 and A.1.5). These extended only $\sim 0.6 \mathrm{~m}(\sim 2 \mathrm{ft})$ below the floor of the tank and were used to determine if leaked solution had spread near the tank floor.

Neutron counts were acquired on six dates using two Campbell-Pacific Nuclear neutron probes (probe serial numbers H33115140 and H30089808, herein referred to as neutron probe 5140 and 9808 , respectively). The wells were logged at $0.305 \mathrm{~m}(1 \mathrm{ft})$ vertical intervals to a depth of $10.67 \mathrm{~m}(35 \mathrm{ft})$, with all measurements being performed at a 16-sec count time. Before logging the wells, a standard count of thermalized neutrons was performed to assure the probe was working properly. Table 3.5 lists the dates that neutron logging was performed, as well as the ERT wells logged and the corresponding serial number of the neutron probe used.

The relevant calibration curve was applied to the neutron-count data to convert counts to volumetric moisture content. The moisture content data were interpolated between wells using the kriging function

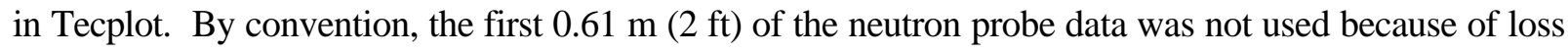
of neutrons to the surface. 


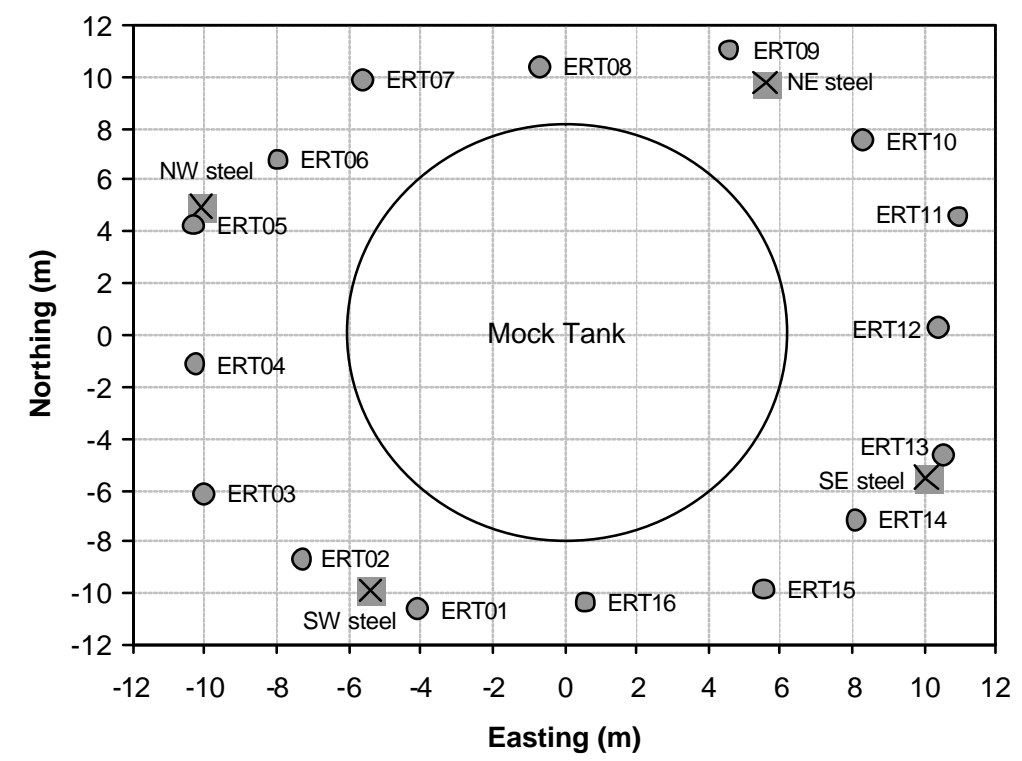

Figure 3.4. Plan View of the Mock Tank Monitoring-Well Layout Showing External Monitoring Points

Table 3.5. Neutron Probe Loggings Performed for the 2002 PE Test at the Mock Tank Site

\begin{tabular}{||l|l|c||}
\hline \multirow{2}{*}{ Measurement Date } & \multicolumn{1}{|c|}{ ERT Wells Logged } & $\begin{array}{c}\text { Serial Number of Neutron } \\
\text { Probe Used }\end{array}$ \\
\hline 5 July 2002 & $1,2,3,4,5,6,7,8,9,10,11,12,13,14,15,16$ & $\mathrm{H} 30089808$ \\
\hline 30 August 2002 & $1,2,3,4,5,6,7,8,9,10,11,12,13,14,15,16$ & $\mathrm{H} 30089808$ \\
\hline 13 September 2002 & $1,2,4,5,7,9,11,13,15$ & $\mathrm{H} 30089808$ \\
\cline { 2 - 3 } & $3,6,8,10,12,14,16$ & $\mathrm{H} 33115140$ \\
\hline \multirow{2}{*}{ October 2002 } & $1,3,5,7,9,11,13,15$ & $\mathrm{H} 30089808$ \\
\cline { 2 - 4 } & $2,4,6,8,10,12,14,16$ & $\mathrm{H} 33115140$ \\
\hline \multirow{2}{*}{ 4 October 2002 } & $2,4,6,8,10,12,14,16$ & $\mathrm{H} 30089808$ \\
\cline { 2 - 4 } & $1,3,5,7,9,11,13,15$ & $\mathrm{H} 33115140$ \\
\hline \multirow{2}{*}{ 13 November 2002 } & $1,3,5,7,9,10,11,12,13,14,15,16$ & $\mathrm{H} 33115140$ \\
\cline { 2 - 4 } & $2,4,6,8$ & \\
\hline
\end{tabular}

Eight neutron-probe access tubes located in the floor of the mock tank were also monitored during the simulated leaks to a depth of $0.76 \mathrm{~m}(2.5 \mathrm{ft})$. Due to the shallowness of the measurements, the data are not discussed in this report other than to state that the lack of a positive response in neutron counts during the monitoring indicated rapid drainage of the simulated leaks.

\subsubsection{Cross Calibration}

Because two different probes were used during the surveys, a series of cross calibrations was performed to attain the necessary calibration equations for neutron probes 5140 and 9808 . A calibration curve for Probe 5140 obtained from steelcased well calibration data was reported by Zhang et al. (2002) as

Probe 5140:

$$
\theta_{\mathrm{v}}=5.8293 \times 10^{-10} \times \text { Neutron Counts } \text { steel }^{2.2675}
$$


where subscript steel represents neutron counts obtained in a steelcased well. Because the casing material of the ERT wells logged at the Mock Tank test site are PVC, it was necessary to correct Equation (3.1) to allow for neutron counts acquired in the PVC wells to be correctly converted to moisture content. A correction factor was obtained by logging the steel wells at the Mock Tank Site at 0.305-m (1-ft) increments to a depth of $10.67 \mathrm{~m}(35 \mathrm{ft})$ using neutron probe 5140 . Using the same neutron probe, an adjacent ERT well was logged at 0.305-m (1-ft) increment to a depth of $10.67 \mathrm{~m}(35 \mathrm{ft})$. The resulting ratio of steel-cased-well neutron counts to the adjacent PVC-cased-well neutron counts was applied to Equation (3.1), giving

Probe 5140: $\quad \theta_{\mathrm{v}}=5.8293 \times 10^{-10} \times \mathrm{Neutron}$ Counts $_{\mathrm{PVC}}{ }^{2.2718}$

where the subscript PVC represents neutron counts obtained in a PVC-cased well.

During the cross-calibration process, erratically high neutron-count readings were obtained while logging all four steel-cased wells. The erratic readings are believed to be due to the steelcased wells momentarily being electrically charged for HRR data acquisition, potentially disturbing the electronics in the neutron probe. Due to the large number of unusually high counts measured in the SE and SW steel wells, only the NE and NW steel wells were used in the cross calibration, with wells ERT9 and ERT5 being the adjacent PVC wells logged, respectively. Duplicate neutron-probe counts of the NE and NW steel-cased wells were compared against one another, and counts that were clearly erroneous were removed; otherwise, the average of the duplicate measurements was used in the calibration.

A similar method was used to cross calibrate Neutron Probe 9808 to Neutron Probe 5140. The ERT wells were logged with both neutron probes at $0.305-\mathrm{m}$ (1-ft) increments to a depth of $10.67 \mathrm{~m}(35 \mathrm{ft})$. The ratio of measured neutron counts for Probe 9808 to neutron counts for Probe 5140 was applied to Equation (2), giving

Probe 9808: $\quad \theta_{\mathrm{v}}=5.8293 \times 10^{-10} \times$ Neutron Counts ${ }_{\mathrm{PVC}}^{2.4631}$

\subsubsection{Results of Neutron Logging}

Figure 3.5 shows the neutron-probe-measured two-dimensional baseline moisture content around the periphery of the mock tank. The moisture content throughout the measurement domain is fairly uniform, with moisture content values ranging from a high value of $0.0434\left(\mathrm{~m}^{3} \mathrm{~m}^{-3}\right)$ in the south quadrant to a low value of $0.0169\left(\mathrm{~m}^{3} \mathrm{~m}^{-3}\right)$ near the surface of the southwest quadrant. The measured difference in duplicate measurements for neutron-probe moisture content taken on July $5^{\text {th }}$ is shown in Figure 3.6. On average, the difference in duplicate measurements was $\pm 0.002\left(\mathrm{~m}^{3} \mathrm{~m}^{-3}\right)$, with the maximum difference in duplicate measurements being $0.009\left(\mathrm{~m}^{3} \mathrm{~m}^{-3}\right)$. The relatively small difference between duplicate measurements demonstrates the stability of the neutron-probe method. 


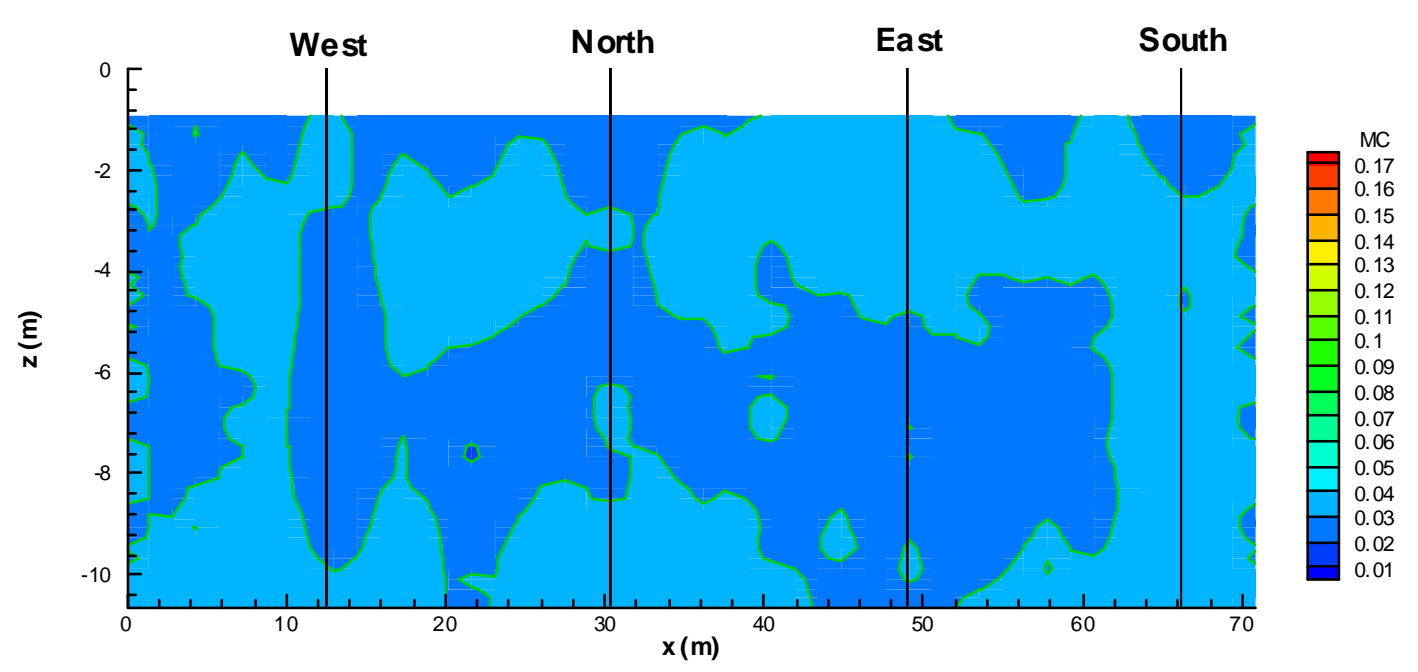

Figure 3.5. Mock Tank Baseline Water Content (July $5^{\text {th }}$ )

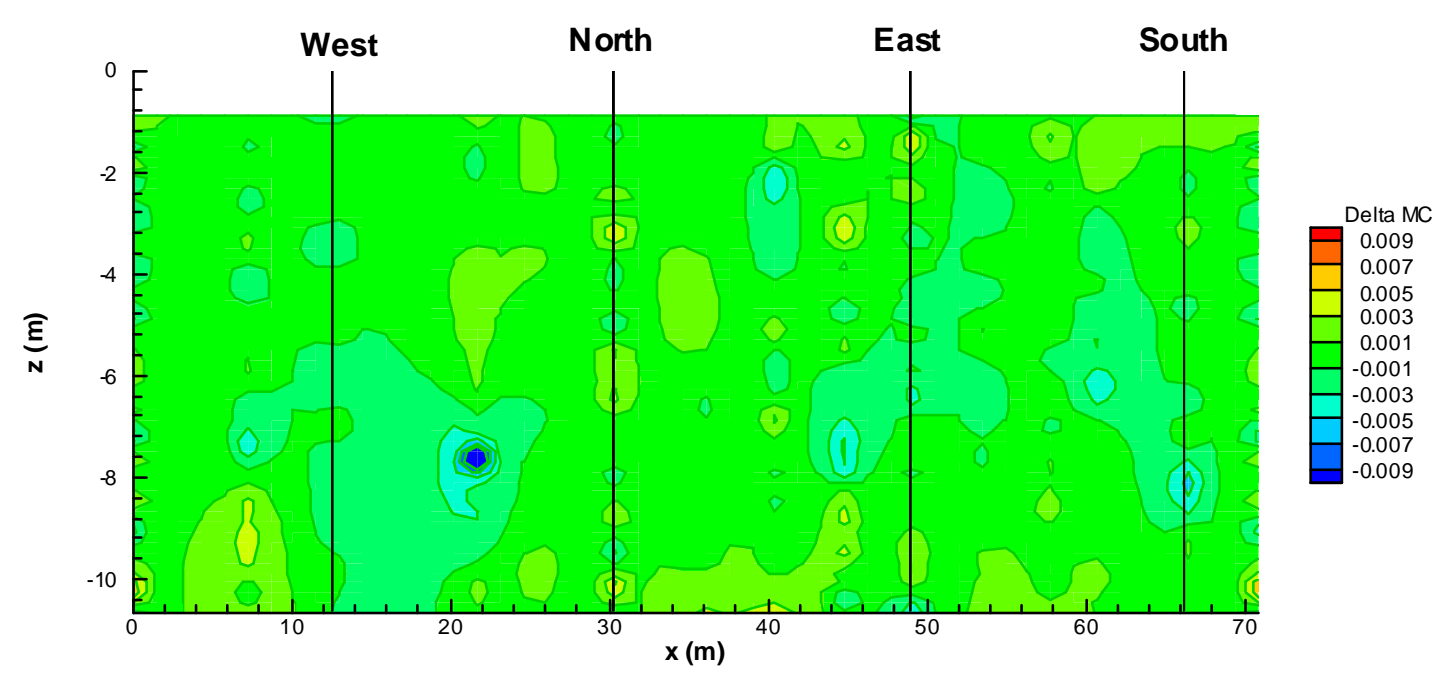

Figure 3.6. Difference in Duplicate Moisture Content Measurements (July $5^{\text {th }}$ )

Figure 3.7 through Figure 3.9 again show the neutron-probe-measured two-dimensional moisture content at the Mock Tank Site for the dates of August $30^{\text {th }}$, September $13^{\text {th }}$, and October $2^{\text {nd }}$, respectively. The August $30^{\text {th }}$ moisture content is stable and essentially unchanged from the baseline measurement. Alternatively, the September $13^{\text {th }}$ measurements capture an increase in moisture content at the maximum measurement depth in the southeast quadrant of the site. Although not entirely evident in Figure 3.8 due to kriging effects, the moisture content has increased from a baseline measurement of $0.0344\left(\mathrm{~m}^{3} \mathrm{~m}^{-3}\right)$ to $0.0978\left(\mathrm{~m}^{3} \mathrm{~m}^{-3}\right)$. This increased moisture content is likely due to lateral movement of the simulated tank leak. The increased moisture content in the southeast quadrant continued to persist on October $2^{\text {nd }}$, now encompassing a larger area and attaining maximum moisture content of $0.1539\left(\mathrm{~m}^{3} \mathrm{~m}^{-3}\right)$. 


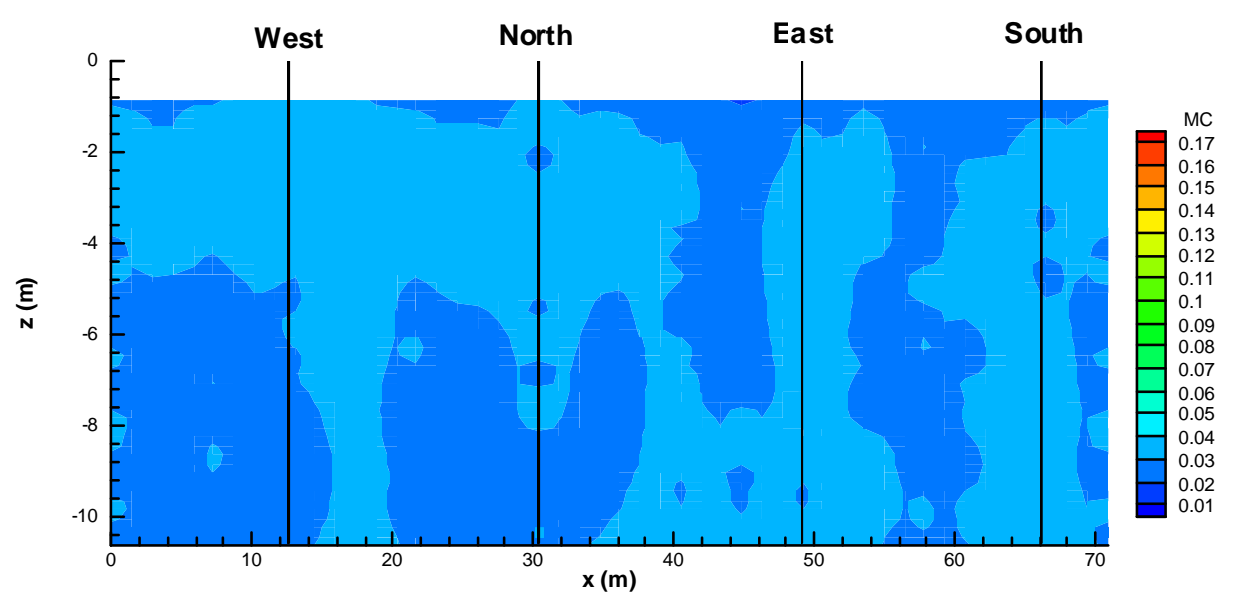

Figure 3.7. August $30^{\text {th }}$ Measured Moisture Content

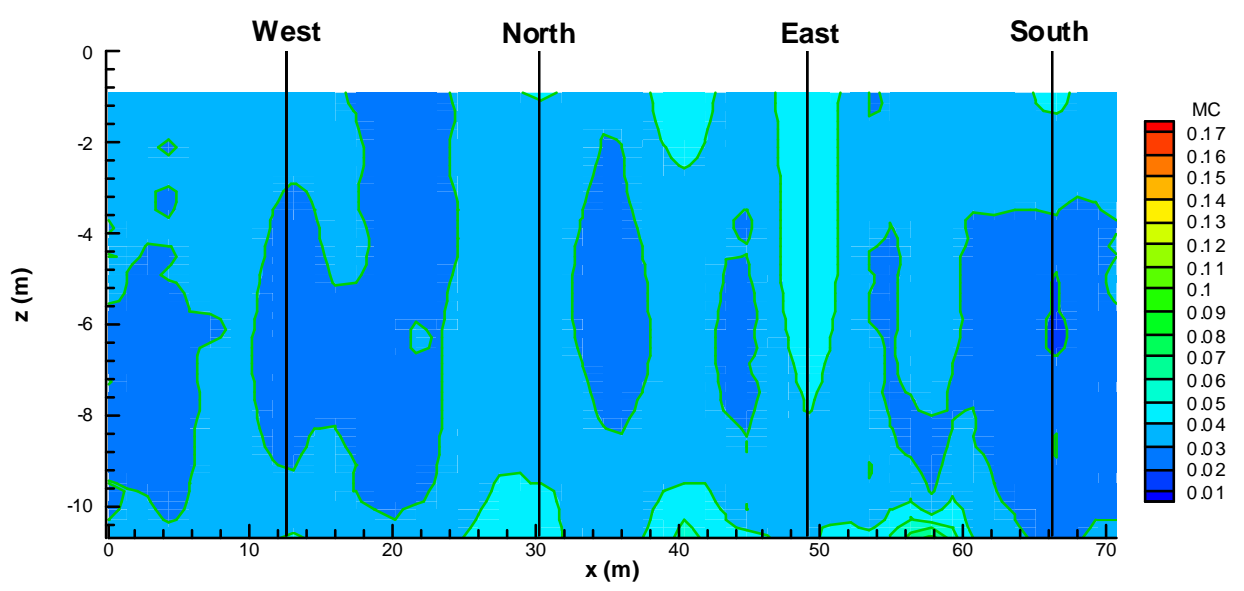

Figure 3.8. September $13^{\text {th }}$ Measured Moisture Content

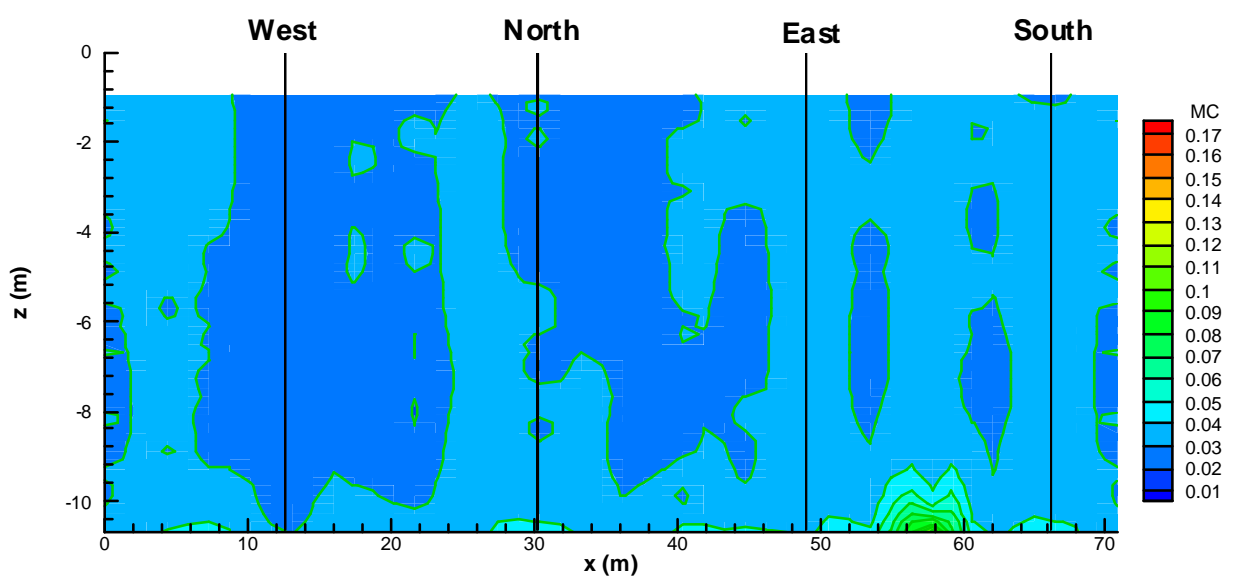

Figure 3.9. October $2^{\text {nd }}$ Measured Moisture Content 
The moisture content as measured on October $24^{\text {th }}$ is displayed in Figure 3.10. The October $24^{\text {th }}$ neutron logging occurred one week after a planned flood event was initiated in the northeast and northwest quadrants of the Mock Tank Site. The increased moisture content due to the flood event is apparent, with the moisture content increasing throughout the vertical profile of the north quadrant and near the maximum measurement depth in the northwest and northeast quadrants, possibly indicating the existence of a restrictive soil layer (Figure 3.11). The presence of an increased moisture-content area in the southeast quadrant is still evident, with the maximum moisture content being $0.169\left(\mathrm{~m}^{3} \mathrm{~m}^{-3}\right)$.

Figure 3.12 and Figure 3.13 reveal that by November $13^{\text {th }}$, much of the infiltrated water present in the north quadrant on October $24^{\text {th }}$ had either redistributed throughout the profile or moved beyond the vertical extent of our measurement. Increased moisture content in the southeast quadrant still remains and has not experienced an appreciable change in size or moisture content since the October $2^{\text {nd }}$ moisturecontent measurements.

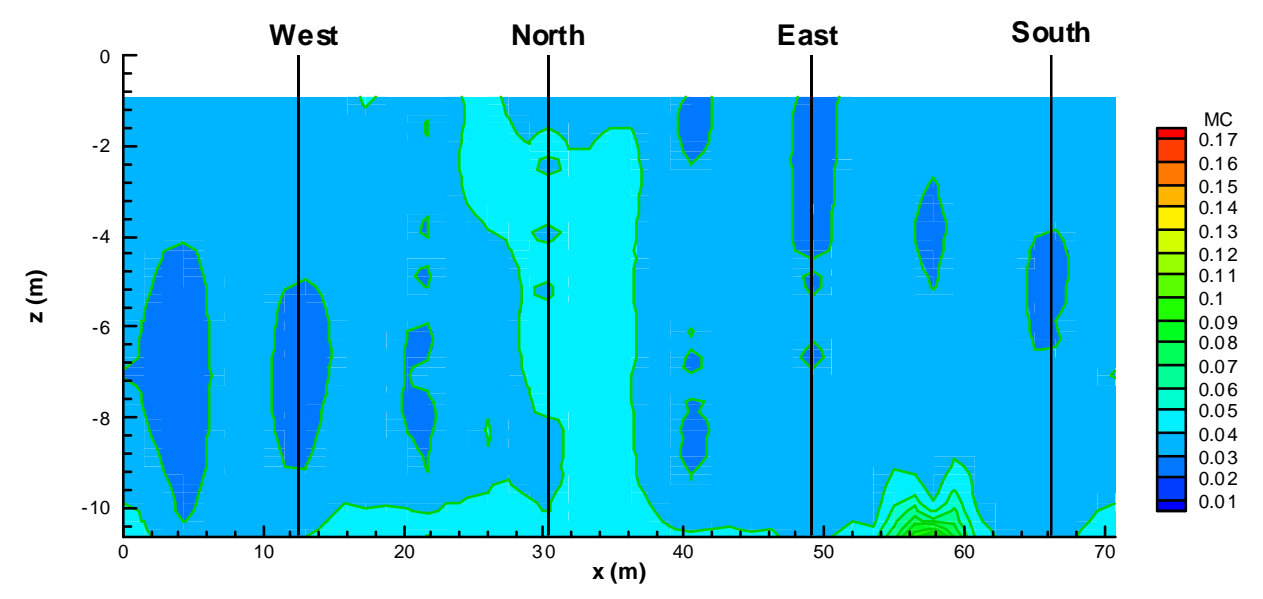

Figure 3.10. October $24^{\text {th }}$ Measured Moisture Content

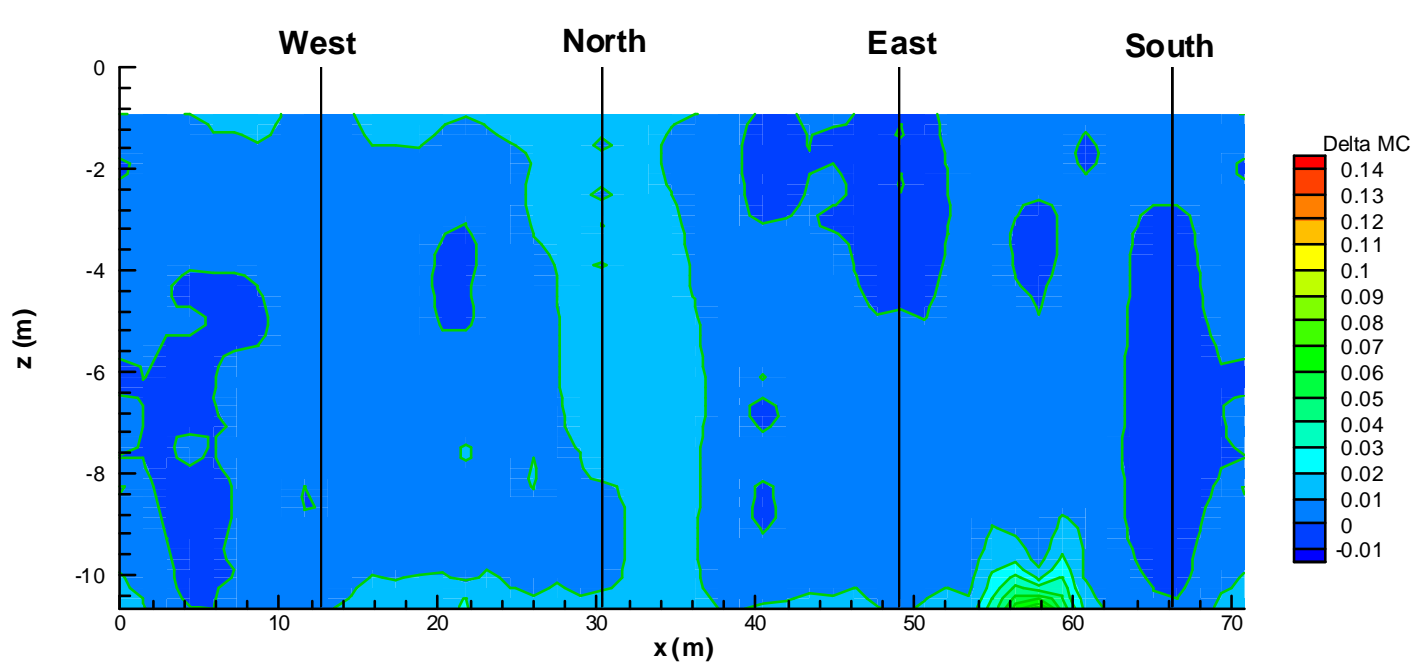

Figure 3.11. Measured Change in Moisture Content Between July $5^{\text {th }}$ and October $24^{\text {th }}$ 


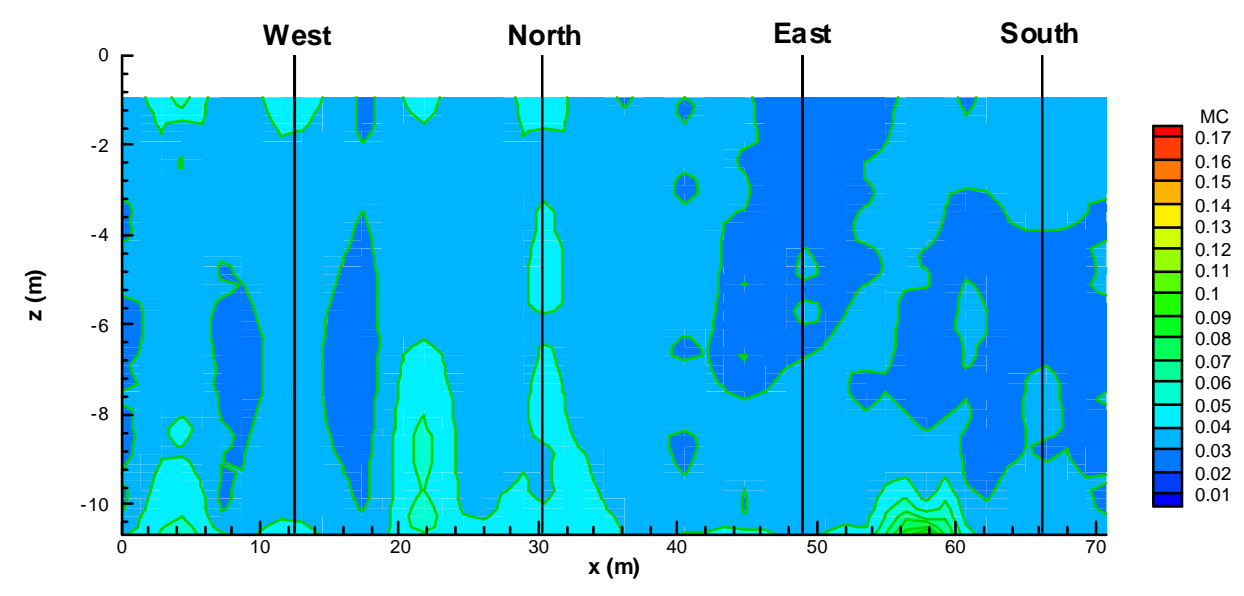

Figure 3.12. November $13^{\text {th }}$ Measured Moisture Content

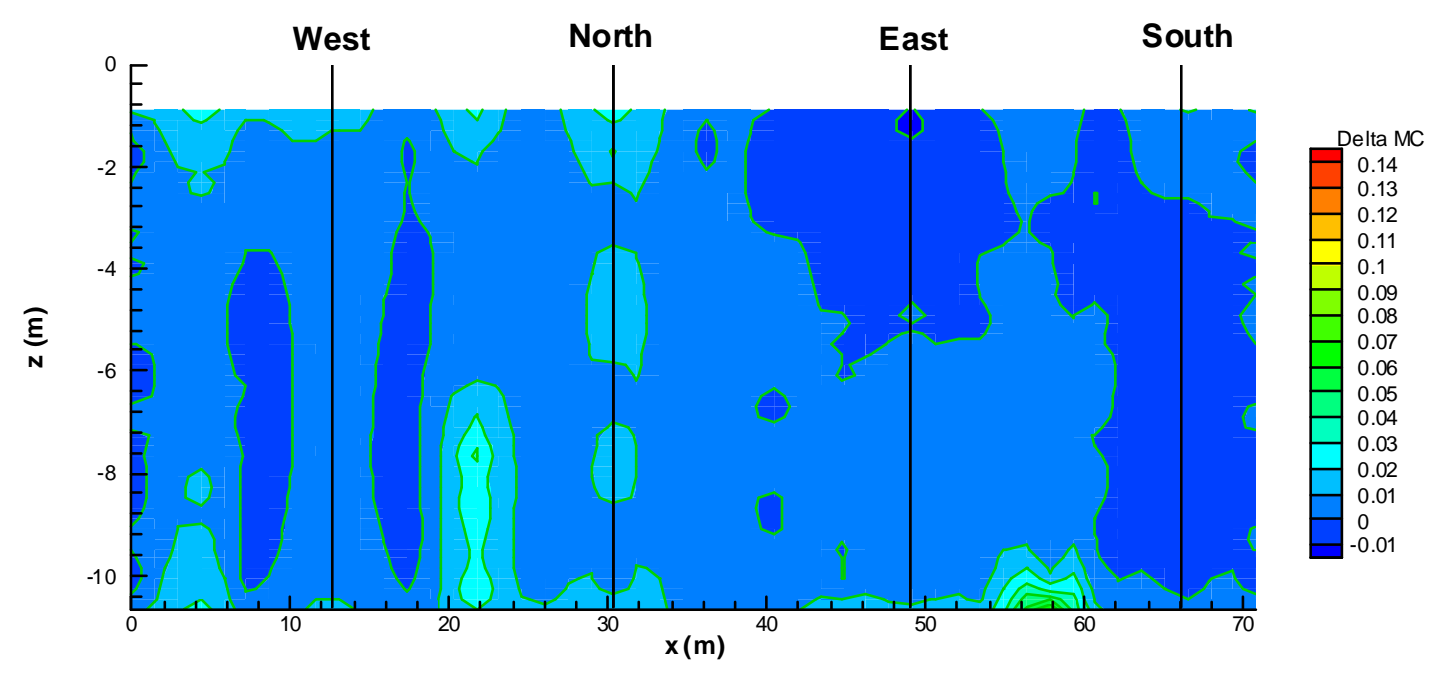

Figure 3.13. Measured Change in Moisture Content Between July $5^{\text {th }}$ and November $13^{\text {th }}$

\subsubsection{Interpretation of Neutron-Probe Results}

Lateral flow of the simulated tank leak was captured by the neutron-probe measurements, marked by the increased moisture content at the $10.67-\mathrm{m}(35-\mathrm{ft})$ depth in the southeast quadrant. The occurrence of lateral movement at the lowest monitoring depth suggests the presence of a heterogeneous subsurface system (i.e., layered system) and corresponds with lateral movement observed with other subsurface injection experiments at the Hanford site (Sisson and $\mathrm{Lu} \mathrm{1984).} \mathrm{It} \mathrm{should} \mathrm{be} \mathrm{noted} \mathrm{that} \mathrm{the} \mathrm{increased}$ moisture content related to lateral movement of the simulated leak was at the vertical lower limit (lowest depth) of our neutron-probe sampling scheme. As such, this lateral flow may not have been captured by the neutron probe measurements had more lateral flow occurred at a greater depth. This reinforces the need of either a spatially dense sampling network or a globalmeasurement method when trying to detect the existence of a tank leak. It also suggests that in the case of the Mock Tank, the layer immediately below the tank did not provide a pathway that spread the injected fluid to the monitoring points until the 
fluid was nearly $10 \mathrm{~m}$ (33 ft) below the injection point. This is supported by the results of logs from the shallow access ports inside the tank, there being no increase in moisture detected at these locations.

Because approximately 53,000 L (14,000 gal) of fluid was injected in 2002 at the Mock Tank Site and only a small change in fluid content was detected at the greatest depth, we conclude that neutron-probe monitoring provided little quantitative measure of the fluid discharge at the Mock Tank Site. If similar sediment layering exists at a tank farm and similar discharges occur, it is likely that similar insensitivity in leak detection would occur. Indirect evidence of insensitivity in neutron-probe logging for fluid contents has been demonstrated previously. Isaacson (1982) reported for dry-well monitoring using gamma detection methods that a 326,000 L (117, 000 gal) leak could go undetected if the leak was as much as $11 \mathrm{~m}$ (36 ft) away from the dry well. Neutron logging for moisture tends to be less sensitive than gamma logging in terms of leak detection because the detection distance (sphere of influence) for neutrons is less than $0.5 \mathrm{~m}(1.5 \mathrm{ft}$ ) away from the monitoring well (IAEA 1970). This is true for water contents typical of those found in Hanford sediments (e.g., 0.05 to $0.3 \mathrm{~m}^{3} \mathrm{~m}^{-3}$ ). The Mock Tank leak observations suggest that neutron logging of tank leaks will likely not be reliable enough to use for any but the largest leaks and those that occur almost next to the dry-well monitoring point.

\subsubsection{Results of Neutron Logging Inside the Mock Tank}

Eight of the access (soil-monitoring) ports inside the Mock Tank were selected to monitor soil moisture content below the floor of the tank. This was done to determine if injected sodium thiosulfate solution was spreading laterally at shallow depth and making contact with the steel underside of the tank floor. Such a condition could have significant effects on the electric al-measurement systems, particularly HRR-SCRT. The access ports were slightly deepened and 5-cm (2-in.) aluminum alloy pipe was installed within each port to a depth of approximately $180 \mathrm{~cm}$ (71 in.) (see Appendix A, Section D.3). The aluminum alloy pipe allowed for data collection immediately below the existing steel casing. The eight wells were labeled L4, L5, L6, L7, L8, L9, L11, and L13 (See Figure 2.12 for locations).

Soil moisture measurements were taken from each port using a Hydroprobe (neutron probe) at five 15 $\mathrm{cm}$ intervals $(105 \mathrm{~cm}, 120 \mathrm{~cm}, 135 \mathrm{~cm}, 150 \mathrm{~cm}$, and $165 \mathrm{~cm})$ from the surface inside the tank. Measurement dates were chosen to coincide with other field tests at the study site, including artificial rain and flood events outside the tank, to observe any noticeable drainage. An initial (base) measurement of the soil moisture was conducted on July 5, 2002. Other measurements were conducted on August 30, September 13, and November 14, 2002.

The results of logging the access ports inside the mock tank show that soil moisture remained virtually unchanged during the PE test. It appears that the wetting events during the field studies, which occurred outside of the mock tank, and solution releases in adjacent ports inside the tank did not affect the soil immediately below the tank. Consequently, it is assumed that the solution moved mostly vertically downward beneath the tank and did not impart any appreciable electrical effects to the measurement systems through extensive contact with the tank floor.

\subsection{Data Archiving}

One of the principal objectives of the testing protocol is data retention and preservation. It is the intent of $\mathrm{CH} 2 \mathrm{M}$ HILL to have a complete data record of the test and to maintain that data in a manner that 
will permit future analysis of the results. The need for future analysis is predicated on vetting a particular technology for deployment as well as providing the necessary data for regulatory permitting.

Data archives from both the solution-control computer and the data-acquisition computer were performed on a routine basis during testing. Data were retrieved from the computers on a non-regular basis, but the time between backups did not exceed 1 week. Generally, operational interruptions due to scheduling of solution releases, equipment failures (e.g., data-acquisition computer lockup), and network failures made the process of daily backups difficult. No data were lost during the test, although the investigators removed some data inadvertently. Those data were recovered, and a full complement of the test data was compiled.

Data were recorded in proprietary format by individual digital recording devices. The solution control equipment was built using components manufactured by National Instruments, Inc. The sensors and control moisture content as measured commands from their graphical user-interface software, LabView (see Section 2.4.3). LabView is compiled for specific tasks or environments. The user interface compiled for this test series recorded solution-injection duration and flowrate and provided nominal control of the flow system; it also recorded data from the rain gauges located at various stations surrounding the Mock Tank structure. The data were exported to a commercial spreadsheet format (Microsoft $\odot$ Excel) at the termination of each solution-injection period.

The electricalresistivity data-acquisition unit manufactured by Zonge, Inc. records potential measurements as well as injected current values, station location, and time stamps, in two formats, .raw and .zrt. The raw data is a stream of electricalproperty measurements that are saved with a .raw extension. Individuals who have the requisite experience in evaluating the information can decode the data by using a simple text viewer. The .zrt-formatted data present the same information in tabular form with columns that identify each of the relevant parameters (e.g., transfer resistance, current, time, date, and electrode station).

Each investigative team performed post-processing of the recorded data. The intermediate results of this post-processing exercise were not archived during the test. Final results from the post-processing exercises were used to assess a leak/no-leak condition during testing and were used to make releasevolume estimates. The final reports from each of the two investigative teams were saved as they were submitted and are part of the final data archive.

The medium selected for final data archival is the compact disk read only memory (CDROM) format. This medium is not subject to degradation due to magnetic hysteresis as is magnetic tape or other magnetic removable storage media. It is subject to degradation from heat, although this can be minimized by storing the medium in a cool, dry location. The CDROM medium has a life expectancy of approximately 10 years. This is considered adequate time to find an alternative storage format should further archival of the data be required.

\subsection{Uncontrolled Events}

These are events that occurred during the course of the PE test that were unplanned or that required remedial response by test operators. Most of these events were related to equipment or systems failure during the $4 \frac{1}{1} 2$-month test period. No problems occurred as a result of weather, but several measures 
were taken to avoid complications due to cold temperatures. Prominent events that were uncontrolled and the corrective measures taken are described below.

\subsubsection{Equipment Malfunction}

Most equipment failures involved the solution delivery system - primarily flow controllers and meters. These occurrences and the remedial measures for recovery are listed in Table 3.6 and Table 3.7.

Table 3.6. Equipment Problems and Solutions

\begin{tabular}{|c|c|c|}
\hline Problem & Impact & Solution \\
\hline $\begin{array}{l}\text { Omega Totalizer } \\
\text { malfunctioned. }\end{array}$ & $\begin{array}{l}\text { No totalizer for flow events B, } \\
\text { D, \& F. }\end{array}$ & $\begin{array}{l}\text { 1. Calculated total gallons delivered using the Alicat } \\
\text { flow controller reading. } \\
\text { 2. Ordered replacement pulse totalizers. }\end{array}$ \\
\hline $\begin{array}{l}\text { Alicat controller\#1 } \\
\text { malfunctioned on } 8 / 21 / 02 \text {. }\end{array}$ & $\begin{array}{l}\text { Startup of flow event D was } \\
\text { delayed several hours. }\end{array}$ & Replaced with backup Alicat controller (Alicat \#2) \\
\hline $\begin{array}{l}\text { Alicat \#2 proved to have } \\
\text { unsteady operation. }\end{array}$ & $\begin{array}{l}\text { Start of flow event } F \text { was } \\
\text { delayed while unit was } \\
\text { recalibrated. }\end{array}$ & $\begin{array}{l}\text { 1. Recalibrated the unit to get a flow relationship for } \\
\text { test. } \\
\text { 2. Checked flow daily using gravimetric } \\
\text { measurements. } \\
\text { 3. Replaced the Alicat flow controller with the } \\
\text { metering-pump control system for flow event I. }\end{array}$ \\
\hline $\begin{array}{l}\text { The mechanical pulse } \\
\text { totalizer did not function at } \\
\text { the 2-gph level (outside } \\
\text { design parameters) }\end{array}$ & $\begin{array}{l}\text { No totalizer measurements } \\
\text { for flow event } \mathrm{T} \text {. }\end{array}$ & $\begin{array}{l}\text { 1. Generated calibration curve for the Signet flow } \\
\text { meter for } 2 \mathrm{gph} \text {. } \\
\text { 2. Checked consistency by daily gravimetric flow } \\
\text { measurements. }\end{array}$ \\
\hline $\begin{array}{l}\text { Metering Pump } 1 \text { was not } \\
\text { functioning properly for } \\
\text { Test Y. }\end{array}$ & Minimal impact. & $\begin{array}{l}\text { Generated calibration curve for pump } 2 \text {, which } \\
\text { operated properly. }\end{array}$ \\
\hline $\begin{array}{l}\text { The mechanical pulse } \\
\text { totalizer malfunctioned on } \\
\text { Flow Event Y. }\end{array}$ & $\begin{array}{l}\text { No totalizer measurements for } \\
\text { Flow Event Y. }\end{array}$ & $\begin{array}{l}\text { 1. Performed daily gravimetric flow measurements. } \\
\text { 2. Related these to flow-meter data collected using } \\
\text { the lab view system. } \\
\text { 3. Used this relationship to calculate total flow. }\end{array}$ \\
\hline
\end{tabular}

Table 3.7. Overflow Events at Infiltration Points

\begin{tabular}{||c|c|l||}
\hline \hline Date & Well Affected & \multicolumn{1}{c||}{ Remedial Action } \\
\hline \hline $9 / 11 / 02$ & L10 & Flow restored by reworking soil with a digging bar. \\
\hline $9 / 19 / 02$ & L14 & $\begin{array}{l}\text { 1. Flow diverted to L7. } \\
\text { 2. L14 was augured in 9/23, which allowed for new flow application. }\end{array}$ \\
\hline $9 / 20 / 02$ & L7 & Flow changed to L2. \\
\hline $10 / 5 / 02$ & L14 & Flow changed L12 \\
\hline $10 / 8 / 02$ & L12 & Flow diverted to L14, then to L5 \\
\hline $10 / 12 / 02$ & L12 & Didn't actually overflow, but lack of draining noted. Flow diverted to L5 \\
\hline $10 / 28 / 02$ & L3 & Flow diverted to L1 \\
\hline
\end{tabular}




\subsubsection{Power Disruptions}

Two power failures and several power surges occurred during the 4.5-month period of the test. The power failures required PNNL personnel to restart some of the data-recording equipment and troubleshoot the systems while in contact with LLNL and HGI. The two power failures resulted in the loss of some data, but did not critically affect the course of the test or impart any significant aberrations to the test results.

\subsubsection{Unplanned Discharges}

Approximately 950 to $1135 \mathrm{~L}$ ( 250 to $300 \mathrm{gal}$ ) of simulant solution were leaked from a faulty connecting flange on the solution tank during background data collection prior to July $11^{\text {th }}$; a new tank was deployed to the site on July $12^{\text {th }}$.

On August $21^{\text {st }}$, approximately $340 \mathrm{~L}$ (90 gal) of river water from the precipitation-simulation system was inadvertently leaked over approximately $50 \mathrm{~min}$. No report of any resultant anomalies was received from HGI or LLNL. A spring-loaded discharge valve was installed to prevent inadvertent discharges of this type.

\subsubsection{Climatic Summary}

Weather predictions and events were tracked carefully for the duration of the testing for safety concerns, systems performance, and the effects on geophysical method response. Appendix A (Section A-3.4) describes the various safety concerns with weather events. Weather-precaution statements were sent to all test participants when special conditions, such as thunderstorms, wind, precipitation, or extreme temperatures were predicted or seemed imminent. During the test, 15 of these statements were sent to the participants by PNNL staff. Most of the advisories concerned low temperatures experienced in late October 2002 and wind warnings issued by the Hanford Meteorological Station (HMS). Seven advisories were sent to warn of thunderstorm activity during July and August. Table 3.8 provides a synopsis of climatic and weather information during the period of the test, as recorded at the HMS, which is approximately 3 miles west of the Mock Tank Site (Figure 1.1). A more complete record of weather events as recorded at HMS during the PE test is provided in Appendix B, Table B.3. Another meteorological station (No. 6) is located in the 200 East Area, approximately 1 mile east of the Mock Tank. No significant differences in precipitation were noted between this site and the HMS during the period of the test. The month of June summary is also included in the table to show conditions just before the background data-collection phase of the testing. 
Table 3.8. Synopsis of Climatic Parameters During the FY 2002-2003 PE Test

\begin{tabular}{|c|c|c|c|c|}
\hline Month & $\begin{array}{l}\text { Total Inches } \\
\text { Precipitation }^{(a)}\end{array}$ & $\begin{array}{c}\text { Average Temperature } \\
\qquad\left({ }^{\mathbf{0}} \mathbf{F}\right)^{(\mathbf{a})}\end{array}$ & $\begin{array}{c}\text { Temperature } \\
\text { Extremes }\left({ }^{\circ} \mathbf{F}\right)^{(\mathbf{a})}- \\
\text { Date }\end{array}$ & $\begin{array}{c}\text { Other } \\
\text { Phenomena/Comments }\end{array}$ \\
\hline June & 0.65 & 71.6 & $104-26^{\text {th }} ; 46-8^{\text {th }}$ & \\
\hline July & 0.16 & 79.6 & $113-13^{\text {th }} ; 50-4^{\text {th }}$ & $\begin{array}{l}\text { Maximum temperature tied } \\
\text { record; thunderstorms on } 7^{\text {th }}, 8^{\text {th }}, \\
13^{\text {th }}, 23^{\text {rd }}\end{array}$ \\
\hline August & 0.01 & 75.5 & $103-14^{\text {th }} ; 50-17^{\text {th }}$ & $\begin{array}{l}\text { Thunderstorms on } 6^{\text {th }}, 20^{\text {th }}, 21^{\text {st }} ; \\
\text { smoke reported on } 16^{\text {th }}\end{array}$ \\
\hline September & Trace & 66.3 & $96-12^{\text {th }} ; 38-22^{\text {nd }}$ & $\begin{array}{l}\text { Greatest diurnal temperature } \\
\text { variation }\end{array}$ \\
\hline October & 0.12 & 50.4 & $81-6^{\text {th }} ; 7-31^{\text {st }}$ & $\begin{array}{l}\text { Highest daily average wind on } \\
29^{\text {th }} \text {, with dust; all-time record } \\
\text { low }\left(7^{\circ}\right) \text { on } 31^{\text {st }}\end{array}$ \\
\hline November* & 0.28 & 41.0 & $61-11^{\text {th }} ; 11-1^{\text {st }}$ & \\
\hline
\end{tabular}

Precipitation events were very few during the period of testing (July $11^{\mathrm{TH}}$ [background] to November $15^{\mathrm{TH}}$ [the end of the post-test measurements]), and natural precipitation amounted to a total of only $1.8 \mathrm{~cm}$ (0.71 in.), as recorded at the HMS. Measurable events occurred on only 9 days during the entire test period. Precipitation amounting to a "trace" occurred on 6 days during the test. Because the HMS is located a few miles from the Mock Tank Site, some differences may exist between the two sites in precipitation amounts, particularly when localized shower-type (thunderstorm) precipitation occurs. For example, on August $21^{\mathrm{ST}}$, a "dry" thunderstorm was observed at the HMS with no trace of precipitation reported. However, puddled rain water was observed the following morning inside the Mock Tank on the plastic tarp and on similar ground coverings at the adjacent SAFE development area. Confirmation that the HMS provides a reasonable estimate of the onsite precipitation record is found in comparisons of HMS data and Station 6 (weather station located in the 200 East Area just south of the Mock Tank Site; Hoitink et al. 2002). The records indicate that Station 6 precipitation records for 2002 are virtually identical to those at HMS, suggesting that for the test period at least, the HMS record is a good surrogate for natural precipitation records at the Mock Tank Site.

Automated rain gauges were installed, primarily to monitor the artificial rain events performed during the test series (see Section 2.4.2); these also provided a tool to monitor natural precipitation at the site. The rain gauges were not operational until August $27^{\text {th }}$ since no artificial rain events were planned until after that date. Many of the rain-gauge readings were caused by factors other than natural precipitation. For example, on September $5^{\text {th }}$, a single rain gauge was intentionally tripped by manually pouring water into it to test its operation. Two trace events, on October $4^{\text {th }}$ and October $23^{\text {rd }}$, involved the tripping of a single rain gauge, resulting in a reading of 1 pulse. These two events are assumed to have involved some accumulation of dew in the gauge at a high enough level to trip the counter, but not an actual precipitation event. Nevertheless, the rain gauges did appear to record some natural precipitation events. These are summarized in Table 3.9. Of these, the event on October $3^{\text {rd }}$ may actually be an artifact of a rain event conducted the previous day (water may have been trapped on the bucket, and then slid down). However, seven of the gauges did record $1 \mathrm{~mm}(0.04 \mathrm{in}$.) of precipitation. 
Table 3.9. Natural Precipitation Events Recorded by the Rain Gauges

\begin{tabular}{||l|c|c|c||}
\hline \multicolumn{1}{|c|}{ Date } & $\begin{array}{c}\text { Time of First } \\
\text { Reading }\end{array}$ & $\begin{array}{c}\text { Range \& Average of } \\
\text { Readings in Tank Area }\end{array}$ & $\begin{array}{c}\text { Reading from Roof of } \\
\text { Field Office }\end{array}$ \\
\hline October $3^{\text {rd })}$ & $10: 03$ & $\begin{array}{c}\text { Range: } 0 \text { to } 1 \mathrm{~mm} \\
\text { Average } 0.58 \mathrm{~mm}\end{array}$ & $0 \mathrm{~mm}$ \\
\hline October $29^{\text {th }}$ & $0: 48$ & $\begin{array}{c}\text { Range: } 1 \text { to } 6 \mathrm{~mm} \\
\text { Ave: } 1.42 \mathrm{~mm}\end{array}$ & $0 \mathrm{~mm}$ \\
\hline November $7^{\text {th }}$ & $21: 34$ & $\begin{array}{c}\text { Range: } 2 \text { to } 3 \mathrm{~mm} \\
\text { Ave: } 2.08 \mathrm{~mm}\end{array}$ & $0 \mathrm{~mm}$ \\
\hline November $8^{\text {th }}$ & $0: 05$ & $\begin{array}{c}\text { Range: } 0 \text { to } 1 \mathrm{~mm} \\
\text { Average: } 0.67 \mathrm{~mm}\end{array}$ & \\
\hline (a) instrument malfunction
\end{tabular}

Average monthly temperatures measured at the HMS ranged from $79.6^{\circ} \mathrm{F}$ in July to $41.8^{\circ} \mathrm{F}$ in November (through the $15^{\text {th }}$ ). Hourly averages of soil temperatures are routinely measured at HMS at the 1.3-cm (0.5-in.) depth during the period of the PE test. Although no correlative analyses have been performed, diurnal variations in shallow soil temperature (as much as $23^{\circ} \mathrm{C}\left[42^{\circ} \mathrm{F}\right]$ on July 9) appear to coincide with diurnal signal fluctuations in HRR-SCRT data (see Appendix C). Alternate heating and cooling of the wires leading from the electrodes to the patch panel are cited as possible causes of the signal variations. The greatest average diurnal variation in air temperature occurred in late August and September $\left(\sim 18.9^{\circ} \mathrm{C}\left[\sim 34^{\circ} \mathrm{F}\right]\right)$ with some days producing contrasts of greater than $25^{\circ} \mathrm{C}\left(45^{\circ} \mathrm{F}\right)$. This period appears to correspond with the greatest diurnal fluctuations in signal.

The month producing the highest average winds during the test was July ( $9.3 \mathrm{mph})$, but the day with the highest average $(16.8 \mathrm{mph})$ occurred on October $29^{\text {th }}$, during which there was reported a dust storm. The highest gust of wind at HMS during the test period (53 $\mathrm{mph}$ ) occurred on July $7^{\text {th }}$ during a thunderstorm. 


\subsection{Summary of Results of Electrical Methods Leak Detection}

\subsection{FY 2002 PE Data and Test Results}

Results from the FY 2002 test are discussed in the following sections. More detailed discussions of HRR-SCRT and ERT results are presented by the principal investigators in Appendices C and D. Statistical analyses relating to performance are in preparation and will appear in subsequent documents.

\subsubsection{Comparison of Actual Versus Detected Releases}

In this section, we focus on the comparison that was made of the actual vs. detected releases for ERT long-electrode and HRR-SCRT long-electrode methods. There were a total of 13 leak events, excluding the surface flood event. During the PE testing, there were also 7 natural rain events, 4 simulated rain events, and a simulated flood (water-line leak) event.

\section{ERT}

The resistivity results for the ERT Long Electrode Technique (ERT-LET) were mixed. This technique detected the onset of 12 leak periods; 10 leaks were detected on the same day as injection began; one leak was detected on the second day of injection and one on the third day. Leaks were not detected continuously after commencing injections; however, the method accurately assigned a leak/noleak condition in 65 of the 110 test days. This is believed to result from the establishment of a steadystate flow channel that produced no discernable resistivity changes until the steady-state condition was altered (the one back-to-back leak campaign based on a change in flowrate was detected on the first day the flow rate changed). While ERT-LET detection systems erred on 45 days, only one case was a false positive (leak condition declared when solution injection was not occurring). The standard deviation calculated for this method is 1.46 deviations improved over a normal distribution. Estimates of leaked volume (based solely on ERT-PET tomographs) were uniformly high.

Similarly, artificial and simulated rainfall events did not affect the analysis of ERT data. No falsepositive declarations were made as a result of either artificial or natural precipitation.

\section{$H R R-S C R T$}

Of the 13 leaks, 4 were outside the designated HRR-SCRT test configuration. These were 3 events that occurred when the SCRT electrodes were not connected to the solution and 1 event during which the sheet piling was disconnected. Of the remaining 9 events that conformed to the test specification, HRRSCRT detected all of these (using the time-series analysis method).

The detection criteria cited here differ significantly from the Test Specification. HGI relied on timeseries analysis of data spanning several days to declare a leak condition rather than relying on the fixed or moving time-window protocol as outlined in the Test Specification. The fixed or moving time-window analysis proved to be unreliable for this resistivity technique because the time series spanned more than a single day. 
During the rain events, none were detected or posed a technical problem for the HRR-SCRT methods. There were no false-positive assessments or declarations due to natural or artificial precipitation events. None of the four were detected or posed a technical problem for the HRR-SCRT methods. The artificial flood (water-line leak) event was readily detected and recognized as a non-leak event.

At one point in the test program, the sheet piling wall was electrically disconnected from the Mock Tank structure and then reconnected at a later time. The disconnection was immediately apparent in HRR-SCRT data and was recognized as a non-leak event. The reconnection returned the HRR-SCRT system to normal operation. No false alarms were reported as a result of the disconnection, even though active leaks were occurring concurrent to the electrical disconnection and subsequent reconnection.

\subsubsection{Comparison of Actual Versus Estimated Release Volumes}

HRR-SCRT was approximately 14 percent below the actual volume delivered to the ground during testing (volume estimate using time-series analysis). The ERT long-electrode method did not compute a volume. Instead, analysis of ERT tomographs reported a range of 34,503 to $133,418 \mathrm{~L}$ (9,115 to $35,246 \mathrm{gal}$ ) for the duration of the test. The ERT volume estimates were uniformly high by as much as a factor of 2 or more.

\subsubsection{Sources of Error or Interference}

Geophysical tests show that relative resistivity of greater than $500 \mathrm{ohm}-\mathrm{m}$ is typical of the Hanford subsurface. Resistivities due to high salt content are typically lower than $1 \mathrm{ohm}-\mathrm{m}$. Consequently, the contrast between the target and background is high and desirable for leak detection deployed in tank farms with previous leaks. Sensitivities will increase with either higher salt content or increased leak volume. After discharges have occurred for a period of time, the sensitivity of the electrical methods is expected to decrease to some extent. However, the point at which this occurs is expected to be in the range well beyond 37,854 L (10,000 gal). In the testing at the Mock Tank, there were previous discharges of fluid prior to the 52,995 L (14,000 gal) of salt solution and $7570 \mathrm{~L}$ (2000 gal) of water that were added in the 2002 test (Barnett et al. 2001). A total of approximately 90,850 L (24,000 gal) of fluids (salt solutions plus water) has been discharged to ground at the Mock Tank since testing began in 1995, yet detection of leakage was easily achieved from the beginning to the end of testing. Based on these observations, it is not expected that leak-detection protocols using electrical methods will vary much between the tanks that have been declared non leakers and those that have been declared leakers (where there is documentation of leakage in the subsurface near the tank). Volume estimates from known leakers will be affected by existing plumes, but actual leak detection should not be affecte $\mathrm{d}$.

\section{ERT}

ERT long-electrode methods were found to suffer from low selectivity between initiation of a leak and a leak that has reached steady-state flow. In some cases, more than 1 day was required to positively identify a leak. The ERT-LET was not used in this test to calculate volume but with some adjustments could be calibrated to a volume estimate. However, volume estimates are difficult to calculate accurately without prior knowledge of field porosity, soil saturation, and pore fluid conductivity. Issues discussed previously, related to existing leaks, will affect any ERT-LET diagnostics, but should not hinder the capability of the ER-LET method to detect leaks in settings similar to those observed at the Mock Tank 
site. The changes in subsurface bulk resistivity observed with ERT-LET during the 2002 test were substantial enough that in tank farm conditions, it is expected that detection of a few thousand gallons or less is possible. Further testing of this method is desirable because it uses only the steel casing of existing drywells as electrodes and is essentially the simplest method for electrical monitoring.

\section{$H R R-S C R T$}

The greatest source of error for the HRR-SCRT system has been identified as diurnal fluctuations observed daily during testing. It is believed that these fluctuations are due to thermal variation (0.3 percent) and to electricalsystem noise (+/-0.2 percent). HRR-SCRT sensitivity will tend to decrease with increasing ground saturation because of the introduction of highly saline solutions to the subsurface. However, this reduction is not expected to significantly affect leak detection during retrieval operations. This method is inherently more sensitive than the ERT-LET method but does require more electrical connections.

\subsection{Implications for Tank-Farm Deployment}

The implications for tank-farm deployments based on the performance of electrical methods, specifically ERT-LET and HRR-SCRT as described in this report, are significant. The positive results of the methods, in particular, the results from HRR-SCRT, suggest that testing HRR-SCRT under tank-farm conditions should be a logical next step in confirming that leak monitoring using electrical methods is superior to present baseline monitoring (gamma and neutron logging of dry wells). With some modification, ERT-LET has also shown promise for deployment, so both methods could be reasonably tested at full scale within a tank farm. One system (ERT-LET) could provide backup for the other system (HRR-SCRT), and the combination could become a versatile, robust tool for leak detection at Hanford Tank Farms.

Such events as natural rainfall, ponded irrigation water, electrical noise, electrical disconnections, and surface heating and cooling were all possible sources of error for the HRR-SCRT method, but did not reduce the effectiveness of leak detection. This suggests that tank-farm infrastructure and operations should have little or no influence on the monitoring results obtained with HRR-SCRT within a tank farm. Leak detection of several hundred gallons could be expected under tank-farm conditions using HRRSCRT and the time-series data-analysis method. While there are a number of issues related to full deployment within a tank farm that were not addressed directly by the 2002 testing at the Mock Tank, the overall performance was superior to any method previously tested. Neutron logging at the Mock Tank Site failed to detect the relatively large 52,995 L (14,000 gal) leak. Not only was each individual leak detected by HRR-SCRT, but the total volume was predicted within 15 percent of the actual amount over the course of the test using the previous year's calibration. Similarly, ERT-LET detected all of the major leak events. Recalibration using the PE test results will result in an even better prediction rate. Both RET-LET and HRR-SCRT demonstrated a very low probability of false alarms and a capability to detect leaks in near real time. Leak rates were also predicted within a few hours of the onset of a leak for HRRSCRT and generally within a day or two for ERT-LET.

The year 2002 tests at the Mock Tank Site suggest that electrical methods are substantially more effective than baseline monitoring, which has previously been shown to be insensitive as a leak-detection system (Isaacson 1982). Baseline monitoring requires manual readings and attendant complications and 
expense. Gamma logging requires an equipment truck system and maneuvering of instruments to each dry-well monitoring station every time logging is initiated. Neutron probe logging is also a manual operation and requires, as a minimum, that readings are taken at each well and for each monitoring depth each time the well is sampled. Thus, the monitoring is noncontinuous, which is a significant technical drawback (Isaacson 1982) and adds both cost and risk to the data collection.

An additional benefit to the deployment of ERT-LET and/or HRR-SCRT is that no changes or modifications to the tank-farm infrastructure are required, other than simply connecting wires to the existing infrastructure. A single installation effort could encompass several tanks, and it is possible to connect to drywells or groundwater monitoring wells located at the perimeter of the tank farm, thus avoiding entry into the operations area. While sensitivity of the external monitoring would be reduced over direct monitoring of an individual tank, there are some distinct advantages for such a system. Testing a system that operates over a wider scale than a single tank would be desirable and a pilot deployment of such a system is recommended.

Before the commencement of PE testing, ERT acquired background data for approximately 10 days, and HRR acquired background data for approximately 4 days. It is estimated that tank-farm deployment of either technology would require no longer than a 2-week interval of background data acquisition.

\subsubsection{Flammable Gas and Electrical Connections}

HRR method C employed a mise-a-la-masse (excitation of mass) scheme using a set of electrodes to energize leaking waste simulant. Electrical connections to the SSTs are governed by UL Standard 913 (adopted by ASTM); any equipment or connectivity devices must be approved under this set of standards. Since the tank will be used as a receiving electrode in a reciprocal mise-a-la-masse (excitation of mass) configuration (only field electrodes will have voltage applied), it is only necessary for the receiver unit to be brought into conformance with UL 913. This would be achievable by circuit modifications to limit current output in the event of a catastrophic failure in the receiver equipment (implementation of multiple fail-safe design configuration). 


\subsection{References}

Barnett DB, GW Gee, MD Sweeney. 2001. Test Plan for the Demonstration of Geophysical Techniques for Single-Shell Tank Leak Detection at the Hanford Mock Tank Site_Fiscal Year 2001. PNNL-13598, Pacific Northwest National Laboratory, Richland, WA.

Barnett DB, GW Gee, MD Sweeney. 2002. Results of Tank-Leak Detection Demonstration Using Geophysical Techniques the Hanford Mock Tank Site-Fiscal Year 2001. PNNL-13818, Pacific Northwest National Laboratory, Richland, WA.

Boger RM. 2002. Ex-Tank LDMM Performance Evaluation Strategy. RPP-10904, CH2M Hill Hanford Group, Richland, WA.

Bratton WL, JW Maresca, and WC Dickerson. 2002. Ex-Tank LDMM Performance Evaluation Test Specification. Vista Engineering Technologies, LLC, Richland, WA.

Bratton WL. 2002. Ex-Tank LDMM Technology Assessment and Down-Selection Report. RPP-10604, Rev. 1. U. S. Department of Energy, Office of River Protection, Richland, WA.

Collard LB, JD Davis, DB Barnett. 1996. Potential Effects of Low-Volume Effluent Discharges on PastPractice Vadose Zone Contamination. WHC-SD-LEF-ER-001, Rev. 0, Westinghouse Hanford Company, Richland, WA.

Ecology et al. 1998. Hanford Federal Facility Agreement and Consent Order. Washington State Department of Ecology, U.S. Environmental Protection Agency, and U.S. Department of Energy. Available at: http://www.hanford.gov/tpa/coverpg.htm.

Gephart RE, and RE Lundgren. 1998. Hanford Tank Cleanup: A Guide to Understanding the Technical Issues. Battelle Press, Columbus, $\mathrm{OH}$.

Goodspeed MJ. 1981. "Neutron moisture Meter Theory." In Soil Water Assessment by the Neutron Method, E.L. Greacen (ed.), pp.16-23, CSIRO Australia.

Hoitink, DJ, KW Burk, JV Ramsdell, and WJ Shaw. 2002. Hanford Site Climatological Data Summary 2001 with Historical Data. PNNL-13859, Pacific Northwest National Laboratory, Richland, WA.

International Atomic Energy Agency (IAEA). 1970. Neutron Moisture Gauges. Technical Report Series. No. 112. International Atomic Energy Agency. Vienna, Austria.

Isaacson RE. 1982. Supporting Information for the Scientific Basis for Establishing Dry Well Monitoring Frequencies. RHO-RE-EV-4 P, Rockwell Hanford Operations, Richland, WA.

Narbutovskih SM, TD Halter, MD Sweeney, W Daily, and AL Ramirez. 1996a. Electrical Resistivity Tomography at the DOE Hanford Site. WHC-SA-3035-VA, Westinghouse Hanford Company, Richland, WA. 
Narbutovskih SM, DF Iwatate, MD Sweeney, AL Ramirez, W Daily, RM Morey, and L Christensen. 1996b. Feasibility of CPT-Deployed Vertical Electrode Array in Single-Shell Tank Farms. WHC-SDEN-TA-004 Rev. 0, Westinghouse Hanford Company, Richland, Washington.

Ramirez A, W Daily, A Binley, D LaBrecque, and D Roelant. 1995. Detection of Leaks in Underground Storage Tanks Using Electrical Resistance Methods. UCRL-JC-122180, Lawrence Livermore National Laboratory, Livermore, CA.

Ramirez A, W Daily, A Binley, and D LaBrecque. 1996. Tank Leak Detection Using Electrical Resistance Methods. UCRL-JC-122875, Preprint prepared for the Symposium on the Application of Geophysics to Engineering and Environment, Keystone, CO, Lawrence Livermore National Laboratory, Livermore, CA.

Sisson JB, and A Lu. 1984. Field Calibration of Computer Models for Application to Buried Liquid Discharges: A Status Report. RHO-ST-46 P, Rockwell Hanford Operations, Richland, WA.

U.S. Department of Energy (DOE). 1996. Vadose Zone Characterization Project at the Hanford Tank Farms, SX Tank Farm Report. DOE/ID/12584-268, Albuquerque Operations Office, Grand Junction Operations Office, Grand Junction, CO.

Williams BA, BN Bjornstad, R Schalla, and WD Webber. 2000. Revised Hydrogeology for the Suprabaslat Aquifer System, 200 East Area and Vicinity, Hanford Site, Washington. PNNL-12261, Pacific Northwest National Laboratory, Richland, WA.

Williams BA, BN Bjornstad, R Schalla, and WD Webber. 2002. Revised Hydrogeology for the Suprabaslat Aquifer System, 200 West Area and Vicinity, Hanford Site, Washington. PNNL-13858, Pacific Northwest National Laboratory, Richland, WA.

Zhang ZF, AL Ward, and GW Gee. 2002. Estimating Field-Scale Hydraulic Parameters of Heterogeneous Soils Using a Combination of Parameter Scaling and Inverse Methods. PNNL-14109, Pacific Northwest National Laboratory, Richland, WA. 


\section{Appendix A}

\section{LDMM Ex-Tank-Leak Detection Performance Evaluation Test}

Implementation Plan-FY 2002-2003 



\section{LDMM Ex-Tank-Leak Detection Performance Evaluation Test Implementation Plan- FY 2002-2003}
D. B. Barnett
M. D. Johnson
G. W. Gee
M. D. Sweeney
V. F. Medina

July 2002

Prepared for the U.S. Department of Energy under Contract DE-AC06-76RL01830 


\title{
DISCLAIMER
}

This report was prepared as an account of work sponsored by an agency of the United States Government. Reference herein to any specific commercial product, process, or service by trade name, trademark, manufacturer, or otherwise does not necessarily constitute or imply its endorsement, recommendation, or favoring by the United States Government or any agency thereof, or Battelle Memorial Institute.

\author{
PACIFIC NORTHWEST NATIONAL LABORATORY \\ operated by \\ BATTELLE \\ for the \\ UNITED STATES DEPARTMENT OF ENERGY \\ under Contract DE-AC06-76RL01830
}

This document was printed on recycled paper. 


\section{LDMM Ex-Tank-Leak Detection Performance Evaluation Test Implementation Plan- FY 2002-2003}
D. B. Barnett
G. W. Gee
M. D. Johnson
M. D. Sweeney
V. F. Medina

July 2002

Prepared for

the U.S. Department of Energy

under Contract DE-AC06-76RL01830

Pacific Northwest National Laboratory

Richland, Washington 99352 


\section{Acronyms}

$\begin{array}{ll}\text { bgs } & \text { below ground surface } \\ \text { CEMI } & \text { Cross-Borehole Electromagnetic Induction } \\ \text { CHG } & \text { CH2M HILL Hanford Group, Inc. } \\ \text { CPT } & \text { cone penetrometer } \\ \text { DOE-RL } & \text { U.S. Department of Energy Richland Operations Office } \\ \text { ERT } & \text { Electrical Resistance Tomography } \\ \text { ERT-LET } & \text { Electrical Resistivity Tomography-Long Electrode Tomography } \\ \text { ERT-PET } & \text { Electrical Resistivity Tomography-Point Electrode Tomography } \\ \text { FY } & \text { fiscal year } \\ \text { GFI } & \text { Ground-Fault Interrupter } \\ \text { HMS } & \text { Hanford Meteorological Station } \\ \text { HRR-SCRT } & \text { High-Resolution Resistivity-Steel Casing Resistivity Technology } \\ \text { HVAC } & \text { heating, ventilation, and air conditioning } \\ \text { I.D. } & \text { inside-diameter } \\ \text { LDMM leak detection } & \text { monitoring, and mitigation } \\ \text { LLNL } & \text { Lawrence Livermore National Laboratory } \\ \text { PNNL } & \text { Pacific Northwest National Laboratory } \\ \text { PVC } & \text { polyvinyl chloride } \\ \text { QA } & \text { quality assurance } \\ \text { SAFE } & \text { Subsurface Air Flow and Extraction } \\ \text { SBMS } & \text { Standards-Based Management System } \\ \text { SDA } & \text { SAFE Development Area } \\ \text { SST } & \text { single-shell tank } \\ \text { TLDD } & \text { Tank Leak Detection Demonstration } \\ \text { VEA } & \text { Vertical Electrode Array } \\ \text { XBR } & \text { Cross-Borehole Radar } \\ \text { XBS } & \text { Cross-Borehole Seismic Tomography } \\ & \end{array}$





\section{Contents}

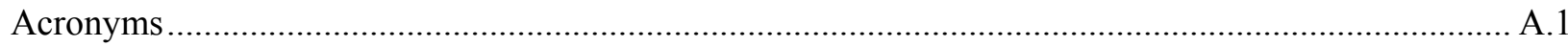

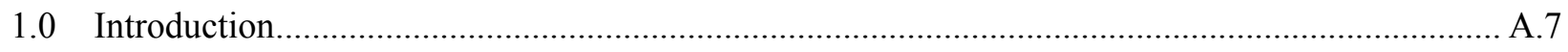

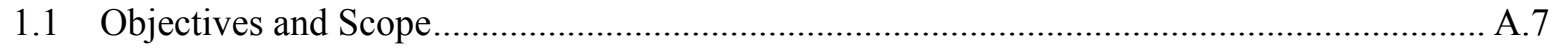

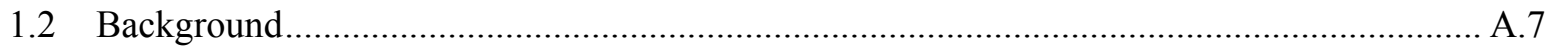

1.2.1 Historical Electrical Measurements at the Hanford Site ......................................... A.10

1.2.2 Results of SST S-112 Electrical Measurements.................................................... A.14

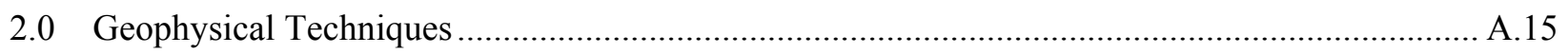

2.1 Electrical Resistance Tomography (ERT) ................................................................ A.15

2.2 High-Resolution Resistivity-Steel Casing Resistivity Technology (HRR-SCRT) .............. A.16

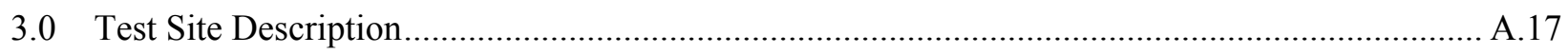

3.1 The Mock Tank Site Following FY 2001 Tests ......................................................... A.17

3.2 Preparations and Modifications to the Mock Tank Site for FY 2002-2003 Tests .............. A.17

3.3 Hydrogeology and Stratigraphy of the Mock Tank Site................................................. A.18

3.4 Site Safety and Protection Provisions ............................................................................. A.19

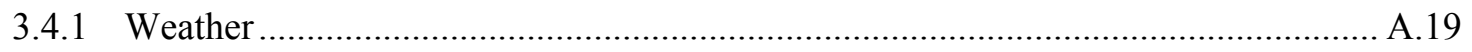

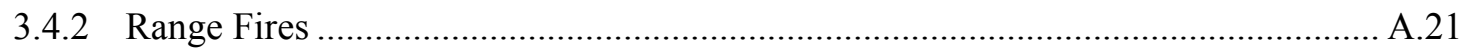

3.4.3 Other Potential Site Hazards ............................................................................... A.2

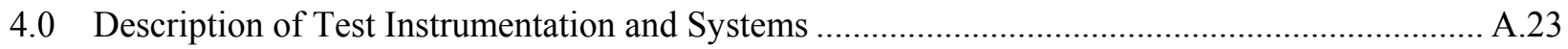

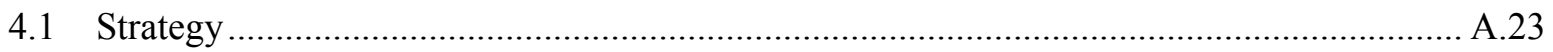

4.2 ERT (LET and PET) Electrode Configurations......................................................... A.23

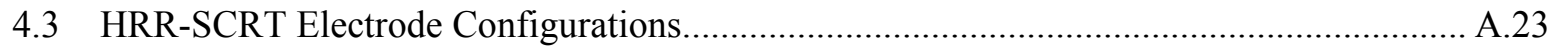

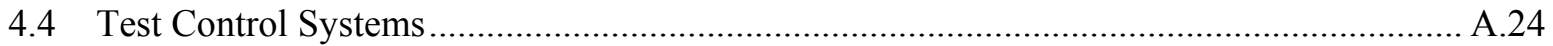

4.4.1 Manual Collection, Manual Switching System................................................. A.25

4.4.2 Manual Collection, Automated Switching System ............................................. A.25

4.4.3 Automated Collection, Automated Switching System.......................................... A.25

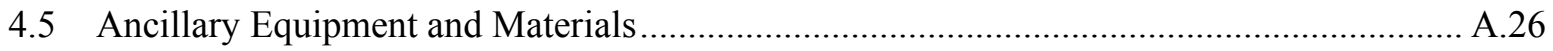


5.0 Performance Evaluation Testing Procedures ........................................................................ A.29

5.1 Activation and Control of Data-Collection Systems .................................................... A.29

5.2 Activation and Control of Solution Release System .................................................... A.29

5.3 Protocol for Changing Test Procedures....................................................................... A. 30

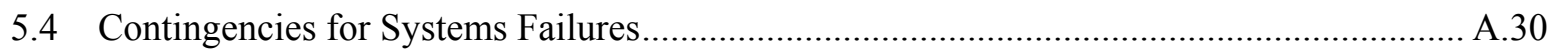

5.5 Post-Test Dispositioning and Site Control .............................................................. A. 31

6.0 Collection of Ground-Truth and Physical Properties Data ...................................................... A.33

6.1 Neutron Probe Soil Moisture Measurements................................................................. A.33

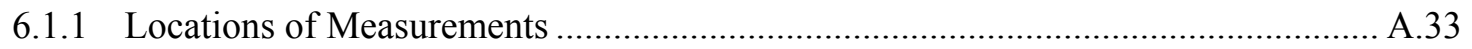

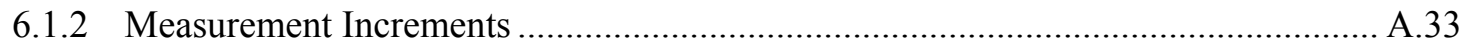

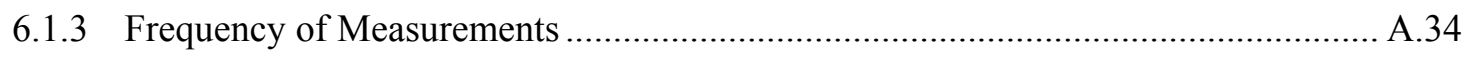

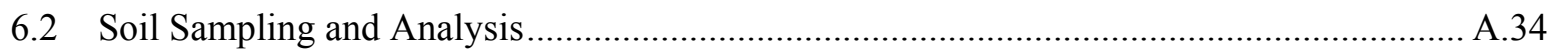

6.3 Other Physical and Quality-Control Data Collection .................................................. A.35

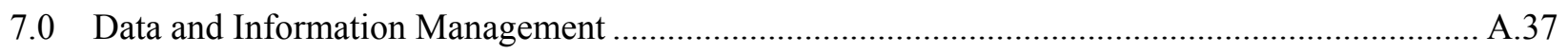

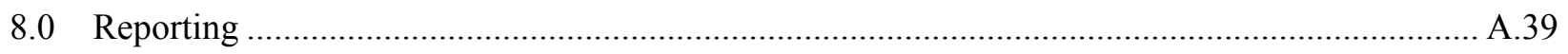

9.0 Environmental Health and Safety Requirements ............................................................... A.41

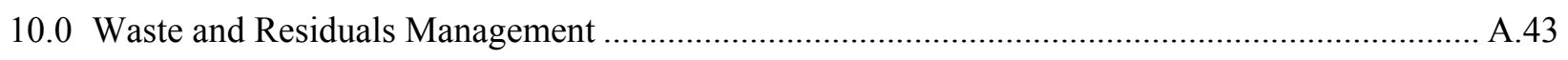

10.1 Management Activity A-Solid Waste Management Plan for Borehole Construction ......... A.43

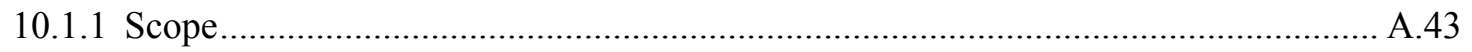

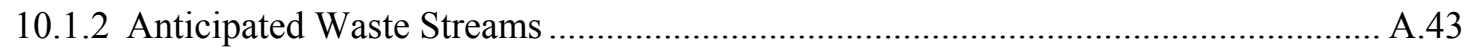

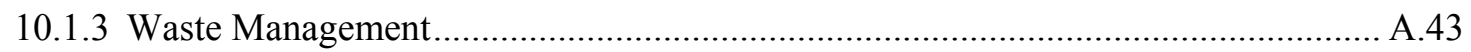

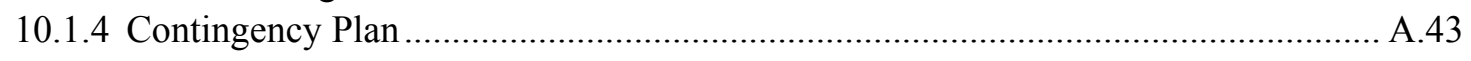

10.2 Management Activity B-Soil and Water Sample Management Plan ................................ A.43

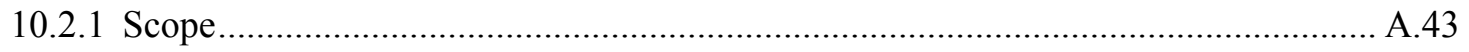

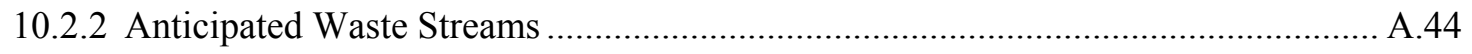

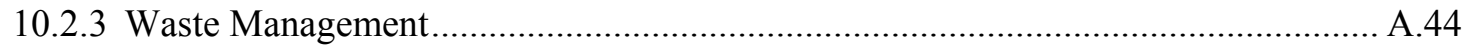

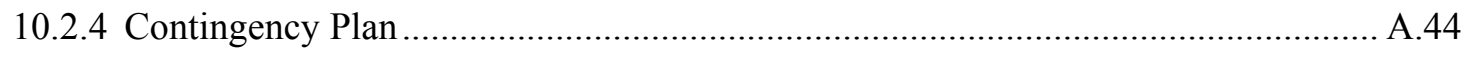

11.0 Quality Assurance and Quality Control ............................................................................45

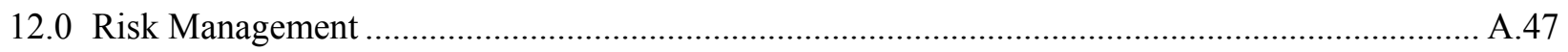


12.1 Introduction to the Risk Management Process ........................................................... A.47

12.2 Identification, Assessment of Risks and Mitigation Procedures ...................................... A.48

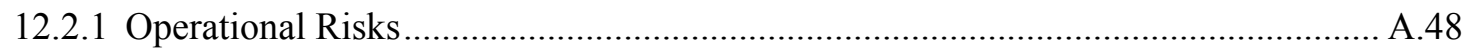

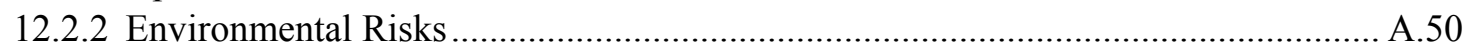

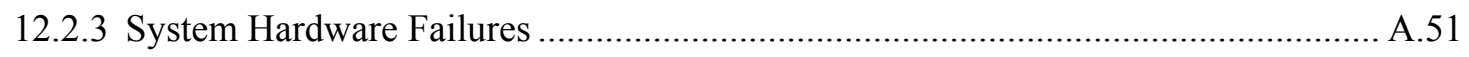

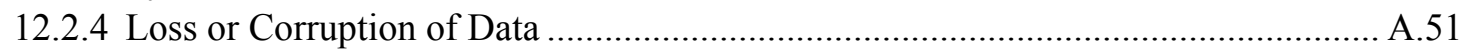

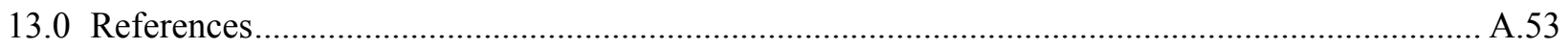

Attachments

A Participants, Organizational Responsibilities, and General Schedule for the FY 2002-2003

Performance Evaluation Testing …..................................................................................... A.55

B Site Operating Requirements and Permits ................................................................................ A.60

C Site Access and Conduct Requirements Industrial Health and Safety Plan-Site Safety

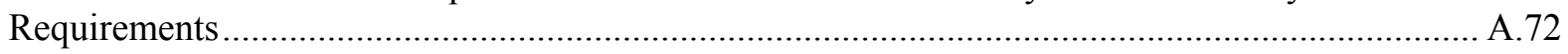

D Specifications for FY 2002-2003 Mock Tank Modifications ........................................................ A.95

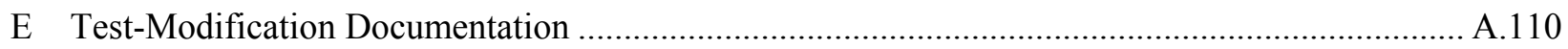

F Details of Data Collection, Processing, and Interpretive Techniques Planned for FY 2002 LDMM Long Electrode and Point Electrode Performance Evaluation Testing ........................... A.119

G Details of Data Collection, Processing, and Interpretive Techniques Planned for FY 2002 LDMM for HRR-SCRT Performance Evaluation Testing....

H Procedure for Measuring Soil Moisture Using Neutron Probe ................................................. A.195

I Field Procedures ............................................................................................................... A.216 


\section{Figures}

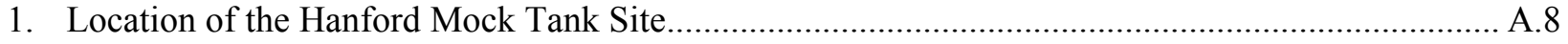

2. Top: The Mock Tank Site Before Start of FY 2001 Activities. ..................................................... A.9

3. Details of the Mock Tank Construction in Relation to One of the 1995 ERT Installations............. A.12

4. Site Layout for the Mock Tank Showing Additional Infrastructure Planned for the FY 2002-2003 Performance Evaluation Testing ..................................................................... A.13

5. Locations of Boreholes, ERT Arrays, and Interior Access Ports ("leak points") at the Mock Tank Site (after Bratton et al. 2002b) ...................................................................................... A. 34

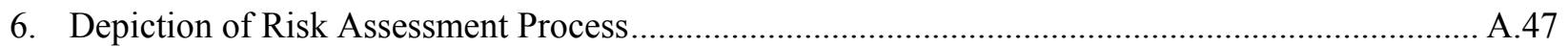

\section{Tables}

1. Definitions of Low, Moderate, and High Probabilities and Impacts ............................................. A.48

2. Summary of Risks and Actions for LDMM Project.........................................................................49 


\subsection{Introduction}

The M-45 series of milestones under the Hanford Federal Facility Agreement and Consent Order (Tri-Party Agreement; Ecology et al. 1998) requires removal of wastes from single-shell tanks (SSTs) and other miscellaneous underground tanks for storage in the double-shell tank system. Under the Tri-Party Agreement, CH2M HILL Hanford Group, Inc (CHG) is demonstrating several retrieval methods as alternatives to past practice sluicing that use minimal amounts of liquid to dislodge, mobilize, and remove the wastes. As additional assurance of protection of the vadose zone beneath the SSTs, tank wastes and tank conditions will be monitored aggressively during retrieval operations. Hence, significant effort is aimed at detecting, monitoring, and devising mitigation techniques for tank leakage. In addressing this effort, $\mathrm{CHG}$ and their subcontractors have been evaluating a variety of potential in-tank and ex-tank (monitoring conducted from outside a tank) technologies in support of the development of a leak detection, monitoring, and mitigation (LDMM) system for use during waste-retrieval operations.

Current strategy for development of external leak-detection of SSTs is represented by Bratton et al. (2002a). The Ex-Tank LDMM Performance Evaluation Strategy. The model for, and development of evaluation protocol for ex-tank LDMM systems are presented in this document, and, in part, guide technical specifications and implementation of performance evaluation tests.

During July and August 2001, CHG engaged Pacific Northwest National Laboratory (PNNL) to deploy five "ex-tank" geophysical, leak-detection technologies at the Hanford Site Mock Tank Site (Figures 1 and 2) in a Tank Leak Detection Demonstration (TLDD). These technologies consisted of 1) Electrical Resistance Tomography (ERT), 2) Cross-Borehole Electromagnetic Induction (CEMI), 3) High-Resolution Resistivity-Steel Casing Resistivity Technology (HRR-SCRT), 4) Cross-Borehole Radar (XBR), and 5) Cross-Borehole Seismic Tomography (XBS). In January 2001, final results for this deployment were received and evaluated during a "down-selection" workshop held at the Hanford Site (Bratton 2002).

\subsection{Objectives and Scope}

This document provides operational and field-deployment guidance for implementing technical specifications dictated by Ex-Tank LDMM Performance Evaluation Test Specification (Bratton et al. 2002). Attachments include all necessary permitting, safety, construction, and test-systems specification requirements.

\subsection{Background}

Performance evaluation testing represented by this plan is based largely on previous work of investigators applying the ERT and HRR-SCRT methods in various configurations over the past several years, but most specifically in fiscal year (FY) 2001 tests (Barnett et al. 2002). The basic approaches to field deployment (i.e., sensor locations) and data recording and processing during FY 2001 are 


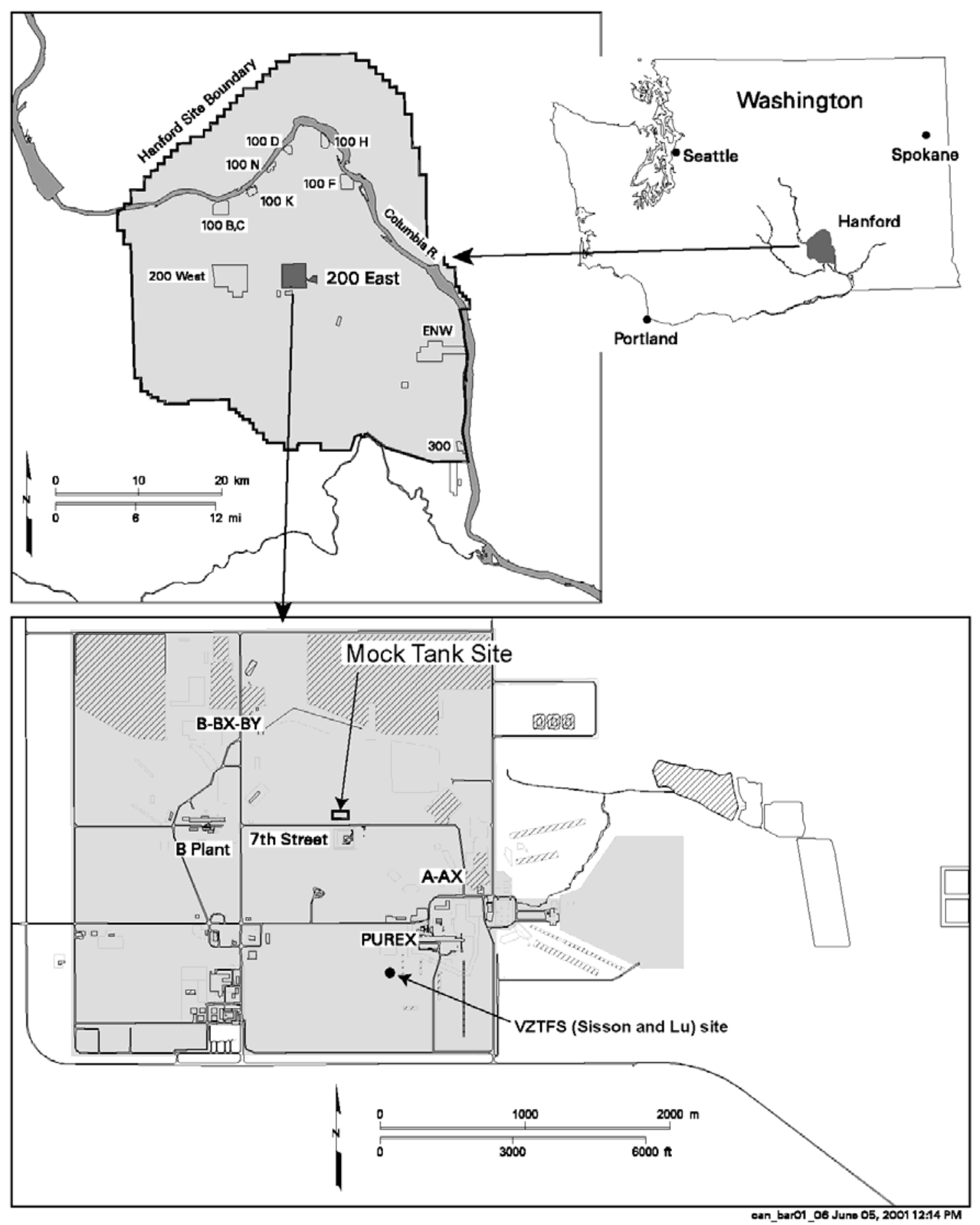

Figure 1. Location of the Hanford Mock Tank Site 

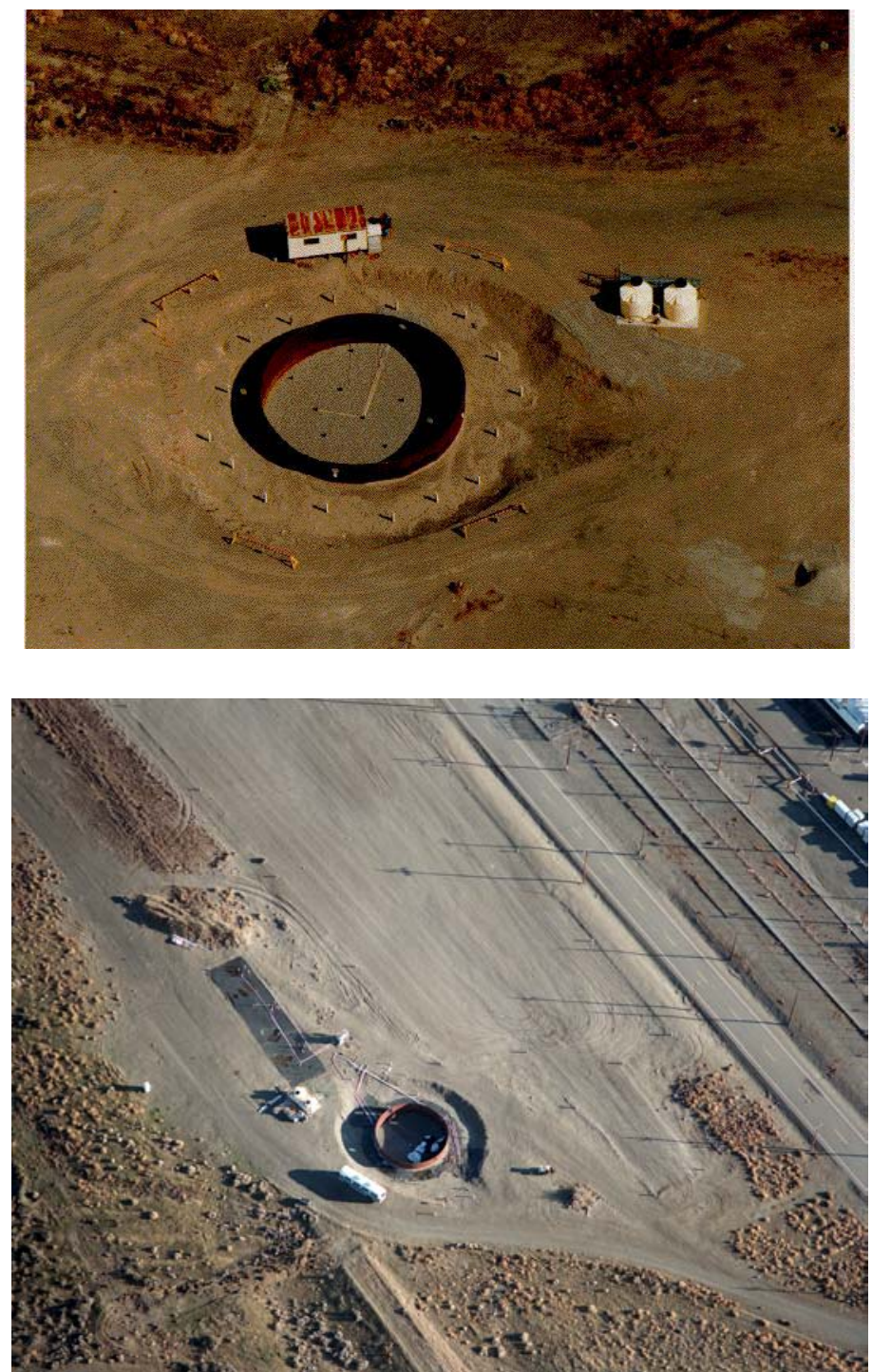

Figure 2. Top: The Mock Tank Site Before Start of FY 2001 Activities. Shown are the sixteen 1995 ERT arrays, the previous field laboratory, and two 2,500-gal (9,464-L) tanks used in the 199596 experiments. Bottom: Oblique aerial view of the Mock Tank from the northwest following FY 2001 testing, showing the mobile geophysics laboratory (bus lower left of tank) and SAFE Development Area (SDA) (upper left of mock tank). A 4,000-gal $(15,140-\mathrm{L})$ tank, which contained the sodium thiosulfate solution for the FY 2001 testing, had already been removed at the time of the photograph. 
essentially identical with those for the FY 2002-2003 performance evaluation, except that instrumentation for data collection is streamlined to allow remote control (see Section 4.0). The primary differences in evaluation represented by FY 2002-2003 testing are the planned statistical applications (evaluation of repetitive trials) and uniformly blind nature of each trial (i.e., variable release amount or no release) to those collecting and analyzing the data.

During the early and mid-1970s, electrical resistivity methods were first explored as methods for external SST leak detection. Reports from that era describe systems that were based on the use of steel well casings as electrodes to detect saline wastes leaked from SSTs. These systems were tested outside of and within SST farms; a summary of these historical efforts is provided in Section 1.2.1.

The Mock Tank was constructed in 1994 specifically to test tank leak detection capabilities of the ERT method. From 1994 to 1996, ERT was deployed at the Mock Tank site using cone penetrometer (CPT)-emplaced vertical electrode arrays and similar installations. Because of its specialized features, accessibility, and existing infrastructure, the Mock Tank was selected for the FY 2001 testing. Similar considerations led to selection of this site for the FY 2002-2003 performance evaluation testing (Bratton et al. 2002).

Baseline Resistance measurements were made by LLNL and HGI around SST S-112 in May, 2002 to collect information that may be used to determine differences and transferability of results between the Mock Tank site and an SST. This exercise involved installation of connections to dry wells and tank superstructure at the S-112 SST and subsequent measurements of electrical properties surrounding the tank and within the S Tank Farm. Results of these measurements are currently undergoing interpretation.

\subsubsection{Historical Electrical Measurements at the Hanford Site}

Electrical geophysical methods have been considered a potentially viable approach to leak detection and monitoring beneath Hanford Site SSTs. The earliest testing of these methods began in the mid-1970s using electrical resistivity (conductivity), and was deployed at several tank farms and subsequently analyzed for deployability and performance. In 1994 through 1996, the first work at the Mock Tank site was conducted using ERT.

\subsubsection{Tank Farms}

Jensen et al. (1973) reviewed the historical tank leak monitoring system at the Hanford Site. In addition to evaluating within tank monitoring (e.g., FIC and tape systems for liquid levels), and mass balance methods (tank inflow vs. outflow) they evaluated dry-well monitoring system used for ex-situ tank-leak detection and suggested improvements using both vertical dry wells and horizontal laterals where available (e.g., SX and A tank farms). They focused mainly on assessment of monitoring changes in radioactivity (with gamma scintillation). From geometric considerations they inferred changes in leak volumes depending on the number of dry wells, the position of the leak with respect to the tank bottom and the monitoring frequency (assumed to be as often as daily). For example, with only four dry wells around a tank for monitoring, their analysis showed that undetected leaks could range from 28,000 to 78,000 gal, while increasing the number of monitoring wells using 10 dry wells could reduce undetected 
leaks to the range of 2,600 to 7,900 gal. Leak monitoring around all of the tanks, assuming an optimal number of 20 wells per day would require, an unrealistic number of 50 trucks to be continuously on the move. Clearly such a system was prohibitively expensive and in reality not possible to implement. Recommendations for alternatives to down-well logging of the dry wells with gamma scintillation included a proposal to string radiation sensitive tape or strings of small GM tubes down wells to continuously monitor changes in radioactivity. Such a system was never implemented. Also, it was proposed to monitor water content of leaks using down-well neutron probe logging (which suffered from the same problem as gamma logging with respect to monitoring frequency requirements). While periodic monitoring of water content using neutron probes in dry wells was initiated (Isaacson 1982), such monitoring has been sporadic and not used routinely. No mention of electrical methods, or similar continuous monitoring schemes, was made in the Jensen et al. (1973) report.

Isaacson (1982) proposed a "scientific basis" for establishing the frequency of leak detection using gamma monitoring of the dry wells. The analysis required knowledge of leak rate, radiation dose, dose attenuation, detector response, geometries of the dry well and wetted soil, and hydrologic properties of the soil. The assumption was that dry well monitoring using gamma scintillation logging would be the standard method for leak detection in the vadose zone under the high-level waste tanks at Hanford. Depending on the interval of monitoring for a specific tank, leak detection sensitivity ranged from a few thousand gallons to more than a hundred thousand gallons. Recommended frequency ranged from 1- to 10 -week intervals. No electrical methods (which could overcome the frequency and manual-monitoring issues) were offered as an alternative to the gamma scintillation-monitoring scheme even though there had been electrical methods tested in several tank farms prior to the Isaacson (1982) analysis. It is not clear why electrical methods for leak detection were not implemented in the tank farms.

Key (1975) reported that four systems were tested for leak detection capabilities in the early 1970s. These included three electrical methods; namely, the Boeing Aerospace Company conductivity system and two Battelle Pacific Northwest Laboratory (BNW) systems; a high-frequency radio system. In addition, an acoustical system by Holosonics, Inc. was tested. All four of the systems were tested at a simulated waste tank site in the 200-W Area. Subsequently, after modification for tank-farm conditions, the Boeing and Battelle d.c. systems were tested in operating tank farms. The Boeing system used an alternating current (a.c.) potential field and the Battelle system utilized a direct current (d.c.) field (generated by the cathodic protection system and the electro-chemical potential of the soil). The dry wells surrounding the tank were used as electrodes to measure the distribution of the potential field and its distortion introduced by a simulated leak solution. The results indicated that a 53 gal $(200 \mathrm{~L})$ leak from a tank could be detected readily in a dry environment (i.e., where there had been no prior leak) but the sensitivity decreased as the fluid content increased in the subsurface. The Boeing (a.c.) system was selected for adoption to tank farm operation and tested for more than a year on selected tanks (e.g., 101-BX, 103-BX, 105-C, 104-A, 102-AX, 106-TX, and 110-U). In June 1977, the Boeing System was installed as an operational feature in the A and AX tank farms (Deichelborer 1978). After the initial tests and analysis (Key 1975 and 1977), there was a transition of tank-farm contractors, from ARCO to North American Rockwell, and the electrical monitoring system was abandoned. There are no records of its use past 1980. Deichelborer (1978) suggests that the Boeing system had some deficiencies: there were problems with instability in the voltage readings (and significant differences from tank to tank), requiring a significant calibration effort on the electrical system. Additional simulated slow leaks were recom- 
mended but there is no evidence that such testing was conducted; as indicated earlier, the system was abandoned before 1980 .

\subsubsection{Mock Tank}

Leak-detection studies at the Mock Tank site were conducted from 1995 through 1996 (Ramirez et al. 1995, 1996; Narbutovskih et al. 1996a, 1996b), and for the FY 2001 TLDD. In 1995 and 1996, vertical electrode arrays (VEAs), installed in 16 boreholes around the Mock Tank were used to evaluate the performance of ERT as a leak detection method using injections of saline solution through the tank leak points. Figure 3 shows a layout of the Mock Tank Site as it was maintained during the most recent (FY 2001 TLDD) testing. An example of one of the sixteen electrode arrays in relation to the Mock Tank is shown in Figure 3. Both the 1995 and 1996 studies consisted of releases of 0.08 molar saline $(\mathrm{NaCl})$ solutions at different leak points within the Mock Tank.

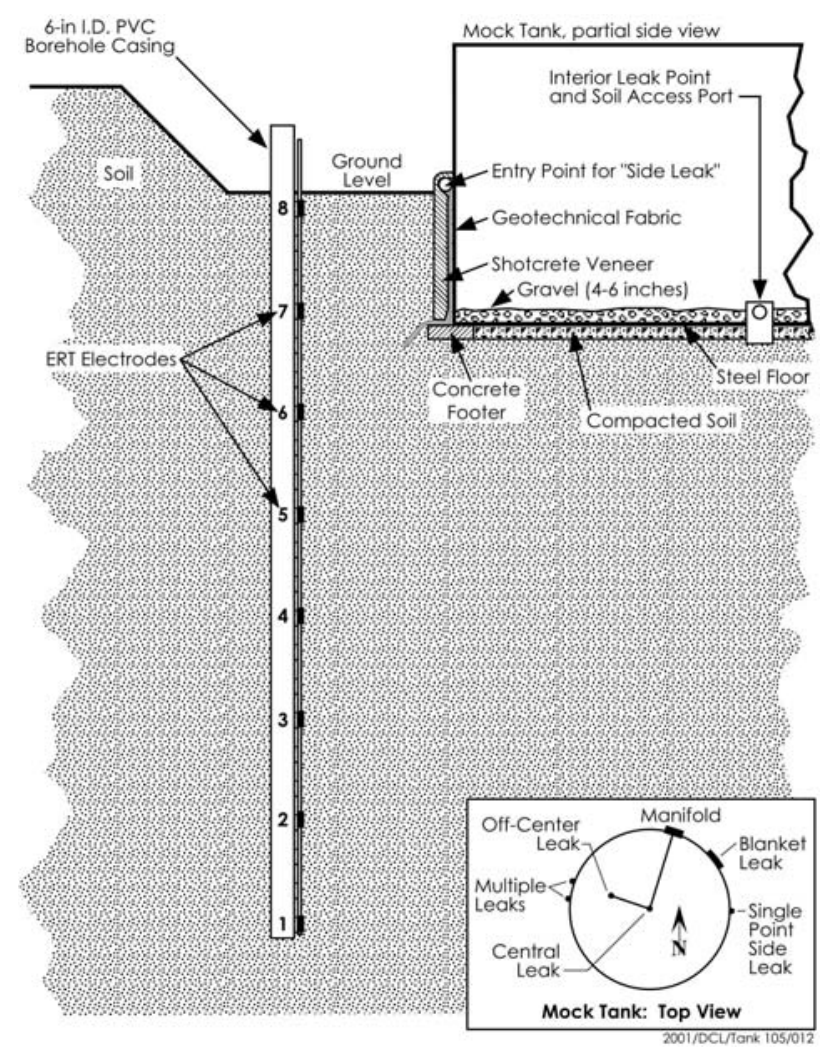

Figure 3. Details of the Mock Tank Construction in Relation to One of the 1995 ERT Installations.

The Mock Tank is approximately $50 \mathrm{ft}(15.2 \mathrm{~m})$ in diameter; the ERT array extends to 35 ft $(\sim 10.6 \mathrm{~m})$ below ground level, with an electrode every $5 \mathrm{ft}(1.52 \mathrm{~m})$.

The ERT (VEA) array installed in 1995 consists of 16 boreholes, each completed with 6-in.(15.24-cm-) inside-diameter (I.D.) polyvinyl chloride (PVC) casings to a depth of $35 \mathrm{ft}(10.7 \mathrm{~m})$. The casings were sealed at the bottom so they are isolated from the soil environment. On the outside of the 6-in $(15.24-\mathrm{cm})$ casings was strapped a smaller tube, upon which were mounted eight electrodes (see 
Figure 3). This array was found to be in serviceable condition and was used in the FY 2001 TLDD. In the 1995 study (Ramirez et al. 1995), three release/monitoring events were staged. The first consisted of 1,004 $\mathrm{gal}(3,800 \mathrm{~L})$ of solution released at a rate of $9.5 \mathrm{gal} / \mathrm{hr}(26 \mathrm{~L} / \mathrm{hr})$ at the side leak location at the northeast portion of the tank (see inset in Figure 3). The second release of 502 gal (1,900 L) was conducted at the center release point at a rate of $0.85 \mathrm{gal} / \mathrm{hr}(3.2 \mathrm{~L} / \mathrm{hr})$. A third release was discharged at the off-center leak location but was aborted because of difficulties with the release system. The leaks were imaged using the 16 auger-hole ERT array shown in Figure 4.

Approximately $82 \mathrm{ft}(25 \mathrm{~m})$ east of the Mock Tank are two drilled boreholes with a central infiltration well installed in 1996. These installations (B2469 and B2470 in Figure 4) are within the Subsurface Air Flow \& Extraction (SAFE) Development Area (SDA) and consist of a VEA in each well to a depth of approximately $49 \mathrm{~m}(160 \mathrm{ft})$. These were completed with a $3.8 \mathrm{in} .(9.65 \mathrm{~cm}) \mathrm{PVC}$ casing and fitted with an array of electrodes at intervals of $10 \mathrm{ft}(3 \mathrm{~m})$. This testing was aimed at determining the effectiveness of ERT in mapping vadose-zone plume-migration monitoring apart from tank leak scenarios. Some success was achieved in imaging the downward migration of a saline plume with ERT at this site.

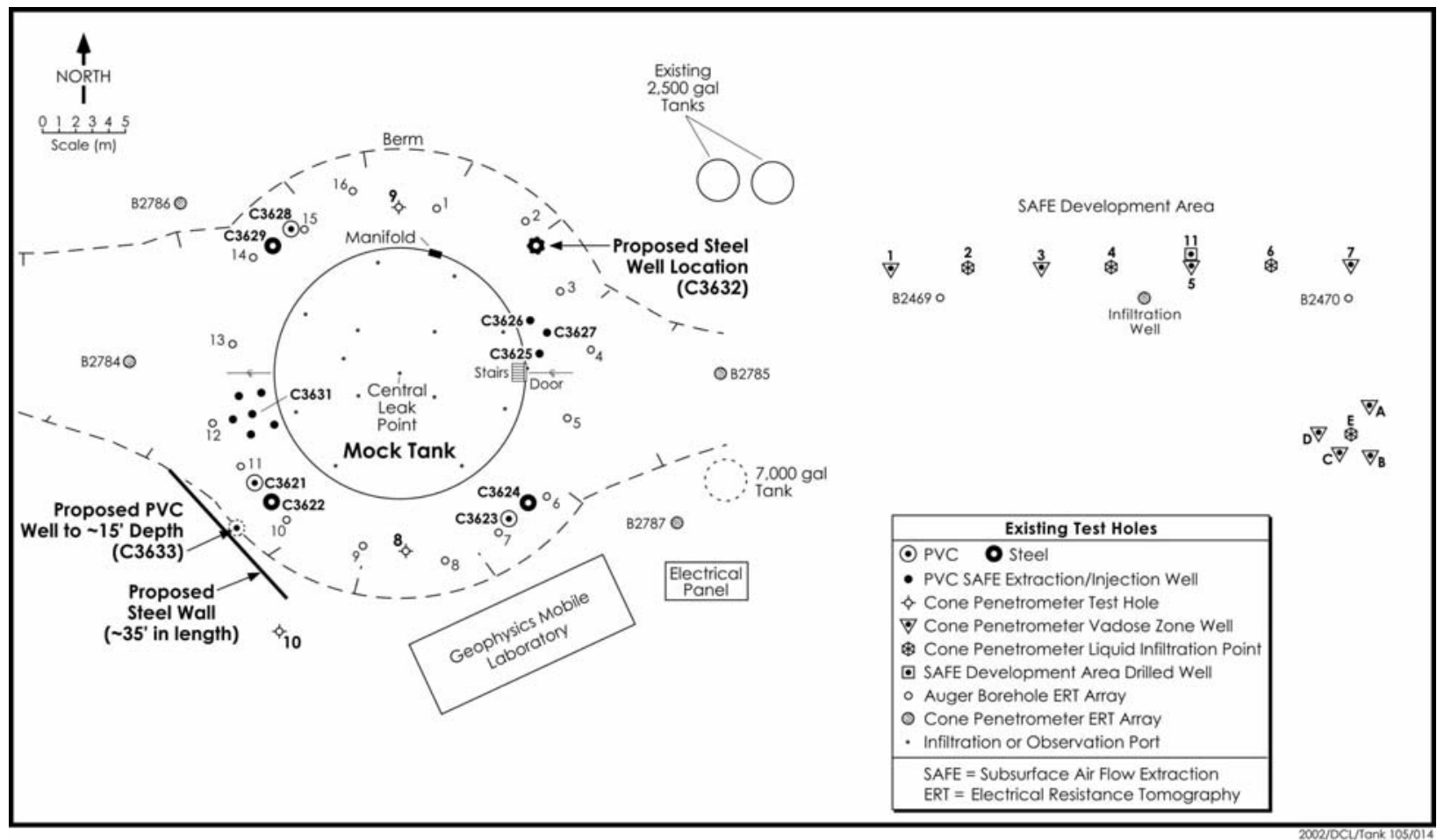

Figure 4. Site Layout for the Mock Tank Showing Additional Infrastructure Planned for the FY 2002-2003 Performance Evaluation Testing

An additional four VEAs were installed east and west of the tank (wells B2784 through B2787 in Figure 4) outside of the original 16 installations. These were used not only to perform additional ERT evaluation but also as a technology transfer using the CPT as an installation method. The arrays were installed to a depth of $100 \mathrm{ft}(30.5 \mathrm{~m})$ and have eight electrodes equally spaced on each array 
(Narbutovskih et al. 1996b). The blanket leak point on the northeast portion of the tank (see Figure 3) was used in the 1996 study (Narbutovskih et al. 1996a) to receive 3,000 gal (11,500 L) of saline solution over a period of 12 days at rates between 8 and $10 \mathrm{gal} / \mathrm{hr}(30$ and $40 \mathrm{~L} / \mathrm{hr}$ ). For this study, the four CPTemplaced electrode arrays (wells B-2784 through B2787 in Figure 4) were used for generating twodimensional tomographic images of the leak.

\subsubsection{Results of SST S-112 Electrical Measurements}

A collaborative investigation of resistivity characteristics at the S-112 SST by LLNL and HGI was conducted on May 8, 2002. The investigators each had common access to an electrical survey with various electrode configurations. Details of electrode configurations and results of this investigation are provided in a PNNL letter report (TWS02.036).

The results indicated that the field conditions of the Mock Tank Site and a SST farm are entirely dissimilar in moisture distribution, and as a consequence, resistivity. Neither of the investigators was willing, however, to recommend wholesale or expanded modifications to the Mock Tank site. Surface soil moisture conditions at the Mock Tank exhibit extreme desiccation. Moisture at depth is also lower due the relatively undisturbed construction profile of the tank foundation. The field conditions at SST S-112 exhibit higher subsurface moisture conditions, despite the similar moisture profile at the surface, due to a half-century of annual precipitation events captured without the benefit of a vegetative groundcover. The excavation and backfilling of the tank farm also assures that moisture distribution at depth cannot be adequately modeled at the Mock Tank site.

Moisture alone will not be the determining factor for most S-112-type ex-tank surveying operations in the SST farms. The change in field conductivity is affected more by the ionic strength of the materials in measured volume than by changes in moisture. A limit to this relationship can be observed as successive releases of highly ionic solutions occur in the subsurface. Evidence of a conductive field capacity is alluded to in Key (1975, Figure 40), but has not been exhibited at the Mock Tank site. The response of resistivity instrumentation to changes in conductivity declines as the overall conductivity of a volume reaches an arbitrary saturation point.

If a variable representing differences in fill material is combined with differences in moisture content and field conductivity, it becomes apparent that no amount of timely modification to the Mock Tank site could prepare the site to be strictly comparable to S-112. The magnitude of the differences between the Mock Tank site and projected SST waste recovery campaigns can be accounted for without additional site upgrades. The resulting analysis and final reporting for this test will be portable to other facilities with modification. 


\subsection{Geophysical Techniques}

Descriptions of the electrical geophysical techniques used in the FY 2001 TLDD testing are described in detail in Barnett et al. (2002). Subsets of these techniques have been selected for performance evaluation during FY 2002-2003 testing. These techniques, as they will be applied at the Mock Tank site, are outlined below. Complete descriptions of these methods are provided by Barnett et al. (2002), and detailed descriptions of the specific systems planned for deployment during FY 2002-2003 are provided in Attachments F and G, and reports by Bratton et al. (2002b). Below are summaries of these methods and implications for method integration into the overall testing environment.

\subsection{Electrical Resistance Tomography (ERT)}

The two electrical methods to be fielded by Lawrence Livermore National Laboratory (LLNL) this year include a point electrode design similar to resistivity surveys conducted at the Mock Tank Site (references) as well as a method that uses steel well casings as electrodes. The concept underlying each of these methods, as well as the HRR-SCRT described in Attachment G, includes injecting a current via a pair of electrodes into the subsurface near the target feature. The resulting potential field is measured using another pair of electrodes. Successive measurements are gathered on other electrode pairs until all permutations of electrode receiver pairs have been exhausted, or until a predetermined lower threshold of electrode measurements have been gathered.

The point electrode design, termed Electrical Resistivity Tomography-Point Electrode Tomography (ERT-PET) in the test specification (reference), is the method that produces apparent resistivity measurements that can be resolved into a three-dimensional resistivity plot. The electrodes in each of the vertical array strings are electrically isolated enough to produce geometrically discrete sampling for potential measurements. The density of the electrodes, as well as their position in the subsurface with respect to the target, determines the resolution of this method. Electrode pairs are alternatively used as current sources and potential measurement points throughout one sampling cycle. A schedule read by the data acquisition unit changes the arrangement of electrode charging and sampling points by remotely activating a multiplexing unit that handles both incoming and outgoing signals. As signals are passed through the target area, the potential field's distribution is mapped and recorded by the data acquisition unit for further post-processing. As fluids pass through the target area, the effect they have on the electrical properties of the subsurface are preserved in the data as changes in the potential field.

The second electrical method used by the LLNL researchers involves using less discrete continuous steel well casings for electrodes. The concept of electrical resistance surveys is preserved, but the level of detail captured and recorded by the method is less than that of ERT-PET. This method, referred to as Electrical Resistivity Tomography-Long Electrode Tomography (ERT-LET) in the test specification, also uses two current and two potential-measuring electrodes to gather subsurface data. The difference is in the resolution that can be attained: ERT-PET produces three-dimensional images from multiple ray paths using high-density potential field measurements; ERT-LET produces two-dimensional images from multiple ray paths using low-density potential field measurements. This difference is due to the limited 
amount of geometric information that can be gathered from non-discrete electrodes. The method is still capable of generating a map of potential field distribution, but only as a slice of the target volume.

The post-processing techniques used in converting the apparent resistivity recorded in the field to resistivity is generally the same for both ERT-PET and ERT-LET. In both cases the data is compared to an initial numerical model of subsurface resistivity. This first assumption of resistivity is unlikely to match close enough to the measured values so the model is adjusted to attempt a closer fit and the comparison is made again. By successive comparison of the data to the model, a tomogram of the resistivity is eventually produced showing its distribution. In the three-dimensional case, the plot shows both the horizontal plot of resistivity as well as depth of the modeled volume. The ERT-LET produces a plot that only describes the horizontal distribution of resistivity.

\subsection{High-Resolution Resistivity-Steel Casing Resistivity Technology (HRR-SCRT)}

The third electrical method involves the same concept of injecting current in the subsurface and then measuring the potential fields that are produced. The significant differences between High-Resolution Resistivity-Steel Casing Resistivity Technology (HRR-SCRT) and the ERT methods include the use of linear surface arrays and a proprietary algorithm for calculating resistivity distribution. As with the ERT methods, the HRR-SCRT technique uses two electrodes to inject current into the subsurface around a target and then measures the resulting potential field with a second pair of electrodes. The electrodes that are comprised by the linear arrays provide a dense measurement grid at the surface. The tank and the steel well casings are alternatively used as both a source of current and as a potential field measurement electrode. The use of a current electrode at the point of injection creates a mise-à-la-masse configuration where the test fluid is charged, and its effect on the subsurface resistivity distribution is tracked with the potential field measurements. The steel well casings also measure the change in resistivity distribution can be used as a current source electrode. The linear surface arrays are used only to measure potential fields - their effect on the method is to provide additional horizontal distribution information and to provide depth correction/information.

The data are post-processed by investigators using a proprietary algorithm, which allows plotting of resistivity distribution in plan and profile view. The data are corrected for topographic elevation, and the resultant plots show the changes of resistivity in the target area in response to changes brought about by liquid movements. 


\subsection{Test Site Description}

Performance Evaluation Testing during FY 2002-2003 will occur at the 105-A Mock Tank site, which is the site of the FY 2001 TLDD tests. Much of the permanent equipment and infrastructure installed during 2001 and previous years is still in place at the facility, and is usable for the FY 2002-2003 Performance Evaluation. Specific features of the site and application to testing are described below.

\subsection{The Mock Tank Site Following FY 2001 Tests}

All SAFE (Subsurface Air Flow and Extraction) system equipment deployed during the FY 2001 LDMM Technology Demonstration has been demobilized and stored offsite; the tarp over the Technology Development Area (see Figure 4) was left in place (this area will have no impact on FY 2002-2003 activities). The tarp covering the tank floor, which was used for sealing against air leaks for SAFE deployment, will be left in place to prevent infiltration of meteoric water.

\subsection{Preparations and Modifications to the Mock Tank Site for FY 2002-2003 Tests}

The Mock Tank site, with anticipated modifications for the FY 2002-2003, is shown in Figure 4. A temporary power supply will be provided to the site from the $13 \mathrm{KV}$ line on the south side of 7th Street; a span of $13 \mathrm{KV}$ line will be extended to a pole emplaced south of the site. A $100 \mathrm{~A}$, single-phase $220 \mathrm{~V}$ service will be provided for an office trailer; an additional 30A, single-phase $220 \mathrm{~V}$ service will be provided for a solution-tank circulating heater and discharge-line heat cable. Two GFI-protected 20A, single-phase $120 \mathrm{~V}$ circuits will provide general-purpose site power. Three $50 \mathrm{~A}$, three-phase $480 \mathrm{~V}$ circuits will be available for powering blowers/compressors during future SAFE activities. (Details of site modifications are included in Attachment D).

A 6,900-gal (26,119-L ) poly tank will be emplaced south of the mock tank structure to contain the $36 \mathrm{wt} \%$ sodium thiosulfate solution employed in the Performance Evaluation. Equipment for the solution dispensing system will be located adjacent to the tank (see Attachment D for a detailed description of the solution-dispensing system). An existing 2,500-gal (9,464-L) tank north of the mock tank structure will contain water for simulating precipitation events, should the decision be made to conduct these events; the precipitation-simulation control system will be co-located with the solution-dispensing system, with control leads leading to sensors and control valves near the mock-tank structure.

A steel-cased well will be completed to $45 \mathrm{ft}(13.7 \mathrm{~m})$ below ground surface (bgs) at the northeast corner of the mock tank structure (see Figure 4 and Attachment D); its location will be squarely symmetrical with the three steel-cased boreholes installed during the FY 2001 LDMM geophysical activities. The casing of this well will serve as an electrode for the ERT and HRR-SCRT methods, closing the gap in mock-tank resistivity coverage in the northeast corner.

A 35 -ft-(10.7-m-) long sheet-steel subsurface electrode will be emplaced to $15 \mathrm{ft}(4.6 \mathrm{~m}) \mathrm{bgs}$ at the southeast corner of the mock-tank structure, approximately $10 \mathrm{ft}(3 \mathrm{~m})$ southeast of ERT arrays \#10 and 
\#11 (see Figure 4). The long axis of this sheet electrode will be orthogonal to the axis through the new steel-cased well on the northeast side of the mock tank structure and the center leak-point inside the mock tank. This electrode will simulate an adjacent tank, and will be alternately connected and disconnected (electrically) from the mock tank structure to investigate the effects of tank-farm cascade lines that electrically connect SSTs. A screened, PVC-cased leak point will be installed with the sheet electrode for possible use in simulating leaks from an adjacent tank. (Details of sheet-electrode construction are included in Attachment D).

An office trailer (mobile laboratory) will be located southeast of the tank near the electrical panel; sufficient heating, ventilation, and air conditioning (HVAC) equipment to meet the needs of geophysical/ computer-control equipment and personnel will be provided. First-aid supplies and fire extinguishers will be available in the office trailer. The mobile laboratory will also include land line phone and internet connections to allow remote access to the test controls.

A reserve of water will be kept in one of the 2,500-gal (9,464-L) tanks (from the 1995 ERT project) on the north end of the site for fire-fighting purposes. An eyewash station will be located adjacent to the thiosulfate solution storage tank.

\subsection{Hydrogeology and Stratigraphy of the Mock Tank Site}

The details of the stratigraphy and hydrogeology of the 200 East Area have been described by numerous authors over the years of Hanford Site operations, with the most recent and authoritative including Reidel et al. (1992), Lindsey et al. (1992), and Williams et al. (2000). Site-specific lithologic data for the Mock Tank area were collected from drilled boreholes (B2469 and B2470 in Figure 4) and included in the report by Narbutovskih et al. (1996b). This information is represented by the stratigraphic column in Attachment D.1.

Surficial sediments at the Mock Tank consist of a thin veneer of dune sand up to $3 \mathrm{ft}(1 \mathrm{~m})$ thick. Fluvial (catastrophic floods) sand and gravel of the Pleistocene Hanford formation extend from about $3 \mathrm{ft}$ $(1 \mathrm{~m}) \mathrm{bgs}$ to greater than $400 \mathrm{ft}(120 \mathrm{~m}) \mathrm{bgs}$. Lindsey described some of this section as Pliocene/Miocene Ringold Formation sand and gravel, but Williams et al. (2000) interpret this area to be scoured by Pleistocene flood events and thus, the entire section to be underlain by the less-consolidated Hanford formation sediments. These sediments, in turn, overlie the basalt flows of the Miocene Columbia River Basalt Group.

Thus far, the only detailed lithologic records of the subsurface at the Mock Tank Site are those derived from borehole drilling for the ERT investigation by Narbutovskih et al. (1996b). These borings each extended to approximately $160 \mathrm{ft}(49 \mathrm{~m}) \mathrm{bgs}$, with the nearest (B2469) located approximately $80 \mathrm{ft}$ $(24 \mathrm{~m})$ from the eastern edge of the Mock Tank. Data collected during the FY 2001 TLDD (Barnett et al. 2002) confirmed some of the stratigraphic details garnered from earlier work, but additional information will be gathered during FY 2002-2003 to augment sediment details for ground truth activities. 


\subsection{Site Safety and Protection Provisions}

\subsubsection{Weather}

Because of the length of time required to perform the testing ( $\sim 5$ months), weather events will be a factor in safe and efficient operation of the Mock Tank site and associated test systems. Some factors may be mitigated by specific preparatory measures; other factors will require awareness for safety purposes. These hazards or factors are discussed below, and mitigation procedures are suggested, where appropriate. The Mock Tank site will be inspected for safety and operational conditions following any significant weather events.

\subsubsection{Precipitation}

Precipitation at the Mock Tank site may come in the form of liquid (rainfall) or solid precipitation (snow, graupel, sleet) during the anticipated months of testing (July through November). Average precipitation amounts for the anticipated period of testing are as follow (Hoitink et al. 2002):

\begin{tabular}{||l|l||}
\hline \multicolumn{1}{|c|}{ Month } & \multicolumn{1}{c||}{ Average Precipitation Totals (inches) ${ }^{(\mathrm{a})}$} \\
\hline \hline July & 0.22 \\
\hline August & 0.23 \\
\hline September & 0.31 \\
\hline October & 0.54 (includes 0.1 in. snowfall) \\
\hline November & 0.92 (includes 1.7 in. snowfall) \\
\hline (a) For the period $1945-2001$. \\
\hline
\end{tabular}

Rainfall that occurred during the FY 2001 testing (see Barnett et al. 2002) had no observable effects on testing or electrical signals for ERT or HRR-SCRT. However, safety concerns with precipitation could include slippery surfaces and potential for electrical touch hazard. Mitigation measures for these conditions will be:

- Monitor e-mail and receive predictions for precipitation.

- Use increased caution in movement about the site when surfaces are wet or icy.

- Ensure near-surface electrode connections are not energized when work is occurring near these in wet weather.

- Consult personnel responsible for site safety (see Attachment C.2) during or following precipitation events.

\subsubsection{Lightning}


At least 3 months of the testing period are considered at risk for the effects of lightning. While the safety aspects may be somewhat obvious, the range of effects are less familiar. Lightning may affect the Mock Tank site in several ways: by direct contact of the lightning channel with the tank, ancillary equipment, or personnel; by electromagnetic pulse induction in critical circuitry, and/or by ground currents created near the point of channel/earth contact. Lightning associated with thunderstorms can cause serious (even fatal) injuries, and may occur up to 10 miles from the edge of a storm. All three of these carry safety risks as well as potential for serious damage to equipment. Fortunately, lightning is relatively infrequent at the Hanford Site. Climatic data for the Hanford Site (Hoitink et al. 2002) indicate that an average of 7.3 thunderstorms occur on or near the site during the scheduled months of the FY 2002-2003 operations (June-November). Safety warnings are issued by the Hanford Meteorological Station (HMS) when thunderstorms are in the region. Lightning and thunderstorm activity can also be monitored via several websites such as http://www.accuweather.com/adcbin/ lightning_storms_large?thisReg=NE\&btnreg=Go\&nav=home and http://intellicast.com/LocalWeather/ World/UnitedStates/RadarSummary/. Data from most of these sites is delayed 20 to 60 minutes.

Mitigation measures currently in use on the Hanford Site for lightning hazard include lightning rods for diversion to ground, and fuses to avert burnout of electrical devices. Some of these are currently in use at the tank farms.

Procedures for lightning protection and safety at the Mock Tank site will include:

- Monitor e-mail for lightning advisories from HMS

- Check websites for lightning activity when conditions warrant

- Avoid personal exposure at the site when storms are in the area

- Ensure that mobile laboratory is grounded to protect equipment/personnel

- Consider efficacy of circuit protection devices.

Circuit protection devices may be appropriate for some portions of the control systems at the Mock Tank. These devices will be considered for deployment during site preparation. PNNL will supply all warnings, protection devices, and advice concerning this risk.

\subsubsection{Wind}

Wind at the Hanford Site represents a perennial risk to unsecured, unanchored objects, especially in unprotected areas away from buildings. The average wind speed at the HMS is highest during the month of June, with the largest number of days with gusts greater than $25 \mathrm{mph}$ occurring during June and July. These are also peak months for thunderstorms, which may produce even higher wind gusts. Thus, the Mock Tank site could be subject to consistent threat of wind disruption if precautions are absent. These precautions will be put in place prior to background testing, and will include:

- Anchoring of all test structures and housing units capable of dislocation by wind

- Monitoring of conditions via website or e mail warnings

- Wearing of eye protection when outdoor work is necessary during high wind. 


\subsubsection{Range Fires}

The Hanford Site is at risk from wildfire during most of the period of FY 2002-2003 testing at the Mock Tank. The core of the risk period is during June, July, and August, with significantly reduced risk (due to lower temperatures and humidities) for September, October, and November. Fire may be started by human activities or lightning.

Fire near or at the Mock Tank site will be addressed with the following minimum procedures:

1. Call 911 and/or 373-3800 for fire dispatch and Hanford Patrol.

2. Call 375-2400 (PNNL Emergency) and advise that emergency units have been contacted.

3. Fight the fire if it is local and small, and if able; otherwise evacuate the site.

4. Advise project staff (see Attachment A) of site status.

Fire evacuation route for the Mock Tank site will be via $7^{\text {th }}$ Street in the 200 East Area, proceeding either east or west, depending on from which direction the fire is coming (see Figure 1).

\subsubsection{Other Potential Site Hazards}

All other safety and operational concerns are addressed in Attachments B and C. These include biological, tripping, electrical, overhead (only temporary during construction activities), and chemical. The Attachments contain Job Hazard Analyses and pertinent documentation to safe operation of the Mock Tank Site and conduct of the performance evaluation testing. The sodium thiosulfate solution used as a surrogate waste liquid is non-hazardous, non-flammable. MSDS documentation is provided at the test site. 



\subsection{Description of Test Instrumentation and Systems}

\subsection{Strategy}

Because of the complexities of operating two methods (SCRT \& ERT) continuously for the duration of 104 days, dependable and redundant systems are necessary. The most efficient solution would be a single remotely controlled automated system. However, time constraints for the FY 2002-2003 testing require that fall-back options be put in place to allow testing to occur on schedule with minimal chance for failure. Therefore, monitoring will involve a three-pronged approach that will allow data collection, should the optimum systems be unavailable at the start of testing. This strategy also provides essential redundancy and alternatives in the case of failure or destruction of the primary test-control system. This includes three separate system options that include:

1. Manual collection, manual switching system

2. Manual collection, automated switching system

3. Automated collection, automated switching system.

\subsection{ERT (LET and PET) Electrode Configurations}

As noted in Section 2.1, two deployment strategies using ERT technology will be used during testing. Details for these configurations are provided in Attachment F. The electrode configuration for the ERTLET relies on eight of the sixteen original vertical arrays. The survey objective for ERT-LET is to gather apparent resistivity data from beneath a buried tank using electrodes similar to the existing tank farm vadose boreholes. The eight vertical arrays will simulate steel-cased boreholes, initially, by shorting out the individual electrodes with copper wire. The resulting electrodes will be used as transmitter and receiver pairs for ERT sampling. At least one sampling event with the ERT-LET system will be recorded each day.

The ERT-PET system will rely on the remaining eight vertical arrays. The objective of this survey configuration is to gather more discrete apparent resistivity measurements from beneath a solid metal structure. Because of the closer electrode spacing (compared to ERT-LET), each pair function as points in the survey field, positioning the information gathered more precisely in the sampled volume. The ERT-PET system will gather at least one data set per day. More data sets may be needed as dictated by trends in the observed data.

\subsection{HRR-SCRT Electrode Configurations}

A combination of electrode types is used in HGI's HRR-SCRT configuration. The survey includes: fifty-six electrodes from the original sixteen vertical arrays, the four steel-cased electrodes, two remote reference electrodes, eighteen surface arrays, and two fluid injection electrodes. The survey's objective is to measure apparent resistivity at the Mock Tank Site using all available subsurface electrodes (with the exception of the cone-penetrometer VEAs), and adds a small number of surface electrodes for boundary 
control and horizontal resolution. Ninety individual electrodes will be sampled at least once a day for the duration of the test. Details of the HRR-SCRT deployment are provided in Attachment G.

\subsection{Test Control Systems}

Control systems for data collection during the FY 2002-2003 performance evaluation testing will consist of computer interfaces, network access system, switching logic units, multiplexers, and controllers. These components and the requisite interconnections are illustrated and discussed in detail in Attachments D and E.

The final data acquisition unit to be used by both investigators is the Zonge GDP-32. This unit is a microprocessor controlled, field portable digital receiver designed primarily for geo-electric and electromagnetic surveys. The GDP-32 can be remotely activated and controlled via a standard serial communication connection to a personal computer.

Current for the electrical resistivity surveys is produced by a DC power supply activated by a Zonge ZT-30 transmitter. The transmitter is capable of delivering 30A, but the testing at the Mock Tank Site will not exceed 1A of continuous DC current. The transmitter is activated by the GDP-32. The GDP-32 receives the survey schedule (firing order) from a portable computer via Zonge control software. The firing order determines which pair of electrodes will receive current from the power supply (through the transmitter), and which pair will measure the potential.

All connections from the receiver and transmitter pass through a muliplexer (MUX) unit capable of addressing multiple electrodes. The testing at the Mock Tank Site will rely, initially, on one MX-30 MUX with a 30-electrode capacity. The system will be operated manually, with investigators changing electrode configurations leading to the MUX through a patch panel. The patch panel will allow up to 90 electrodes to be measured during one complete survey.

Although the primary task of the performance assessment is to determine the performance characteristics of the leak detection system, there is also a commitment to test a remotely activated multiplexing system. The conceptual design for such a system integrates remotely operated personal computers located at the Mock Tank Site, computer-operated MUX units replacing the patch panel described in the manual operation, and batch fed instructions from the personal computers to the GDP-32.

The first iteration of the remotely operated system relies on the HP 3488A controller with HP 44471A relays. Up to 50 electrodes per controller are addressable. Two will be deployed as transmitters and two for receivers. The controllers will take the place of the GDP-32, the ZT-30 transmitter, and the MX-30 unit. Each transmitter will fire on a pre-programmed schedule with the receivers gathering data on opposing channels. Data will be transferred from the receiving 3488A units to a personal computer.

The final remote system will be entirely comprised by Zonge equipment. The GDP-32 will control three MX-30 units all connected in series. The system will have a total capacity of 90 electrodes. All MUX units will be fired and sampled in a fashion similar to the manual operation but with three times the number of electrodes. The GDP-32 will be batch loaded from a local personal computer, operated by 
LLNL or HGI employees from their respective offices. The system will be remotely accessed through a virtual private network between the contractors and the Hanford Local Area Network (HLAN). Lockheed Martin Services Inc. operates the HLAN, and user accounts will be established for the contractors as well as the Test Director.

\subsubsection{Manual Collection, Manual Switching System}

This system will be similar to the configuration used in the 2001 Mock Tank Demonstration where two manually operated electrical resistivity systems were used. In this setup, all sensors (wells, shallow electrodes, ERT point electrodes, tank, etc.) were connected to patch panels and switching between sensors and the two instruments was performed manually by onsite operators.

As a fall back option for the 2002 LDMM PE we propose using one electrical resistivity instrument (most likely the Zonge GDP-32 with one MUX) that is run manually by an onsite operator. This will reduce the cost of having two simultaneous instruments and will eliminate the need for switching electrodes between separate instruments.

\subsubsection{Manual Collection, Automated Switching System}

This system will be assembled in conjunction to the development of option 3) Automated collection, automated switching system. It will be made up of a series of electro-mechanical relays/switches that will drastically reduce the time consuming operation of switching between sensors (wells, shallow electrodes, ERT point electrodes, tank, etc.) and configuration differences between SCRT and ERT. LLNL has used a similar arrangement on previous projects and will supply the Hewlett Packard switches for early integration into the control system. The relay switch box is specifically tailored to the demands of electrical geophysics and accounts for the high current flow, ground loop problems, and compatibility with the Zonge GDP-32 instrument. As with option 1) Manual collection, manual switching system, all data collection will still be performed using one electrical resistivity instrument by an onsite operator.

\subsubsection{Automated Collection, Automated Switching System}

This system would provide the most efficient means of data collection given the complexity of the LDMM performance evaluation. This configuration would require the use of a Zonge GDP-32 that is connected to three multiplexer (MUX) boxes. Each MUX box supports up to 30 electrodes and the successful combination would support up to 90 electrodes. The ability to simultaneously connect to all possible sensors (wells, shallow electrodes, ERT point electrodes, tank, etc.) eliminates the need for manual switching. Furthermore, the MUX's can be controlled by the GDP and so one could program and therefore automate different array configurations (SCRT or ERT).

Configuration of electrodes and MUX boxes are:

MUX 1:

1,2 SCRT remote reference electrodes

3, 4 SCRT tank and injection well 
5-8 SCRT / ERT steel well casings

9-16 SCRT / ERT fused ERT electrodes "pseudo-casings"

17-30 SCRT shallow electrodes

MUX 2:

31-60 ERT point electrodes

MUX 3:

61-86 ERT point electrodes

HGI, LLNL, and PNNL are collaborating with Zonge Engineering and Research Organization to complete the necessary compatibility upgrades and install the multi-MUX software.

PNNL is leading efforts to remotely access the GDP-32, so that an operator might run the data collection offsite. This will require a dedicated computer that has full time network access (provided by PNNL). PNNL, HGI, and LLNL will develop a Virtual Private Networks (VPN) to the onsite computer to retrieve data and monitor the experiment.

\subsection{Ancillary Equipment and Materials}

To accommodate remote access, dedicated onsite computer(s) will be linked to the GDP-32 and the PNNL computer network. All power for geophysical equipment will be physically isolated with a floating ground. This will require running all power through an isolation transformer. Communications between the dedicated computer and the geophysical instruments will also be isolated. This will require optical separation of either the serial connections from the GDP-32 to the computer or the network line from the computer, or preferably both.

Specifications for the dedicated computer(s) are:

Pentium III based

Super fan or liquid cooled (cannot rely on trailers air conditioning)

Provide a minimum of 2 serial ports

10/100 BaseT NIC PCI card

Analog to digital PCI card

WIN 98 2ED or WIN 2000

Contain a controlling software like (Terminal Server/PC Anywhere)

Network:

Provide dedicated Virtual Private Network (VPN) tunneling to both HGI and LLNL.

Isolation transformer should be rated at least $1 \mathrm{KW}$ (must check with LNLL). Optical isolators usually require batteries to operate, for long-term use this could be solved by using power from the isolation transformer. More expensive optical isolators can use power from computer ports, but are highly specialized and typically require USB ports. 


\subsubsection{Solution-Release and Rainfall-Simulation Controls}

Control of the release of sodium thiosulfate to the designated leak points in the Mock Tank (Bratton et al. 2002b) will be via computed automated systems that will be accessible by internet connection. This system will be accessible to PNNL and Vista only to maintain blindness of releases. The details of construction of this system are described in Attachment D.9, and the procedures for operation are presented in Section 5.2. Initially, a manifold for directing solutions between leak points will be operated manually. The manifold will be covered to help ensure blindness of leak location.

Rainfall effects on electrodes and surface soil conductivity may be simulated by spraying a specific area around the Mock Tank according to the schedule provided in Bratton et al. (2002b). Distribution of water simulating rainfall would be through a sprinkler system described in Section 5.3 and detailed in Attachment D.10. 



\subsection{Performance Evaluation Testing Procedures}

Measurement methods, testing parameters, and testing schedule for the FY 2002-2003 performance evaluation test are provided in Ex-Tank LDMM Performance Evaluation Test Specification (Bratton et al. 2002b).

\subsection{Activation and Control of Data-Collection Systems}

The system may initially require manual operation of the data acquisition unit at the Mock Tank Site. Over the course of the first few weeks of testing, the data acquisition will gain progressively more autonomous in operation. The data acquisition unit will receive the firing order for injecting current from a personal computer located inside the mobile laboratory (see Section 3.2). This connection is maintained via the Internet and operators from LLNL and HGI will be able to independently collect data and retrieve data sets.

The first stage of automation may occur with a HP 3844A-based switching network, operated by batch-loaded BASIC programs from the personal computer. Data gathered during the collection process will be off-loaded to a central directory where the investigators can retrieve individual daily data sets. Minor changes in the data acquisition-sampling schedule can be made and uploaded into the equipment, with the proper authorization from the Test Director.

The final system will rely on entirely Zonge-designed equipment. Ninety electrodes will be available to the investigators for sampling and current injection. The firing order will again be loaded directly into the Zonge GDP-32 from the personal computer. Data sets from each sampling cycle will be available for both investigative teams.

\subsection{Activation and Control of Solution Release System}

The Test Director will provide instruction to PNNL on timing and volume of simulated tank waste solution discharges which will ultimately be remotely controlled via computer network link. The solution release system employs a pressurized-loop recirculation system and a computer-interfaced, proportional/ integral/differential (PID)-type flow controller. The Alicat TC-4.5LPM-D flow controller will receive instructions from a second personal computer stationed in the mobile laboratory. This computer will be under the control of PNNL. Under normal operating conditions, only the Test Director will make changes to the solution release schedule. PNNL staff will monitor the solution discharge equipment for system faults that would harm the test. Flow rate, solution temperature, and pressure will be monitored regularly to ensure that plugging of the discharge lines has not occurred and that the quantity of solution released is within the tolerance range of the Test Specifications. 


\subsection{Protocol for Changing Test Procedures}

Data requirements needed to collect sufficient information during the test are currently documented in the Test Specifications (Bratton et al. 2002b). The physical infrastructure, mechanical and electronic controls, and electrode layout to achieve the data goals are provided in the Test Implementation Plan. Unanticipated disruptions, aberrant results, or system failures could necessitate amendment of performance evaluation testing procedures prior to beginning of testing, or during the course of the test. It will be necessary to reconcile such amendments with both guidance documents to ensure efficient recovery and continuation of the testing. If amendments to the Test Specifications or Test Implementation Plan are required, the following actions will be effected:

- The Test Director or other LDMM Team Leader (see Attachment A) will call a meeting (or conference call) between PNNL, CHG, VISTA, and other administrative participants, as necessary. The nature of the variance in procedures will be discussed. LLNL and HGI will be consulted via PNNL, as needed, and where test blindness is not compromised.

- All participants will reach an agreement on changes to be made to the test procedure and document these changes in meeting minutes.

- Meeting minutes that embody recommended, agreed-upon amendments will be captured as an Interim Change Notice (ICN) or revision letter, and Engineering Change Notice (ECN), to be attached to the Test Implementation Plan and Test Specification, respectively. PNNL is responsible for initiating and tracking ICNs and letters of revision (see Attachment E); CHG is responsible for initiating and tracking ECNs.

- CHG will approve of any test changes in writing.

- All modifications to testing will be documented via Project Change Agreement (see Attachment E) and placed in the project field log.

Because of crucial time constraints of the testing schedule, any field changes will be implemented by field personnel immediately upon agreement between all meeting participants. Formal documentation attached to the Test Implementation Plan and Test Specification may follow actual implementation.

\subsection{Contingencies for Systems Failures}

Major system failures of a catastrophic nature can be classified based on their origin as a natural disaster/intervention, Hanford site-wide operational change, or Mock Tank system failure. Section 12.0 describes the heuristics of the Implementation Plan risk management in detail.

A natural disaster/intervention episode could lead to system inoperability an extended period of time. The PNNL staff at Mock Tank Site will follow guidance from Hanford emergency services in the event of a natural disaster/intervention. High winds, lightning, and hailstorms are the most likely agents to cause 
damage to the monitoring and control systems at the Mock Tank Site. Recovery of test systems will proceed after the entire Mock Tank Site has been evaluated and the state of all recording and control devices has been documented.

Operational changes that could affect testing at the Mock Tank Site include those implemented in response to safety and health issues occurring throughout the Hanford Site, or in response to security threat assessments. The Test Director will evaluate how the operational changes will impact the Performance Evaluation, and will document responses to the LDMM Team Leaders.

Interruptions in power, instrumentation failure, controller errors that would impact data quality, networking, and software failures fall under the category of Mock Tank systems. Uninterruptible power supplies (UPS) are selected for deployment in this Performance Evaluation. The UPS systems will allow for the orderly shutdown of all data acquisition subsystems with the intent of maintaining data integrity. PNNL personnel, who remain primarily responsible for these subsystems, will make onsite instrument self-checks periodically. Unless there is an indication of instrument, computer operating system, or network failure (i.e., remote software does not establish a connection to the data acquisition system), the computers will be checked for remote connectivity at least daily. If there is reason to believe that the remote connection has failed, PNNL field personnel will respond to the Mock Tank Site, they will document state indicators and error messages, start the failed unit, and then notify the Test Director.

\subsection{Post-Test Dispositioning and Site Control}

Following FY 2002-2003 testing, the Mock Tank site will be reconfigured for an indefinite period of inactivity. Test systems and associated, temporary infrastructure at the site will be removed or stabilized by PNNL and returned to the control of CHG. At minimum, the following activities will occur upon cessation of testing:

- All electrical resistivity recording equipment, computers, and communication equipment will be removed from the mobile lab.

- The mobile lab will be removed from the site, and all electrical, communications connections thereto will be disconnected and configured for safe standby.

- The sodium thiosulfate storage tank will be cleaned and removed.

- Solution delivery and rainfall-simulation systems will be disassembled and stored offsite.

- Well casings will be locked; (Extensions for the well-construction variance periods are being sought with the Washington State Department of Ecology to allow the site to remain usable for research)

- All wiring to resistivity systems will be stored in a safe manner to allow future use. 
- All debris and miscellaneous equipment not part of a permanent installation will removed and stored offsite.

The sodium thiosulfate solution is not considered a waste material, and no other residual products will be generated. Hence, no cleanup activities regarding this material or any other residual materials are planned. The official end of testing will not occur until all data are collected at the site, including CPT soil testing and neutron probe surveying. Post-test site management will be conducted by $\mathrm{CHG}$, under consultation with PNNL staff (see Attachment A ). 


\subsection{Collection of Ground-Truth and Physical Properties Data}

PNNL staff will conduct independent verification of subsurface conditions during and following the performance evaluation testing. Specific "ground-truth" activities include neutron- soil moisture logging, sampling, and analysis of soil around the periphery of the Mock Tank immediately following the conclusion of testing, and interim neutron logging of subsurface moisture.

\subsection{Neutron Probe Soil Moisture Measurements}

Soil moisture data will be collected by neutron probe surveying prior to, during, and/or following the performance evaluation testing. These measurements will provide an independent evaluation soil conditions within, or on the periphery of the area interrogated by the electrical methods. Initial background measurements will be conducted prior to calibration, but calibration of the instrument will be complete before the cessation of testing. This will allow comparisons with background conditions immediately, and moisture volume estimations when calibration is applied. Detailed procedures for using the neutron probe are provided in Attachment $\mathrm{H}$.

\subsubsection{Locations of Measurements}

Figure 6.1 indicates the locations of available boreholes and casings for neutron logging around the Mock Tank. With the exception of the steel-cased boreholes and "outer-point electrode arrays" all the features shown are available for neutron probe measurements. In addition, two PVC SAFE extractioninjection wells (see Figure 4) extending to $\sim 30 \mathrm{ft}$ below grade (approximately $25 \mathrm{ft}$. below tank bottom) will be used for logging.

Nine of the 14 access ports or "leak points" inside the tank are being refitted (see Attachment D) to accommodate neutron logging to a shallow depth ( $4 \mathrm{ft})$ beneath the tank floor. Only the lower $2 \mathrm{ft}$ of these ports will be logged because of the preexisting steel casings which extend to $\sim 2 \mathrm{ft}$ below tank bottom. Nine of these access ports will be used, but the actual ports to be used are not disclosed here to maintain blindness in the testing.

The sixteen ERT array casings ("point and long electrode arrays" in Figure 5) extend to $\sim 35$ feet and are spaced evenly around the tank, approximately $2.5 \mathrm{~m}$ from tank edge. The casings are 6-in diameter $\mathrm{PVC}$, and will accommodate neutron logging to a minimum of $30 \mathrm{ft}$ below ground surface (approximately $25 \mathrm{ft}$ below tank bottom).

\subsubsection{Measurement Increments}

All boreholes and casings outside the Mock Tank will be logged at 1-ft intervals beginning at the top of the casing or ground surface. The access ports inside the tank will be logged at minimum increments 


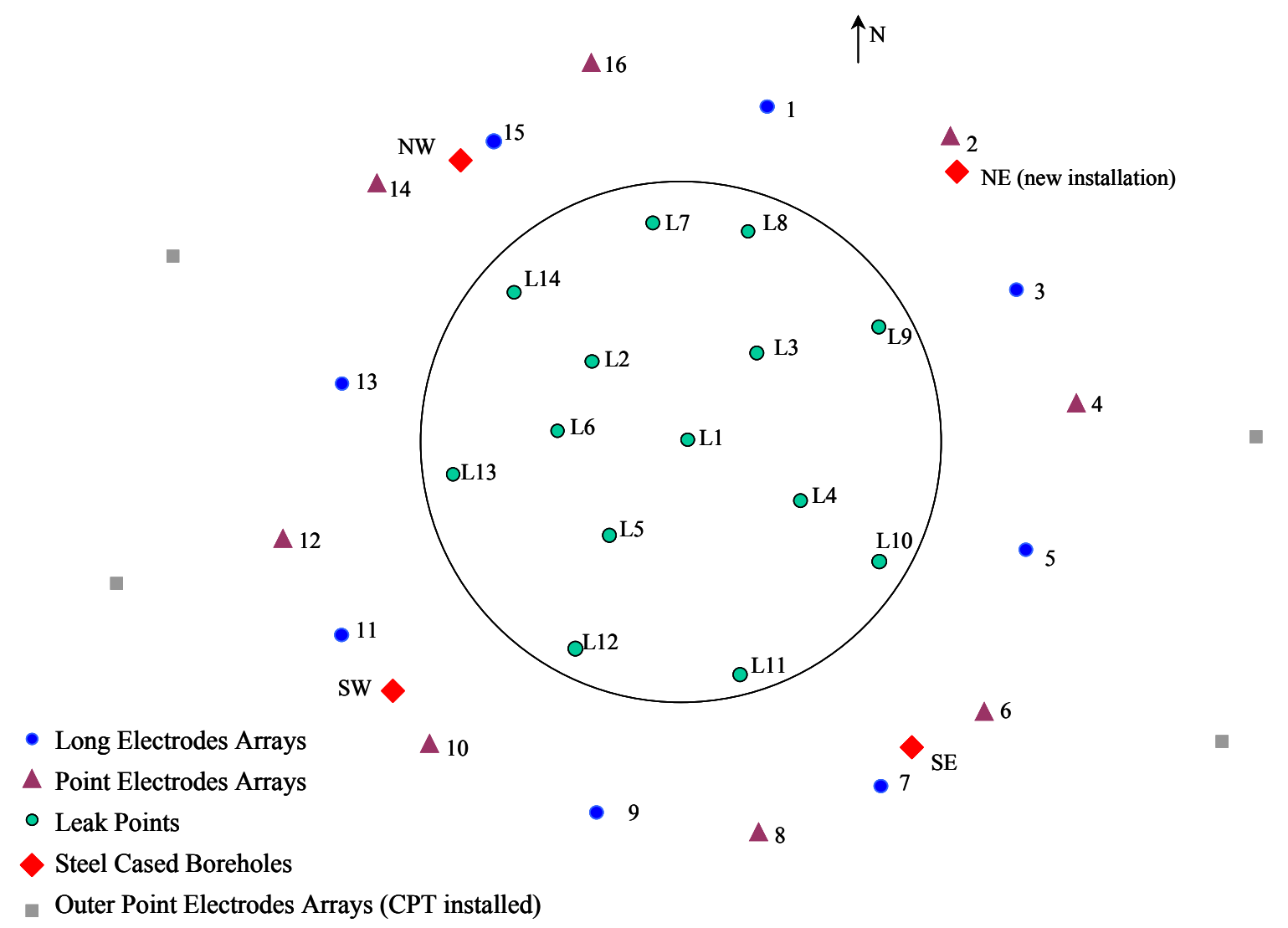

Figure 5. Locations of Boreholes, ERT Arrays, and Interior Access Ports ("leak points") at the Mock Tank Site (after Bratton et al. 2002b)

of six inches. The closer spacing of measurements inside the tank will provide more detailed information on the proximity of the solution to the steel floor of the tank. This circumstance may be important to interpretation of electrical responses.

\subsubsection{Frequency of Measurements}

Background measurements for soil moisture using the neutron probe will be conducted in duplicate in each of the boreholes and ports described above, within a two-week period prior to test startup. Thereafter, a minimum of one additional full suite of measurements will be made in each of the ports or boreholes. The exact time of measurements that follow test startup will be determined during the testing period based on resistivity data. Measurements that produce suspect logs or error will be re-logged.

\subsection{Soil Sampling and Analysis}

Cone-penetrometer wire line cores scheduled for this Performance Evaluation are the primary means of establishing ground-truth at the Mock Tank Site. The sedimentary parameters of porosity, grain size distribution, and specific retention are some of the physical properties that can be analyzed in soil cores. At the conclusion of the performance evaluation testing, CPT pushes may be emplaced at locations 
around the Mock Tank based on neutron probe and ERT/HRR-SCRT results. Specific sample intervals will be determined when these results are available near the end of performance evaluation testing. Moisture retention will be evaluated with the core samples may be compared with point-scale measurements with neutron-logging results. Up to $8 \mathrm{CPT}$ boreholes may be completed in the vicinity of the Mock Tank for ground-truth evaluation purposes.

Samples from the access ports inside the tank will be taken and analyzed for moisture content before commencement of the leak schedule; these will also be logged using the neutron probe for background conditions for comparison with soil moisture analyses.

\subsection{Other Physical and Quality-Control Data Collection}

Solution (sodium thiosulfate) samples will be collected prior to test startup and analyzed for qualitycontrol and physical parameters. Samples will also be collected and analyze during each release to document stability of the solution. The minimum parameters to be analyzed for each sample are:

- Density

- Percent Solids (concentration)

- Conductivity.

PNNL will maintain a log of these parameters that will be updated weekly on the appropriate website for access by all LDMM team members.

Solution, soil, and ambient air temperatures will be monitored continuously during the test via computer-based data-collection system (see Attachment D.4) at various points in the system. The precise locations of soil and air thermocouple sensors will be determined following construction of the flow delivery system (Figure D.4). Sample rate for temperatures will be no less than once per hour. Downloading of these data will occur weekly for archiving, and real-time, remote viewing of temperatures will be available for the most recent measurements. 



\subsection{Data and Information Management}

A project archive has been established for storing and managing laboratory and field data. A project (PNNL) data custodian will be designated to control and maintain the data and to make them available on a secure project web site. The apparent resistivity data will be stored electronically in a widely compatible format, and task leaders will provide electronic copies to the data custodian for storage in the project files. During the course of the experiment, data access will be vital to the success of each test, and data sharing and their interpretation are encouraged. All raw data must be backed up or archived at the end of each collection event. Atmospheric data, such as ambient surface temperature, humidity, and pressure also will be recorded during the tests and must be incorporated into the data set as appropriate.

Processed data and interpretive results from the FY 2001 work described in this document will also be posted on the appropriate PNNL web site. To ensure that project milestones are met in a timely fashion, it may be necessary to publish data in reports before task leaders have the opportunity to develop

peer-reviewed publications. In such instances, publication of data in project reports supersedes the rights of task leaders. 



\subsection{Reporting}

Separate Draft and final reports of the FY 2002-2003 performance evaluation test will be submitted for ERT (PET and LET, combined) and HRR-SCRT. The report content will follow topical guidance presented in the informal reports as presented in Attachments F and G, but with updates to include test results and findings. The report content should also describe sources of data error, levels of precision, discussion of how accurately the imagery or tomogram portrays the subsurface environment during the tests, and what comparisons were made to calibrate or otherwise derive accuracy. These reports will also be included in an omnibus report covering all aspects of the test.

Components of the report will, at minimum, include the following content as an extension of, or in addition to, the topics presented in Attachments $F$ and $G$ :

1. Introduction

- Brief description of the method principles and prior applications that apply to the performance evaluation testing and the Mock Tank application (background)

- Description of the objectives for testing the method

2. Methodology and Approach

- Type and brand of sensors, sources, and recording equipment

- How were the data recorded, processed, analyzed, and stored

- How the instrumentation/sensors were deployed and the rationale for the configuration of deployment (reference to Test Specification)

3. Results

- Success of method in detecting the leak

- Success of method in estimating volume(s) of leak

- Success of method in discriminating recent leaks from early leaks

- How the method performed in PVC versus steel boreholes (where applicable)

- Sources of error or interference discovered during the testing and how these were addressed

- Comparison of results with other methods (if available)

4. Recommendations and Conclusions

- Reasons why the method should (should not) be further investigated

- Next steps in deployment (particularly concerning potential SST S-112 deployment)

- Estimated cost of a permanent operating system. 



\subsection{Environmental Health and Safety Requirements}

The excavation permit to be used in FY 2002-2003 for the Mock Tank site is provided in Attachment B. The work will be conducted in an environmentally compliant manner; biological and cultural reviews and operation approvals are also included in Attachment B. Safety and health issues relating to the Mock Tank site are addressed in site-specific safety documents (Attachment C) that identify industrial safety health hazards as well as other measures to protect against these hazards. Safety documents include specific training requirements that must be met by all site workers and visitors. Jobspecific health and safety plans for drilling, instrument-installation/operational activities, and sampling activities are also specified in Attachments $\mathrm{C}$ and D. Briefings will be conducted with all site visitors to ensure that health and safety issues are understood and that safe practices will be followed during the course of the experiments. All Mock Tank site test participants and visitors are required to read and sign the health and safety plan before entering the field site. Certain areas of the site will have limited access to reduce the risk of injury and disruption of work. Access to mobile buildings or work vehicles will be allowed only through appropriate egress/ingress openings (doors). 



\subsection{Waste and Residuals Management}

PNNL will be responsible to manage wastes and residuals. These activities will be accomplished according to specific procedures followed during drilling and sampling operations.

\subsection{Management Activity A-Solid Waste Management Plan for Borehole Construction}

\subsubsection{Scope}

This plan covers waste disposition for the waste generated from installation of boreholes for the Mock Tank site.

\subsubsection{Anticipated Waste Streams}

Based on the project test plan, the only anticipated waste streams from the above activities are nonregulated, non-hazardous solid wastes, which may include paper, plastic, rags, etc. These materials have been designated as non-hazardous. The determination has also been made that the test site is a nonradiological area, and therefore, none of the waste would be classified as radiological low-level waste.

\subsubsection{Waste Management}

The waste stream described above will be disposed of to a normal "trash" receptacle. The management of any other unanticipated solid waste will be in accordance with PNNL internal waste management procedures.

\subsubsection{Contingency Plan}

In the event of a spill or accidental release of a material to the environment, the procedure for spill response (http://sbms.pnl.gov/standard/0e/0e00t010.htm) will be in effect.

If a spill occurs, call 375-2400.

\subsection{Management Activity B-Soil and Water Sample Management Plan}

\subsubsection{Scope}

This plan covers the disposition of the soil and solution samples generated from drilling activities for the Mock Tank site. 


\subsubsection{Anticipated Waste Streams}

Based on the project test plan for the drilling activities, there are no anticipated waste streams from these activities.

The soil from the drilling activity is environmental media and, other than soil samples to be taken for characterization and analysis, all will be backfilled in the borehole annulus.

If solid waste is produced during these activities, it is anticipated that it would be non-regulated, nonhazardous solid wastes, which may include paper, plastic, rags, etc. These materials have been designated

as non-hazardous. The determination has also been made that the test site is a non-radiological area, and therefore, none of the waste would be classified as radiological low-level waste.

\subsubsection{Waste Management}

The waste stream described above (paper, plastic, etc.) will be disposed of to a normal "trash" receptacle.

The management of any other unanticipated solid waste will be in accordance with PNNL internal waste management procedures.

\subsubsection{Contingency Plan}

In the event of a spill or accidental release of a material to the environment, the procedure for spill response (http://sbms.pnl.gov/standard/0e/0e00t010.htm) will be in effect.

If a spill occurs, call 375-2400. 


\subsection{Quality Assurance and Quality Control}

All work conducted by PNNL will be performed in accordance with appropriate standards of quality, reliability, environmental compliance, and safety based on client requirements, cost and program objectives, and potential consequences of malfunction or error. To provide clients with quality products and services, PNNL has established and implemented a formal Quality Assurance (QA) Program. These management controls are documented in the PNNL Standards-Based Management System (SBMS). Staff at PNNL, CHG, and DOE-RL (DOE Richland Operations Office) can access the SBMS menu. PNNL staff can go to PNNL's internal home page at http://labweb.pnl.gov/ and select "Policies \& Procedures (SBMS)." Offsite users can access SBMS by going to http://sbms.pnl.gov/. Netscape Communicator 4.5 is the recommended and supported World Wide Web browser at PNNL. This QA Plan also complies with the format requirements of QAMS-005/80 (Interim Guidelines and Specifications for Preparing Quality Assurance Project Plans). If other quality-related activities are later performed, the appropriate SBMS requirements and procedures will be applied, unless specifically excluded.

Contents of this test plan, and guidance discussed above have also been compared with Testing Practices Requirements for test plans (HNF-IP-0842) for comparability and coverage. The test plan presented here addresses the checklist provided in Testing Practices and Requirements, where appropriate. 



\subsection{Risk Management}

\subsection{Introduction to the Risk Management Process}

The purpose of this section is to develop the framework for managing risks that may result in negative consequences to the project. These negative consequences may include unsuccessful results, overruns in the schedule of the project, and overruns in the costs of the project. The greatest threat to the success of the project would be an accident resulting in serious injury or death. However, mitigating procedures regarding these are covered in Section 3.4 (Site Safety and Protection Provisions) and Attachment C (Site Access and Conduct Requirements Industrial Health and Safety Plan - Site Safety Requirements).

Therefore, this section shall focus on risks to the project itself.

Figure 6 graphically displays the risk management process. The process involves identifying risks and evaluating them in terms of the possibility of their occurrence and in terms of their impact. Those risks that have low probability and/or low impacts are monitored, but may have no specific action. But those with a high probability and/or have high impacts to the project have mitigation plans and preemptive actions may be taken. Table 1 summarizes definitions used for "low," "moderate," and "high" probabilities and impacts for this analysis.

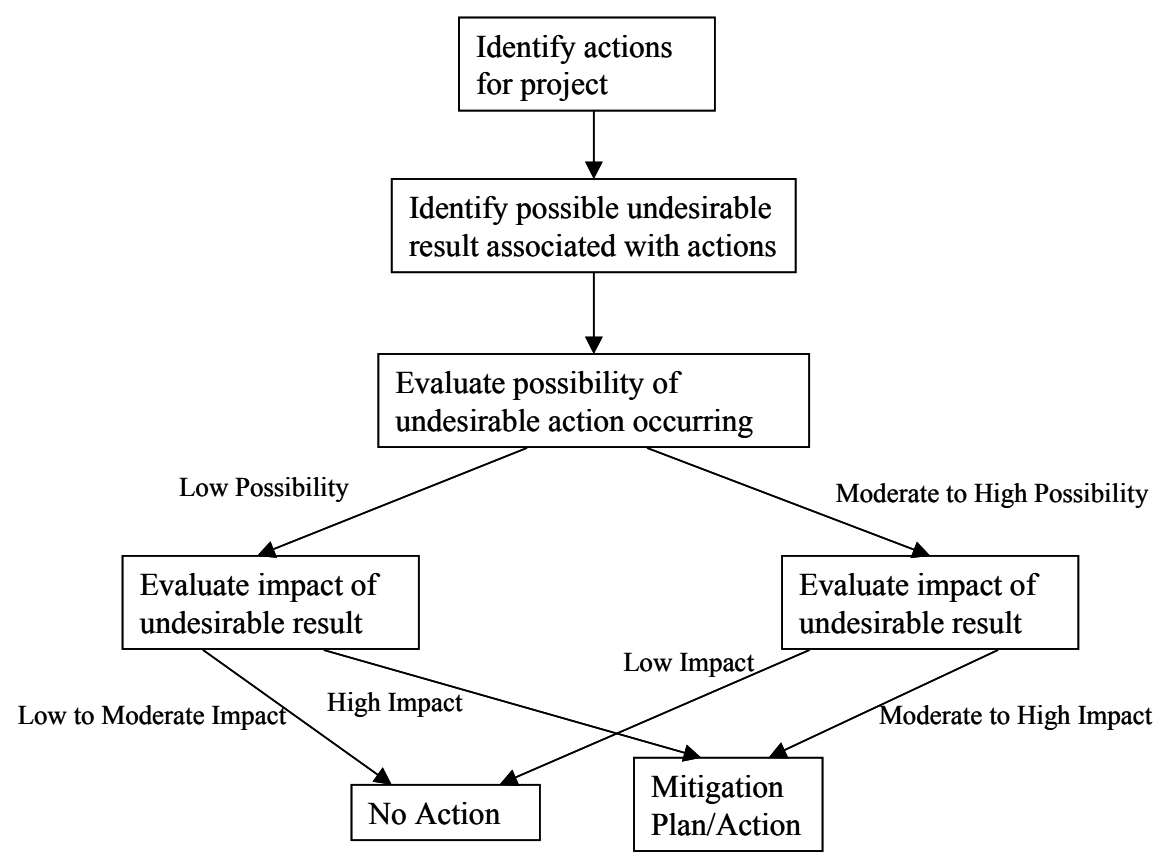

Figure 6. Depiction of Risk Assessment Process 
Table 1. Definitions of Low, Moderate, and High Probabilities and Impacts

\begin{tabular}{||c|c|l||}
\hline \hline \multirow{3}{*}{ Probability } & Level & \multicolumn{1}{|c|}{ Definition } \\
\hline \hline \multirow{3}{*}{ Low } & $\begin{array}{l}\text { Less than 1\% probability of } \\
\text { occurrence during experimental } \\
\text { period }\end{array}$ \\
\cline { 2 - 3 } & Moderate & $\begin{array}{l}\text { Between } 1 \% \text { and } 50 \% \text { probability } \\
\text { of occurrence. }\end{array}$ \\
\cline { 2 - 3 } & High & $\begin{array}{l}\text { About 50\% probability of } \\
\text { occurrence }\end{array}$ \\
\hline \multirow{2}{*}{ Impact } & Low & 0 to 24 hour impact \\
\cline { 2 - 3 } & Moderate & 1 day to 5 days impact \\
\cline { 2 - 3 } & High & $>5$ days impact \\
\hline
\end{tabular}

\subsection{Identification, Assessment of Risks and Mitigation Procedures}

Table 2 summarizes the identified risks, includes an assessment of probability and impact, and discusses mitigation measures. These are discussed at length below.

\subsubsection{Operational Risks}

Operational risks are potential problems associated with the operation of the mock tank facility. As the mock tank facility is considered a part of the tank farm operation, it can be affected by tank farm operations. In fact, in 2001, the tank farm had a unit wide work stoppage due to a labor dispute. This affected the mock tank project, stopping work for about five weeks. Unit-wide work stoppages are a risk to the schedule of the project. However, in anticipation of this occurring again, Battelle has secured assurances that future work stoppages will not affect work the mock tank site.

Another risk is the possibility of competing site usage. There is a possibility that other studies may be conducted at the mock tank site. As such, there may be some conflicts. Nonetheless, the possibility of a simultaneous project is low. And if one should occur, the LDMM project has priority, and the other project will be discontinued until the LDMM project is completed.

Another concern is that there might be some problems if hydroGeophysics, Inc. should fall behind in analyzing data for the project. Such a problem may jeopardize the incremental salt solution addition schedule that has been planned. It is not believed that this will be a problem. However, Battelle will monitor the progress of hydroGeophysics, Inc. in a discrete manner (as the chemical additions are to blind to hydroGeophysics) in order to identify problems occurring in this area. 
Table 2. Summary of Risks and Actions for LDMM Project

\begin{tabular}{|c|c|c|c|}
\hline Identified Risk & $\begin{array}{l}\text { Probability of } \\
\text { Occurrence }\end{array}$ & $\begin{array}{l}\text { Potential } \\
\text { Magnitude of } \\
\text { Damage }\end{array}$ & Mitigating Plan/Action \\
\hline \multicolumn{4}{|c|}{ Operational Risks } \\
\hline $\begin{array}{l}\text { Unit Wide Work } \\
\text { Stoppages }\end{array}$ & Moderate & Low to High & $\begin{array}{l}\text { Negotiated permission to continue to work on } \\
\text { LDMM project }\end{array}$ \\
\hline Competing Site Usage & Low & Low & The LDMM project has been given top priority \\
\hline $\begin{array}{l}\text { Problems with maintaining } \\
\text { schedules }\end{array}$ & $\begin{array}{l}\text { Perceived to be } \\
\text { low }\end{array}$ & $\begin{array}{l}\text { Perceived to be } \\
\text { low }\end{array}$ & $\begin{array}{l}\text { Maintenance of communication between Battelle, } \\
\text { hydroGeophysics, Inc., and CHG, Inc. }\end{array}$ \\
\hline \multicolumn{4}{|c|}{ Environmental Risks } \\
\hline Fire & Moderate & Low to high & $\begin{array}{l}\text { Potential damage to equipment will be minimized } \\
\text { by maintaining the mock tank facility brush free. }\end{array}$ \\
\hline Lightning & Moderate & Moderate & $\begin{array}{l}\text { Grounding of mobile laboratory exterior surface. } \\
\text { Surge protection, breakers. Back up electronic } \\
\text { equipment. }\end{array}$ \\
\hline Wind & High & Moderate & Anchoring of all test structure and housing units. \\
\hline Other Natural Disasters & Extremely Low & $\begin{array}{l}\text { Moderate to } \\
\text { High }\end{array}$ & $\begin{array}{l}\text { Back up equipment and parts will be maintained } \\
\text { for rapid repairs. }\end{array}$ \\
\hline \multicolumn{4}{|c|}{ System Hardware Failures } \\
\hline $\begin{array}{l}\text { Leak in the main salt } \\
\text { solution storage tank }\end{array}$ & Minimal & Low to High & $\begin{array}{l}\text { Proper tank selection (to minimize effects of } \\
\text { weather, etc). Daily inspections. Back up tanks } \\
\text { are available on site. }\end{array}$ \\
\hline Leaks to Piping System. & Minimal & $\begin{array}{l}\text { Most likely low, } \\
\text { but may be high. }\end{array}$ & $\begin{array}{l}\text { Initial testing. Daily inspections. Supplies for } \\
\text { repairs are readily available. }\end{array}$ \\
\hline $\begin{array}{l}\text { Damages to filters, pumps, } \\
\text { regulators, thermocouples, } \\
\text { \& valving in distribution } \\
\text { system }\end{array}$ & Minimal & Low & Key back up supplies will be stocked. \\
\hline $\begin{array}{l}\text { Damages to sensors or to } \\
\text { associated wiring }\end{array}$ & $\begin{array}{l}\text { Minimal } \\
\text { (sensors) to } \\
\text { moderate } \\
\text { (wiring) }\end{array}$ & Low & $\begin{array}{l}\text { There are more sensors than needed, which } \\
\text { provides back up. Sensor failure can be deduced } \\
\text { relatively rapidly from results. Replacement } \\
\text { sensors will be stocked. On-site training stresses } \\
\text { care in disturbing wires in area. }\end{array}$ \\
\hline $\begin{array}{l}\text { Damage to computer } \\
\text { system }\end{array}$ & Minimal & Up to High & $\begin{array}{l}\text { Monitored daily. Back up data systems will be } \\
\text { maintained. Extra computers are readily available } \\
\text { from Battelle. }\end{array}$ \\
\hline $\begin{array}{l}\text { Problems with phone } \\
\text { system }\end{array}$ & $\begin{array}{l}\text { Minimal to } \\
\text { Moderate }\end{array}$ & Low & $\begin{array}{l}\text { The data will be stored on the on-site computer, } \\
\text { which can be directly downloaded if necessary. }\end{array}$ \\
\hline $\begin{array}{l}\text { Interruptions in power } \\
\text { supply }\end{array}$ & Low & $\begin{array}{l}\text { Low to High, } \\
\text { depending on } \\
\text { when and how } \\
\text { long. }\end{array}$ & $\begin{array}{l}\text { Battelle has arranged for uninterruptible power } \\
\text { supply for the duration of the performance } \\
\text { evaluation. Back up generators are available, if } \\
\text { needed. }\end{array}$ \\
\hline
\end{tabular}


Table 2. (contd)

\begin{tabular}{||l|l|l|l||}
\hline \hline \multicolumn{1}{||c|}{ Identified Risk } & \multicolumn{1}{|c||}{$\begin{array}{c}\text { Probability of } \\
\text { Occurrence }\end{array}$} & $\begin{array}{c}\text { Potential Magnitude } \\
\text { of Damage }\end{array}$ & \multicolumn{1}{|c||}{ Loss or Corruption of Data } \\
\hline \hline $\begin{array}{l}\text { Damage to Computer } \\
\text { System }\end{array}$ & Moderate & Potentially High & $\begin{array}{l}\text { Periodic back up (limiting impact time to a } \\
\text { maximum of one week). Back ups will be kept in } \\
\text { geographically separate areas. }\end{array}$ \\
\hline $\begin{array}{l}\text { Manipulation of results } \\
\text { by system operators }\end{array}$ & Low & Potentially High & $\begin{array}{l}\text { The use of blind testing makes any attempt for } \\
\text { system manipulation doubtful. }\end{array}$ \\
\hline $\begin{array}{l}\text { Inadvertent changes in } \\
\text { results from changes in } \\
\text { equipment }\end{array}$ & Low & $\begin{array}{l}\text { Probably low, but } \\
\text { may be high in certain } \\
\text { circumstances. }\end{array}$ & $\begin{array}{l}\text { Changes in equipment will be avoided unless } \\
\text { necessary. If possible, side-by-side tests will be } \\
\text { conducted when important changes are made. If } \\
\text { not possible, then a similar test condition will be } \\
\text { duplicated. }\end{array}$ \\
\hline $\begin{array}{l}\text { Data corruption by } \\
\text { intentional or } \\
\text { unintentional intruders } \\
\text { into the system. }\end{array}$ & Low & High & $\begin{array}{l}\text { A password-protected system will control access } \\
\text { to the computer system, whether remotely or on- } \\
\text { site. }\end{array}$ \\
\hline \hline
\end{tabular}

\subsubsection{Environmental Risks}

Environmental risks are those risks associated with the natural environment in which the mock tank facility exists. The facility resides in a desert environment on the Columbia Plain. As such, there are several threats that may affect the project. These include fire, earthquake, lightening strikes.

There is a historic precedent for fire in the general area of the mock tank facility. A large fire burned in the Hanford facility from June 27 through July 1, 2000 (http://www.hanford.gov/hanfordfire.html). The mock tank site is maintained with no vegetation surrounding it for a distance of about $100 \mathrm{~m}$, making it unlikely that fire will actually damage any of the on-site equipment. However fire anywhere on the Hanford facility most likely be to result in a work shutdown that could last for as little as a day, to up to three weeks.

Lightning strikes are a possibility but overall the probability must be considered low. The greatest threat would be a lightening strike on the trailer, resulting in a shut down of the electrical equipment used in the experiment. If not properly protected, this could be catastrophic, resulting in a loss of data and in equipment. However, the on-site building will be electrical grounded and electrical equipment at the site will be protected by surge protection and breaker switches whenever possible. Therefore, the magnitude of effect would more likely be moderate.

There are possibilities of earthquakes, floods and volcanic eruptions affecting the area. Each of these may have a high impact on the project. However, the probability of any of these happening during the project must be considered extremely remote. 


\subsubsection{System Hardware Failures}

The project depends on the solution control system (Figure D.4) to store and deliver the salt solution (sodium thiosulfate) into the proper injection points in the mock tank facility. The system includes storage tanks, piping, pumps, valves, regulators, etc., which must operate properly to insure proper experimental results. Also critical are the hardware involved with the probes and wiring that are used to collect the data. Hardware is also a key part of data storage.

The storage system begins with the tank. The greatest risk associated with the storage tank is an uncontrolled leak. The impact of a catastrophic leak would be high because it would change the resistivity of the soil near or in the test area. However, possibility of this happening is considered extremely low, because care was taken in ordering the tank to insure that is would be suitable for its task. The tank will be checked each workday as part of the daily walk through for leaks or evidence of structural damage. Flows will be monitored, allowing for mass balances to assess for small leaks. A tank level indicator will also allow monitoring for changes in tank level. There are nearby tanks that could be used if the main tank is damaged.

The piping system may also be a source of an uncontrolled leak. Once again, the likelihood of this occurring is low, but the effect could be high. Once again, this will be monitored by daily inspection. Additional hardware problems may result from faulty filters, pumps, regulators, thermocouples, and valves. The possibility of this occurring is considered moderate, but the impact would likely be low. Spare valves will be kept so that they can be rapidly replaced if needed.

There is a moderate possibility of a failure of the operating computer. The impact depends on how quickly it can be replaced. PNNL maintains a large inventory of late model computers that can be quickly installed at the site if needed. Daily checks on the computer will be conducted, either on site or remotely (Section 5.4, Contingencies for Systems Failure).

An HPI system is available for rapid replacement should a failure of the Zonge GDP-32 system occur (see below regarding addressing system differences). A replacement Zonge system could then be obtained from hydroGeophysics, Inc. Replacement wires sensors will be maintained on site. On site training will stress awareness in not damaging sensors, distribution systems, and wiring.

Power failure is also a potential problem at the site. As discussed in Section 5.4 (Contingencies for Systems Failure), Battelle has arranged for uninterruptible power supply for the duration of the performance evaluation. Back up generators are available, if needed.

\subsubsection{Loss or Corruption of Data}

A critical concern is that there would be a loss or a corruption of data collected from the project. The most likely cause of data loss would be a catastrophic failure of the computer operating the system. Although computer crashes are common, generally, data can be recovered from hard drives. However, 
there are situations in which data recovery is not possible. During key tests, daily backups of the data will be made and these will be stored in a separate facility. This will limit data losses to a 24-hour period maximum.

A second concern is the possibility of changing the operating conditions of the detection systems to improve the results of subsequent tests. This is not a factor because the tests will be conducted blindly, and there will be no feedback available to change the operating conditions.

A final concern involves the possibility of inadvertent changes in results if changes are made to the system, such as the installation of a new operating computer. If possible, side-by-side evaluations will be conducted if major changes are made. Otherwise, tests will be conducted with similar conditions to allow comparison of results between the two equipment types. Computer security systems, including layered password-protected access, will prevent intentional or unintentional data corruption by unauthorized personnel.

\begin{tabular}{|c|c|c|c|c|c|}
\hline ITEM & FAILURE MODE & EFFECT & PROBABILITY & $\begin{array}{c}\text { CORRECTIVE } \\
\text { ACTION }\end{array}$ & INDICATOR \\
\hline FILTER & Clog & System shutdown & Low & Clean Filter & PT \\
\hline PUMP & Stops & System shutdown & Very low & Replace & PT \\
\hline HEATER & Shutdown & Solution crystallization & Very low & $\begin{array}{l}\text { Replace heater (Use } \\
\text { heat tape on P-loop) }\end{array}$ & Thermosensors, PT \\
\hline PT & $\begin{array}{c}\text { Incorrect reading/ } \\
\text { failure }\end{array}$ & Require site visit & Extremely low & Replace PT & CSSC \\
\hline \multirow{2}{*}{$\begin{array}{l}\text { PRESSURE } \\
\text { REGULATOR }\end{array}$} & Under $\mathrm{P}$ & Low flow & Extremely low & Replace & PT \\
\hline & Over $\mathrm{P}$ & Relief valve operates & Extremely low & Replace & PT \\
\hline R VALVE & $\begin{array}{l}\text { Opens Low P/ } \\
\text { sticks }\end{array}$ & System shutdown & Extremely low & Replace & PT,CSSC \\
\hline $\mathrm{FC}$ & Error & $\begin{array}{c}\text { Wrong amount solution } \\
\text { dispensed }\end{array}$ & Extremely low & Replace & CSSC, totalizer \\
\hline $\begin{array}{l}\text { SOLENOID } \\
\text { VALVES }\end{array}$ & Stick/ inop & $\begin{array}{c}\text { Wrong amount solution } \\
\text { dispensed }\end{array}$ & Extremely low & Replace & $\begin{array}{l}\text { Thermosensor, } \\
\text { CSSC }\end{array}$ \\
\hline cssc & Inop & System shutdown & Extremely low & Repair/replace & HLAN/ Remote \\
\hline THERMO SENSOR & Inop & No T data & Extremely low & Replace & cssc \\
\hline \begin{tabular}{|l|} 
PRECIPITATION \\
SIMULATION \\
PUMP \\
\end{tabular} & Inop/ failure & No precipitation & Very low & Replace & Site camera \\
\hline \multirow{2}{*}{$\begin{array}{l}\text { PRECIPITATION } \\
\text { SIMULATION } \\
\text { VALVES }\end{array}$} & Sticks closed & No precipitation & Very low & Replace & Site camera \\
\hline & Sticks open & Excess precipitation & Very low & Replace & Site camera \\
\hline
\end{tabular}




\subsection{References}

Barnett, D. B., G. W. Gee, and M. D. Sweeney. 2002. Results of Tank Leak Detection Demonstration Using Geophysical Techniques at the Hanford Mock Tank Site-Fiscal Year 2001. PNNL-13818, Pacific Northwest National Laboratory, Richland, Washington.

Bratton, W. L. 2002. Ex-Tank LDMM Technology Assessment and Down-Selection Report. RPP-10604, Rev. 0, Vista Engineering Technologies L.L.C., Kennewick, Washington.

Bratton, W. L., J. W. Maresca, and W. C. Dickerson. 2002a. Ex-Tank LDMM Performance Evaluation Strategy (Draft, May 2002). RPP-10903, Rev. 0, Vista Engineering Technologies for CH2M HILL Hanford Group, Richland, Washington.

Bratton, W. L., J. W. Maresca, and W. C. Dickerson. 2002b. Ex-Tank LDMM Performance Evaluation Test Specification. RPP-10904, Rev. 0, Vista Engineering Technologies for CH2M HILL Hanford Group, Richland, Washington.

Ecology - Washington State Department of Ecology, U.S. Environmental Protection Agency, and U.S. Department of Energy. 1998. Hanford Federal Facility Agreement and Consent Order. Document No. 89-10, Rev. 5 (The Tri-Party Agreement), Olympia, Washington.

Hoitink, D. J., K. W. Burk, J. V. Ramsdell, and W. J. Shaw. 2002. Hanford Site Climatological Data Summary 2001 With Historical Data. PNNL-13859, Pacific Northwest National Laboratory, Richland, Washington.

Isaacson, R. E. 1982. Supporting Information for the Scientific Basis for Establishing Dry Well Monitoring Frequencies. R-RE-EV-4 P, Rockwell Hanford Operations, Richland, Washington.

Jansen, G., D. P. Granquist, R. D. Dierks, J. N. Hartley, O. H. Koski, J. A. Merrill, and C. A. Ratcliff. 1983. Review of ARCHO Waste Tank Leak and Level Monitoring System and Material Balance Techniques. BNWL-B.308, Pacific Northwest Laboratory, Richland, Washington.

Lindsey, K. A., B. N. Bjornstad, J. W. Lindberg, and K. M. Hoffman. 1992. Geologic Setting of the 200 East Area; An Update. WHC-SD-EN-TI-012 Rev. 0, Westinghouse Hanford Company, Richland, Washington.

Narbutovskih, S. M., T. D. Halter, M. D. Sweeney, W. Daily, and A. L. Ramirez. 1996a. Electrical Resistivity Tomography at the DOE Hanford Site. WHC-SA-3035-VA, Westinghouse Hanford Company, Richland, Washington. 
Narbutovskih, S. M., D. F. Iwatate, M. D. Sweeney, A. L. Ramirez, W. Daily, R. M. Morey, and L. Christensen. 1996b. Feasibility of CPT-Deployed Vertical Electrode Array in Single-Shell Tank Farms. WHC-SD-EN-TA-004 Rev. 0, Westinghouse Hanford Company, Richland, Washington.

Ramirez, A., W. Daily, A. Binley, D. LaBrecque, and D. Roelant. 1995. Detection of Leaks in Underground Storage Tanks Using Electrical Resistance Methods. UCRL-JC-122180, Lawrence Livermore National Laboratory, Livermore, California.

Ramirez, A., W. Daily, A. Binley, and D. LaBrecque. 1996. Tank Leak Detection Using Electrical Resistance Methods. UCRL-JC-122875, Preprint prepared for the Symposium on the Application of Geophysics to Engineering and Environment, Keystone, Colorado, Lawrence Livermore National Laboratory, Livermore, California.

Reidel, S. P., K. A. Lindsey, and K. R. Fecht. 1992. Field Trip Guide to the Hanford Site. WHC-MR0391, Westinghouse Hanford Company, Richland, Washington.

Williams, B. A., B. N. Bjornstad, R. Schalla, and W. D. Webber. 2000. Revised Hydrogeology for the Suprabasalt Aquifer System, 200 East Area and Vicinity, Hanford Site, Washington. PNNL-12261, Pacific Northwest National Laboratory, Richland, Washington. 


\section{Attachment A}

Participants, Organizational Responsibilities, and General Schedule for the FY 2002-2003 Performance Evaluation Testing 


\section{Attachment A}

\section{Participants, Organizational Responsibilities, and General Schedule for the FY 2002-2003 Performance Evaluation Testing}

The fiscal year (FY) 2002-2003 test is a multidisciplinary and collaborative effort among national laboratories, universities, commercial vendors, and geophysical consultants who are experts in vadosezone monitoring. Table A.1 is a list of the collaborators involved in the FY 2001 field tests at Mock Tank 105-A (Mock Tank). Tables A.2 and A.3 lists Pacific Northwest National Laboratory (PNNL) and Vista Engineering Technologies, L.L.C. staff responsible for the development, direction, and implementation of the testing and related logistical considerations.

Table A.1. Participants in FY 2002-2003

\begin{tabular}{|c|c|c|}
\hline Institution & Collaborator & Expertise \\
\hline \multirow[t]{2}{*}{ LLNL } & Bill Daily & Geophysics \\
\hline & Abe Ramirez & Geophysics \\
\hline Lancaster University & Andrew Binley & Geophysics \\
\hline \multirow[t]{2}{*}{ HydroGEOPHYSICS, Inc. } & Jim Fink & Geophysics \\
\hline & Marc Levitt & Geophysics \\
\hline \multirow[t]{4}{*}{ PNNL } & Brent Barnett & Geology/Hydrology \\
\hline & Glendon Gee & Soil Physics \\
\hline & Mike Johnson & Engineering \\
\hline & Mark Sweeney & $\begin{array}{l}\text { Geology/Geophysic } \\
\text { s }\end{array}$ \\
\hline \multirow[t]{3}{*}{ Vista } & Wes Bratton & Engineering \\
\hline & Willie Dickerson & Engineering \\
\hline & Joe Maresca & Engineering \\
\hline
\end{tabular}

\section{A1 Organizational Responsibilities of LDMM Team Members}

The flow charts illustrate internal organizational relationships within each major LDMM team component (CHG, PNNL, and Vista Engineering), and contacts for individual team members. Geophysicists from Lawrence Livermore National Laboratory (LLNL) and HydroGEOPHYSICS, Inc., and construction components are under contract with PNNL. CHG is responsible for inter-organizational coordination, assignation of tasks, and final approval of procedures. PNNL is responsible for implementation (per this plan) of site preparation and performance evaluation test activation. Vista is responsible for the technical specifications of the test and overall test direction during testing. 


\section{2 - 2003 LDMM \\ Roles and Responsibilities - PNNL}

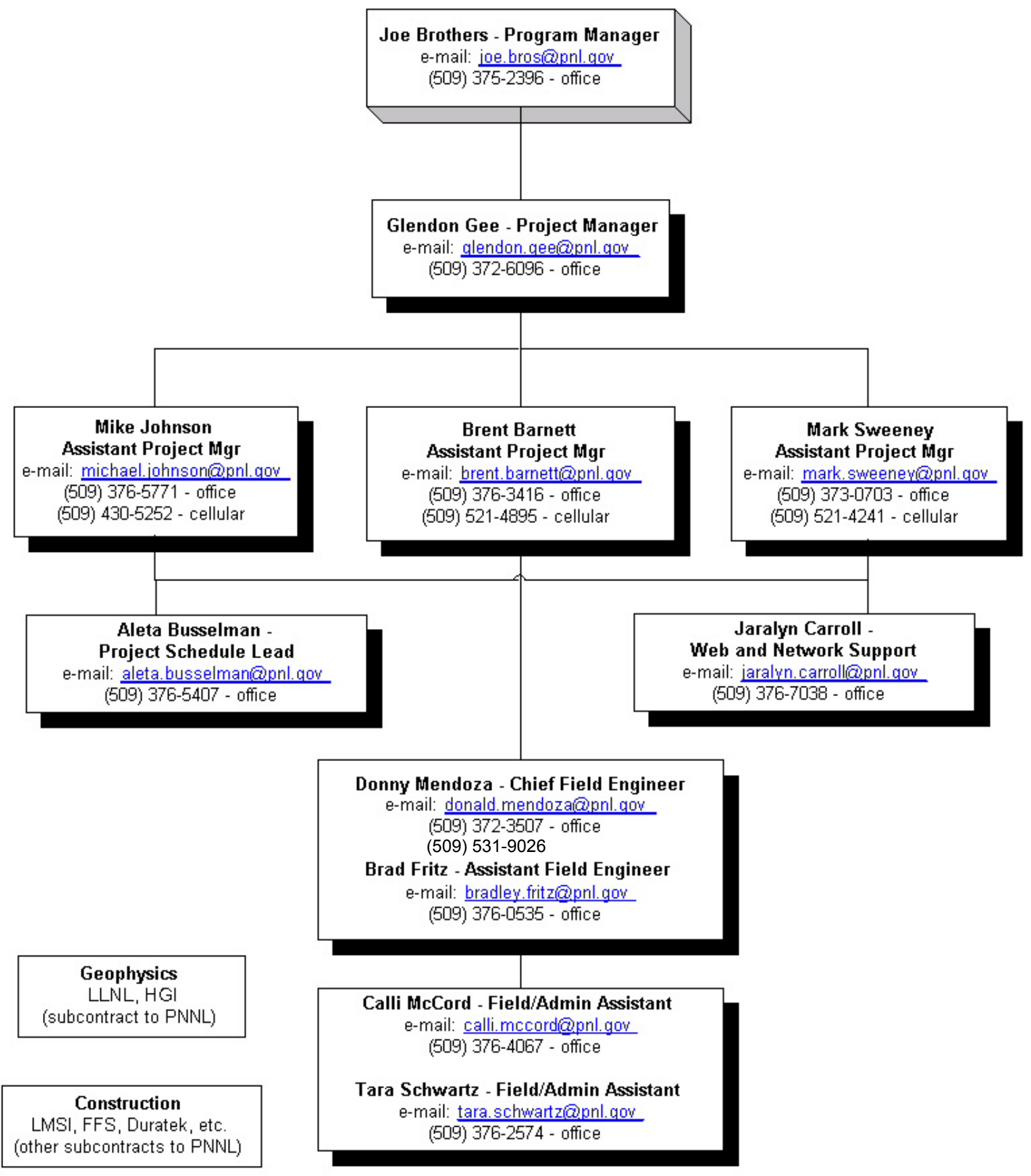

July 2002 


\section{2 - 2003 LDMM \\ Steering Committee - CHG / COGEMA}

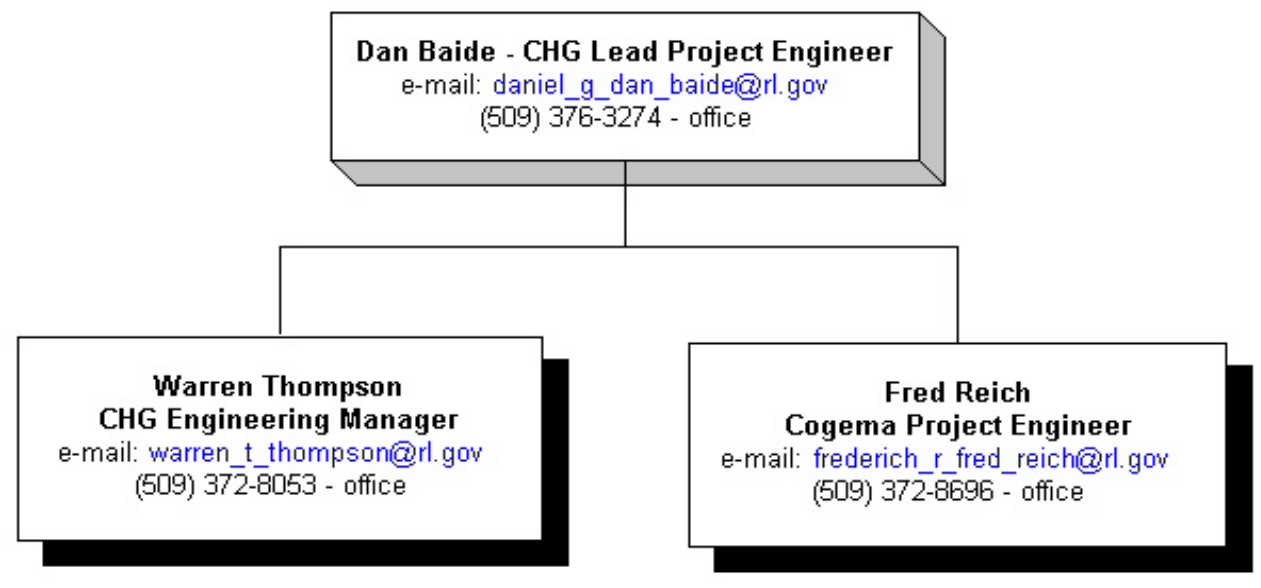

Responsible Personnel--Vista Engineering Technologies, L.L.C.

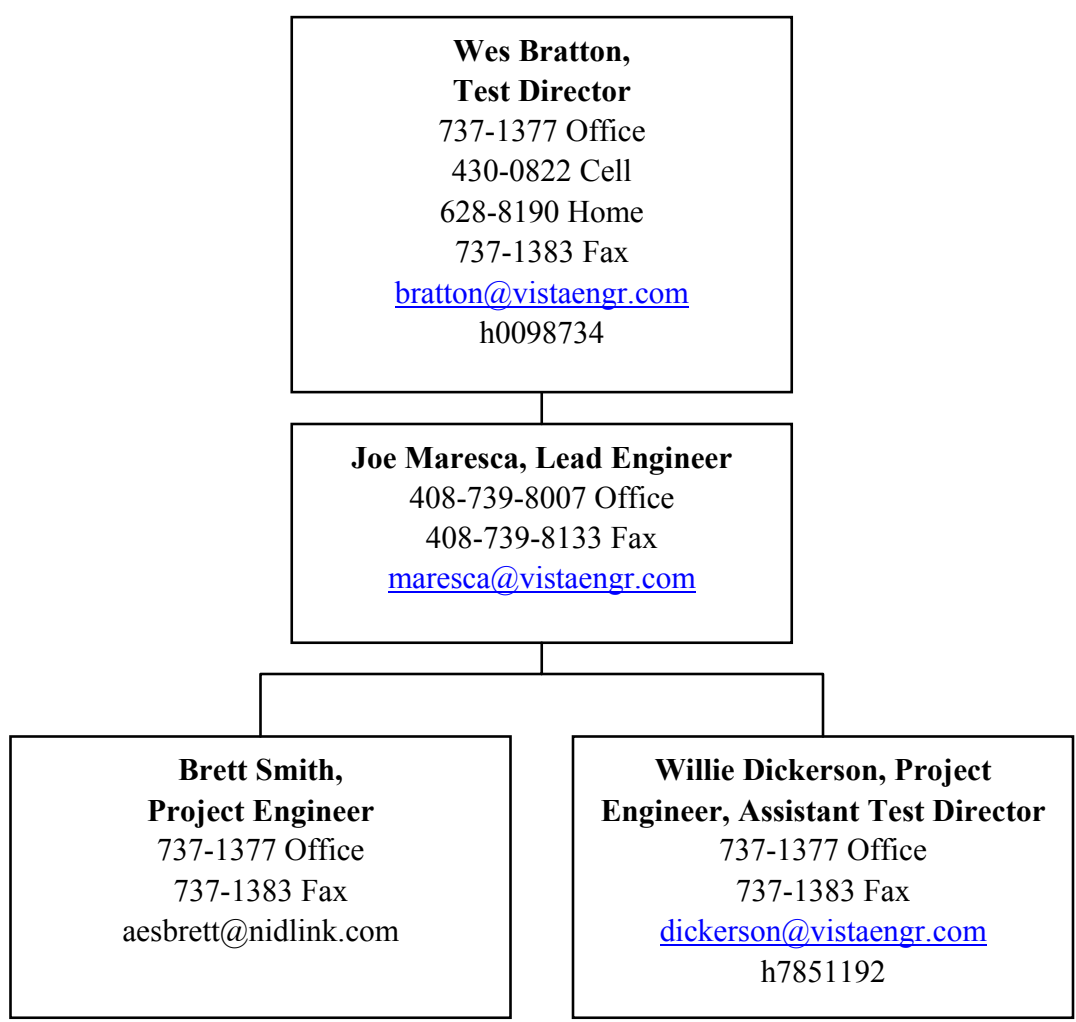




\section{A2 General Schedule}

The general schedule for implementation of the FY 2002-2003 LDMM Performance Evaluation Testing is as illustrated in the following table. Site restoration and "post-test management" activities will tentatively occur subsequent to the end of performance evaluation testing, ending by March 31, 2003. Site reclamation and cleanup will also depend on interim decisions on further work at the Mock Tank site, and will be documented by change procedures noted in Section 5.3 Protocol for Changing Test Procedures.

Table A.2. General Schedule

\begin{tabular}{|lllll}
\hline WBS & WBS Title & Duration & Baseline Start & Baseline Finish \\
\hline 1 & LDMM 105-A Performance Test & 250 days & $04 / 22 / 02$ & $04 / 04 / 03$ \\
\hline 1.1 & Performance Test Plan Support (VISTA) & 25 days & $04 / 22 / 02$ & $05 / 24 / 02$ \\
\hline 1.2 & Performance Evaluation Implement. Plan (PNNL) & 180 days & $05 / 06 / 02$ & $01 / 10 / 03$ \\
\hline 1.3 & Test Site Preparation and Restoration & 200 days & $05 / 06 / 02$ & $02 / 07 / 03$ \\
\hline 1.3 .1 & Permitting & 30 days & $05 / 06 / 02$ & $06 / 14 / 02$ \\
\hline 1.3 .2 & Tank Site Modifications & 34 days & $05 / 06 / 02$ & $06 / 20 / 02$ \\
\hline 1.3 .3 & Site Restoration (No Budget Included) & 61 days & $11 / 15 / 02$ & $02 / 07 / 03$ \\
\hline 1.3 .4 & Remote Access System & 21 days & $05 / 27 / 02$ & $06 / 24 / 02$ \\
\hline 1.4 & Performance White Papers & 181 days & $05 / 14 / 02$ & $01 / 21 / 03$ \\
\hline 1.5 & Ground Truth Parameters & 126 days & $07 / 01 / 02$ & $12 / 23 / 02$ \\
\hline 1.6 & Performance Testing & 99 days & $07 / 01 / 02$ & $11 / 30 / 02$ \\
\hline 1.7 & Test Report (PNNL) & 60 days & $11 / 15 / 02$ & $02 / 06 / 03$ \\
\hline & & & & $02 / 21 / 03$ \\
\hline 1.9 & Subcontracts Performance & 178 days & $06 / 19 / 02$ & $04 / 04 / 03$ \\
\hline 1.10 & Project Management & 240 days & $05 / 06 / 02$ & \\
\hline
\end{tabular}




\section{Attachment B}

Site Operating Requirements and Permits 


\section{Attachment B}

\section{Site Operating Requirements and Permits}

\section{B1 Excavation Permit for FY 2002-2003}

\section{B1.1 Excavation Permit}

Excavation permit DAN 1971 was completed on May 14, 2002. The permit allows drilling, steel wall installation, and cone penetrometer techniques (CPT) installations at Mock Tank 105-A (Mock Tank) site as illustrated Attachment D. 


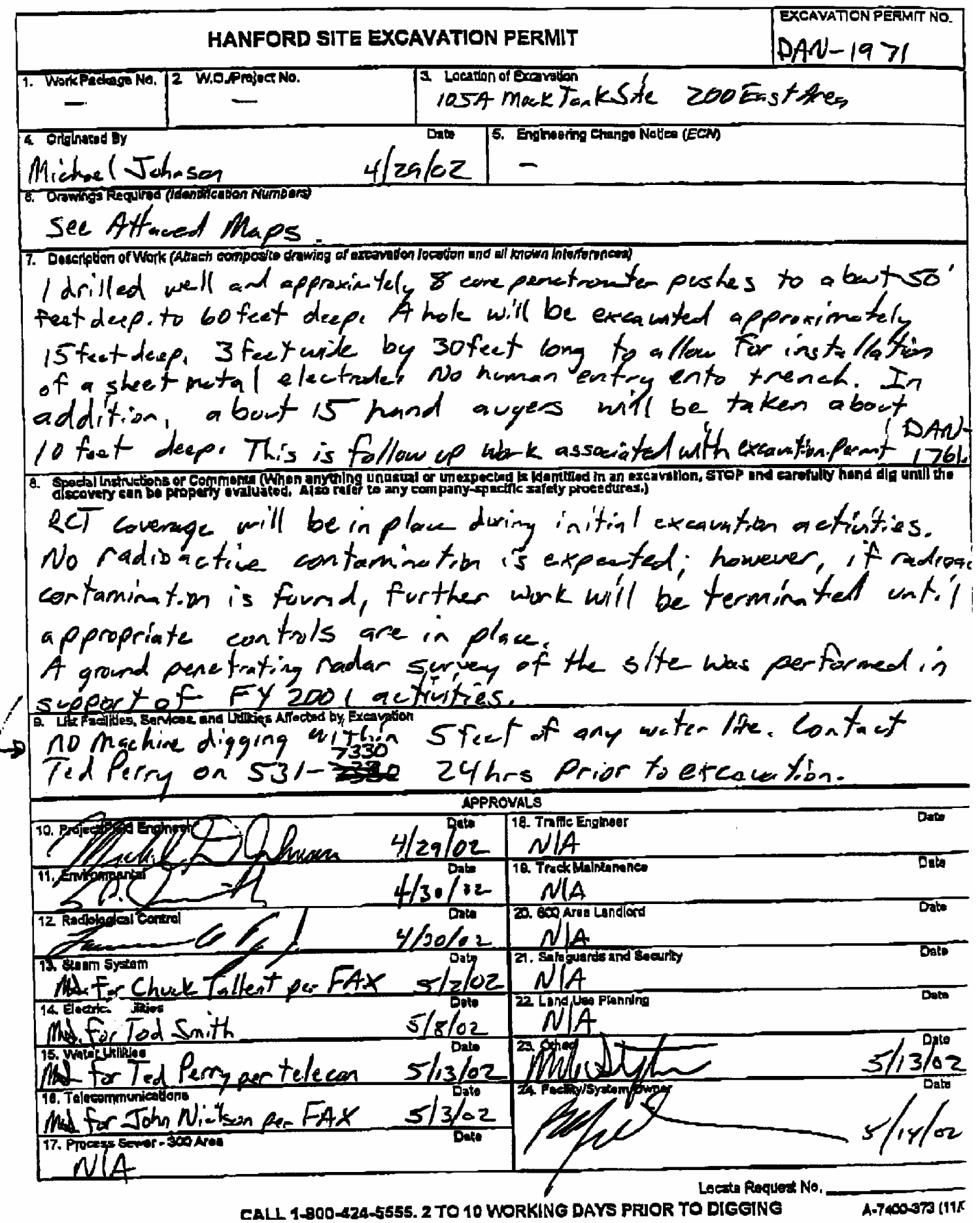




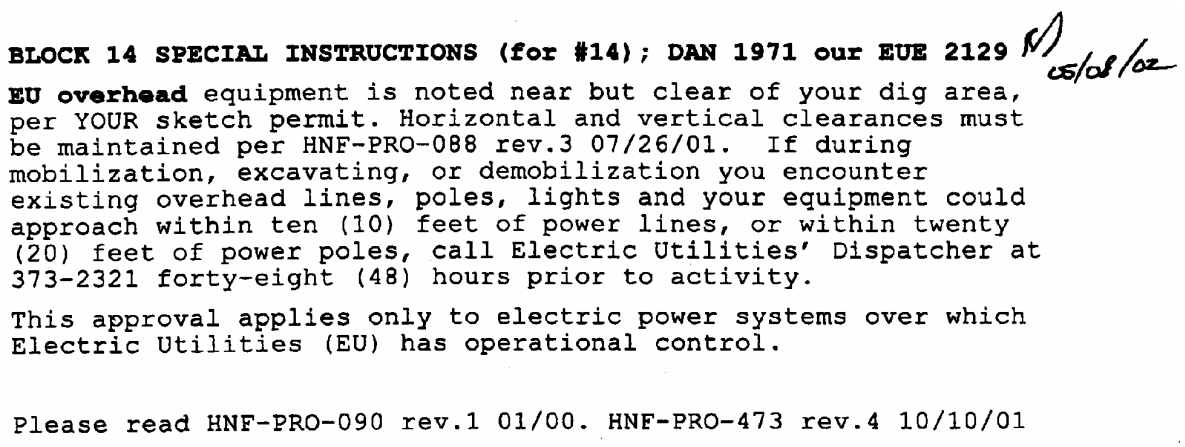

B2 Ground-Penetrating Radar Survey Results-Updated for FY 2002-2003 Activities

To ensure site safety, protect subsurface structures, and optimize the locations of boreholes, the entire area involving the FY 2001 Tank Leak Detection Demonstration (TLDD) project was surveyed with GPR in May of 2001. Because additional area would be disturbed by the installation of electrical service, a new GPR survey was conducted to the south of the Mock Tank. The results of this survey, combined with the FY 2001 survey, are illustrated in Figure B.1.

Several buried linear features, interpreted to be pipelines, are located within or near the site. The most prominent of these include the corridor southeast of the Mock Tank aligned in a southwest-northeast trending direction. At least four linear conductors were identified in this corridor. Another major linear feature is located north of the study area (i.e., north of the N130 survey line) within an excavated area. At least two pipelines and several other buried features are identified along this trend. Northwest of the Mock Tank are two buried pipes approximately $3.3 \mathrm{ft}(1 \mathrm{~m})$ deep. Of these two, the pipe trending eastwest has been truncated in the area of the tank and is only $0.66 \mathrm{ft}(20 \mathrm{~cm})$ deep in the Partitioning Interwell Tracer Test (PITT) demonstration area east of the Mock Tank. This feature will be easily avoided because of its shallow depth. The conductor labeled as " 1 " (indicating a depth of $0.33 \mathrm{ft}[10 \mathrm{~cm}]$ ) and trending west-northwest from the N114 survey line is a \#10 gauge copper wire at the surface. This was installed for grounding purposes during the 1995-1996 Electrical Resistivity Tomography (ERT) studies, and may be used for FY 2001 activities.

Isolated objects denoted by shallow depths from 4 to 11.8 in $(10-30 \mathrm{~cm})$ represent small discarded items of limited dimensions, such as drink cans or fragments of "rebar," and can be avoided or removed without difficulty. The cross-lined areas northwest and east of the Mock Tank indicate partial disruption of the radar signal by cables leading from the ERT installations.

Prior to installation of the steel sheet wall (to simulate an adjacent tank), installation of an additional steel well casing (see Attachment D), and installation of electric services, supplementary GPR scans were performed. These scans were performed in the areas of the steel sheet wall and the electrical panel and pole installation area near the mobile lab trailer (see Figure 4). No obstructions that would prevent installation of this equipment were observed. The installation of the new steel well casing was performed based on FY 2001 GPR results shown in Figure B.1. 


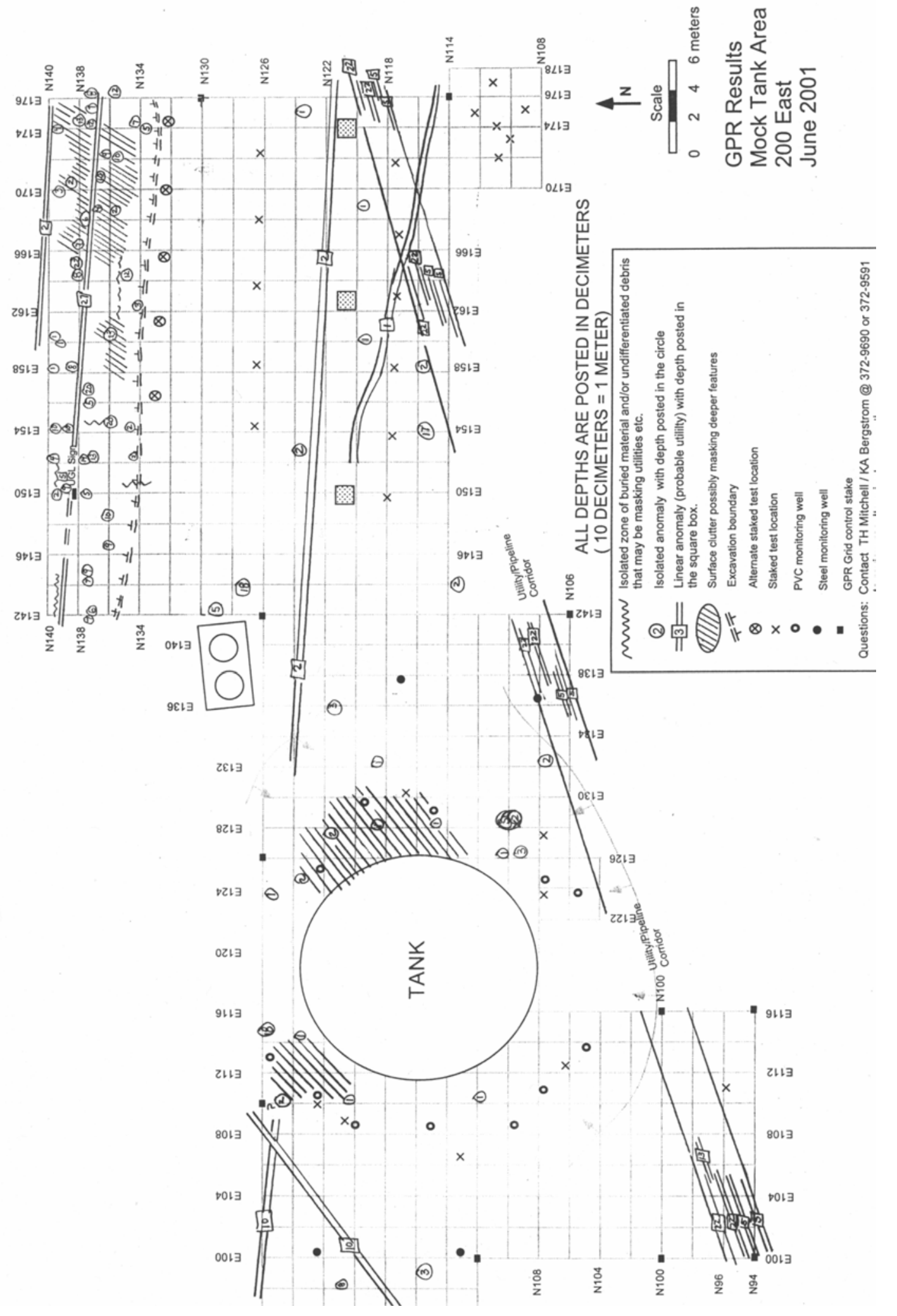

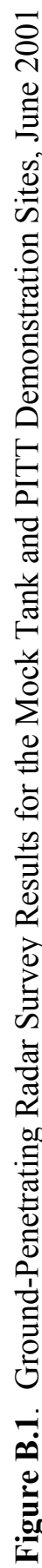




\section{B3 Biological and Cultural Reviews FY 2002-2003}

\section{Pacific Northwest National Laboratory \\ Operated by Battelle for the U.S. Department of Energy}

April 24, 2002

Mr. Michael D. Johnson

Battelle Pacific Northwest National Laboratory

P. O. Box 999, MSIN K6-96

Richland, WA 99352

Dear Mr. Johnson:

BIOLOGICAL REVIEW OF THE GEOPHYSICAL TANK-LEAK DETECTION TECHNOLOGY DEMONSTRATION, 200 East Area, ECR \#2002-200-028.

\section{Project Description:}

- Excavate and install permanent power and up to 6 CPT pushes around an existing mock tank.

\section{Survey Objectives:}

- To determine the occurrence in the project area of plant and animal species protected under the Endangered Species Act (ESA), candidates for such protection, and species listed as threatened, endangered, candidate, sensitive, or monitor by the state of Washington, and species protected under the Migratory Bird Treaty Act.

- To evaluate and quantify the potential impacts of disturbance on priority habitats and protected plant and animal species identified in the survey.

Survey Methods:

- Pedestrian and ocular reconnaissance of the proposed project site were performed by M.R. Sackschewsky and C.A. Duberstein on 22 April 2002.

- Priority habitats and species of concern are documented as such in the following: Washington Department of Fish and Wildlife $(1994,1996)$, Washington State Department of Natural Resources (1997), and for migratory birds, U.S. Fish and Wildlife Service (1985). Lists of animal and plant species considered Endangered, Threatened, Proposed, or Candidate by the USFWS are maintained at 50 CFR 17.11 and 50 CFR 17.12.

\section{Survey Results:}

- Much of the project area has been previously disturbed with the installation and subsequent testing around the mock tank. Cheatgrass (Bromus tectorlum) and Sandberg's bluegrass (Poa secunda) are the dominant plant species present. 
Mr. Michael Johnson

2002-200-028

Page 2 of 2

- No migratory birds were observed nesting within the project area.

\section{Considerations and Recommendations:}

- No plant or animal species protected under the ESA, candidates for such protection, or species listed by the Washington state government as threatened or endangered were observed in the vicinity of the proposed site.

- No adverse impacts to species, habitats, or other biological resources are expected to result from the proposed actions.

- This Ecological Compliance Review is valid until 15 April 2003.

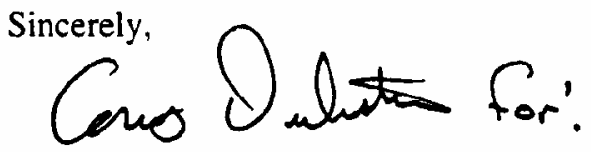

Michael R. Sackschewsky

Project Manager

Ecological Compliance Assessment Project

MRS:cad

\section{REFERENCES}

U. S. Fish and Wildlife Service. 1985. Revised List of Migratory Birds; Final Rule. 50 FR 13708 (April $5,1985)$.

Washington Department of Fish and Wildlife. 1994. Species of Special Concern in Washington. (April 1994).

Washington Department of Fish and Wildlife. 1996. Priority Habitats and Species List. (January 1996).

Washington Department of Natural Resources. 1997. Endangered, Threatened \& Sensitive Vascular Plants of Washington (August 1997). 
Stephenson, Michael J

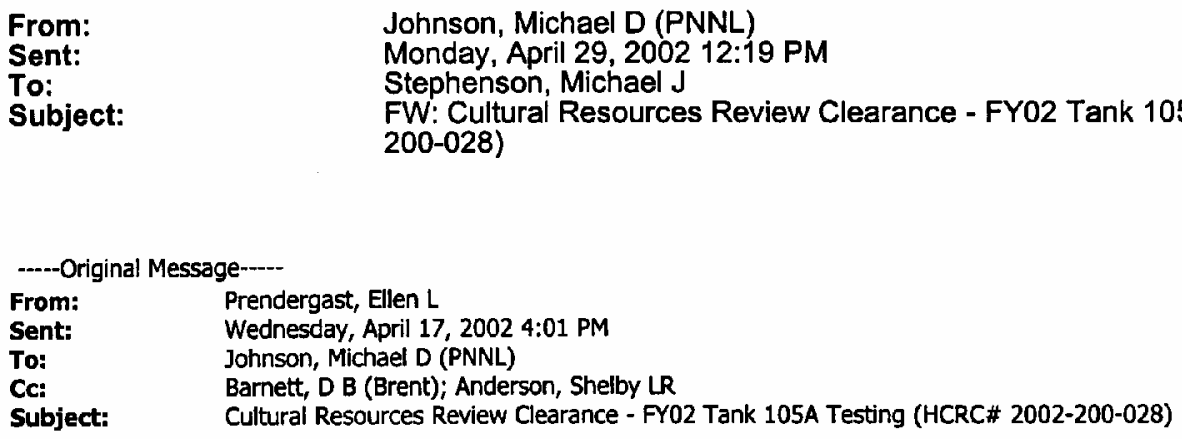

Mr. Johnson,

Thank you for contacting our office regarding your project. The project area is located at the Mock Tank 105A in the 200 East Area of the Hanford Site. This project entails carrying out the FY02 test plan for conducting various geophysical tank leak detection technologies.

Per 36 CFR Part 800, Subpart B, 800.3.a, the DOE-RL Cultural Resources Program has concurred that this project is not the type of undertaking with potential to effect historic properties and no further actions are required. The finding is based on the following:

- The project is located in an area of low cultural sensitivity.

- The project area is highly disturbed by previous construction activities.

- 3 previous reviews have determined that there are no historic properties in the area of potential effect.

All workers should be directed to watch for cultural materials (e.g. bones, artifacts) during all work activities. If any are encountered, work in the vicinity of the discovery must stop until and HCRL archaeologist has been notified, assessed the significance of the find, and, if necessary arranged for mitigation of the impacts to the find. The HCRL must be notified if any changes to project location or scope are anticipated.

We are tracking these kinds of projects, thus HCRC\# 2002-200-028 as been assigned to your request. This is your official notice of cultural resources review clearance.

Again, thank you for contacting us regarding your project.

Ellen Prendergast, M.A.

Cultural Anthropologist/Section 106 Coordinator

Hanford Cultural Resources Laboratory

Pacific Northwest National Laboratory

P.O. Box 999, K6-75

Richland, Washington 99352

(509) $376-4626$ 


\title{
B4 Solution Discharge Permit
}

\author{
From: $\quad$ Raney, Elizabeth A \\ Sent: $\quad$ Friday, May 24, 2002 3:50 PM \\ To: $\quad$ Barnett, D B (Brent); Johnson, Michael D (PNNL); Juracich, Samuel P \\ Ce: $\quad$ Bartel-Bailey, Gregg M; Atencio, Brad P; Stephenson, Michael J; Shields, Keith D; Gee, \\ Glendon W; Sweeney, Mark D; Edwards, Daniel L \\ Subject: $\quad$ Items \# 80771 and \# 80774 - Discharge to Ground Approval at the 105A Mock Tank site \\ Brent, Mike, and Sam - \\ Per Kathy Conaway's (Washington State Department of Ecology) e-mail message below, I am issuing you a \\ Discharge to Ground approval for Items 80771 and $\mathbf{8 0 7 7 4}$ at the 105A Mock Tank Site located in the 200 East Area \\ of the Hanford Site. This approval is for FY2002 and 2003 discharges associated with the Tank Leak Detection \\ Demonstration Project (as described in the listed CDRRs, FY02-03 Project Test Plan, and attached e-mails). \\ Please familiarize yourself with the discharge conditions described in the approval below. These conditions are \\ taken directly from State Waste Discharge Permit ST-4508, Hydrotest, Maintenance and Construction and the \\ Pollution Prevention \& Best Management Practices Plan (both of which can be found electronically at \\ http://w3.pnl.gov/safety/ems/effluent_management/hydro.htm).
}

You were briefed on these requirements last year, but as a reminder your main action is to (1) assign a "responsible party" for answering questions about the project should the need arise and to let everyone working at the site know who this person is (2) minimize ponding and erosion during discharge and (3) minimize discharges in the proximity of the nearby underground radioactive crib. I also suggest keeping a copy of this approval and the Best Management Practices Plan with your project papers. Use of any other materials or chemicals, or a change in quantity of approved materials, must be approved prior to use.

Also, per our registration of Underground Injection Control Wells last year, you are authorized to install one (1) new injection well for this year's activities. Any additional installations will require registration with Ecology (as we have filled our limit).

Thanks and please contact either myself or Brad Atencio (376-8662) if you have any questions or need further information as your project progresses.

Liz Raney

\section{DISCHARGE TO GROUND REQUEST}

The Request to Discharge the Below Items:

From: $\quad$ FY $2002-2003$ Tank Leak Detection Demonstration Project

To: $\quad$ The Ground at the 105A Mock Tank Site (located in the 200 East Area)

Item(s): Item 80771 - 15,000 GALLONS OF 36\% SODIUM THIOSULFATE IN WATER Item 80774 - 8,000 GALLONS OF CLEAN WATER APPLIED VIA IRRIGATION SPRINKLERS 
Status: $\quad \underline{\text { APPROVED }}$

Expires: January 31, 2003

\section{Discharge Conditions}

1. Each discharge must be less than 10 gallons per minute averaged annually. Annual average flow is calculated for each discharge as total gallons discharged in a calendar year, divided by the number of minutes in that year.

2. Each discharge must be less than 150 gallons per minute instantaneously.

3. Single discharges with a volume greater than 14,500 gallons in a 24-hour period, or with a total volume greater than 50,000 gallons in a calendar year must be reported to Effluent Management group prior to discharge.

4. The only allowed source waters to be used for hydrotest, maintenance, and construction activities are Columbia River water, potable water (treated Columbia River water or groundwater), or demineralized water (treated potable water).

\section{General Requirements and Best Management Practices}

1. Each discharge must meet WAC-173-200 Ground Water Quality Criteria (GWQC) unless the discharge is expected to have a contaminant that exceeds the GWQC solely because the source water has a contaminant that exceeds one or more of the GWQC. Discharges that exceed the GWQC at the effluent, but are prevented from impacting groundwater water quality, would be covered by this permit.

2. All discharges will follow the appropriate Pollution Prevention and Best Management Practices (BMPs) listed below and those listed in the Pollution Prevention and Best Management Practices Plan for State Waste Discharge Permits ST-4508, ST-4509, and ST-4510 (DOE/RL-97-67, Rev. 3, date 01/00).

- No discharge will be allowed within a surface contaminated area (areas with dangerous waste and/or radioactive contaminants).

- No discharge will be allowed within 300 feet horizontal radius of a known active or inactive crib, ditch, or trench used for disposal of dangerous and/or radioactive contaminants.

- No discharge will be allowed to affect an ecologically sensitive area.

- Reasonable efforts will be taken to prevent ponding due to discharge rates above the expected soil infiltration capacity.

- There will be no discharge of runoff of wastewater to any surface waters of the state or to any land not owned by or under control of the Permittee, except as authorized by a wastewater discharge permit.

- Efforts will be made to recycle, store, and reuse all water to the maximum extent practical.

3. Every discharge will have an assigned responsible person on site who is familiar with the section of the Pollution Prevention and Best Management Practices Plan (DOE/RL-97-67, Rev. 3) that applies to the discharge. This responsible person should confirm compliance with the Plan and be prepared to answer any Ecology questions in the event of an inspection. The discharge of any wastewater not done as specified in the Pollution Prevention and Best Management Practices Plan (DOE/RL-97-67, Rev. 3) will constitute a violation of the terms and conditions of the permits.

4. Collected screenings, grit, solids, sludges, filter backwash, or other pollutants removed in the course of treatment or control of wastewaters will not be resuspended or reintroduced to the effluent stream for discharge.

-----Original Message------

From: Conaway, Kathleen (ECY) 
Sent: Thursday, May 23, 2002 7:28 PM

To: Atencio, Brad P; Raney, Elizabeth A

Cc: Jarvis, Mary F; Jamison, Fred (ECY)

Subject: RE: DISCHARGE TO GROUND PERMIT EVALUATION, PERMIT \# ST-4508 (FISC AL YEAR

Importance: High 
B5 Variance To Well Construction Requirements

May 31, 2002

Brent,

I have read, understood, and approve of your request for a variance to WAC 173-160 (letter to me dated May 30,2002$)$ to construct the identified wells using moistened drill cuttings in the annulus to maintain casing to formation contact. Furthermore, I agree that steel posts (as usually constructed) and a cement pad would interfere with signal propagation and lower the signal to noise ratio. Therefore, elimination of steel posts during construction is acceptable.

Please proceed with construction as specified. Should there be any changes to this proposal or any questions arising from this construction, please contact me.

Joseph Caggiano

Washington State Department of Ecology

Nuclear Waste Program

1315 W. Fourth Ave.

Kennewick, WA 99336 


\section{Attachment C}

Site Access and Conduct Requirements Industrial Health and Safety Plan-Site Safety Requirements 


\section{Attachment C \\ Site Access and Conduct Requirements Industrial Health and Safety Plan-Site Safety Requirements}

\section{C1 Application and Scope}

This document controls Pacific Northwest National Laboratory (PNNL) Science and Technology Project safety and conduct activities related to the Mock Tank 105A (Mock Tank) site in the 200 East Area. It serves as the site safety briefing and provides general requirements for staff, contractors, and visitors involved in performing testing and monitoring activities on the Mock Tank site.

The Mock Tank 105-A is located in the 200 East Area across 7th Street from the former Hot Semiworks. The legal coordinates for the Mock Tank site are SE 1/4, NW 1/4, Section 2, T12N, R26E.

A detailed description of the site and the past history of the site are found in the Waste Information Data System (WIDS) database accessible on the Hanford Web. Records show that the Mock Tank (Mock Tank 105-A Site) is a radiologically clean site.

Visitors accessing the site must follow safety precautions that pertain to PNNL staff working onsite. Signing of this document indicates that the individual has read the document and is willing to abide by the safety and access protocols specified herein.

Subsequent versions of this document may be prepared if access or conduct requirements change. Notification of subsequent versions will be made to project staff and authorized workers. Each new version of the document will require the review and signature of each worker before that person's continued work at the site.

\section{C2 Responsible Staff}

The person responsible for this document is the PNNL project manager, Glendon W. Gee, and can be reached at (509) 372-6096. The alternate responsible persons are Mark D. Sweeney (373-0703) or Mike D. Johnson (376-3416).

\section{C3 Testing and Monitoring Goals}

The goals of the tests at the Mock Tank site during FY 2002-2003 are to determine performance capabilities of electrical-based geophysical methods under controlled solution-release scenarios. The tests will be conducted in collaboration with a number of specially qualified scientists and engineers from 
other national laboratories and research firms. This testing follows FY 2001 Leak Detection, Monitoring, and Mitigation (LDMM) for the U.S. Department of Energy also conducted at this site during July and August 2001.

It is the responsibility of each person working at the site to ensure that his or her activities do not jeopardize the integrity of the other monitoring activities that are ongoing at the site.

\section{C4 Safety Requirements}

Any accidents or immediate, uncontrollable safety concerns observed by workers at the site should be reported to site emergency services by calling 911. Note that 911 calls from cellular phones may be redirected. For additional assistance, call 373-3800 (Hanford Patrol) or radio the Safety Net at Frequency KOB743 (monitored by Hanford Patrol and by the PNNL Control Room [Station 62]). Minor first aid care is available at the 200-West Area (2719WB Building) Monday through Friday on day shift only. All other times will require emergency response (911 or 373-3800) or publization to Kadlec Medical Center in Richland.

Site access and safety requirements refer only to the area within and immediately adjacent to the Mock Tank site. No radiological hazards are present at the site, but staff should be aware that radiological hazards do exist in areas surrounding the site.

In the event of a site-wide emergency, the PNNL control room will call the Mock Tank site to advise any onsite personnel of impending situations or evacuation procedures. The Mock Tank mobile laboratory telephone ([509] 373-1656) will be equipped with an outside ringer to alert personnel in the vicinity of the facility who are not inside the laboratory.

\section{C4.1 Emergency Telephone Numbers}

PNNL Emergency

Hanford Emergency Response

Hanford Patrol/Fire/Ambulance
$375-2400$

911 or $373-3800$

911 or $373-3800$

\section{C4.2 Warning Sirens}

The following action should be taken relative to warning sirens:

- For all gongs and horns, go to the staging area, Baltimore Ave, 2750 parking lot.

- Wavering Siren (get in vehicle, call emergency phone \#, and follow directions).

- Howler (AH-OO-GAH). Get in vehicle, drive off the Mock Tank site, and leave area-preferably away from the criticality area. 
Planned siren tests are frequent. Call DynCorp Emergency Prep. (373-4308) if questions arise regarding specific siren tests.

\section{C4.3 Accidents}

The following actions should be performed if any accidents or immediate, uncontrollable safety concerns are observed by anyone at the site:

Immediately stop work. Evaluate the scene for safety. If safe, lend medical aid or prevent further damage. If unsafe conditions exist, deactivate and turn off applicable electrical and mechanical systems before lending assistance. Immediately notify site emergency services (above). If a telephone is available, call the emergency assistance number (373-3800) and be prepared to describe the accident and your location (the site location is described above). If no phone is available, use a radio to contact Hanford Patrol. In the absence of communication devices, send someone for help to the First-Aid Station in 2719WB (200-West Area). Notify your line manager and the project manager (Glendon W. Gee - 3726096) or assistant project managers (Mark Sweeney - 373-0703, cell: 521-4241; or Brent Barnett - 3763416, cell: 521-4895).

\section{C4.3.1 General Work}

When drill rigs are on the site and workers and collaborators are on the site, workers will use hard hats and safety glasses and will wear closed-top shoes. Steel toes in the shoes are not required for general work. For specific activities that pose additional potential hazards, such as digging or working with electrical or water-supply systems, additional requirements may include protective clothing (long-sleeve coveralls or equivalent work clothes), gloves, steel-toed shoes, or other safety needs. The project manager in cooperation with specific task leaders will analyze hazards and will identify the additional appropriate combination of safety precautions (clothes, procedures, training, supervision, etc.) necessary for each type of work. Workers will follow these requirements and only perform work for which they agree with procedural and safety requirements. Work will not be performed when ambient weather conditions pose a threat to safety and health. Workers will use caution in extended work in the full sun. To avoid heat stroke, workers are encouraged drink ample quantities of fluids.

A fire extinguisher will be located onsite.

\section{C4.3.2 Additional Safety Requirements}

The general requirements of this procedure are based on PNL-MA-43 and applicable Standards Based Management System (SBMS) Subject Areas. Specific requirements for other activities typically conducted at the site include:

Workers will adhere strictly to all postings, caution, warning, and danger signs. Failure to do so will result in immediate work stoppage. Workers will pay attention to personal safety. 
The need of a particular job to be controlled by a procedure will be determined using PNL-MA-43 and applicable SBMS subject areas (e.g., working with chemicals, electrical safety, machine guarding). In this study, operation of neutron probes is the only task requiring a procedure and is governed by PNL-PSB-10-0. Workers performing these jobs must demonstrate knowledge of hazards associated with the work before commencing work.

\section{C5 Site Access Requirements}

There are no formal site-access requirements. Access is gained via gravel roads from Seventh, and vehicular traffic is encouraged to travel only on the gravel roadways. Parking of vehicles adjacent to the roads is permitted, but vehicle parking is restricted to the north side of the Mock Tank injection site. Vehicles can be turned around by driving on the gravel perimeter road that goes around Crib 216-A-38-1.

In general, workers and collaborators should be cognizant of monitoring activities and work together under the defined schedule for the selective monitoring activities that are ongoing throughout the duration of the project.

Because there is a possibility that radioactive contamination may migrate onto the site via surface transport, it is recommended that staff walking on the vegetation because of requirements to conduct civil and biological surveys should be aware of the potential for surface contamination via biotic pathways of biologic activity. For this reason, no animal droppings (feces) are to be removed from the surface without first contacting radiation safety and the project manager.

Minimum precautionary information for site entry will be reviewed by all personnel prior to accessing the Mock Tank site. These minimum requirements are:

- Review of Site Safety Checklist (see p. C.13)

- Signing of Site Visitor Register

- Review of Site Layout Map showing key safety features and safety equipment locations (Figure C.1)

- Contacting project personnel prior to entry

- Receive guided site orientation and briefing.

These procedures are the minimum requirements for entry to the Mock Tank site inside road barricades.

\section{C6 Potential Site-Impact Requirements}

Activities that pose the potential to significantly affect monitoring conditions must be authorized and documented by the project manager. Examples of activities that pose such potential include 1) excavating sediments in unauthorized locations, 2) driving vehicles onto the Mock Tank site when monitoring is ongoing unless a drill rig or similar vehicle is scheduled and has been authorized for access on to the site, and 3) destroying, obscuring, or relocating radiation markers. This list is not intended to be complete, but is included to provide examples of the type of activities that may pose a potentially significant impact. 
It is the responsibility of the project manager to determine if a monitoring or site-visit activity poses the risk to cause a significant impact based on the examples provided above and to obtain appropriate approval from the project manager. Before work, resolve with the project manager any uncertainty about the potential to cause a significant impact. Guidelines should be followed as outlined in PNL-MA-26 (Radiological Control Procedures) and PNL-MA-50 (Facilities Management Department PNL Operations Manual).

An activity is authorized if approval is obtained from the project manager. It is the responsibility of the project manager to determine the level of documentation needed for each unusual activity (no action, memo-to-file, or other documentation). Activities that pose the potential to affect the monitoring project must be documented in the project manager's site file. Workers who observe unexpected operations or conditions at the site must report the incident to the project manager (see Section 2.0)

\section{C7 Training Requirements}

Signing this document provides the authority to access the site and perform monitoring work at the Mock Tank site.

Radiation Worker I training is required for operators of neutron probes. Training records for these activities will be on file with the individual worker and will be available upon request.

\section{C8 Site Safety Documentation}

The following Job Hazard Analyses identify general site hazards associated with the deployment and operation of the geophysical methods planned for the FY 2002-2003 Performance Evaluation Testing. The forms have been prepared and approved by the operator for each specific activity (ERT and HRRSCRT), and are based on expected conditions and experience with the 1995 project. The associated Site Safety Checklist is designed to ensure implementation of prevention and mitigation measures for the identified hazards.

The Chemical Process Permit addresses the solution release planned for the injection phase of the project. This permit requires that an eyewash station be installed at the work site during the handling and use of the $36 \%$ sodium thiosulfate solution. 


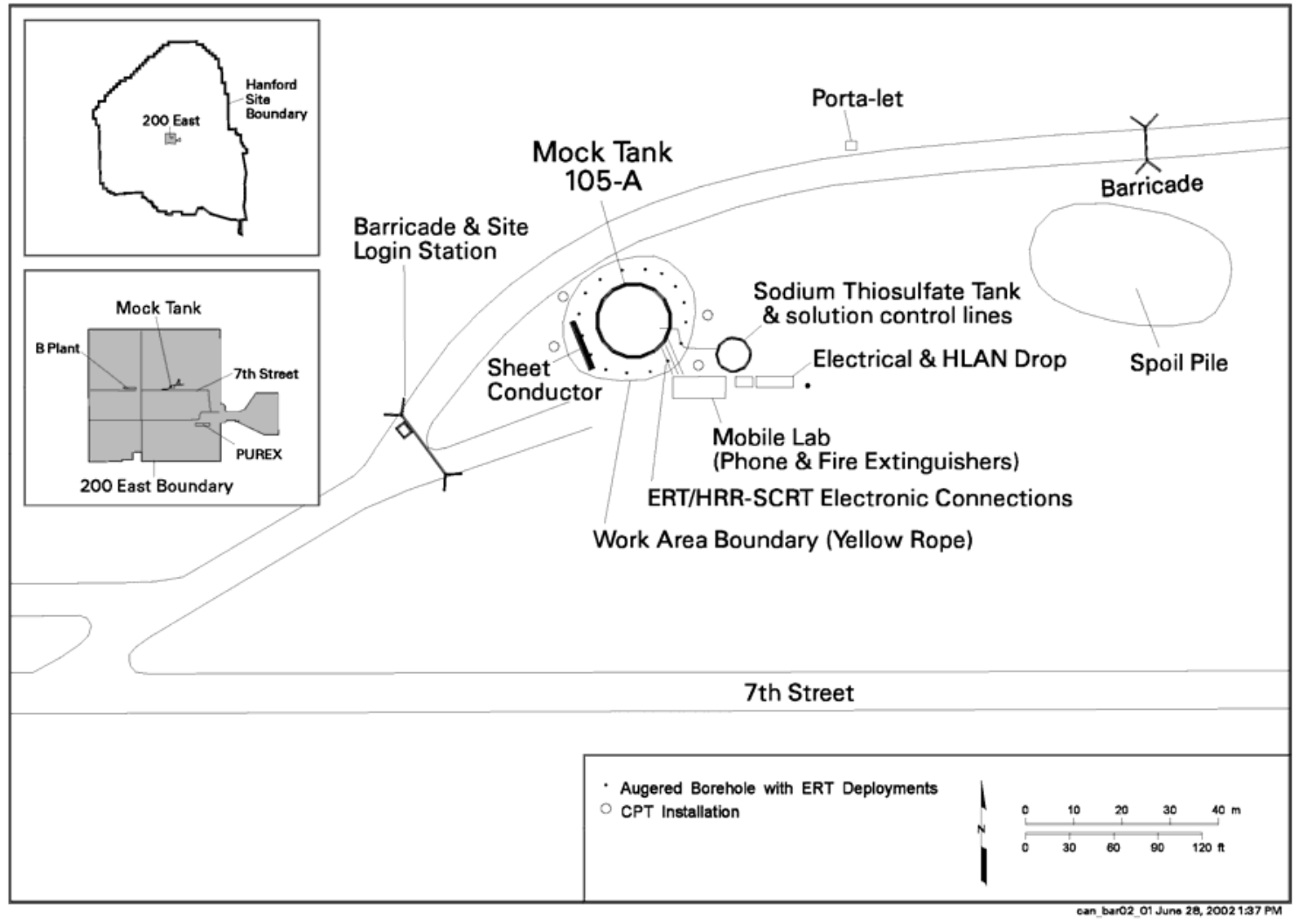

Figure C.1. Location of Key Safety and Infrastructural Features at the Mock Tank Site for 2002-2003 


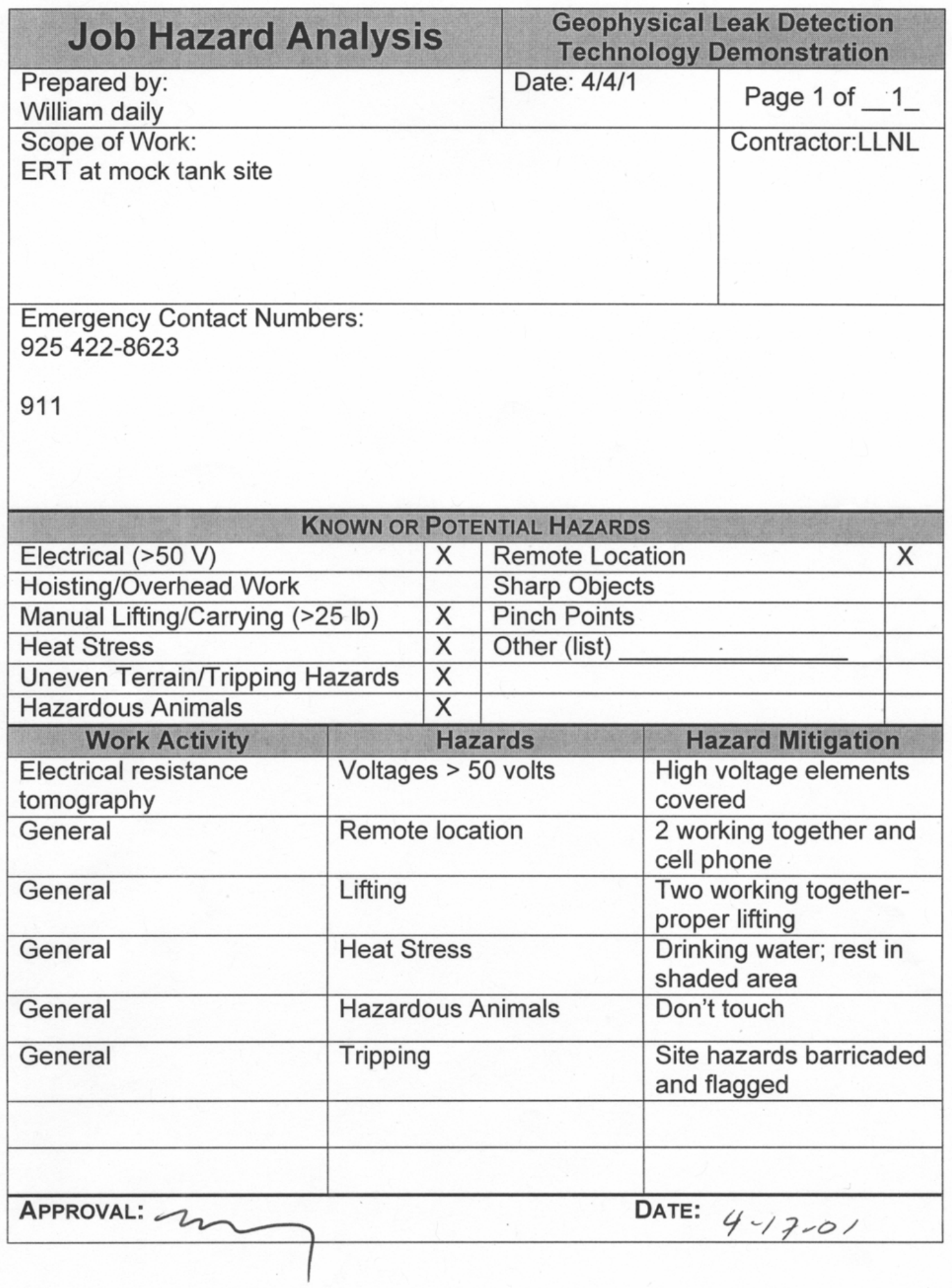

A. 79 


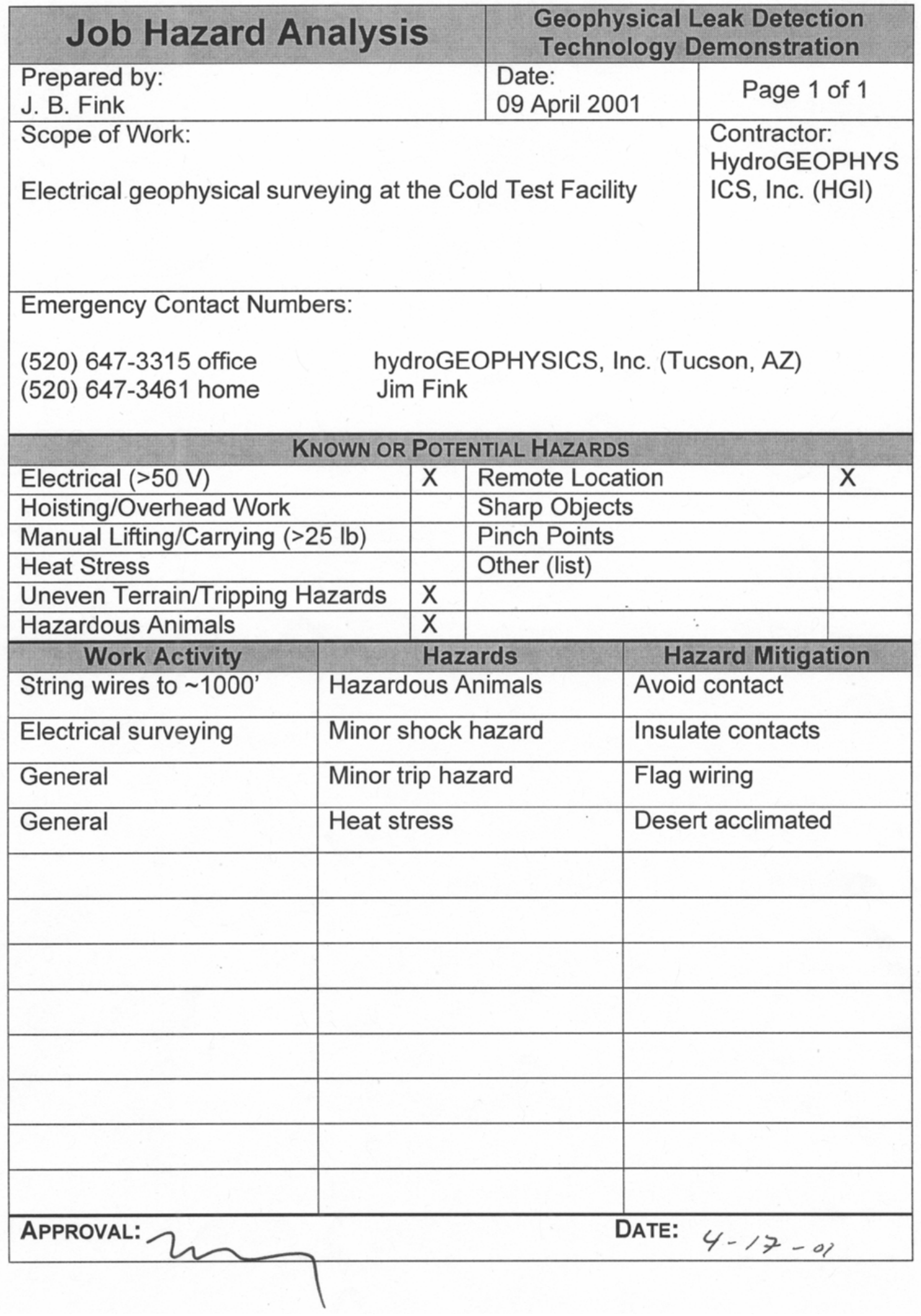

A. 80 


\begin{tabular}{|l|l|l|}
\hline Chemical Process Permit & $\begin{array}{l}\text { Permlt No.: CPP-D9T81-Mock Tank } \\
\text { Rev. No.: } 1\end{array}$ \\
\hline Title: Subsurface injection & $\begin{array}{l}\text { Author: Mark } \\
\text { Sweeney }\end{array}$ & Page l of 4 \\
\hline
\end{tabular}

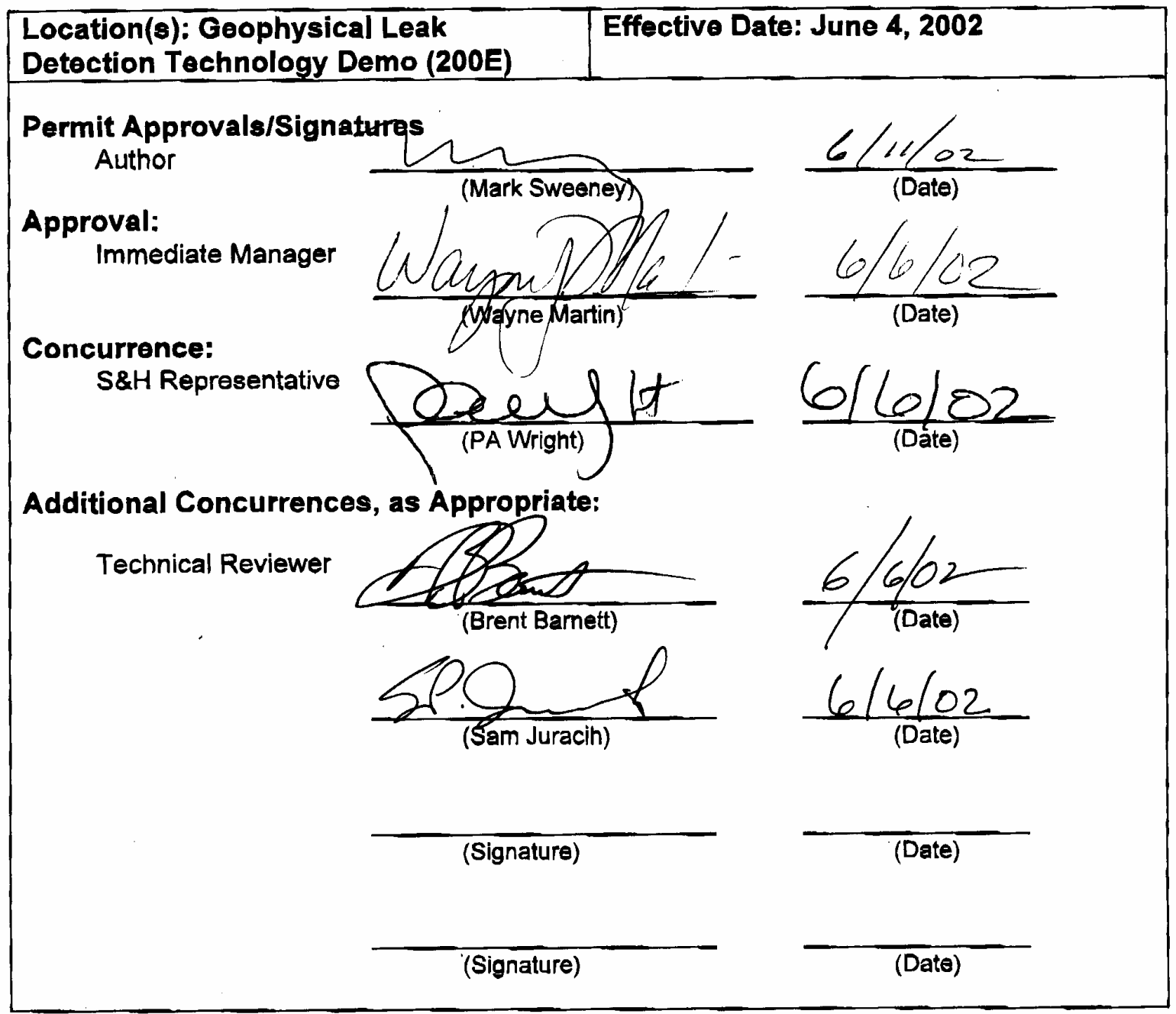

Identify Use Category: [ ] Mandatory Use [X] Reference Use 


\begin{tabular}{|l|l|l|}
\hline Chemical Process Permit & $\begin{array}{l}\text { Permit No.: CPP-D9T81-Mock Tank } \\
\text { Rev. No.: } 1\end{array}$ \\
\hline Title: Subsurface injection & $\begin{array}{l}\text { Author: Mark } \\
\text { Sweeney }\end{array}$ & Page 2 of 4 \\
\hline
\end{tabular}

\section{CHEMICAL IDENTIFICATION}

The chemical hazards of each of the individual chemicals must be assessed. Chemicals with similar hazards may be grouped below. Chemicals on the OSHA-regulated chemicals, compounds, and carcinogens list (see AExhibit: OSHA-Regulated Chemicals, Compounds, and Carcinogens $\cong$ in Working with Chemicals SBMS subject area) must be identified individually.

\begin{tabular}{|c|c|c|c|}
\hline $\begin{array}{l}\text { Chemical/ } \\
\text { Chemical Group } \\
\text { - Sodium Thiosulfate } \\
\text { - Sodium Chloride }\end{array}$ & $\begin{array}{l}\begin{array}{l}\text { Chemical } \\
\text { Hazard }\end{array} \\
\text { - Irritant } \\
\text { - None }\end{array}$ & $\begin{array}{l}\text { Volume/ } \\
\text { Quantity per Use } \\
\text { - } 12,000 \mathrm{Gal}\end{array}$ & $\begin{array}{l}\begin{array}{l}\text { Frequency } \\
\text { of Use }\end{array} \\
\text { - Weekly }\end{array}$ \\
\hline
\end{tabular}

Description of Chemical Process: 15000 gal of saturated sodium thiosulfate will be injected into test wells weekly using an elevated tank and a pump/flowmeter to transport the liquid from the tank into the well. The solution will be metered in at a rate to allow absorption of the solution by the soil.

\section{Chemical Process Hazards Analysis}

\begin{tabular}{|l|l|l|l|l|}
\hline $\begin{array}{l}\square \text { Flammable/ } \\
\text { Combustible }\end{array}$ & $\square$ Pyrophoric & $\square$ Toxic & $\square$ Oxidizer & $\square$ Asphyxiant \\
\hline$\square$ Corrosive & $\begin{array}{l}\square \text { OSHA } \\
\text { Regulated }\end{array}$ & $\begin{array}{l}\square \text { Compressed } \\
\text { Gas }\end{array}$ & $\square$ Cryogen & Other \\
\hline
\end{tabular}

Description of Hazards: Sodium thiosulfate is an irritant.

\begin{tabular}{|l|l|l|l|}
\hline$囚$ Toxic by Inhalation & $\square$ Toxic by Absorption & $\bigotimes$ Toxic by Ingestion & Toxic by Injection \\
\hline
\end{tabular}

Description of Risk Analysis: Sodium thiosulfate can be toxic at high enough concentrations if exposed for long periods of time or if exposure is to sensitive (e.g. mucous) tissues.

\begin{tabular}{|l|l|l|l|l|l|}
\hline \multicolumn{5}{|c|}{ ENGINEERED CONTROLS } \\
\hline $\begin{array}{l}\square \text { General } \\
\text { Ventilation }\end{array}$ & $\begin{array}{l}\square \text { Local } \\
\text { Ventilation }\end{array}$ & $\begin{array}{l}\square \text { Snorkel } \\
\text { Ventilation }\end{array}$ & $\square$ Enclosure & $\square$ Separation & $\square$ Storage \\
\hline
\end{tabular}

Description of Engineered Controls: None 


\begin{tabular}{|l|l|l|}
\hline Chemical Process Permit & $\begin{array}{l}\text { Permit No.: CPP-D9T81-Mock Tank } \\
\text { Rev. No.: } 1\end{array}$ \\
\hline Title: Subsurface injection & $\begin{array}{l}\text { Author: Mark } \\
\text { Sweeney }\end{array}$ & Page 3 of 4 \\
\hline
\end{tabular}

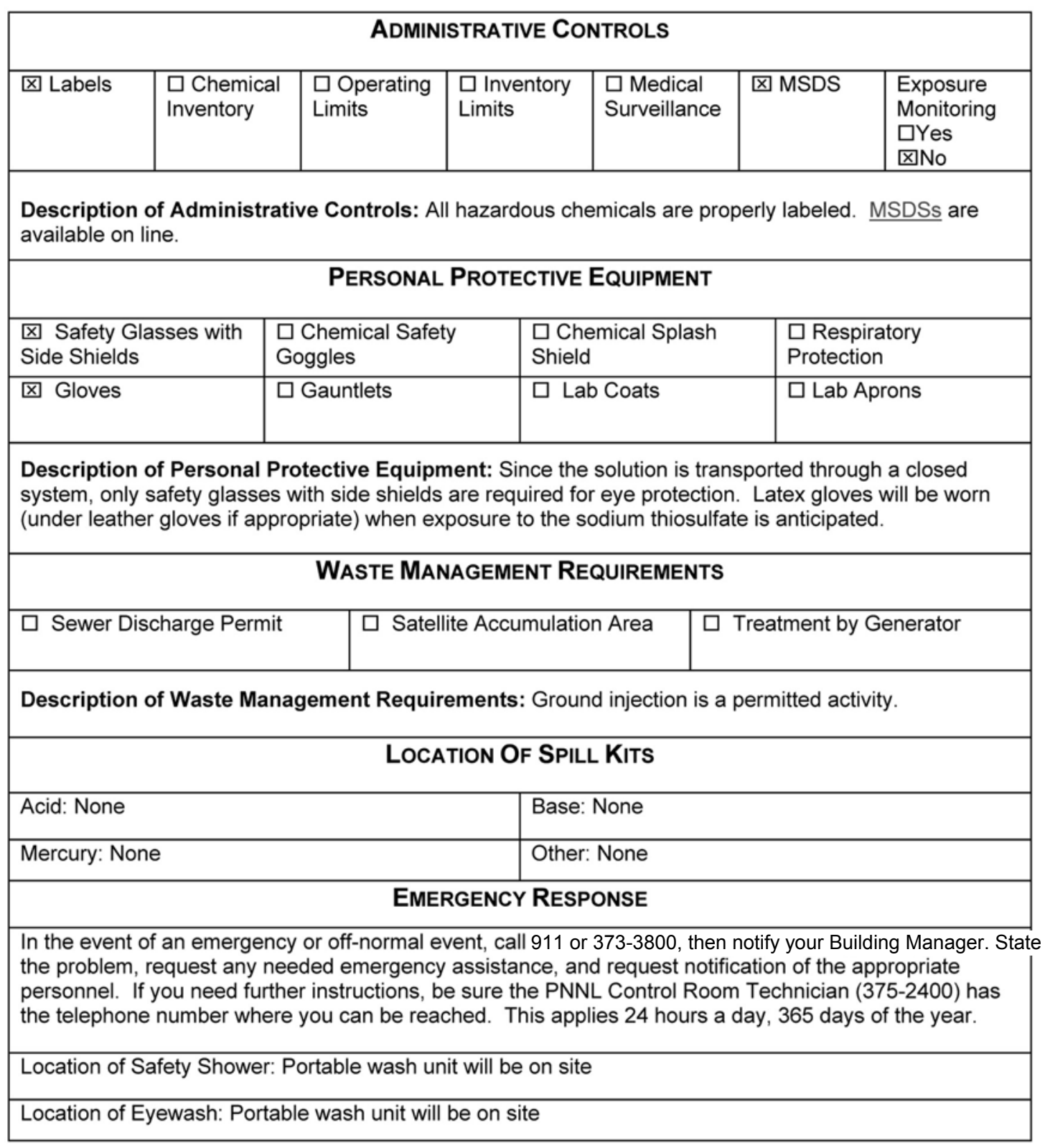




\begin{tabular}{|l|l|l|}
\hline Chemical Process Permit & $\begin{array}{l}\text { Permit No.: CPP-D9T81-Mock Tank } \\
\text { Rev. No.: } 1\end{array}$ \\
\hline Title: Subsurface injection & $\begin{array}{l}\text { Author: Mark } \\
\text { Sweeney }\end{array}$ & Page 4 of 4 \\
\hline
\end{tabular}

\begin{tabular}{|c|c|c|c|}
\hline \multicolumn{2}{|c|}{$\begin{array}{l}\text { Cognizant Space Glendon Gee } \\
\text { Manager (Name): (alt) Mark Sweeney }\end{array}$} & \multicolumn{2}{|l|}{$\begin{array}{r}\text { Telephone: } 372-6096 \\
373-0703\end{array}$} \\
\hline \multicolumn{4}{|c|}{ Formal Training: [check required training] } \\
\hline $\begin{array}{l}\text { 区 Hazard } \\
\text { Communications (671) }\end{array}$ & $\begin{array}{l}\square \text { Confined Space } \\
(694)\end{array}$ & \begin{tabular}{|l|}
$\square$ Waste Management \\
$(833)$
\end{tabular} & $\square$ Lock and Tag (692) \\
\hline $\begin{array}{l}\text { Laboratory Hoods } \\
(685 / 686)\end{array}$ & $\begin{array}{l}\text { E Eyewash Safety } \\
\text { Shower (695/696) }\end{array}$ & $\square$ GERT (817) & $\square$ Other \\
\hline \multicolumn{4}{|c|}{$\begin{array}{l}\text { Job-Specific Training: Staff must understand the hazards presented by their specific work tasks, how } \\
\text { to protect themselves from those hazards, and know the location of emergency showers and eye } \\
\text { washes. Job-specific training will be fulfilled when the user has read this document and signed his/her } \\
\text { name above. }\end{array}$} \\
\hline
\end{tabular}




\section{Site Safety Checklist}

\section{Field Work Checklist}

- Site orientation (contact Mark D. Sweeney)

- Emergency communications available (e.g., cellular telephone)

- "Buddy System" (avoid working alone)

- Appropriate attire:

- Shirt (consider sun protection)

- Durable slacks

- Substantial footwear

- Hat (recommended)

- Sunglasses (optional)

- Leather gloves

- Protect from sunburn (clothing, sunscreen, shade)

- Drinking water - Stay hydrated!

- Water for hand washing

- Emergency eye wash during chemical injection, or when other chemicals are being handled

- Combustible vegetation "grubbed" or cleared well away from equipment

- Fire Extinguisher present, maintained, and inspected

- Watch for spiders and snakes - avoid them if they are present

\section{Electrical Safety:}

- Equipment grounded (including generator bonding to "earth" ground)

- Electrical wiring in good condition

- Ground Fault Circuit Interrupter (GFCI)

- Generator operated only when site is attended

\section{Emergency Procedure}

Site location: 223E/105-A Mock Tank Facility, 7th Street, immediately north of Hot Semiworks in 200 East Area; legal location: SE 1/4, NW 1/4, Section 2, T12N, R26E. Phone number in mobile lab: (509) 373-1656

Medical Emergency: Contact 9-1-1 and/or 373-3800

Transport minor injuries to $200 \mathrm{~W}$ medical aid station $(2719 \mathrm{WB}$ - open only M-F day shift; all other times must call 911 or go to Kadlec Medical Center, Richland)

Fire: Contact 9-1-1 and/or 373-3800

Fight fire if you are able

Evacuate site

200 Area Emergency Alarms: Constant siren - evacuate

Wavering siren - leave site and seek cover in nearest building

Site Contact Mock Tank: Glendon Gee - 372-6096; Mark Sweeney - 373-0703 (cell 521-4241); Mike Johnson 376-5771 (cell 430-5252); Brent Barnett - 376-3416 (cell 521-4895) 


\section{C9 References}

PNL-MA-26 Radiological Control Procedures

PNL-MA-43 Industrial Hygiene, Occupational Safety and Fire Protect. Programs

PNL-MA-50 Facilities Management Department PNL Operations Manual

SBMS Standards Based Management Systems-Subject Areas. 


\section{ACTIVITY-BASED SELF ASSESSMENT EVALUATION FORM}

\begin{tabular}{|l|l|}
\hline \multicolumn{1}{|c|}{ Date of Assessment 5/17/2002 } & Assessor Name: Michael Fullmer \\
\hline $\begin{array}{c}\text { Location of Assessment: 200 East Area } \\
\text { Building: Outdoor Test Area } \\
\text { Room(s) N/A }\end{array}$ & Organization Code: D9T84 \\
\hline $\begin{array}{l}\text { Name of Manager/Senior Staff Member Participating: Michael Stephenson } \\
\text { Staff Member(s) Performing Work: Michael Johnson }\end{array}$ \\
\hline Project \#/Activity Name: 105-A Mock Tank Site \\
\hline
\end{tabular}

\section{Description of Work Assessed:}

The mock tank area is located outdoors and consists of area of $\sim 1 / 2$ acre. There is a large carbon steel tank that is partially below ground level. There is support equipment that includes electrical and instrument wiring, poly tanks for water, portable water piping, and other miscellaneous support equipment. The site is used to run tests in support of tank operations located in the 200 Areas.

\section{Hazards/Scope/Observation:}

- Staff members are exposed to the outside elements that could include inclement weather, insects, and vermin.

- There are potential tripping hazards from instrument wiring and piping systems placed on the ground.

- The area has uneven walking surfaces i.e. gravel and sand.

- Potential fall hazards when accessing the poly tanks and the access into the steel tank.

- The site has been inactive for a period of time and the housekeeping has deteriorated.

- There are not any legible signs/placards at the site to indicate controls or marking of containers.

- There is not any emergency first aid equipment at the site i.e. first aid kit and fire extinguisher.

Conclusion/Corrective Actions: (Note: Any corrective actions noted need to be submitted on the ETD Corrective Action Form so they can be added to the Division Self Assessment Database. The Corrective Action form should be submitted with the Self Assessment Report. Corrective Action Topic Areas include: Hazards, PPE, Procedures, Permits, Practices, Lab Space, Chemicals, Lab Equipment, Air Emissions, Liquid Effluents, Waste, Radiological.)

The responsible staff member for the site has taken action to improve housekeeping and reroute wiring and pipes to reduce tripping hazards. Signs and placards will be placed where necessary for proper information. All potential fall hazards have proper guarding. A portable fire extinguisher and first aid kit will be provided before work commences. Staff members will be advised of potential for vermin and insect bites. Vehicles will be at the site if staff members have to take cover during inclement weather. 


\section{PRELIMINARY HAZARD ASSESSMENT FORM (CHG)}

\begin{tabular}{|l|l|l|}
\hline PHA ID: & Date: & $\begin{array}{l}\text { Performed By: } \\
\text { Signature: (original on file) }\end{array}$ \\
\hline Brief Description: & \\
\hline
\end{tabular}

\begin{tabular}{|c|c|c|}
\hline 区 & Hazard Communication Program & $\begin{array}{l}\text { 1. } 29 \text { CFR 1910, Subpart Z, "Toxic and Hazardous Substances." } \\
\text { a. Section 1200, "Hazard Communication." } \\
\text { b. Section 1450, "Occupational exposure to hazardous chemicals in laboratories," } \\
\text { paragraph (f), "Employee information and training", paragraphs (1), (2), and (4)(I). } \\
\text { (S/RID) } \\
\text { 2. DOE 5480.10, "Contractor Industrial Hygiene Program," paragraphs 9.a(3), 9.b, } \\
\text { 9.b(1), 9.b(2), 9.b(4), 9.b(5), and 9.f(1). (S/RID) } \\
\text { 3. DOE 5483.1A, "Occupational Safety and Health Program for DOE Contractor } \\
\text { Employees at Government-Owned Contractor-Operated Facilities," } \\
\text { a. Chapter I, "Standards, Instructions, and Inspections," paragraphs 5.d, 5.e, and } \\
\text { 6.g. (S/RID) } \\
\text { b. Chapter III, "Nondiscrimination, Injury and Illness Information, and Accident } \\
\text { Investigations," paragraph 3. (S/RID) }\end{array}$ \\
\hline$\square$ & Respiratory Protection & $\begin{array}{l}\text { 1. } 29 \text { CFR 1910.134, "Respiratory Protection." } \\
\text { 2. DOE 5480.4, "Environmental Protection, Safety, and Health Protection } \\
\text { Standards." (S/RID) } \\
\text { 3. ANSI Z88.2, "American National Standard for Respiratory Protection." } \\
\text { 4. ANSI/CGA, "Commodity Specification for Air G-7.1." }\end{array}$ \\
\hline 冈 & $\begin{array}{l}\text { Comprehensive Ergonomics } \\
\text { Program Plan }\end{array}$ & $\begin{array}{l}\text { 1. } 29 \text { CFR 1910.5 (a), "General Duty Clause." } \\
\text { 2. DOE 5480.10, "Contractor Industrial Hygiene Program," Section 9.b., } \\
\text { "Requirements." }\end{array}$ \\
\hline 区 & $\begin{array}{l}\text { Industrial Hygiene Personal } \\
\text { Monitoring Program Plan }\end{array}$ & $\begin{array}{l}\text { 1. } 29 \text { CFR 1910, "General Industry Standards." (S/RID) } \\
\text { 2. } 29 \text { CFR 1926, "Construction Standards." (S/RID) } \\
\text { 3. DOE 5480.8, "Occupational Health Program." (S/RID) } \\
\text { 4. DOE 5480.10, "Contractor Industrial Hygiene Program," Section 9. (S/RID) }\end{array}$ \\
\hline$\bigotimes$ & Safety Inspections & $\begin{array}{l}\text { 1. } 29 \text { CFR 1926.20(b)(2), "Accident Prevention Responsibilities." } \\
\text { 2. DOE Order 5483.1A, "Occupational Safety and Health Program For DOE } \\
\text { Contractor Employees at Government-Owned Contractor-Operated Facilities." } \\
\text { 3. DOE Order 5480.9A, "Construction Project Safety and Health Management." }\end{array}$ \\
\hline 冈 & $\begin{array}{l}\text { Control of Working Hours and } \\
\text { Working Alone }\end{array}$ & 1. Occupational Safety and Health Act of 1970 , OSHA Section $5(a)(1)$. \\
\hline 区 & Hearing Conservation & $\begin{array}{l}\text { 1. } 29 \text { CFR 1910, "Occupational Safety and Health Standards," Subpart 95, } \\
\text { "Occupational Noise Exposure." } \\
\text { 2. } 29 \text { CFR 1926, "Safety and Health Regulations for Construction," Subpart 52, } \\
\text { "Occupational Noise Exposure." } \\
\text { 3. ACGIH, "Threshold Limit Values for Chemical Substances and Physical Agents } \\
\text { and Biological Exposure Indices." } \\
\text { 4. DOE O 440.1A, "Worker Protection Management for DOE Federal and } \\
\text { Contractor Employees." } \\
\text { 5. DOE G 440.1-1, "Worker Protection Management for DOE Federal and } \\
\text { Contractor Employees Guide for use with DOE Order 440.1." }\end{array}$ \\
\hline$\square$ & $\begin{array}{l}\text { Concrete and Masonry } \\
\text { Construction }\end{array}$ & $\begin{array}{l}\text { 1. } 29 \text { CFR 1926, "Safety and Health Regulations for Construction," Subpart Q, } \\
\text { "Concrete and Masonry Construction." (S/RID) }\end{array}$ \\
\hline$\square$ & Beryllium Program & 1. 10 CFR Part 850, "Chronic Beryllium Disease Prevention Program (CBDPP)." \\
\hline$\square$ & Erecting Steel Structures & $\begin{array}{l}29 \text { CFR 1926, "Safety and Health Regulations for Construction," Subpart R, "Steel } \\
\text { Erection." (S/RID) }\end{array}$ \\
\hline
\end{tabular}




\begin{tabular}{|c|c|c|}
\hline 区 & Hoisting and Rigging & $\begin{array}{l}\text { 1. } 29 \text { CFR 1910, "Occupational Safety and Health Standards," Subpart N, } \\
\text { "Materials Handling and Storage." } \\
\text { 2. } 29 \text { CFR 1926, "Safety and Health Regulations for Construction," Subpart H, } \\
\text { "Materials Handling, Storage, Use and Disposal," Subpart N, "Cranes, Derricks, } \\
\text { Hoists, Elevators, and Conveyors," and Subpart W “Rollover Protective Structures; } \\
\text { Overhead Protection." } \\
\text { 3. DOE-RL-92-36, Hanford Site Hoisting and Rigging Manual. }\end{array}$ \\
\hline$\bigotimes$ & Confined Space & OSHA 29 CFR 1910.146, "Permit-Required Confined Spaces." \\
\hline 凶 & $\begin{array}{l}\text { Safety Signs, Tags, Barriers, and } \\
\text { Color Coding }\end{array}$ & $\begin{array}{l}\text { 1. } 29 \text { Part 1910, "Occupational Safety and Health Administration, Department of } \\
\text { Labor." } \\
\text { a. Subpart J, "General Environmental Controls." (S/RID) } \\
\text { b. } 29 \text { CFR 1910.144, "Safety Color Code for Marking Physical Hazards." } \\
\text { c. } 29 \text { CFR 1910.145, "Specifications for Accident Prevention Signs and Tags." } \\
\text { 2. } 29 \text { Part 1926, "Safety and Health Regulations." } \\
\text { a. Subpart G, "Signs, Signals, and Barricades." (S/RID) } \\
\text { b. } 29 \text { CFR 1926.200, "Accident Prevention Signs and Tags." }\end{array}$ \\
\hline$\square$ & Carcinogen Control & $\begin{array}{l}\text { 1. } 29 \text { CFR 1910, Subpart Z - "Toxic and Hazardous Substances." (S/RID) } \\
\text { 2. DOE 5480.10, "Hazard Controls." } \\
\text { a. Section 9.b(3). (S/RID) } \\
\text { b. Section 9.c(4)(a). (S/RID) } \\
\text { c. Section 9.c(4)(b). (S/RID) } \\
\text { d. Section 9.c(4)(c). (S/RID) } \\
\text { e. Section 9.c(4)(e). (S/RID) }\end{array}$ \\
\hline 冈 & Scaffolding & $\begin{array}{l}\text { 1. } 29 \text { CFR 1910, Subpart D, "Walking-Working Surfaces." (SRID) } \\
\text { 1910.28, "Safety requirements for scaffolding." } \\
\text { 1910.29, " Manually propelled mobile ladder stands and scaffolds (towers)." } \\
\text { 2. 29 CFR 1926, Subpart L, "Scaffolds" (SRID) } \\
\text { 1926.450, "Scope, application and definitions applicable to this subpart." } \\
\text { 1926.451, "General requirements." } \\
\text { 1926.452, "Additional requirements applicable to specific types of scaffolds." } \\
\text { 1926.454, "Training requirements." }\end{array}$ \\
\hline$\square$ & Office Safety & 1. 29 CFR 1910, Subpart E. (S/RID) \\
\hline$\square$ & $\begin{array}{l}\text { Storing, Using, and Handling } \\
\text { Compressed Gasses }\end{array}$ & $\begin{array}{l}\text { 1. } 29 \text { CFR 1910, Subpart G, "Occupational Health and Environmental Control." } \\
\text { (S/RID) } \\
\text { 2. } 29 \text { CFR 1910, Subpart H, "Hazardous Materials." (S/RID) } \\
\text { 3 } 29 \text { CFR 1910, Subpart M, "Compressed Gas and Compressed Air Equipment." } \\
\text { (S/RID) } \\
\text { 4. } 29 \text { CFR 1910, Subpart Q, "Welding, Cutting and Brazing." (S/RID) } \\
\text { 5. } 29 \text { CFR 1926, Subpart J, "Welding and Cutting." (S/RID) }\end{array}$ \\
\hline$\bigotimes$ & Elevating Work Platforms & $\begin{array}{l}\text { 1. ANSI/SIA A92.2, "Vehicle Mounted Elevating and Rotating Aerial Devices" } \\
\text { 2. ANSI/SIA A92.3, "Manually Propelled Elevating Work Platforms" } \\
\text { 3. ANSI/SIA A92.5, "Boom-Supported Elevating Work Platforms" } \\
\text { 4. ANSI/SIA A92.6, "Self-Propelled Elevating Work Platforms" } \\
\text { 5. } 29 \text { CFR 1910, "Occupational Safety and Health Administration, Department of } \\
\text { Labor." } \\
\text { a. Subpart F, "Powered Platforms, Manlifts, and Vehicle-Mounted Work } \\
\text { Platforms." (S/RID) } \\
\text { b. } 1910.67 \text {, "Vehicle-Mounted Elevating and Rotating Work Platforms." } \\
\text { 6. } 29 \text { CFR 1926, "Safety and Health Regulations for Construction." } \\
\text { a. Subpart L, "Scaffolds." (S/RID) } \\
\text { b. } 1926.453, \text { "Aerial Lifts." }\end{array}$ \\
\hline
\end{tabular}




\begin{tabular}{|c|c|c|}
\hline 区 & Portable Ladders & $\begin{array}{l}\text { 1. 29 CFR 1910, Subpart D, "Walking-Working Surfaces." (S/RID) } \\
\text { 1910.21 - Definitions. } \\
\text { 1910.25 - Portable wood ladders. } \\
\text { 1910.26 - Portable metal ladders. } \\
\text { 2. } 29 \text { CFR 1926, Subpart X, "Stairways and Ladders." (S/RID) } \\
\text { 1926.1050 - Scope, application, and definitions applicable to this subpart. } \\
\text { 1926.1051 - General requirements. } \\
\text { 1926.1053 - Ladders. } \\
\text { 1926.1060 - Training requirements. } \\
\text { 3. ANSI A14.1, "Portable Wood Ladders." } \\
\text { 4. ANSI A14.2, "Portable Metal Ladders." } \\
\text { 5. ANSI A14.4, "Job-Made Ladders." } \\
\text { 6. ANSI A14.5, "Portable Reinforced Plastic Ladders." }\end{array}$ \\
\hline$\bigotimes$ & Hand and Portable Power Tools & $\begin{array}{l}\text { 1. } 29 \text { CFR 1910, Subpart P, "Hand \& Portable Powered Tools \& Other Hand-Held } \\
\text { Equipment." (S/RID) } \\
\text { 1910.242, "Hand and portable powered tools and equipment, general." } \\
\text { 1910.243, "Guarding of portable powered tools." } \\
\text { 1910.244, "Other portable tools and equipment." } \\
\text { 2. } 29 \text { CFR 1926, Subpart I, "Tools - Hand and Power." (S/RID) } \\
\text { 1926.300, "General requirements." } \\
\text { 1926.301, "Hand tools." } \\
\text { 1926.302, "Power operated hand tools." } \\
\text { 1926.303, "Abrasive wheels and tools." } \\
\text { 1926.304, "Woodworking tools." } \\
\text { 1926.305, "Jacks - lever and ratchet, screw and hydraulic." } \\
\text { 1926.306, "Air receivers." } \\
\text { 1926.307, "Mechanical power-transmission apparatus." }\end{array}$ \\
\hline 凶 & Machine Guarding & $\begin{array}{l}\text { 1. } 29 \text { CFR 1910, Subpart O, "Machinery and Machine Guarding." (S/RID) } \\
\text { • 1910.211, "Definitions." } \\
\text { • 1910.212, "General requirements for all machines." } \\
\text { • 1910.213, "Woodworking machinery requirements." } \\
\text { • 1910.215, "Abrasive wheel machinery." } \\
\text { • 1910.217, "Mechanical power presses." } \\
\text { • 1910.219, "Mechanical power-transmission apparatus." } \\
\text { 2. } 29 \text { CFR 1926, Subpart I, "Tools - Hand and Power." (S/RID) } \\
\text { - 1926.300, "General requirements." } \\
\text { • 1926.303, "Abrasive wheels and tools." } \\
\text { - 1926.304, "Woodworking tools." } \\
\text { • 1926.307, "Mechanical power-transmission apparatus." }\end{array}$ \\
\hline 凶 & $\begin{array}{l}\text { Safety Meetings and } \\
\text { Communications }\end{array}$ & $\begin{array}{l}\text { 1. } 29 \text { CFR 1903.2, "Posting of Notice." } \\
\text { 2. } 29 \text { CFR 1904.5, "Annual Summary." } \\
\text { 3. } 29 \text { CFR 1926.21(a), "Safety Training and Education." }\end{array}$ \\
\hline$\square$ & $\begin{array}{l}\text { Laser Safety and Nonionizing } \\
\text { Radiation }\end{array}$ & $\begin{array}{l}\text { 1. } 29 \text { CFR 1910, Subpart G, "Occupational Health and Environmental Control." } \\
\text { 2. } 29 \text { CFR 1910.97, "Nonionizing Radiation." (S/RID) } \\
\text { 3. DOE 5480.4, Appendix 2, Section 2.d.(3)(c)." (S/RID) }\end{array}$ \\
\hline$\square$ & Lead Program & $\begin{array}{l}\text { 1. } 29 \text { CFR 1910, Subpart Z, "Toxic and Hazardous Substances." } \\
\text { 2. } 29 \text { CFR 1910.1025, "Lead (general industry)." (S/RID) } \\
\text { 3. } 29 \text { CFR 1926 Subpart D, "Occupational Health and Environmental Controls." } \\
\text { 4. } 29 \text { CFR 1926.62, "Lead Exposure (Construction)." }\end{array}$ \\
\hline 区 & Heat Stress Control & $\begin{array}{l}\text { 1. ACGIH, "Threshold Limit Values for Chemical Substances and Physical Agents } \\
\text { and Biological Exposure Limits." } \\
\text { 2. } 29 \text { CFR 1910.120, "Hazardous Waste Operations and Emergency Response." } \\
\text { 3. } 29 \text { CFR 1926.10(a), "Scope of Subpart." } \\
\text { 4. } 29 \text { CFR 1926.65, "Hazardous Waste Operations and Emergency Response." }\end{array}$ \\
\hline$\square$ & Safety Showers and Eyewashes & $\begin{array}{l}\text { 1. } 29 \text { CFR 1910, Subpart K, "Medical and First Aid." (S/RID) } \\
\text { 2. } 29 \text { CFR 1910.151, "Medical services and first aid." }\end{array}$ \\
\hline
\end{tabular}




\begin{tabular}{|c|c|c|}
\hline 凶 & $\begin{array}{l}\text { Exposure Monitoring, Reporting, } \\
\text { and Records Management }\end{array}$ & $\begin{array}{l}\text { 1. 1926, "Substance Specific Standards." (S/RID) } \\
\text { 2. American Conference of Governmental Industrial Hygienists (ACGIH), } \\
\text { "Threshold Limit Values for Chemical Substances, Physical Agents and Biological } \\
\text { Exposure Indices." (S/RID) } \\
\text { 3. } 29 \text { CFR 1910, "Substance Specific Standards." } \\
\text { a. Subpart Z, "Toxic and Hazardous Substances." (S/RID) } \\
\text { b. } 29 \text { CFR 1910.1020, "Access to Employee Exposure and Medical Records." } \\
\text { 4. DOE 5480.10, "Contractor Industrial Hygiene Program. (S/RID) } \\
\text { a. Section 9.b(6). } \\
\text { b. Section 9.e. } \\
\text { c. Section 9.f(2). } \\
\text { d. Section 9.f(3). } \\
\text { e. Section 9.f(5). } \\
\text { 5. DOE 5480.4, "Environmental Protection, Safety, and Health Protection } \\
\text { Standards," Appendix 2, Section 2.d.(3)(a). (S/RID) } \\
\text { 6. DOE 5480.8A, "Contractor Occupational Medical Program." (S/RID) } \\
\text { a. Section 11.a(2). } \\
\text { b. Section 11.a(3). } \\
\text { c. Section 11.b(3)(a). } \\
\text { d. Section 11.b(3)(b). } \\
\text { e. Section 11.b(3)(c). } \\
\text { f. Section 11.b(3)(d). } \\
\text { g. Section 11.b(3)(f). } \\
\text { 7. DOE 1324.2A, "Records Disposition." } \\
\text { 8. DOE 5000.3B, "Occurrence Reporting and Processing of Operations Information." }\end{array}$ \\
\hline 凶 & Electrical Safety & 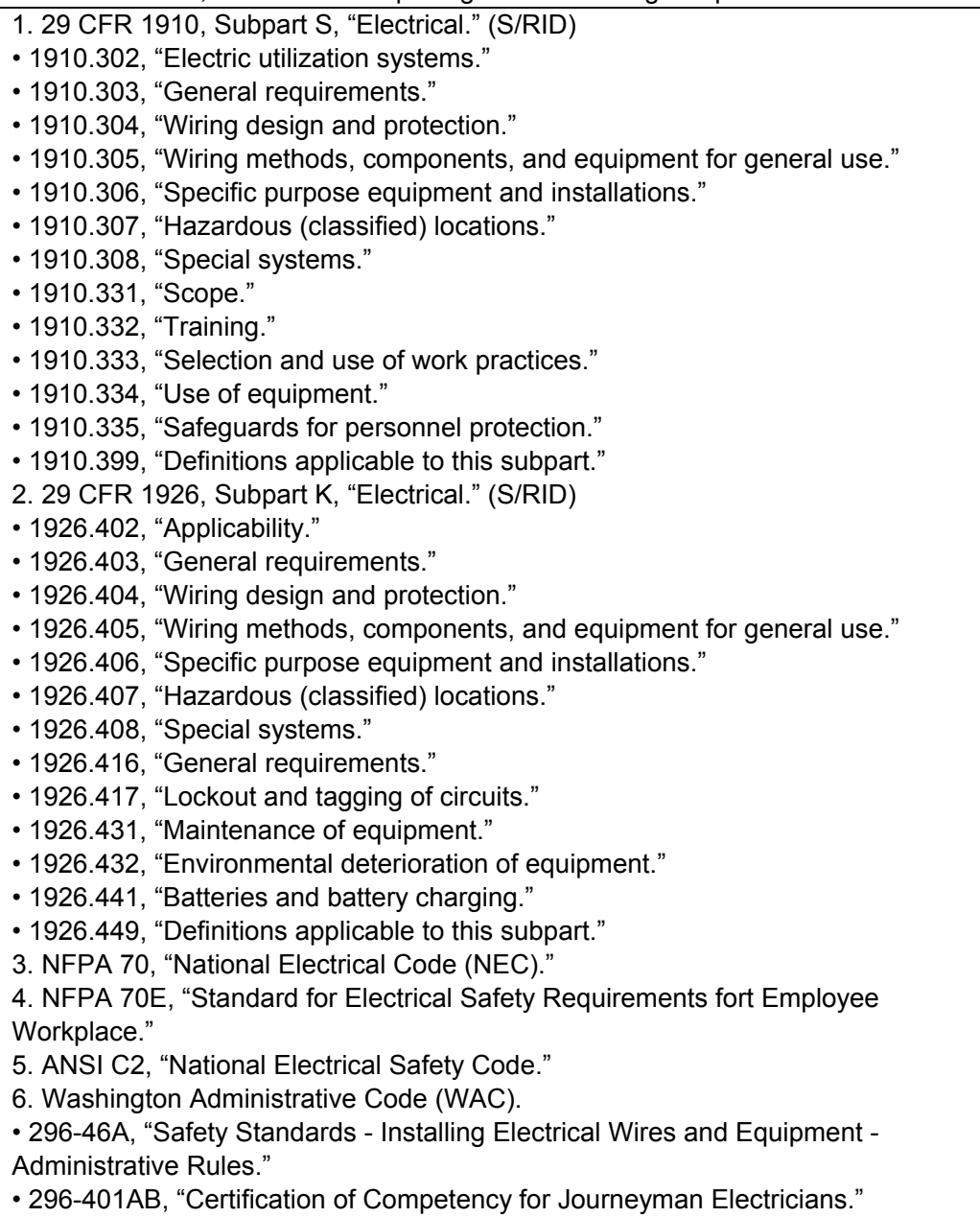 \\
\hline
\end{tabular}




\begin{tabular}{|c|c|c|}
\hline & & $\begin{array}{l}\text { 7. Revised Code of Washington (RCW) Title } 19.28 \text { "BUSINESS REGULATIONS - } \\
\text { MISCELLANEOUS - Electricians and Electrical Installations." } \\
\text { 8. DOE 5480.4 "Environmental Protection, Safety, and Health Protection } \\
\text { Standards," Appendix 2, Section 2.e.(5)(a) and (b). (S/RID) }\end{array}$ \\
\hline$\bigotimes$ & Fall Protection & $\begin{array}{l}\text { 1. } 29 \text { CFR } 1910 \text { Subpart D, "Walking-Working Surfaces" (SRID) } \\
\text { - } 1910.23 \text { "Guarding floor and wall openings and holes." } \\
\text { 2. } 29 \text { CFR 1926, Subpart M, "Fall Protection." (SRID) } \\
\text { - 1926.500, "Scope, application, and definitions applicable to this subpart." } \\
\text { - 1926.501, "Duty to have fall protection." } \\
\text {-1926.502, "Fall protection systems criteria and practices." } \\
\text {-1926.503, "Training requirements." }\end{array}$ \\
\hline$\square$ & $\begin{array}{l}\text { Asbestos Control - Facility } \\
\text { Management/General Industry }\end{array}$ & $\begin{array}{l}\text { 1. ANSI 9.2-1979, "Fundamentals Governing the Design and Operation of Local } \\
\text { Exhaust Systems." } \\
\text { 2. } 29 \text { CFR 1910.1001, "Asbestos (General Industry)." (S/RID) } \\
\text { a. Subpart Z. } \\
\text { b. Section } 1001(j)(7)(I) . \\
\text { c. Section 1001(j)(7)(ii). } \\
\text { 3. } 29 \text { CFR 1926.1101, "Asbestos (Construction)." }\end{array}$ \\
\hline 区 & Transportation Safety & $\begin{array}{l}\text { 1. } 29 \text { CFR 1910, Subpart Z, "Toxic and Hazardous Substances." (S/RID) } \\
\text { 1910.1201, "Retention of DOT markings, placards and labels." } \\
\text { 2. } 29 \text { CFR 1926, "Subpart O, Motor Vehicles, Mechanized Equipment, and Marine } \\
\text { Operations." (S/RID) } \\
\text { 1926.600, "Equipment." } \\
\text { 1926.601, "Motor vehicles." } \\
\text { 1926.602, "Material handling equipment." } \\
\text { 1926.603, "Pile driving equipment." } \\
\text { 1926.604, "Site clearing." } \\
\text { 3. } 29 \text { CFR 1926, "Subpart W, Rollover Protective Structures; Overhead Protection." } \\
\text { (S/RID) } \\
\text { 1926.1000, "Rollover protective structures (ROPS) for material handling } \\
\text { equipment." } \\
\text { 1926.1001, "Minimum performance criteria for rollover protective structures for } \\
\text { designated scrapers, loaders, dozers, graders, and crawler tractors." } \\
\text { 1926.1002, "Protective frames (roll-over protective structures, known as ROPS) for } \\
\text { wheeltype agricultural and industrial tractors used in construction." } \\
\text { 1926.1003, "Overhead protection for operators of agricultural and industrial } \\
\text { tractors." } \\
\text { 4. } 49 \text { CFR, "Transportation," Chapter II, Federal Railroad Administration, } \\
\text { Department Of Transportation, Parts } 211-240 .\end{array}$ \\
\hline 凶 & $\begin{array}{l}\text { Subcontractor Safety \& Health } \\
\text { Management }\end{array}$ & $\begin{array}{l}\text { 1. DOE 5480.9A, "Construction Project Safety and Health Management." (S/RID) } \\
\text { 2. DOE 5480.10, "Contractor Industrial Hygiene Program." (S/RID) } \\
\text { 3. DOE O 440.1A, "Worker Protection Management for DOE Federal and } \\
\text { Contractor Employees." }\end{array}$ \\
\hline 凶 & Walking/Working Surfaces & $\begin{array}{l}\text { 1. } 29 \text { CFR 1910, Subpart D, "Walking-Working Surfaces." (S/RID) } \\
\text { • 1910.21, "Definitions." } \\
\text { • 1910.22, "General Requirements." } \\
\text { • 1910.23, "Guarding floor and wall openings." } \\
\text { - 1910.24, "Fixed industrial stairs." } \\
\text { • 1910.25, "Portable wood ladders." } \\
\text { - 1910.26, "Portable metal ladders." } \\
\text { • 1910.27. "Fixed ladders." } \\
\text { - 1910.28, "Safety requirements for scaffolding." } \\
\text { • 1910.29, "Manually propelled mobile ladder stands and scaffolds (towers)." } \\
\text { - 1910.30, "Other working surfaces." } \\
\text { 2. } 29 \text { CFR 1910, Subpart E, "Means of Egress." (S/RID) } \\
\text { - 1910.35, "Definitions." } \\
\text { • 1910.36, "General requirements." } \\
\text { - 1910.37, "Means of egress, general." } \\
\text { 3. 29 CFR 1926, Subpart M, "Fall Protection." (S/RID) } \\
\text { - 1926.500, "Scope, application, and definitions applicable to this subpart." } \\
\text { • 1926.501, "Duty to have fall protection." }\end{array}$ \\
\hline
\end{tabular}




\begin{tabular}{|c|c|c|}
\hline & & $\begin{array}{l}\text { 4. } 29 \text { CFR 1926, Subpart X, "Stairways and Ladders." (S/RID) } \\
\text { - 1926.1050, "Scope, application, and definitions applicable to this subpart." } \\
\text { - 1926.1051, "General requirements." } \\
\text { - 1926.1052, "Stairways." } \\
\text { - 1926.1053, "Ladders." } \\
\text { • 1926.1060, "Training requirements." }\end{array}$ \\
\hline$\bigotimes$ & $\begin{array}{l}\text { Occupational Medical Qualification } \\
\text { and Monitoring }\end{array}$ & $\begin{array}{l}\text { 1. } 29 \text { CFR 1910.120, "Hazardous Waste Operations and Emergency Response." } \\
\text { (S/RID) } \\
\text { 2. } 29 \text { CFR 1910.151, "Medical Services and First Aid." (S/RID) } \\
\text { 3. DOE 5480.8A, Chapter I, Section 11.e(4), "Contractor Occupational Medical } \\
\text { Programs." (S/RID, entire procedure). } \\
\text { 4. DOE 5480.20A, Chapter 1, Section 10.a, "Qualification and Requalification." } \\
\text { (S/RID) }\end{array}$ \\
\hline$\square$ & Excavating, Trenching, and Shoring & $\begin{array}{l}\text { 1. } 29 \text { CFR Part 1926, Subpart P, "Excavations." (S/RID) } \\
\text { a. "Authority for 1926 Subpart P." } \\
\text { b. Appendix A, "Soil Classification." } \\
\text { c. Appendix B, "Sloping and Benching." } \\
\text { d. Appendix C, "Timber Shoring for Trenches." } \\
\text { e. Appendix D, "Aluminum Hydraulic Shoring for Trenches." } \\
\text { f. Appendix E, "Alternatives to Timber Shoring." } \\
\text { g. Appendix F, "Selection of Protective Systems." } \\
\text { 2. } 29 \text { CFR Part 1926.650, "Scope, application, and definitions applicable to this } \\
\text { subpart." } \\
\text { 3. } 29 \text { CFR Part 1926.651, "Specific Excavation Requirements." } \\
\text { 4. } 29 \text { CFR Part 1926.652, "Requirements for Protective Systems." } \\
\text { 5. ANSI/ASTM D120-95, "Standard Specification For Rubber Insulating Gloves." } \\
\text { 6. American Public Works Association (APWA), "Excavator's Damage Prevention } \\
\text { Guide" (1997). }\end{array}$ \\
\hline 凶 & Personal Protection & $\begin{array}{l}\text { 1. } 29 \text { CFR 1910, Subpart I, "Personal Protective Equipment." } \\
\text { 2. } 29 \text { CFR 1926, Subpart E, "Personal Protective and Life Saving Equipment." }\end{array}$ \\
\hline$\square$ & $\begin{array}{l}\text { Asbestos Control - Construction } \\
\text { Industry }\end{array}$ & 1. 29 CFR 1926.1101, "Asbestos (Construction)." \\
\hline$\square$ & Storing and Handling Chemicals & $\begin{array}{l}\text { 1. } 29 \text { CFR 1910.1450, "Occupational Exposure to Hazardous Chemicals in } \\
\text { Laboratories." } \\
\text { 2. } 29 \text { CFR 1910.1450, "Occupational Exposure to Hazardous Chemicals in } \\
\text { Laboratories." }\end{array}$ \\
\hline 凶 & Fire Protection Program & $\begin{array}{l}\text { 1. } 29 \text { CFR 1910, A Occupational Safety and Health Standards, Subpart E.(S/RID) } \\
\text { 2.29 CFR 1926, A Safety and Health Regulations for Construction. (S/RID) } \\
\text { a. Section 150(a)(5). } \\
\text { b. Section 157(g)(1). } \\
\text { c. Section 38(b)(4). } \\
\text { 3. DOE 5480.7A, A Fire Protection. (S/RID) } \\
\text { a. Section 5. } \\
\text { b. Section 8.i. } \\
\text { c. Section 9, Paragraph 1. } \\
\text { d. Section 9, Paragraph 2. } \\
\text { e. Section 9.a.(1). } \\
\text { f. Section 9.b.(5). } \\
\text { g. Section 9.b.(16). } \\
\text { h. Section 9.b.(17). } \\
\text { i. Section 9.c.(1). } \\
\text { j. Section 9.c.(2). } \\
\text { k. Section 9.c.(3). } \\
\text { l. Section 9.c.(4). }\end{array}$ \\
\hline$\square$ & Fire Protection Design Criteria & 1. RLID 5480.7, Fire Protection. \\
\hline
\end{tabular}




\begin{tabular}{|c|c|c|}
\hline$\square$ & $\begin{array}{l}\text { Fire Protection Requirements for } \\
\text { Construction, Occupancy and } \\
\text { Demolition Activities }\end{array}$ & $\begin{array}{l}\text { 1. } 29 \text { CFR 1926, "Safety and Health Regulations for Construction." (S/RID) } \\
\text { a. Section 150(a)(4) } \\
\text { 2. DOE 5480.7A, "Fire Protection." (S/RID) } \\
\text { a. Section 9.c.(1). } \\
\text { 3. RLID 5480.7, "Fire Protection." (S/RID) } \\
\text { a. Section 8.4.a. } \\
\text { b. Section 8.4.b. } \\
\text { c. Section 8.4.c. }\end{array}$ \\
\hline$\square$ & $\begin{array}{l}\text { Fire Hazard Analysis/Facility } \\
\text { Assessment Requirements }\end{array}$ & $\begin{array}{l}\text { 1. DOE 5480.7A, "Fire Protection." (S/RID) } \\
\text { a. Section 8.i. } \\
\text { b. Section 9.a.(2). } \\
\text { c. Section 9.a.(3). } \\
\text { 2. RLID 5480.7, "Fire Protection." (S/RID) } \\
\text { a. Section 6.2. }\end{array}$ \\
\hline$\square$ & $\begin{array}{l}\text { Fire Protection System Testing, } \\
\text { Inspection, and Maintenance }\end{array}$ & $\begin{array}{l}\text { 1. DOE 5480.7A, "Fire Protection." (S/RID) } \\
\text { a. Section 8.i. } \\
\text { b. Section 9.a.(2). } \\
\text { c. Section 9.a.(3). } \\
\text { 2. RLID 5480.7, "Fire Protection." (S/RID) } \\
\text { a. Section 8.2.b. }\end{array}$ \\
\hline$\square$ & Hanford Fire Marshal Permits & $\begin{array}{l}\text { 1. DOE 5480.7A, "Fire Protection." } \\
\text { 2. National Fire Protection Association, Standard } 1 \text { (NFPA 1), "Fire Prevention } \\
\text { Code" } \\
\text { 3. RLID 5480.7, "Fire Protection." } \\
\text { 4. Uniform Fire Code (UFC), Article 80, "Hazardous Materials," } 1997 \text { edition. }\end{array}$ \\
\hline$\square$ & Controlling Hot Work & $\begin{array}{l}\text { 1. DOE 5480.7A, "Fire Protection," Section 9.c.(1). (S/RID) } \\
\text { 2. RLID 5480.7, "Fire Protection," Section 8.7. (S/RID) } \\
\text { 3. National Fire Protection Association, Standard 51B, "Cutting and Welding } \\
\text { Processes." }\end{array}$ \\
\hline$\square$ & Flammable/Combustible Liquids & $\begin{array}{l}\text { DOE 5480.7A, "Fire Protection," Section 9.c(1). (S/RID) } \\
\text { 1. NFPA 30, "Flammable and Combustible Liquids Code." } \\
\text { 2. NFPA 45, "Fire Protection For Laboratories Using Chemicals." }\end{array}$ \\
\hline 区 & Fire Extinguishers/Fire Barriers & $\begin{array}{l}\text { 1. } 29 \text { CFR 1910, "Occupational Safety and Health Standards." (S/RID) } \\
\text { a. Section 157(g)(1). } \\
\text { b. Section 157(g)(2). } \\
\text { 2. DOE 5480.7A, "Fire Protection" } \\
\text { 3. RLID 5480.7, "Fire Protection" } \\
\text { 4. National Fire Protection Association, Standard } 10 \text { (NFPA 10), " Portable Fire } \\
\text { Extinguishers." } \\
\text { 5. NFPA 80, "Fire Doors and Fire Windows." } \\
\text { 6. NFPA 101, "Life Safety Code." }\end{array}$ \\
\hline$\square$ & $\begin{array}{l}\text { Hazardous/Waste Absorbent } \\
\text { Material Storage }\end{array}$ & $\begin{array}{l}\text { 1. DOE 5480.7A, "Fire Protection," Section 9.c.(1). (S/RID) } \\
\text { 2. RLID 5480.7, "Fire Protection," Section 8.5. (S/RID) } \\
\text { 3. WAC 173-303. (S/RID) } \\
\text { a. Section 395(1). } \\
\text { b. Section 630(8) and (8)(a). } \\
\text { c. Section 630(8)(b). } \\
\text { 4. NFPA 1, "Fire Prevention Code." } \\
\text { 5. NFPA 10,"Portable Fire Extinguishers." } \\
\text { 6. NFPA 70,"National Electrical Code®." } \\
\text { 7. NFPA 72, "National Fire Alarm Code®" } \\
\text { 8. NFPA 1221,"Standard for the Installation, Maintenance, and Use of Emergency } \\
\text { Services Communication Systems." } \\
\text { 9. Uniform Building Code. } \\
\text { 10. Uniform Fire Code. }\end{array}$ \\
\hline$\square$ & $\begin{array}{l}\text { Fire Protection System } \\
\text { Winterization/Portable Heater Use }\end{array}$ & $\begin{array}{l}\text { 1. DOE 5480.7A, "Fire Protection," Section 9.c.(1). (S/RID) } \\
\text { 2. RLID 5480.7, "Fire Protection," Section 8.9. (S/RID) }\end{array}$ \\
\hline
\end{tabular}




\section{Attachment D}

Specifications for FY 2002-2003 Mock Tank Modifications 



\section{Attachment D \\ Specifications for FY 2002-2003 Mock Tank Modifications}

\section{D1 Geophysical Borehole Drilling}

Contractor will perform as detailed in this Statement of Work, all preparation, construction, waste handling, and other work necessary to provide drilling and completion of one vadose zone geophysical logging borehole. The borehole is planned to be 6 in. $(15.2 \mathrm{~cm})$ in diameter. Completion materials will consist of natural formation or drill cuttings.

\section{D1.1 2002 Geophysical Logging Borehole Installation - General Description}

One vadose zone geophysical logging borehole will be constructed for the Geophysical Leak Detection Technology Demonstration project under this contract. Construction will consist of one 6-in. $(15.2-\mathrm{cm})$ borehole with appropriately sized auger flights to keep the borehole open during drilling and completion. The borehole will be completed with a 6 -in. $(15.2-\mathrm{cm})$ carbon steel casing in the vadose zone to a depth of $40 \mathrm{ft}(12.2 \mathrm{~m})$ below grade. The casing will extend to approximately $2.5 \mathrm{ft}(76 \mathrm{~cm})$ above ground. Drilling will stop at approximately $45 \mathrm{ft}(13.8 \mathrm{~m})$, or at the point of refusal. The borehole will be sealed (water tight) at the joints and bottom. A coating of varnish will be on the delivered casing and will have a 1-in. $(2.5-\mathrm{cm})$ strip removed from it in the field under the direction of PNNL personnel.

\section{D1.2 Subsurface Contamination at the 105-A Mock Tank Site}

- Radiological Contamination: No radiological contamination is expected during drilling.

- Field monitoring will be conducted by PNNL for radiological contaminants at the discretion of PNNL or at the request of contractor personnel.

\section{D1.3 General Geology - 200 East Area}

The geology of the site, determined from well site geologist logs, is relatively consistent across the site. The depth to water is generally about $270 \mathrm{ft}(82 \mathrm{~m})$ in the area proposed for drilling. The general stratigraphy in the vicinity of the site, to the depths of interest is illustrated below. 


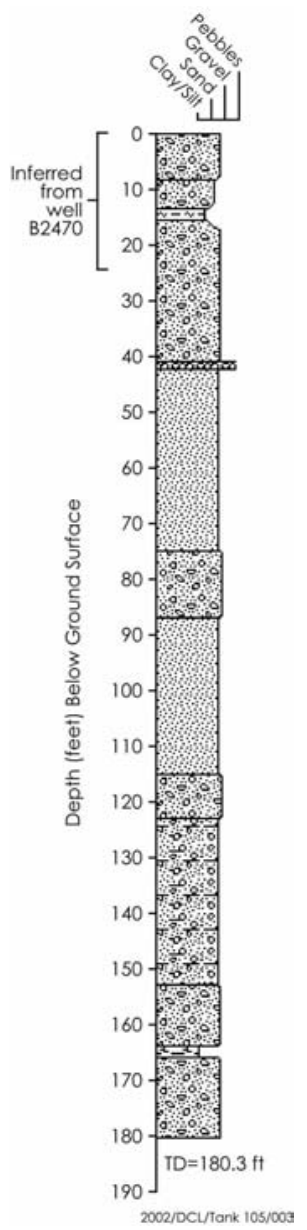

\section{D1.4 Work Included}

The preparation of specified permits, schedules, readying of equipment and personnel, mobilization, drilling, and demobilization are the key work items of this specific subcontract as executed under the Master Agreement.

\section{D1.5 Preparation}

Contractor will be responsible for the following preparatory activities:

- Submittals in accordance with this contract two weeks prior to start of work.

- Prepare and submit Washington Department of Ecology (WDOE) Notification of Intent to Construct a Monitoring/Resource Protection Well forms and WDOE fee in accordance with WAC 173-160 with a copy of the forms and a copy of the payment or receipt to PNNL. 
- Prepare and submit at least two weeks prior to start of drilling for contractor Review a Site Specific Health and Safety Plan in accordance with 29 CFR 1910.120. All hazards not addressed in the Site Specific Health and Safety Plan will be addressed in a Contractor's Activity Hazard Analysis or Job Safety Analysis and submitted to contractor for review.

- Submit worker status reports showing workers meet the Contractor's required training, medical, bioassay, and qualification expirations. Coordinate training and bioassay needs with Contractor's Training Representative.

- Ready equipment, materials and personnel for the execution of this Scope of Work.

- Ascertain and certify that the site is adequately accessible for work to proceed at least 2 weeks prior to drilling.

\section{D1.6 Construction}

Contractor should be aware that one well will be drilled. Contractor will be responsible for construction of the geophysical logging borehole to include mobilization, drilling, waste handling, demobilization, and other work necessary to construct the wells in accordance with this contract. Borehole will be drilled at least to $45 \mathrm{ft}(13.8 \mathrm{~m})$ below ground surface. The well casing temporarily secured and sealed if left unattended. The boreholes will meet project test requirements for seals and backfilling boreholes. A coating of varnish will be on the delivered casing and installation will occur with this varnish in place.

\section{D1.7 Mobilization}

Contractor will mobilize drill rigs, required equipment and materials to the work site.

Site will be set-up in accordance with Contractor's Site Specific Health and Safety Plan and/or Activity Hazard Analysis and concurrence of the Contractor's Field Superintendent.

Establish construction boundaries and restrict access by physical barrier (e.g., yellow rope, construction netting, barricades).

Contractor will control access to the work site.

\section{D1.8 Drilling}

Contractor will be responsible for advancing the well in accordance with this contract to the depths required and to install the casing and lengths of screen. Acceptable drilling methods do not include water, or mud, but do not preclude other circulation methods (e.g., air circulation). Sonic, auger, and cable-tool drive barrel methods are also acceptable. Hard tool cable-tool method will only be used where debris fill is present in the subsurface or if boulders are encountered. 
Drill cuttings will be placed on appropriate storage media (e.g., visqueen, tarps) for later completion of the wells. A means of assuring that the cuttings will not become airborne during storage will be employed.

\section{D1.9 Completion}

Contractor is responsible for procuring and installing all temporary materials in accordance with this contract.

When the drill string has reached total depth, the Contractor will set the permanent casing in the well.

Backfill will consist of drill cuttings, or moistened drill cuttings. For this geophysical logging borehole, electrical coupling with the soil is required. The contractor will ensure that the Contractor provides a means for introducing moisture into the drill cuttings and uses the moistened cuttings to backfill around the permanent casing. A PNNL representative prior to emplacement will evaluate the moisture content of the cuttings.

\section{D1.10 Waste Handling}

Contractor will be responsible for packaging, handling, all wastes generated during construction, development, and demobilization in accordance with the Site Specific Waste Management Instruction. Contractor will affix appropriate labels onto the drums once they are sealed, wiped, and moved away from the immediate work area. Contractor will collect and dispose of all non-regulated trash and debris associated with the installation, sampling, or other activity associated with this scope of work. The contractor is also responsible to cleanup and dispose of any and all waste generated from spills (i.e., broken hydraulic/oil/fuel). The basic containment strategy is as follows:

All soil to the depth of interest is clean unless determined to radiologically contaminated by field screening. Clean soil will be stockpiled on a plastic sheet near the point of origin. Provided the screening indicates contamination is present, contaminated soil will be drummed in 55-gal (208-L) drums with 10 mil nylon-reinforced plastic liners and non-corrosive pad, and stored neatly on barrel pallets.

Contractor is responsible to minimize waste generation. Because of the drilling techniques to be used, contractor needs to be cognizant of formation washouts and use best available technology to minimize.

\section{D1.11 Demobilization}

The drill rig derrick, all down-hole equipment and temporary casing will be field decontaminated (i.e., steam cleaned) prior to leaving the site.

Demobilize all equipment and materials from the site.

Submit Well Reports per WAC 173-160 with a copy to the contractor. 


\section{D1.12 Borehole Design}

Below are shown schematic diagrams of the geophysical boreholes planned for FY 2002 construction at the Mock Tank. Both PVC (CPT-installed following FY 2002-2003 testing) and steel-cased completions are represented in Figure D.1. The right-hand diagram illustrates the configuration of these wells following decommissioning.

\section{D2 Construction of Steel Sheet Wall}

Excavation for and installation of seven vadose zone sheet electrodes. Each sheet electrode is planned to be 15 by $5 \mathrm{ft}$ ( 4.5 by $1.5 \mathrm{~m}$ ) in size. Completion materials will consist of natural formation or drill cuttings. The design and location of this equipment is based on information in Ex-Tank LDMM Performance Evaluation Test Specification (Bratton et al. 2002), discussions with the excavation contractor, dimensional comparisons between SSTs and the Mock Tank, and an inspection of the Mock Tank site.
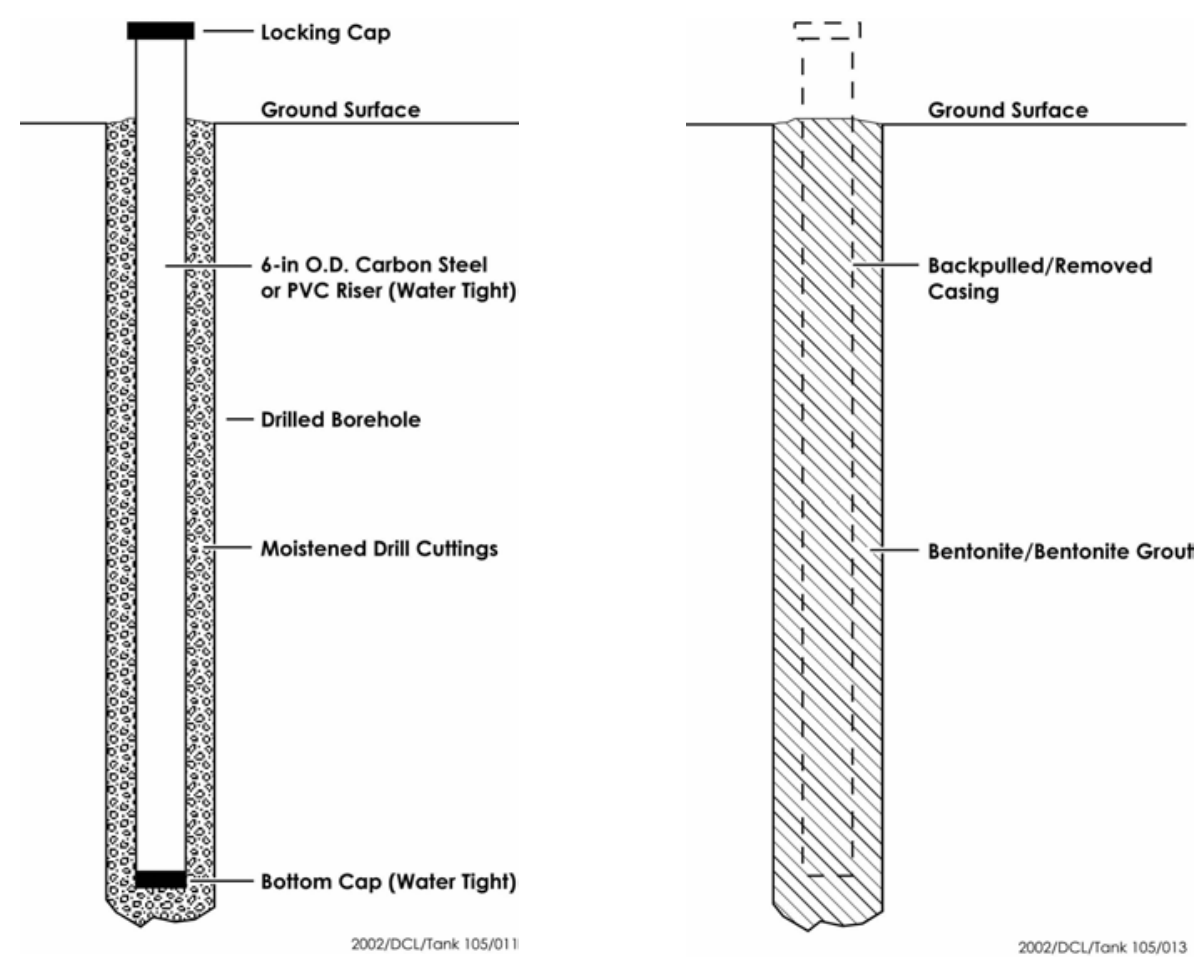

Figure D.1. Configuration of Geophysical Boreholes after Construction (left) and Following Decommissioning (right) 


\section{D2.1 2002 Sheet Electrode Installation - General Description}

Seven vadose zone sheet electrodes will be constructed for the Geophysical Leak Detection Technology Demonstration project under this contract. Construction will nominally consist of seven 15 by $5 \mathrm{ft}$ ( 4.5 by $1.5 \mathrm{~m}$ ) sheet electrodes installed with the 5 - $\mathrm{ft}$ side installed at the base of the excavation. The top of the sheet electrodes will rest 2 to 6 in. $(5$ to $15 \mathrm{~cm}$ ) below grade. The composition of the sheet electrodes will be corrugated or plate steel not to exceed $0.125 \mathrm{in} .(3.2 \mathrm{~mm})$ in thickness. Materials will not be galvanized or coated. The contractor prior to delivery at the Mock Tank Site will remove all surface coatings. Each sheet electrode will be separated by a minimum of 6 in. $(15 \mathrm{~cm})$ to allow for the installation of two 6-in. $(15-\mathrm{cm})$ diameter PVC pipes. The top of each sheet electrode will be electrically bonded to the adjacent sheet electrode by tack-welded wire.

A copy of ground-penetrating radar scans and a location diagram indicating the placement of the sheet electrodes will be provided to the contractor prior to start of excavation. Excavation permitting has been completed by PNNL prior to excavation.

\section{D2.2 Subsurface Contamination at the 105-A Mock Tank Site}

- Radiological Contamination: No radiological contamination is expected during drilling.

- Field monitoring will be conducted by PNNL for radiological contaminants at the discretion of PNNL or at the request of contractor personnel.

\section{D2.2.1 Work Included}

The preparation of specified permits, schedules, readying of equipment and personnel, mobilization, drilling, and demobilization are the key work items of this specific subcontract as executed under the Master Agreement.

\section{D2.3 Preparation}

The contractor will be responsible for the following preparatory activities:

- Submittals in accordance with this contract two weeks prior to start of work.

- Prepare and submit at least 2 weeks prior to start of drilling for contractor Review a Site Specific Health and Safety Plan in accordance with 29 CFR 1910.120.

- All hazards not addressed in the Site Specific Health and Safety Plan will be addressed in a Contractor's Activity Hazard Analysis, or Job Safety Analysis and submitted to contractor for review. 
- Submit worker status reports showing workers meet the Contractor's required training, medical, bioassay, and qualification expirations. Coordinate training and bioassay needs with Contractor's Training Representative.

- Ready equipment, materials and personnel for the execution of this Scope of Work.

- Ascertain and certify that the site is adequately accessible for work to proceed at least 2 weeks prior to excavation.

\section{D2.4 Design Details}

Figure D.2 is a plan and elevation design layouts of the steel sheet pile wall. The separate steel pilings will be placed nominally in contact, edge to edge, as shown in the elevation view, with a tack weld at the upper (near-surface) ends to ensure electrical continuity. A nominal 2-in. $(5-\mathrm{cm})$ inside diameter (I.D.), schedule $40 \mathrm{PVC}$ casing will be installed to $15 \mathrm{ft}(4.6 \mathrm{~m})$, as shown. The bottom $5 \mathrm{ft}(1.5 \mathrm{~m})$ of this casing will be PVC screen with 20 -to-40 slot size. The bottom $\sim 7 \mathrm{ft}(\sim 2.1 \mathrm{~m})$ of the casing should be completed in gravel-sized pack to enhance infiltration capacity.

\section{D2.5 Construction}

The contractor and all Contractors will be responsible for mobilization, excavation, installation, waste handling, demobilization, and other work necessary to construct the sheet electrodes in accordance with this contract. The Contractor will mobilize all required equipment and materials to the work site. The site will be set-up in accordance with all contractor and Contractor's Site Specific Health and Safety Plan and/or Activity Hazard Analysis and concurrence of the Contractor's Field Superintendent.

The Contractor and all Contractors will control access to the work site, and all construction boundaries will be adequately defined and access will be restricted by physical barrier (e.g., yellow rope, construction netting, barricades).

\section{D2.6 Excavation}

The Contractor and all Contractors will be responsible for excavation in accordance with this contract to the depths required and to install the sheet electrodes. Excavated materials may be placed on the ground or appropriate storage media (e.g., visqueen, tarps) for later backfill around the sheet electrodes. A means of assuring that the spoils will not become airborne during storage will be employed.

\section{D2.7 Completion}

The Contractor and all Contractors are responsible for procuring and installing all materials in accordance with this contract. 


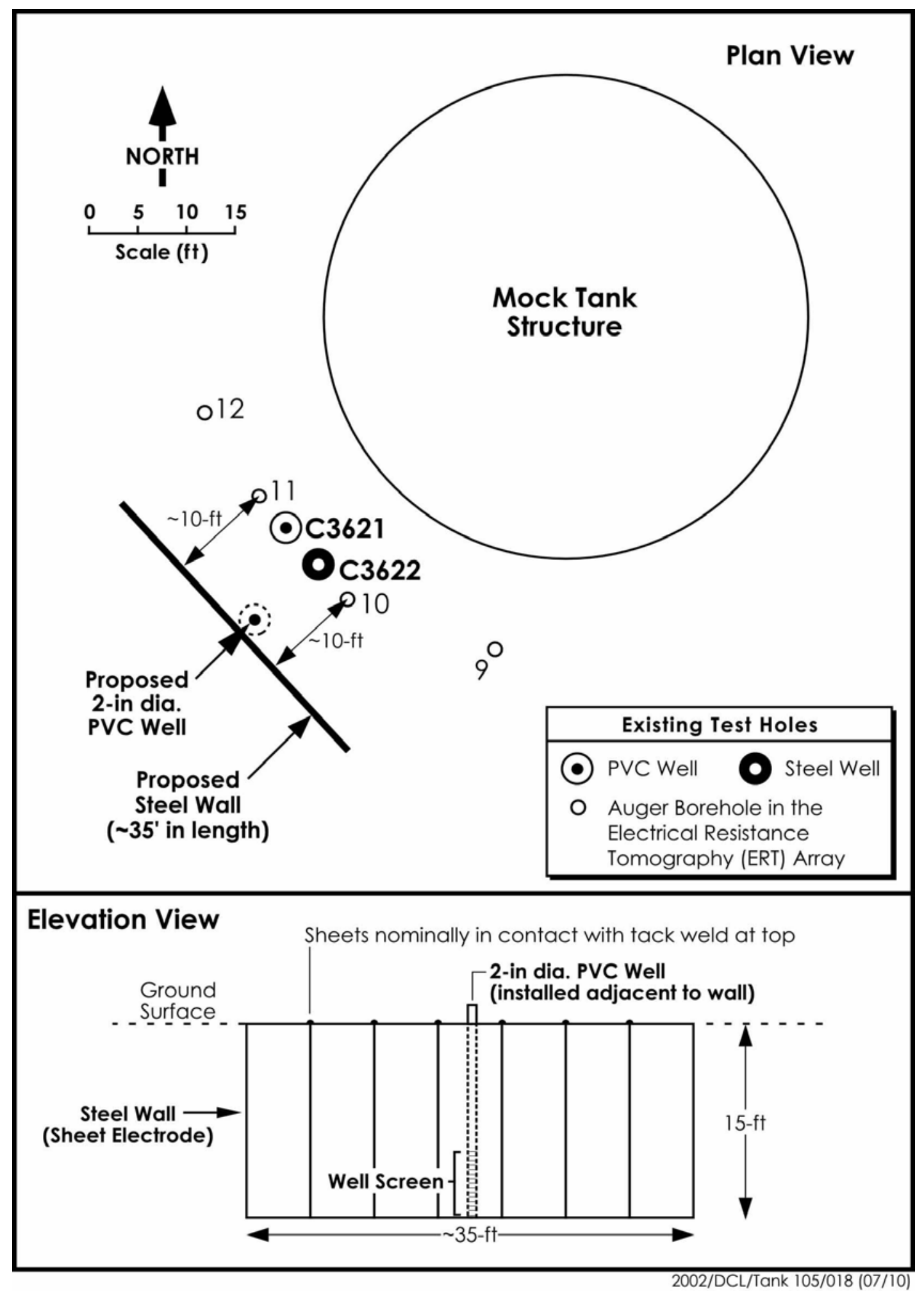

Figure D.2. Design Layout of Steel Sheet Wall to be Installed near the Mock Tank 
Backfill will consist of excavated materials. For these steel sheet electrodes, electrical coupling with the soil is required. The Contractor will provide a means for introducing moisture into the excavated materials and uses the excavated materials to backfill around the sheet electrodes. A PNNL representative will evaluate the moisture content of the cuttings prior to emplacement.

\section{D2.8 Waste Handling}

The Contractor will be responsible for packaging, handling, all wastes generated during construction, development, and demobilization in accordance with the Site Specific Waste Management Instruction. The Contractor will affix appropriate labels onto the drums, if any, once they are sealed, wiped, and moved away from the immediate work area. The Contractor will collect and dispose of all non-regulated trash and debris associated with the installation, sampling, or other activity associated with this scope of work. The Contractor and all Contractors are also responsible to cleanup and dispose of any and all waste generated from spills (i.e., broken hydraulic/oil/fuel). The basic containment strategy is as follows:

All soil to the depth of interest is clean unless determined to radiologically contaminated by field screening. Clean soil will be stockpiled on a plastic sheet near the point of origin. Provided the screening indicates contamination is present, contaminated soil will be drummed in 55-gal (208-L) drums with 10 mil nylon-reinforced plastic liners and non-corrosive pad, and stored neatly on barrel pallets. The Contractor is responsible to minimize waste generation. All excavation equipment will be field decontaminated prior to leaving the site.

\section{D.3 Refitting of Mock Tank Access Ports for Neutron Logging}

Nine of the fourteen access ports in the bottom of the Mock-Tank structure will be modified to accommodate neutron logging; the remaining five ports will be employed as leak points during the LDMM Performance Evaluation. The existing 6-in. (15-cm) diameter steel-cased access ports extend approximately $2 \mathrm{ft}(61 \mathrm{~cm}$ ) below the sheet-steel tank floor (see FigureD.3); the port boreholes will be deepened by an additional $\sim 2 \mathrm{ft}(\sim 61 \mathrm{~cm})$ and a 4-in $(10-\mathrm{cm})$ PVC casing emplaced inside the existing steel casing to allow neutron logging for ground-truth purposes (desired depth of penetration is $1 \mathrm{ft}$ $(30 \mathrm{~cm})$ into the sandy sub-base beneath the Mock-Tank structure).

\section{D.4 Design and Installation of Solution Delivery Control System}

The leak-simulant solution feed employs a turbine flow sensor and PID (proportional/integral/ differential) controller (with $\pm 2 \%$ accuracy, $1 \%$ repeatability) to meter the setpoint flow rate from a 20 30 psi (138-207 kPa) constant-pressure loop; the controller has logging and totalizing capabilities and will be linked to a PC running remote-access software for offsite control. The constant-pressure loop employs a pump, filter, circulating heater, and pressure regulator; this loop also serves to circulate leak simulant solution through the tank for heating purposes during cold-weather periods (see Figure D.4). Manual operation will be provided for as a backup, employing a rotameter and needle valve to regulate 


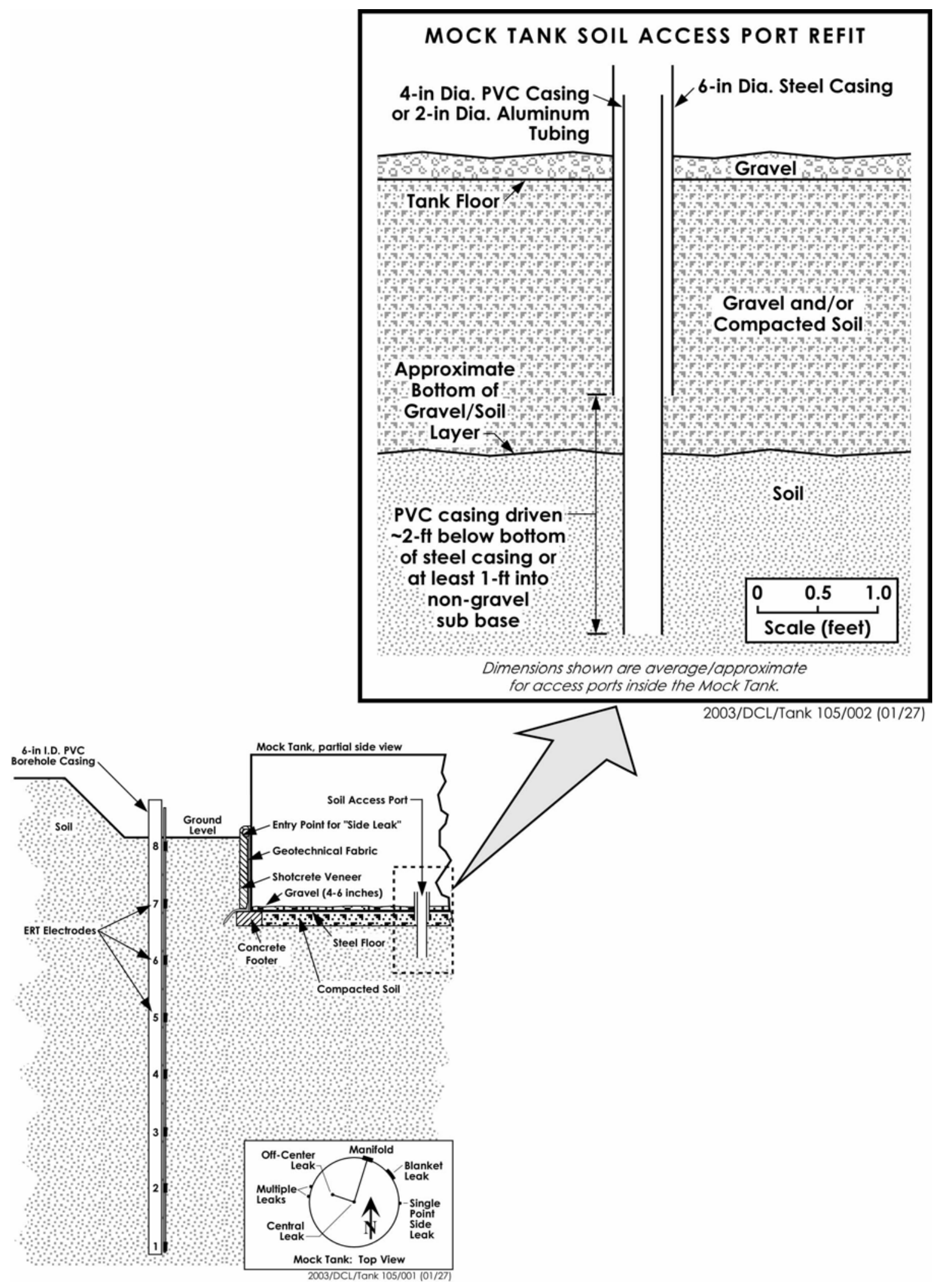

Figure D.3. Refitting of Access Ports for Neutron Probe Measurements 


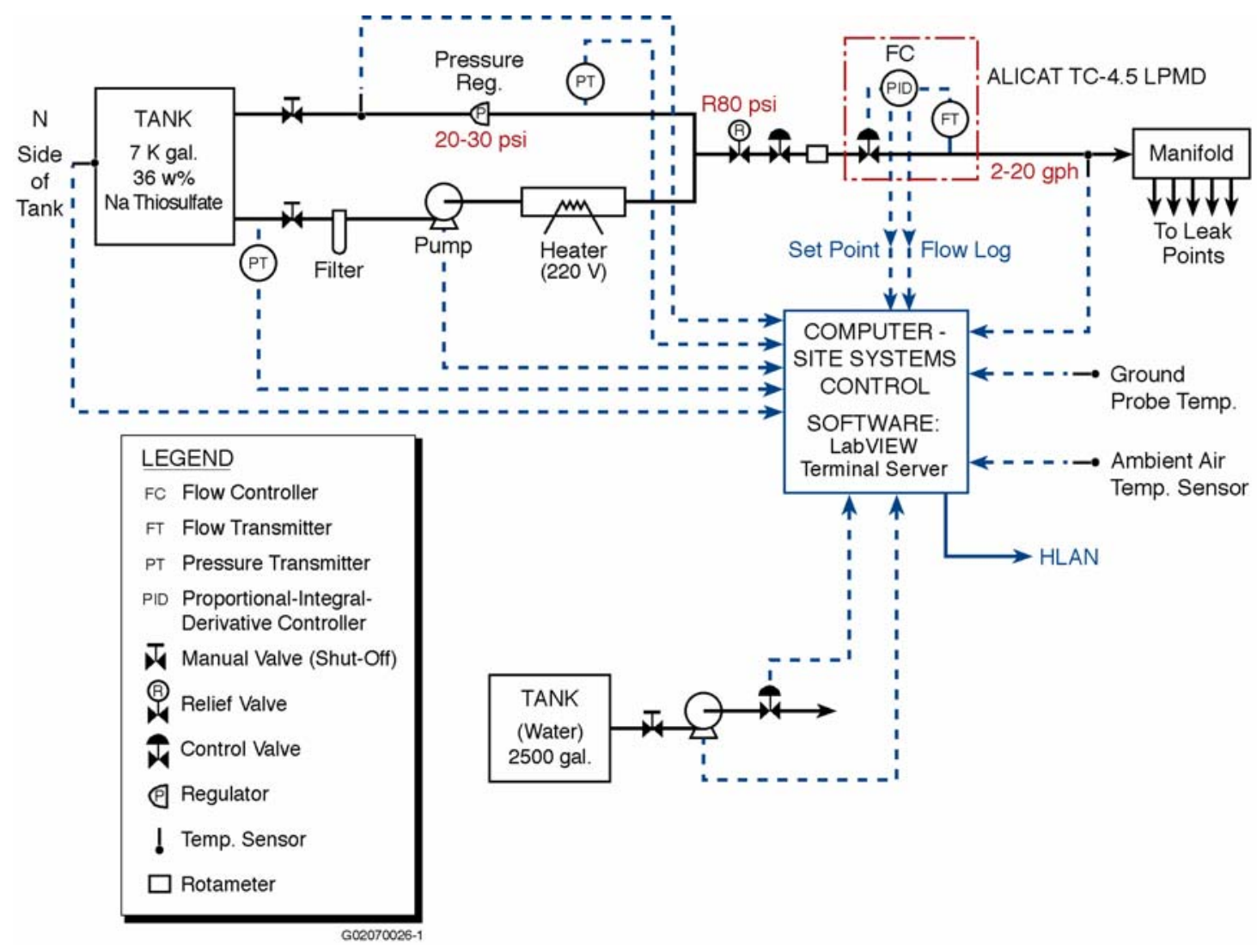

Figure D.4. Schematic Diagram of Solution Control System

flow. A mechanical totalizer ( $\pm 1 \%$ acc.) will provide a durable record of the leak volumes; other system components will have accuracy of $\pm 5 \%$ ( $\pm 2 \%$ repeatability) or better. The system will be enclosed in a covered, insulating structure to protect the components and preserve leak-data blindness.

Control of the leak-simulant solution feed is through a PC running LabVIEW software for control and data-logging purposes; Terminal Server software will provide reliable remote-access capability. The setpoint of the PID flow controller can be changed (manually or remotely) from 0 to $70 \mathrm{gph}(0-265 \mathrm{Lph})$; the controller will also provide flow data to the LabVIEW software for logging and totalizing purposes. Leak-point location will be controlled by a manifold in a covered, insulated box. Sensors will log solution temperature at the position-control manifold, in the tank, and in the pressure loop; ambient air temperature, tank head pressure (liquid level) and metering-loop pressure will also be logged. All controls and data logs will be remotely accessible using the HLAN and Terminal Server software.

The failure points for the logging and control system include recording incorrect data, improper calibration, and equipment failure. The totalizer will be calibrated prior to installation and operation. The readout of the mechanical totalizer will be used to verify the reading from the software. The accuracy of the entire injection system will rely on the calibration of the mechanical totalizer. 


\section{D.5 Rainfall Simulation System}

Application of water to simulate rainfall events is contingent upon pending decisions on the representativeness of this exercise. Should this contingency be selected, the following design will be used.

The precipitation system will employ a pump system that can be turned on and off by Terminal Server software; after pump flow calibration, the LABView software will employ a time-based totalizer function to automatically shut off flow when the totalizer setpoint is reached (see Figure D.4). Eight rain gauges positioned around the tank will verify the precipitation amount $(0.1$ inches $[0.25 \mathrm{~cm}] /$ event minimum) and distribution. The precipitation will be delivered over a circle $\sim 115 \mathrm{ft}$. diameter, based on the center of the tank (see Figure D.5) including all ERT and HRR surface, peripheral electrodes. Remote electrodes and any tank-interior connections will not be included in the area to receive simulated precipitation. Delivery rates will be determined in the field based on sprinkler performance.

Storage tanks $(2,500$ gal [9464 L] capacity each) currently located onsite will supply raw water for simulated rainfall; a supply hose will connect the tanks with the constant-flow pump. The hose leading

from the pump to the arc-pattern sprinklers will have junctions and/or Ts to allow proper positioning and numbers of sprinklers. 


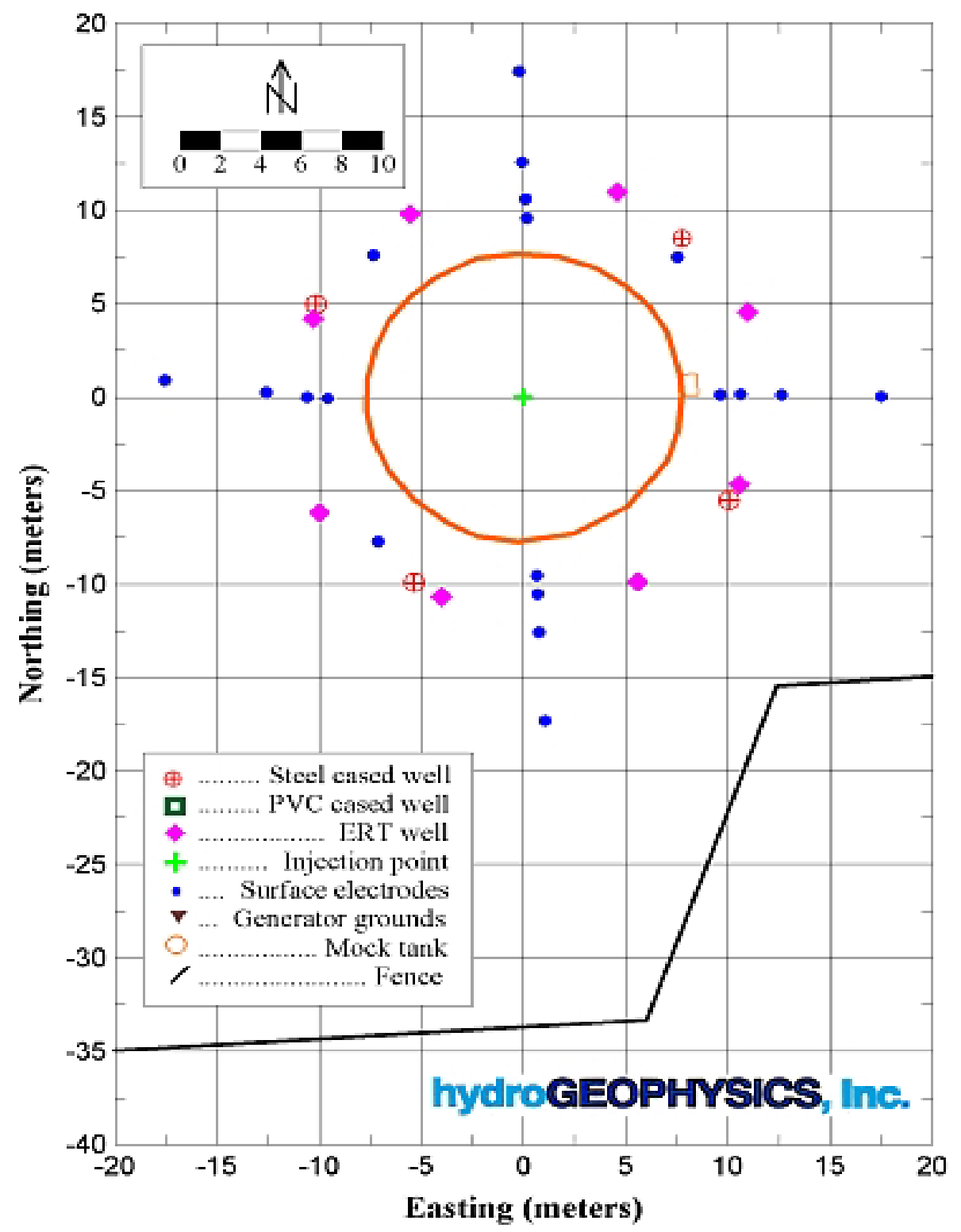

Figure D.5. Layout of Electrodes at the Mock Tank for FY 2002-2003 Performance Testing. The outermost surface electrodes shown in the diagram describe the circumference of the area to which water will be applied to simulate rainfall (After hydroGEOPHYSICS, Inc.). 


\section{Attachment E}

\section{Test-Modification Documentation}




\title{
Attachment E
}

\section{Test-Modification Documentation}

\author{
E.1 Form For Letter Report Revision \\ PNNL Letter Report Revision $\quad$ Revision No. \\ Project Title: SST Ex-Tank LDMM Performance Test and Demonstration \\ Letter Report Number: TWS02.043 \\ Report Title: LDMM Ex-Tank Leak Detection Performance Evaluation Test Implementation Plan-FY \\ 2002-2003
}

Report Authors: D. B. Barnett, G. W. Gee, M. D. Johnson, M. D. Sweeney, V. F. Medina.

Approvals

Primary Author Date

Line Manager Date

Project Manager Date

Peer Reviewer Date

(Send to complete distribution and attach to document) 


\section{E.2 Form For Project Change Agreement}

\section{Project Change Agreement \\ LDMM Ex-Tank Leak Performance Evaluation Test \\ FY 2002-2003}

The undersigned project participants hereby agree to the following modifications to the performance evaluation test:

Description of Modification to Test:

Impact if Modification Not Approved:

Effective Date of Modification

Project Participant Requesting Modification

Project Participant Responsible for Modification

Approvals

CHG/Cogema Steering Committee Approval Date

PNNL Team Approval Date

Test Director Concurrence Date

The completed form will be attached to the field log book maintained by PNNL for the 2002-2003 Performance Evaluation Test. Custodians of the log book are M. D. Sweeney (373-0703) and M. D. Johnson (376-5771). 


\section{Add-On E1}

\section{Signed Project Change Agreements}




\section{Project Change Agreement LDMM Ex-Tank Leak Performance Evaluation Test \\ FY 2002-2003}

The undersigned project participants hereby agree to the following modifications to the performance evaluation test:

Description of Modification to Test: Two Modifications:

Modification 1: A resistor has been added to the receiver input to avoid saturating the detector. $\quad 7 / 311^{12}$ to $811 / 02$

Modification 2: A filter algorithm has been added to HRR-SCRT data processing procedures.

(See attachment)

Impact if Modification Not Approved:

1. If the resistor is not installed as described, the signal amplitude will saturate the receiver's detector circuit and the system will not support mutual data collection capabilities for ERT and HRR-SCRT.

2. Data collected for HRR-SCRT needs additional processing to remove effects of diurnal temperature variations. The effects of the modification will be retroactively applied to all data showing these effects. Documentabion will be Rept what the filter algorythm is, along with method documents.

Effective Date of Modification: $\quad$ 8/5/02

Project Participant Requesting Modification: PNNL for HydroGEOPHYSICS, Inc.

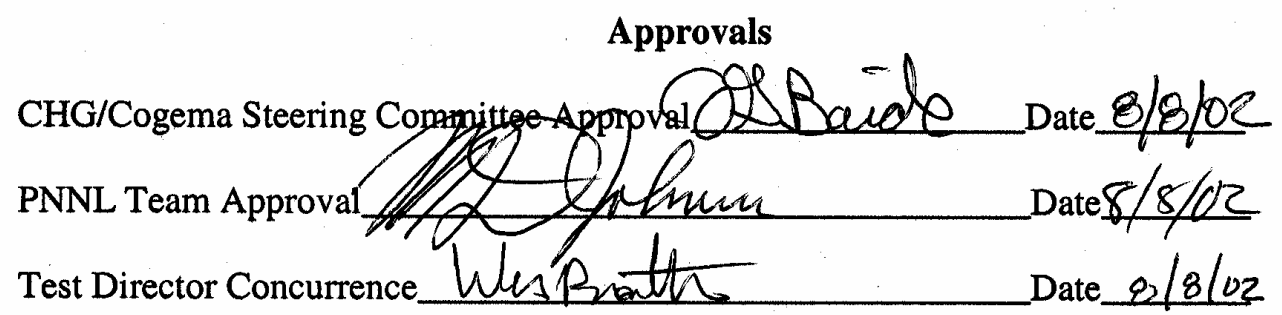

The completed form will be attached to the field log book maintained by PNNL for the 2002-2003 Performance Evaluation Test. Custodians of the log book are M. D. Sweeney (373-0703) and M. D. Johnson (376-5771). 


\section{Project Change Agreement \\ LDMM Ex-Tank Leak Performance Evaluation Test \\ FY 2002-2003}

The undersigned project participants hereby agree to the following modifications to the performance evaluation test:

Description of Modification to Test:

1) Test B was extended by one day due to unexpected results from the ERT-LET approach. The extension will permit an additional confirmation or rejection of the previous day results.

2) Test $\mathrm{C}$ start date and length was adjusted to permit additional flow monitoring equipment that is necessary for cooler weather operation to be installed and calibrated by PNNL.

3) To maintain the overall length of the test series, Test $D$ was also adjusted. The total number of tight test days within the matrix was maintained at the level above that required for the data analysis.

Impact if Modification Not Approved:

Total length of Test Program may lengthen by a couple of days.

Effective Date of Modification: $8 / 15 / 02$

Project Participant Requesting Modification: Wes Bratton, VET

Project Participant Responsible for Implementing Change: Mike Johnson, PNNL

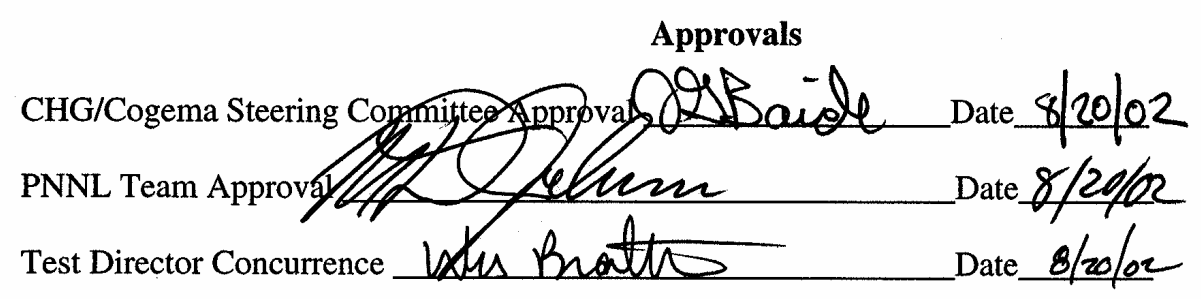

The completed form will be attached to the field log book maintained by PNNL for the 2002-2003 Performance Evaluation Test. Custodians of the log book are M. D. Johnson (376-5771) and M. D. Sweeney (373-0703). 


\section{Project Change Agreement \\ LDMM Ex-Tank Leak Performance Evaluation Test \\ FY 2002-2003}

The undersigned project participants hereby agree to the following modifications to the performance evaluation test:

Description of Modification to Test:

1) Moved the neutron logging schedule for Friday $9 / 12 / 02$ to Monday $9 / 15 / 02$

2) Extended intra-test analysis reference point day 36 for two days instead of switching to day 39 . Both reference days are in the same tight test so the net effect was no change in the intra-test volume values.

Impact if Modification Not Approved:

PNNL would have to perform neutron logging after hours and in the dark, due to late finish of Injection Test $\mathbf{J}$.

Effective Date of Modification: $\underline{9 / 10 / 02}$

Project Participant Requesting Modification: Wes Bratton, VET

Project Participant Responsible for Implementing Change: Mike Johnson, PNNL

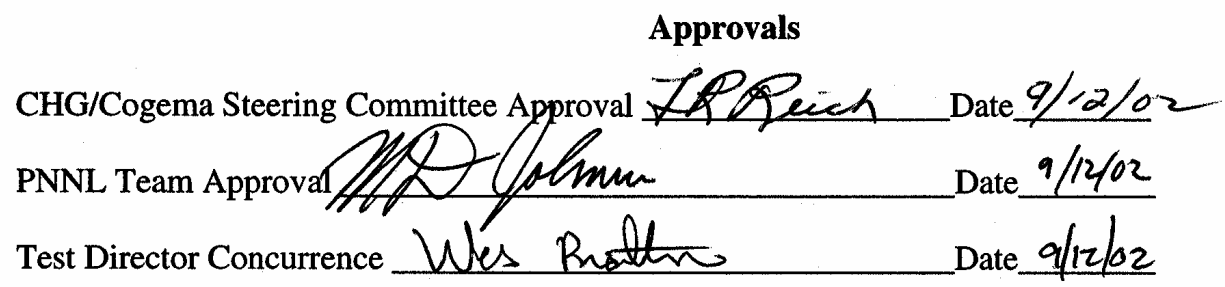

The completed form will be attached to the field log book maintained by PNNL for the 2002-2003

Performance Evaluation Test. Custodians of the log book are M. D. Johnson (376-5771) and

M. D. Sweeney (373-0703). 


\section{E.1 Form For Project Change Agreement}

\section{Project Change Agreement \\ LDMM Ex-Tank Leak Performance Evaluation Test}

FY 2002-2003

The undersigned project participants hereby agree to the following modifications to the performance evaluation test:

Description of Modification to Test:

- Removed "tight day" from Test $N$

- Added "tight day" to Test $\mathrm{K}$

- Missed change over from well L-10 to L-14 in Test J

- Completed neutron logging on 9-13 rather than 9-16

Impact if Modification Not Approved:

Test Sequence discrepancy

Effective Date of Modification__ 9/16/02

Project Participant Requesting Modification___ Sweeney/Bratton

Project Participant Responsible for Modification__Sweeney

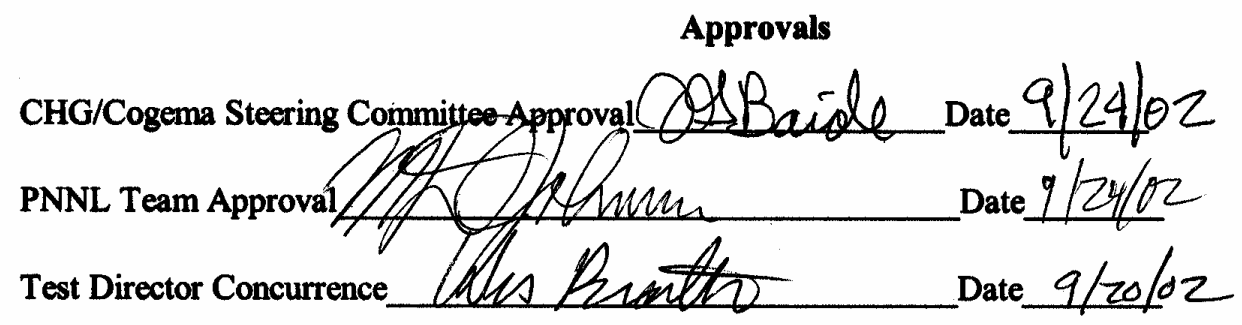

The completed form will be attached to the field log book maintained by PNNL for the 2002-2003 Performance Evaluation Test. Custodians of the log book are M. D. Sweeney (373-0703) and M. D. Johnson (376-5771). 


\section{Project Change Agreement LDMM Ex-Tank Leak Performance Evaluation Test FY 2002-2003}

The undersigned project participants hereby agree to the following modifications to the performance evaluation test:

Description of Modification to Test:

The test matrix was revamped based upon the results presented for the mid-test review workshop. The changes to the matrix included:

1) Larger leak volumes to gather data for assessing performance in the 3000 to 5000 gallon range.

2) Incorporation of additional tests at 2, 10,20 gph to be used as a calibration set for the HRR slope methods.

3) Incorporation of five days of testing without the sheetpiling wall connected to further evaluate the effect of nearby metal walls on the technologies.

4) Combination of all addition rainfall simulation events into a single large flood type event applied to only half the site.

Impact if Modification Not Approved:

Insufficient data to evaluate methods based upon method triggering levels.

Effective Date of Modification: $10 / 16 / 02$

Project Participant Requesting Modification: Wes Bratton, VET

Project Participant Responsible for Implementing Change: Mike Johnson, PNNL

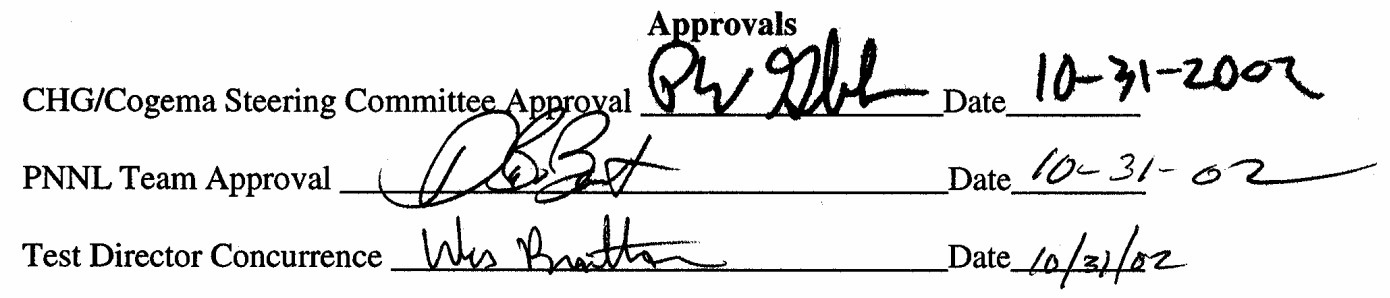

The completed form will be attached to the field log book maintained by PNNL for the 2002-2003 Performance Evaluation Test. Custodians of the log book are M. D. Johnson (376-5771) and M. D. Sweeney (373-0703). 


\section{Attachment F}

Details of Data Collection, Processing, and Interpretive Techniques Planned for FY 2002 LDMM Long Electrode and Point Electrode Performance Evaluation Testing 



\title{
Attachment F
}

\section{Details of Data Collection, Processing, and Interpretive Techniques Planned for FY 2002 LDMM Long Electrode and Point Electrode Performance Evaluation Testing}

\author{
Submitted by: William Daily and Abe Ramirez \\ Lawrence Livermore National Laboratory \\ Livermore, CA 94550 \\ Andrew Binley \\ University of Lancaster \\ Lancaster, UK LA1 4YQ
}

Date: June 10, 2002

\subsection{Introduction}

\subsection{Purpose}

This external tank leak lead detection method depends on the proposition that any leak from a single shell tank at Hanford will create a plume in the subsurface which is more electrically conductive than the native soil. With an appropriate measurement of the subtank soil electrical resistivity, this conductive plume can be detected and the presence of a leak inferred. There is no known mechanism for relating the leak rate to the subsurface electrical conditions, however, a leak rate can be estimated by comparing subtank soil conditions at two different times.

The purpose of this work is to test the performance of several methods of measuring and interpreting subtank electrical property changes to detect the presence of a leak, to estimate the volume of fluid leaked, and to estimate the rate of leakage.

\subsection{Methods}

Four methods will be examined to determine the subtank electrical properties:

1-Bulk apparent resistivity measured using dry wells as electrodes.

2-Two dimensional tomography images of resistivity changes using dry wells as electrodes

3-Bulk apparent resistivity measured using the point ERT arrays as electrodes

4-Three dimensional tomography image of resistivity changes using point ERT arrays as electrodes. 
Methods 1 and 3 can easily be used to define a leak/no leak flag. This is the case because each method yields a single number, bulk apparent resistivity, representing the electrical conditions under the tank and it is a simple matter to define statistically meaningful errors for these numbers. Therefore, if the bulk apparent resistivity changes from baseline by an amount larger than these errors, a leak condition flag is set. On the other hand, if the bulk apparent resistivity changes (we note here that a quantity measured at two different times will always be different if only by measurement errors) by an amount smaller than these errors, a no leak condition flag is set. [The actual threshold values will be defined later.] This bulk resistivity approach provides necessary but not sufficient evidence to conclusively establish a leakage condition. For example, movement of a pre-existing plume can provide a change similar to the development of a new plume. Thus, a leak condition can only be established with high degree of confidence by including results from methods 2 and 4 above.

Methods 2 and 4 can be used to determine a leak condition as well as allow estimates of leak volume. This is the case because each method yields an image of the resistivity distribution under the tank. It is not a simple matter to define a statistically meaningful error to these images. However, if a leak is present, the image of the resulting plume and especially its movement and growth over time, its location, and its magnitude are valuable diagnostics of the leak. This change in the image helps us to distinguish between movement of a pre-existing plume and the development of a new plume. This plume information can be difficult to quantify in the same way as the bulk apparent resistivity was quantified for methods 1 and 3; however, it is important information and should be used because it allows the use of expert judgment and comparisons to prior knowledge regarding the movement of subsurface plumes. We plan to use these images to help set a leak condition in the following way: a leak condition will be defined if two conditions are met. The first is that both flags from methods 1 and 3 have been set for a leak condition. The second is that the authors of this proposal (Daily, Ramirez and Binley) concur that the 2 and 3D images support the conclusion of a leak condition based on a comparison of data errors and magnitude of the changes in the images.

The algorithm we have just described for determining a leak condition contains both objective and subjective criteria. We believe that this is the best approach because excluding the subjective part would mean ignoring important data that is difficult to quantify-qualitative information in the images pertaining to plume behavior. Such information can be included by using the knowledge and experience of specialists.

\subsubsection{Brief description of FY 01 work as basis for continuation}

\subsection{Information from Historical Electrical Methods (e.g., the 1973-1978 Reports)}

- Differences in instrumentation/configurations between the Boeing and other systems, and the three electrical systems to be used for FY -2002 testing at Mock Tank? Earlier systems used electrical methods to determine the bulk electrical environment of the tank. This included the soil around as well as the soil under the tank. The Boeing system used a balanced bridge circuit to accomplish this and because such bridges have a very high ' $Q$ ', the method had a very good sensitivity to changes in soil conditions. All the earlier systems could determine the leak volume only by assuming that changes in the bulk conditions (averaged over the 
entire target volume) were proportional to the leak volume. None of the systems could provide information about the leak location.

- Implications of 1975-1976 results for future testing. These early method demonstrate that electrical methods are very sensitive to changes in electrical properties in the soil beneath the tanks. This is important because it means that the response of the tank itself does not dominate the measurement. Therefore, we have an empirical basis for the using ERT methods to detect and characterize plums under the tanks.

- Suggested modifications, if any, to testing procedures and instrumentation as a result of historical tests. We suggest that no changes be made to the Mock tank site or the Performance testing procedure based on this early work.

\subsection{FY 2002 Electrical Measurements of SST S-112}

\subsection{Test Objectives}

The purpose of this work is to establish the electrical similarity of the Mock Tank site to S-112 tank site to determine if the Mock Tank requires modifications for the tests this summer. We accomplish this objective by determining the effective electrical resistivity of S-112 and comparing it with that of the Mock Tank. We also compare the expected sensitivities under S-112 and Mock Tank assuming that long electrodes are used.

\subsection{Test Measurements}

Resistance measurements were made on 4/8/02 in the vicinity of S-112 using nearby dry wells as long electrodes. In addition, thermocouple trees in some of the tanks were used as electrodes (only as receivers, not as transmitters); we expect that when a thermocouple tree is used, the whole tank becomes an electrode.

All measurements were made with the Zonge data acquisition system owned by LLNL. An analogue ohm meter was also used to make some 2 pole measurements. However, we use 4 pole measurements exclusively for the analysis reported herein. Figure 1 shows the tank and dry well layout in plan view.

Point electrodes were also deployed along the surface, south of S-112. The purpose of this survey was to establish the bulk resistivity of the soils around S-112.

\section{Methodology}

We used the resistance measurements made around S-112 and the Mock Tank together with numerical forward and inverse models to estimate the effective electrical resistivity of the tank. We have used several approaches to calculate the estimate:

1) Comparisons between the measured data and calculated data for a range of contrasts (tank to soil). The tank to soil contrast that produced the smallest RMS difference should identify the most likely resistivity for the tank. A 3D finite difference technique was used to calculate the predicted potential fields.

2) Inversion of the measured data to produce tomographic images of the tank resistivity. These inversions were made in a variety of ways (e.g. different starting models, different electrode 
configurations) to get a range of values that cluster around a center value. The range of values within a cluster gives a coarse estimate of the error in this analysis.

3) Using the values established for the resistivities of both tanks and their respective numerical models, we calculated the current densities that should be observed under each tank. We then compared the current densities under each tank to estimate differences in sensitivities that may be expected due to differences in spatial scale and electrical resistivities.

\subsection{Test Results}

\section{S112 - forward calculations for a range of tank to soil resistivity contrasts}

With this method we used the 7 electrode surface array to calculate a typical soil resistivity for the site. We then used this typical value in a 3D finite difference model to calculate potentials at each long electrode in the survey around S-112. A simple comparison of measured potentials and calculated potentials on each electrode reveals how the model matches reality. Figure 2 and 3 show these comparisons. The model accounts for S-112 and the three adjacent tanks, and assumes a given effective resistivity for the tanks and a uniform resistivity for the remaining volume. We note that the effective tank resistivity is that due to the metal shell, any coating on the shell (tar, cement, etc.) and contact resistance at the metal interface. This effective resistivity is of interest here because the resistance measurements made are sensitive to the presence of all these materials.

When only the 9 dry wells are used as electrodes, the best fit to the data was for a tank less resistive than the soil by a factor of 100 or more. The method is not sensitive to values of the tank that are less resistive than this. The analysis sets the tank resistivity at $10^{-2} \mathrm{ohm} \mathrm{m}$ or less (see Figure 2). When the thermocouple tree was added to the receiver electrodes, the tank values could be less than $10^{-2}$ to $10^{0} \mathrm{ohm}$ $\mathrm{m}$ (Figure 3). This range of values is to be expected in this type of analysis because limited data are available.

In summary, this approach indicates that S112 is at least 100 times less resistive than the surrounding soil but we cannot tell if the electrical contrast is even greater than this.

\section{S112 - Tomographic inversions - long electrodes}

With this method we use data from the electrodes at S112 to invert for values of tank resistivity assuming that we know the soil resistivity and the location and shape of the tank (i.e., we know the top and bottom boundary location). Analysis is done for two different starting models (soil to tank contrasts of 1:1 and 1000:1) and for data with (Figure 5) and without (Figure 4) the thermocouple tree as one of the electrodes. The results were very uniform, for the most part predicting a tank resistivity between $10^{-2}$ to $10^{-1} \mathrm{ohm} \mathrm{m}$. Soil resistivity was constrained at $200 \mathrm{ohm} \mathrm{m}$.

In Figure 5, where the tank is used as an electrode, note that the reconstruction tends to yield a tank outline rather than a solid body as in Figure 4, where only dry wells were used as electrodes. Figure 5 shows a reconstructed tank that is a conductive shell in-filled with relatively resistive material. The reconstruction using only the 9 dry wells (Figure 4) finds a uniformly resistive tank because the tank

\section{A. 124}


walls are so conductive that no current can flow inside the tank. Where no current flows the method has no sensitivity - i.e., the search algorithm cannot determine what the internal resistivity is. This is a pathological case. The algorithm is constrained to find the smoothest possible solution, one in which the tank volume is uniform and equal to the value at the tank wall. When an electrode is placed within the tank, the inversion algorithm has more information. If the electrode is in good contact with the tank walls (i.e., a highly conducting material connects the electrode and walls) the algorithm will find the smoothest solution and produce a result similar Figure 4. On the other hand, if the electrode in the tank is not in good contact with the liquid (resistance is comparable to that between a dry well and the tank) the algorithm will be forced to disconnect that electrode and the tank and the only way it can do this and satisfy the smoothness constraint is to make the inside of the reconstructed tank more resistive (as in Figure 5).

The lesson to learn from this result is that the thermocouple tree is not in good electrical contact with the tank contents (perhaps the tree is imbedded in dry salt-cake). This result is important for any leak detection method that requires a thermocouple tree in good electrical contact with the tank steel walls to carry current to a leak point. It is likely in S-112 that the thermocouple tree is not now in good electrical contact with the tank and that contact will change as the water content of the salt cake changes during waste retrieval. In other words, measurements that use the thermocouple tree as an electrode will be sensitive to resistivity changes within the tank walls (e.g. waste retrieval water changing the moisture content of the waste) and outside of the tank (tank fluids invading the soil around the tank).

\section{Mock Tank - Tomographic inversions - point and long electrodes}

The goal of this study is to compare the properties of S-112 and the Mock Tank. In order to be able to do the comparison, we have processed some of the data from the Mock Tank tests last summer in a similar manner to the S-112 analysis presented above. Figure 6 shows reconstructions of the Mock Tank site using point electrodes, with and without the tank as an electrode. The results are similar in the two cases and show that the tank effective resistivity is between $10^{0.5}$ and $10^{1} \mathrm{ohm}-\mathrm{m}$.

When the long electrode data are used (see Figure 7) the tank resistivity is between $10^{-0.5}$ and $10^{+0.5} \mathrm{ohm}$ $\mathrm{m}$. The long electrode results are weakly dependent on the starting model and require fixing the soil at $600 \mathrm{ohm} \mathrm{m}$. 


\begin{tabular}{|c|c|c|}
\hline S-112 Results & $\begin{array}{l}\text { Resistivity estimated } \\
\text { based on forward } \\
\text { calculations(ohm-m) }\end{array}$ & $\begin{array}{l}\text { Resistivity estimated based on } \\
\text { inverse calculation (tomograph) } \\
\underline{\text { (ohm-m) }}\end{array}$ \\
\hline Data from 9 dry wells & $10^{-2}$ & \\
\hline $\begin{array}{l}\text { Data from S-112 thermocouple tree }+ \\
9 \text { dry wells }\end{array}$ & $10^{-2}$ to $10^{0}$ & \\
\hline $\begin{array}{l}\text { Data from } 9 \text { dry wells, } \\
\text { Starting contrast }=1: 1\end{array}$ & & $10^{-2}$ to $10^{-1}$ \\
\hline $\begin{array}{l}\text { Data from } 9 \text { dry wells, } \\
\text { Starting contrast }=1: 1000\end{array}$ & & $10^{-2}$ to $10^{-1}$ \\
\hline $\begin{array}{l}\text { Data from S-112 thermocouple tree }+ \\
9 \text { dry wells, } \\
\text { Starting contrast }=1: 1\end{array}$ & & $10^{-2}$ to $10^{0}$ \\
\hline $\begin{array}{l}\text { Data from S-112 thermocouple tree }+ \\
9 \text { dry wells, } \\
\text { Starting contrast }=1: 1000\end{array}$ & & $10^{-2}$ to $10^{-1}$ \\
\hline Mock Tank Results & $\begin{array}{l}\text { Resistivity estimated } \\
\text { based on forward } \\
\text { calculations(ohm-m) }\end{array}$ & $\begin{array}{l}\text { Resistivity estimated based on } \\
\text { inverse calculation (tomograph) } \\
\underline{\text { (ohm-m) }}\end{array}$ \\
\hline Data from 128 point elec + tank & & $10^{0.5}$ to $10^{1}$ \\
\hline Data from 128 point elec & & $10^{0.7}$ \\
\hline $\begin{array}{l}\text { Data from } 16 \text { long elec, } \\
\text { Starting contrast }=1: 1000\end{array}$ & & $10^{-0.5}$ to $10^{0.5}$ \\
\hline $\begin{array}{l}\text { Data from } 16 \text { long elec, } \\
\text { Starting contrast }=1: 1\end{array}$ & & $10^{0}$ to $10^{0.5}$ \\
\hline
\end{tabular}

Table 1 summarizes the estimates of effective electrical resistivity for the S-112 and Mock Tanks.

\section{Summary and Conclusions}

We have used electrical resistance data collected near the S-112 and Mock Tanks to estimate the effective electrical resistivity of each tank, and to compare sensitivities of long electrode measurements to the sediment electrical resistivity under each tank. Due to the assumptions we had to make and the approximations used, we consider these results to be approximate but believe that reliable conclusions can be made about the relative electrical properties of the tanks.

We used a variety of methods to estimate the tanks' resistivity. The results of the various methods are summarized in Table 1 . The S-112 results range from $10^{-2}$ to $10^{0} \mathrm{ohm}-\mathrm{m}$, and the most likely value is probably $10^{-1} \mathrm{ohm}-\mathrm{m}$. Similarly, the Mock Tank values range from $10^{-0.5}$ to $10^{1} \mathrm{ohm}-\mathrm{m}$; we have picked a value near the middle of this range $\left(10^{0} \mathrm{ohm}-\mathrm{m}\right)$ as the most representative value for the Mock Tank. These results suggest that the S-112 and Mock Tank resistivities are about an order of magnitude different, and that S-112 is more conductive than the Mock Tank. 
We note that the estimated resistivities are much larger than those of fresh carbon steel $\left(10^{-8} \mathrm{ohm}-\mathrm{m}\right)$. Both tanks are steel construction and should be more or less electrically equivalent except for important construction details such as coatings on the steel (tar paper, rust) and soil-metal contact resistance. We believe these details dominate the results we report.

The data indicate that S-112 appears more conductive than the Mock Tank by a factor of about 10. This implies that the tar coating on S-112 is no longer resistive or that the concrete top is dominating the response. The results also imply that the contact impedance of the Mock Tank is relatively high, most probably due to very dry soil at shallow depths and/or rust on the metal.

This finding also implies that sensitivity results from the Mock Tank tests will not be directly applicable to S-112. Since S-112 is more conductive and it presents a larger volume than the Mock Tank, more current will be shunted away from the region of interest below the tank, especially for long electrode work. Therefore, for a given source current, the current density below S-112 will be lower than below the Mock Tank and this translates into a lower sensitivity to changes in resistivity below S-112.

This principle is illustrated in Figure 8 where we compare the calculated current density for the two sites. The calculations show that the current density is about 3 times larger at the bottom center (the worst case) of the Mock Tank than in that location at S-112. While this is not a surprising result, we do believe that the Mock Tank results from this summer will be approximately three times more sensitive to leaks as will S-112 results during waste retrieval.

The current density differences are caused by two factors: (a) the differences in effective resistivity and size of each tank and (b) the difference in electrode separation and electrode length in the two cases. Contributions from these effects are separated by comparing current density for the two cases with the tanks present (Figure 8) and without the tanks present (Figure 9) in the model calculations. Without the tanks, the current density just below where the tanks would have been is about 3 times larger at the Mock Tank site than at S-112. When the tanks are present the current density is more than 5 times higher at the Mock Tank site.

However, the important conclusion is to be made by considering the two factors together, which is that the current density below the Mock Tank is about 5 times higher than beneath S-112. Therefore, we conclude that using long electrode data, sensitivity to a conducting plume will be about 5 times larger at the Mock Tank site than at S-112 and that this difference should be a factor in applying results from tests this summer to any quantitative conclusions during waste retrieval.

We have also determined that the thermocouple tree in S-112 is likely to be in poor electrical contact with the tank contents and tank wall. One possibility is that the structure is imbedded in a dry, resistive saltcake. If we use the thermocouple tree as an electrode, the coupling between it and the tank walls will change during the waste retrieval operation as the salt-cake is eroded and takes up water. This means that the measurements will be sensitive to changes in resistivity occurring within the tank as well as in the soil around the tank. The possibility of a false-positive prediction increases because of this dual sensitivity. 
Figures:

A. 128 

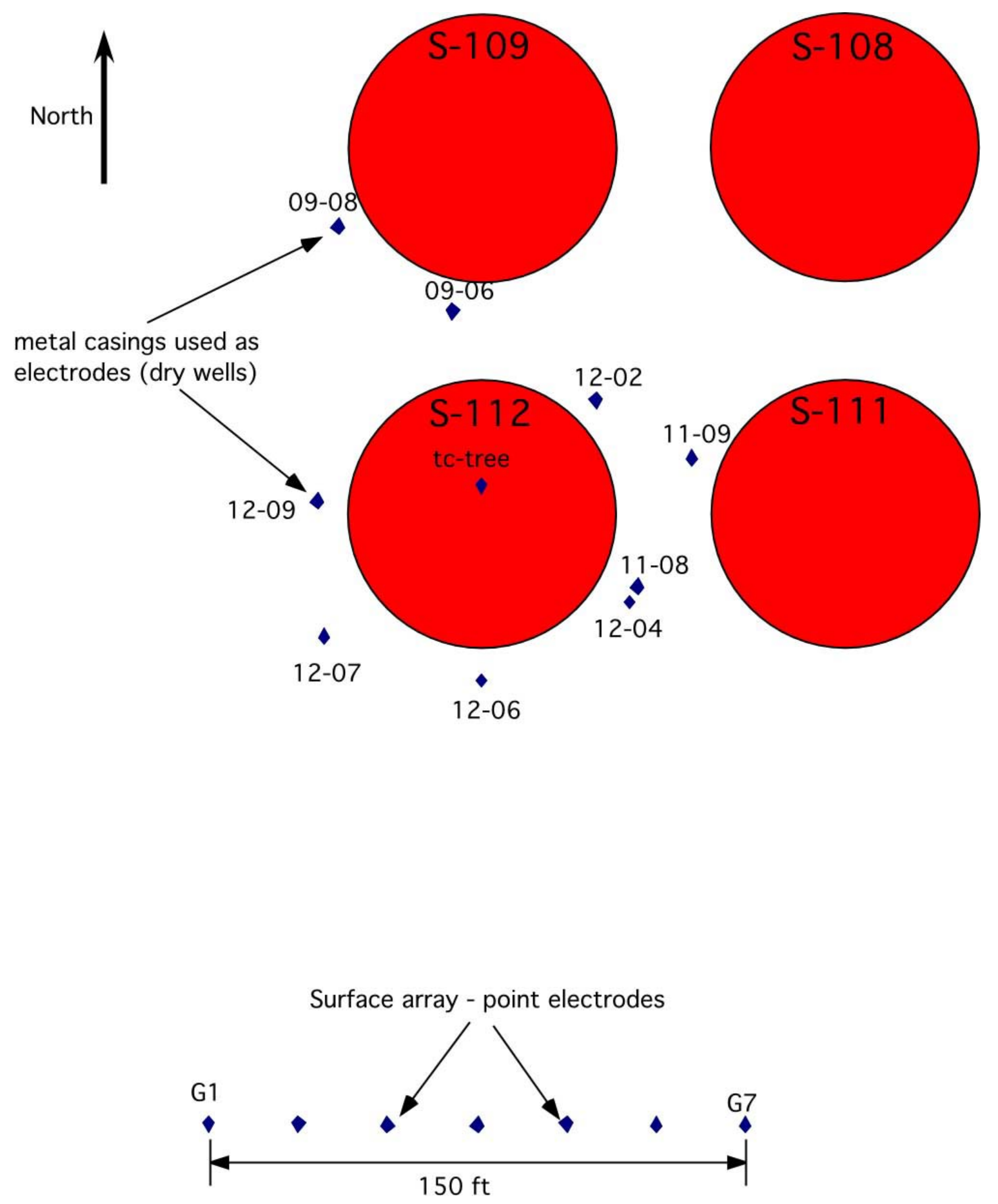

Figure 1. The location of the dry wells and thermocouple (tc) tree used as electrodes is shown. Only the dry wells and trees used to collect the data discussed in this report are shown. Also shown are surface (point) electrodes used to measure the bulk resistivity of the sediments near S-112. 


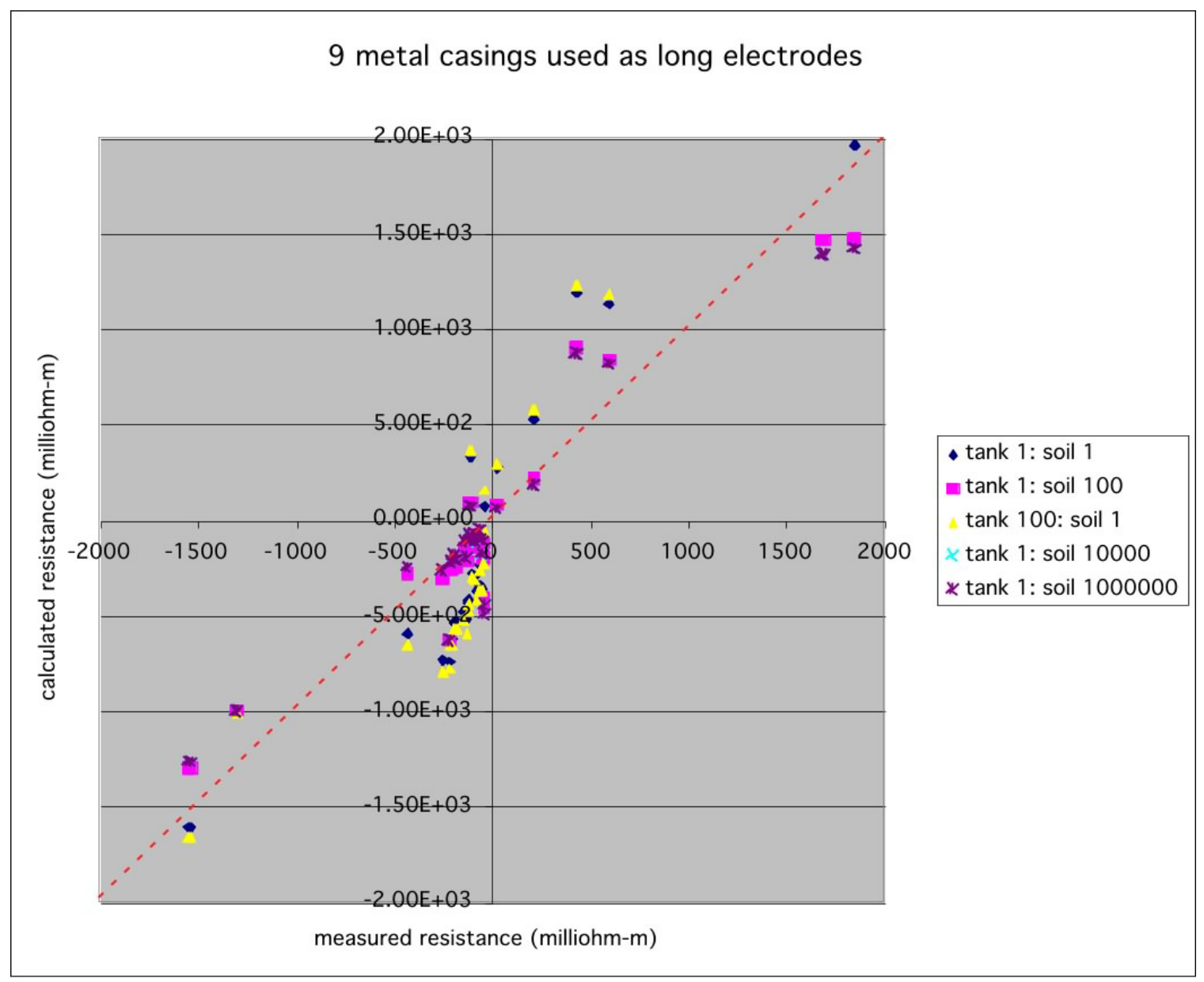

\begin{tabular}{|l|r|}
\hline Resistivity contrast (tank to soil) & root mean square difference \\
\hline 100 to 1 & 353.4 \\
\hline 1 to 1 & 314.5 \\
\hline 1 to 100 & 139.5 \\
\hline 1 to 10000 & 138.6 \\
\hline 1 to 1000000 & 138.6 \\
\hline
\end{tabular}

Figure 2 compares the measured and calculated data for various resistivity contrasts. In this case 9 dry wells were used to collect the data. The dashed red line indicates where the points would plot if there was perfect agreement between the measurements and the calculations. Also shown are the sums of the root mean squared (RMS) differences for the various plots. Note that the RMS sum reaches a minimum when the contrast is $1: 10000$. 


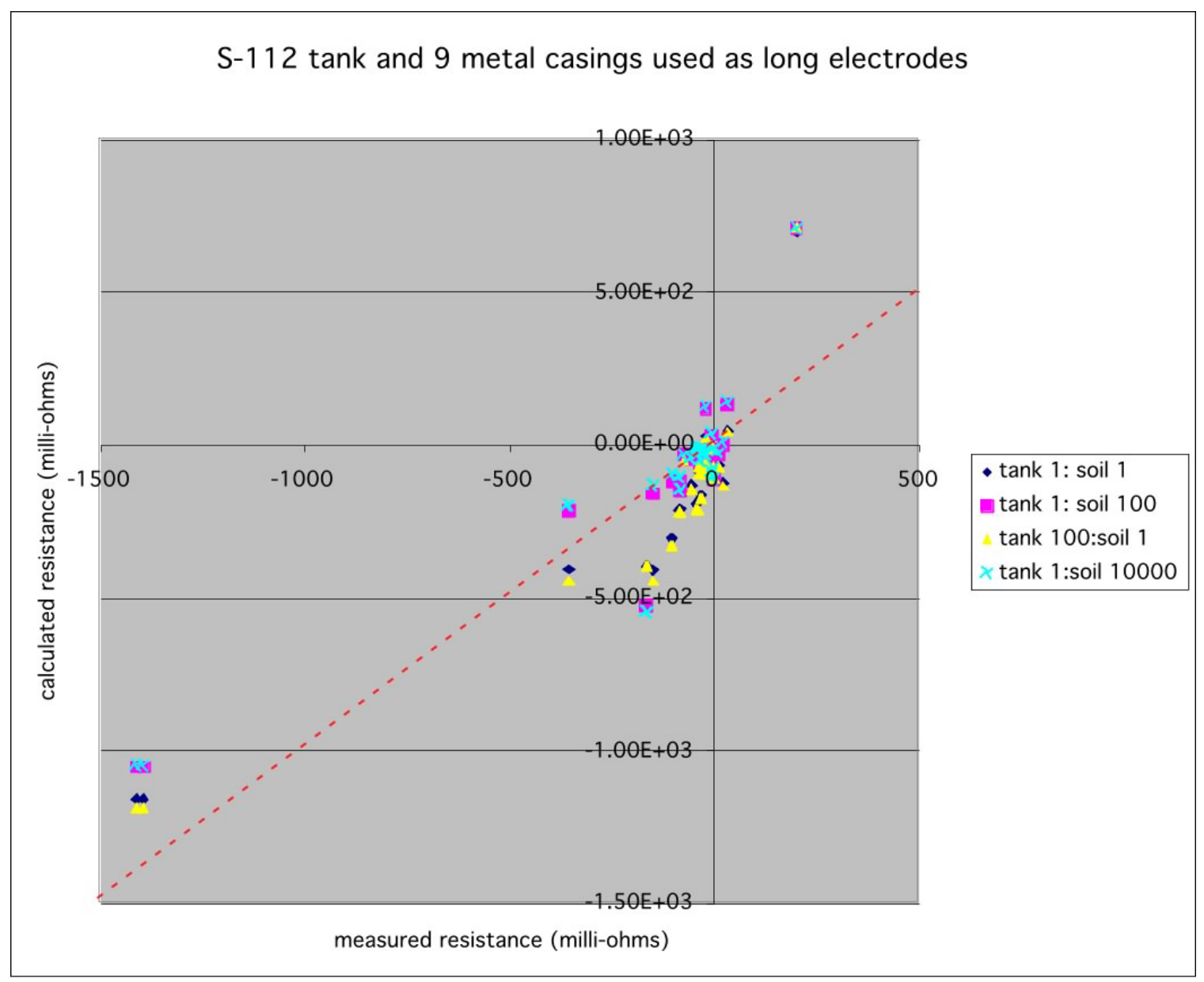

\begin{tabular}{|l|r|}
\hline Resistivity contrast (tank to soil) & root mean square difference \\
\hline 100 to 1 & 114.8 \\
\hline 1 to 1 & 107.7 \\
\hline 1 to 100 & 72.8 \\
\hline 1 to 10000 & 75.2 \\
\hline
\end{tabular}

Figure 3 compares the measured and calculated data for various resistivity contrasts. In this case the thermocouple tree in S-112 plus 9 dry wells were used to collect the data. The dashed red line indicates where the points would plot if there was perfect agreement between the measurements and the calculations. Also shown are the sums of the root mean squared (RMS) differences for the various plots. Note that the RMS sum reaches a minimum when the contrast is 1:100 but the values for the 1:10000 case is very similar. 


\section{Reconstruction of S112 Tank Electrical Resistivity using data from 9 dry wells}

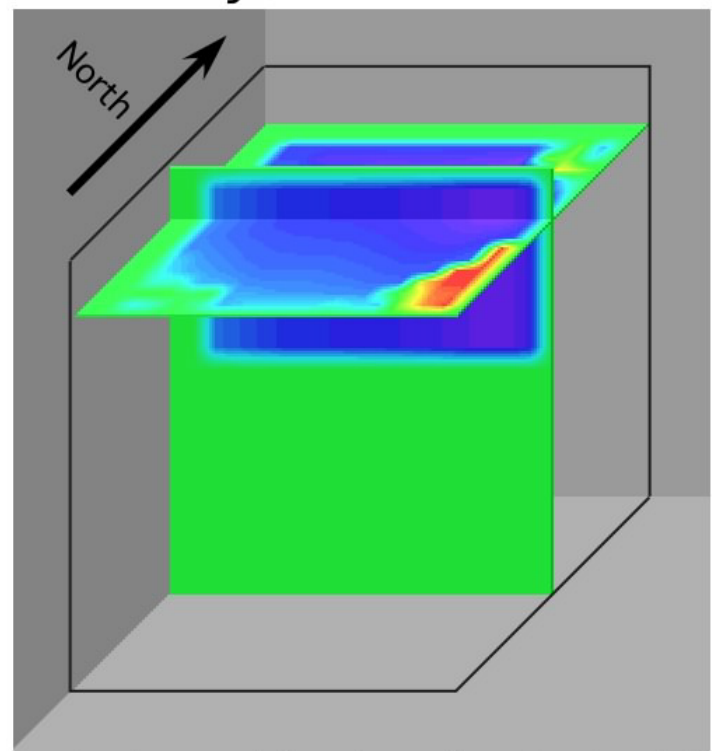

starting model tank : soil contrast $=1: 1$

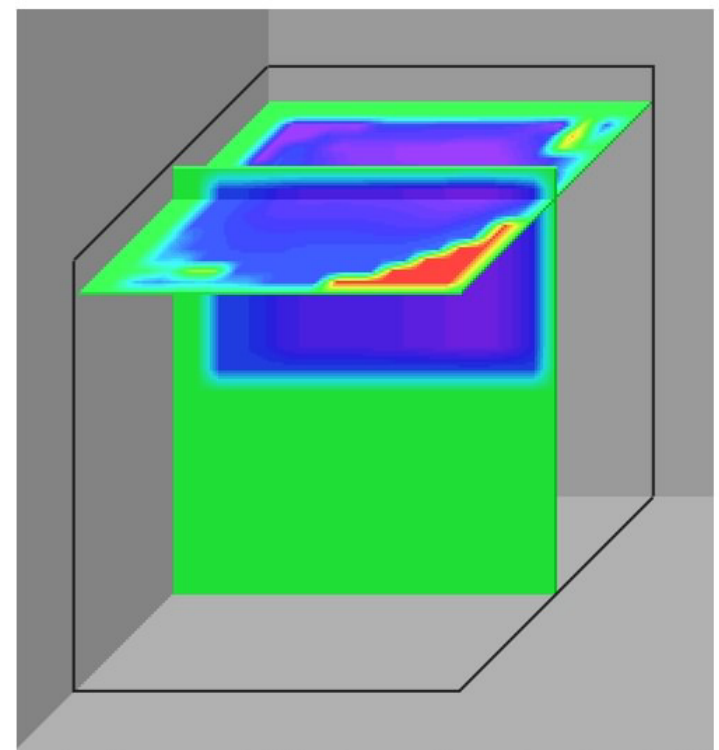

starting model tank : soil contrast $=1: 1000$

\section{$\log 10$ resistivity $($ ohm-m)

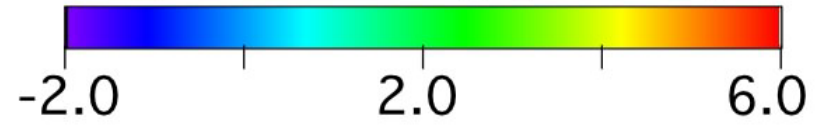

Reconstruction parameters:

1) initial condition - as specified above

2) location of tank is specified and its resistivity is allowed to change

3) sediment resistivity is fixed at $200 \mathrm{ohm}-\mathrm{m}$

Figure 4 compares two tomographs showing the resistivity for S-112. In this case, 9 dry wells were used to collect the data. Two starting models were assumed for the inversions: for the left tomograph, the tank to soil resistivity contrast is $1: 1$; for the right tomograph the contrast assumed is 1:1000. The inversions were constrained to change the electrical resistivity only in the depth range occupied by the tank. The properties of the surrounding sediment remained fixed at $200 \mathrm{ohm}-\mathrm{m}$. 


\section{Reconstruction of S112 Tank Electrical Resistivity using data from S-112 thermocouple tree and 9 dry wells}
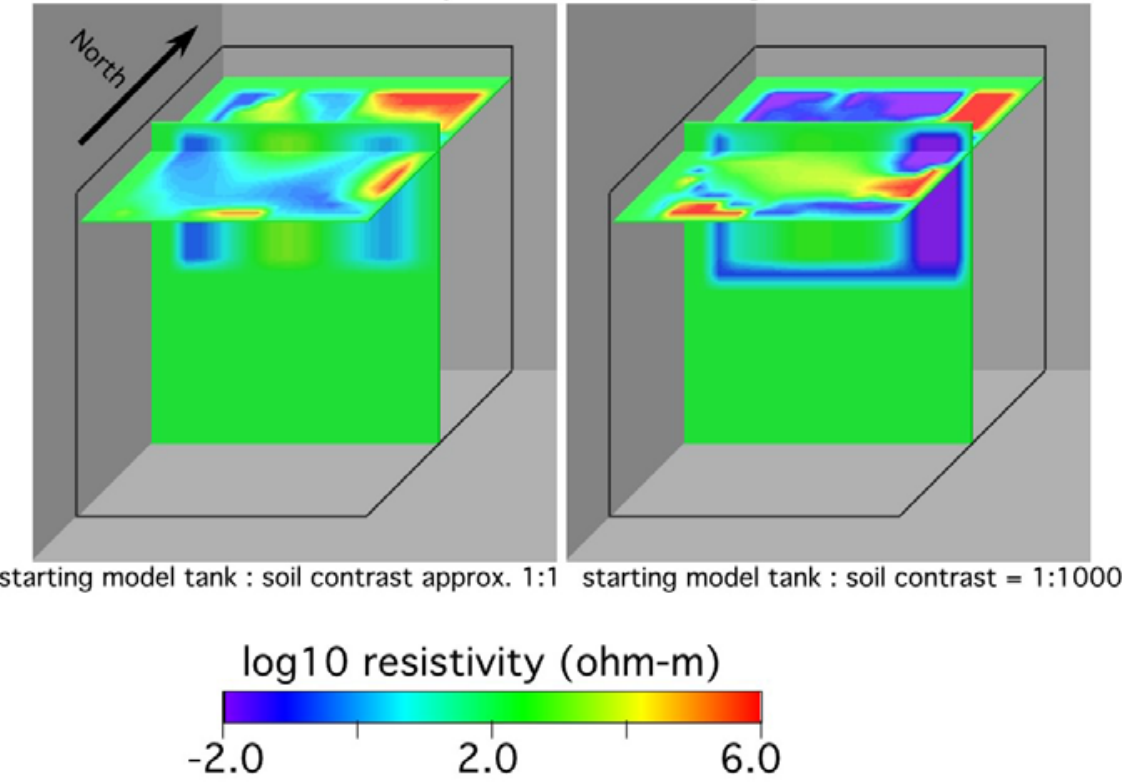

Reconstruction parameters:

1) initial condition - as specified above

2) location of tank is specified and its resistivity is allowed to change

3) sediment resistivity is fixed at $200 \mathrm{ohm}-\mathrm{m}$

Figure 5 compares two tomographs showing the resistivity for S-112. In this case, the S-112 thermocouple tree and 9 dry wells were used to collect the data. Two starting models were assumed for the inversions. For the left tomograph, the tank to soil resistivity contrast is 1:1; for the right tomograph the contrast assumed is 1:1000. The inversions were constrained to change the electrical resistivity only in the depth range occupied by the tank. The properties of the surrounding sediment remained fixed at 200 ohm-m. 


\section{Reconstruction of Mock Tank Electrical Resistivity}

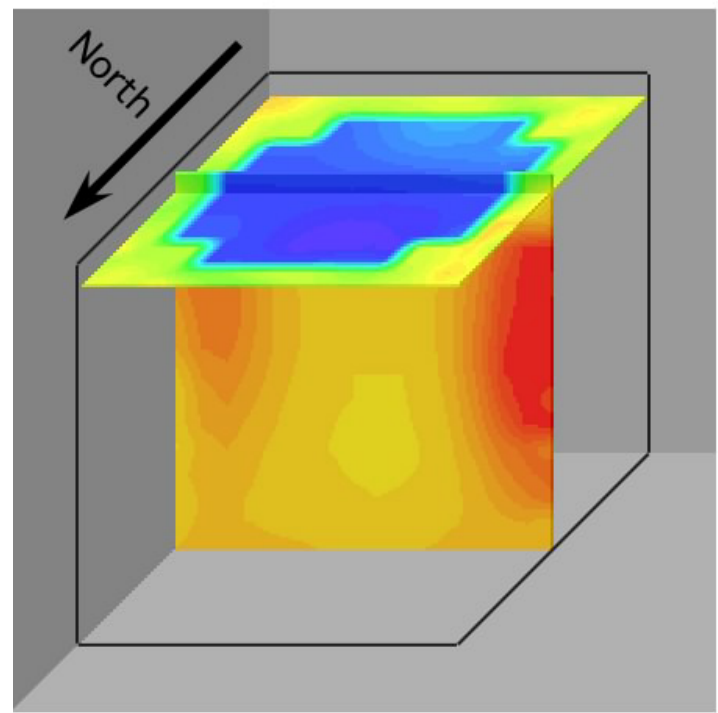

tank +128 point electrodes used

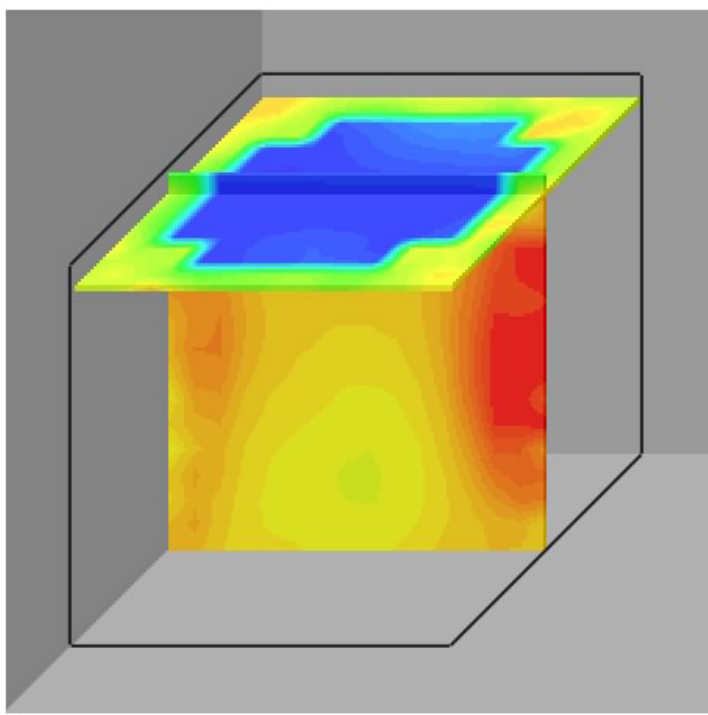

128 point electrodes used

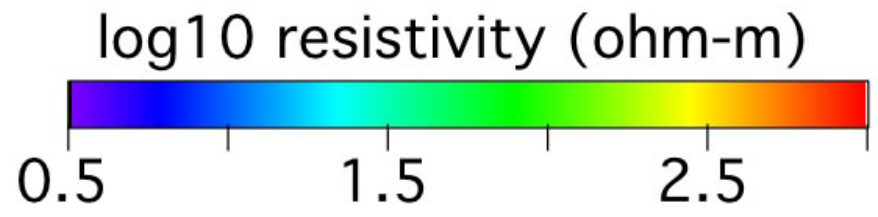

Reconstruction parameters:

1 ) initial condition - homogeneous half-space with a resistivity of $1000 \mathrm{ohm}-\mathrm{m}$

2) location of tank is specified and its resistivity is allowed to change

3) sediment resistivity is allowed to change

Figure 6 compares two tomographs showing the resistivity for The Mock Tank. For the left tomograph, the tank was used as an electrode together with 128 point electrodes; for the right tomograph, only data from the 128 point electrodes was used. The properties of the tank and surrounding sediments were allowed to change. 


\section{Reconstruction of Mock Tank Electrical Resistivity using data from 16 long electrodes}

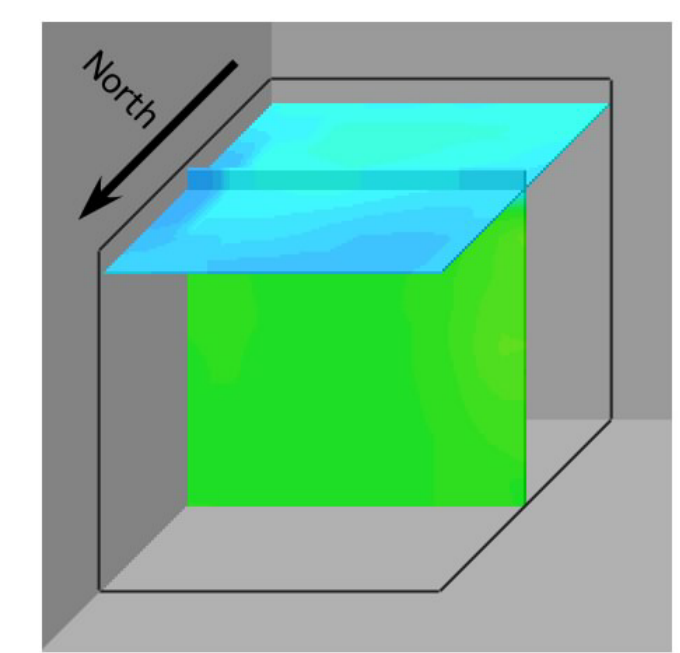

starting tank : soil contrast approx. 1:1

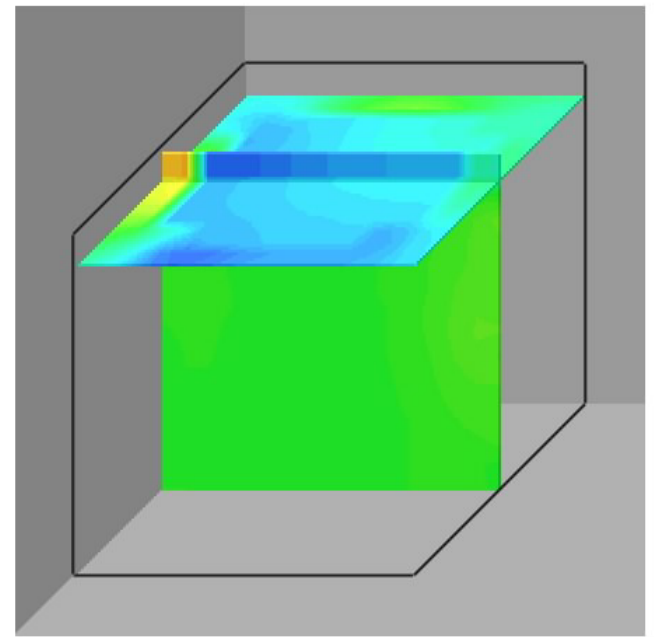

starting tank : soil contrast approx. 1:1000

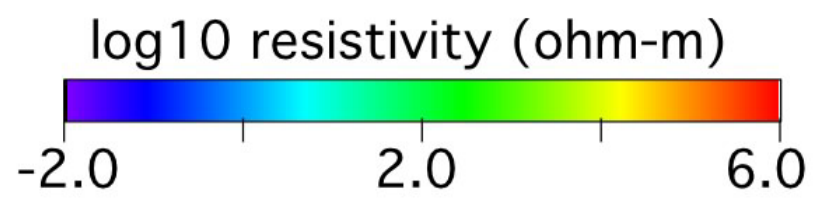

\section{Reconstruction parameters:}

1 ) initial condition - as specified above

2) location of tank is specified and its resistivity is allowed to change

3) sediment resistivity is fixed at approximately $600 \mathrm{ohm}-\mathrm{m}$

Figure 7 compares two tomographs showing the resistivity for The Mock Tank. In this case, 16 long electrodes were used to collect the data. Two starting models were assumed for the inversions. For the left tomograph, the tank to soil resistivity contrast is $1: 1$; for the right tomograph the contrast assumed is 1:1000. The inversions were constrained to change the electrical resistivity only in the depth range occupied by the tank. The properties of the surrounding sediment remained fixed at approximately 600 ohm-m. 


\section{Current distribution under the S-112 and Mock Tanks}

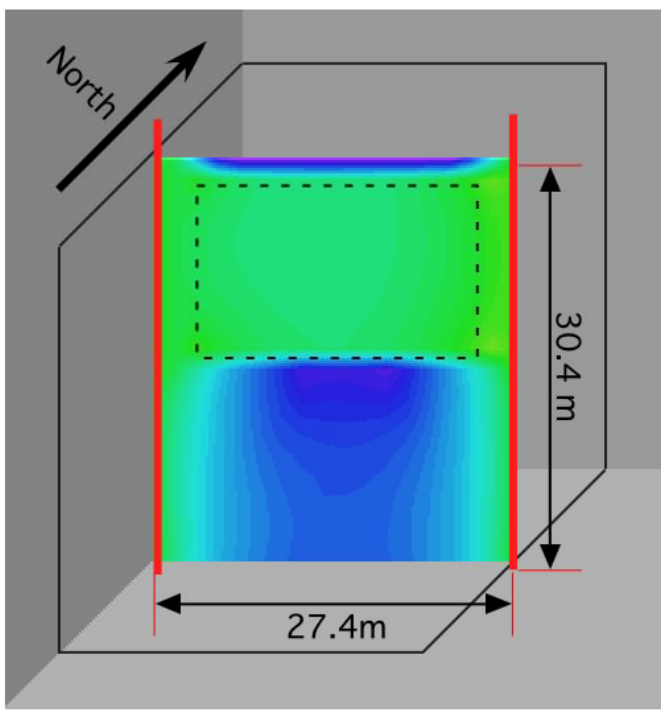

S-112 tank $($ tank $=0.1$ ohm-m, soil $=200$ ohm-m)

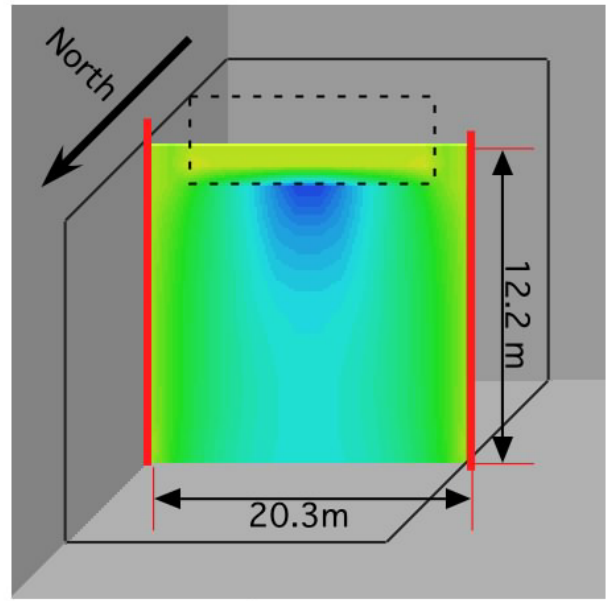

Mock tank ( tank $=1$ ohm-m, soil $=600$ ohm-m)

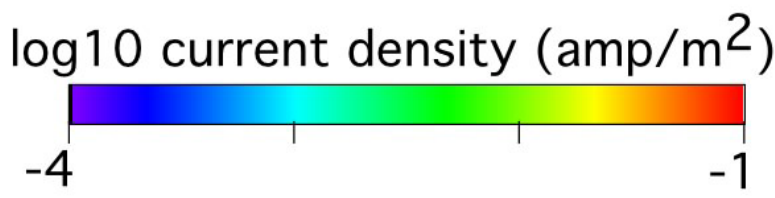

. . tank outline

long electrode location
Model parameters:

1) tanks modeled as solid structures

2) long electrodes inject $1 \mathrm{amp}$ of current

Figure 8. Calculations of current density beneath S-112 and the Mock Tank from long electrodes diametrically opposed and producing 1 amp of current. The electrical resistance measurements are most sensitive to regions showing the highest current density. Based on these calculations, we expect higher sensitivities at the Mock Tank site. 


\section{Current distribution at the S-112 and Mock Tanks sites when the tanks are not present}

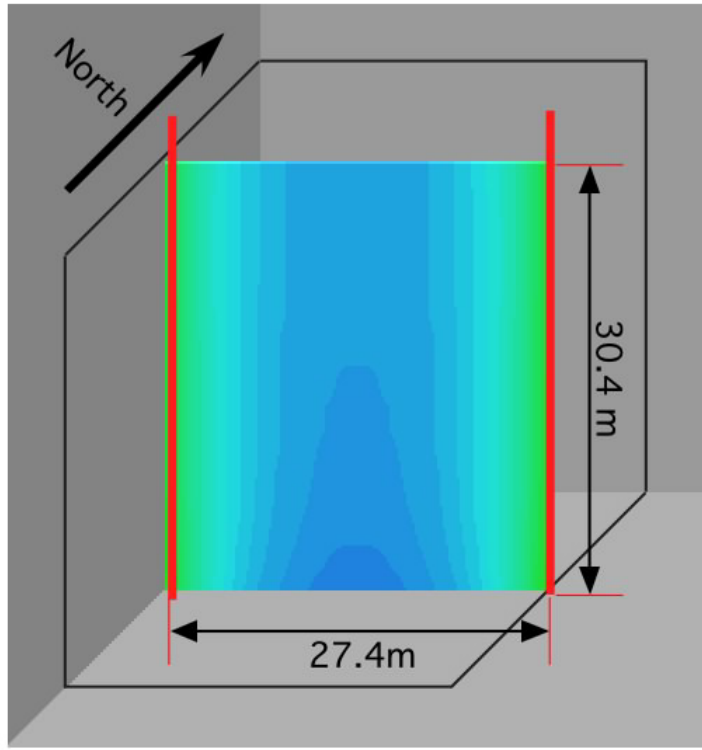

S-112 tank site $($ soil $=200$ ohm-m)

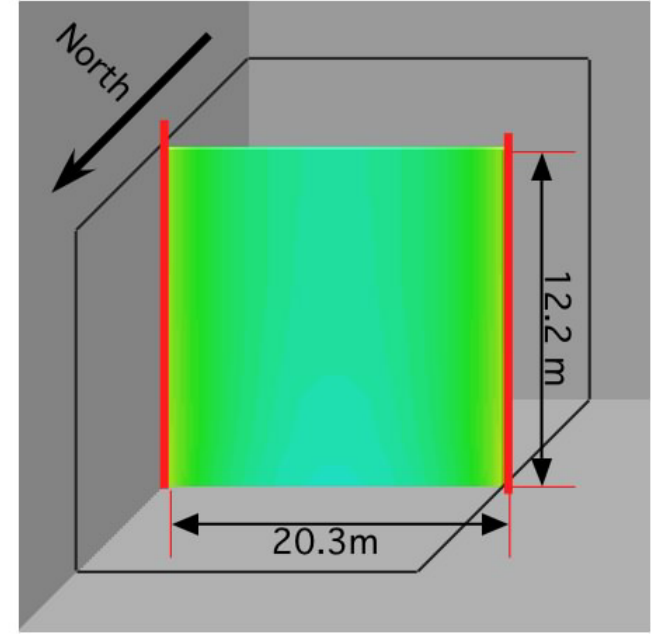

Mock tank site $($ soil $=600$ ohm-m)

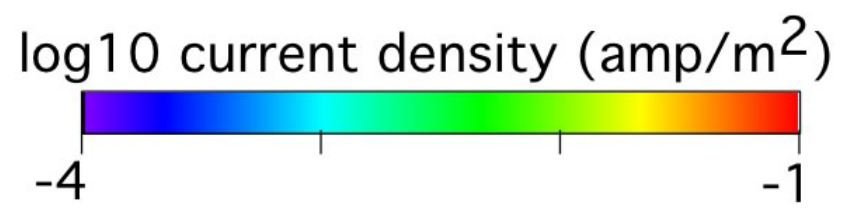

long electrode location

Model parameters:

1) tanks removed from the problem

2) long electrodes inject 1 amp of current

Figure 9. Calculations of current density when the tanks are removed from the problem. Other parameters as indicated for Figure 8. The electrical resistance measurements are most sensitive to regions showing the highest current density. Based on these calculations, we expect higher sensitivities at the Mock Tank site. 


\subsection{Conduct of FY 2002 Measurements for Performance Evaluation Testing at the Mock Tank}

- General: Where applicable, all elements are based on LDMM Performance Evaluation Test Specification)

\subsection{Description of System (provide diagrams)}

LONG ELECTRODE (ERT-LET)

ERT-LET testing requires four electrodes to take measurements of soil resistivity. Two electrodes will act at transmitter electrodes and inject current into the ground. Two electrodes will act as receivers and measure the voltage induced by the injected current. Both the transmitter pair and receiver pair of electrodes will vary among the eight long electrodes (the odd numbered fused ERT arrays). The results are processed to calculate apparent resistivity of the soil and to produce two dimensional, horizontal images of the leak in the subsurface.

\section{ERT-LET Equipment}

ERT-LET testing will be conducted using the same 8 fused ERT arrays as used in the HRR testing. A junction board will direct the electrodes to the appropriate measurement system. The measurement equipment used will be the Zonge GDP-32 receiver, ZT30 transmitter, and MX-30 multiplexer. A laptop computer is used to setup and control the ERT measurements. Figure 1 below shows the ERT system.

\section{ERT-LET Measurements}

ERT-LET measurements will be recorded at least daily during the evaluation testing. Measurements are performed by exciting one pair of odd ERT arrays and recoding the potential on other odd pairs of ERT arrays. This protocol can be described in the following way: number each of the 8 electrodes 1 through 8 . Use the following schedule for taking data where $\mathrm{x}$ is a transmitter dipole and $\mathrm{r}$ is a receiver dipole. Ignore the second and forth columns (all 1s). The third and fifth columns give the electrode number.
$\begin{array}{lllll}X & 1 & 1 & 1 & 3\end{array}$
r $1 \begin{array}{llllll} & 2 & 1 & 4\end{array}$
r $114 \begin{array}{llll}6 & 1 & 6\end{array}$
r $\begin{array}{lllll}1 & 5 & 1 & 7\end{array}$
r $\begin{array}{lllll}1 & 6 & 1 & 8\end{array}$
r $\begin{array}{llllll}1 & 8 & 1 & 2\end{array}$
$\begin{array}{llllllll}X & 1 & 2 & 1 & 4\end{array}$
r $\begin{array}{llll}1 & 1 & 1 & 3\end{array}$
r $1 \begin{array}{llll}1 & 3 & 1 & 5\end{array}$
r $\begin{array}{llll}1 & 5 & 1 & 7\end{array}$
$\begin{array}{lllll}\text { r } & 1 & 6 & 1 & 8\end{array}$
r $\begin{array}{lllll}1 & 7 & 1 & 1\end{array}$
X 1315
r $122 \quad 14$
r 14416 

r $\begin{array}{llll}1 & 6 & 1 & 8\end{array}$
r $\begin{array}{llll}1 & 7 & 1 & 1\end{array}$
r $\begin{array}{llll}1 & 8 & 1 & 2\end{array}$
X 14416
r $\begin{array}{llll}1 & 1 & 1 & 3\end{array}$
r $\begin{array}{llll}1 & 3 & 1 & 5\end{array}$
r $1 \begin{array}{llll}1 & 5 & 1 & 7\end{array}$
r $\begin{array}{llll}1 & 7 & 1 & 1\end{array}$
r $\begin{array}{llll}1 & 8 & 1 & 2\end{array}$
X 1517
r $\begin{array}{llll}1 & 1 & 1 & 3\end{array}$
r 12214
r 14416
r $\begin{array}{llll}1 & 6 & 1 & 8\end{array}$
r $\begin{array}{llll}1 & 8 & 1 & 2\end{array}$
$\begin{array}{lllll}\text { X } & 1 & 6 & 1 & 8\end{array}$
r $\begin{array}{llll}1 & 1 & 1 & 3\end{array}$
r $\begin{array}{llll}1 & 2 & 1 & 4\end{array}$
r $133 \quad 15$
r $1 \begin{array}{llll}1 & 5 & 1 & 7\end{array}$
r $\begin{array}{llll}1 & 7 & 1 & 1\end{array}$
$\begin{array}{lllll}X & 1 & 7 & 1 & 1\end{array}$
r $1 \begin{array}{llll}1 & 2 & 1 & 4\end{array}$
r 13315
r 14416
r $\begin{array}{llll}1 & 6 & 1 & 8\end{array}$
r $\begin{array}{llll}1 & 8 & 1 & 2\end{array}$
X 1812
$\begin{array}{lllll}\text { r } & 1 & 1 & 1 & 3\end{array}$
r 11315
r 14416
r 15517
r $\begin{array}{llll}1 & 7 & 1 & 1\end{array}$

\section{ERT-LET Data Processing Description}

ERT-LET measures the bulk apparent resistivity of the soil between the electrodes. This data will be processed in two different ways to detect a leak during the test. 
The first method will use the distribution of apparent resistivities calculated during the test from the resistances. Standard statistical significance tests will be applied to two distributions, one as a baseline and one measured later in the test, to determine if the two distributions represent the same population. If so, a no leak condition will be set. If not then a leak condition will be set.

The apparent resistivity is calculated by weighting each resistance measurement by a geometrical factor, transforming it into the resistivity that would be necessary to produce the measurement if the soil were entirely uniform. This weighting factor is only a function of the geometrical arrangement of the electrodes. It is found by solving the forward electrostatic problem, for a homogeneously resistive half space. We can write

$$
\rho=G R_{t}
$$

Here $\rho$ is the resistivity, $\mathrm{R}_{\mathrm{t}}$ is the measured transfer resistance and $\mathrm{G}$ is the geometrical or weighting factor (see Keller and Frischknecht, 1966, or Hearst et al., 2000). For example, for point electrodes at significant depth, it can be shown that:

$$
G=2 \pi\left(\frac{1}{C_{1} P_{1}}-\frac{1}{C_{1} P_{2}}-\frac{1}{C_{2} P_{1}}+\frac{1}{C_{2} P_{2}}\right)
$$

where $\mathrm{C}_{1} \mathrm{P}_{1}$ is the distance between the positive current pole and the positive potential pole, $\mathrm{C}_{1} \mathrm{P}_{2}$ is the distance between the positive current pole and the negative potential pole, $\mathrm{C}_{2} \mathrm{P}_{1}$ is the distance between the negative current pole and the positive potential pole, and $\mathrm{C}_{2} \mathrm{P}_{2}$ is the distance between the negative current pole and the negative potential pole.

The second method will use the $2 \mathrm{~d}$ reconstructed image of the volume under the tank. This method will yield a 2D image of resistivity changes as previously described in our final report for the 2001 Mock Tank work. Details of the computer algorithms are discussed later in Section 5.

\section{POINT ELECTRODE}

ERT-PET operates in much the same way as the ERT-LET configuration. The difference being each array consists of eight point electrodes rather just one long electrode. The eight even numbered ERT electrodes will be used in the point electrode configuration for the ERT-LET measurements. The PET configuration creates three dimensional images of the subsurface. The measurement equipment is the same as the ERT-LET and is shown in Figure 1.

\section{ERT-PET Measurements}

ERT-PET measurements are performed by exciting a pair of the point electrodes and measuring the potential on each of the remaining pairs. This is the most detailed and rigorous(offering the highest resolution and robustness) leak detection methods to be evaluated and requires many more measurements. The 8 even numbered electrode arrays consists of 64 electrodes and from these 64 electrodes a total of 3136 measurements of transfer resistance will be made. The exact sampling scheme will be determined after some sample data is acquired. From this sample data signal levels will be known and these will be used to determine the sampling protocol. Once the protocol is set it will not be changed during the test. 


\section{ERT-PET Data Processing Description}

Like ERT-LET, ERT-PET measures the bulk apparent resistivity between the electrodes.

With an increased number of electrodes compared to HRR-SCRT and ERT-LET and the fact that the discrete depths are known of each electrode, a three dimensional tomography image of the soil volume that has experienced a change in resistivity value can be produced. This volume is not the volume of the leak but rather the volume of the soil impacted by the leak. To determine the volume of fluid within the impacted soil volume, a model using Archie's Law will be used to calculate the volume of fluid released.

This data will be processed in two different ways to detect a leak during the test.

The first method will use the distribution of the apparent resistivities calculated from the transfer resistances measured during the test. We will compare this distribution with the distribution from the previous day to establish if there is a statistically significant change in the distribution of apparent resistivities. This method does not account for the spatial distribution of resistivity, this will be assessed with the more sophisticated imaging test carried out in the second method.

The second method will use the $3 \mathrm{~d}$ reconstructed image of the volume under the tank. This image will yield a 3D image of resistivity changes which will be used to evaluate the presence of a leak and also be used to estimate the leak volume.

Estimating the volume of the plume (i.e., the volume of soil invaded by the released solution) is relatively easy. One simply sums the volume of all voxels that exhibit a level of change that is determined to be credible. However, tank managers are not interested in the plume volume; they are very interested in knowing the released volume (i.e., the volume of liquid tank wastes that have leaked). Estimates of released volume require that we use the volume of the plume together with a petrophysical model relating resistivity to soil moisture content to estimate released volume.

The petrophysical model we chose is widely accepted and is known as 'Archie's' equation (Hearst et al., 2000). This model relates the soil's resistivity $\left(\rho_{s}\right)$ to the soil's saturation $(\mathrm{S})$, porosity $(\phi)$, and pore fluid conductivity $\left(\rho_{w}\right)$ as follows:

$$
\frac{\rho_{s}}{\rho_{w} \phi^{-m}}=S^{-n}
$$

The exponents $\mathrm{m}$ and $\mathrm{n}$ are empirically derived constants. Given that we are primarily interested in changes and that porosity is unlikely to change, we can derive the following equation:

$$
\frac{S_{a}^{-n}}{S_{b}^{-n}}=\frac{\rho_{w, b}}{\rho_{w, a}} \frac{\rho_{s, a}}{\rho_{s, b}}
$$

The subscripts $b$ and a indicate conditions before and after the soil's property change due to fluid invasion. Hearst et al. indicate that the exponent $\mathrm{n}$ is generally determined based on laboratory data and 
when such data is unavailable, an acceptable value is about $2.0+/-0.5$. Once the change in change in saturation is established, the change in pore water volume can be calculated as follows:

$$
\Delta V_{w}=\left(\frac{S_{a}}{S_{b}}-1\right) S_{b} \phi V_{v}
$$

where $\Delta V_{w}$ is the change in the volume of water in each tomograph voxel and $V_{v}$ is the volume of the voxel.. In most cases, good estimates of $S_{b}$ and $\phi$ can be obtained from geophysical well logs (neutron) and /or laboratory measurements made on core.

Equation 2 says that in order to calculate $\frac{S_{a}}{S_{b}}$ (change in saturation), we need to know $\frac{\rho_{w, b}}{\rho_{w, a}}$ (the change in pore water conductivity) and the changes in soil resistivity $\left(\frac{\rho_{s, a}}{\rho_{s, b}}\right)$. This implies that from one known value $\left(\frac{\rho_{s, a}}{\rho_{s, b}}\right)$, we need to estimate two unknown values. Clearly, this calculation cannot be performed unless one assumes the value for $\frac{\rho_{w, b}}{\rho_{w, a}}$.

We will use equations 2 and 3 to estimate $\Delta V_{w}$.

Liquid waste released from a tank will likely cause the pore water resistivity to decrease or stay the same. It is very unlikely that the pore water resistivity will increase as a result of a leak. Based on this conceptual model, we have chosen to use two estimates of $\frac{\rho_{w, b}}{\rho_{w, a}}$. In one case, we assume that $\frac{\rho_{w, b}}{\rho_{w, a}}=1$. This assumption will result in an upper bound estimate of $\Delta V_{w}$ in which we will have a high degree of confidence because we know that if $\frac{\rho_{w, b}}{\rho_{w, a}}$ is less than 1 , our estimate will over predict $\Delta V_{w}$, and that $\frac{\rho_{w b}}{\rho_{w, a}}$ is very unlikely to be less than one.

A second approach is to estimate $\frac{\rho_{w b}}{\rho_{w, a}}$ based on a re-analysis of the tomographs from last year's spills. An estimate of the range for $\frac{\rho_{w, b}}{\rho_{w, a}}$ can be obtained when the volumes released are known; this estimate will be the average change in pore water conductivity over the whole tomograph volume. The re-analysis of last year's tomographs suggests that the likely range for $\frac{\rho_{w, b}}{\rho_{w, a}}$ is 1.09 to 1.11 . We assume that for 
future releases, where an unknown volume of solution was used, the same range of values for $\frac{\rho_{w, b}}{\rho_{w, a}}$ applies. This second approach will likely yield an estimate for $\Delta V_{w}$ that is closer to the true $\Delta V_{w}$. However, we will have less confidence in it because we will not know the exact value of $\frac{\rho_{w, b}}{\rho_{w, a}}$ that should be used. Thus we will have to arbitrarily select values over that range to calculate $\Delta V_{w}$.

The ERT methods discussed here are not directly capable of estimating the leak flow rate. Neither Archie's equation (equation 2) nor any other petrophysical model that we are aware of indicates that soil resistivity is a direct function of flow rate. Indirectly, it is possible to get a qualitative flow rate estimate by looking at the increases in released fluid volume (as determined the analysis above) and dividing by the intervening time.

- electrode and connection configurations (all electrodes including surface electrodes, the numbers of each electrode types and their placement at the test site) - see figure 4 below for the numbering scheme used to identify the point electrodes and figure 5 for the long electrodes.

- Equipment Model numbers and configurations

The following is a block diagram for data acquisition consisting of

Equipment model

GDP-32

ZT-30

MX-30

Dell laptop computer

HP DC power supply (anything that will provide the current and voltage output required)

The Diagram below shows the set up for a single Mux as would be used for the manual data acquisition or for the remotely switched option. The set up for the fully automatic acquisition is the same except that three multiplexers are daisy chained together providing a 90 channel capacity (in other words this configuration will look in block form like a single Mux with 90 channels instead of 30 channels). LLNL will provide two MUX30's and PNNL will provide the third MUX30. 


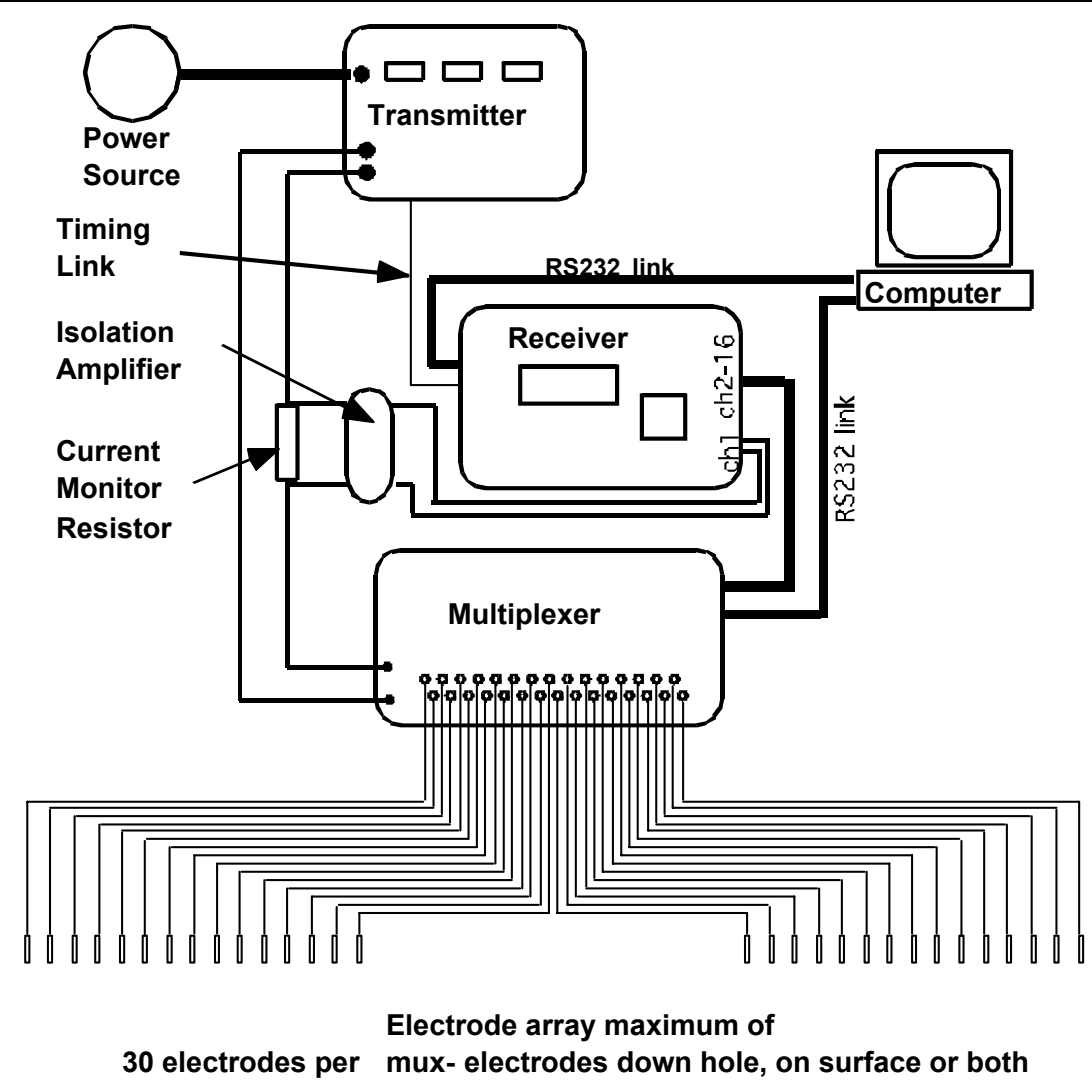

Figure 1. Measurement system used for point electrode and long electrode data acquisition.

Description of how equipment is operated and planned settings. A block diagram of the system is shown in Figure 1. Settings cannot be planned, and in fact, will change during the test to accommodate the dynamic range of the equipment, the noise level of the site and the electrical environment (like site resistivity). We plan to work at $2 \mathrm{~Hz}$ frequency.

\subsection{Description of planned sequence of measurements}

Frequency of each type of measurement

What measurements will be made (i.e. what is excited and what is measured)?

The following figure defines the connections to a single MX30 multiplexer. These diagrams are included here because they define the way measurements will be made whether we use the (a) manual connection method using a patch panel (b) automated connection method using a supplementary set of switches to connect between one Mux 30 and the electrodes or (c) automated connection method using 3 MX30's to connect to the electrodes. 


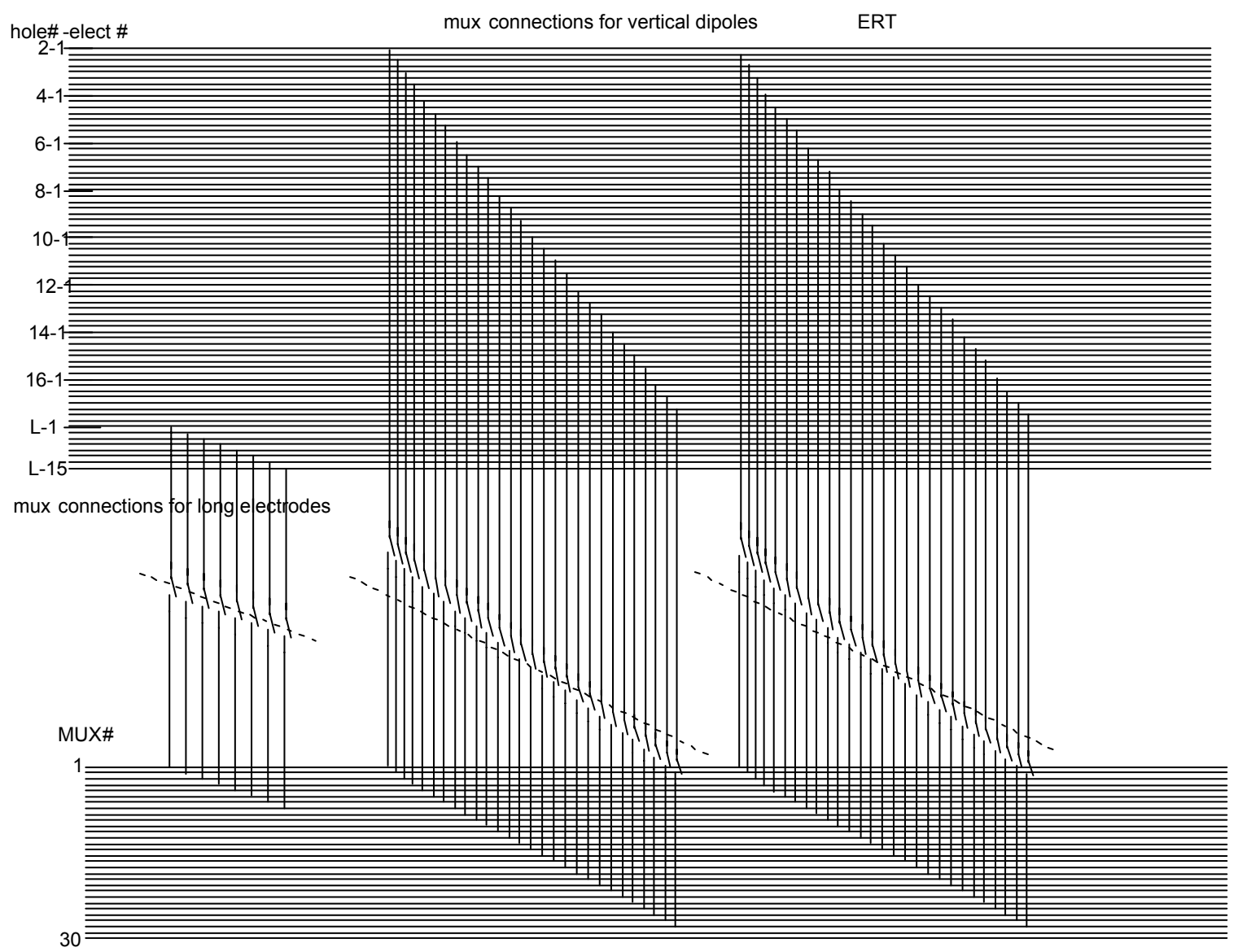

Figure 2. Electrode/Mux connections for the point electrode-vertical dipole measurement sequence (the two blocks of connections on the right of the figure) and for the long electrode measurement sequence (the 8 connections on the left of the figure). 


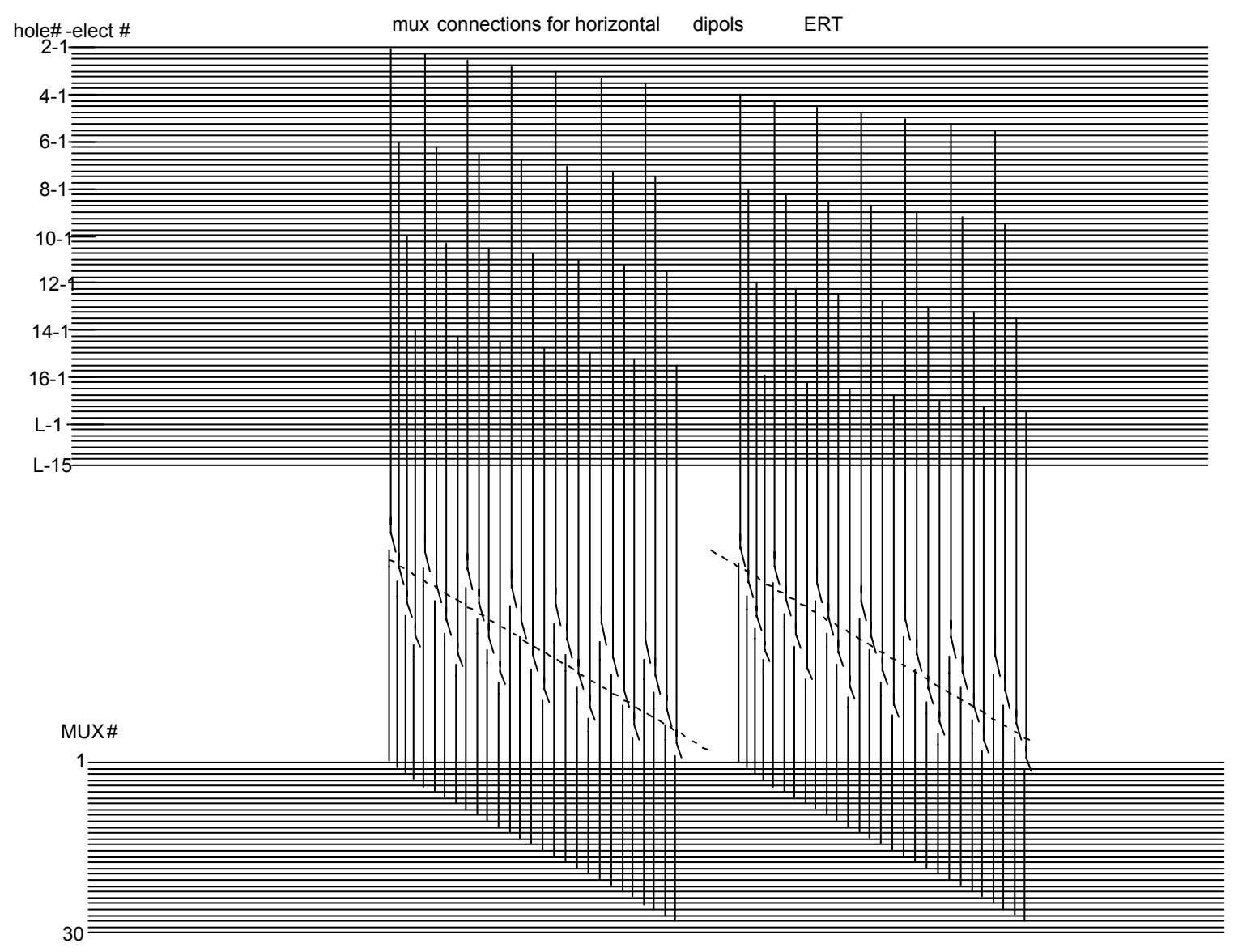

Figure 3. Electrode/Mux connections for the point electrode-horizontal dipole measurement sequence (shown in two blocks of connections).

\begin{tabular}{|c|c|c|c|c|c|c|c|c|}
\hline \multirow[t]{2}{*}{ hole \# } & 2 & 4 & 6 & 8 & 10 & 12 & 14 & 16 \\
\hline & 8 & 8 & | 8 | & 8 & 8 & 8 & 8 & 8 \\
\hline \multirow{7}{*}{ electrode \# } & 7 & $7 \mid$ & 7 & 7 & $|7|$ & 7 & 7 & 7 \\
\hline & 6 & 6 & 6 & 6 & \begin{tabular}{|l|l|}
6 &
\end{tabular} & 6 & 6 & 6 \\
\hline & 5 & 5 & $|5|$ & 5 & 5 & 5 & 5 & 5 \\
\hline & 4 & 4 & 4 & 4 & 4 & 4 & 4 & 4 \\
\hline & 3 & 3 & 3 & 3 & 3 & 3 & 3 & 3 \\
\hline & 2 & 2 & 2 & 2 & 2 & 2 & 2 & 2 \\
\hline & 1 & 1 & 4 & 1 & 1 & 1 & 1 & 1 \\
\hline
\end{tabular}


Figure 4. Electrode numbering scheme used for the 8 point electrode wells. A designation 12-6 is for the third electrode down from the surface in hole number 12. this is the numbering scheme used for the point electrode sampling in Figures 2 and 3.

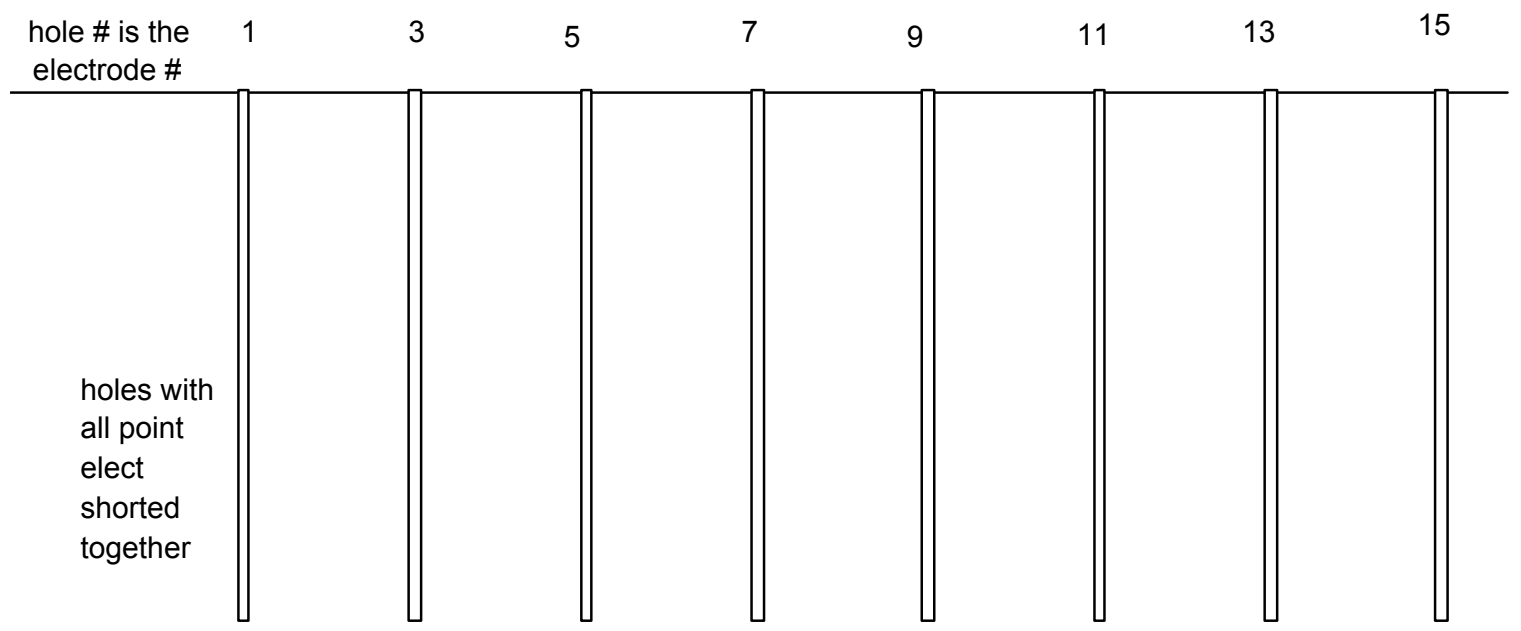

Figure 5. Electrode numbering scheme used for the 8 long electrodes. Note that each long electrode is made by shorting all the point electrodes in that well. This is the numbering scheme used in Figure 2.

The frequency at which measurements will be made has not been determined. We expect that a complete long electrode and a complete point electrode data set will be acquired at least once per day. However, more frequent collection may be necessary, especially early in the test. Data will be collected as required, dictated in part by trends we observe in the data.

How measurements are initiated? For work in manual data collection initiation will be by operator (Bill Daily) — in remote mode initiation will be from a remote computer at LLNL in Bill Daily's office.

What data is collected? All data are transfer resistance values (current normalized voltages). How and where data will be stored? Data will be stored in ASCI format on the field computer (Dell latitude laptop) and on the remote computer at LLNL.

4.3 Required infrastructure support (power, accessory supplies, tank modifications, instrument housing requirements)-We require one $20 \mathrm{amp}$ circuit of $120 \mathrm{~V}, 60 \mathrm{~Hz}$ power accessible in the work space. We request that the work space be air conditioned. The point and long electrode cables should be labeled and terminated in the work space:

(a) for manual data acquisition the termination should be banana plugs. I will connect the wires into a patch panel and then into the single Mux. 
(b) for the semi automatic data acquisition termination should be directly into the HP switching units.

(c) For the fully automatic operation termination should be by banana plugs. These will go directly into the daisy chained Muxes.

(d) We request that the cable labeling be thoroughly checked for errors. A single mislabeled cable can cause days of wasted time during the data processing.

We recommend that no modifications be made to the mock tank site to make it look electrically similar to the S-112 site.

4.4 Description of remote access of system (in consultation with HGI, PNNL)

- Describe remote end equipment and software in detail (end at LLNL)

We request an Ethernet link at the mock tank site. If a high-speed phone line is provided instead, communication will be slower and not as robust. A computer running the Zeta software (control of the GDP and Mux) will be used on the field computer. Timbuktu will link the field computer to the lab computer.

- Describe the expectations for the host end equipment and software in detail (Hanford). For manual or for semi remote operation the field computer will run the original version of Zeta (control MXGDP). For the fully automatic operation the field computer will run the version of Zeta now being tested at Zonge (yet unspecified version).

- Describe how equipment configuration control will be monitored and logged. Configuration control will be logged in a scientific note book kept by the PI. All day to day relevant data pertaining to system configuration (hardware and software) and data files will be logged into this scientific notebook.

\subsection{Contingencies for instrument/system malfunction or failure}

A complete set of Zonge system hardware (except for a MUX30) will be kept at LLNL. If needed, parts of this system will be shipped (overnight express) to Hanford to replace malfunctioning equipment. In the event of a MUX30 malfunction it will be necessary to rent a unit. Zonge Engineering has a good record for speedy repair. 


\subsection{Proposed Interpretation of FY 2002 Performance Evaluation Test Results and Analysis Algorithms}

The following protocol will be used for daily data reduction and analysis for both ERT-PET and ERTLET methods.

1) Edit the point electrode (PET) data:

-reject any reciprocal pair where the values are different by more than $5 \%$

2) Calculate the apparent resistivity for each normal and reciprocal measurement.

3) Edit the apparent resistivity values using the following criteria:

-reject any value of apparent resistivity which is greater than $1000 \mathrm{ohm} \mathrm{m}$.

4) Calculate the geometric mean for both the normal and reciprocal of the above apparent resistivity data values

4) Determine the maximum and minimum value of the mean apparent resistivity during the stable baseline measurement period. Define del as the difference between the maximum and minimum value.

5) Define threshold values th1, th3 and th 10 as 1 times del, 3 times del and 10 times del respectively as described below

6) Repeat steps 1-5 for long electrodes (LET).

Do each of the following steps, A, B and C.

A. If, during the test, the difference between two consecutive days of mean apparent resistivity is greater than th1:

-produce the 2D difference image from the long electrode data comparing resistivity between those two days. If the difference images show an anomaly under or at the edge of the tank that looks like a plume in the judgment of LLNL (Abe Ramirez and/or Bill Daily), then decide if it is necessary to process the 3D point electrode data. After considering the images, if all indications point to a plume developing under the tank, LLNL will call a leak condition code leak1 for the second of the two days under consideration. If the difference images show resistivity changes that look like rain (surface), over fitting (checkerboard), or other than a leak then a decision of no leak1 will be made.

B. If, during the test, the difference between two consecutive days of mean apparent resistivity is greater than th3:

-produce the 2D difference image from the long electrode data comparing resistivity between those two days. If the difference images show an anomaly under or at the edge of the tank that looks like a plume in 
the judgment of LLNL, then decide if it is necessary to process the 3D point electrode data. After considering the images, if all indications point to a plume developing under the tank, LLNL will call a leak condition code leak 3 for the second of the two days under consideration. If the difference images show resistivity changes that look like rain (surface), over fitting (checkerboard), or other than a leak then a decision of no leak3 will be made.

C. If, during the test, the difference between two consecutive days of mean apparent resistivity is greater than th10:

-produce the 2D difference image from the long electrode data comparing resistivity between those two days. If the difference images show an anomaly under or at the edge of the tank that looks like a plume in the judgment of LLNL, then decide if it is necessary to process the 3D point electrode data. After considering the images, if all indications point to a plume developing under the tank, LLNL will call a leak condition code leak10 for the second of the two days under consideration. If the difference images show resistivity changes that look like rain (surface), over fitting (checkerboard), or other than a leak then a decision of no leak10 will be made.

\subsection{Description of analytical/modeling code(s) or how these can be evaluated with respect to proprietary rights}

For both the $2 \mathrm{D}$ and the 3D data processing the algorithms are similar. We discuss them here although the details can be found in the following references:

Daily, W., A. Ramirez, A. Binley and D. LaBrecque, Electrical resistance tomography-Theory and practice, submitted July 2001 to Near Surface Geophysics, Dwaine Butler, Editor, Soc. Exploration Geophysicists, 2002.

LaBrecque, D. J., M. Miletto, W.Daily, A. Ramirez and E. Owen, The Effect of Noise on OCCAM's Inversion of Resistivity Tomography Data, Geophysics, 61, 538-548, March-April 1996.

For the inverse model the region is discretized into parameters, denoted here as vector $\mathbf{m}^{*}$. These may be assigned to blocks of elements, or they may be assigned to individual, elements (or cells). Because of the large possible range in earth conductivity, log transformed conductivity is normally used at the inversion parameter:

$$
m_{j}^{*}=\ln \sigma_{j}^{*} \quad(j=1, \ldots, M)
$$

where $M$ is the number of parameter blocks.

The inverse model attempts to determine the 'best' set of parameters $\mathbf{m}^{*}$ that match the data using the forward model (Equation (1) or (3)) to compute the transfer impedances for the given measurement 
configurations. If we denote the transfer impedances as $Z_{i}^{*},(i=1, \ldots, N)$, where $N$ is the number of measurements then a log transformed data vector $\mathbf{d}^{*}$ may be used, where:

$$
d_{i}^{*}=-\ln \left(Z_{i}^{*}\right) \quad(i=1, \ldots, N)
$$

The log transformation in Equation (5) is used because of the wide range in measured impedances for arbitrary electrode configurations. Note that use of the log transformation in Equation (5) requires the polarity of measured and modeled impedances to be identical, which is not necessarily guaranteed for the general ERT problem. Consequently if such an approach is used then those measurements not satisfying this criteria must not be included in the inversion process, or be temporarily neglected in the inversion until they satisfy the criteria. Because of the extra bookkeeping required the log transformation of data in Equation (5) is often not used.

The $\mathrm{L}_{2}$ measure of data misfit may be used as an objective function for which the inverse solution seeks to minimize. This is expressed as:

$$
\Psi_{d}\left(\mathbf{m}^{*}\right)=\left\|\mathbf{W}_{\mathrm{d}}^{*}\left[\mathbf{d}^{*}-\mathbf{f}^{*}\left(\mathbf{m}^{*}\right)\right]\right\|^{2}
$$

where $\mathbf{f}^{*}$ is the forward model operator and $\mathbf{W}_{\mathrm{d}}^{*}$ is a complex data weighting matrix.

Assuming uncorrelated data errors, the data weighting matrix may be expressed in terms of the data errors $\varepsilon_{i}^{*}(i=1, \ldots, N)$ as:

$$
\mathbf{W}_{\mathrm{d}}^{*}=\operatorname{diag}\left(1 / \varepsilon_{1}^{*}, \ldots, 1 / \varepsilon_{N}^{*}\right)
$$

Unfortunately due to the ill-posedness of the inverse solution for ERT, using the objective function in Equation (6) usually results in unstable solutions. To constrain the inversion, regularization is normally adopted. To achieve this it is necessary to modify the objective function to include stabilizing terms that constrain the parameter search. In general terms this composite objective function may be written as:

$$
\Psi\left(\mathbf{m}^{*}\right)=\Psi_{d}\left(\mathbf{m}^{*}\right)+\Psi_{m}\left(\mathbf{m}^{*}\right)
$$

where $\Psi_{m}\left(\mathbf{m}^{*}\right)$ is a measure of the model misfit. It can contain a measure of 'roughness', that is, how variable adjacent parameter values vary and also a measure of how much the parameters differ from some specified model, such that deviation away from this model is penalized.

Equation (8) may be expressed as: 


$$
\Psi\left(\mathbf{m}^{*}\right)=\left|\mathbf{W}_{\mathrm{d}}^{*}\left[\mathbf{d}^{*}-\mathbf{f}^{*}\left(\mathbf{m}^{*}\right)\right]^{2}+\alpha\right| \mathbf{W}_{\mathrm{m}}\left(\mathbf{m}^{*}-\mathbf{m}_{0}^{*}\right) \|^{2}
$$

where $\alpha$ is a regularization parameter, $\mathbf{W}_{\mathrm{m}}$ is a weight (or roughness) matrix that defines the spatial extent and nature of smoothing between each parameter and its neighbors and $\mathbf{m}_{0}{ }^{*}$ is a reference parameter vector, not necessarily uniform. Penalizing relative to a reference vector can be removed by assigning $\mathbf{m}_{0}{ }^{*}$ to the null vector. Similarly, smoothing between adjacent parameter blocks can be avoided by making $\mathbf{W}_{\mathrm{m}}$ a unit diagonal matrix.

The weight matrix $\mathbf{W}_{\mathrm{m}}$ may be constructed to permit anisotropic smoothing, for example forcing greater horizontal smoothing than that in the vertical. The vector $\mathbf{m}_{0}{ }^{*}$ may be expected values of $\log$ conductivity within the region or may be the result of a previous inverse model - the latter is useful for study of temporal changes with time-lapse data. The second penalty term in Equation (8) may then be viewed as a means to incorporate a priori information into the inversion. The principle role, however, is to stabilize the inversion. Care must be taken when applying these terms, in some cases, for example, a smooth model, although stable, may be inappropriate (e.g., layered media where adjacent layers have vastly different resistivity).

Regularization of this type has been well established in the literature (Tikhonov and Arsinen, 1977), however, the work of Constable et al. (1987) and deGroot-Hedlin and Constable (1990) brought wider appreciation through their applications to magnetotelluric data and coined the term Occam's inversion. Numerous variants on this approach have been used since.

Minimization of Equation (9) may be achieved through application of gradient search methods. Using the Gauss Newton approach, minimization of Equation (9) results in the iterative equations (Kemna and Binley, 1996; Kemna, 2000):

$$
\begin{aligned}
& \left(\mathbf{J}_{k}^{* \mathrm{H}} \mathbf{W}_{\mathrm{d}}^{* \mathrm{H}} \mathbf{W}_{\mathrm{d}}^{*} \mathbf{J}_{k}^{*}+\alpha \mathbf{W}_{\mathrm{m}}^{\mathrm{T}} \mathbf{W}_{\mathrm{m}}\right) \Delta \mathbf{m}_{k}^{*}=\mathbf{J}_{k}^{* \mathrm{H}} \mathbf{W}_{\mathrm{d}}^{* \mathrm{H}} \mathbf{W}_{\mathrm{d}}^{*}\left[\mathbf{d}^{*}-\mathbf{f}^{*}\left(\mathbf{m}_{k}^{*}\right)\right]-\alpha \mathbf{W}_{\mathrm{m}}^{\mathrm{T}} \mathbf{W}_{\mathrm{m}}\left(\mathbf{m}_{k}^{*}-\mathbf{m}_{0}^{*}\right) \\
& \mathbf{m}_{k+1}^{*}=\mathbf{m}_{k}^{*}+\Delta \mathbf{m}_{k}^{*}, \quad k=1,2,3, \ldots
\end{aligned}
$$

In Equation (10) $\mathbf{J}_{k}^{*}$ is the complex Jacobian (or sensitivity) matrix evaluated for the current model $\mathbf{m}_{k}^{*}$. This matrix may be computed using the principle of reciprocity (Geselowitz, 1971) as described in detail by Kemna (2000). The solution of Equation (10) may be obtained by direct or iterative methods, the latter being preferred for large problems. Zhang et al. (1995) show, for DC resistivity inversion, that it is not necessary to form the entire Jacobian matrix for conjugate-gradient type solutions and thus significant storage restrictions are avoided. Similar algorithms can be applied to the general complex resistivity problem.

Satisfactory solution of Equation (10) is dependant on appropriate assignment of regularization parameter $\alpha$ and data errors in $\mathbf{W}_{\mathrm{d}}^{*}$. The two terms are implicitly linked (see LaBrecque et al., 1996). Whereas a 
number of studies have adopted fixed values of the regularization parameter, in the approach of deGrootHedlin and Constable (1990) a search is made at each iteration $k$ of the solution of Equation (10) to find the optimum value. As the iterative procedure progresses, the value of $\alpha$ decreases as data misfit becomes more dominant towards the end of the iterative search.

Underestimation of data noise will result in poor convergence or significantly 'rough' images.

Overestimation of data noise will result in overly smooth images with degraded sensitivity and resolution. LaBrecque and Ward (1990) proposed a scheme which allows reweighting of data during the iterative

process in Equation (10). Morelli and LaBrecque (1996) have shown how this scheme may be used for 3D DC resistivity ERT. Kemna (2000) utilized this scheme for 2-D complex resistivity inversion and further incorporated a means of accounting for phase angle errors in the complex inversion. 


\begin{abstract}
Attachment G
Details of Data Collection, Processing, and Interpretive Techniques Planned for FY 2002 LDMM for HRR-SCRT

Performance Evaluation Testing
\end{abstract}




\begin{abstract}
Attachment G
Details of Data Collection, Processing, and Interpretive Techniques Planned for FY 2002 LDMM for HRR-SCRT Performance Evaluation Testing
\end{abstract}

White Paper

Details of Data Collection, Processing, and Interpretive Techniques Planned for FY 2002 LDMM for HRR-SCRT: Performance Evaluation Testing

by James B. Fink

jim@hydrogeophysics.com

Marc T. Levitt

marc@hydrogeophysics.com

Chris Baldyga

chris@hydrogeophysics.com

hydroGEOPHYSICS, Inc.

2302 N. Forbes Blvd.

Tucson, AZ 85745

(520) 647-3315

May 2002

Prepared for

Pacific Northwest National Laboratory

Richland, Washington 99532 


\section{TABLE OF CONTENTS}

1.0 Statement of the problem

1.1 Basis for electrical leak detection and monitoring

1.2 Description of HRR-SCRT

1.3 Brief description of FY 01 work as basis for continuation

2.0 Glossary

3.0 Background

3.1 Information from Historical Electrical Methods

3.2 Differences in instrumentation/configurations between the Boeing and other systems, and the three electrical systems to be used for FY -2002 testing at Mock Tank?

3.3 Implications of 1975-1976 results for future testing

3.4 Suggested modifications to testing procedures and instrumentation as a result of historical tests

4.0 FY 2002 Electrical Measurements of SST S-112

4.1 Test Objectives

4.2 Test Measurements

4.3 Test Results

4.4 Comparison of results with measurements at mock tank from FY 2001

4.5 Modifications indicated for Mock Tank based on S-112 measurements and modeling

4.6 Lessons-Learned to be applied to the Performance Testing.

4.7 Comparison of results with historical SST resistance measurements

5.0 Conduct of FY 2002 Measurements for PE Testing at the Mock Tank

5.1 Description of System

5.2 Description of planned sequence of measurements

5.3 Required infrastructure support

5.4 Description of remote access of system (in consultation with HGI, PNNL)

5.5 Contingencies for instrument/system malfunction or failure

6.0 Proposed Interpretation of FY 2002 Performance Evaluation Test Results

6.1 Declaration of a leak

6.2 Method of leak volume determination

7.0 Description of analytical/modeling code(s) or how these can be evaluated with respect to proprietary rights 


\subsection{Statement of the problem}

There are two approaches to leak detection with leaking underground storage tanks (LUSTs); in-tank and ex-tank measurements. In-tank techniques depend on some method of measuring a decrease in volume of contained solution. Ex-tank techniques depend on an increase in volume of leaked solution. The detection limits for both methods are volume-dependent. For any method, a threshold volume must be exceeded to be detectable.

The primary criterion for geophysical leak detection is that on which all geophysical methods depend; there must be a physical property contrast. A leak must produce a physical property contrast between the leaked solution and the surrounding medium into which the solution is leaked, or, the leaked solution must impact the medium in such a manner that a physical property contrast is created. Our interest is in presenting a variety of electrical geophysical methods for observing and monitoring changes in the electrical properties of the soil around a LUST. For example, a water leak into the vadose zone is detectable because water is a good conductor compared to the resistivity of the surrounding vadose zone medium.

A number of electrical geophysical methods have been used for ex-tank leak detection. General problems related to those methods are discussed in the context of the mock tank and preliminary measurements at tank S-112 in the S-tank farm. A modification of more common electrical methods is the combined use of "direct contact" or "excitation of the mass" which involves electrical contact with the contents of a tank and the associated measurement of physical property changes outside the tank.

Ex-tank measurements are generally directed towards either two- or three-dimensional imaging methods. To be imaged, a minimum threshold volume must be present outside and, to some degree, displaced from the tank. Problems related to imaging are: 1 . the leaking solution may be electrically inert, 2 . the leak rate may be very low, 3. the cultural environment around the tank may be complex, 4. the leak may be deep, and 5. there may be other constraints on placing sensors close to the tank or leak. In the case of the tank farms at Hanford, the problem is further exacerbated by the concrete and asphalt encapsulation of the tanks, their depth of burial, and the electrical contact with other grounded tanks and pipelines.

This paper deals with those problems as they were encountered at the mock tank and S-112 and how they have influenced the understanding of the geophysical results. Additionally, suggestions for future testing are presented. The orientation of the discussion is around High Resolution Resistivity (HRR) and Steel Casing Resistivity Technology (SCRT). A glossary is also included to help explain some terminology used in geophysics. 


\subsection{Glossary}

It is very difficult to discuss the leak detection methodology without using the technical jargon that goes along with it. For that reason, this glossary is offered as an aid to understanding. Those that are familiar with the terminology may skip over the glossary. Those that are not, really should read through the term definitions to appreciate the sometimes subtle differences between similar sounding terms.

\subsection{CONDUCTION of ELECTRICITY}

\subsubsection{Dielectric conduction}

The conduction of electrical current in dielectrics takes place through the displacement of bound electrons. Conduction is dynamic and occurs only during changes in the applied field. An ideal dielectric cannot conduct continuous current. Highly resistive material that conducts some continuous current is considered a "lossy" dielectric. Dry ground, such as much of the Hanford Formation, has reasonably good dielectric properties and behaves as a lossy dielectric. High dielectric constants typically represent low conductivity.

\subsubsection{Electronic conduction}

The conduction of electrical current in metals takes place through the presence of "free electrons," i.e. unbound negative electrons. An additional mode of electronic conduction is by way of positive holes or defects in semi-metals and semi-conductors. For the purposes of this white paper, conductive media other than metals are not considered. In our studies, metallic electrodes, steel well casings, and metal tanks are the electronic conductors. Total charge carrying capacity is determined by the sum of both free electrons and holes.

\subsubsection{Ionic (electrolytic) conduction}

The conduction of electrical current in electrolytic media takes place through the presence of "free ions," i.e. unbound ions. Ions may be either cations (positive ions) or anions (negative ions). Ionic conduction is characteristic of liquids but can also take place in solids. For the purposes of this white paper, electrolytic media other than liquids are not considered. In our studies vadose zone moisture is the primary conduction liquid. Leaked liquids are excellent ionic conductors. Total charge carrying capacity is determined by the sum of both cations and anions.

\subsection{ELECTROCHEMICAL CONSIDERATIONS}

\subsubsection{Charge transfer reactions}

Reduction-oxidation reactions must take place as the charge-carrying current changes from electronic to ionic as it crosses the interface between materials. The charge transfer reaction is one step in a series of steps that are involved in passing charge from metal to solution and vice versa. The study of such phenomena is called "Electrodics" and is but one aspect of the more comprehensive discipline of electrochemistry. The presence of a metal in an ionic solution will either generate a reaction (e.g. oxidizing iron) or create a conduction barrier (e.g. platinum electrodes). Driving a current across the interface forces such reactions to take place faster, cease, reverse, or create new altogether new reactions. 


\subsubsection{Contact potential}

A geophysical transmitter generates an electrical current within the electronically conducting components. It must then inject this electronic current into the ground through "grounded" electrodes between which ionic electrical conduction takes place. The simple contact between the metal stake and the moist earth gives rise to the problem of "contact potential." That problem consists of the rate-limiting, electrochemical reactions that take place between the electronically-conducting metal probes (electrodes) and the ionically-conducting earth. Virtually all metal-to-earth contacts have an associated contactpotentials. Such reactions are generally biased and flow in one direction, have a measurable potential difference, and dominate any measurement in which they are part of the circuit. Contact potential is the reason two electrode measurements are not useful in quantitative geophysics and the reason for fourelectrode measurements.

\subsection{ELECTRODES and ARRAYS}

\subsubsection{Electrode}

An electrode is a terminal or manipulated contact through which electrical current may flow for the purposes of signal injection into a circuit (or for geophysical purposes the ground) or signal detection in the circuit (or for geophysical purposes the ground).

Volumes could be, and have been, written about electrodes. The presence of a metallic object in the earth almost always generates a potential difference between the metal and the surrounding moisture. This is due to the inability of the metal and moisture to freely exchange charge and constitutes the definition of a "polarizing" electrode. The degree of polarization of the electrode depends on the metal and the chemical environment. The discipline of electrochemistry deals with such phenomena. Corrosion studies are one aspect of electrochemical engineering that deals directly with buried metallic objects.

Generally, for geophysical purposes, current injection into the ground is via metallic electrodes. This isn't absolutely necessary, but it has become a standard procedure in geophysical exploration because of the need for high power levels and large electrode surface areas.

\subsubsection{Point and linear electrodes}

A point electrode is an electrode that is sufficiently small compared to the inter-electrode spacings that it can be regarded as a point. A linear electrode is an electrode that is sufficiently long that its length must be accounted for in data reduction and modeling.

\subsubsection{Electrode array}

Since geophysical measurements are generally made on the surface of the earth, the term "array" is used to indicate the relative locations of the electrodes. Numerous arrays have been given names for the convenience of identifying the arrangement.

\subsubsection{Two-electrode measurements}

Basic voltage, current, and resistance measurements are normally made using a two-electrode connection, i.e. two probes, and rely only on electronic conduction. For linear circuits this is adequate and most 
people are quite familiar with this method. This is the type of measurement typically made with a voltohm meter (VOM).

For a two-electrode voltage measurement an analog voltmeter consists of a permanent-magnet, movingcoil, meter connected in series with the signal to be measured. The measuring circuit is completely passive, i.e. it supplies no power to the measured signal.

\subsubsection{Three-electrode measurements}

Three-electrode measurements are essentially confined to the realm of electrochemistry. A three-electrode measurement consists of a common electrode between the current driving portion of the instrument and the potential measuring portion of the instrument. Most electrochemical instrumentation is designed around this approach. Measurements using a common electrode are only viable with low currents and low voltages, such as are used in electrochemical cells.

\subsubsection{Four-electrode measurements}

Four electrode measurements consisted of paired transmitting and receiving circuits. The transmitting circuit consists of two electrodes through which a signal of controlled (or at least measured) current (I, in amperes) is injected into the medium (the ground in the case of geophysical measurements). The receiving circuit is separate from the transmitting circuit and consists of two electrodes across which a voltage is measured, or more correctly, a difference in voltage ( $\mathrm{dV}$ in volts or millivolts). The ratio of the injected current to the measured voltage $(\mathrm{I} / \mathrm{dV})$ is defined, in simple terms, as resistance, and constitutes Ohm's Law $(\mathrm{R}=\mathrm{V} / \mathrm{I})$.

\subsubsection{Separation of current and voltage circuits}

Contact potential problems are concentrated in the vicinity of the electrodes, tend to dominate the measurements, and are inherently non-linear (i.e. non-Ohmic). For this reason it is very difficult to make reliable two-electrode measurements of earth properties. The simple expedient of separating the voltage measuring circuit from that of current injection significantly decreases the contact-potential noise and has allowed electrical methods to grow to be a mature discipline within geophysics.

There are numerous electrode arrays in use in geophysics. We use what are misleadingly called; dipoledipole and pole-pole. The terminology in both cases is technically incorrect.

\subsubsection{Dipole-dipole versus pole-pole arrays}

We commonly use the term dipole to refer to two grounded electrodes, say, the transmitter pair or the receiver pair. 


\section{Dipole-Dipole Array}

The term "dipole-dipole array" refers to two equal-length transmitting and receiving dipoles, not necessarily, but usually, oriented collinearly on the surface of the earth. When they are not of equal length, the nomenclature falls back on bipole-dipole to indicate the length difference. Generally, during a typical surface survey, all four electrodes (i.e. both dipoles) move along the survey line. As used in electrical resistance tomography (ERT), dipole-dipole refers to both equal and unequal length pairs of dipoles.

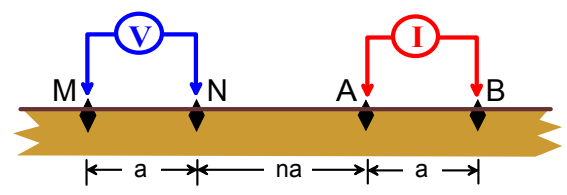

$$
\rho=n(n+1)(n+2) \Pi \text { a V/I }
$$

Pole-Pole Array

The term "pole-pole array" refers a particular arrangement of four electrodes (same dipoles) that places one electrode of each dipole very far away from the area being surveyed. These two remote electrodes remain in a fixed location while the two "active" electrodes are moved along the survey line. The remote electrodes minimally influence the readings, so, we use the term "pole-pole" to indicate that we are only using two active electrodes.

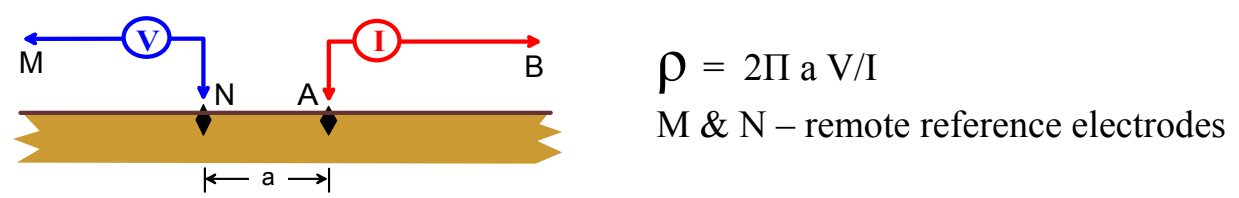

As the above explanations show, the use of the terms dipole-dipole and pole-pole are technically incorrect, but they convey the general practice of how the electrodes are arranged.

\subsubsection{Resistance, resistivity, and apparent resistivity}

Resistance is the physical property of a material that resists the flow of electricity. It is expressed as the ratio of voltage drop to driving current and is defined in units of ohms. Electrical resistivity is the volume physical property of a material and is defined in units of ohm-meters ${ }^{2}$ per meter, or more simply, ohmmeters.

For geophysical methods using four electrodes on the surface of the earth, the volume of earth involved in any given measurement is unknown. The term "apparent" resistivity is used to reflect that lack of knowledge. 


\subsection{Background}

The SCRT-HRR method involves a combination of measurements normally associated with different electrode arrays and applications other than leak detection. SCRT-HRR uses both installed surface (point) electrodes, metallic well casings as (linear) electrodes, and direct contact with the potentially leaking solution. The surface electrodes may be in linear arrays but are preferably arranged in two-dimensional grids. SCRT-HRR makes temporal measurements using various combinations of the above configurations where all electrodes are monitored for temporal changes. By spatially monitoring temporal changes dynamic characteristics of the progression of the leak may be determined and, if the arrangement of electrodes allows, a dynamic three-dimensional model can be produced.

\subsection{Historical background (previous investigations at Hanford)}

Boeing's approach

Boeing used an AC (10 kilohertz) bridge-balancing method that had the ability to "tune out" certain effects of the tank farm. It measured bulk effects and demonstrated the effectiveness of electrical methods in the tank farms.

In a December 1975 report by K. T. Key (1975) the following statements were made under the heading General Observations (p. 40-44) with our comments:

Key: "Data plotted on the polar coordinate had not been corrected for the distance of the wells to the tank."

HGI: We correct for distances and casing lengths.

Key: "The development of the polar plot was intended for a cursory assessment of the tank in question."

HGI: We calculate essentially the same results using contour plan maps of normalized residual potential.

Key: "For a more detailed and precise evaluation, distance correction and soil condition and distribution should be taken into consideration."

HGI: Soil condition and distribution are two of the reasons we prefer using as dense a network of surface electrodes as possible.

Key: "This and other features, such as the significance of the slope of $\Delta \mathrm{Q}$ (quantity leaked) versus $\Delta \mathrm{P}$ (potential change), will be studied as the need arises."

HGI: We considered this observation and statement solid vindication for our observations in 2001 of precisely the same phenomenon. See their Figure 40 on page 108. 
Key: "As was pointed out previously, both systems displayed a reversing trend when the injection of salt solution ceased. This dynamic characteristic should be taken into account when comparison is made between real and simulated leakages and when data are processed."

HGI: We refer to their reversing trend as perturbation analysis and we, too, see the same effects occurring when the test leaks start and stop."

Key: "With improvements in the hardware and equipment, some difficulties are correctablesome are not."

HGI: Advances in technology in general have already solved some of the problems. Increases in data density will help solve some of the infrastructure problems.

Key: "The systems are based on the distortion or the magnitude of the potential fields."

HGI: This has not changed in thirty years and is a sound concept.

Key: "The change in potentials in reacting to the pluming, which in turn is related to the quantity leaked, is quasi-logarithmic in nature. This implies that both systems will not have a rapid response in detecting leakage in a highly salted area, as in the BX Tank Farm. Also, as the leak quantity increases, the rate of decrease in potential decreases."

HGI: Unfortunately, this tends to support one of our concerns; i.e. the sensitivity of the systems in areas of previous leaks. However, improvements instrumental sensitivity since that time may offset the problem as they experienced it. This cries out for some testing in areas of known leakage.

Key: "The Boeing system can be used to:

1. Pattern tanks for pre-existing conditions."

HGI: We believe this is one of the strengths of electrical methods in general for this application.

Key: "2. Detect and differentiate center or side leaks..."

HGI: The resolution of leak location is entirely dependent on the number of dry-wells surrounding the tank and density of other grounding points (e.g. shallow electrodes).

Key: "3. Detect new leaks in old salt areas. ... albeit the effect was small and the response slow." HGI: Again, this is confirmation of our own predictions.

Key: "4. Determine transfer line leak."

HGI: We have done similar metallic pipeline leak detection for over ten years.

Key: "5. Detect tank leak before it can be seen by gamma probe."

HGI: In our opinion this is one of the greatest strengths of electrical methods in this environment.

This alleviates, but does not eliminate, the need for more monitoring wells and expands the volume of sensitivity around existing dry-wells. 
Key: "6. Discriminate against normal rainfall."

HGI: The use of shallow electrodes in the detection of precipitation should be obvious. The addition of rain gauges would be an additional source of information. The difference in electrical response to a minor change in grounding at the top of a dry-well due to precipitation (compared to the excellent grounding conditions existing at depth) will be minor and should not adversely affect the system performance, if it would even be detectable (at the dry-wells).

Key: "The Boeing system developed so far cannot:

1. Detect tank leaks which do not plume from the tank surface, as it requires certain conductive volume in contact with the tank to distort the imposed potential field."

HGI: Imaging capabilities today will allow imaging of conductive volumes completely disconnected from their source. However, electrically, the route taken by a plume usually leaves a conductive path that will be detected by a direct contact method.

Key: "2. Detect water leaks unless the soil is extremely dry."

HGI: This is entirely dependent on the proximity of electrodes to the leak. A clean water leak certainly is not as favorable a target as a high-ionic-solution leak.

Key: "3. Detect tank leaks in a wet salted area as rapidly as in unsalted or dry areas."

HGI: We agree, the higher the electrical properties contrast, the more readily the leak will be detected. However, even low contrast leaks are detectable.

Key: "4. Profile tank leak vertically without segmented electrodes."

HGI: Key forsaw the application and relevance of point-electrode ERT.

Hanford's approach

The Hanford approach differed somewhat from Boeing's in that direct current (DC) was used instead of an alternating current (AC) signal. In addition, temporal measurements were made that indicated a relationship between leak rate and changes in potential that corresponded with observations made during the 2001 mock tank study.

Again, Key discusses the pros and cons point-by-point on pages 45-46.

Key: "The Battelle-Northwest system can be used to:

1. Evaluate the existing soil condition around the tank. The observation that wells about tanks are negative with respect to the tanks suggests that corrosion may be accelerated in these regions.

Therefore the system appears to be useful in determining the presence of conditions which may be precursors to tank failure, which is of prime concern to tank farm operations."

HGI: The soil condition evaluation is equivalent to that of Boeing's and is a strength of electrical methods in general. Key also points out something that might be desirable to observe in the future if monitoring systems are installed. 
Key: "2. Assess a pre-existing static leakage. ... The wrap-around plots of measured magnitude of potentials and their signs were used to determine areas of possible leakage. High conductivity implies leakage might exist."

HGI: Again, this shows the strength of electrical measurements. Sisson and Lu measurements made by HGI one year after saline injection tests show a residual signature of a conductive plume.

Key: "3. Detect dynamic tank leakage. For leakage in progress, the potential measurements responded vividly."

HGI: We saw the same effects and couldn't agree more.

Key: "4. Evaluate the effectiveness of cathodic protection system...."

HGI: We understand the cathodic protection system has been dismantled but not removed.

Key: "5. Detect water line leak and transfer line leak. ..."

HGI: As mentioned above, HGI has done such pipeline leak detection for over ten years.

Key: "The Battelle-Northwest system cannot:

1. Locate vertically the leakage from the tank."

HGI: This is still a difficult problem that is best handled by buried point-electrodes (ERT).

Additional surface electrodes may or may not help, depending on the depth to, and the size of, the leak."

Key: "2. Be used to provide contour plots for leakage distribution."

HGI: Here is one point where we completely disagree with Key. We provide already contour plots of potential distribution that specifically show the leakage distribution.

Key: "3. Distinguish normal rainfall and water usage in normal tank farm operations."

HGI: Again, we tend to disagree. We believe that a sufficiently dense network of surface electrodes, combined with the dry-wells, etc. will produce ample information to monitor precipitation and water leakage.

One of Key's conclusions with which we wholeheartedly agree is "Because of its low cost and good promise, further developments in the Battelle-Northwest system are recommended..."

\subsection{S-112 Tank Electrical Geophysical Measurement Tests (May 2002)}

Lawrence Livermore National Laboratory (LLNL) and hydroGEOPHYSICS, Inc. (HGI) provided personnel, test equipment, and ancillary materials (wire, clamps, etc.) to conduct resistance and resistivity testing of soils and structures around tank S-112. Operation of the test equipment by LLNL and HGI was restricted to unregulated areas outside the fence line of the S Tank Farm. CHG operations personnel prepared the electrical connections to the S-112 thermocouple tree and to nine dry wells surrounding S112. Seven shallow electrodes were also emplaced by CHG personnel south of the tank. 


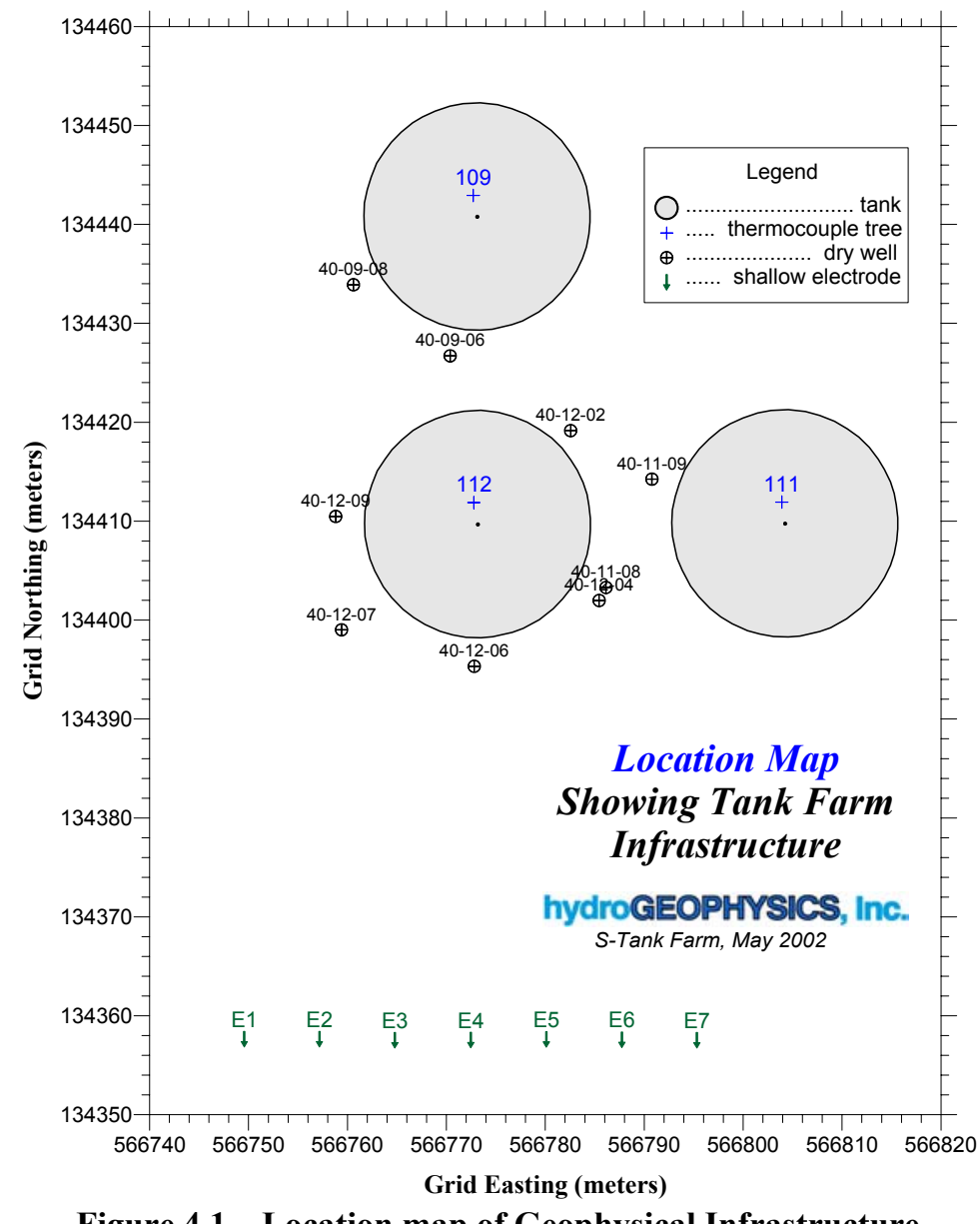

Figure 4.1 - Location map of Geophysical Infrastructure

The locations of the three tanks (S-109, S-111, and S-112), their thermocouple positions, the nine dry wells, and the seven shallow electrodes are shown in Figure 1. Survey information was provided by PNNL surveyors.

For the S-112 investigation, the instrument used for the electrical resistivity measurements was a Zonge Engineering and Research Organization Geophysical Data Processor (GDP-32). Resistance measurements between various combinations of dry wells, thermocouple trees, and shallow electrodes were performed using a Triplett analog Volt-Ohm Meter (VOM).

\subsection{Test Measurements}

A total of 11 data sets were acquired using both the GDP-32 (for resistivity) and VOM (for resistance). All resistivity measurements were made using four electrodes and the GDP instrument. All resistance measurements were made using two electrodes and the VOM. 


\begin{tabular}{|c|c|c|c|c|}
\hline $\begin{array}{l}\text { Measurement } \\
\text { Type }\end{array}$ & Test No. & \begin{tabular}{|l|} 
No. \\
Electrodes
\end{tabular} & Array & Electrodes \\
\hline Dry Well & $1 \& 2$ & 4 & $\begin{array}{l}\text { Dipole- } \\
\text { Dipole }\end{array}$ & $\begin{array}{l}\text { Test } 1 \text { uses six dry wells surrounding S-112; 40-12-02, 40- } \\
12-04,40-12-06, \text {, 40-12-07, 40-12-09, 40-09-06. } \\
\text { Test } 2 \text { uses nine dry wells surrounding S-112; 40-12-02, } \\
40-12-04,40-12-06,, 40-12-07,40-12-09,40-09-06,40- \\
09-08,40-11-08,40-11-09 .\end{array}$ \\
\hline \multirow[t]{2}{*}{\begin{tabular}{|l|} 
Shallow \\
Electrode
\end{tabular}} & 3 & 4 & $\begin{array}{l}\text { Dipole- } \\
\text { Dipole }\end{array}$ & 7 shallow electrodes; E1 through E7 \\
\hline & $4 \& 5$ & 4 & Pole-Pole & $\begin{array}{l}7 \text { shallow electrodes (E1 through E7) and wells 40-09-08 / } \\
40-11-09 \text { as remote reference electrodes. } \\
\end{array}$ \\
\hline $\begin{array}{l}\text { Dry Well to } \\
\text { Shallow } \\
\text { Electrode } \\
\text { (not processed) }\end{array}$ & $\begin{array}{l}6,7,8 \& \\
9\end{array}$ & 4 & $\begin{array}{l}\text { Dipole- } \\
\text { Dipole }\end{array}$ & $\begin{array}{l}\text { Test } 6 \text { uses 40-09-08/40-11-09 and the seven shallow } \\
\text { electrodes (E1 through E7). } \\
\text { Test } 7 \text { uses 40-12-09/40-11-08 and the seven shallow } \\
\text { electrodes (E1 through E7). } \\
\text { Test } 8 \text { uses } 40-09-06 / 40-12-07 \text { and the seven shallow } \\
\text { electrodes (E1 through E7). } \\
\text { Test } 9 \text { uses } 40-12-02 / 40-12-06 \text { and the seven shallow } \\
\text { electrodes (E1 through E7). }\end{array}$ \\
\hline $\begin{array}{l}\text { Dry Wells to } \\
\text { Thermocouple } \\
\text { (not processed) }\end{array}$ & 10 & 4 & $\begin{array}{l}\text { Dipole- } \\
\text { Dipole }\end{array}$ & $\begin{array}{l}\text { All } 9 \text { dry wells }(40-12-02,40-12-04,40-12-06,, 40-12-07 \text {, } \\
40-12-09,40-09-06,40-09-08,40-11-08,40-11-09) \text { and } \\
\text { the S- } 112 \text { thermocouple tree as receiver only. }\end{array}$ \\
\hline VOM & 11 & 2 & none & $\begin{array}{l}\text { Various combinations of dry wells, thermocouple trees and } \\
\text { shallow electrodes. }\end{array}$ \\
\hline
\end{tabular}

The logistics of the experiment allowed us to collect more data than was necessary or could be processed before the implementation of the upcoming 2002 LDMM PE. Furthermore, safety concerns during the S112 test prevented the placement of remote reference electrodes outside of the tank farm fence. This greatly restricted our ability to record the most desirable data and prevented us from making HRR/SCRT type measurements similar to those recorded at the Mock Tank site.

Three data sets were recorded that proved beneficial for processing and allow us to make many interpretations that will further our understanding of electrical geophysical leak detection.

\subsubsection{Dry Well Measurements - Test $1 \& 2$}

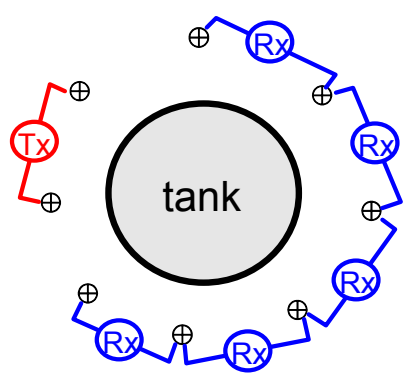

Data collection consisted of energizing pairs of dry wells $(\mathrm{Tx}=$ transmitter dipole) and recording the resulting potentials at various pairs of receiver dry wells $(\mathrm{Rx}=$ receiver dipole). The dipole-dipole array was used for Test 1 and 2 . Test 1 consisted of the nearest six wells that surround tank S-112; 4009-06, 40-12-02, 40-12-04, 40-12-06, 40-12-07, 4012-09. Test 2 used the same six wells but also included two additional wells; 40-11-09 and 40-1108 . 


\subsubsection{Shallow Electrode Measurements - Test 3, 4 \& 5}

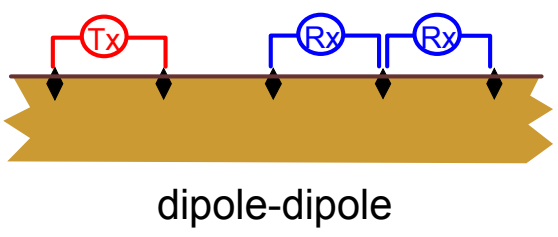

Shallow electrode measurements were recorded using two electrode arrays. Test 3 used the dipole-dipole array and Test $4 \& 5$ used a modified pole-pole array.

For Test 3, data collection consisted of energizing pairs of shallow electrodes $(\mathrm{Tx}=$ transmitter dipole $)$ and recording the resulting potentials at various pairs of receiver shallow electrodes $(\mathrm{Rx}=$ receiver dipole $)$. Seven shallow electodes, which consisted of three foot long stainless steel rods, were placed at 7.6 meter stations approximately 50 meters south of the center of S-112 tank (see Figure 1).

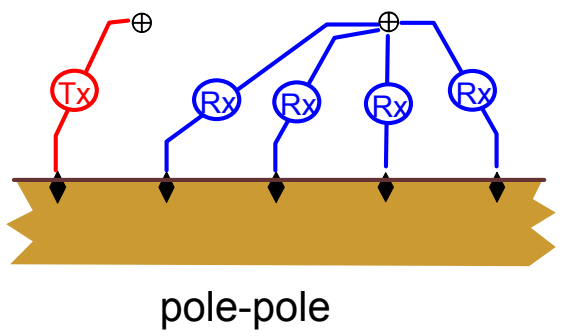

Tests 4 and 5 used a modified pole-pole array that consisted of energizing one shallow electrode and one dry well, and recording the resulting potential at various receiver electrodes and a receiver dry well. The pole-pole array uses two remote reference electrodes that are theoretically placed at an infinite distance from the active electrodes (shallow electrodes). In reality, once the remote reference electrodes exceed a sufficient distance from the active electrodes, mathematically the effect is quite similar to placing them at an infinite distance. However, safety concerns during the S112 test prevented the placement of remote reference electrodes outside of the tank farm fence. Consequently we used two dry wells as the remote reference electrodes, but their close proximity to the active electrodes is a violation of the fundamental pole-pole mathematics. Furthermore, the equation assumes a point source electrode and the long tubular dry well casings are again in violation of this assumption. Therefore, the resulting data from test 4 and 5 should only be used for general evaluation.

\subsubsection{Dry Well to Shallow Electrode Measurements - Test $6,7,8$ \& 9}
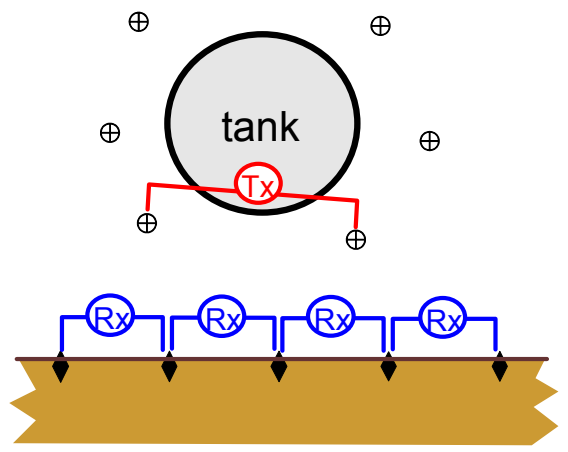

All measurements were recorded using the dipole-dipole array configuration. Data collection consisted of energizing a pair of dry wells $(\mathrm{Tx}=$ transmitter dipole $)$ and recording the resulting potentials at various pairs of receiver shallow electrodes $(\mathrm{Rx}=$ receiver dipole).

Four different transmitter dipoles were used and correspond with the individual tests; 6, 7, 8 and 9. Test 6 uses 40-09-08 and 4011-09, Test 7 used 40-12-09 and 40-11-08, Test 8 used 40-09-06 and 40-12-07, Test 9 used 40-12-02 and 40-12-06. 


\subsubsection{Dry Well to Thermocouple Measurements - Test 10}

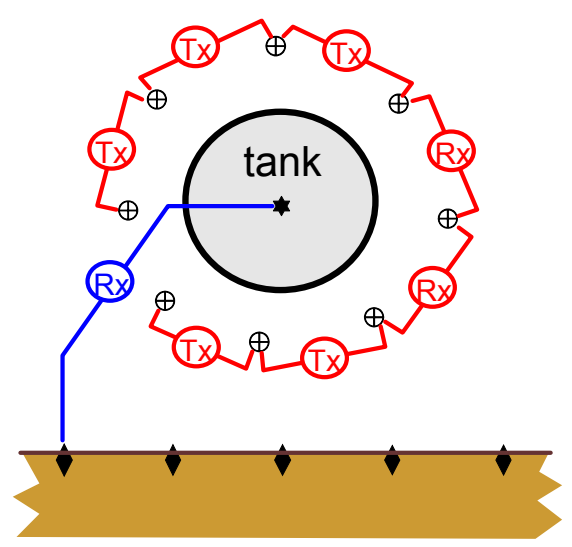

All measurements were recorded using the dipole-dipole array configuration. Safety concerns prevented us from energizing the tank thermocouple tree, so instead we recorded data using the thermocouple as a passive receiver.

Unlike the previous Tests, we transmitted on various dipoles which consisted of energizing pairs of dry wells $(\mathrm{Tx}=$ transmitter dipole) recording the resulting potential received on a stationary receiver dipole $(\mathrm{Rx}=$ receiver dipole $)$.

\subsubsection{VOM Resistance Measurements - Test 11}

A Triplett Volt-ohm meter was used to record resistance measurements between various tank farm infrastructure that included dry wells, thermocouple trees, and shallow electrodes. Measurements were made by connecting one sensor to the positive lead of the VOM and another sensor to the negative lead. All readings were recorded in ohms, a table of which can be viewed in section 4.2.

\subsection{Test Results}

At S-112 we have a conglomeration of bipole-dipole and pseudo-pole-pole arrays, few of which are collinear, and all of which are a mixture of point and linear electrodes. Consequently, data reduction has been slow, cumbersome, and not yet completed. Meaningful results are almost restricted to threedimensional modeling that incorporates all the above problems and limitations. The combinations of hookups and measurements are detailed in tables.

\subsubsection{Dry Well Measurements - Tests $1 \& 2$}

Using the dry-well casings as electrodes, two sets of "dipole-dipole" measurements were made. These consisted of transmitting on two dry wells, regardless of their distance apart, and receiving on two other dry-well casings, again, regardless of their separation. So, the arrangement is not truly "dipole-dipole" and the source and receiver electrodes are certainly not point equivalents. Nevertheless, because of the reasonable consistency in the lengths of the dry-well casings, some of the data can be treated in a conventional manner, acknowledging shortcomings due to the above deviations from convention.

For a quick look, the data for sequential dipoles around the tank were reduced using point-electrode formulation. The resultant apparent resistivities are much too low because of the length of the casings relative to the distances involved, but, that aside, the relative values of the data reveal an interesting trend. The contoured data are presented in Figure 4.2. 
To generate the contour area, plot points were located mid-way between the dipoles. This unfortunately places them all within the tank boundary. Such presentation is always dangerous in that the implication is that the data represent something within the tank, which is definitely not the case here. The plot points could be easily placed elsewhere, but this approach is simply an expedient method of viewing the data to get an idea of trends.

The data acquired for measurements made on opposing sides of the tank show higher values than the data acquired alongside the tank. As a first order approximation, this suggests that the tank presents an electrically resistive obstacle to the flow of current. A second trend of interest is the lower valued resistivities on the east side of the contoured area. This suggests a more favorable electrical pathway in that area.

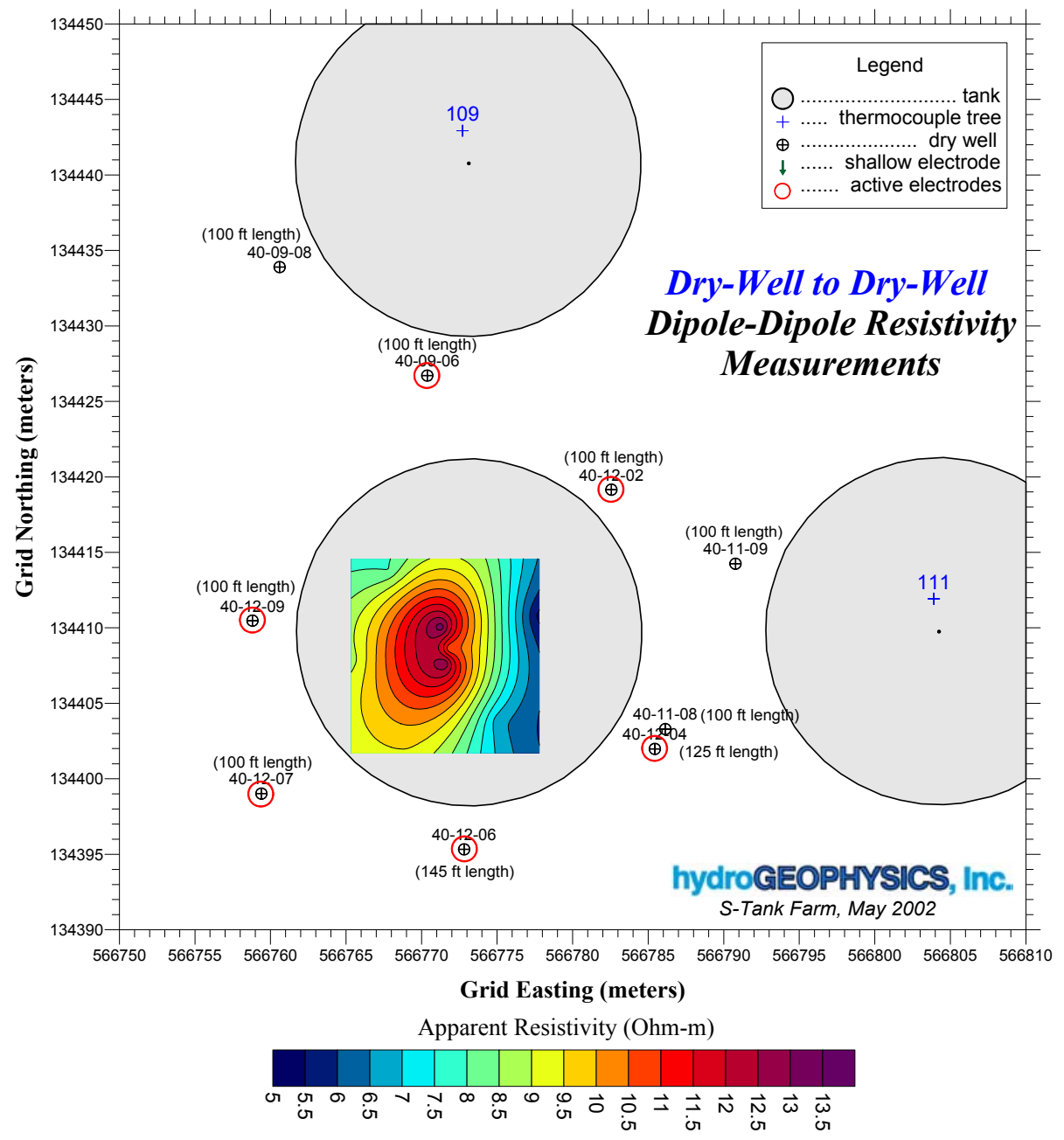

Figure 4.2 - Contour Plot of calculated apparent resistivity values from dry-well-to-dry-well measurements using point-electrode approximations. 


\subsubsection{Shallow Electrode Measurements - Test 3, 4 \& 5}

\section{“Quasi” Pole-Pole Array - Test 4 \& 5}

The "Quasi" Pole-Pole Measurements show three "pseudo-sections" of apparent resistivity data calculated for the seven-electrode linear array located to the south of S-112. The apparent resistivity data were calculated using point-source assumptions (obviously incorrect) as an expedient exercise to obtain at least relative values for comparison. Values are in hundreds of ohm-meters, which compares well with data acquired at the Sisson and Lu and mock-tank sites. However, it should be noted that all apparent resistivity calculations are heavily influenced by the use of dry wells as remote reference electrodes rather than more appropriate point electrodes. As a result, the calculated apparent resistivity values are much lower than they should be. Plot points were inverted to half-space depths (using an analytic formulation to be explained later), but, again, using point-source assumptions. The data are presented in Figure 4.3 and are shown looking north.

It appears there might be a conductive feature ten meters or more deep and to the southeast of the tank. With the limited information (a single row of shallow electrodes) we can't say that this is not due to buried pipelines or other culture nearby. The trend from more resistive soil at surface to more conductive soil with increasing depth was anticipated. However, the problem of possible interference from conductive infrastructure is acknowledged.

The shallowest data suggest resistivities above $300 \mathrm{ohm}$-meters for the relatively dry surface soil; say the first few meters or so. Compare these results with those of test 3 where the equivalent resistivities range from 500 to over $700 \mathrm{ohm}$-meters. This difference is a combined effect of using nearby casings as remote references and a variable distribution of current density along the casings.

The localized low resistivities in the vicinity of electrode 15.2 may suggest the presence of infrastructure or a localized variation in soil properties due to backfilling the site.

The data are definitely informative and show that shallow electrodes can produce useful results within the tank farm environment. 
hydroGEOPHYSICS, Inc.

S-Tank Farm, May 2002
"Quasi" Pole-Pole Measurements

using shallow buried electrodes

and dry wells 40-11-09 and 40-09-08

as remote reference electrodes
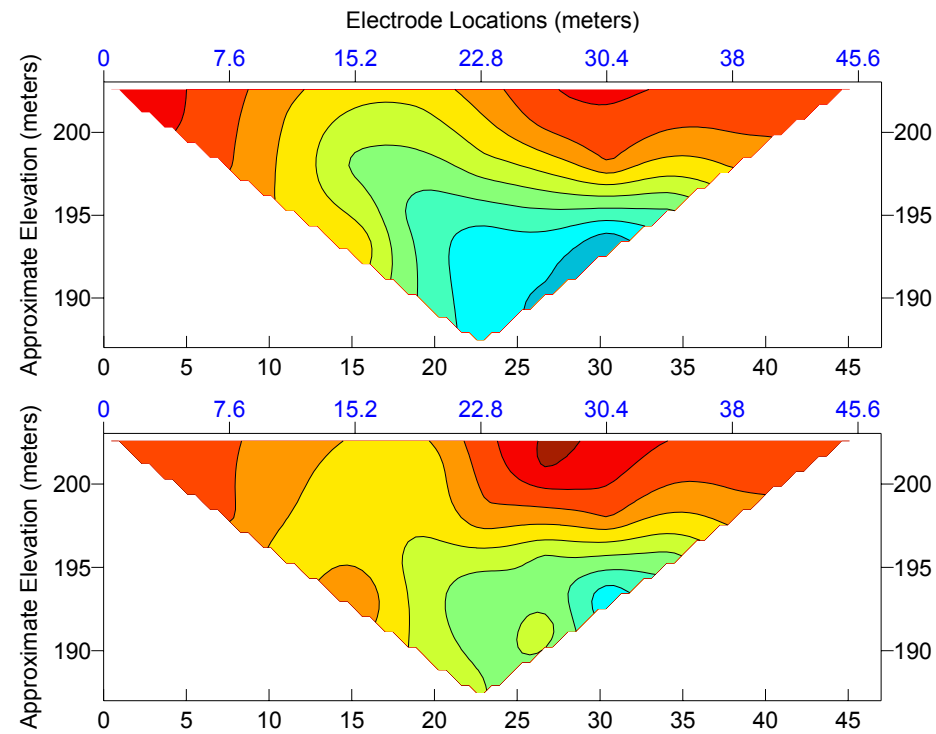

Complete

-195 Reciprocal

$-190$

Active

Electrode

Reciprocal 1

(normal electrodes)

Configuration AMBN

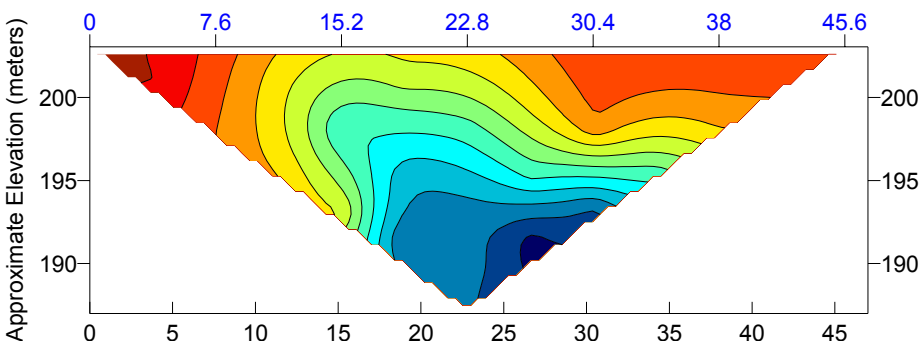

Active

Electrode

Reciprocal 2

190 (reversed electrodes)

Configuration MANB

Approximate Rho-a (Ohm-m)

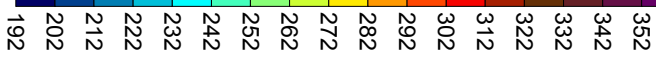

Electrode Legend

A: Tx active electrode

B: Tx remote electrode

C: Rx active electrode

$\mathrm{D}$ : Rx remote electrode

Figure 4.3 - Contour Sections of calculated apparent resistivity values from "quasi" pole-pole, shallow electrode measurements. Note: Apparent resistivity values are lower than they should be because calculations do not account for using dry wells as remote reference electrodes rather than point source electrodes. 


\subsubsection{VOM Resistance Measurements - Test 11}

Four configurations of resistance measurements were recorded using a Triplett VOM and can be viewed in the table below.

Tx
\begin{tabular}{|lll|}
\hline \multicolumn{1}{|l|}{ Thermocouple to Thermocouple } \\
\hline S112 & s111 & \multicolumn{1}{l|}{$\begin{array}{l}\text { Resistance } \\
\text { (Ohms) }\end{array}$} \\
S112 & s109 & 6 \\
S111 & s109 & 8 \\
\hline \multicolumn{4}{|l}{ Shallow Electrode } \\
\hline E1 & E2 & 600 \\
E2 & E3 & 600 \\
E3 & E4 & 600 \\
E4 & E5 & 500 \\
E5 & E6 & 600 \\
E6 & E7 & 800 \\
\hline
\end{tabular}

\begin{tabular}{|c|c|c|}
\hline Tx & $\mathrm{Rx}$ & $\begin{array}{l}\text { Resistance } \\
\text { (Ohms) }\end{array}$ \\
\hline \multicolumn{3}{|c|}{ Thermocouple to Dry Well } \\
\hline S112 & $40-12-04$ & 17 \\
\hline S112 & $40-12-02$ & 27 \\
\hline S112 & $40-12-06$ & 25 \\
\hline S112 & $40-09-06$ & 25 \\
\hline S112 & $40-12-09$ & 30 \\
\hline S112 & $40-09-08$ & 16 \\
\hline S112 & $40-11-08$ & 17 \\
\hline S112 & 40-11-09 & 26 \\
\hline $\mathrm{S} 112$ & $40-12-07$ & 16 \\
\hline S109 & $40-12-04$ & 17 \\
\hline S109 & $40-12-06$ & 23 \\
\hline S109 & $40-12-02$ & 26 \\
\hline S109 & $40-12-09$ & 30 \\
\hline S109 & $40-09-06$ & 25 \\
\hline S109 & 40-09-08 & 16 \\
\hline S109 & 40-11-09 & 26 \\
\hline S109 & $40-11-08$ & 16 \\
\hline S109 & $40-12-07$ & 15 \\
\hline S111 & $40-12-06$ & 25 \\
\hline S111 & $40-09-08$ & 18 \\
\hline S111 & $40-12-04$ & 19 \\
\hline S111 & $40-11-08$ & 19 \\
\hline S111 & 40-11-09 & 30 \\
\hline S111 & $40-12-07$ & 18 \\
\hline S111 & $40-12-02$ & 30 \\
\hline S111 & 40-09-06 & 26 \\
\hline S111 & $40-12-09$ & 30 \\
\hline
\end{tabular}

The data are also presented in the following figures which show the site layout and the points between which various sets of resistance data were measured. 


\section{Dry-Well to Dry-Well VOM Measurements}

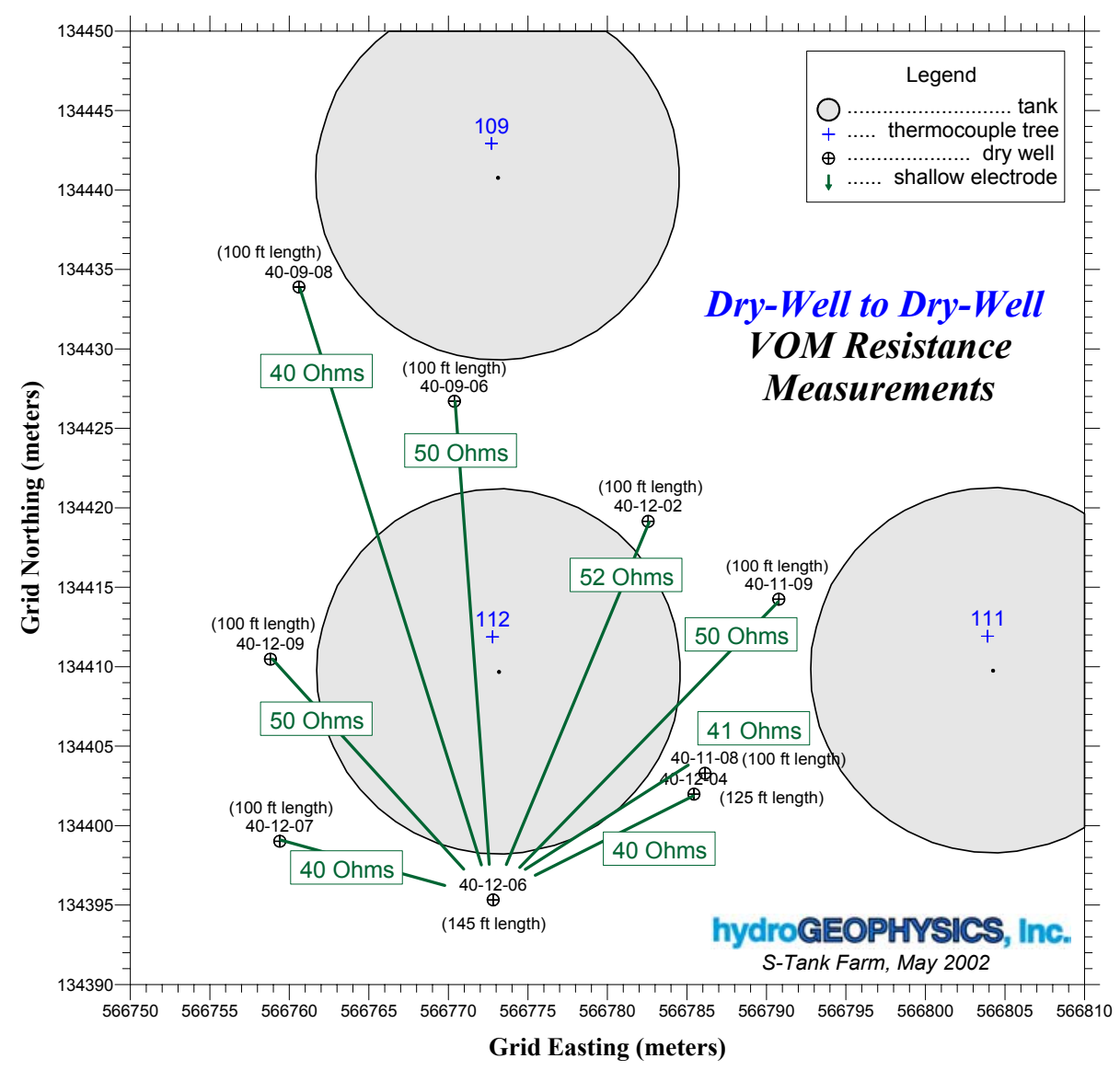

Figure 4.4 - Drywell-to-drywell Volt-Ohm meter measurements

Figure 4.4 shows solid lines between the points of measurements with the related resistances in boxes plotted on the corresponding line length. The average resistances for the well-to-well measurements is $45.4 \pm 5$ ohms. With the single exception of well 40-09-06, the resistances appear to be somewhat dependent on distance; i.e. the nearest casings to 40-12-06 have the lowest resistance. Typically, resistance measurements between two grounding points are dominated by the electrode-to-ground contact resistance and are seldom dominated by the resistivity of the intervening earth. Other data sets show the earth resistivity to be in the several hundreds of ohm-meters. So, these relatively low inter-well resistances indicate the casings are well grounded. Because of the interpreted tendency for resistivity to decrease with depth (from four-electrode measurements) we assume that the lower portion of each casing is better grounded that the upper portion. If the assumption is valid, it will increase the current density beneath the tanks, which should be beneficial, but only up to a point. If the ground beneath the tank is too conductive it will simply shunt the current across and any leaks might not make much difference in the overall resistivity. 


\section{S-112 Thermocouple to Dry-Well VOM Measurements}

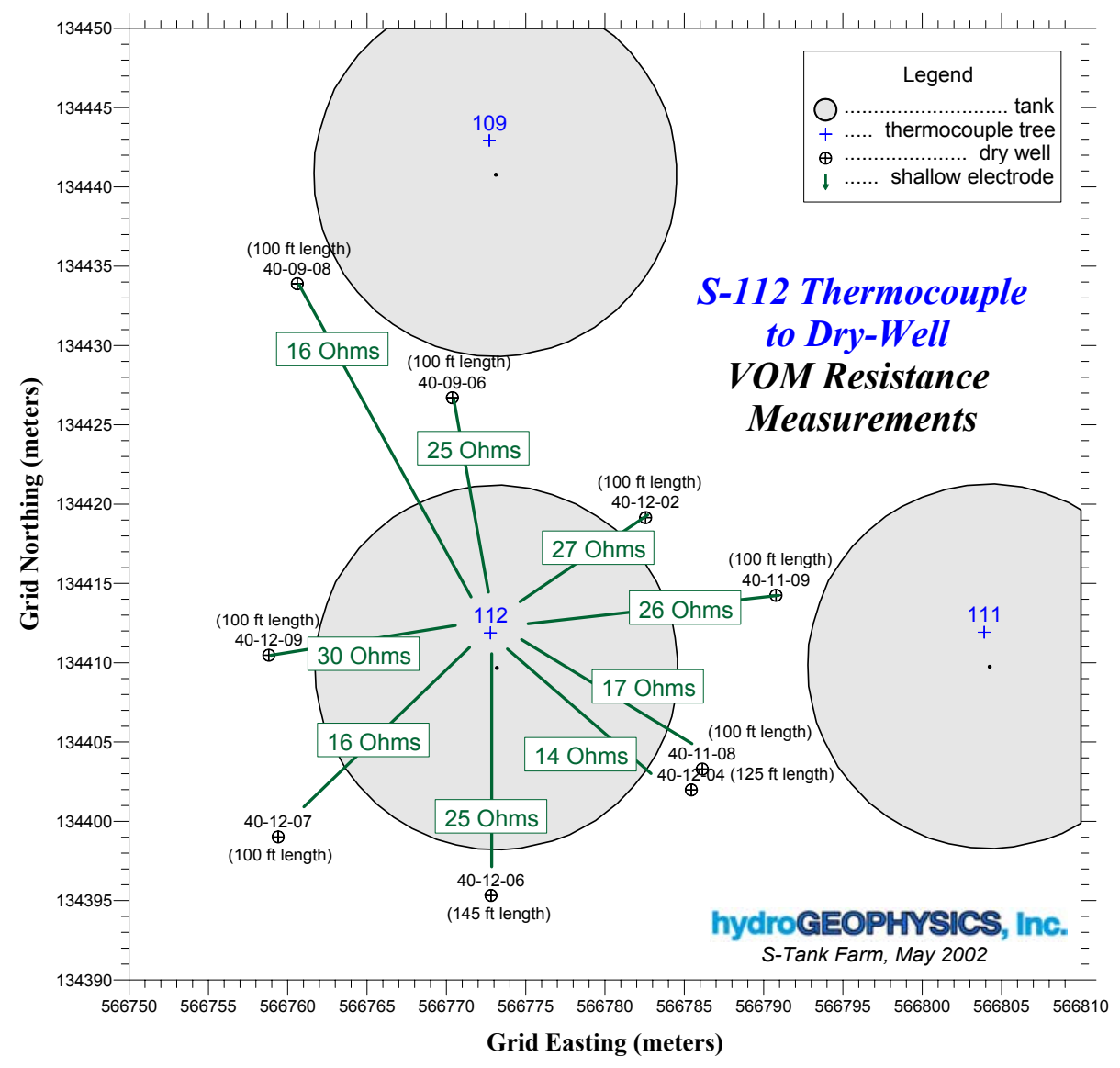

Figure $4.5-\mathrm{S}-112$ thermocouple-to-drywell Volt-Ohm meter measurements

Figure 4.5 shows solid lines between the points of measurements with the related resistances plotted directly on the lines. The average resistances for the S-112 thermocouple tree-to-well measurements is $22.1 \pm 5.5 \mathrm{ohms}$. This is roughly half the average of the well-to-well measurements and indicates a less resistive path between the thermocouple tree and the wells than between the wells themselves. Because of instrumentation reportedly attached to the thermocouple tree and not knowing where the instrumentation grounds are located, it is difficult to exclude that electrical path is a major contributor to the measured resistance. However, presumably, such grounds are shallow and will not have as low a contact resistance as the wells. This allows the possibility that the primary path measured is through the tank (and associated external coatings) and to the wells. There is no relationship between distance and resistance. 


\section{S-111 Thermocouple to Dry-Well VOM Measurements}

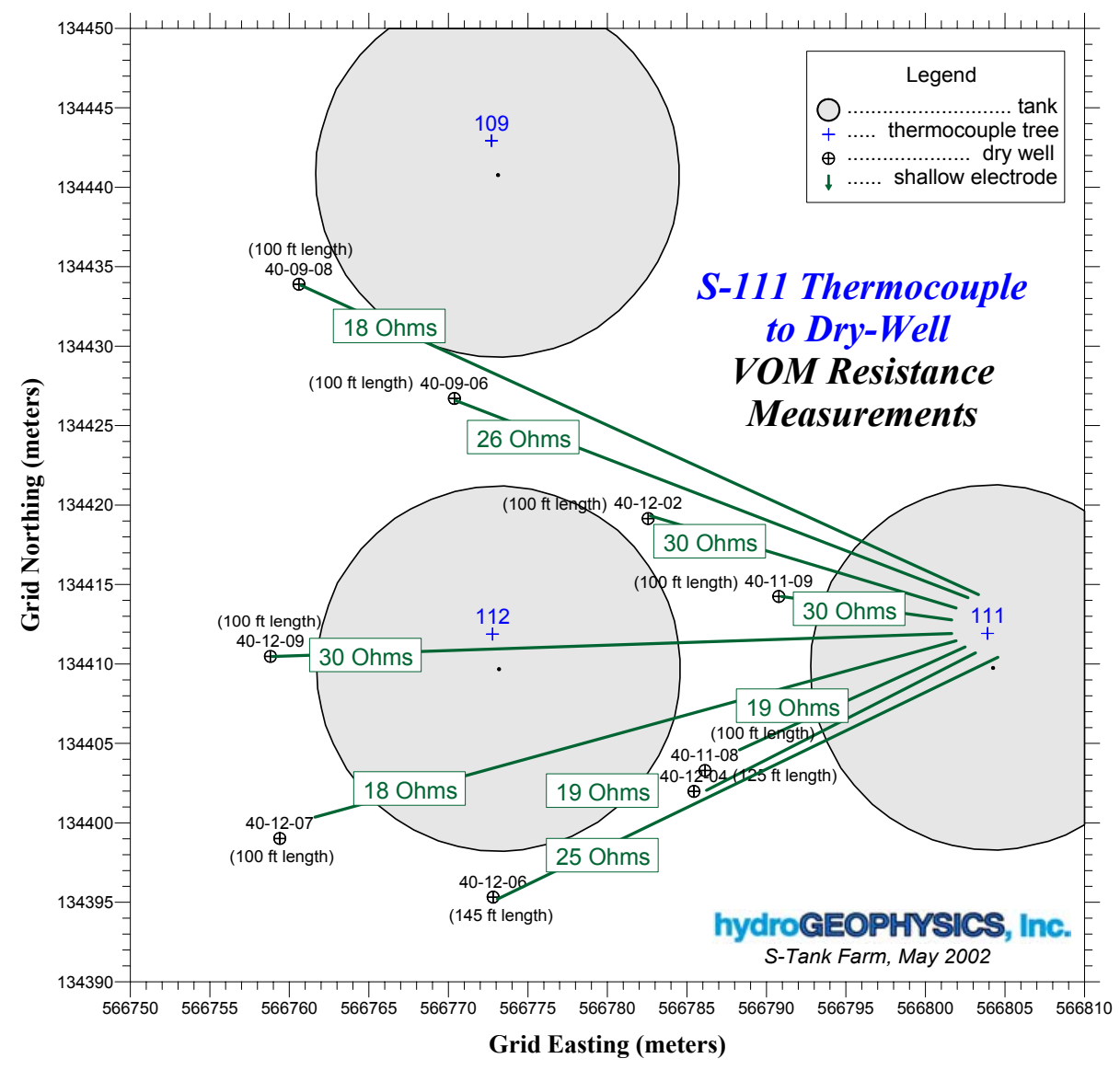

Figure 4.6-S-111 thermocouple-to-drywell Volt-Ohm meter measurements

Figure 4.6 shows solid lines between the points of measurements with the related resistances plotted directly on the lines. The average resistances for the S-111 thermocouple tree-to-well measurements is $23.9 \pm 5.4 \mathrm{ohms}$. As with S-112, this is roughly half the average of the well-to-well measurements and indicates a less resistive path between the thermocouple tree and the wells than between the wells themselves. Also as with S-112, instrumentation reportedly attached to the thermocouple tree and unknown instrumentation ground locations makes it difficult to exclude that electrical path as a major contributor to the measured resistance. Presumably, however, such grounds are shallow and will not have as low a contact resistance as the wells. This allows the possibility that the primary path measured is through the tank (and associated external coatings) and to the wells. There is no relationship between distance and resistance. However, note the similarity in readings to S-112 on a well-to-well basis. This will be discussed later. 


\section{S-109 Thermocouple to Dry-Well VOM Measurements}

Figure 4.7 shows solid lines between the points of measurements with the related resistances in boxes on the lines. The average resistances for the S-109 thermocouple tree-to-well measurements is 21.6 \pm 5.6 ohms. As with S-112 and S-111, this is roughly half the average of the well-to-well measurements and indicates a less resistive path between the thermocouple tree and the wells than between the wells themselves. Also as with S-112 and S-111, instrumentation reportedly attached to the thermocouple tree and unknown instrumentation ground locations makes it difficult to exclude that electrical path as a major contributor to the measured resistance. However, presumably, such grounds are shallow and will not have as low a contact resistance as the wells. This allows the possibility that the primary path measured is through the tank (and associated external coatings) and to the wells. There is no relationship between distance and resistance. However, note the similarity in readings to S-112 and S-111 on a well-to-well basis.

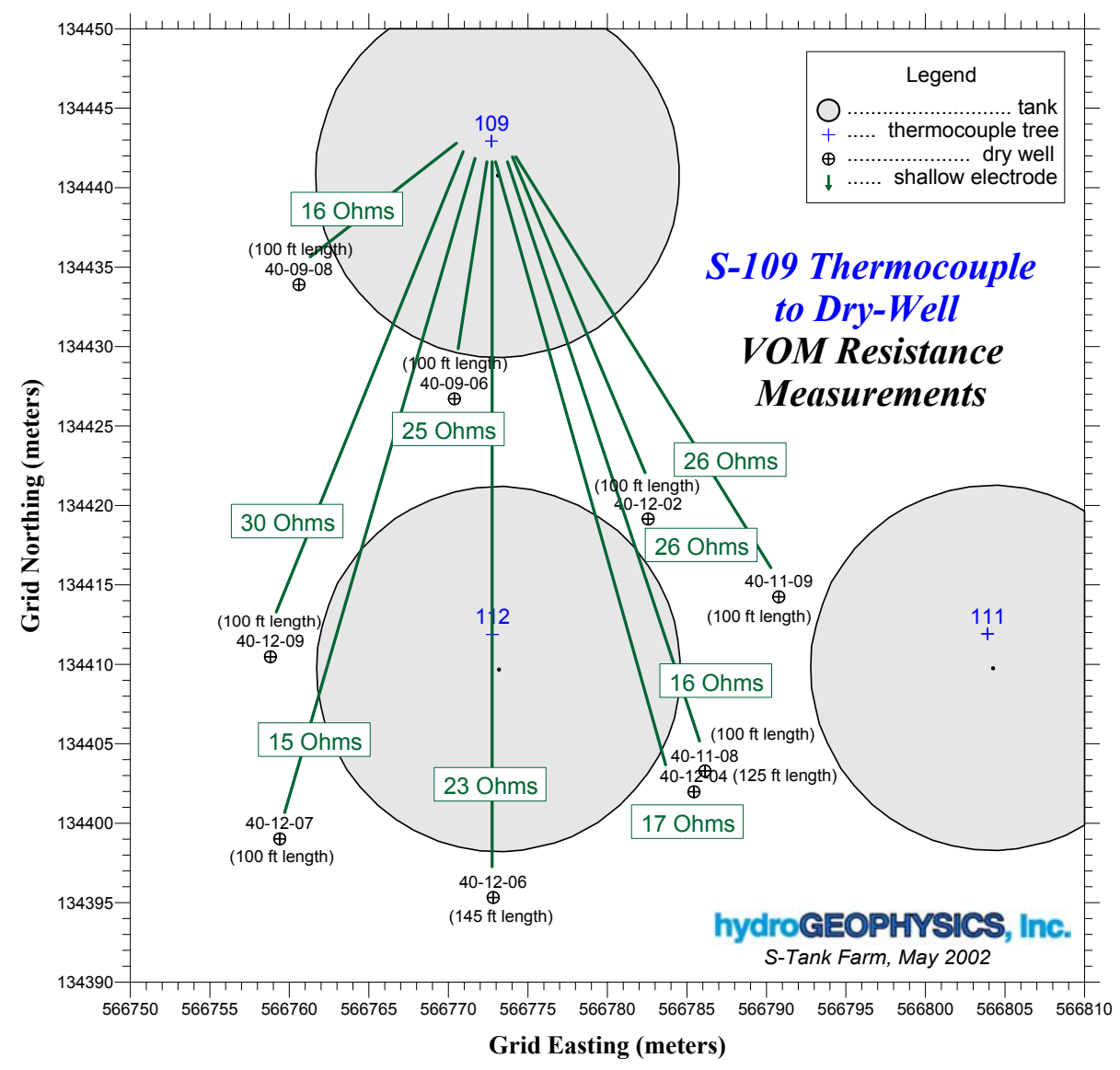

Figure $4.7-$ S-109 thermocouple-to-drywell Volt-Ohm meter measurements 


\section{Summary of Thermocouple to Dry Well Measurements VOM Measurements}

The consistency of the resistances between specific wells and each of the three thermocouple trees indicates the resistance is dominated by the casing-to-ground contact resistance. For a given pair of measurements (for example, consider S-112 to 40-12-06 for one measurement and S-112 to 40-09-08 for the second), the tree-to-well resistances are 25 and 16 ohms, respectively, which summed are 41 ohms. The well-to-well resistance between 40-12-06 and 40-12-09 is $40 \mathrm{ohms,}$ or nearly equal to the sum of the tree-to-well resistances (within measurement error for reading the analog VOM). Similar combinations are presented in the following table. In each case, the sum of the two tree-to-well resistances is nearly equal to the direct well-to-well measurement.

\begin{tabular}{|c|c|c|c|c|c|}
\hline Well 1 & Well 2 & $\begin{array}{c}\text { A } \\
\text { S-112-to-Well 1 }\end{array}$ & $\begin{array}{c}\text { B } \\
\text { S-112-to-Well 2 }\end{array}$ & $\begin{array}{c}\text { Sum of } \\
\text { A and B }\end{array}$ & Well 1-to- Well 2 \\
\hline $40-12-06$ & $40-09-08$ & 25 & 16 & 41 & 40 \\
\hline $40-12-06$ & $40-12-07$ & 25 & 16 & 41 & 40 \\
\hline $40-12-06$ & $40-12-04$ & 25 & 17 & 42 & 40 \\
\hline $40-12-06$ & $40-11-08$ & 25 & 17 & 42 & 41 \\
\hline $40-12-06$ & $40-12-02$ & 25 & 27 & 52 & 52 \\
\hline $40-12-06$ & $40-11-09$ & 25 & 26 & 51 & 50 \\
\hline $40-12-06$ & $40-09-06$ & 25 & 25 & 50 & 50 \\
\hline $40-12-06$ & $40-12-09$ & 25 & 30 & 55 & 50 \\
\hline
\end{tabular}

The implication of these comparisons is that the majority of the resistance measured for any combination of grounding points involving the dry-wells is due to the casing-to-ground contact resistance. We believe that this also indicates that the thermocouple trees are very well grounded to the tank circuit.

Additionally, because the thermocouple trees are so well grounded, we should be able to use the tree-towell resistance as the actual grounding resistance for each casing.

Accordingly, we made basic two-electrode resistance measurements between various pairs of dry-well casings at S-112. We applied industry-standard calculations for grounding electrodes to the S-112 data. The following expanded formula was used:

$$
R=\rho /(4 \pi L)\left\{\ln (4 L / a)-1+\ln \left(\left(2 L+\sqrt{s^{2}+4 L^{2}}\right) / s+s / 2 L-\left(\sqrt{s^{2}+4 L^{2}}\right) / 2 L\right\}\right.
$$

where $\mathrm{R}=$ resistance in ohms

$\rho=$ surrounding earth resistivity (ohm-meters)

$\mathrm{L}=$ length of the casing (meters)

$\mathrm{s}=$ distance between two casings (meters)

$\mathrm{a}=$ radius of the casing (meters) 
The following table shows calculations made in an Microsoft Excel spreadsheet for all combinations of dry-wells. True distances were calculated from the GPS survey coordinates. All wells were considered to be 30.48 meters (100 feet) long, although wells 40-12-04 and 40-12-06 were 38.1 meters (125 feet) and 44.2 meters (145 feet), respectively.

Analog resistance calculations for steel casings at S-112

\begin{tabular}{|c|c|c|c|c|c|c|c|c|c|c|}
\hline Casing & X-coord & Y-coord & Len $(\mathrm{m})$ & $\operatorname{Diam}(\mathrm{m})$ & \multicolumn{6}{|c|}{ Resistivity (ohm-m) } \\
\hline $40-09-06$ & 70.378 & 26.71 & 30.48 & 0.2 & \multicolumn{6}{|c|}{600} \\
\hline $40-09-08$ & 60.605 & 33.90 & & & & & & & & \\
\hline $40-11-08$ & 86.133 & 3.30 & & & & & & & & \\
\hline $40-11-09$ & 90.776 & 14.25 & & & & & & & & \\
\hline $40-12-02$ & 82.563 & 19.15 & & & & & & & & \\
\hline $40-12-04$ & 85.442 & 1.98 & & & & & & & & \\
\hline $40-12-06$ & 72.816 & -4.67 & & & & & & & & \\
\hline $40-12-07$ & 59.401 & -0.98 & & & & & & & & \\
\hline $40-12-09$ & 58.811 & 10.48 & & & & & & Predicted & Actual & Resistivity \\
\hline \multicolumn{2}{|c|}{ Combinations } & Dist & Factor1 & Factor2 & Factor3 & Factor4 & Factor5 & tance & tance & measured \\
\hline $40-12-06$ & 40-09-08 & 40.45 & 1.566486 & 6.412803 & 1.198564 & 0.663630 & 1.200169 & 9.52 & 40 & 2522.03 \\
\hline $40-09-06$ & $40-12-06$ & 31.48 & 1.566486 & 6.412803 & 1.414925 & 0.516364 & 1.125447 & 9.74 & 50 & 3079.63 \\
\hline $40-09-08$ & $40-12-06$ & 40.45 & 1.566486 & 6.412803 & 1.198564 & 0.663630 & 1.200169 & 9.52 & 40 & 2522.03 \\
\hline $40-11-08$ & $40-12-06$ & 15.52 & 1.566486 & 6.412803 & 2.077138 & 0.254573 & 1.031895 & 10.52 & 41 & 2339.47 \\
\hline $40-11-09$ & $40-12-06$ & 26.09 & 1.566486 & 6.412803 & 1.584829 & 0.427947 & 1.087722 & 9.93 & 50 & 3021.71 \\
\hline $40-12-02$ & $40-12-06$ & 25.74 & 1.566486 & 6.412803 & 1.597149 & 0.422257 & 1.085496 & 9.94 & 52 & 3138.19 \\
\hline $40-12-04$ & $40-12-06$ & 14.27 & 1.566486 & 6.412803 & 2.158491 & 0.234122 & 1.027041 & 10.62 & 40 & 2260.26 \\
\hline $40-12-06$ & $40-12-07$ & 13.91 & 1.566486 & 6.412803 & 2.183281 & 0.228240 & 1.025716 & 10.65 & 40 & 2253.54 \\
\hline $40-12-06$ & $40-12-09$ & 20.63 & 1.566486 & 6.412803 & 1.804054 & 0.338433 & 1.055716 & 10.18 & 50 & 2946.52 \\
\hline
\end{tabular}

Four-electrode measurements to the south of S-112 demonstrated the bulk earth apparent resistivity to be around $600 \mathrm{ohm}$-meters. Forward calculations predicted grounding resistances of approximately $10 \mathrm{ohms}$ using a resistivity of $600 \mathrm{ohm}$-meters. Actual measured resistances ranged from 40 to $50 \mathrm{ohms}$. The only variable is the earth resistivity. Inverting the results, that is, using the observed resistances and determining the probable earth resistivity results in 2000 to $3000 \mathrm{ohm}$-meters. The low contact resistances for the dry-well casings (approximately $25 \mathrm{ohms}$ ) will contribute minimally to the overall resistance for resistivities ranging from 500 to 3000 . So, we interpret this to indicate that the tank is acting as a resistive electrical barrier within the general $600 \mathrm{ohm}-$ meter environment. 


\section{Shallow Electrode to Shallow Electrode VOM Measurements}

The average resistance between electrodes is roughly $600 \mathrm{ohms}$. Interestingly, the background apparent resistivity is similarly valued. This suggests that the electrodes may be well grounded and that the observed resistance is due to the intervening earth. This may also support the interpretation that the lower portion of the casings are better grounded than the upper portions. We say this because the individual casing-to-ground resistance is roughly $25 \mathrm{ohms}$. If the casings were uniformly grounded top to bottom in the same medium as the shallow electrodes, then, the casing-to-casing resistance should also show hundreds of ohms. Additionally, the casing-to-shallow-electrode four-electrode measurements

We interpret this to mean that the lower portion of the casings is much better grounded and, in all likelihood, will dominate current flow.

\section{Thermocouple to Thermocouple VOM Measurements}

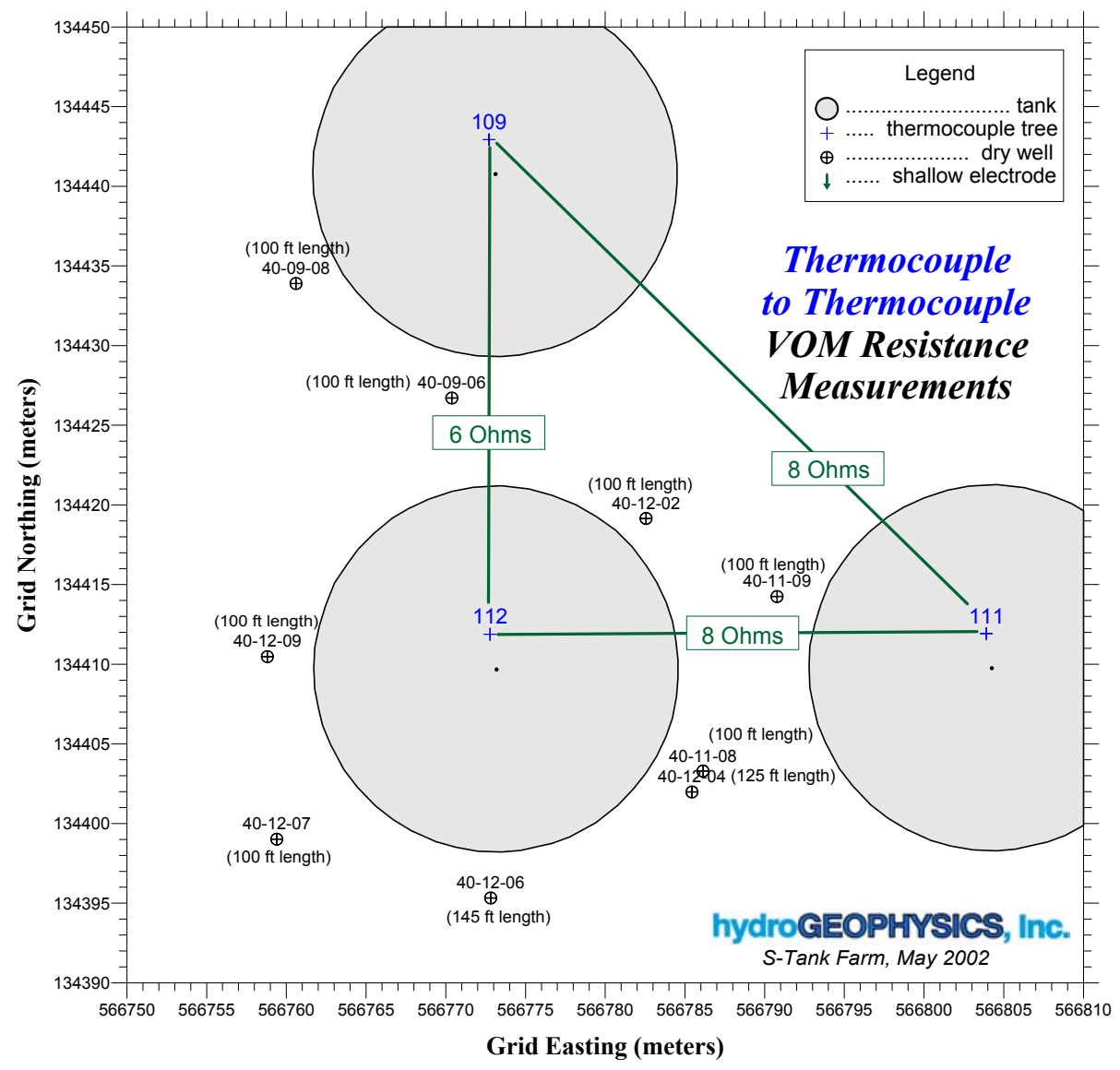

Figure 8 - Thermocouple-to-Thermocouple Volt-Ohm meter measurements 
Three thermocouple trees were made available. Analog VOM measurements were made between the three pairs and resulted in 6,8 , and 8 ohms. These resistances represent the following electrical path; thermocouple tree (first tank), tank contents (liquid and salt-cake), tank body, cascade flange, grounding strap, cascade pipeline, grounding strap, second tank cascade flange, (second) tank body, tank contents (liquid and salt-cake), and the next thermocouple tree. Regardless of how conductive any portion of the electrical path might be, a single resistive contact in the path will dominate the measurements, such as we have shown in the previous section.

Ostensibly, this electrical path (which involves both ionic and electronic conduction) should be relatively low resistance, presumably, less than one ohm. That the measured resistance is as much as $8 \mathrm{ohms}$ suggests that there is some point of continuity in the above path that is less than ideal. We cannot tell where it is by such simple measurements, but, because of the minimal contribution by the tree to the treeto-casing resistances, we suspect the cascade line grounding strap. This opinion is also partly a result of verbal information provided to us that those grounding straps have been found completely corroded apart in other tanks. The other most reasonable possibility is the condition of the insides of the tanks, which could be corroded and well oxidized.

For subsequent monitoring this level of resistance may be beneficial in that, if the thermocouple tree is used as an electrode, it may be more responsive to sensing electrical paths through possible leakage from the tank as opposed to the cascade pipe path.

\subsection{Comparison of results with measurements at the mock tank from FY 2001}

For us, the measurements made at S-112 differed considerably from those at the mock tank because of deployment differences. Due to safety considerations at the time, we were unable to deploy remote reference electrodes which are used for nearly all HRR-SCRT measurements. Consequently, we provided support and suggested additional measurements to those already proposed that would fit in with the deployment constraints.

The independent observations were made at the S-112 study compare favorably with those at the mock tank. In both situations, we conclude that tank S-112 and the mock tank are not as well grounded (electrically) as they might be. Both appear to be electrically isolated from the surroundings, but for different reasons.

\section{S-112 Tank}

The S-112 tank is encapsulated in a double layer cocoon. Asphalt was applied to the outside of the steel tank prior to a concrete enclosure completely surrounding the tank. Both of these could act as electrically insulating barriers. The asphalt should be so, but, the concrete, which has remesh and rebar within it, may or may not be electrically conductive. The degree to which the concrete will pass electrical current depends entirely on the moisture content and-or the possibility that the steel rebar-remesh may make electrical contact with the tank at some point. 
Both of these possibilities have a reasonably probability of happening, particularly the possibility of the underlying concrete being saturated with either infiltrating moisture or minimal tank leakage.

Mock Tank

The mock tank has only a concrete coating around the outer edge of the bottom of the tank and partially up the outside. There is no asphalt coating. Nevertheless, the tank did not prove to be unusually well grounded during the 2001 study. In that respect, we believe that the mock tank and S-112 are similar.

\subsection{Modifications indicated for the Mock Tank based on S-112 measurements}

It is our opinion that no further modifications at the mock tank are necessary. We believe that more emphasis should be put on the Performance aspect of the methodology rather on trying to improvise similarities to the tank farms. Any installations required removal and or replacement of soil will disturb the short-term equilibrium of the site and measurements would be taken during the period of reequilibration. This is not comparable to the tank farms where the infrastructure has been in the ground for years and has reached equilibrium with the surroundings.

Nevertheless, the installation of the sheet piling and various shorting exercises will be interesting. However, we caution that use of the various configurations during the PE test will lessen the statistical results for consistent environmental conditions.

\subsection{Lessons learned to be applied to the Performance Testing}

The primary lesson learned from historic work at other tank farms and with the S-112 measurements is that each tank is likely to have its own environment. What is observed at the mock tank or at any subsequent studies at other tank farms, for all practical purposes, the results will have similar qualitative characteristics, but will likely have minor quantitative differences.

The mock tank and S-112 tests have proven that electrical measurements in difficult cultural environments can be robust, quantitative, and easily deployed.

The range of observed values for various hook-ups at S-112 suggests that all reasonable connections to grounded structures should be made to maximize the information gathered during any future study or deployment. 


\subsection{Comparison of results with historical SST resistance measurements}

In Attachment B (pp53-58) Key discusses resistance measurements made in the BX tank farm. They used a digital voltmeter (Fluke 8000) which we believe is inappropriate for earth measurements. Analog measurements, although less precise, are more accurate for reasons explained in the glossary. As might be expected, they experienced "significant drift and instability of readings" and "major differences in wellto-tank measurements ... when lead attachments were reversed." Nevertheless, their data are useful and compare well with what we observed. They observed tank-to-well values ranging from 2 to 6 ohms. We observed 6 to 8 ohms. We suspect the minor differences are likely due to the presence of existing leakage at the BX tank farm.

At any rate, they observed substantially lower resistances between tanks which is likely due to the lack of precision of the analog system we used. Our objective was not high precision but relative resistances, so, we made no attempt to be precise at the same level.

They observed increasing resistances with distance beyond the tank clusters, but observed reasonably uniform resistances in the areas between tanks. We observed the same pattern within the tanks and made no measurements outside the tank farm.

They observed very low resistances between tanks as did we.

\subsection{Conduct of FY 2002 Measurements for Performance Evaluation Testing at the Mock Tank}

The specific details of the PE test instrument deployment and data acquisition are presented below in the relevant sections.

\subsection{Description of System}

Because we are using the same system as LLNL, their system description should be more representative and detailed than what we would produce.

\subsection{Description of planned sequence of measurements}

\subsubsection{Strategy}

We have been given a short time window to solve the complexities of operating two methods (SCRT \& ERT) continuously for the duration of 104 days. The most efficient solution would be a single remotely controlled automated system. However given the time and funding constraints, this option may or may not be feasible. In order to accomplish our goal we must prepare for the event that the fully remote and automated system may not be completed in time. Therefore, we propose a three pronged approach that will allow data acquisition, should remote and automated capabilities not succeed. 
This includes three separate systems that will provide:

1. Manual collection, manual switching system

2. Manual collection, automated switching system

3. Automated collection, automated switching system

\section{Manual collection, manual switching system}

This system will be similar to the configuration used in the 2001 Mock Tank Demonstration where two manually operated electrical resistivity systems were used. In this setup, all sensors (wells, shallow electrodes, ERT point electrodes, tank, etc.) were connected to patch panels and switching between sensors and the two instruments was performed manually by onsite operators.

As a fall back option for the 2002 LDMM PE we propose using one electrical resistivity instrument (most likely the Zonge GDP-32 with one MUX) that is run manually by an onsite operator. This will reduce the cost of having two simultaneous instruments and will eliminate the need for switching electrodes between separate instruments.

\section{Manual acquisition, automated switching system}

This system will be assembled in conjunction to the development of option 3) Automated acquisition, automated switching system. It will be made up of a series of electro-mechanical relays/switches that will drastically reduce the time consuming operation of switching between sensors (wells, shallow electrodes, ERT point electrodes, tank, etc.) and configuration differences between SCRT and ERT. Bill Daily of LLNL has used a similar arrangement on previous projects and will supply the Hewlett Packard switches to Mark Sweeney of PNNL. The relay switch box is specifically tailored to the demands of electrical geophysics and accounts for high current flow, ground loop problems, and compatibility with the Zonge GDP-32 instrument.

As with option 1) Manual collection, manual switching system, all data collection will still be performed using one electrical resistivity instrument by an onsite operator.

\section{Automated collection, automated switching system}

This system would provide the most efficient means of data acquisition given the complexity of the LDMM performance evaluation. This configuration would require the use of a Zonge GDP-32 that is connected to three (3) MX-30 multiplexers (MUXs). Each MUX supports up to 30 electrodes and the successful combination of three MUXs would support up to 90 electrodes. The software is in final development at Zonge Engineering, two existing MUXs have been upgraded, and a third purchased for the PE test.

The ability to simultaneously connect to all possible sensors (wells, shallow electrodes, ERT point electrodes, tank, etc.) eliminates the need for manual switching. Furthermore, the MUX's can be 
controlled by the GDP and so one could program and therefore automate different array configurations (SCRT or ERT). Software to be developed by LLNL.

\section{Configuration of electrodes and MUX boxes:}

MUX 1: (HGI \& LLNL)

1, 2 SCRT remote reference electrodes

3,4 SCRT tank and injection well

5-8 SCRT / ERT steel well casings

9-16 SCRT / ERT fused ERT electrodes "pseudo-casings"

17-30 SCRT shallow electrodes

MUX 2: (HGI \& LLNL)

SCRT shallow electrodes

35-60 ERT point electrodes

MUX 3: (LLNL)

61-90 ERT point electrodes

Total Electrodes:

- LLNL

- HGI

HGI and LLNL are working with Zonge Engineering and Research Organization to complete the necessary compatibility upgrades and install the multi-MUX software.

LLNL is working to remotely access the GDP-32 so that an operator might run the data acquisition offsite. This will require a dedicated computer that has full time network access (provided by PNNL). HGI and LLNL would set up Virtual Private Networks (VPNs) to the onsite computer to retrieve data and monitor the experiment.

\subsection{Required infrastructure support}

To accommodate remote access, we will need a dedicated onsite computer linked to the GDP-32 and the PNNL computer network. All power for geophysical equipment should be physically isolated with a floating ground. This will require running all power through an isolation transformer. Communications between the dedicated computer and the geophysical instruments will also have to be isolated. This will require optically separating either the serial connections from the GDP-32 to the computer or the network line from the computer, or preferably both. 
Onsite dedicated computer:

- Pentium III based

- Super fan or liquid cooled (cannot rely on bus' air conditioning)

- Provide a minimum of 2 serial ports

- 10/100 BaseT NIC PCI card

- Analog to digital PCI card

- WIN 98 2ED or WIN 2000

- Contain a controlling software such as Terminal Server or PC Anywhere

Network:

Provide dedicated Virtual Private Network (VPN) tunneling to both HGI and LLNL.

Isolators:

Isolation transformer should be rated at least $1 \mathrm{KW}$. Optical isolators usually require batteries to operate, for long term use this could be solved by using power from the isolation transformer. More expensive optical isolators can use power from computer ports, but are highly specialized and typically require USB ports.

\subsection{Description of remote access of system}

Bill Daily (LLNL) is currently working on remote access of the GDP-32. To date, successful remote operations have been performed using both Ethernet and dual modem connection. However, remote operation at the Mock Tank will require the following:

The GDP-32 will be connected to an onsite computer using an isolated serial connection.

The onsite computer will be connected to the PNNL network via a DSL line.

Access to the onsite computer will be through Terminal Server software which allows remote control of a foreign terminal, or in this case, the onsite computer.

Connection will be made using a Virtual Private Network (VPN) tunnel that will be temporarily (daily) established between the onsite computer and either LLNL or HGI.

\subsection{Contingencies for instrument/system malfunction or failure}

Because LLNL and HGI are combining efforts and using the same system we are strongly dependent on LLNL's capability to repair or replace any malfunctioning equipment within their capabilities. We have independently confirmed with Zonge Engineering (in Tucson, AZ) that they will have backup multiplexers available for overnight delivery should we need one on short notice. They have offered rapid turn-around for any instrument shipped to them during the PE test.

Our primary backup system is manual operation. This would require having trained personnel in the TriCities area available for instrument operation when needed.

On a worst case basis (for example, a complete failure of the GDP-32 system components such that it is rendered unoperational), we are prepared to use PNNL's OYO McOhm-21 system with HGI's 
peripherals. We have performed two series of experiments at the Sisson and Lu site with the McOhm and it has been a stable performer. It has some shortcomings, however, that make other instruments more attractive.

\subsection{Proposed Interpretation of FY 2002 Performance Evaluation Test Results}

Each data set downloaded from the field system will be process as soon as possible. If it is during the week, processing will likely be the same day, unless of course the data are only available in the late afternoon. During a weekend, the data will be processed the following Monday morning.

Each day's data will be added to previous data to form as continuous a time-series as possible. Subtle and consistent changes in slope will be analyzed. Slope perturbations will be time-stamped for commencement and cessation of leaks. Estimated leak rates will be determined from linear portions of the time series. The following process represents basics elements of the HRR-SCRT Approaches (Algorithms):

There are three approaches used for HRR-SCRT leak detection.

1. Slope and perturbation analysis (individual casings)

2. SCRT imaging (multiple casings)

3. Surface electrode imaging (multiple electrodes)

4. Reciprocal data for 1 and 2

The following methods will be used for daily data reduction and analysis for each of the methods.

Slope and perturbation analysis (individual casings):

1. Acquire and edit the raw data (using "reciprocals").

2. Perform smoothing.

3. Normalize the data to the transmitted current.

4. Remove the background value or background trend.

5. Flag any data that differ from the bulk of their neighbors (in time) by $10 \%$. [once a bulk average or trend has been established] 
6. If there are sufficient points to determine a new trend that is greater than $5 \%$ change in slope (plus or minus), then calculate new slope based on points forming new trend. [must have 5 or more points to establish a trend] [flag new trend as a possible leak, but perform further checks (criterion 1: possible leak)]

7. Back track along the data to determine whether or not there had been a perturbation event (flagged data from 5.) close to the time of the change in slope. [this helps identify and confirm the onset of a leak (criterion 2: probable leak)]

8. Acquire and process an additional 5 data points.

9. If the trend is confirmed then check to see if there are any known sources of noise that could have caused the trend.

10. If noise sources can be ruled out, then confirm the above process on other steel casings and fused ERT arrays.

11. If $75 \%$ of time series data sets (out of 4 steel casings and 8 fused arrays) show a similar trend, then identify the trend as a confirmed leak (criterion 3; confirmed leak).

SCRT imaging (multiple casings) [concurrent with slope analysis]:

1. Take the processed data from step 4 above.

2. Create a 2-D image through algebraic reconstruction.

3. Subtract an image created from the background data.

4. Plot the differenced image.

5. Evaluate the differenced image for localized changes more than $5 \%$ from the previous image.

6. If changes greater than 5\% are present, then identify the time of, and location in, the image as a possible leak (criterion 1: possible leak).

7. Repeat the process for each of five consecutive times.

8. If each image shows a consistent change (as in 6.), then increase the level of concern (criterion 2: probable leak).

9. Delay further image processing until slope analysis shows a suggested termination to the trend.

10. Take the last five data set images and process as before. 
11. If the images show a trend consistent with that earlier determined, then raise the level of concern (criterion 3: confirmed leak and location).

Surface electrode imaging (concurrent with slope analysis and SCRT imaging):

1. Acquire surface electrode data.

2. Remove background data.

3. Produce 2-D image.

4. Subtract new image from previous image.

5. Evaluate the differenced image for localized changes more than $5 \%$ from the previous image.

6. If localized changes are close to the tank, then consider an edge leak (criterion 1: possible leak).

7. If changes are reasonably uniform across the image, then consider the changes due to a precipitation event.

Reciprocal data for 1 and 2: (parallel processing stream)

Reciprocal data in our approach means reversing the "active" electrodes in the area of investigation, but not reversing the remote reference electrodes. As long as the distances between active electrodes is small (less than $5 \%$ of the distance to the remote reference electrodes) the lack of a "complete" reciprocal makes little difference.

1. Individually process the "reciprocal" data using the tank as a potential electrode following the slope analysis procedure.

2. Maintain a concurrent record of results with and without the use of the reciprocal data.

3. Compare performance at end of test.

4. Provide results at the end of the test. 


\subsection{Description of analytical/modeling code(s) or how these can be evaluated with respect to proprietary rights}

Within this section we will analyze the procedures in place for estimating leak detection within a tank farm environment. It is an important mathematical topic since analyzing paired data in this way and researching links between various factors can be crucial to making decisions regarding the amount of volume leakage and the timing of leak commencement and cessation (at least during the PE test where those factors are specifically controlled).

The primary factors in leak detection as determined during the 2001 LDMM study were the slopes and perturbations of time series data acquired during the study. We found that the slopes of the residual time series appeared to be proportional to the leak rates and that sudden changes in the residual time series were closely correlated with the start and stop times for the controlled leaks. We refer to the determination of these phenomena as "slope analysis" and "perturbation analysis."

We also found that increased data density was very beneficial in confirming trend characteristics and allowing more accurate timing for perturbations. We foresee a need for sufficient data density during the PE test to allow such features to be reliably established. Considering the demands for remote control of instrumentation, this may be a concern to be resolved.

\section{Slope Analysis}

The data presented in this section refer to the paper, "Report on High Resolution Resistivity Measurements", prepared for the LDMM Study at the mock tank site at Hanford, Washington during the summer 2001.

Figure 1 shows a plot of collected during the LDMM study residual-normalized-potentials for the southwest steel casing using the tank as a source electrode (for simplicity purposes the northwest and southeast data sets were omitted from this plot). Time is on the abscissa in Julian days. The ordinate is the normalized potential in units of millivolts per milliamp ( $\mathrm{mv} / \mathrm{mA}$ or $\mathrm{V} / \mathrm{A})$. Note that the times of injection and amount of injected fluid are also included. 


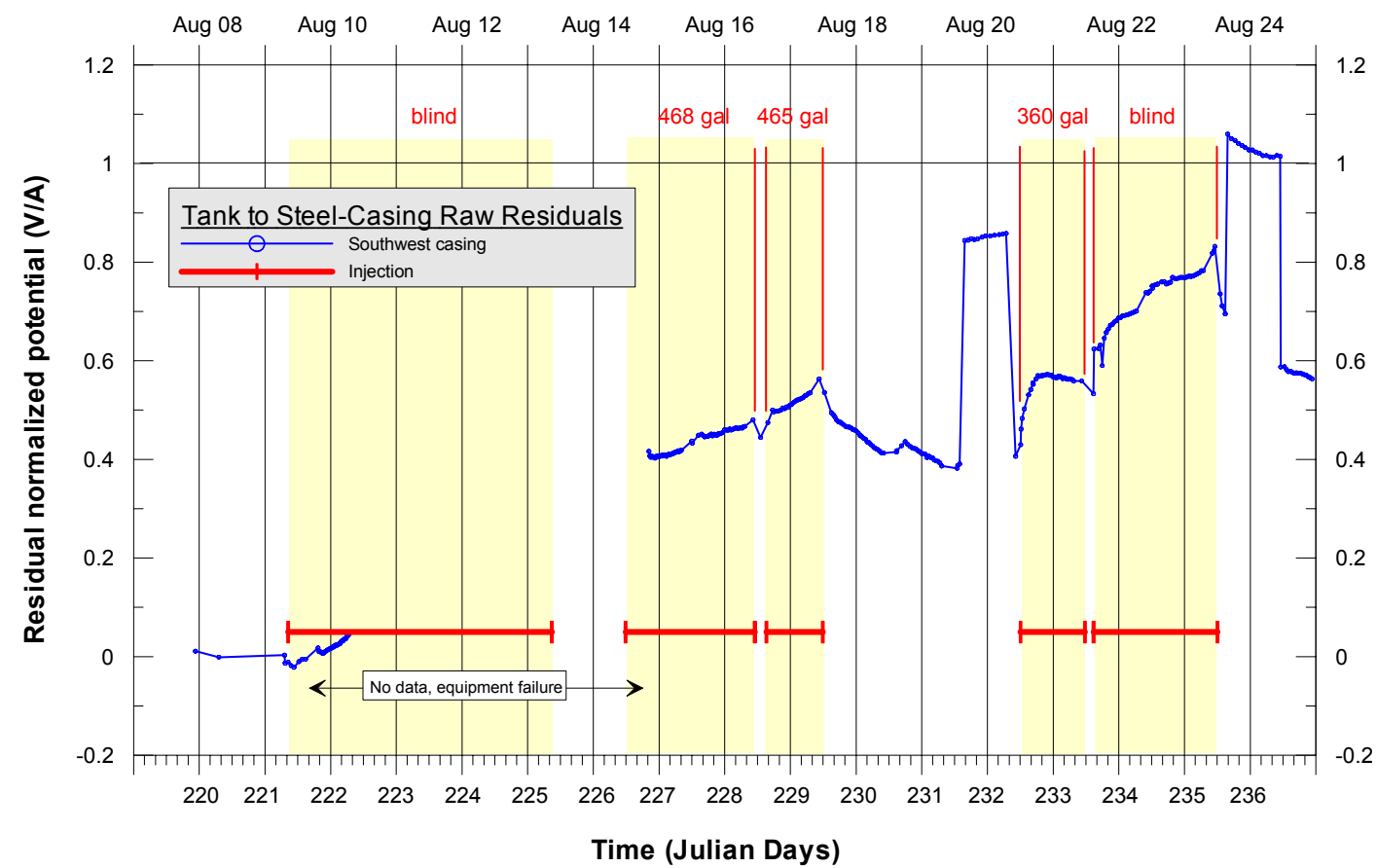

Figure 7.1 - Residual-normalized potentials versus time using the tank as a transmitter and the steel casings as receivers.

Figure 7.2 expands on the injection periods bracketed by August $14^{\text {th }}$ through August $18^{\text {th }}, 2001$.

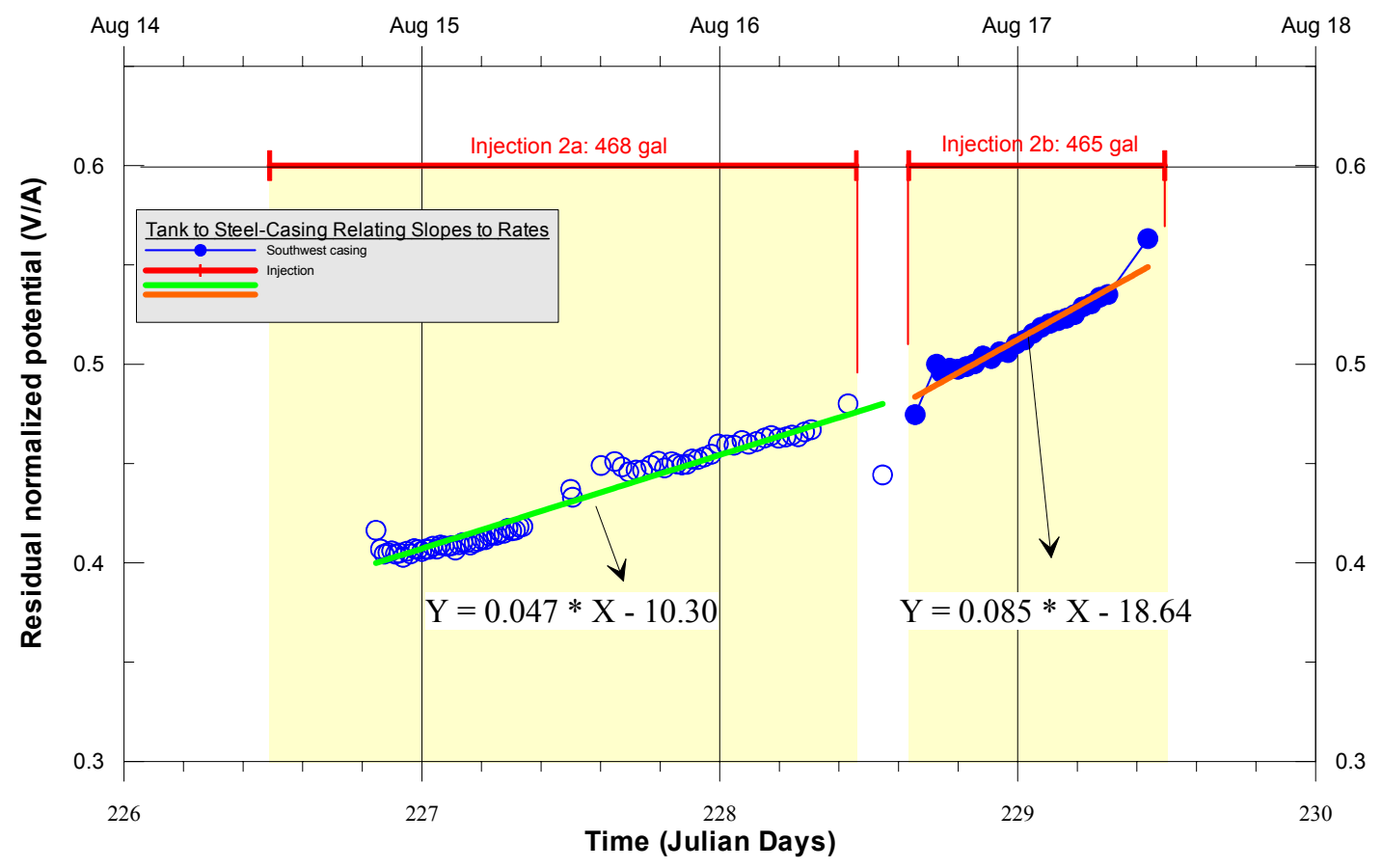

Figure 7.2 - Southwest Casing during Injection $2 \mathrm{a}+2 \mathrm{~b}$ (August 14 to 18,2001 ). 
A linear regression was made on selected portions of the time series acquired during Injection $2 \mathrm{a}$ for the purpose of "calibrating" the slope to known injection parameters. Simple linear regression involves determining the equation for a straight line that best fits the given data. That linear equation is then used as either a predictor or comparator of results for other portions of the time series. Therefore, careful consideration was given for the selection of data so as not to include the outlying points at the beginning and end of injection 2a. These can be seen in Figure 7.2. The normalized potential measurements near the onset and terminations of injections show conspicuous deviation (in this example at least) from the overall linear trends. Consequently, manual inspection and editing will be required until the nature of the deviations can be established. This will allow automatic data selection and trend extraction methods to be refined.

The application of slope analysis to future data not only depends on such inspection but also depends to some degree on the character of the data, frequency of sampling, and the local electrical environment. A sense of the influence of these concerns will be established during the PE test.

The linear regression model postulates that

$$
Y=a+b X
$$

where $a$ is the value at which the best fit line crosses the $\mathrm{Y}$-axis $\mathrm{Y}$ axis and where $b$ is the slope of the line i.e. measuring the steepness of a line relative to the $\mathrm{x}$-axis. Note that linear regression assumes linearity does not test whether the data are linear. For Injection 2a, the equation of the line that best fit the geophysical data was:

$$
\mathrm{Y}=0.047 * \mathrm{X} .-10.3
$$

A total of 465 gallons of solution was injected into the ground during the 47.5 hours of injection $2 \mathrm{a}$. This equates to a flow rate of 9.85 gallons per hour (gph).

At this point, we made the assumption that the slope of the best-fit line from the linear regression is related to injection rate, such that an increase in flow rate would be observed as a steepening of the slope through the geophysical data.

$$
\begin{gathered}
\text { Flow Rate } \sim \text { Slope } \\
9.85 \text { gph } \sim 0.047
\end{gathered}
$$

This assumption is validated from data collected during Injection $2 \mathrm{~b}$, see Figure 7.2 (blue circles). In this case, the injection rate was for all practical purposes twice as fast as injection rate from 2a, $20.7 \mathrm{gph}$. The slope of the best fit line was 0.087 which is nearly twice the value from Injection $2 \mathrm{a}$.

It is possible to produce a calibration curve to help predict future flow rates based solely on the analysis of injections $2 \mathrm{a}$ and $2 \mathrm{~b}$. Figure 7.3 shows a plot of flow rates for injections $2 \mathrm{a}$ and $2 \mathrm{~b}$ versus the slope values based on the southwest steel casing using the mock tank as a source electrode. Note that the linear regression method could not be used here because there were only two data points. Adding more points, 
i.e. a controlled study with variable rate injections should be performed to make the calibration curve more robust.

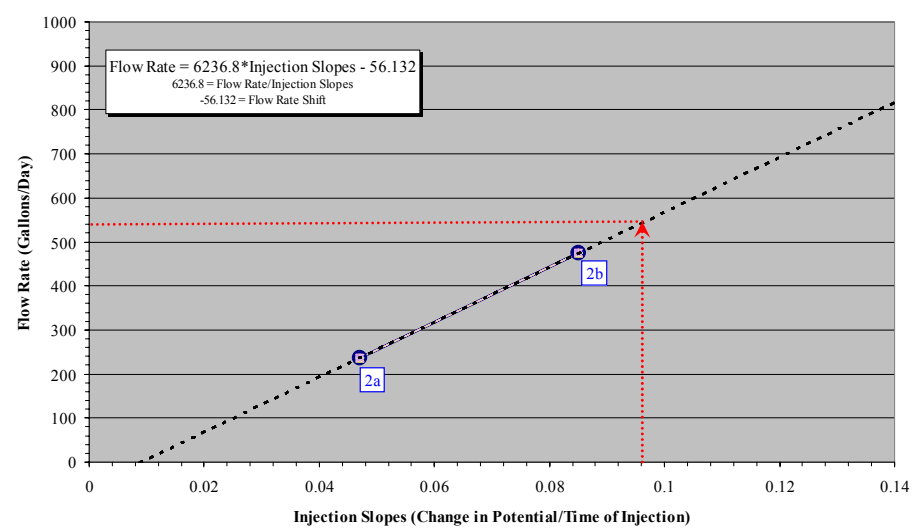

Figure 7.3: Predicted Flow Rates Based on Measurements from SW Steel Casing Measurements

However, even in this primitive form the slope of this line very accurately predicted the flow rates during the blind injection 4. The best fit line through the data collected is shown in Figure 7.4.

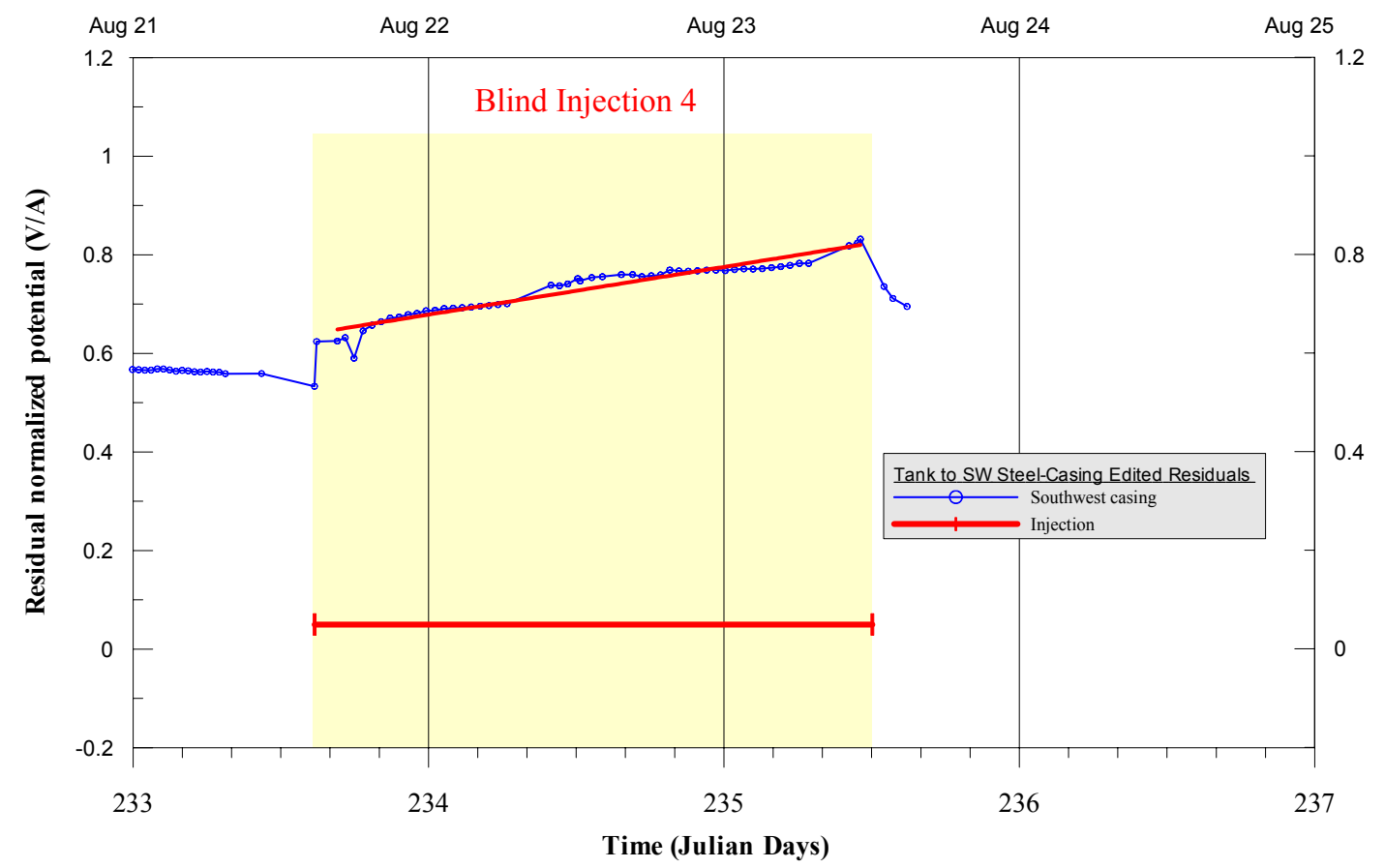

Figure 7.4: Residual-normalized potentials versus time using the tank as a transmitter and SW steel casing as a receiver during Blind Injection \#4.

The equation of the best-fist line is: 
$\mathrm{Y}=0.0967 * \mathrm{X}-21.7$

Using the calibration curve from Figure 3, the calculated slope, 0.0967 is projected onto the curve and then the flow rate can be calculated by projected this point back to the y-axis, see figure 3 (red arrows). The obtained value is approximately $540 \mathrm{gpd}$ or $22.5 \mathrm{gph}$. Subsequent, to the report we received the values for this blind injection: flow rate was $571 \mathrm{gpd}$ or $23.8 \mathrm{gph}$.

Our estimate of flow rate based purely on our calibration curve was within $5 \%$ of the actual value.

\section{Perturbation Analysis}

A quantifiable relation is more difficult to obtain just at the onset and termination of injections. However, an encouraging aspect of these curves is that for each brief period of high gradient correlates with either an injection commencement or termination. The commencement of the initial injection is represented by a decrease in potential, such as was seen at the Sisson and Lu site for the more distant casings from the injection well. Subsequent injection commencements (at the Mock Tank site) are indicated by noticeable increases in potential. Terminations of injections are indicated by noticeable decreases in potential. Interestingly, the amplitude change during the short periods of high gradients increases with larger amounts of conductive material injected. See Figure 7.1 at these following times in Julian days: 228.5, $229.5,232.5,233.5$ and 235.5. The perturbation of the potential data is in close concordance with the injection schedules.

The only quantitative information to be derived from perturbation analysis is the length of time between leak sessions. The magnitude of the downward deviation has yet to be related to any specific leak parameter.

\section{References}

Key, K. T., 1975, Nuclear Waste Tank and Pipeline External Leak Detection Systems, Informal Report ARH-LD-120, Atlantic Richfield Hanford Co., Richland, WA.

Andrews, J. S., 1976, Waste Tank Leak Detection System: CPFF Contract \#217, Boeing Co., Seattle, WA.

Miscellaneous authors, 1975-1976, Relevant memos, progress reports, data plots, data notes, drawings, schematics, and maps related to the leak detection monitoring efforts of that time. Extracted from larger memos retrieved from the Records Information Management (RIM) RMIS System, Atlantic Richfield Hanford Co., Hanford, WA. 


\section{Attachment H}

\section{Procedure for Measuring Soil Moisture Using Neutron Probe}





\section{Attachment H}

\section{Procedure for Measuring Soil Moisture Using Neutron Probe}

The attached instructions for soil moisture measurements using neutron probe techniques will be applied to groundtruth data collection as described in Section 6.0. Any deviation from these procedures, due to instrumental or field conditions, will be documented in field notes during data collection activities, as appropriate. The exact measurement locations, depths and vertical increments of measurement, and schedule of measurements is presented in Section 6.1. 


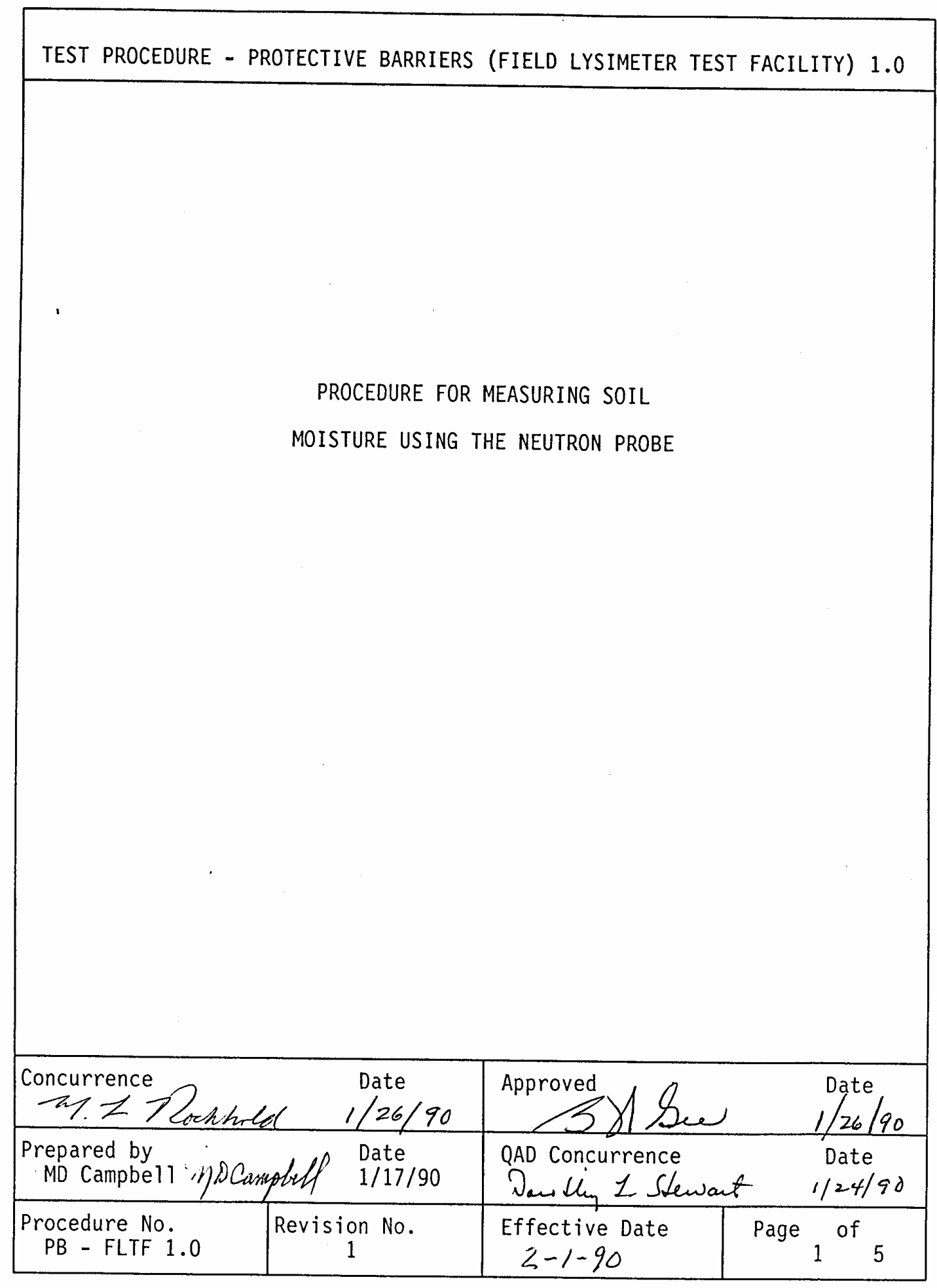


TEST PROCEDURE - PROTECTIVE BARRIERS (FIEID LYSIMETER TEST FACILITY) 1.0

\subsection{APPLICABILITYY}

This procedure describes the use of the 503DR Hydroprobe (Neutron Depth Moisture Gauge) in measuring soil moisture in the Field Lysimeter Test Facility. The 503DR measures subsurface moisture in soil by using a probe containing a source of fast (high energy) neutrons and a slow (thermal) neutron detector. Impact of the fast neutrons with hydrogen present in the water in the soil slows some of the neutrons and deflects them back for detection. The measurement of the number of slow neutrons detected per time interval is displayed on a digital readout unit attached to the source shield assembly. If the digital readout unit operates on NICAD batteries, they should be charged before being used. For further information concerning the 503DR see the operator's manual on file in the field lab, room 1519 Sigma V. Also for information on FLTF lysimeter design, neutron access port configuration, and monitoring requirements see PNL-6351 (FLTF Experimental Plan).

\subsection{DEFINITIONS}

No special definitions. For further technical information see the operators manual in room 1519 of Sigma V.

\subsection{RESPONSIBLE STAFF}

Task Ieader, Technical Support Personnel.

\subsection{PROCEDURE}

\subsection{Equipment}

- 503DR Hydroprobe, Neutron Depth Moisture Gauge or equivalent

- Appropriate cable with depth markers set for the site (compare with cable stop image painted on FLTF wall)

- Laboratory Record Book

- Wax and dry-soil transfer standards

\subsection{Setting the Format, Units, and Time}

Before setting the format, download any data in memory to avoid loss. Follow instructions in PB - FLTF 7.0. When the format is changed in the direct readout unit, data present are erased.

\begin{tabular}{|c|c|c|c|}
\hline $\begin{array}{c}\text { Procedure No. } \\
\text { PB - FIIF 1.0 }\end{array}$ & $\begin{array}{c}\text { Revision No. } \\
1\end{array}$ & Effective Date & Page of \\
\hline
\end{tabular}


TEST PROCEDURE - PROTECTIVE BARRIERS (FIETD LYSIMETER TEST FACILITY) 1.0

4.2.1. Press the FORMAT button on the readout unit. Press STEP to step through the available records. The readout will display KDATA and a value. Press zero and ENTER to set it to zero. Next, the readout will display DEPIH and a value. Type in the number of depths to be measured and press ENTER.

4.2.2. The readout will then display SET FMI? Press ENIER to set the format. The number of available records will be displayed. Press STEP to get to the ready prompt.

4.2.3. Set the time interval on the readout unit by first pressing the TIME key. Then step through the times until the desired time shows on the screen (e.g., 16 for 16 seconds count), and then press the ENTER button. The units are set in the same manner as the time. First press the UNIT key on the readout unit. Then step through measurement units until MUNT CNT appears and press ENTER. (Note: TAKE ALL READINGS AS COUNTS.)

\subsection{Standard Counts}

The neutron probe must be tested in a reference standard at the beginning and end of each day of use. The reference standard may be any invariable medium that will absorb energy from fast neutrons to allow them to react with the detector while they are within its range. A wax and a dry-soil standard have been prepared for this purpose. In the past, the neutron probe shield has been used as a standard but the shield counts vary too much. In the future, this practice should be limited to probe function field tests only. In every test, thirty-two measurements must be made in the reference standard. (A thirty-two reading set is the sample size required for the statistics used).

4.3.1. Attach the digital readout unit to the hydroprobe and connect the cable from the probe to the readout unit.

4.3.2. Place the probe in the proper position in the selected test standard. Take 32 readings. The CPN 501DR and 503DR probes take 32, 8-sec counts automatically.

To take automatic counts:

4.3.3. Press STD on the readout unit. The unit will display the last standard count taken. STEP through to display the chi value and the previous mean standard count.

4.3.4. Press STEP again; the readout unit will inquire, NEW STD? Press

\begin{tabular}{|c|c|c|c|}
\hline $\begin{array}{c}\text { Procedure No. } \\
\text { PB - FLTF 1.0 }\end{array}$ & $\begin{array}{c}\text { Revision No. } \\
1\end{array}$ & Effective Date & Page of \\
\hline
\end{tabular}


TEST PROCEDURE - PROTECTIVE BARRTERS (FIEID LYSIMETER TEST FACILTTY) 1.0

ENTER; the probe will then begin taking the 32 readings to compute the new standard. Stand at least 5 feet from the probe while the standard counts are being taken to minimize any effects on the standard count.

The following text describes how the standard counts are used to evaluate the function of the neutron probe (Remember that the 503DR and 501DR perform these operations for the user).

- Compute the average (A) of the 32 readings.

- Compute the standard deviation (s) of the 32 readings using the following equation:

$$
s=\left(\frac{\Sigma(X-A)^{2}}{n-1}\right)^{\frac{1}{2}} \text {, where } n=32 \text {, in this case. }
$$

- Compute the square-root of the average. $\mathrm{A}^{\frac{3}{2}}$

- Calculate Ratio: $R=s / A^{\frac{1}{2}}$ (Equivalent to chi)

If $R>1.25$, the detector is not counting some of the neutrons. If $R<0.75$, the detector is counting pulses other than neutrons. If $R$ is between these values, the probe is working properly.

4.3.5. If the $R$ value (CHI) is too high or too low, repeat the test. If the average $R$ is outside the range 0.75 to 1.25 , set the count time to 16 seconds, wait 20 minutes, and take 32 readings manually. Compute $A, s$, and $R$, manually. If $R$ lies outside 0.75 to 1.25 , return the readout to the factory for repair. Otherwise, continue.

NOTE: The range 0.75 to 1.25 is based on a sample size of 32 and a probability interval of 0.95 .

The 503 DIRECT READOUT displays "S" with the current standard count, "P" with the previous Standard count and "Chi" is equivalent to the ratio $R$ above.

The Direct Readout automatically adjusts all readings to a 16-second reading equivalent. Even the automatic calibration makes this adjustment after taking 32 eight-second readings and computing the Chi value.

Therefore, if probe calibration is done manually, select the 16-second time interval because any other time interval will yield an incorrect chi value.

\begin{tabular}{|c|c|c|c|}
\hline $\begin{array}{c}\text { Procedure No. } \\
\text { PB - FLTF 1.0 }\end{array}$ & $\begin{array}{c}\text { Revision No. } \\
1\end{array}$ & Effective Date & Page of \\
\hline
\end{tabular}


TEST PROCEDURE - PROTECTIVE BARRTERS (FIELD LYSIMETER TEST FACILITYY) 1.0

\subsection{Soil Moisture Measurements}

4.4.1. Place the probe on top of the access tube.

4.4.2. Lower the probe to the deepest depth and secure the stop on the top of the probe.

4.4.3. Press $L O G$ on the keypad on the readout unit.

4.4.4. Key in the appropriate I.D. number and press ENTER. (The I.D. number consists of a location code and the access tube number; for example, 991 where 99 is the location code and 1 is the access tube number).

Location codes:

$\begin{array}{ll}\text { BWIF } & 55 \\ 300 \text { N Grass Site } & 99 \\ \text { FLTF } & 44 \\ \text { CWLA } & 66 \\ 200 \text { East Lysimeter } & 22\end{array}$

4.4.5. Key in and enter or STEP through the K DATA query.

4.4.6. The unit will then display TAKE _ where the _ is the deepest depth that you set in the FORMAT statement. Press START. The probe will then take the count and display the value on the readout unit.

4.4.7. Record the value in the Laboratory Record Book and press ENIER. The readout unit will then display TAKE _, for the next depth.

4.4.8. Move the cable to the next depth to be measured, and repeat steps 4.4.6 and 4.4.7 until all measurements for an access tube are logged. After entering the value for DEPIH 1, the readout will query: DATA OK?

4.4.9. If data agree with LRB values, press ENTER, and go on to log the next access tube. If a mistake was made in taking a reading, STEP through to that depth, position the probe correctly, and retake that count. Then STEP through to the DATA OK? query and press ENTER.

4.4.10 Return the neutron probe to its authorized storage area and secure it.

4.4.11 Remove the readout from the probe shield assembly and carry it to the computer in Sigma 5. Download data into the database by following steps in procedure PB-FLTF 7.0. Compare with IRB data. Correct errors.

\begin{tabular}{|c|c|l|l}
\hline $\begin{array}{c}\text { Procedure No. } \\
\text { PB - FLIT 1.0 }\end{array}$ & $\begin{array}{c}\text { Revision No. } \\
1\end{array}$ & Effective Date & Page of \\
\hline
\end{tabular}


PROCEDURE FOR DOWN LOADING DATA FROM THE NEUTRON

PROBE 503 DIGITAL READOUT UNIT

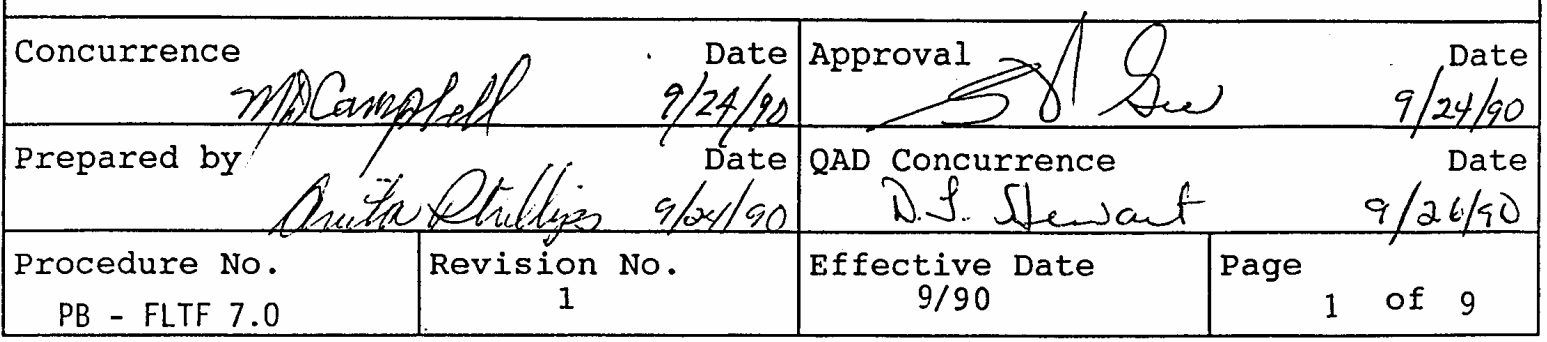


PNL TECHNICAL PROCEDURES

\subsection{APPLICABILITY}

This procedure describes the method used to down load data from the Campbell Pacific Nuclear Neutron Probe 503 digital readout to an IBM AT computer running ST240, Program Editor (PE), and network package DECnet DOS.

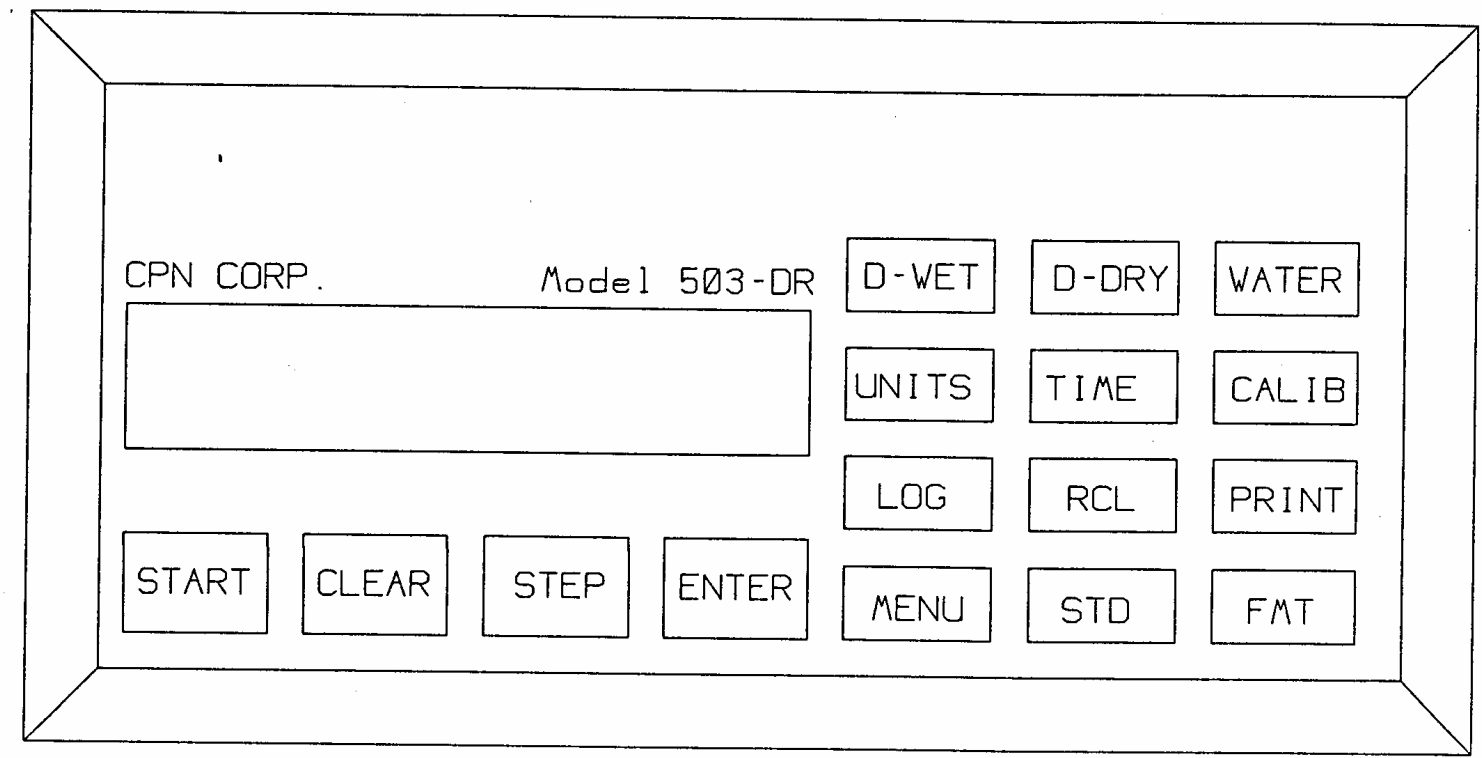

Procedure No. Revision No. Effective Date PB - FLTF 7.0 1 


\section{PNL TECHNICAL PROCEDURES}

\subsection{DEFINITIONS}

Readout means the entire electronic unit used to record and display the measurements made by the probe.

RS-232 Cable refers to the cable used to link the readout unit with the IBM AT computer.

Black Box refers to the switch box used to switch between the communications port and the probe port.

ST240 refers to the communications software package used to capture the data from the readout unit.

PE refers to the WordPerfect Library's Program Editor used to edit the down Toaded text file.

DECnet DOS refers to the software package used to communicate with the Barriers VAXstation.

VAXstation refers to the Digital Corp. micro VAX workstation where the Barriers database resides.

Username refers to the micro VAX workstation login name which is your payroll number preceded by the letter "D".

Database refers to the collection of data we have gathered at the Field Lysimeter Test Facility (FLTF).

FLTFNP 2 refers to the second version of the RS1 procedure (computer program) used to process the neutron probe data into a usable format.

EDT is the text editor used on the VAXstations to edit files.

\subsection{RESPONSIBLE STAFF}

Task Leader, Technical Support Personnèl.

\subsection{EQUIPMENT NEEDED}

1. 503-DR unit containing collected data.

2. RS-232 cable.

3. IBM AT computer system.

4. Floppy disk containing neutron probe files.

\begin{tabular}{|c|c|c|l|}
\hline $\begin{array}{c}\text { Procedure No. } \\
\text { PB - FLTF 7.0 }\end{array}$ & $\begin{array}{c}\text { Revision No. } \\
1\end{array}$ & $\begin{array}{c}\text { Effective Date } \\
9 / 90\end{array}$ & Page \\
3 of 9 \\
\hline
\end{tabular}


PNL TECHNICAI PROCEDURES

\subsection{PROCEDURE}

1. Insert FLTF Neutron Probe diskette found in the file cabinet next to AT computer into B: drive (lower unit) on the AT.

2. Connect RS-232 cable from digital readout unit to AT com port via the black IBM cord connected to the Black Box and multicolored ribbon cable.

3. Switch the Black Box to the B position.

4. Make sure the readout unit if possible is plugged into an electrical outlet to keep the unit from running out of power while you're dumping the data.

5. Move to the ST240 directory by typing CD\ST240. Type ST240 to execute the SmartTerm program.

6. After SmartTerm loads, choose configuration 8, NPROBE. Type in Alt $C$ to initiate the capture mode.

7. Type $F$ while in the capture set-up screen to change the file name.

8. Type the correct file name according to the site abbreviation and the date of the collected data (ex. F16Jan90.NP = FLTF, 16 January, 1990; the extension, .NP, indicates that the file is a neutron probe text file). $F=$ Field Lysimeter Test Facility. (Barriers has only one field site we
collect neutron probe data from.)

9. Type <RET> <RET> to enter the filename and to start capture of data

10. Press the PRINT button on the readout unit; press step until the screen reads PRINT LP, press the ENTER button on the readout unit.

11. Data will flow onto the screen. When it stops, press Alt $C$ on the Keyboard; this returns you to ST240 capture command level.

12. Press Alt $X$ on the keyboard to return to the ST240 DOS directory (the C: prompt).

13. At the C: prompt, do a DIR to ensure that the file you specified was created in the ST240 directory. If you receive a 'File not found' error the file was either not created or not correctly entered in Step 8. Return to Step 6 and make sure you keyed in the filename correctly.

14. At the C: prompt, enter TYPE filename.ext to see if the data has been transmitted to the file. If no data have been transmitted, check the digital readout connections and return to Step 6 .

\begin{tabular}{|c|c|c|l|}
\hline $\begin{array}{c}\text { Procedure No. } \\
\text { PB - FLTF 7.0 }\end{array}$ & Revision No. & $\begin{array}{c}\text { Effective Date } \\
9 / 90\end{array}$ & Page \\
\hline
\end{tabular}


PNL TECHNICAL PROCEDURES

15. If data has been transmitted, type PE filename.ext at $C$ : to get in to Program Editor. The 'filename.ext' you determined in Step 8 .

16. If PE gives a 'File not found' error then press F7, enter No to save the file, and enter Yes to exit PE. Repeat Steps 13 \& 14 and make sure the file exists, contains data and that you typed it correctly in Step 15.

17. Here is an example of what you will be editing out of the probe files; the following appears at the beginning of an unedited probe file.

A. Start by deleting the empty line before the line "MODEL SERIAL UNIT . . ." Keep the lines which start with "MODEL" and "503A-203".

[BOF] - beginning of file

$\begin{array}{llllll}\text { MODEL } & \text { SERIAL } & \text { UNIT } & \text { STD } & \text { KDATA } & \text { DEPTH } \\ 503 A-230 & 143 & \text { CNT } & 934 & 0 & 13\end{array}$

\begin{tabular}{lll} 
CAL & A & \multicolumn{1}{c}{$B$} \\
1 & 0.1949 & -0.0056 \\
2 & 0.0 & 0.0 \\
3 & 0.0 & 0.0 \\
4 & 0.0 & 0.0 \\
5 & 0.0 & 0.0 \\
6 & 0.0 & 0.0 \\
7 & 0.0 & 0.0 \\
8 & 0.0 & 0.0 \\
9 & 0.0 & 0.0 \\
10 & $* . *$ & 0.0 \\
11 & 0.0 & 0.0 \\
12 & 0.0 & 0.0 \\
13 & $\star . *$ & $* . *$ \\
14 & 0.0 & 0.0 \\
15 & 0.0 & 0.0 \\
16 & 0.0 & 0.0
\end{tabular}

$\begin{array}{llrrrrrrrr}\text { ID } & \text { C } & \text { M13 } & \text { M12 } & \text { M11 } & \text { M10 } & \text { M9 } & \text { M8 } & \text { M7 } & \ldots \\ 441 & 1 & 4609 & 6794 & 10408 & 9982 & 9682 & 9763 & 9969 & \ldots \\ 442 & 1 & 3149 & 3577 & 4574 & 4470 & 4384 & 4278 & 4229 & \ldots \\ 443 & 1 & 0 & 0 & 0 & 3341 & 3519 & 4507 & 4669 & \ldots\end{array}$

Editing

Steps: $\quad P E$ has many features that allow you to edit the file more efficiently and accurately. They are as follows:

\begin{tabular}{|c|c|c|c|}
\hline $\begin{array}{c}\text { Procedure No. } \\
\text { PB - FLTF 7.0 }\end{array}$ & Revision No. & Effective Date \\
$9 / 90$ & Page & 5 of 9 \\
\hline
\end{tabular}


PNL TECHNICAL PROCEDURES

Alt-F2 is the Replace function which allows you to replace many of the same value with another value all at one time.

Alt-F4 is the Block function which allows you to mark a section of text.

Del key (decimal key located on the keypad next to the 0 ) allows you to del one character at a time or to delete the block of text if the Block function is on.

B. Press Alt-F2. Type No in answer to the confirm question. Enter <RET> <RET> for the Search query and press F2. Enter $<$ RET $>$ for the Replace query and again press F2. This will remove most of the blank lines.

C. . You will now be on a blank line at the end of the file. Press the backspace key (upper right key of the alphanumeric keys NOT including the keypad) to move to the top of the file. Delete any preceding blank lines to the text using the Del Key.

D. Move your cursor to the line below the two header lines and press Alt-F4. Type Home Down arrow (number 2 on the keypad). Your cursor should now be on the line starting with 'ID'. If it is not move it Up or Down until it is. Press the Del key and answer Yes to the 'Delete Block'

E. There may be one or two more blank lines which you can use the Up Down arrow keys to move to and the Del key to delete until there are no blank lines.

Delete the empty line which follows and continue to delete lines until you reach the line starting with "ID"; delete the empty line beneath "ID" so the raw data lies directly below. Make sure all the data is present for each hole and check for flyers.

Note: A flyer data value is a value that is out of range for that well and location stop. It is a visual comparison of data to flag any suspicious values for further investigation based against the values normally collected at the field site.

18. Edit out the unnecessary information (i.e. in bold type previous page was described in the previous editing steps) and leave no empty lines in the file. The procedure which reads in the data considers empty lines as missing values.

19. Once you have finished editing a neutron probe file, it should look similar to this: (data would continue off to the right of the page to include all the probe readings if the margins were set at 0 and 250 ).

\begin{tabular}{|c|c|c|c|}
\hline $\begin{array}{c}\text { Procedure No. } \\
\text { PB - FLTF 7.0 }\end{array}$ & Revision No. & Effective Date \\
1 & $9 / 90$ & Page \\
\hline
\end{tabular}




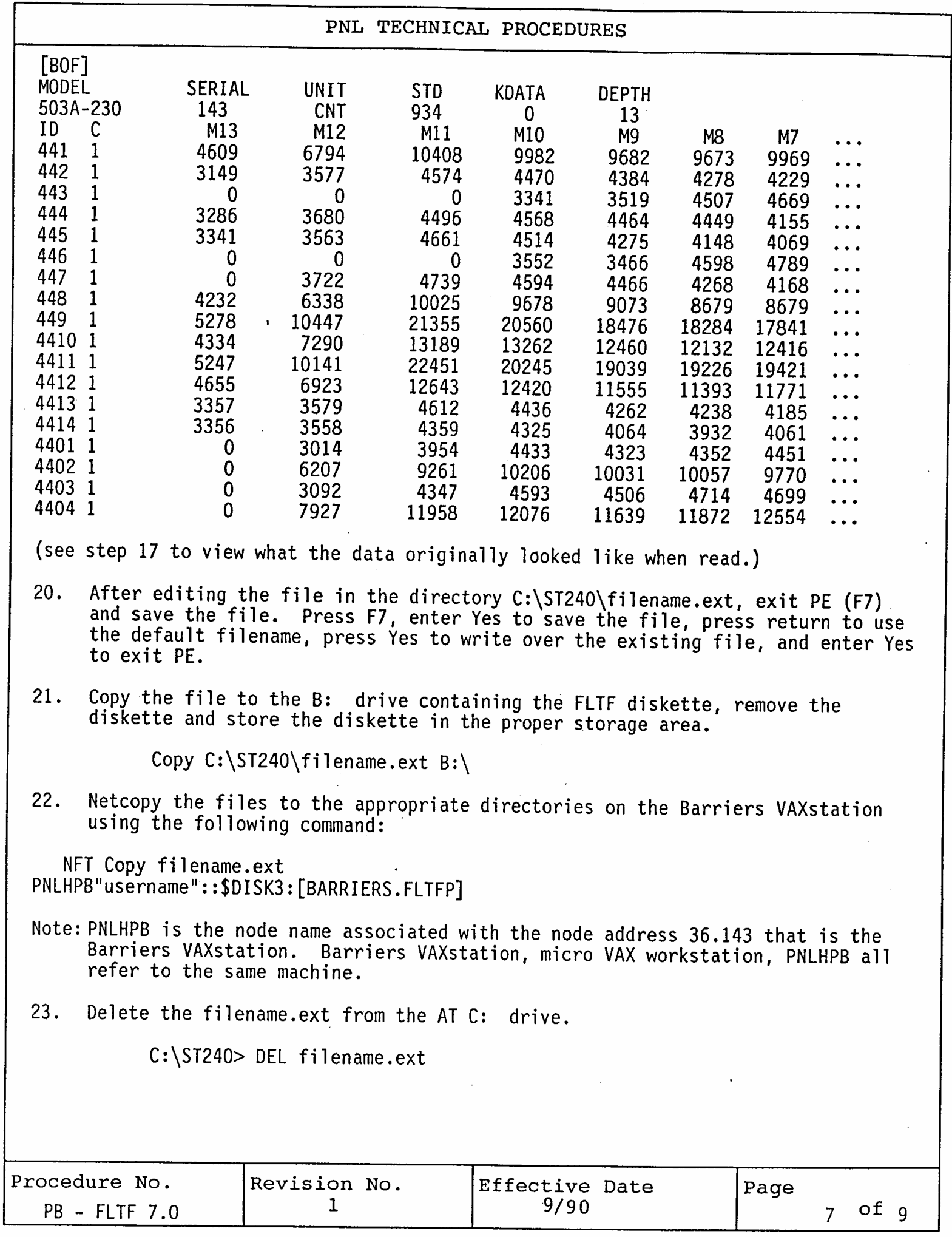


24. Login to the Barriers VAXstation. (Do one of the following)

A) Direct login via the VAXstation monitor and keyboard.

Move pointer to lower left corner of the screen, click the left most mouse button and select "Create ne VT200 window." Enter your Username and Password when prompted.

B) Login via NIU Terminal servers using the PNLnet running DLAT (DEC Local Area Transport).

Type <RET> <RET> to activate the NIU. At the PNLnet > prompt type C[onnect] PNL DLAT $\angle R E T>$. Wait about 3 seconds and type $<R E T><R E T>$ to act ivate the Terminal Server. At the LOCAL $>$ prompt type C PNLHPB $<R E T>$ and follow the normal login procedure.

C) Login via IBM AT running ST240 software.

Enter CD IST240 to change to the ST240 directory. Type ST240 to execute the program and Select 1 for VAX systems and follow Step B to finish connection procedures.

D) Login via DECnet networking software.

On the AT type SETHOST PNLHPB and follow the normal login procedure. From another VAX system type SET HOST PNLHPB and follow the normal login procedure.

25. After logging in then type SET PROJECT BARRIERS to move to the Barriers project and type SD. FLTFNP $\angle R E T>$ to move to the VMS neutron probe directory containing the neutron probe data.

26. Type DIR or DIRE and the filename.ext to determine if the file transferred to the Barriers VAXstation.

27. Start RS/1 by typing RS1

28. At the \# prompt type CALL FLTFNP_3 to execute the neutron probe read in procedure.

29. You will be prompted for any additional information by the procedure you have just invoked. At each question if there is a default answer in brackets [] you can just type return for that answer to be used.

Note: You will enter the EDT editor to edit the note. When in the EDT editor at the * prompt type C<RET> to enter the Keypad editing mode. Type a ctrl- $Z$ to exit Keypad mode. Type EXIT to exit the editor.

30. Type LO at the \# prompt to logout of RS1 and type LO at the \$ prompt to logout of VMS, the VAXstation operating system. If you used ST240 to get to the Barriers VAXstation type an AIt-X to exit back to the DOS prompt.

Procedure No. Revision No.
1 Effective Date Page 
PNL TECHNICAL PROCEDURES

31. The final step is to have the RS1 procedure printout the three tables and one graph. A visual comparison of each data point in the raw RS1 table and the LRB are needed for verification. If correct sign and data the printed data sheet and place all four sheets in the three ring binder dedicated for FLTF neutron probe data. If the data is in some way inconsistent or incorrect see the database steward or the project manager for details on how to handle the problem and the necessary documentation needed to correct the problem.

Note: Steps 1 thru 23 are performed on the IBM AT system used to collect data.

The remaining steps are done at a terminal that can connect to the Barriers VAXstation that we are using for data storage and analysis.

\begin{tabular}{|c|c|c|c|}
\hline $\begin{array}{c}\text { Procedure No. } \\
\text { PB - FLTF 7.0 }\end{array}$ & Revision No. & Effective Date \\
$9 / 90$ & 1 & Page & of 9 \\
\hline
\end{tabular}




\section{Standard field procedure for using the neutron probe to measure soil moisture}

1. Attach read-out unit to the neutron probe and connect neutron probe cable

2. Set format:

i.Push format button (FMT).

ii.Push "step" (yellow button) button twice ("depths" will be displayed on screen).

iii.Enter the amount of depths you want to read then push "step" (yellow button).

iv.You will be asked if you want to set the new format (set fmt?). Push enter/yes (Blue button).

v.Screen will display "ready" status.

3. Take a standard count:

i.Place neutron probe on the yellow metal square on top of neutron probe box

ii.Push the standard button (STD).

iii.Push "step" button twice and Chi will be displayed on screen. Chi should be between 0.90 to

1.25. If higher or lower, contact Fenton Khan or the company (CPN, Corp.).

iv.After checking Chi, push step button once more and you will be asked if you want to obtain a new standard (new std?). Push enter/yes (Blue button)

v.Move away from neutron probe (at least 10 feet).

vi.The read-out unit will take standard counts for approximately 10 minutes. You will hear it beeping every few seconds.

vii. When the beeping stops, the screen on read-out unit should display a standard count (e.g. S 7145

or S 11034). Record number and "step" to next screen which will display the previous standard, "step" again and a Chi number will be displayed. After checking/recording Chi number, push Enter/blue button until "ready" is displayed on screen.

4. You are ready to take soil moisture readings. Readings are generally taken from bottom of well to surface:

i.Place neutron probe over pipe in ground and slowly drop the cable until the probe is at desired depth. If taking a measurement at bottom of well, the measurement should be approximately $15 \mathrm{~cm}$. above the soil surface.

ii.Push "Log" button.

iii.The screen will display a number. You can change the number to a desired number (number of well you are logging) and push Enter/blue button. 
iv.Screen should display "Take $\mathrm{xx}$ " $(\mathrm{xx}=$ the deepest depth you entered in the format). Push Start/green button.

v.Logging takes 16 seconds for each depth interval. The read-out unit will beep once when logging starts and twice when the logging is complete and a number will be displayed on screen (e.g. M10 3456). M10 = depth, $3456=$ measurement. After recording number, push enter/blue button. Next depth measurement will be displayed on screen.

vi.Move cable up to next depth interval (next cable stop or mark on cable) and push start/green button to $\log$ that depth.

vii.Continue process until probe is at the surface or desired depth.

viii.After the last measurement, you will be asked if the data is ok. Push the enter/blue button to save the data.

5. Take another standard count (\# 3):

6. Return neutron probe and cable to the storage shed and bring read-out unit back to the office to download data.

\section{Troubleshooting tips}

- If you enter an incorrect name/number for the well you are logging, push the clear/red button until the screen displays "ready" then push log and enter your desired well number/name.

- If during logging you make a mistake, push the clear/red button. You will be asked if the data is ok. Push clear/red button again to go back to the ready screen and start over.

- If you miss a depth while logging or you are unsure whether you logged all depths or not, you can check your data by "stepping" (yellow button) through all depths after you get the "data ok?" question (don't push enter). If you miss a depth, you will see "take xx" instead of numbers. You can $\log$ that depth by pushing enter/green. If you are satisfied/all depths are logged, step through all depths or push clear/red. You will be asked if data is ok. Push enter/blue button to save the data. 


\section{Neutron Logging For FY 2002-2003 Performance Evaluation Testing}

The purpose of neutron probe logging is to monitor changes in soil moisture profiles during system operation. These will be conducted at discrete periods as specified in the most recent flow schedule. Neutron probes are radioactive sources that must be handled carefully. Detailed instructions on their use are available from Fenton Khan. Neutron probe requires Rad Worker II training. Neutron probe data is recorded on data sheets prepared in M.S. Excel or Word. These sheets, or copies of them, will be stored in the safe along with the logbook.

The neutron probe is stored in a special shed in the 200 area. Fenton Khan is the custodian of this key and of neutron probe accessories (data logger and cables). Moving the neutron probe requires both a transportation permit (stored in the safe at the site) and special training to transport it. There are two neutron probes that will be used in the project, which are identified by the last four numbers of their serial numbers. Probe 9808 should be used preferentially. If multiple people will be conducting the logging, the probe 5105 may also be used. The probe used should always be recorded on the data sheet.

There are 8 interior wells (inside the metal tank) to be probed. These are the non-pumping wells: L4, L5, L6, L7, L8, L9, L11, L13. The well number of each well is written on its well cap. Each well has a thin inner casing in which the probe must be inserted. After insertion, the probe is logged every $15 \mathrm{~cm}$ at 5 points with an initial maximum depth of $165 \mathrm{~cm}$.

There are 16 exterior wells (surrounding the metal tank): numbered 1 to 16 . These are identified by green flags, and each has a green well cap. The well numbers are written both on the flag and on the well casing. These are logged every foot from 37 feet to 3 feet depth.

All standardization parameters and each reading will be recorded by hand on the data sheet, as well as by the data logger. This is particularly critical if the format of the data logger is changed, as data prior to the format change is then overwritten. 
Figure H-1. Locations of Access Ports for Neutron Logging Inside the Mock Tank.

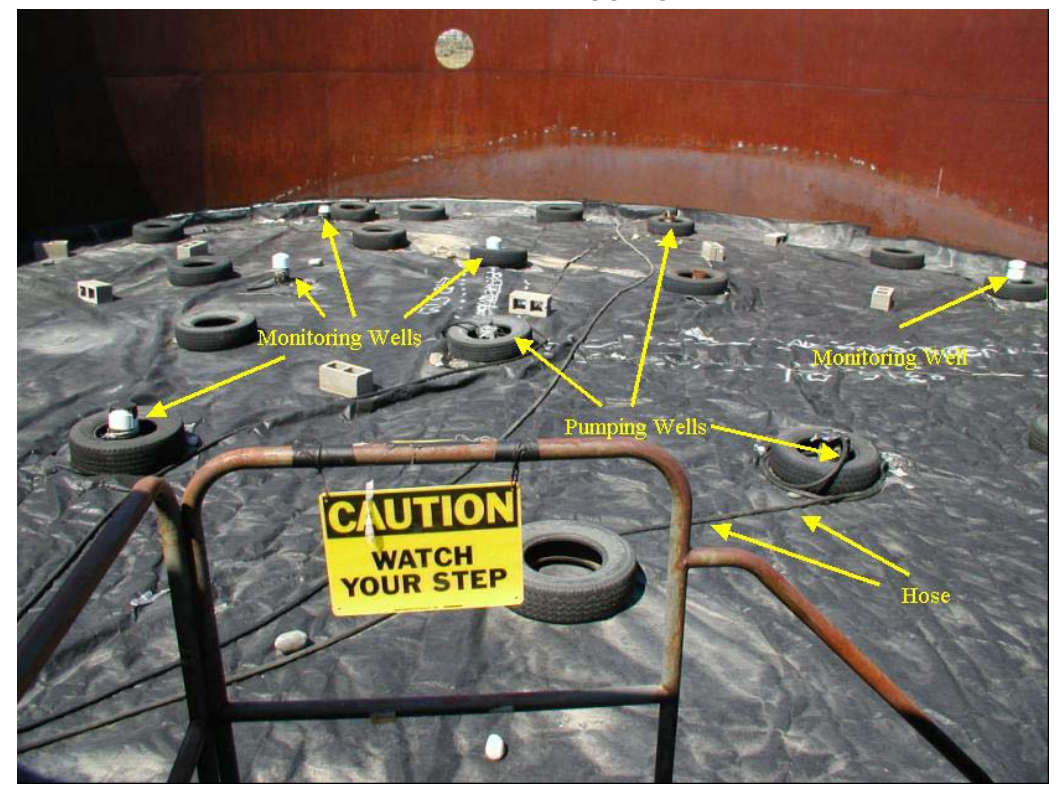


Attachment I

Field Procedures 


\section{Attachment I}

\section{Field Procedures}

TITLE:

MOCK TANK SITE FIELD PROCEDURES

EFFECTIVE DATE: $7 / 20 / 02$

APPLICABILITY: $\quad$ MOCK TANK SITE (Facility IP Designation: 223E) for the FY 2002-2003

Performance Evaluation Test

USE CATEGORY: REFERENCE USE

\section{Purpose}

This attachment documents the procedures used by PNNL for activities at the Mock Tank site during the FY 2002-2003 Performance Evaluation Test. PNNL's role in the project is to manage and maintain the site, operate the solution-delivery and rain-simulation systems, set up and maintain data recording hardware and software, and provide field support to the principal investigators (LLNL and HGI). PNNL is responsible for recording and assessing the leak system and for providing data analysis for the project.

\section{The Mock Tank Site}

The MOCK TANK site is located in the 200 East Area off Seventh Street (about $3 / 4$ mile south of the intersection of Seventh Street and Baltimore Street. Figure 1 is a site location map. Figure 2 is a schematic of the site showing locations of key equipment.

\section{Routine Site Visits}

The site will be visited each workday during the period of the test. A site walk will be conducted during each site visit. Tables 1 and 2 summarize the procedures for site walks during flow and non-flow periods. Figure 3 is a picture of the tank exterior area showing prominent components of equipment. Figure 4 shows the interior of the tank, with key equipment.

\section{Safety Equipment}

The waste surrogate used in the test is sodium thiosulfate, which is relatively non-hazardous. According to the MSDS, use of safety equipment is not mandatory with this compound. Leather and rubber gloves, as well as eye goggles, are maintained at the site and can be used, if deemed appropriate. An eyewash station is located adjacent to the sodium thiosulfate solution storage tank (Figures 2 and 3 ).

\section{Site Log Book}


A site logbook will be maintained and stored in the safe in the trailer. Each site visit will be recorded in the logbook. This should include the person(s) conducting the site visit, the activities conducted, general narratives on the conditions at the site, and all data. The recordings in the book will be done in ink. Any errors or corrections completed in the logbook must be marked through with a single line and initialed and dated by the person performing the correction(s).

\section{LabView Program}

The signet flow meter, the mechanical Omega totalizer, and the rain gauges will be continuously monitored using the LabView program. The LabView program saves the data into a tab delimited file which can be easily imported into Microsoft Excel for calculations and data analysis. The data files are all written to files in the "data" folder in the "C" drive of the on-site computer. The current file can be identified in the LabView program and also by noting the date and time of file modification. Figure 5 illustrates the main LabView screen.

\section{Flow Schedule}

A schedule of flow events (Test Matrix) will be kept at the site in the logbook. This schedule is provided by the Test Director and provides specific dates of flow events, target flow rates, and the discharge well(s). In addition, schedules for artificial rain events and neutron probe loggings are indicated. The most recent schedule of flow events will be posted in the log book. Any revisions or modifications to the schedule must be formally authorized/approved via the test director and recorded or posted in the logbook.

\section{Gravimetric Flow Measurements}

Gravimetric measurement will be used to calibrate the flow system, and to assess the performance of the flow system during a leak test. The test requires two containers, a calibrated top loading balance, a stopwatch, and a calculator. The gravimetric flow measurement procedure is given below:

1. Select a clean container for the test.

2. Record the weight of the container to the nearest $0.1 \mathrm{~g}$ in the logbook using the top loading balance in the trailer.

3. Place the weighed container on the wooden pallet near the diversion valve system.

4. Place the second container near the weighed bucked. Place the diversion hose in this non-weighed container.

5. Open the diversion valve, then close the valve leading to the well manifold box.

6. Raise the hose so it is high enough to clear the top of the weighed container, but keep the solution flowing into the non-weighed container. The flow will temporarily stop until the volume of the hose is filled.

7. When the flow returns, start the test. Move the hose into the weighed container while simultaneously activating the stopwatch.

8. Allow the container to fill for specific indicated time periods. Target times for the tests are: 
- 10 minutes for 2 gph flow

- 4 minutes for 10 gph flow

- 2 minutes for 20 gph flow.

9. Remove the hose and simultaneously stop the watch. Record the time on the watch in the logbook.

10. Record the weight of the filled container in the logbook.

11. Calculate the flow assuming that the density of sodium thiosulfate is $1340 \mathrm{~g} /$ liter, and that there are 3.785 liters per gallon. Record the results in the logbook.

12. Solution generated by the gravimetric test is either returned to the tank (if during a non-flow period, such as calibration or preliminary flow confirmation) or to the discharge well (if during a flow event)

\section{Tank Height Reading}

The purpose of tank height readings during non-flow periods is to monitor for leaks or volatile losses in the solution tank. During flow operation, the tank height readings allow for calculations of flow volumes. A tank measuring stick is kept at the site. Stored between uses on its side under the trailer to prevent any warping. The stick is placed into the tank on a mark (tape) at the top of the tank. It is carefully lowered into the solution to prevent splashing. It is then slowly withdrawn. The interface of liquid with the stick is noted, allowing the depth to be read and recorded in the logbook. The change in liquid height per unit time is related to volume by: $1 " \simeq 44.8$ gallons.

\section{Metering Pump Recirculation Water}

The metering pumps have a water recirculation system to prevent solutions from being pulled up the pump piston into its working parts. This system is driven by a small peristaltic pump, which recirculates into a 1-gallon reservoir. Battelle will maintain this system with distilled water, changing it every two days, as necessary, during operation. Below are the procedures:

1. Obtain distilled water from the trailer.

2. Briefly turn off the peristaltic pump.

3. Dump out the old water in the 1-gallon reservoir.

4. Refill the reservoir with 1-gallon of distilled water.

5. Replace the tubing into the reservoir, then restart the pump.

6. Record event in the logbook.

\section{Flow Calibration}

Following the initial calibrations, further calibrations will only be conducted if there is a change in the operating system. The purpose of calibration is to develop a relationship between the setting on the metering pump and the flow discharged. In addition, the calibration relates the flow measured in liters/min by the Signet meter to the actual discharge in gph. This is used to estimate actual flow rates and total gallons discharged. The flow calibration also checks the performance of the flow totalizer. Currently, PNNL's measurements indicate that the pulse readings of the mechanical totalizer used does not require any correction factor, but this will be reconfirmed if the system's configuration is changed. The flow calibration should be conducted, as indicated below: 
1. Estimate the initial pump setting using Signet flow meter (Figure 6).

2. Develop gravimetric/flow meter calibration data.

3. Calculate desired set point.

4. Obtain Gravimetric confirmation of effectiveness of set point.

5. Confirm totalizer performance at desired setting.

The process requires two people. All calibration activities and results will be recorded in the site logbook.

\section{Estimate the initial pump setting using Signet flow meter}

The pump settings can be adjusted to meet target flows. The effect of each setting can then be related to the flow given on the Signet meter. Initial target flow values for the Signet meter are:

- 0.126 liters/min for 2 gph target

- 0.630 liters/min for $10 \mathrm{gph}$ target

- 1.260 liters $/ \mathrm{min}$ for 20 gph target.

These values are only initial targets to start testing. The actual flow of the sodium thiosulfate will differ from the value on the Signet meter due to differences in density and viscosity.

\section{Development of gravimetric/flow meter calibration data}

Using a value near the start point (as discussed above) gravimetric tests will be conducted. At the start of each test, one of the testers will record the value on the mechanical totalizer. Then, the tester will note readings on the Signet meter. These values change continuously. Therefore, the tester will record values approximately every 10 seconds. At the end of the test, the average of these will be taken as the Signet flow meter reading. The reading of the mechanical flow meter will be recorded at the end of the test. A minimum of four settings will be tested, two above the target and two below. The range of values should at least $10 \%$ above and below the target. This should account for unexpected variations during the actual delivery period. The testers should monitor the Signet meter after each setting change to allow it to stabilize before conducting subsequent tests. At least one of the flow rates will be triplicated to assess variation. During calibration, generated solution is returned to the tank. Results will be recorded in the logbook.

\section{Calculation of desired set point}

The data will be plotted and fitted with a calibration line. The calibration line will be linear and assume that the y-intercept is zero. The testers will review the fit of the line and make a professional judgment on the quality of the fit and determine whether or not more points should be collected. The final calibration line will then be used to calculate the best set point to reach the target value. Calibration equations will be recorded in the site log book.

Gravimetric confirmation of desired set point 
The performance of the set point will be confirmed with triplicate gravimetric measurements. These should be within $10 \%$ of the target value. These activities, data, and results will be recorded in the logbook.

Confirmation of totalizer performance (pulse) at desired setting

This will be confirmed by stopwatch tests conducted using the LabView readout. The tester will start the stopwatch immediately as the totalizer readout changes, simultaneously recording the value. The system will be allowed to run for at least 10 minutes. Then, the stopwatch will be stopped at a change in the readout. The change in volume over time can be compared to the gravimetric confirmations to check if the totalizer (pulse) is accurate. The totalizer flow rate should be within the variation estimated by the triplicates. Triplicate tests are advisable if time permits. All activities and results will be recorded in the site logbook. 


\section{Beginning a Flow Event}

The start of a flow event will be conducted by two Battelle staff:

1. Carefully check the most recent flow schedule for date of flow event and for the well to be targeted.

2. Check with Project Manager or Test Director to confirm the desired startup time and location of leak (identify infiltration port).

3. Check the settings on the metering pumps to confirm that they are at levels to produce the desired flow. Determine (using log book) if the pump recirculation water has been recently changed, and change if needed.

4. Check that the flush line valves are closed. Then open the valves from the tank to the distribution system and set the pump system to recycle. Turn on the pump.

5. Conduct at least one gravimetric flow measurement before start up and check the Signet meter readings during this test to confirm conditions will give desired results. Record the results in the logbook. Remember to switch the system to the metering pumps during the test, then back to "recycle". Turn the metering pumps on and off as needed. After the test, the system should still be operating, but on "recycle".

6. After returning generated solution to the solution tank, measure and record (in the logbook) the tank height prior to startup.

7. Record the mechanical totalizer reading in the flow distribution cabinet and in the LabView program in the logbook.

8. Open the appropriate valve in the well manifold box to the desired well. Obtain concurrence from both Battelle staff on the well selected.

9. Clean out targeted well with metal bar to promote good flow.

10. Open valves on the hose from the well manifold to the flow distribution cabinet.

11. Just prior to the start time, check the clock on the LabView computer and adjust it if needed. Then, briefly shut off the LabView program, change the file name to the appropriate test name, then restart it. Confirm that a new data file was created.

12. At the desired time, redirect the flow in the distribution cabinet to the well line, and start the metering pumps. Record time in the logbook.

13. Allow system time to stabilize, and then take first set of data for the new operation, recording it in the logbook.

\section{System Shutdown}

1. Conduct a last set of key data, including gravimetric and flow rate readings, and record in the logbook.

2. At the desired time, shut down the main pump and the metering pumps

3. Shut down valving leading to well manifold and shut gate valve in well manifold.

4. Shut solution tank valves.

5. Conduct system flush (see below).

6. Reset LabView to write to a new file, primarily to monitor rain gauges. 


\section{System Flush}

The purpose of the system flush is to prevent corrosion and/or buildup of crystalline sodium thiosulfate in the metering pump system. The system will be flushed after each test. Additional flushes may be conducted as needed. The flush is performed as follows:

1. Close valves from solution tank to metering pumps.

2. Open diversion valve, putting diversion hose into container. Close valve to well manifold box.

3. System flush valves up to the valve just before the tee that serves as a spigot. Also, open the valve to the spigot. Leave the valve just after the spigot closed. Then open the valve to the river water tank.

4. Turn on the metering pumps, allowing them to pump out residual sodium thiosulfate solution.

5. Close the spigot valve. Then, open the valve after the spigot to allow river water to flow through the system.

6. Pump about 10 gallons of river water through the metering pumps, then shut down, allowing the river water to stay in the pump heads.

7. Record date and time of system flushes in the logbook.

8. Dispose of rinse water in a location away from the test area, chosen to be away from electrodes and equipment.

\section{Addressing Clogged Wells}

Overflowing wells or wells that are endanger of overflowing will be cleaned by working the sediment with a metal bar.

\section{Rain Event}

Rain events occur at specific times on the flow schedule. These are to test if the geophysical approaches can differentiate between rain and actual leaks. All rain event activities and data will be recorded in the logbook. The rain event procedure follows:

1. Confirm that LabView is operating, as this is used to record rain gauge data. If not, prepare a new file and start the program, recording the activity in the logbook.

2. Plug in both pump and flow controller using long extension cords.

3. Open the valve from the tank to the pump (Figure 7).

4. Check the pump controller to confirm that the total gallons are set to zero and that the target rate is 34. This can be done using the directions on the controller itself.

5. Check that the valves allow flow through the controller, as opposed to the by-pass system (Figure 7).

6. Open the valves to the large sprinklers.

7. At the target time, turn on the pump using the switch.

8. Slowly open the valve to the small sprinklers. Monitor the pressure using the pressure gauge provided. Use the valve to set the pressure at 20 psi.

9. Periodically monitor the volume delivered. At a target of 548 gallons (record actual number in the log book) shut valve to the small sprinkers. This should take about 30 minutes.

10. Continue the flow to the large sprinklers until a target of 721 gallons (record actual number in the logbook) is reached.

11. Shut down pump, then close valves, and disconnect and police extension cords. 
12. Check LabView to confirm that is has recorded the event. And check the data file to also confirm that it has been stored. If it has not been stored, then record the data manually in the logbook.

Figure 1. Location Map to the MOCK TANK Site. 
Figure. Sketch of the MOCK TANK Site Showing Key Components of Field Equipment.

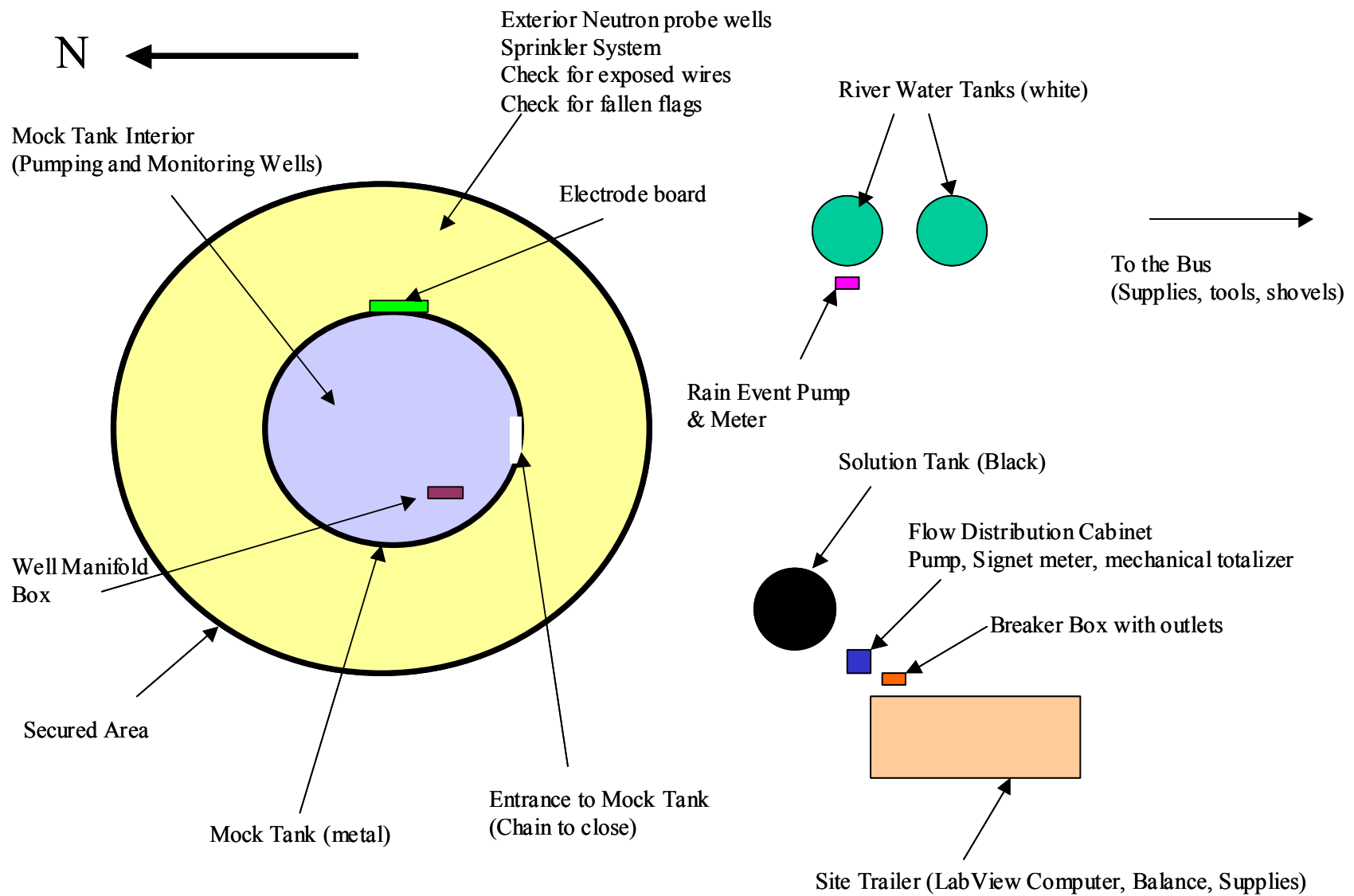


Figure 3. Tank Exterior Area

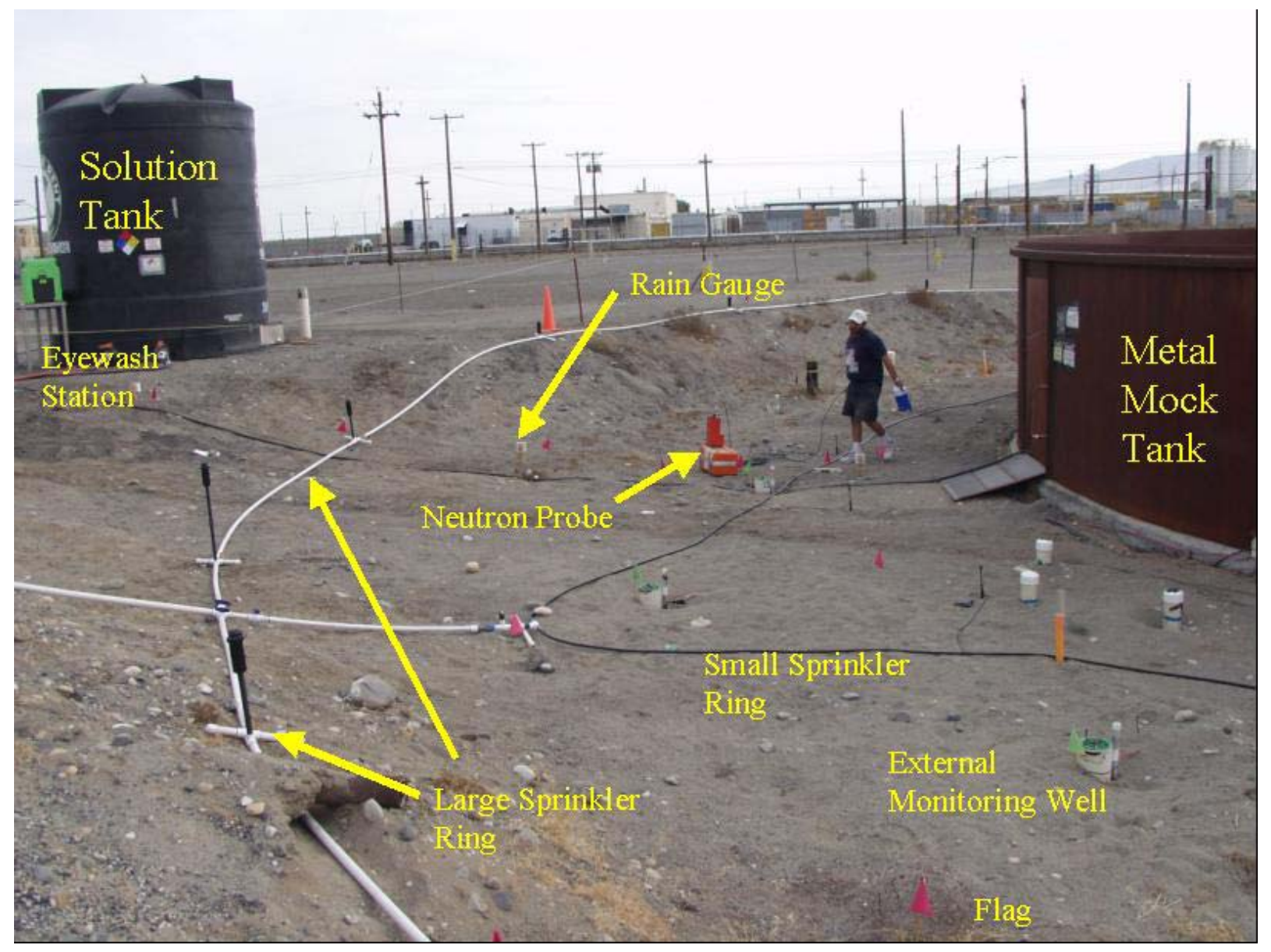


Figure 4. Interior of the Mock Tank showing infiltration ports and solution manifold.

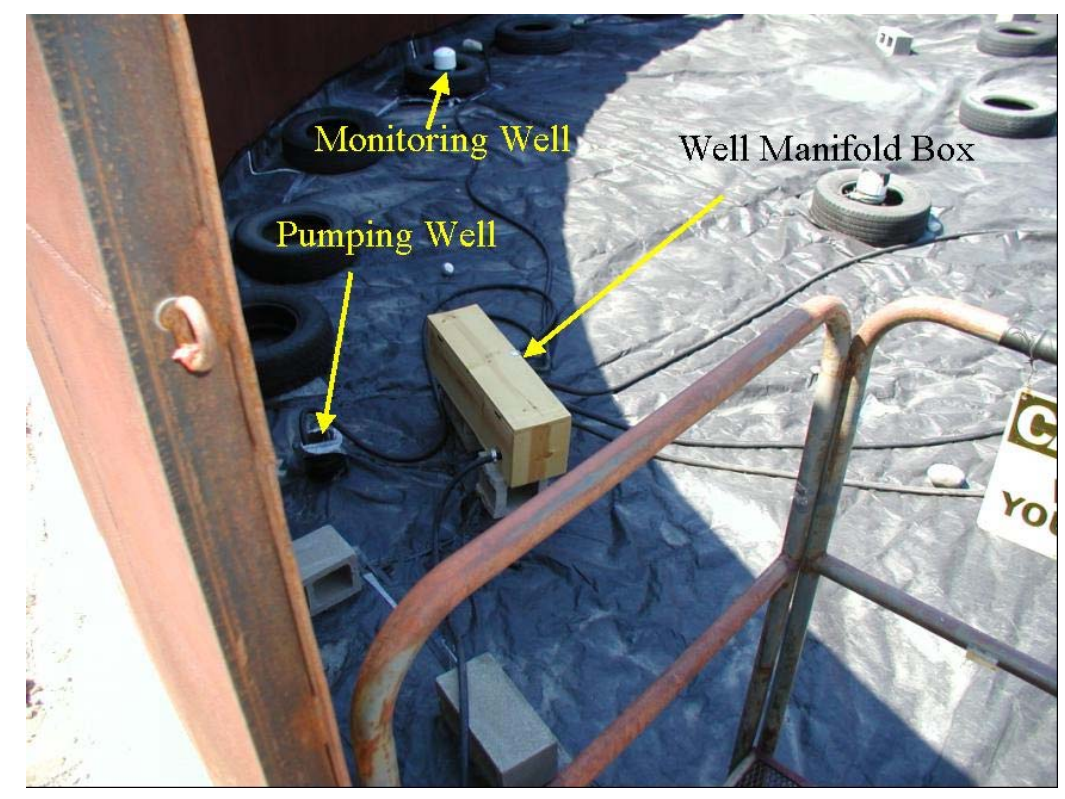


Figure 5. LabView Screen Illustrating Key User Fields.

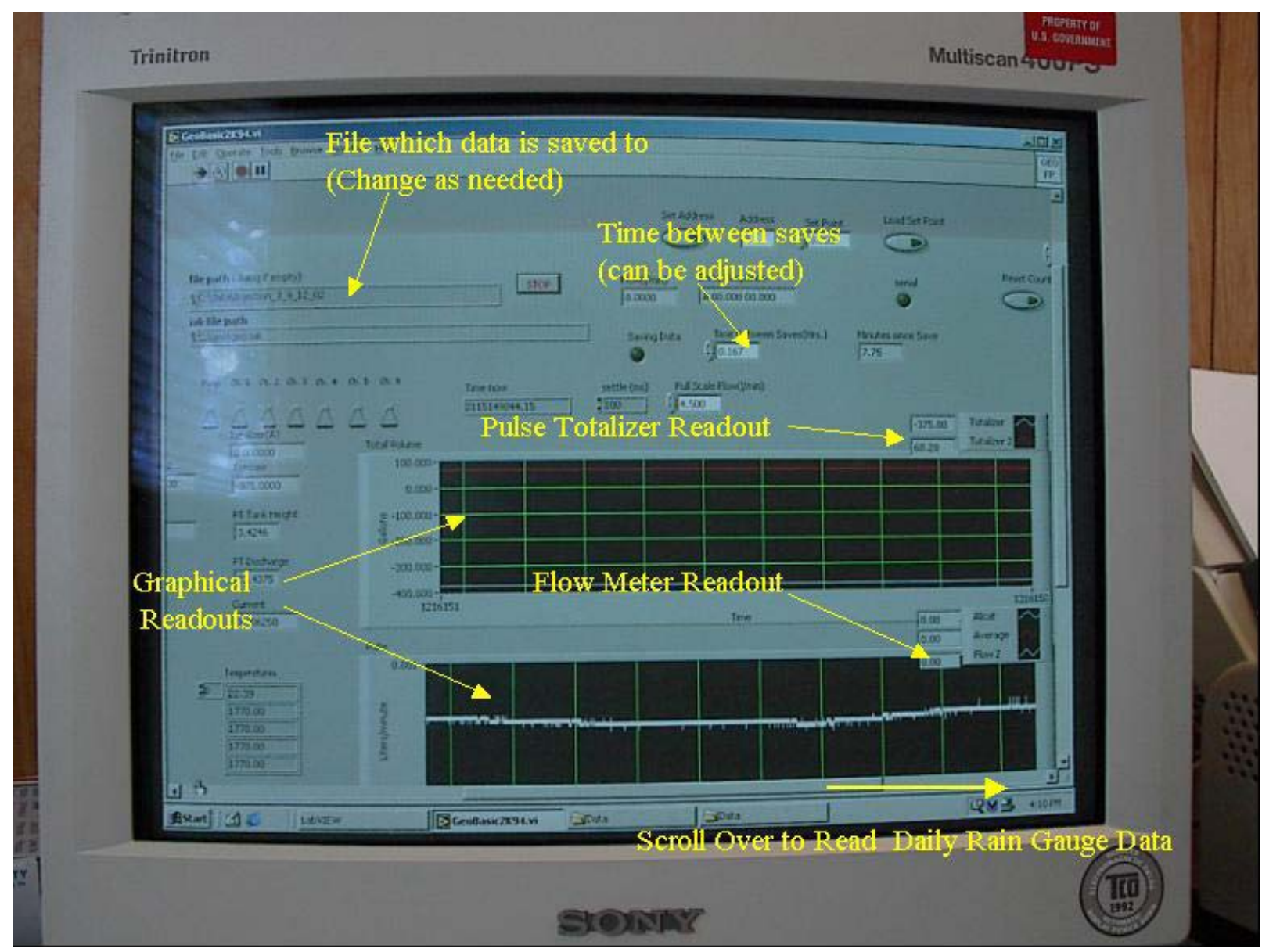


Figure 6. Interior of Flow Distribution Cabinet.

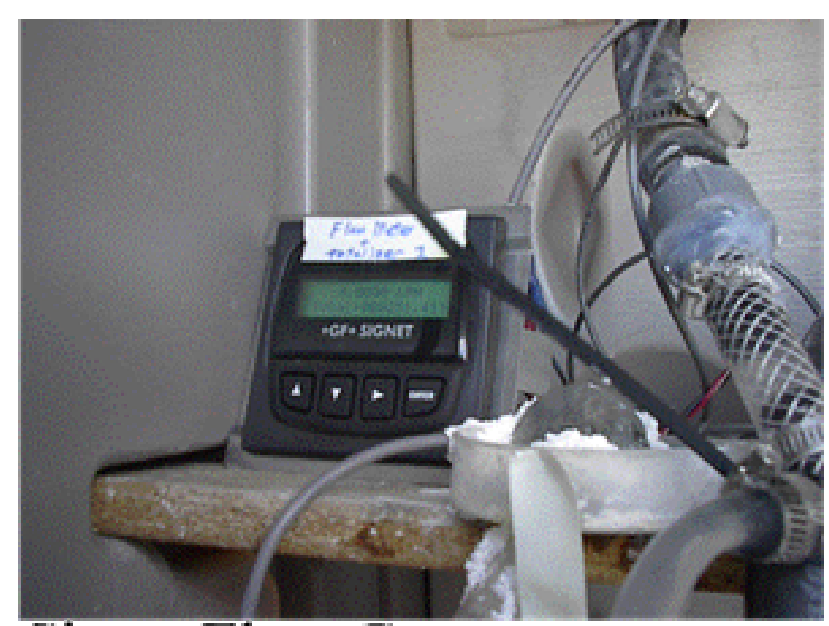

Signet Flow Gauge

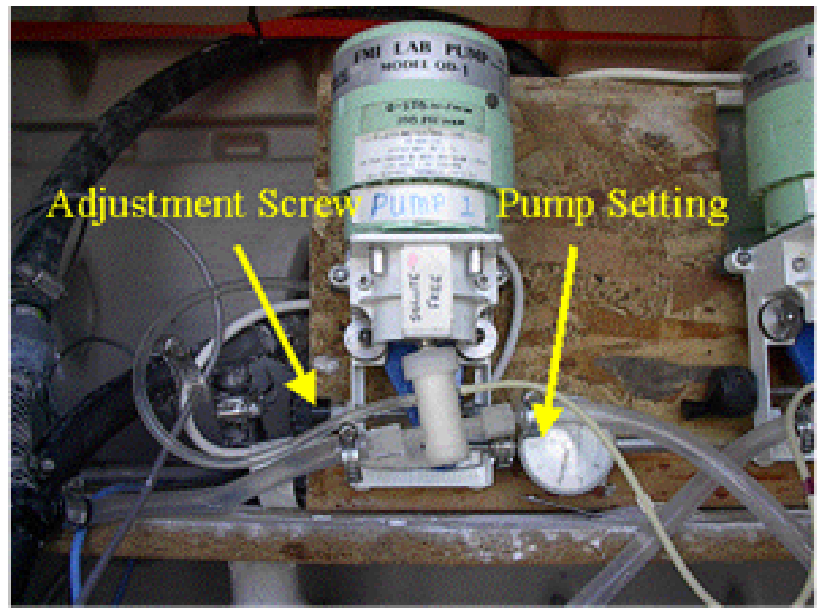

Metering Pump

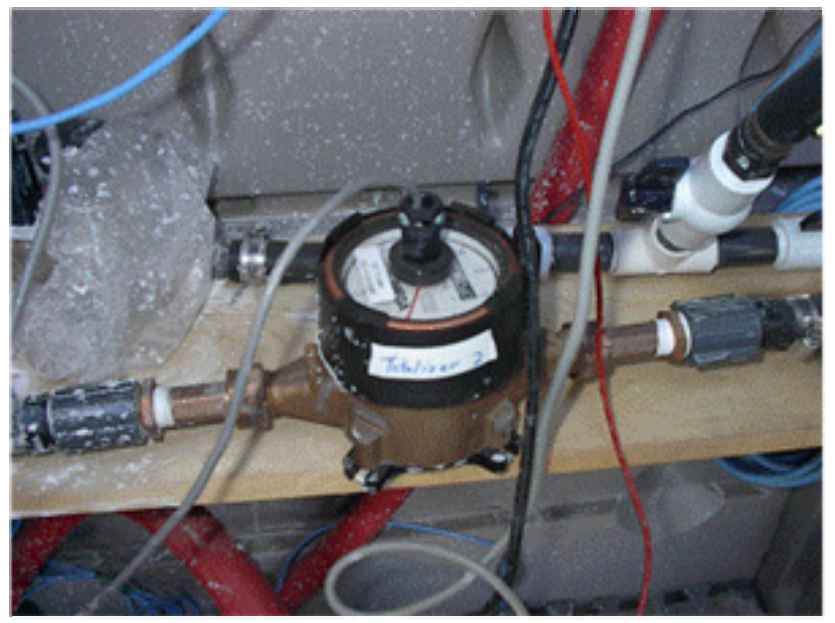

Mechanical Totalizer 
Figure 7. Irrigation System Controls for Rain Events.

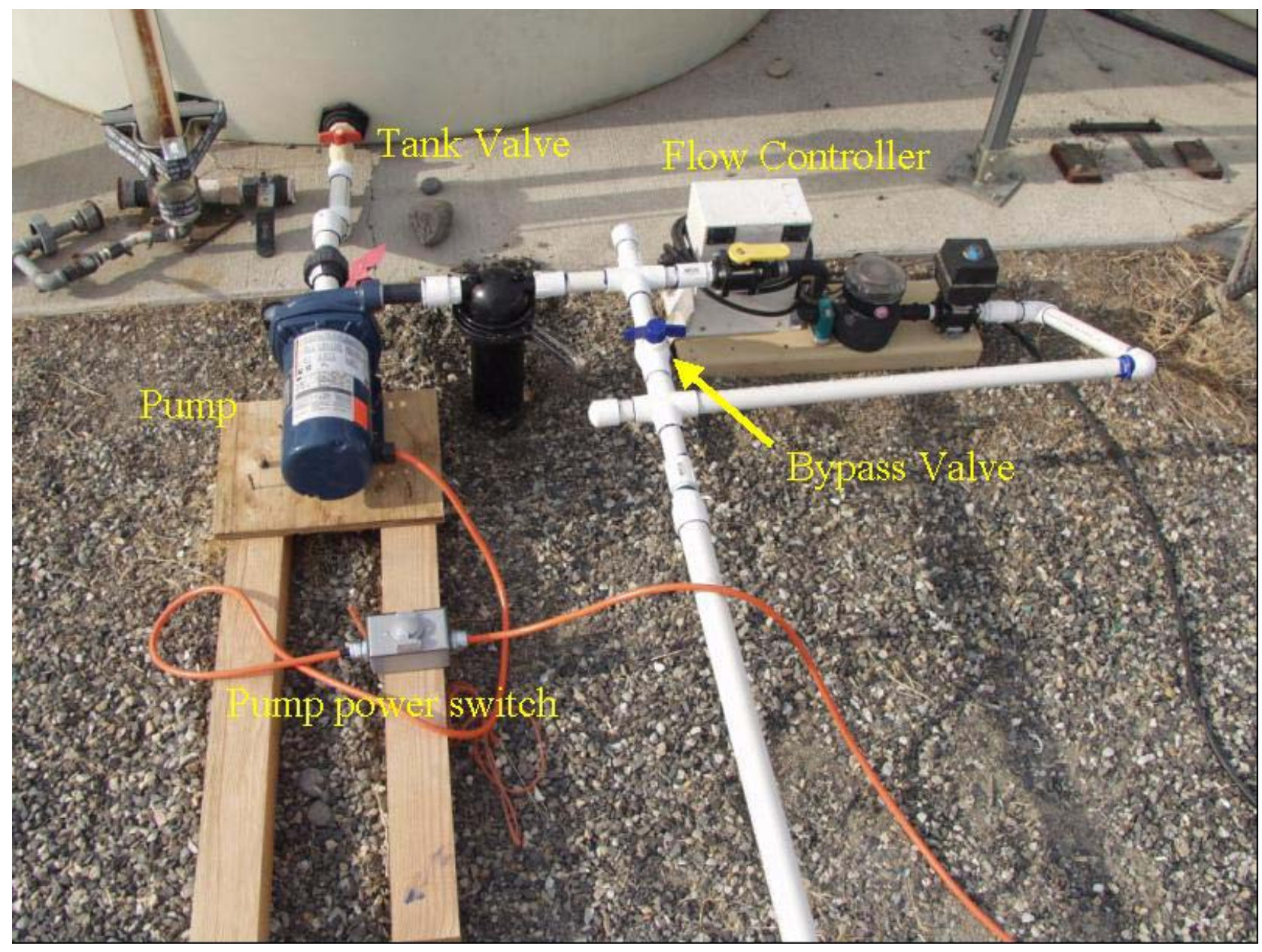


Appendix B

\section{Data Tables}




\section{Appendix B.1}

\section{Data Tables}

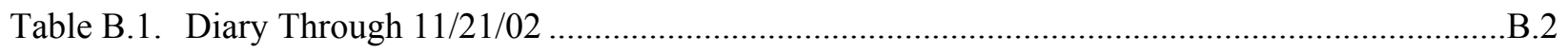

Table B.2. Summary of Tank Height Measurements …....................................................................

Table B.3. Weather Data as Recorded at Hanford Meteorological Station—July Through

November, 2002

Table B.4. Log of Physical Parameters for Sodium Thiosulfate Solution Used in FY 2002-2003

Performance Evaluation Test

B. 14 
Table B.1. Diary Through 11/21/02

\begin{tabular}{|c|c|c|}
\hline Date & Activity (ies) & Comments \\
\hline $\begin{array}{l}6 / 19 \text { and } \\
6 / 21 / 02 \\
\end{array}$ & $\begin{array}{l}\text { Delivery of Sodium Thiosulfate to Site } \\
\text { Background Neutron logging }\end{array}$ & \\
\hline $07 / 10 / 02$ & Submitted revised work plan & \\
\hline $\begin{array}{l}7 / 15 \text { to } \\
7 / 19 / 02\end{array}$ & $\begin{array}{l}\text { 1. Buried wires. } \\
\text { 2. Covered electrode system. } \\
\text { 3. Flagging. } \\
\text { 4. Installation of the manifold system. }\end{array}$ & \\
\hline $07 / 18 / 02$ & Delivery of River Water to Site & \\
\hline 07/19/02 & $\begin{array}{l}\text { 1. Conducted calibration on Alicat System } \\
\text { 2. Obtained Log Book for Project }\end{array}$ & \\
\hline $07 / 22 / 02$ & $\begin{array}{l}\text { 1. Completed lab view formatting } \\
\text { 2. Completed Calibration on Alicat system } \\
\text { 3. Started pump system on recycle }\end{array}$ & \\
\hline 7/23 to & Daily Site visits & \\
\hline $7 / 26 / 02$ & Began flow event "B" (2 gph flow) & \\
\hline $\begin{array}{l}7 / 27 \text { to } \\
8 / 14 / 02 \\
\end{array}$ & Daily site visits to monitor flow event "B" & \\
\hline \begin{tabular}{|l}
$07 / 31$ to \\
$09 / 05 / 02$
\end{tabular} & Repair of Small Leaks in the Manifold System & \\
\hline $08 / 05 / 02$ & Installation of Timbuktu@ software. & $\begin{array}{l}\text { Allows for remote access of } \\
\text { computers. }\end{array}$ \\
\hline $8 / 13 / 02$ & Repaired system shutdown & $\begin{array}{l}\text { Brief system shutdown due to } \\
\text { electrical problem }\end{array}$ \\
\hline $08 / 05 / 02$ & Obtained Hanford SecureID for Abe Ramirez of LLNL & \\
\hline $8 / 16 / 02$ & $\begin{array}{l}\text { 1. Last flow event "B" data collected } \\
\text { 2. Shutdown of flow event "B" at } 1100\end{array}$ & \\
\hline $8 / 19 / 02$ & Begin installation of rain-simulation system & \\
\hline $8 / 21 / 02$ & $\begin{array}{l}\text { 1. Installation of new Alicat } \\
\text { 2. Calibration of new Alicat } \\
\text { 3. Start flow event "D" ( } 20 \mathrm{gph}) \text { at } 1242 \\
\text { 4. Cleanup of lab after lab experiments } \\
\end{array}$ & $\begin{array}{l}\text { Accidental leak of the river water } \\
\text { tank at northern end of pad. About } \\
100 \text { gallons leaked. }\end{array}$ \\
\hline $8 / 22 / 02$ & Site walkdown & \\
\hline $8 / 23 / 02$ & $\begin{array}{l}\text { 1. Site walkdown } \\
\text { 2. Shutdown flow event "D" }\end{array}$ & \\
\hline $\begin{array}{l}8 / 26 \text { to } \\
8 / 30 / 02 *\end{array}$ & Installation of new rain gauges & \\
\hline $8 / 27 / 02$ & $\begin{array}{l}\text { 1. Neutron logging } \\
\text { 2. Discovered Alicat damaged - Repaired } \\
\text { 3. New calibration of Alicat } \\
\text { 4. Start up of flow event "F" ( } 20 \mathrm{gph}) \\
\text { 5. Completion of rain-simulation system }\end{array}$ & \\
\hline
\end{tabular}


Table B.1 (contd)

\begin{tabular}{|c|c|c|}
\hline Date & Activity (ies) & Comments \\
\hline $8 / 28 / 02$ & Site visit & \\
\hline $08 / 29 / 02$ & $\begin{array}{l}\text { 1. Neutron Probing } \\
\text { 2. Site Meeting } \\
\text { 3. Testing of sprinkler system. } \\
\text { 4. Final collection of site data for flow event "F" } \\
\text { 6. Shutdown of flow event "F" }\end{array}$ & \\
\hline $08 / 30 / 02$ & $\begin{array}{l}\text { 1. Completion of Neutron logging } \\
\text { 2. Completion Sprinkler System installation } \\
\text { 3. Initial testing of rain gauges } \\
\text { 4. Rain Event } 1 \text { ( } 406.1 \text { gallons) }\end{array}$ & \\
\hline $09 / 03 / 02$ & $\begin{array}{l}\text { Installation of new flow controller and measurement system } \\
\text { (metering pumps, new mechanical totalizer, flush systems) }\end{array}$ & \\
\hline $09 / 04 / 02$ & Installation of new flow system & \\
\hline $09 / 05 / 02$ & Calibration of new flow system & \\
\hline $09 / 06 / 02$ & $\begin{array}{l}\text { 1. Finished calibration of new flow system } \\
\text { 2. Conducted troubleshooting for geophysics contractors } \\
\text { 3. Site Meeting } \\
\text { 4. Started flow event "I" ( } 10 \mathrm{gph}) \text { at } 1445\end{array}$ & \\
\hline $\begin{array}{l}9 / 7 \text { to } \\
9 / 9 / 02\end{array}$ & Site Visits and Collection of Operational Data & \\
\hline $09 / 10 / 02$ & $\begin{array}{l}\text { 1. Started flow event "J" by increasing flow on test to } 20 \mathrm{gph} \\
\text { at } 1500 \text {. } \\
\text { 2. Collected data before and after increase. }\end{array}$ & \\
\hline $09 / 11 / 02$ & $\begin{array}{l}\text { 1. Rain event ( } 725 \text { gallons) } \\
\text { 2. Collected field data } \\
\text { 3. Repair overflowing infiltration point }\end{array}$ & L10 overflowed. This was repaired \\
\hline $09 / 12 / 02$ & $\begin{array}{l}\text { 1. Site Meeting } \\
\text { 2. Site Visit and Collection of Operational Data } \\
\text { 3. Shutdown of flow event "J". } \\
\text { 4. Obtained carboy for DI water storage. }\end{array}$ & \\
\hline $09 / 13 / 02$ & $\begin{array}{l}\text { 1. Neutron logging. } \\
\text { 2. General site cleanup. }\end{array}$ & \\
\hline $09 / 17 / 02$ & $\begin{array}{l}\text { 1. Project meeting. } \\
\text { 2. Delivery of sodium thiosulfate solution - filled solution tank. }\end{array}$ & \\
\hline $09 / 18 / 02$ & Extensive testing of flow delivery system & \\
\hline $09 / 19 / 02$ & $\begin{array}{l}\text { 1. Startup of flow event "L" (10 gph into L14) with associated } \\
\text { data collection } \\
\text { 2. Installation of heat tape \& insulation on solution line from flow } \\
\text { cabinet to well manifold box. } \\
\text { 3. Change to well L7 after L14 overflow } \\
\text { 4. LDMM Procedures completed (QA requirement) }\end{array}$ & Well L14 overflowed. \\
\hline $09 / 20 / 02$ & $\begin{array}{l}\text { 1. Site walk and collection of operational data } \\
\text { 2. Switched flow to L2 } \\
\text { 3. Obtained supplies to insulate tank. } \\
\text { 4. Density sample collected. }\end{array}$ & L7 overflowed \\
\hline $09 / 21 / 02$ & Site visits and data collection & L2 draining fine. \\
\hline
\end{tabular}


Table B.1 (contd)

\begin{tabular}{|c|c|c|}
\hline Date & Activity (ies) & Comments \\
\hline $09 / 23 / 02$ & $\begin{array}{l}\text { 1. Site walkdown. } \\
\text { 2. Auguring of Well L14 } \\
\text { 3. Return flow to L14 } \\
\text { 4. Installation of lower half of Tank Insulation. } \\
\text { 5. Installation of hose insulation inside mock tank. } \\
\text { 6. } \text { Calibrated balance brought to site. }\end{array}$ & $\begin{array}{l}\text { L14 now draining fine } \\
\text { Test } \mathrm{K} \text { ended, Test } \mathrm{M} \text { begun }\end{array}$ \\
\hline $09 / 24 / 02$ & $\begin{array}{l}\text { 1. Site Walkdown and data collection } \\
\text { 2. Repaired fallen Tank Insulation } \\
\text { 3. Neutron logging: calibration }\end{array}$ & \\
\hline $09 / 25 / 02$ & $\begin{array}{l}\text { 1. Site walkdown \& data collection } \\
\text { 2. Heat tape end caps ordered. } \\
\text { 3. Completed insulation of solution tank } \\
\text { 4. Completed insulation of lines from solution tank to flow } \\
\text { manifold. } \\
\text { 5. Site meeting and client walkdown. }\end{array}$ & \\
\hline $09 / 26 / 02$ & Site walkdown & \\
\hline $09 / 27 / 02$ & $\begin{array}{l}\text { 1. Site walkdown } \\
\text { 2. Shutdown of flow event "M". } \\
\text { 3. Planning for water heater installation. } \\
\text { 4. End caps arrived for heat tape. }\end{array}$ & $\begin{array}{l}\text { Test } \mathrm{M} \text { ended. Test } \mathrm{N} \text { (no flow) } \\
\text { begun }\end{array}$ \\
\hline $09 / 30 / 02$ & $\begin{array}{l}\text { 1. Site walkdown. } \\
\text { 2. Rain Event } \\
\text { 3. Installation of in-line water heater. }\end{array}$ & $\begin{array}{l}\text { Rain event shortened because tank } \\
1 \text { emptied of water. ( } 678 \text { gal. } \\
\text { delivered vs. goal of } 721 \text { gal.) }\end{array}$ \\
\hline $10 / 01 / 02$ & $\begin{array}{l}\text { 1. Site walkdown } \\
\text { 2. Movement of water from water tank } 2 \text { to tank } 1 \text { to prepare for } \\
\text { next rain event. } \\
\text { 3. Site schedule prepared through } 10 / 15\end{array}$ & Heat left on in trailer. \\
\hline $10 / 02 / 02$ & $\begin{array}{l}\text { 1. Site walkdown } \\
\text { 2. Rain event. } \\
\text { 3. Neutron logging. }\end{array}$ & \\
\hline $10 / 03 / 02$ & $\begin{array}{l}\text { 1. Site Walkdown } \\
\text { 2. Site Meeting }\end{array}$ & \\
\hline $10 / 04 / 02$ & $\begin{array}{l}\text { 1. Site Walkdown } \\
\text { 2. Start up of flow event "P" ( } 20 \text { gph in L14) and associated data } \\
\text { collection. } \\
\text { 3. Repair of bad internet connection } \\
\text { 4. Replumbing of water tanks } \\
\text { 5. Schedule of water drop (Monday at } 1 \mathrm{pm}) \\
\text { 6. Neutron logging }\end{array}$ & \\
\hline $10 / 05 / 02$ & Site walkdown & \\
\hline $10 / 06 / 02$ & Site walkdown. & \\
\hline $10 / 07 / 02$ & $\begin{array}{l}\text { 1. Site walkdown } \\
\text { 2. Reestablished offsite communications with help of Qwest } \\
\text { personnel (following } 10 / 4 \text { repair of internet connection). } \\
\text { 3. Filling of } 2,500 \text { gallon water tanks. }\end{array}$ & L14 overflow, moved flow to L5. \\
\hline $10 / 08 / 02$ & $\begin{array}{l}\text { 1. Weekly Meeting } \\
\text { 2. Site Walkdown \& data collection } \\
\text { 3. Ended test P, system flush }\end{array}$ & \\
\hline
\end{tabular}


Table B.1 (contd)

\begin{tabular}{|c|c|c|}
\hline Date & Activity (ies) & Comments \\
\hline $10 / 09 / 02$ & $\begin{array}{l}\text { 1. Mid-test evaluation meeting ( } 2 \text { presentations and attendance). } \\
\text { 2. Site Walkdown } \\
\text { 3. Corrected loss of remote data acquisition. } \\
\text { 4. Installed thermocouples. }\end{array}$ & \\
\hline 10/10/02 & $\begin{array}{l}\text { 1. Site Walkdown } \\
\text { 2. Ecology Walkdown }\end{array}$ & \\
\hline $10 / 11 / 02$ & $\begin{array}{l}\text { 1. Startup of test "R". (20 gph to wells L5 \& L13). } \\
\text { 2. Site walkdown }\end{array}$ & \\
\hline $10 / 12 / 02$ & Site walkdown & \\
\hline $10 / 13 / 02$ & Site walkdown & \\
\hline $10 / 14 / 02$ & Site walkdown & \\
\hline $10 / 15 / 02$ & $\begin{array}{l}\text { 1. Site walkdown } \\
\text { 2. Shutdown of test "R" }\end{array}$ & \\
\hline $10 / 16 / 02$ & $\begin{array}{l}\text { 1. Site Walkdown } \\
\text { 2. Conducted Large Rain/Spill event (delivered } 2000 \text { gallons via } \\
\text { hoses from 15:30 to } 18: 00 \text { ) }\end{array}$ & "Flood event" \\
\hline $10 / 17 / 02$ & $\begin{array}{l}\text { 1. Conducted metering pump calibration at } 2 \mathrm{gph} \\
\text { 2. Site Walkdown }\end{array}$ & \\
\hline $10 / 18 / 02$ & Site Walkdown & Collected LRB for copying \\
\hline $10 / 19 / 02$ & No activities & \\
\hline $10 / 20 / 02$ & Copied LRB & \\
\hline $10 / 21 / 02$ & $\begin{array}{l}\text { 1. Startup of flow event "T" (2 gph) } \\
\text { 2. Site Walkdown }\end{array}$ & \\
\hline $10 / 22 / 02$ & 1. Site walkdown \& data collection & \\
\hline $10 / 23 / 02$ & $\begin{array}{l}\text { 1. Site Walkdown \& Data Collection } \\
\text { 2. Sprinkler system removed }\end{array}$ & \\
\hline $10 / 24 / 02$ & $\begin{array}{l}\text { 1. Site Walkdown \& Data Collection } \\
\text { 2. Additional insulation installed on solution delivery hoses } \\
\text { 3. Site Meeting }\end{array}$ & \\
\hline $10 / 25 / 02$ & $\begin{array}{l}\text { 1. Site Walkdown \& Data Collection } \\
\text { 2. Shutdown of Test "T" }\end{array}$ & \\
\hline $10 / 26 / 02$ & No activities & \\
\hline $10 / 27 / 02$ & Copied LRB & \\
\hline $10 / 28 / 02$ & $\begin{array}{l}\text { 1. Startup of Test "V" (10 gph) } \\
\text { 2. Site Walkdown }\end{array}$ & \\
\hline $10 / 29 / 02$ & Site Walkdown & \\
\hline $10 / 30 / 02$ & $\begin{array}{l}\text { 1. Disconnection of iron wall from tank. } \\
\text { 2. Change from Test "V" to Test "W" by changing flow to } 20 \mathrm{gph} \\
\text { 3. Site Walkdown }\end{array}$ & \\
\hline $10 / 31 / 02$ & Site Walkdown & \\
\hline $11 / 01 / 02$ & Site Walkdown & \\
\hline $11 / 02 / 02$ & $\begin{array}{l}\text { 1. Site Walkdown } \\
\text { 2. Shutdown of Test "W" } \\
\text { 3. System Flush }\end{array}$ & \\
\hline $11 / 03 / 02$ & No Activity & \\
\hline $11 / 04 / 02$ & Site Walkdown & \\
\hline $11 / 05 / 02$ & $\begin{array}{l}\text { 1. Startup of Test "Y" (20gph) } \\
\text { 2. Site Walkdown }\end{array}$ & $\begin{array}{l}\text { Pulse and mechanical totalizer not } \\
\text { working. }\end{array}$ \\
\hline
\end{tabular}


Table B.1 (contd)

\begin{tabular}{|c|c|c|}
\hline Date & Activity (ies) & Comments \\
\hline $11 / 06 / 02$ & Site Walkdown & \\
\hline $11 / 07 / 02$ & $\begin{array}{l}\text { 1. Site Walkdown } \\
\text { 2. Shutdown of Test "Y" } \\
\text { 3. System flush }\end{array}$ & \\
\hline $11 / 08 / 02$ & End of test program & \\
\hline $\begin{array}{l}11 / 11 / 02 \\
\& \\
11 / 12 / 02\end{array}$ & $\begin{array}{l}\text { Dismantling of solution delivery system. Rinsing of solution tank. } \\
\text { Discharge of excess river water. Removal of tank insulation. } \\
\text { Removal of flags }\end{array}$ & \\
\hline $11 / 21 / 02$ & Removal of Solution Tank by Rain for Rent. & \\
\hline $\begin{array}{l}11 / 22 \text { to } \\
12 / 11 / 02 \\
\end{array}$ & Site restoration and mothballing & $\begin{array}{l}\text { 1. Electrical service disconnected } \\
\text { 2. Office removed from site }\end{array}$ \\
\hline $12 / 12 / 02$ & Final walkdown of mothballed mock tank site & Site approved \\
\hline
\end{tabular}


Table B.2. Summary of Tank Height Measurements

\begin{tabular}{|c|c|c|c|c|}
\hline Date & Time & $\begin{array}{l}\text { Tank Height } \\
\text { (in) }\end{array}$ & $\begin{array}{l}\text { Cumulative Volume } \\
\text { (gal) }\end{array}$ & Comments \\
\hline $07 / 25 / 02$ & 8:03 & 131.00 & 0.00 & $\begin{array}{l}\text { Initial height was back calculated based on } \\
\text { measurements with the PVC stick initially } \\
\text { used }\end{array}$ \\
\hline $08 / 01 / 02$ & $11: 30$ & 125.25 & 270.94 & $\begin{array}{l}\text { First measurement using tank measuring } \\
\text { stick }\end{array}$ \\
\hline $08 / 02 / 02$ & $11: 00$ & 124.25 & 318.06 & \\
\hline $08 / 03 / 02$ & $8: 25$ & 123.50 & 353.40 & \\
\hline $08 / 04 / 02$ & $12: 37$ & 123.13 & 371.07 & \\
\hline $08 / 07 / 02$ & 14:04 & 118.38 & 594.89 & \\
\hline $08 / 08 / 02$ & $13: 28$ & 118.00 & 612.56 & \\
\hline $08 / 10 / 02$ & 10:10 & 116.00 & 706.80 & \\
\hline $08 / 11 / 02$ & $15: 45$ & 115.63 & 724.47 & \\
\hline $08 / 12 / 02$ & 13:30 & 114.63 & 771.59 & \\
\hline $08 / 13 / 02$ & 14:47 & 112.88 & 854.05 & \\
\hline $08 / 14 / 02$ & $10: 35$ & 111.75 & 907.06 & \\
\hline $08 / 15 / 02$ & $10: 30$ & 110.50 & 965.96 & \\
\hline $08 / 19 / 02$ & $10: 00$ & 110.00 & 989.52 & \\
\hline $08 / 21 / 02$ & 13:17 & 109.38 & 1018.97 & \\
\hline $08 / 22 / 02$ & 10:00 & 101.00 & 1413.60 & \\
\hline $08 / 23 / 02$ & $13: 15$ & 91.00 & 1884.80 & \\
\hline $08 / 27 / 02$ & 15:35 & 81.38 & 2338.33 & \\
\hline $08 / 29 / 02$ & $15: 25$ & 72.13 & 2774.19 & \\
\hline $08 / 29 / 02$ & $15: 45$ & 72.00 & 2780.08 & \\
\hline 09/06/02 & $14: 45$ & 70.75 & 2838.98 & \\
\hline $09 / 06 / 02$ & $14: 50$ & 70.75 & 2838.98 & \\
\hline 09/07/02 & $15: 00$ & 66.00 & 3062.80 & \\
\hline $09 / 08 / 02$ & $16: 20$ & 61.63 & 3268.95 & \\
\hline $09 / 09 / 02$ & 17:00 & 56.13 & 3528.11 & \\
\hline $09 / 10 / 02$ & $14: 45$ & 52.00 & 3722.48 & \\
\hline $09 / 11 / 02$ & 18:30 & 46.00 & 4005.20 & \\
\hline $09 / 12 / 02$ & $14: 30$ & 30.50 & 4735.56 & \\
\hline $09 / 17 / 02$ & $15: 30$ & 130.00 & 4735.56 & Tank refilled \\
\hline $09 / 19 / 02$ & 9:45 & 129.10 & 4777.97 & \\
\hline $09 / 19 / 02$ & $15: 45$ & 128.25 & 4818.02 & \\
\hline $09 / 20 / 02$ & 13:00 & 122.38 & 5094.85 & \\
\hline $09 / 21 / 02$ & $14: 30$ & 118.50 & 5277.44 & \\
\hline $09 / 22 / 02$ & $14: 08$ & 109.38 & 5707.41 & \\
\hline $09 / 23 / 02$ & $13: 30$ & 109.13 & 5719.19 & \\
\hline
\end{tabular}


Table B.2. (contd)

\begin{tabular}{|c|c|c|c|c|}
\hline Date & Time & \begin{tabular}{|l} 
Tank Height \\
(in)
\end{tabular} & $\begin{array}{l}\text { Cumulative Volume } \\
\text { (gal) }\end{array}$ & Comments \\
\hline $09 / 24 / 02$ & $11: 05$ & 105.88 & 5872.33 & \\
\hline $09 / 25 / 02$ & $14: 00$ & 100.38 & 6131.49 & \\
\hline $09 / 26 / 02$ & $13: 35$ & 95.25 & 6372.98 & \\
\hline $09 / 26 / 02$ & $14: 01$ & 92.13 & 6520.23 & \\
\hline $09 / 30 / 02$ & $13: 37$ & 90.75 & 6585.02 & \\
\hline $10 / 01 / 02$ & $15: 10$ & 91.13 & 6567.35 & \\
\hline $10 / 02 / 02$ & $13: 30$ & 91.63 & 6543.79 & \\
\hline $10 / 03 / 02$ & $10: 30$ & 90.88 & 6579.13 & \\
\hline $10 / 04 / 02$ & $10: 55$ & 90.50 & 6596.80 & \\
\hline $10 / 05 / 02$ & $14: 15$ & 78.75 & 7150.46 & \\
\hline $10 / 06 / 02$ & $15: 30$ & 68.75 & 7621.66 & \\
\hline $10 / 07 / 02$ & $14: 48$ & 58.63 & 8098.75 & \\
\hline $10 / 08 / 02$ & $11: 52$ & 50.00 & 8505.16 & \\
\hline $10 / 11 / 02$ & $12: 45$ & 49.88 & 8511.05 & \\
\hline $10 / 12 / 02$ & $13: 00$ & 39.50 & 8999.92 & \\
\hline $10 / 13 / 02$ & $13: 25$ & 39.38 & 9005.81 & \\
\hline $10 / 14 / 02$ & $14: 01$ & 17.38 & 10042.45 & \\
\hline $10 / 15 / 02$ & $12: 14$ & 8.50 & 10460.64 & \\
\hline $10 / 18 / 02$ & $14: 10$ & 8.00 & 10484.20 & \\
\hline $10 / 21 / 02$ & $10: 55$ & 8.25 & 10472.42 & \\
\hline $10 / 22 / 02$ & $10: 25$ & 7.38 & 10513.65 & \\
\hline $10 / 23 / 02$ & $15: 30$ & 6.25 & 10566.66 & \\
\hline $10 / 23 / 02$ & $16: 55$ & 64.88 & 10566.66 & Tank refilled \\
\hline $10 / 24 / 02$ & $10: 20$ & 63.88 & 10613.78 & \\
\hline $10 / 25 / 02$ & $17: 30$ & 62.88 & 10660.90 & \\
\hline $10 / 28 / 02$ & $10: 50$ & 62.25 & 10690.35 & \\
\hline $10 / 29 / 02$ & $14: 19$ & 62.25 & 10690.35 & \\
\hline $10 / 30 / 02$ & $7: 50$ & 53.38 & 11108.54 & \\
\hline $10 / 30 / 02$ & $7: 50$ & 53.38 & 11108.54 & \\
\hline $10 / 31 / 02$ & $13: 30$ & 42.75 & 11609.19 & \\
\hline $11 / 01 / 02$ & $13: 30$ & 37.38 & 11862.46 & \\
\hline
\end{tabular}


Table B.3. Weather Data-July 2002

\begin{tabular}{|c|c|c|c|c|c|c|c|c|c|c|}
\hline Date & $\begin{array}{c}\text { Avg } \\
\text { Temp (F) }\end{array}$ & $\begin{array}{c}\text { High } \\
\text { Temp (F) }\end{array}$ & $\begin{array}{c}\text { Low Temp } \\
\text { (F) }\end{array}$ & $\begin{array}{c}\text { Rel Humidity } \\
\%\end{array}$ & $\begin{array}{l}\text { Total Precip } \\
\text { (in) }\end{array}$ & $\begin{array}{l}\text { Solar Rad } \\
\text { (Langleys) }\end{array}$ & $\begin{array}{l}\text { Avg Wind } \\
\text { Dir }\end{array}$ & $\begin{array}{c}\text { Avg Wind } \\
\text { Speed (mph) }\end{array}$ & $\begin{array}{c}\text { Gust Wind } \\
\text { Dir }\end{array}$ & $\begin{array}{c}\text { Gust Wind } \\
\text { Speed (mph) }\end{array}$ \\
\hline July 1,2002 & 68 & 83 & 53 & 36 & & 694 & NW & 10.3 & NW & 26 \\
\hline July 2, 2002 & 72 & 87 & 56 & 32 & & 647 & NW & 7.4 & NW & 28 \\
\hline July 3,2002 & 70 & 84 & 57 & 31 & & 524 & NW & 13.4 & NW & 38 \\
\hline July 4, 2002 & 64 & 79 & 50 & 41 & & 636 & NW & 10.3 & NW & 31 \\
\hline July 5, 2002 & 68 & 83 & 53 & 34 & & 676 & $\mathrm{~N}$ & 6.3 & NNE & 24 \\
\hline July 6, 2002 & 74 & 94 & 53 & 25 & & 638 & $\mathrm{~W}$ & 5.5 & NNE & 18 \\
\hline July 7, 2002 & 82 & 100 & 64 & 36 & 0.13 & 536 & NW & 12.3 & NW & 53 \\
\hline July 8,2002 & 71 & 84 & 58 & 51 & 0.03 & 584 & NW & 10.7 & WSW & 27 \\
\hline July 9,2002 & 74 & 92 & 57 & 37 & & 671 & NW & 7.9 & $\bar{E}$ & 20 \\
\hline July 10,2002 & 85 & 103 & 67 & 26 & & 664 & NW & 7.8 & NW & 22 \\
\hline July 11,2002 & 90 & 109 & 71 & 27 & & 629 & NW & 6.5 & NW & 22 \\
\hline July 12,2002 & 92 & 112 & 71 & 25 & & 634 & $\mathrm{E}$ & 5.8 & $E$ & 20 \\
\hline July 13, 2002 & 96 & 113 & 80 & 25 & & 562 & NW & 9.5 & NW & 35 \\
\hline July 14,2002 & 81 & 96 & 66 & 27 & & 652 & NW & 11.2 & NW & 34 \\
\hline July 15,2002 & 76 & 95 & 58 & 25 & & 641 & NW & 4.6 & WNW & 20 \\
\hline July 16,2002 & 81 & 100 & 62 & 30 & & 598 & SE & 6.1 & WNW & 20 \\
\hline July 17,2002 & 83 & 101 & 65 & 33 & & 621 & $\mathrm{~W}$ & 9.5 & WNW & 29 \\
\hline July 18,2002 & 81 & 99 & 63 & 36 & & 642 & SW & 9 & WNW & 28 \\
\hline July 19,2002 & 81 & 94 & 68 & 36 & & 646 & NW & 12.5 & WNW & 38 \\
\hline July 20, 2002 & 76 & 94 & 57 & 33 & & 591 & NW & 6.1 & NW & 28 \\
\hline July 21,2002 & 82 & 97 & 68 & 28 & & 636 & $\mathrm{~N}$ & 8.3 & NNW & 25 \\
\hline July 22, 2002 & 86 & 101 & 70 & 25 & & 631 & $\mathrm{~N}$ & 8.9 & $\mathrm{NNE}$ & 23 \\
\hline July 23,2002 & 90 & 103 & 76 & 26 & & 431 & NW & 7.1 & $\mathrm{~W}$ & 27 \\
\hline July 24, 2002 & 88 & 106 & 70 & 28 & & 591 & NW & 6.2 & $\mathrm{~W}$ & 28 \\
\hline July 25,2002 & 87 & 102 & 72 & 28 & & 567 & NW & 11.4 & NW & 38 \\
\hline July 26, 2002 & 82 & 96 & 67 & 35 & & 534 & NW & 15.4 & NW & 39 \\
\hline July 27, 2002 & 80 & 95 & 66 & 32 & & 613 & NW & 12.9 & NW & 41 \\
\hline July 28,2002 & 82 & 94 & 69 & 36 & & 607 & NW & 16.7 & NW & 45 \\
\hline July 29, 2002 & 81 & 96 & 66 & 40 & & 610 & NW & 9.4 & NW & 30 \\
\hline July 30, 2002 & 76 & 90 & 61 & 40 & & 527 & NW & 12.9 & NW & 39 \\
\hline July 31,2002 & 71 & 84 & 58 & 31 & & 626 & NW & 7.5 & NW & 34 \\
\hline
\end{tabular}


Table B.3. Weather Data-August 2002

\begin{tabular}{|c|c|c|c|c|c|c|c|c|c|c|}
\hline Date & $\begin{array}{c}\text { Avg } \\
\text { Temp (F) }\end{array}$ & $\begin{array}{c}\text { High } \\
\text { Temp (F) }\end{array}$ & $\begin{array}{c}\text { Low } \\
\text { Temp (F) }\end{array}$ & $\begin{array}{c}\text { Rel } \\
\text { Humidity \% }\end{array}$ & $\begin{array}{l}\text { Total Precip } \\
\text { (in) }\end{array}$ & $\begin{array}{l}\text { Solar Rad } \\
\text { (Langleys) }\end{array}$ & $\begin{array}{c}\text { Avg Wind } \\
\text { dir }\end{array}$ & $\begin{array}{c}\text { Avg Wind } \\
\text { speed (mph) }\end{array}$ & $\begin{array}{l}\text { Gust Wind } \\
\text { Dir }\end{array}$ & $\begin{array}{l}\text { Gust Wind } \\
\text { Speed (mph) }\end{array}$ \\
\hline August 1, 2002 & 72 & 91 & 53 & 30 & & 615 & NW & 8 & WNW & 40 \\
\hline August 2, 2002 & 72 & 84 & 59 & 30 & & 635 & NW & 15.1 & $\mathrm{~W}$ & 34 \\
\hline August 3, 2002 & 72 & 87 & 56 & 32 & & 624 & $\mathrm{~W}$ & 6.2 & $\overline{W N W}$ & 24 \\
\hline August 4, 2002 & 68 & 78 & 58 & 39 & & 405 & $\mathrm{~W}$ & 10.9 & WNW & 28 \\
\hline August 5, 2002 & 64 & 78 & 51 & 38 & & 461 & $\mathrm{~W}$ & 7.3 & NW & 32 \\
\hline August 6,2002 & 66 & 78 & 54 & 40 & & 446 & $\mathrm{~W}$ & 8.5 & NW & 27 \\
\hline August 7, 2002 & 67 & 83 & 51 & 38 & & 590 & NW & 7 & NW & 23 \\
\hline August 8, 2002 & 73 & 88 & 58 & 32 & & 578 & $\mathrm{~W}$ & 6.2 & $\mathrm{~W}$ & 21 \\
\hline August 9, 2002 & 76 & 97 & 56 & 29 & & 583 & NW & 7.6 & NW & 34 \\
\hline August 10, 2002 & 82 & 96 & 68 & 35 & & 575 & NW & 12.1 & NW & 41 \\
\hline August 11, 2002 & 77 & 91 & 63 & 29 & & 567 & $\mathrm{~W}$ & 7.5 & WNW & 26 \\
\hline August 12, 2002 & 80 & 95 & 65 & 26 & & 577 & NW & 7.1 & $\mathrm{~N}$ & 20 \\
\hline August 13,2002 & 86 & 102 & 69 & 23 & & 581 & NW & 7.4 & NNE & 27 \\
\hline August 14,2002 & 89 & 103 & 75 & 21 & & 577 & NW & 15 & NW & 36 \\
\hline August 15, 2002 & 82 & 96 & 68 & 28 & & 565 & $\overline{N W}$ & 9.6 & $\overline{W N W}$ & 39 \\
\hline August 16, 2002 & 76 & 88 & 63 & 26 & & 561 & $\mathrm{~N}$ & 8.3 & WNW & 33 \\
\hline August 17, 2002 & 73 & 96 & 50 & 26 & & 549 & NW & 9.8 & NW & 39 \\
\hline August 18,2002 & 74 & 89 & 60 & 28 & & 527 & $\mathrm{~W}$ & 6.4 & WNW & 18 \\
\hline August 19, 2002 & 75 & 92 & 58 & 31 & & 516 & $\mathrm{~W}$ & 10 & WNW & 40 \\
\hline August 20, 2002 & 74 & 85 & 62 & 40 & & 491 & NW & 11 & NW & 38 \\
\hline August 21, 2002 & 70 & 82 & 58 & 46 & & 420 & SE & 6 & $\mathrm{E}$ & 22 \\
\hline August 22, 2002 & 70 & 86 & 54 & 49 & 0.005 & 490 & $\mathrm{SE}$ & 5 & ESE & 22 \\
\hline August 23, 2002 & 74 & 89 & 60 & 48 & 0.01 & 507 & $\mathrm{NE}$ & 4.5 & ENE & 24 \\
\hline August 24, 2002 & 78 & 94 & 61 & 36 & & 417 & $\mathrm{NE}$ & 4.6 & ENE & 18 \\
\hline August 25, 2002 & 80 & 96 & 63 & 42 & & 482 & $\mathrm{NW}$ & 7.5 & $\mathrm{NW}$ & 31 \\
\hline August 26, 2002 & 77 & 89 & 65 & 42 & & 496 & NW & 8.3 & WNW & 30 \\
\hline August 27, 2002 & 78 & 93 & 63 & 41 & & 497 & $\mathrm{~N}$ & 7.1 & $\mathrm{NE}$ & 22 \\
\hline August 28, 2002 & 81 & 96 & 66 & 34 & & 493 & $\mathrm{~N}$ & 7.7 & NNW & 23 \\
\hline August 29, 2002 & 81 & 98 & 64 & 34 & & 430 & NW & 8.3 & $\mathrm{NW}$ & 36 \\
\hline August 30,2002 & 76 & 90 & 63 & 40 & & 495 & NW & 7.9 & WNW & 36 \\
\hline August 31, 2002 & 78 & 92 & 65 & 38 & & 467 & $\mathrm{~W}$ & 7.4 & NW & 33 \\
\hline
\end{tabular}


Table B.3. Weather Data-September 2002

\begin{tabular}{|c|c|c|c|c|c|c|c|c|c|c|}
\hline Date & $\begin{array}{c}\text { Avg } \\
\text { Temp } \\
\text { (F) } \\
\end{array}$ & $\begin{array}{c}\text { High } \\
\text { Temp } \\
\text { (F) }\end{array}$ & $\begin{array}{l}\text { Low } \\
\text { Temp } \\
\text { (F) }\end{array}$ & $\begin{array}{c}\text { Rel } \\
\text { Humidity } \\
\% \\
\end{array}$ & $\begin{array}{c}\text { Total } \\
\text { Precip } \\
\text { (in) }\end{array}$ & $\begin{array}{c}\text { Solar } \\
\text { Rad } \\
\text { (Langleys) } \\
\end{array}$ & $\begin{array}{c}\text { Avg } \\
\text { Wind } \\
\text { dir } \\
\end{array}$ & $\begin{array}{c}\text { Avg Wind } \\
\text { speed } \\
\text { (mph) } \\
\end{array}$ & $\begin{array}{c}\text { Gust Wind } \\
\text { Dir } \\
\end{array}$ & $\begin{array}{c}\text { Gust Wind } \\
\text { Speed (mph) }\end{array}$ \\
\hline September 1, 2002 & 74 & 83 & 65 & 41 & & 352 & NW & 16.1 & NW & 37 \\
\hline September 2, 2002 & 72 & 92 & 53 & 44 & & 484 & $\mathrm{~W}$ & 6.1 & NW & 24 \\
\hline September 3, 2002 & 70 & 81 & 58 & 36 & & 389 & NW & 13.6 & WNW & 29 \\
\hline September 4, 2002 & 62 & 77 & 46 & 36 & & 418 & $\mathrm{~W}$ & 5.2 & $\mathrm{~W}$ & 21 \\
\hline September 5, 2002 & 66 & 79 & 52 & 36 & & 431 & NW & 7.7 & WNW & 27 \\
\hline September 6, 2002 & 64 & 77 & 51 & 39 & & 347 & NW & 7.7 & WNW & 25 \\
\hline September 7, 2002 & 61 & 76 & 46 & 40 & & 472 & $\mathrm{~W}$ & 8.4 & $\mathrm{~W}$ & 26 \\
\hline September 8, 2002 & 61 & 78 & 44 & 40 & & 413 & SW & 5.8 & SW & 21 \\
\hline September 9, 2002 & 68 & 85 & 51 & 42 & & 452 & $\mathrm{~W}$ & 5.6 & $\mathrm{~S}$ & 17 \\
\hline September 10,2002 & 74 & 90 & 57 & 38 & & 443 & $\mathrm{~W}$ & 5.7 & NNW & 14 \\
\hline September 11,2002 & 74 & 94 & 54 & 36 & & 439 & $\mathrm{~W}$ & 4.5 & $\mathrm{~W}$ & 11 \\
\hline September 12,2002 & 76 & 96 & 55 & 33 & & 437 & SE & 6.6 & WNW & 29 \\
\hline September 13,2002 & 76 & 94 & 59 & 28 & & 444 & $\mathrm{~W}$ & 5.4 & WNW & 19 \\
\hline September 14,2002 & 74 & 92 & 55 & 35 & & 343 & NW & 4.9 & NW & 20 \\
\hline September 15,2002 & 73 & 92 & 54 & 40 & & 323 & $\mathrm{~W}$ & 8.5 & WNW & 39 \\
\hline September 16,2002 & 66 & 78 & 54 & 48 & & 217 & $\mathrm{~W}$ & 9.8 & WSW & 27 \\
\hline September 17, 2002 & 66 & 76 & 55 & 44 & 0.005 & 367 & NW & 8.2 & NW & 35 \\
\hline September 18,2002 & 64 & 82 & 46 & 41 & & 416 & NW & 10.5 & NW & 31 \\
\hline September 19,2002 & 68 & 88 & 49 & 48 & & 408 & NW & 9.3 & WNW & 35 \\
\hline September 20, 2002 & 64 & 75 & 52 & 37 & & 407 & NW & 6.9 & NW & 31 \\
\hline September 21, 2002 & 60 & 74 & 47 & 31 & & 390 & $\mathrm{~N}$ & 6.7 & WNW & 17 \\
\hline September 22, 2002 & 58 & 78 & 38 & 30 & & 389 & $\mathrm{~W}$ & 4.8 & $\mathrm{SE}$ & 13 \\
\hline September 23,2002 & 64 & 84 & 44 & 28 & & 393 & $\mathrm{SE}$ & 4 & $\mathrm{E}$ & 14 \\
\hline September 24, 2002 & 70 & 84 & 55 & 32 & & 377 & NW & 7.8 & NNE & 28 \\
\hline September 25,2002 & 66 & 80 & 53 & 32 & & 370 & NW & 6.8 & NW & 20 \\
\hline September 26,2002 & 58 & 74 & 43 & 51 & 0.005 & 220 & NW & 5.8 & $\mathrm{~N}$ & 26 \\
\hline September 27, 2002 & 66 & 77 & 54 & 46 & & 293 & $\mathrm{~N}$ & 9.3 & NNE & 30 \\
\hline September 28, 2002 & 61 & 78 & 44 & 46 & & 349 & SE & 5.3 & ESE & 14 \\
\hline September 29,2002 & 61 & 72 & 50 & 40 & 0.005 & 293 & $\mathrm{~W}$ & 11.7 & WSW & 33 \\
\hline September 30, 2002 & 53 & 65 & 41 & 45 & & 266 & $\mathrm{~W}$ & 9.5 & SSW & 30 \\
\hline
\end{tabular}


Table B.3. Weather Data-October 2002

\begin{tabular}{|c|c|c|c|c|c|c|c|c|c|c|}
\hline Date & $\begin{array}{c}\text { Avg } \\
\text { Temp (F) }\end{array}$ & $\begin{array}{c}\text { High } \\
\text { Temp (F) }\end{array}$ & $\begin{array}{c}\text { Low } \\
\text { Temp (F) }\end{array}$ & $\begin{array}{c}\text { Rel } \\
\text { Humidity \% }\end{array}$ & $\begin{array}{l}\text { Total Precip } \\
\text { (in) }\end{array}$ & $\begin{array}{c}\text { Solar Rad } \\
\text { (Langleys) }\end{array}$ & $\begin{array}{l}\text { Avg Wind } \\
\text { dir }\end{array}$ & $\begin{array}{c}\text { Avg Wind } \\
\text { speed (mph) }\end{array}$ & $\begin{array}{c}\text { Gust Wind } \\
\text { Dir }\end{array}$ & $\begin{array}{c}\text { Gust Wind } \\
\text { Speed (mph) }\end{array}$ \\
\hline October 1,2002 & 52 & 67 & 37 & 51 & & 351 & $\mathrm{~N}$ & 5 & NNW & 16 \\
\hline October 2,2002 & 52 & 70 & 34 & 45 & 0.005 & 348 & $\mathrm{~W}$ & 5.9 & $\mathrm{~W}$ & 24 \\
\hline October 3, 2002 & 57 & 62 & 52 & 81 & 0.08 & 110 & $\mathrm{~W}$ & 4 & $\mathrm{~W}$ & 16 \\
\hline October 4, 2002 & 57 & 67 & 47 & 75 & & 211 & $\mathrm{~S}$ & 4.9 & NW & 23 \\
\hline October 5, 2002 & 62 & 76 & 48 & 52 & & 319 & $\mathrm{~W}$ & 9.8 & NW & 29 \\
\hline October 6, 2002 & 62 & 81 & 43 & 50 & & 330 & $\mathrm{~W}$ & 6.5 & $\mathrm{~W}$ & 24 \\
\hline October 7, 2002 & 66 & 79 & 53 & 40 & & 327 & NW & 11.6 & NW & 34 \\
\hline October 8,2002 & 61 & 78 & 44 & 42 & & 312 & $\mathrm{~W}$ & 5.6 & WNW & 23 \\
\hline October 9, 2002 & 64 & 74 & 53 & 45 & & 308 & NW & 9.1 & WNW & 35 \\
\hline October 10, 2002 & 55 & 66 & 44 & 42 & & 263 & NW & 14.2 & NW & 36 \\
\hline October 11,2002 & 50 & 62 & 39 & 41 & & 311 & $\mathrm{~W}$ & 6.2 & $\mathrm{~W}$ & 16 \\
\hline October 12,2002 & 46 & 64 & 29 & 47 & & 305 & NW & 6.5 & NW & 16 \\
\hline October 13,2002 & 50 & 67 & 32 & 43 & & 296 & $\mathrm{~W}$ & 6.1 & WNW & 14 \\
\hline October 14, 2002 & 52 & 70 & 34 & 41 & & 295 & $\mathrm{~W}$ & 4.6 & $\mathrm{~N}$ & 14 \\
\hline October 15,2002 & 54 & 73 & 34 & 38 & & 287 & $\mathrm{NE}$ & 3.6 & $\mathrm{~S}$ & 10 \\
\hline October 16, 2002 & 54 & 73 & 35 & 49 & & 283 & $\mathrm{~S}$ & 3.9 & WSW & 11 \\
\hline October 17,2002 & 52 & 71 & 33 & 50 & & 280 & $\mathrm{E}$ & 4.3 & SSE & 11 \\
\hline October 18, 2002 & 52 & 70 & 35 & 50 & & 266 & $\mathrm{SE}$ & 3.4 & SSE & 10 \\
\hline October 19,2002 & 56 & 74 & 38 & 56 & & 254 & $\mathrm{~W}$ & 3.8 & $\mathrm{SE}$ & 18 \\
\hline October 20, 2002 & 57 & 70 & 44 & 61 & & 187 & $\mathrm{~W}$ & 3.3 & $\mathrm{~W}$ & 11 \\
\hline October 21,2002 & 56 & 71 & 41 & 62 & & 248 & $\mathrm{~N}$ & 3.4 & WSW & 10 \\
\hline October 22, 2002 & 53 & 68 & 38 & 52 & & 247 & $\mathrm{~N}$ & 6.2 & $\mathrm{~N}$ & 21 \\
\hline October 23,2002 & 47 & 61 & 33 & 35 & & 263 & NW & 7.6 & $\mathrm{NNE}$ & 17 \\
\hline October 24, 2002 & 41 & 58 & 24 & 45 & & 251 & $\mathrm{~W}$ & 3.7 & WSW & 11 \\
\hline October 25, 2002 & 40 & 58 & 23 & 49 & & 245 & $\mathrm{~W}$ & 4.1 & $\mathrm{~W}$ & 11 \\
\hline October 26, 2002 & 41 & 57 & 25 & 54 & & 244 & $\mathrm{~W}$ & 5.5 & NW & 14 \\
\hline October 27,2002 & 38 & 51 & 24 & 65 & & 105 & NW & 4 & NW & 20 \\
\hline October 28, 2002 & 46 & 61 & 32 & 57 & 0.005 & 161 & $\mathrm{~S}$ & 6.5 & NNE & 29 \\
\hline October 29, 2002 & 37 & 47 & 27 & 48 & 0.04 & 177 & $\mathrm{NE}$ & 16.8 & NNE & 43 \\
\hline October 30, 2002 & 28 & 40 & 16 & 34 & & 238 & $\mathrm{~N}$ & 6.9 & $\mathrm{NNE}$ & 19 \\
\hline October 31,2002 & 24 & 40 & 7 & 55 & & 228 & $\mathrm{NE}$ & 3.7 & WSW & 10 \\
\hline
\end{tabular}


Table B.3. Weather Data-November 2002

\begin{tabular}{|c|c|c|c|c|c|c|c|c|c|c|}
\hline Date & $\begin{array}{c}\text { Avg } \\
\text { Temp } \\
\text { (F) } \\
\end{array}$ & $\begin{array}{c}\text { High } \\
\text { Temp } \\
\text { (F) }\end{array}$ & $\begin{array}{c}\text { Low } \\
\text { Temp } \\
\text { (F) } \\
\end{array}$ & $\begin{array}{c}\text { Rel } \\
\text { Humidity } \\
\% \\
\end{array}$ & $\begin{array}{c}\text { Total } \\
\text { Precip } \\
\text { (in) }\end{array}$ & $\begin{array}{l}\text { Solar Rad } \\
\text { (Langleys) }\end{array}$ & $\begin{array}{c}\text { Avg Wind } \\
\text { dir }\end{array}$ & $\begin{array}{c}\text { Avg Wind } \\
\text { speed } \\
(\mathrm{mph})\end{array}$ & $\begin{array}{c}\text { Gust Wind } \\
\text { Dir }\end{array}$ & $\begin{array}{c}\text { Gust Wind } \\
\text { Speed (mph) }\end{array}$ \\
\hline November 1,2002 & 27 & 43 & 11 & 50 & & 217 & SW & 3.9 & WSW & 12 \\
\hline November 3, 2002 & 30 & 45 & 14 & 60 & & 199 & $\mathrm{~W}$ & 3.7 & WSW & 10 \\
\hline November 4, 2002 & 30 & 45 & 15 & 59 & & 188 & SE & 3.6 & SSE & 10 \\
\hline November 5, 2002 & 38 & 49 & 27 & 55 & & 135 & $\mathrm{~W}$ & 3.8 & SSW & 9 \\
\hline November 7, 2002 & 48 & 56 & 39 & 63 & 0.13 & 107 & $\mathrm{~W}$ & 6.5 & ENE & 18 \\
\hline November 8,2002 & 50 & 56 & 44 & 66 & 0.03 & 40 & SW & 10.7 & SW & 32 \\
\hline November 9, 2002 & 52 & 59 & 44 & 65 & 0.005 & 106 & SW & 8.7 & SSW & 30 \\
\hline November 10,2002 & 51 & 59 & 43 & 62 & 0.005 & 191 & SW & 10.1 & WSW & 25 \\
\hline November 11,2002 & 47 & 61 & 33 & 66 & 0.005 & 153 & SW & 5 & $\mathrm{~W}$ & 15 \\
\hline November 12,2002 & 52 & 58 & 45 & 81 & 0.08 & 49 & NW & 8.1 & SW & 30 \\
\hline November 13,2002 & 50 & 60 & 39 & 64 & 0.005 & 138 & SW & 7.1 & SW & 31 \\
\hline November 15,2002 & 42 & 50 & 33 & 82 & & 97 & NW & 4.3 & WNW & 15 \\
\hline November 16, 2002 & 44 & 58 & 29 & 78 & & 97 & SW & 7.5 & SSW & 36 \\
\hline November 17,2002 & 46 & 57 & 36 & 60 & & 122 & $\mathrm{~W}$ & 9.3 & WSW & 27 \\
\hline November 18,2002 & 46 & 56 & 35 & 71 & 0.07 & 103 & SW & 7.4 & SSW & 35 \\
\hline November 19,2002 & 57 & 67 & 47 & 68 & 0.01 & 55 & SW & 10.2 & SW & 35 \\
\hline November 20,2002 & 50 & 58 & 43 & 87 & & 119 & $\mathrm{NW}$ & 8.4 & WNW & 22 \\
\hline November 21, 2002 & 51 & 58 & 44 & 88 & 0.02 & 131 & $\mathrm{SE}$ & 5.1 & WNW & 13 \\
\hline November 22,2002 & 50 & 53 & 46 & 94 & 0.005 & 25 & NW & 3.4 & $\mathrm{~W}$ & 10 \\
\hline November 23, 2002 & 48 & 58 & 38 & 71 & & 106 & $\mathrm{~N}$ & 6.5 & $\mathrm{~N}$ & 20 \\
\hline November 24, 2002 & 38 & 51 & 24 & 66 & & 149 & NW & 4.6 & NW & 11 \\
\hline November 25,2002 & 32 & 44 & 19 & 80 & & 165 & $\mathrm{~W}$ & 3.4 & WNW & 9 \\
\hline November 26,2002 & 35 & 45 & 25 & 80 & & 139 & NW & 5.2 & $\mathrm{~W}$ & 12 \\
\hline November 27,2002 & 26 & 30 & 23 & 95 & & 52 & SW & 1.6 & $\mathrm{~S}$ & 8 \\
\hline November 28,2002 & 28 & 30 & 25 & 93 & 0.005 & 35 & $\mathrm{SE}$ & 1.8 & $\mathrm{~S}$ & 8 \\
\hline
\end{tabular}


Table B.4. Log of Physical Parameters for Sodium Thiosulfate Solution Used in FY 2002-2003 Performance Evaluation Test

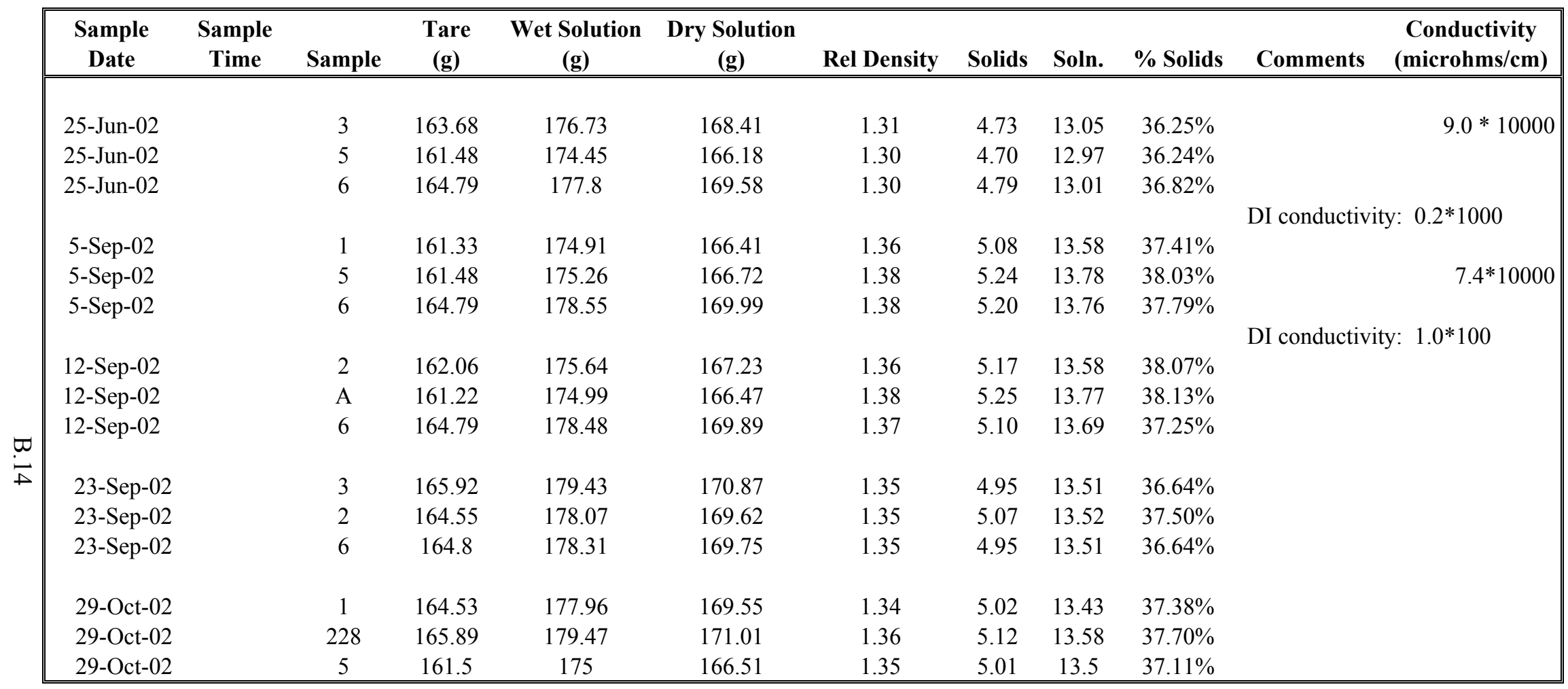


Appendix C

LDMM Performance Evaluation of HRR-SCRT Leak Detection 


\section{Appendix C}

\section{LDMM Performance Evaluation of HRR-SCRT Leak Detection}

\section{Contents}

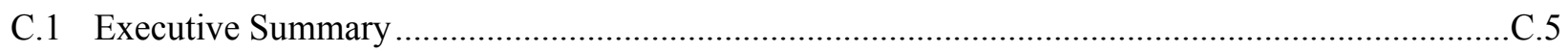

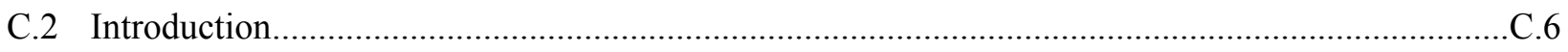

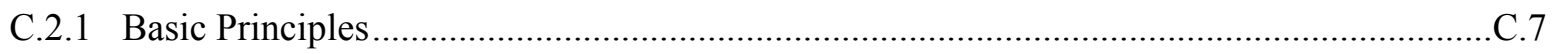

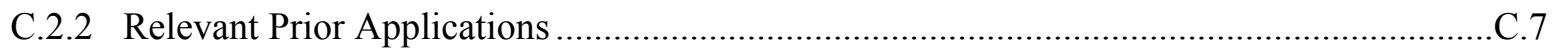

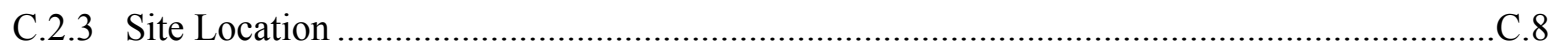

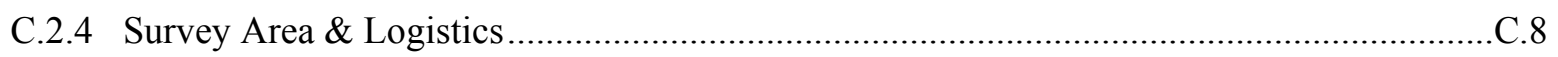

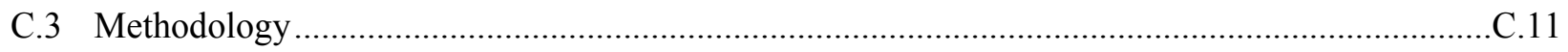

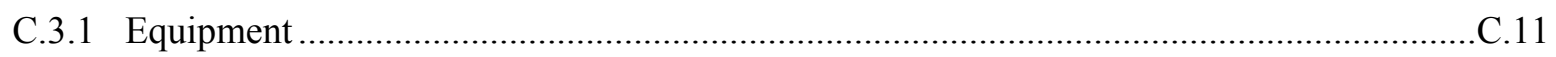

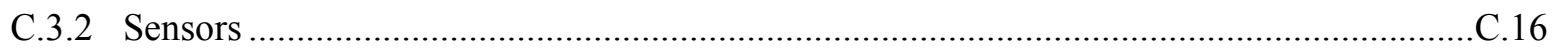

C.3.3 Grounding Points and Wire Arrangement.................................................................. 18

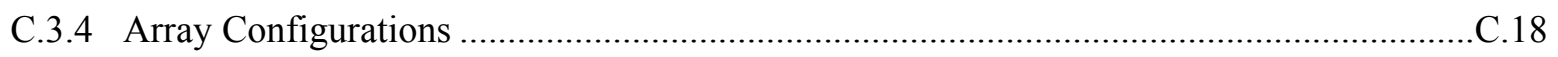

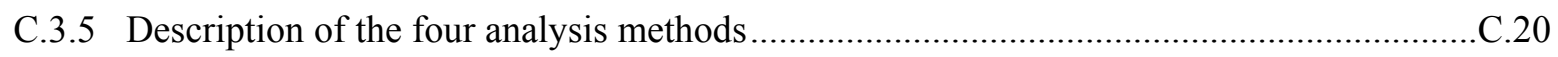

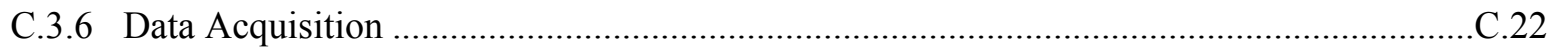

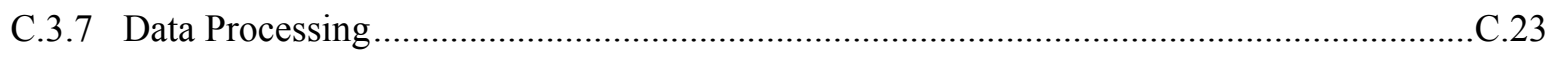

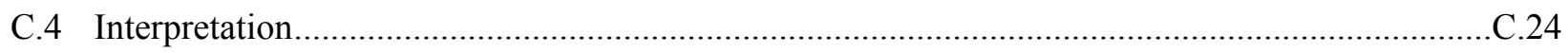

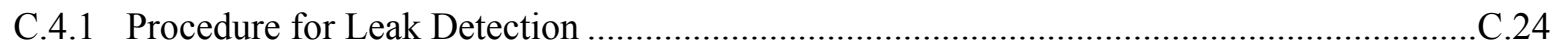

C.4.2 Procedure for leak volume and leak rate determination...............................................2.

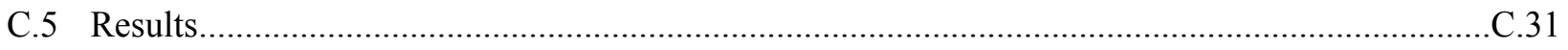

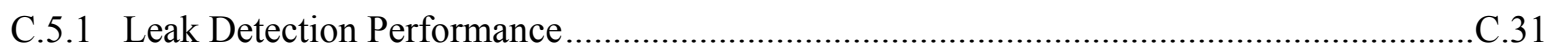

C.1 


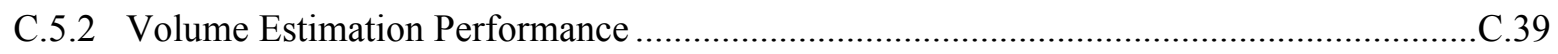

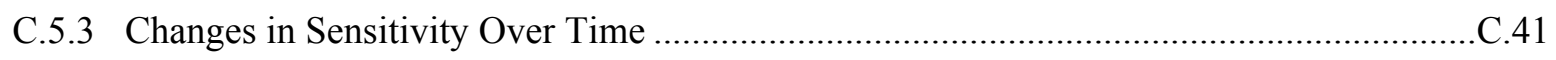

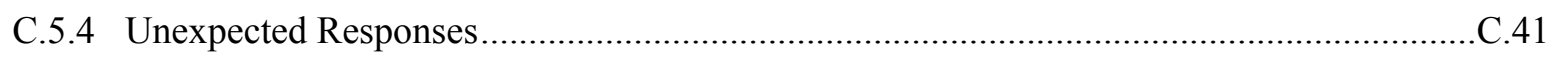

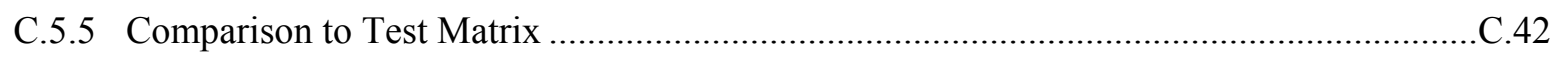

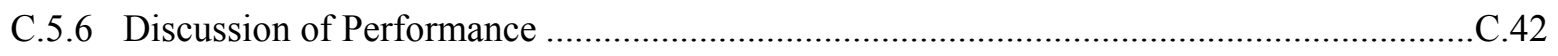

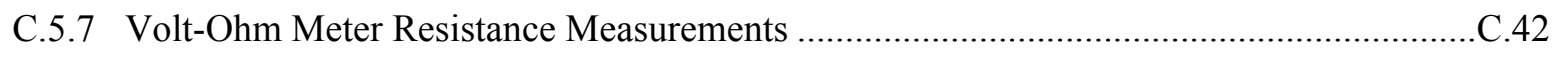

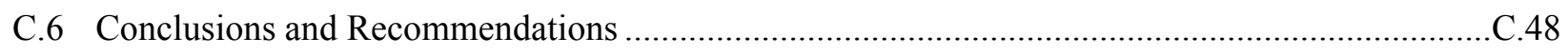

C.6.1 Investigator Perspective on Test Outcome...................................................................48

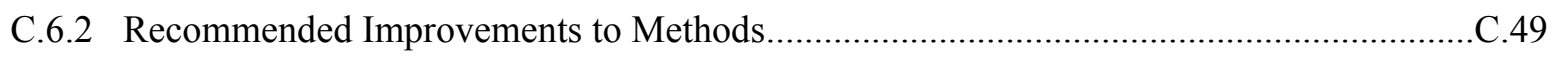

C.6.3 Adaptive Procedures for Tank Farm Deployment …..................................................... 49

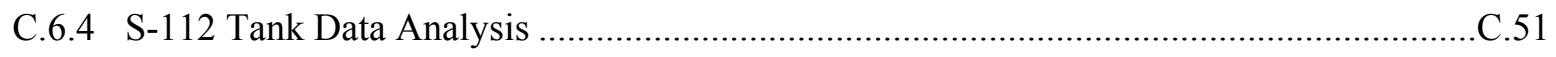

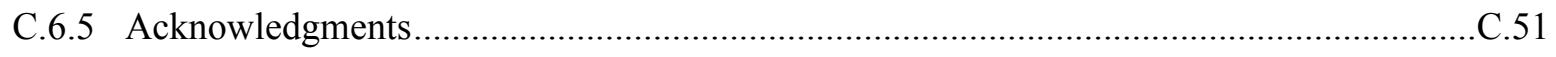

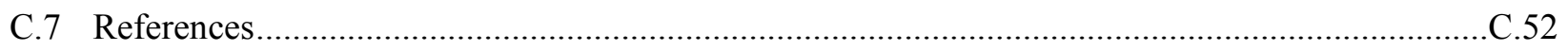




\section{Figures}

C.1. Plan map showing the location of the mock tank, the four steel casings, the surface electrode array, injection ports, and other relevant features for the 2002 LDMM PE Test .......... C.9

C.2. Construction of New Patch Panel................................................................................................. C. 12

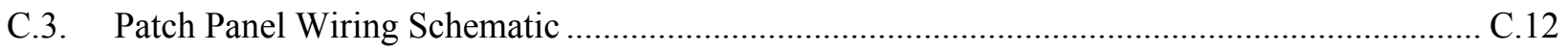

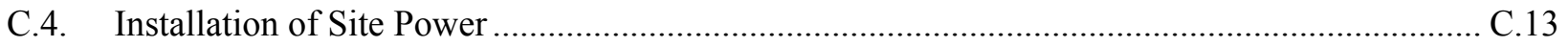

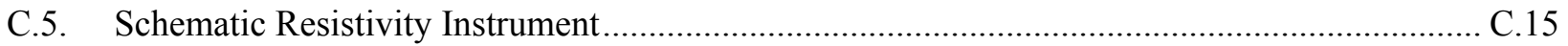

C.6. Shows Resistivity System Setup with HP Power Supply (bottom right), Transmitter (top right), Remote Computer (bottom center), Receiver (top center) and Patch Panel (far left) ...... C.15

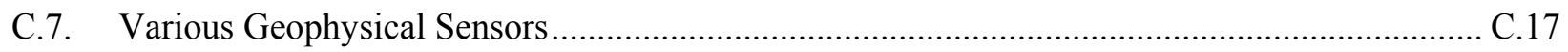

C.8. Schematic of General Pole-Pole Configuration ................................................................. C.19

C.9. An example of the Relative Change in Signal Level that Indicates a Perturbation Event

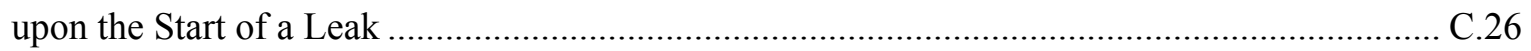

C.10. An Example of the Relative Change in Signal Level that Does Not Indicate a Leak Because the Leak Port Was Not Instrumented. Diurnal variation is more apparent in this example....... C.28

C.11. Example Profile Illustrating the Influence of a Artificial "Flood" Event on HRR-SCRT

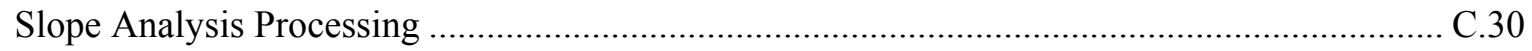

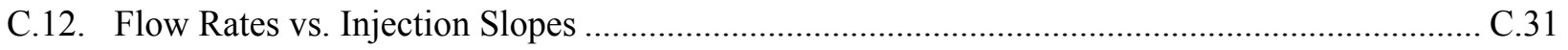

C.13. Interpreted Leak Detection Time Series of "Fused" ERT Well to "Fused" ERT Well

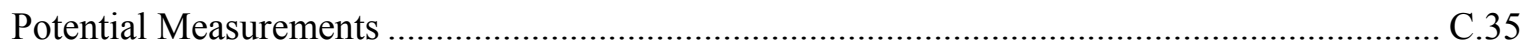

C.14. Interpreted Leak Detection Time Series of "fused" ERT Well to Surface Potential

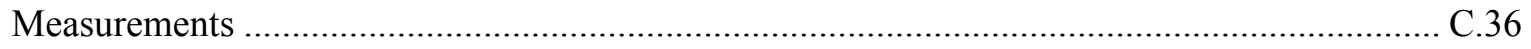

C.15. Interpreted Leak Detection Time Series o Injection System Electrodes to Steel Casing

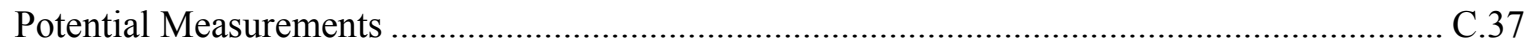

C.16. Interpreted Leak Detection Time Series o Injection System Electrodes to Surface Electrode Potential Measurements 
C.17. Comparison of Modified Method C Time Series Volume Calculations to the Actual Test Matrix

C.18. Summary Plot of Tank-to-Steel-Casing Measurements, Showing the Distribution of Percent Difference Values for Reciprocal Readings... C. 46

C.19. VOM Resistance Measurements Before and After the PE Test...... C. 47

\section{Tables}

C.1. Relationship Between Electrode Number, Multiplexer Channel Number and Sensor Identification C. 17

C.2. Summary of Rate and Volume Calculations C. 40

C.3. Comparison of Injection System to Steel Casing Results Produced from Perturbation Analysis of the Time Series Plot (Figure 5.5)

C.4. Statistical Summary of Percent Differences for Reciprocal Readings. C. 45 


\section{C.1 Executive Summary}

hydroGEOPHYSICS' Inc. (HGI) high resolution resistivity - steel casing resistivity technology (HRR-SCRT) leak detection system was chosen as the number one leak detection technology for future testing and deployment by the Department of Energy (DOE) in the Down-Selection Meeting held in Richland, WA held during January 2002. SCRT was selected due to its ease of deployment in the tank farms, low cost of deployment, and its accuracy in leak detection. SCRT was performance tested during the period of July to November 2002 as part of the Leak Detection, Mitigation, and Monitoring (LDMM) program. SCRT data were acquired, processed, and reported on a daily basis while various leaks were simulated at the Mock Tank (Site 105-A). The intent of this report is to describe the SCRT system, how it was deployed for the PE test, and to discuss the results of the PE test. HRR-SCRT is a proprietary technology of HGI.

The SCRT configuration for the PE test involved; 1.) a sensor distribution similar to that of the 2001 Mock Tank study, 2.) the use of different instrumentation, and 3.) continuous measurements for the duration of the test (110 days). Specific differences between the PE test and earlier studies are discussed in the respective sections in this report. Of particular importance, system calibration was dependent on the 2001 Mock Tank study which involved different instrumentation and somewhat different environmental conditions.

The sensors and wiring installed for the 2001 SCRT study at the Mock Tank were not intended for use beyond last year's testing period. The 1994 electrical resistivity tomography (ERT) arrays also suffered from age and neglect. Nevertheless, both sensor arrangements were successfully used this year after some maintenance, minor modification, and additional wiring installed. Fewer surface electrodes were used this year (15 versus 61$)$ and an additional steel casing was installed increasing that count to four. Previous studies used different instrumentation systems for SCRT and ERT. This year's PE test used a single system designed to be remotely accessed via an Internet connection and allowed the same system to be used for both SCRT and ERT on a shared basis.

At the onset of the PE test HGI provided four specific approaches for qualitative and quantitative leak detection on a daily basis to meet the requirements of the PE test. Those daily reports are presently being statistically evaluated by Vista Engineering Technologies (VET). It is emphasized that this report discusses HGI's approach to leak detection using the SCRT methodology because it differs from the protocols used for the PE test. It also discusses some aspects of the PE test protocols and provides additional insight into alternative methods of SCRT data analysis that we believe show more merit than those of the PE test.

Results presented in the Executive Summary are based on HGI's analysis of SCRT data. This analysis, which was used on the initial mock tank study, relies on variable length time windows which are not fixed in time during any given day. Although such variability produces significantly better test results, test protocol demanded a more constrained approach to allow 
statistical evaluation. Consequently, the test protocol windows were established as a "best approximation" to the variable window approach..

- During the PE test there were 13 actual leak events. Of these 13 leak events, 4 were outside the designated SCRT test configuration*. Of the remaining 9 that conformed to the PE test protocols, SCRT detected all of them (100\%). Of the 4 leaks outside the test configuration, SCRT test protocol methods detected none $(0 \%)$, and alternative SCRT interpretation detected one $(25 \%)$. (*The designated SCRT test configuration is explained in the body of the report.)

- During the PE test there were 7 natural rain events. None of those events were either detected or posed a problem for SCRT procedures. There were no false alarms due to natural precipitation events.

- During the PE test there were 4 artificial rain events and one artificial flood event. None of the artificial rain events were either detected or posed a problem for SCRT procedures. However, the artificial flood event was readily detected and immediately recognized as a non-leak event. So, there were no false alarms due to artificial precipitation events.

- During the PE test the sheet piling was electrically disconnected from and reconnected to the rest of the SCRT injection system. The disconnection was immediately apparent in the SCRT data and recognized as a non-leak event but the cause was only suspected. The reconnection returned the SCRT system to normal operation and was then immediately recognized as the specific activity. No false alarm was associated with the sheet piling event even though leaks were active during the disconnection and reconnection.

- In comparing the SCRT calculated total volume versus the actual test leaks, the calculated total volumes were approximately 33\% too low (this includes the 4 out of specification leaks). Accommodating the out of specification leaks results in a difference of $15 \%$ too low.

- In comparing the SCRT calculated individual volumes versus the actual test leaks, there is a distinct trend indicating last year's calibration could be improved.

- Design, development, and deployment of the remote operating system was accomplished prior to test startup and operated nearly flawlessly for the duration of the test.

\section{C.2 Introduction}

Background information for the Mock Tank site is readily available elsewhere and is not discussed in this report.

hydroGEOPHYSICS acquired HRR-SCRT data and dynamically monitored the induced "leaks" during the 110-day PE test period starting July $22^{\text {th }}$ and ending November $9^{\text {th }} 2002$. 
Two electrical geophysical methods were active for the duration of the PE test. The two methods were: HRR-SCRT and ERT. The ERT method was sub-divided into: a.) point-electrode ERT and b.) long-electrode ERT. LLNL was responsible for both the ERT methods. The instrument system was modified to be remotely controlled and was used alternately between HGI and LLNL.

HGI acquired approximately 3.8 million data points (approx. 11,100 consecutive data sets) for the entire PE test including all electrode combinations. Typically, one day's worth of measurements consisted of 22 hours of continuous data acquisition, or, 88 data sets. Repetitive measurements were made, roughly, every quarter-hour with the exception of time allocated to ERT measurements and equipment-down times.

HGI personnel who completed the field data acquisition portion of the survey were Mr. Marc Levitt, Geological Engineer, and Dr. James B. Fink, President. Subsequent processing was performed on-site and in the Tucson office by Mr. Levitt, Mr. Baldyga, and Dr. Fink.

\section{C.2.1 Basic Principles}

The basic principles of electrical geophysical leak detection have been discussed at varying length in other reports. The most relevant discussion is included in the white paper prepared for the S-112 study during May 2002. The report is titled "Details of Data Collection, Processing, and Interpretive Techniques Planned for FY 2002 LDMM for HRR-SCRT: Performance Evaluation Testing" and is incorporated in this report as Appendix A. Subsequent references to this report will cite it as the "S-112 White Paper". The basic principles of electrical geophysical methods are covered in the Glossary of that report.

The HRR-SCRT method involves a combination of measurements normally associated with different electrode arrays and applications other than leak detection. HRR-SCRT uses both installed surface (point) electrodes, metallic well casings as (linear) electrodes, and direct contact with the potentially leaking solution (although due to a broken wire on the solution-tank electrode found during dismantling, there is some question as to whether this remained consistent throughout the test). The surface electrodes may be in linear arrays but are preferably arranged in two-dimensional grids. HRR-SCRT makes temporal measurements using various combinations of the above configurations where all electrodes are monitored for temporal changes. By spatially monitoring temporal changes dynamic characteristics of the progression of the leak may be determined and, if the arrangement of electrodes allows, a dynamic threedimensional model can be produced.

\section{C.2.2 Relevant Prior Applications}

The most relevant prior applications of the HRR-SCRT method are the previous HRR-SCRT studies performed at the Mock Tank in 2001 and at the Sisson and Lu site in 2000, 2001, and 2002. Historically, similar methods were deployed at tank farms in the 1970's by The Boeing Company. 
Boeing developed a leak detection system that was deployed at tank farms in the 1970s and showed great merit. After the down-selection meeting in January 2002 several reports and memos were found through the Records Information Management (RIM) RMIS system that pertain to the deployment and evaluation of the Boeing Leak Detection system. Many of those reports and memos cited various pros and cons for the Boeing Leak Detection system. Relevant comments were presented in the "S-112 White Paper" in Section 3.0 titled "Background". Concurrently, Battelle Pacific Northwest Laboratory also developed a leak detection system but little information has surfaced regarding that system.

\section{C.2.3 Site Location}

The U. S. Department of Energy's (DOE) Hanford Site is located approximately twenty miles northwest of the town of Richland, Washington. Access to the Site is by all-weather paved roads and a short dirt road. The surrounding area is relatively flat and populated with sagebrush. Remote electrode locations were placed well away from any cordoned-off radiological hazard areas and accessed by walking through the sagebrush. Figure C.1 shows a comprehensive site map that includes geophysical and site infrastructure.

\section{C.2.4 Survey Area \& Logistics}

From a geophysical standpoint, the Site is readily accessible and posed few logistical problems in acquiring data. One complication that is noteworthy for future investigations is that all of the four steel casings installed specifically for this test were covered with a rust-resistant coating. We confirmed that the southwest, northwest, and northeast casings had narrow longitudinal strips of the casing insulation abrasively removed prior to installation. We have been unable to determine if there is a difference in the grounding characteristics between the three treated and one untreated casings. Interestingly, data acquired using untreated casings (including those at the Sisson and $\mathrm{Lu}$ site) were quite similar in character (for time series analysis) but differed in magnitude, which we attribute to geometrical relationships with the energizing source. The polarity of the SE casing data is almost always opposite to that of the other three casings. We initially suspected some geometrical differences with that casing but subsequent observations suggest additional anomalous conditions in the ground in the vicinity of the SE casing. Although this problem remains unresolved at this time, the proximity of the pipelines detected by ground penetrating radar (GPR) in 2001 may provide an explanation. More needs to be done regarding the precise location of the pipelines, what type of pipelines they are, and how they might interact with the southeast casing. Their presence and proximity to the southeast casing may be an inadvertent blessing in that they would be an additional cultural interference similar to those that are anticipated in the tank farms. As will be seen, the polarity of the response associated with the southeast casing is of little consequence in the processing and interpretation of the SCRT data. 


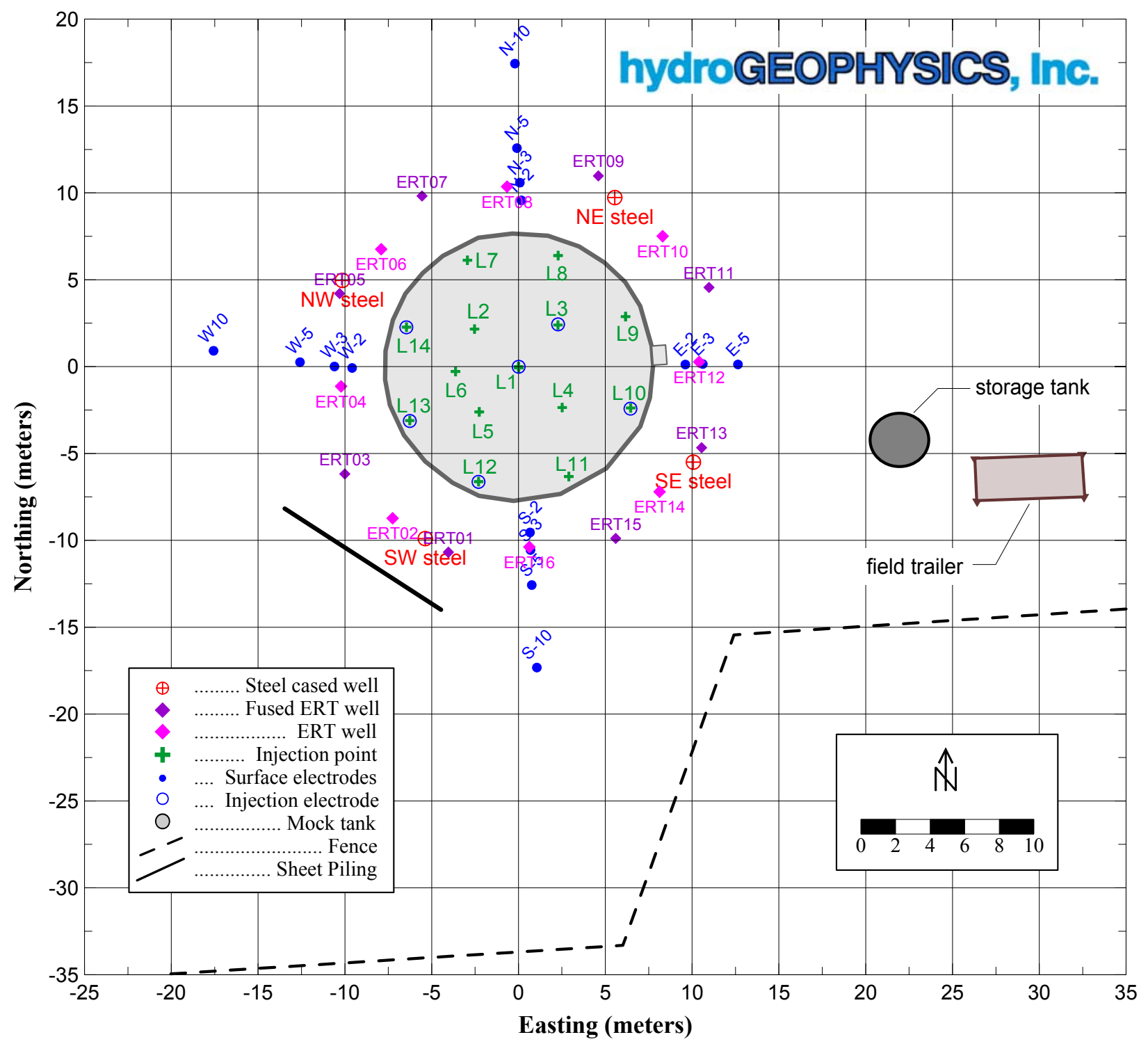

Figure C.1. Plan map showing the location of the mock tank, the four steel casings, the surface electrode array, injection ports, and other relevant features for the 2002 LDMM PE Test

\section{C.2.4.1 Differences between the Mock Tank and Tank Farm tanks}

The mock tank differs from the tanks at the tank farms in a few important ways.

1. The mock tank is smaller than the tank-farm tanks (50 feet in diameter versus 75 feet).

2. The mock tank is only buried a few feet compared to the entire tank being buried at the tank farms. And, what may ultimately be a critical difference, the mock 
tank is not entirely encapsulated in concrete and asphalt as are the tank-farm tanks. The concrete encapsulation exposed at the base of the outside of the mock tank only extends beneath the mock tank for a few feet. The tank-farm tanks are fully encapsulated in concrete with some rebar and remesh enclosed within the concrete. The encapsulation sequence from inside out is: steel tank ( $1 / 2$ " steel plate), asphaltic membrane (3/8" thick), gunite containing steel mesh (5/8" thick), concrete containing two layers of rebar (15" thick), another asphaltic membrane layer (3/8" thick), and a gunite layer with one layer of steel mesh ( $3 / 4$ " thick).

3. The mock tank has a relatively large area of the steel bottom in direct contact with the underlying soil. This is substantially different from the tank farms. The relative ease with which the mock tank can be electrically grounded (through its bottom) may not be realized at the tank farms because of the encapsulation, except in unusual leaking conditions. The mock tank bottom is made up of steel plates tack-welded together. The mock tank will not hold liquid.

4. All "leak" simulations were made using a rubber hose that injected solution into "leak ports". The leak ports consist of 6" steel tubing that extends through the tank bottom and penetrates to a depth of up to 3 feet. Unlike an actual tank, the solution is only in contact with the leak port exit and not the entire surface area on the inside of the tank itself. This is an important difference because it makes simulation of a direct electrical solution contact by way of the thermocouple trees difficult. In an actual tank the thermocouple tree is immersed in the solution and salt cake, and has a relatively large surface area. In turn, we assume that the solution is in contact with a very large area of the inside of the tank. In an effort to most accurately simulate an interface between the solution and tank (as in an actual tank farm), we installed injection port electrodes in the 5 locations established by the test director for injection (see Figure C.1) and an additional electrode within the solution storage tank, the combination of which, when shorted together, we hope will simulate a Tank Farm tank thermocouple tree. It must be understood that the shorted combination of the solution electrode, the injection port electrodes, and the tank, as a whole, is the closest we can approximate a true tank condition. Any deviation from this arrangement, such as injecting solution in an uninstrumented port (as was done during the test) or disconnecting the solution electrode (which also may have happened), alters the simulation to an unknown degree and violates the conditions of closest approximation. Finally, to complete the tank farm simulation, we connected the thermocouple tree simulation to the tank and the sheet piling. Again, all of these electrical contacts shorted together comprise what we call the injection electrode sensor and, we believe, represent the closest possible electrical approximation to tank farm conditions. 


\section{C.3 Methodology}

\section{C.3.1 Equipment}

All geophysical equipment was housed within a climate-controlled, portable field trailer that was located approximately 100 feet southeast of the Mock Tank. Previous experiments were performed from the "Mobile Ecology Bus" which was located approximately 25 feet north of the Mock Tank. New extension cabling and a new patch panel had to be constructed as a result of the new equipment location.

\section{C.3.1.1 Electrodes, Sensors, and Grounding Points}

Points of electrical contact with either the earth or solution are referred to in this report variously as electrodes, sensors, and grounding points. Each term has a subtle distinction from the others. In a generic or systems sense, all items through which the system acquires data are effectively sensors. Regardless of whether they are installed stainless steel electrodes, a simple connection to the tank, or a connection to a steel casing, they are still sensors. They are not all necessarily grounding points in the electrical sense, for example, the electrode suspended in the injection solution when the injection is turned off is not a grounding point, but, it is still a sensor. We refer to any direct contact with the earth as a grounding point. This includes the sheet piling, the mock tank, the steel casings, and installed electrodes. We generally refer to installed stainless steel stakes electrodes, although they are indeed sensors and grounding points. We apologize for any confusion this causes as we, unfortunately, tend to use the terms interchangeably.

\section{C.3.1.2 Cabling}

New cabling was installed in order reach the new trailer location and to combine both ERT and HRR-SCRT sensors into one system. Eight cables (approx 125 feet long) consisting of 18-gauge, 25-conductor, insulated wire were used to accommodate the 84 electrodes (ERT \& SCRT). One end of the cable was connected to either the original ERT patch panel (located along the north edge of the Mock Tank) or the individual HRRSCRT sensor wires. The other ends were then connected to a newly fabricated patch panel that could accommodate the increased number of sensors.

\section{C.3.1.3 Patch Panel}

HGI fabricated a new patch panel to accommodate both ERT and HRR-SCRT sensors. The new panel was constructed using a commercial grade, weather proof, electrical connection box. Female "banana jacks" were installed in two groupings. The top grouping (128) was reserved for ERT sensors and the bottom grouping used for HRRSCRT sensors. Each sensor was connected to a specific contact on the patch panel. Jumpers connected the appropriate contacts on the patch panel to the appropriate channels on the multiplexers. Figure C.2 shows the construction of the panel. Figure C. 3 shows a wiring diagram illustrating the connection of the 8 cables to the patch panel. 

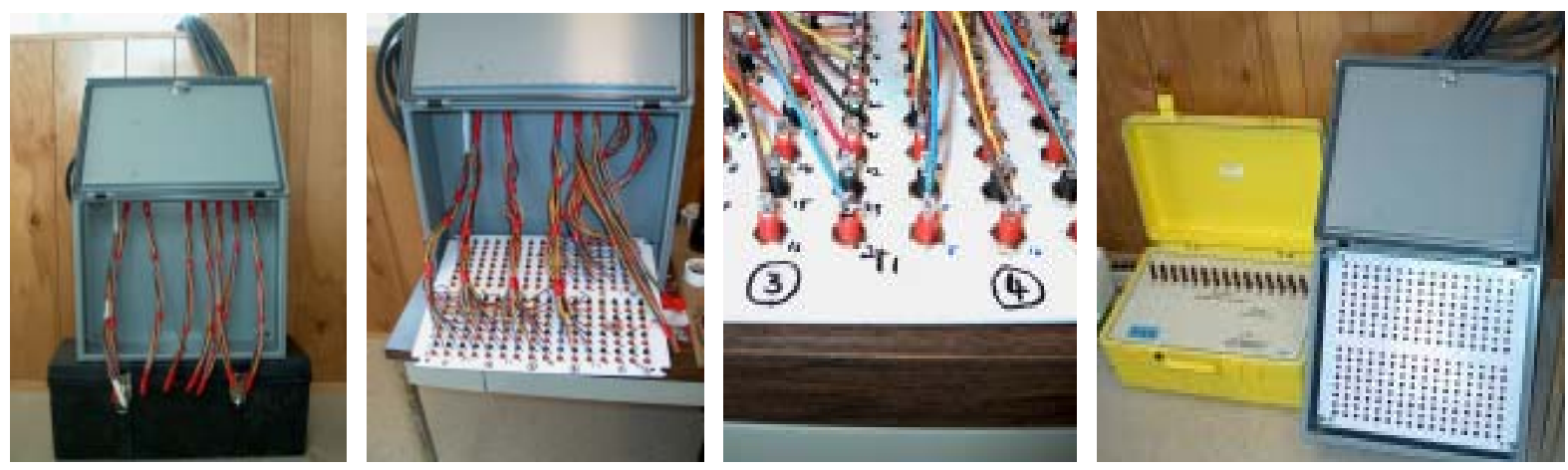

Figure C.2. Construction of New Patch Panel

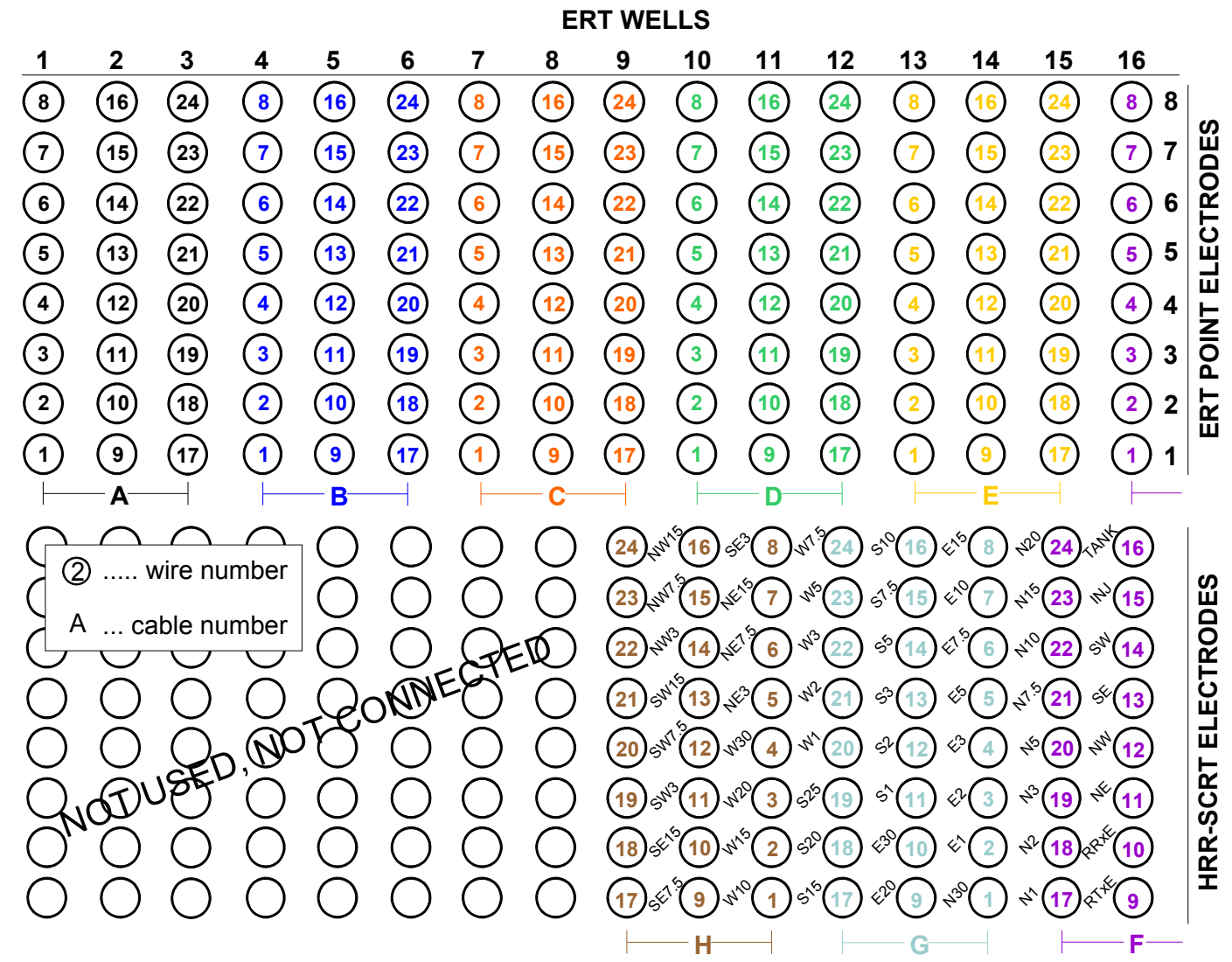

Figure C.3. Patch Panel Wiring Schematic

\section{C.3.1.4 AC power}

A 480 volt, three-phase, alternating current (VAC) service was provided by PNNL to the mock tank site for the PE test. This allowed $120 \mathrm{VAC}$, single phase power to be available for necessary instruments and computers. All instruments that used 120 VAC were 
provided power through two 1,500 watt, ungrounded, isolation transformers provided by HGI. Power was then routed from the isolators to a uninterruptible power supply (UPS), which could supply backup power for approximately 3-5 hours. The UPS provided sufficient power to continue operations during a few power surges and two complete power failures. Figure C. 4 shows the installation of site power.
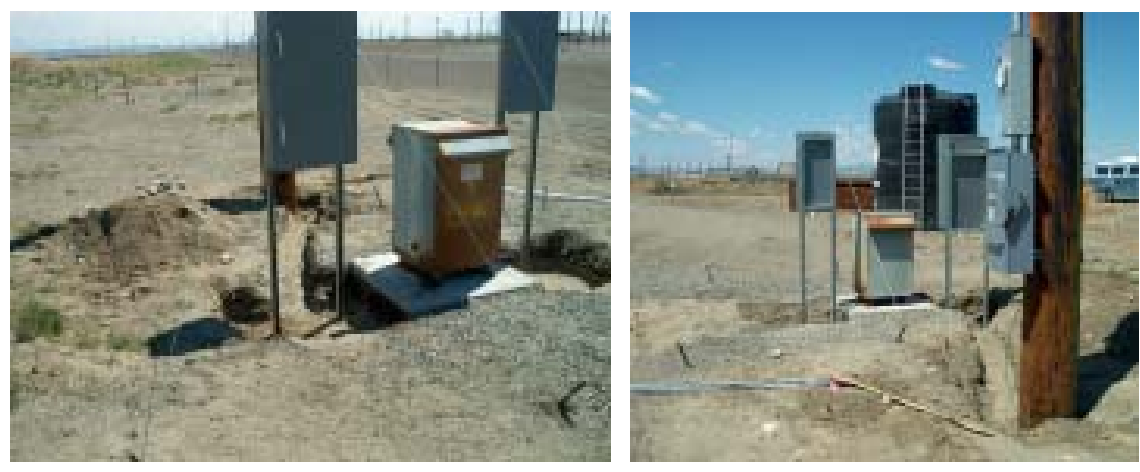

Figure C.4. Installation of Site Power

\section{C.3.1.5 Network}

The duration of the 110 day field test necessitated remote computer operations via telephone and/or internet communication. Both telephone and high-speed DSL internet services were provided by PNNL along with appropriate HLAN access. An onsite virtual private network (VPN) was established to allow remote operations. A VPN uses a public network like the internet to connect remote sites or users together. Instead of using a dedicated, real-world connection such as a static phone line, a VPN uses digital encryption to direct information between two sites. Because such technology uses the internet as the information transfer system, one can conceivably access, control and maintain the geophysical system from almost any secure computer around the world. Timbuktu software was used to manage all remote operations.

\section{C.3.1.6 Computer / Software}

The geophysical resistivity system (GDP-32-II, the ZT-32, and all three MX-30s) were controlled by a personal computer running Zonge's ZETA software (ZETA package, Version 4.01 - 4.05). This computer was, in turn, controlled remotely by computers at HGI's offices in Tucson, Arizona and at LLNL's offices in Berkeley, California through VPN connections (see section 3.1.5 for an explanation of VPN). The ZETA software was modified to allow the simultaneous control of three multiplexers. This innovation allowed both ERT and HRR-SCRT measurements to be acquired using one geophysical system. Multiple versions of the beta software were released in the months prior to the commencement of the PE test. Version 4.05 was used consistently after the first week of the PE test with favorable results. 


\section{C.3.1.7 Resistivity System}

All previous HRR-SCRT and ERT test work used separate resistivity instruments and separate sensor connections. However, the added complexity of the 110 day test prompted the need for a single resistivity system that would allow connection to both HRR-SCRT and ERT electrodes. The system needed to:

1. connect up to 90 electrodes,

2. have a dynamic range suitable for both pole-pole and dipole-dipole electrode arrays,

3. be suitable for remote and nearly autonomous operation,

4. collect multiple electrode data very rapidly

Ultimately we chose to use a combination of LLNL's resistivity instrument (GDP-32-II) and two multiplexers (MX-30), as well as purchase an additional multiplexer. Each MX30 can connect to 30 sensors, the combination of the three providing up to 90 sensor connections. The existing Zeta software, which is used to control the data acquisition by synchronizing the transmitting and receiving signals, was modified to allow the simultaneous control of three multiplexers.

Both the GDP-32-II and MX-30's were connected to a field desktop computer via serial cables. The Zeta software was used to collect a pre-programmed sequence of measurements organized via a schedule-file. HRR-SCRT and ERT had different schedule-files that pertained to the individual electrode configurations. Each schedulefile when completed would constitute a unique data set and multiple schedule-files were combined to allow continuous operation.

The resistivity system was made up of a high voltage power supply (3.1.7.1) which supplied current to a transmitter (3.1.7.2) which was optically isolated (3.1.7.3) from the receiver (3.1.7.4). The receiver was connected to three multiplexers (3.1.7.5) which in turn were connected to the various sensors. Figure C.5 shows a schematic of the resistivity system. 


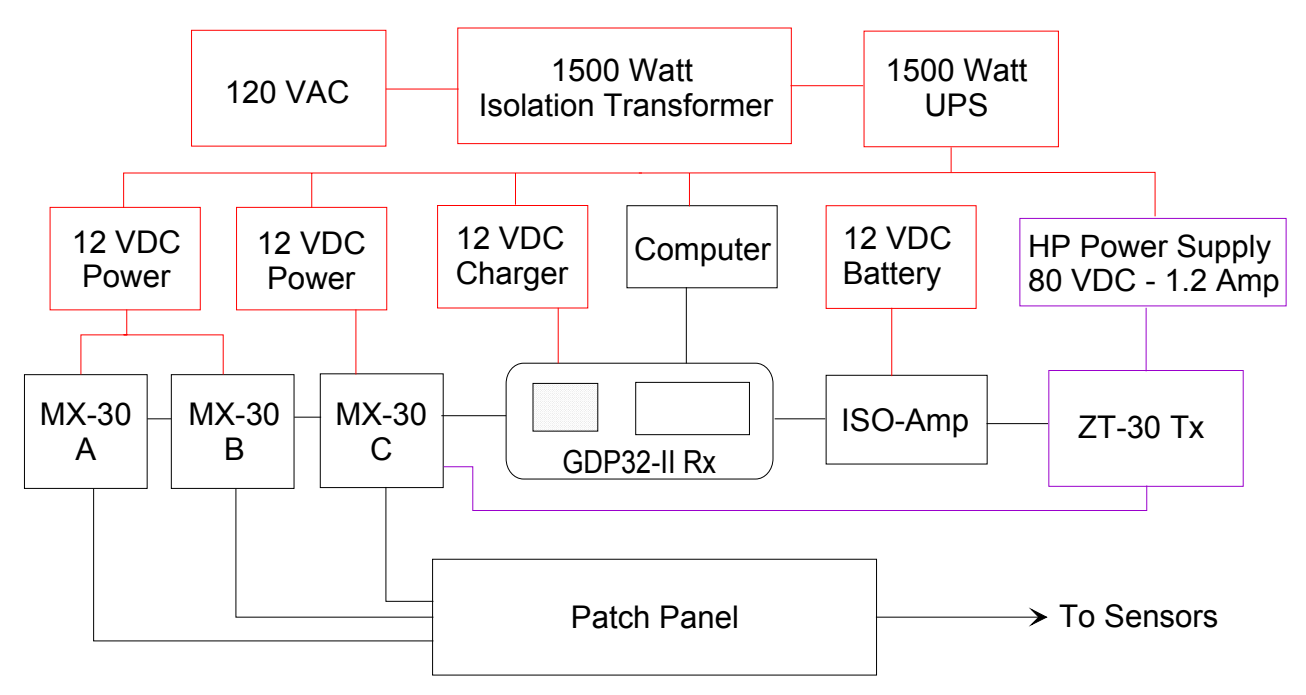

Figure C.5. Schematic Resistivity Instrument

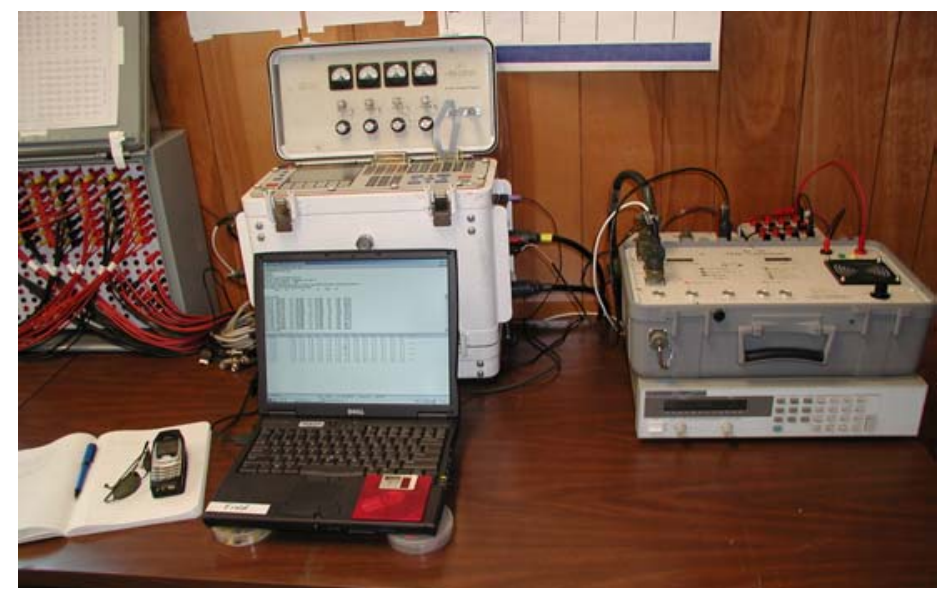

Figure C.6. Shows Resistivity System Setup with HP Power Supply (bottom right), Transmitter (top right), Remote Computer (bottom center), Receiver (top center) and Patch Panel (far left)

\section{C.3.1.7.1 High voltage power supply}

Hewlett Packard direct current (DC) Power Supply was used to generate a current and voltage signal. The power supply required 120 VAC. Nominal output was 80 volts at 1.0 amps. This current level was determined to be optimal for the combined operation of ERT and SCRT. Because of the array differences between the two systems the dynamic range needed was large. The ERT system uses a "dipole-dipole" arrangement requiring substantial current to generate an adequate signal at the receiving sensors. On the other hand, SCRT uses a "pole-pole" arrangement requiring far less current to generate an equivalent signal. This should be a consideration at the tank farms where current and voltage levels are a concern. 


\section{C.3.1.7.2 Transmitter (tx) ZT-30}

The output from the power supply was controlled by a Zonge ZT-30 transmitter controller. The ZT-30 converted the DC signal output into a 50 percent duty cycle, alternating polarity (i.e. + and -), square wave. The transmitter was controlled by the GDP-32-II receiver (rx) which provided timing pulses to synchronize the tx and rx. However, the actual communication was made through a isolation amplifier to avoid ground loop interference. The ZT-32 was powered by a DC power supply which was driven by 120 VAC.

\section{C.3.1.7.3 Isolation amplifier}

The output signal from the ZT-30 was monitored by the GDP-32-II (rx) through an isolation amplifier (iso-amp). The current amplitude was stored in the rx for calculation purposes. The iso-amp required "clean" isolation and was powered by its own external 12 VDC battery. Occasionally, the external battery would drop below operational level before it was replaced causing system failure.

\section{C.3.1.7.4 Receiver (rx) - GDP-32-II}

The signal receiver and processor was a Zonge GDP-32-II with 16 analog-todigital converters. The GDP-32-II was driven by a 12 VDC power supply which in turn was driven by $120 \mathrm{VAC}$.

\section{C.3.1.7.5 Multiplexer - MX-30}

Three Zonge MX-30, 30 channel, 1000 volt, multiplexers were used in tandem to provide 90 channels of directly accessible earth sensors. The MX-30s were operated from DC power supplies which in turn were driven by 120 VAC. Table 3.1.6.5 shows the relationship between the multiplexer electrode number and the sensor identification.

\section{C.3.2 Sensors}

Sensors consist of points of electrical contact with the earth or injection solution through which data may be acquired. They can be carbon-steel well casings, fabricated stainless steel electrodes, the carbon-steel mock tank, stainless steel screens used on the ERT arrays, or a stainless steel electrode in the high density polyethylene (HDPE) tank containing the solution to be injected.

ERT Well \& Steel Well Casing

Shallow buried electrode

Injection port electrode 
Table C.1. Relationship Between Electrode Number, Multiplexer Channel Number and Sensor Identification

MUX 1

\begin{tabular}{|c|c|c|}
\hline Elec. No. & Mux No. & ID \\
\hline 1 & 1 & $2-1$ \\
\hline 2 & 2 & $2-2$ \\
\hline 3 & 3 & $2-3$ \\
\hline 4 & 4 & $2-4$ \\
\hline 5 & 5 & $2-5$ \\
\hline 6 & 6 & $2-6$ \\
\hline 7 & 7 & $2-7$ \\
\hline 8 & 8 & $4-1$ \\
\hline 9 & 9 & $4-2$ \\
\hline 10 & 10 & $4-3$ \\
\hline 11 & 11 & $4-4$ \\
\hline 12 & 12 & $4-5$ \\
\hline 13 & 13 & $4-6$ \\
\hline 14 & 14 & $4-7$ \\
\hline 15 & 15 & $6-1$ \\
\hline 16 & 16 & $6-2$ \\
\hline 17 & 17 & $6-3$ \\
\hline 18 & 18 & $6-4$ \\
\hline 19 & 19 & $6-5$ \\
\hline 20 & 20 & $6-6$ \\
\hline 21 & 21 & $6-7$ \\
\hline 22 & 22 & $8-1$ \\
\hline 23 & 23 & $8-2$ \\
\hline 24 & 24 & $8-3$ \\
\hline 25 & 25 & $8-4$ \\
\hline 26 & 26 & $8-5$ \\
\hline 27 & 27 & $8-6$ \\
\hline 28 & 28 & $8-7$ \\
\hline 29 & 29 & $10-1$ \\
\hline 30 & 30 & $10-2$ \\
\hline & & \\
\hline
\end{tabular}

MUX 2

\begin{tabular}{|c|c|c|}
\hline Elec. No. & Mux No. & ID \\
\hline 31 & 1 & $10-3$ \\
\hline 32 & 2 & $10-4$ \\
\hline 33 & 3 & $10-5$ \\
\hline 34 & 4 & $10-6$ \\
\hline 35 & 5 & $10-7$ \\
\hline 36 & 6 & $12-1$ \\
\hline 37 & 7 & $12-2$ \\
\hline 38 & 8 & $12-3$ \\
\hline 39 & 9 & $12-4$ \\
\hline 40 & 10 & $12-5$ \\
\hline 41 & 11 & $12-6$ \\
\hline 42 & 12 & $12-7$ \\
\hline 43 & 13 & $14-1$ \\
\hline 44 & 14 & $14-2$ \\
\hline 45 & 15 & $14-3$ \\
\hline 46 & 16 & $14-4$ \\
\hline 47 & 17 & $14-5$ \\
\hline 48 & 18 & $14-6$ \\
\hline 49 & 19 & $14-7$ \\
\hline 50 & 20 & $16-1$ \\
\hline 51 & 21 & $16-2$ \\
\hline 52 & 22 & $16-3$ \\
\hline 53 & 23 & $16-4$ \\
\hline 54 & 24 & $16-5$ \\
\hline 55 & 25 & $16-6$ \\
\hline 56 & 26 & $16-7$ \\
\hline 57 & 27 & ERT 1- SSW \\
\hline 58 & 28 & ERT 3 - WSW \\
\hline 59 & 29 & ERT 5 - WNW \\
\hline 60 & 30 & ERT 7 - NNW \\
\hline & & \\
\hline
\end{tabular}

MUX 3

\begin{tabular}{|c|c|c|}
\hline Elec. No. & Mux No. & ID \\
\hline 61 & 1 & ERT 9 - NNE \\
\hline 62 & 2 & ERT 11 - ENE \\
\hline 63 & 3 & ERT 13 - ESE \\
\hline 64 & 4 & ERT 15 - SSE \\
\hline 65 & 5 & Tank \& Inj \\
\hline 66 & 6 & NE Casing \\
\hline 67 & 7 & SE Casing \\
\hline 68 & 8 & SW Casing \\
\hline 69 & 9 & NW Casing \\
\hline 70 & 10 & N2 \\
\hline 71 & 11 & N3 \\
\hline 72 & 12 & N5 \\
\hline 73 & 13 & N10 \\
\hline 74 & 14 & W2 \\
\hline 75 & 15 & W3 \\
\hline 76 & 16 & W5 \\
\hline 77 & 17 & W10 \\
\hline 78 & 18 & S2 \\
\hline 79 & 19 & S3 \\
\hline 80 & 20 & S5 \\
\hline 81 & 21 & S10 \\
\hline 82 & 22 & E2 \\
\hline 83 & 23 & E3 \\
\hline 84 & 24 & E5 \\
\hline 85 & 25 & Tx Inf \\
\hline 86 & 26 & Rx Inf \\
\hline 87 & 27 & Empty \\
\hline 88 & 28 & Empty \\
\hline 89 & 29 & Empty \\
\hline 90 & 30 & Empty \\
\hline & & \\
\hline
\end{tabular}
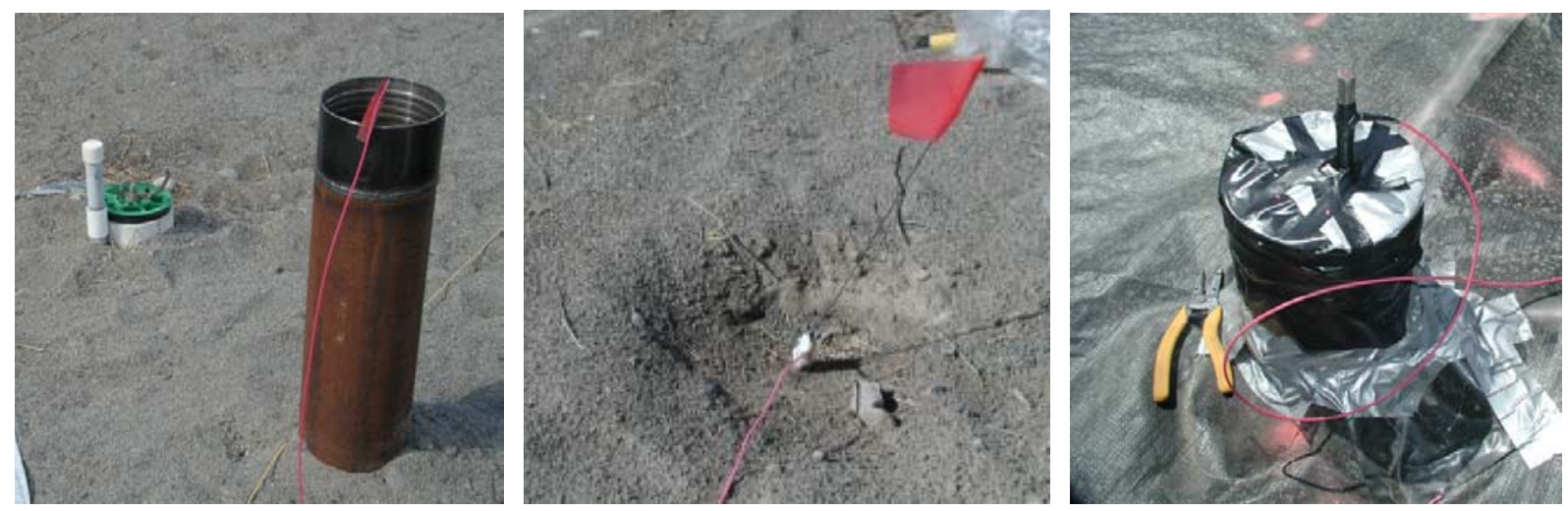

Figure C.7. Various Geophysical Sensors 


\section{C.3.3 Grounding Points and Wire Arrangement}

\section{C.3.3.1 Grounding Points}

A grounding point is considered to be any sensor in contact with the earth through which an imposed electrical signal can be injected into the earth or the resulting electric field in the earth can be measured. At the mock tank, grounding points consisted of:

1. the four carbon-steel casings,

2. the carbon-steel mock tank,

3. the carbon-steel sheet piling,

4. shallow buried stainless-steel electrodes placed in the surface soil (both near-tank and remote reference),

5. stainless-steel electrodes placed in selected injection ports,

6. "fused" stainless-steel ERT electrodes,

7. "point" stainless-steel ERT electrodes

8. and conventional electrical power grounds.

All electrical measurements were made using four grounded electrical contacts at any given time. Two contacts were for current injection and two were for potential measurement. Instrument design allowed 15 simultaneous potential measurements for each transmission. For SCRT measurements, all transmitting and potential measuring electrodes had remotely located counterparts to form the SCRT "pole-pole" arrangement.

\section{C.3.3.2 Wire and Cabling}

Approximately 15,000 feet of combined single and multiple conductor, insulated cable was used for the PE test. Old cabling amounting to approximately 10,000 feet was left in place and partially re-used. Last year's remote reference wiring was re-used. (The remote reference electrodes were approximately 450 meters (1,500 feet) from the tank in two nearly orthogonal directions; west and northeast.) New wire added this year allowed the data acquisition system to be placed in a trailer southeast of the mock tank instead of in the old bus on the north side of the mock tank. New wire added this year connected the new sheet piling to the tank, additional injection port sensors to the tank, a solution-tank sensor to the tank, and the old wiring harness to the temporary instrumentation trailer. The same multi-conductor cabling was used to connect the instrumentation to the ERT arrays. All sensor cabling and wiring was terminated in a temporary patch panel located inside the temporary trailer. For safety purposes all cabling and wires were buried.

\section{C.3.4 Array Configurations}

All HRR-SCRT measurements were acquired using the pole-pole array configuration. The term "pole-pole array" refers to a particular arrangement of four electrodes that places one electrode of each pair very far away from the area being surveyed. These two remote electrodes remain in a fixed location while the two "active" electrodes are moved or varied within the survey area. The remote electrodes have minimal influence on the readings, so, we use the term "pole-pole" 
to indicate that we are only using two active electrodes.

$M$ \& B - remote reference electrodes

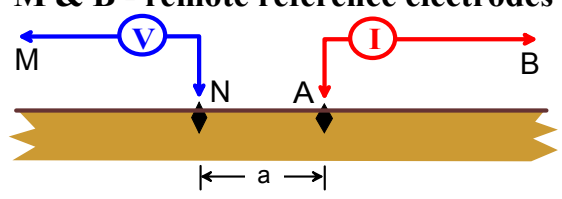

Figure C.8. Schematic of General Pole-Pole Configuration

Electrical measurements were made using four sets of sensors for transmitting and receiving. The four sets consisted of:

1. 15 stainless-steel surface electrodes,

2. the injection system consisting of the tank, 5 electrodes placed in the injection ports designated for the test, one electrode in the solution tank, and the sheet piling,

3. 4 steel casings located around the perimeter of the mock tank, and

4. 8 vertical ERT arrays with their electrodes externally shorted together.

From these four electrode sets several configurations of electrical measurements were employed, although not all were used for the PE test:

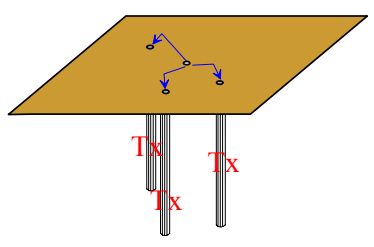

Measurements between steel casings and the injection system. This configuration consisted of energizing the steel casings and measuring potentials with the injection system. For confirmation of the applicability of the methodology to the tank farms measurements in the opposite direction "reciprocal measurements", where the injection system was energized and potentials measured at the steel casings, were also made.

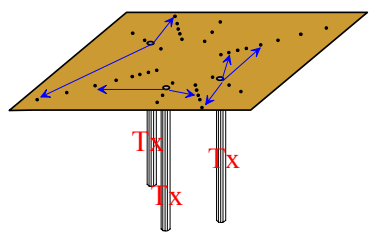

Measurements between steel casings and the surface electrodes. This configuration consisted of electrically energizing each steel casing and measuring potentials at the surface electrodes. Reciprocal measurements were not made.

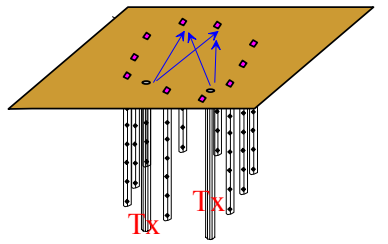

Measurements between steel casings and "fused" ERT electrodes. This configuration consisted of energizing the individual steel casings and measuring potentials at the "fused" ERT arrays. Reciprocal measurements were also made for this configuration. 

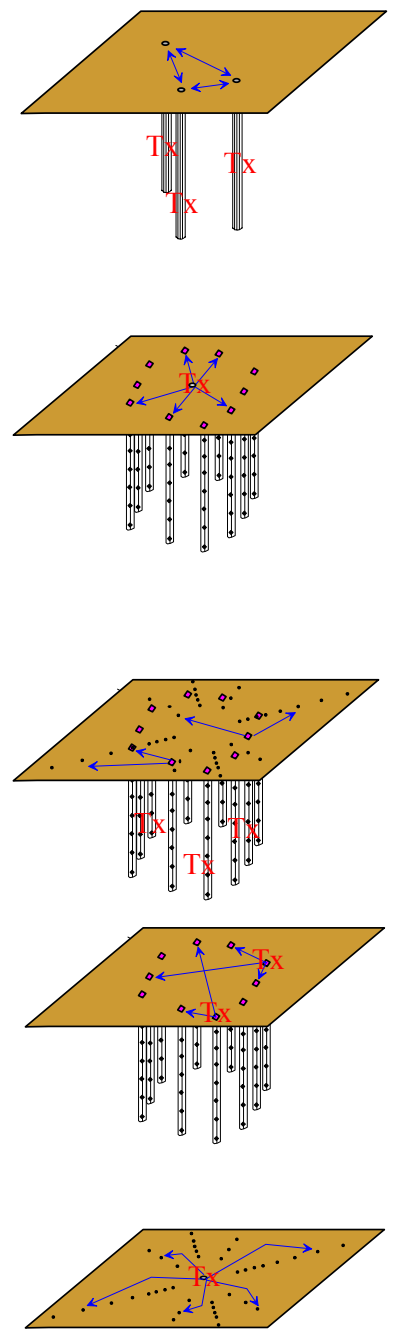

Measurements between steel casings. This configuration consisted of energizing each steel casing and measuring potentials at all the other steel casings. Reciprocal measurements were made.

Measurements between "fused" ERT arrays and the injection system. This configuration consisted of energizing the "fused" ERT arrays and measuring potentials with the injection system. For confirmation of the applicability of the methodology to the tank farms measurements in the opposite direction "reciprocal measurements", where the injection system was energized and potentials measured at the "fused" ERT arrays, were also made.

Measurements between "fused" ERT arrays and the surface electrodes. This configuration consisted of electrically energizing each "fused" ERT array and measuring potentials at the surface electrodes. Reciprocal measurements were not made.

Measurements between "fused" ERT arrays. This configuration consisted of electrically energizing one "fused" ERT array and measuring the resultant potentials at all other "fused" ERT arrays.

Measurements between the injection system and the surface electrodes. This configuration consisted of electrically energizing the injection system and measuring potentials at the surface electrodes. Reciprocal measurements were not made.

More data were acquired than was processed during the PE test, and could be used in further analysis of various configurations at a later stage. As per the PE test protocols four specific data analysis methods were reported each day.

\section{C.3.5 Description of the four analysis methods}

HRR-SCRT data analysis was separated into four methods reported during the PE test as Methods A, B, C, and D. Those methods consisted of variations of the methods presented during the January 2002 Down-Selection Meeting. The two methods presented during the downselection meeting were: perturbation analysis and slope analysis. HGI subdivided each of these categories into two additional categories resulting in Methods A, B, C, and D. 
Two, six and twenty-four hour time-windows were selected for analysis. The time windows were to determine the necessary duration of future Tank Farm monitoring. Unfortunately, diurnal variations were evident throughout all the data. Diurnal problems are minimized when longer analysis windows are used because of the tendency of sinusoidally varying signals to average out. We believe that the diurnal deviations are a function of geophysical infrastructure (e.g. temperature dependence of copper conductors and depth of burial of electrodes) and ambient temperature (e.g. heating and cooling of wire and the ground). HGI had no capability for monitoring and recording temperatures at the mock tank site. Initial attempts to remove diurnal effects produced unfavorable results. Future installations should include both air and ground temperature monitoring.

\section{C.3.5.1 Method A}

Leak detection analysis of data gathered from measurements between the eight fused ERT arrays (surface electrodes are not used).

1. Data reported for a 6-hour window. Additionally, 2-hour and 24-hour windows are reported for comparison.

2. If a contiguous 6-hour window could not be acquired during the designated 24-hour period, then the day was reported as a down day.

3. A leak will be reported if a calculated value shows a statistically significant variation from background at any of three thresholds:

a. if the calculated value exceeds a stable background value by $5 \%$

b. if the calculated value exceeds a stable background value by $10 \%$

c. if the calculated value exceeds a stable background value by $20 \%$

4. No leak volume is calculated or reported for this method.

\section{C.3.5.2 Method B}

Leak detection analysis gathered from measurements between the eight fused ERT arrays and the 15 surface electrodes (steel casings are not used).

5. Data reported for a 6-hour window. Additionally, 2-hour and 24-hour windows are reported for comparison.

6. If a contiguous 6-hour window could not be acquired during the designated 24-hour period, then the day was reported as a down day.

7. A leak will be reported if a calculated value shows a statistically significant variation from background at any of three thresholds:

a. if the calculated value exceeds a stable background value by $5 \%$

b. if the calculated value exceeds a stable background value by $10 \%$

c. if the calculated value exceeds a stable background value by $20 \%$

8. No leak volume is calculated or reported for this method. 


\section{C.3.5.3 Method C}

Slope and perturbation analysis of time series data gathered from measurements between the four steel casings and the injection system electrodes (tank, injection ports, solution tank electrode). Surface electrodes are not used.

1. Data reported for a 6-hour window. Additionally, 2-hour and 24-hour windows are reported for comparison.

2. If a contiguous 6-hour window could not be acquired during the designated 24-hour period, then the day was reported as a down day.

3. A leak was reported if a two-hour segment of the 6-hour window shows a statistically significant variation from background at either of two thresholds:

a. if the calculated value exceeds a stable background value by $2 \%$

b. if the calculated value exceeds a stable background value by $5 \%$

4. A leak volume was calculated whenever a leak was detected.

5. A leak volume was calculated as long as the threshold was exceeded.

\section{C.3.5.4 Method D}

Slope and perturbation analysis of time series data gathered from measurements between the injection system electrodes (tank, injection ports, solution tank electrode) and 15 surface electrodes. Surface electrodes are used to detect any distortions caused by non-leak events (cultural interference).

1. Data reported for a 6-hour window. Additionally, 2-hour and 24-hour windows are reported for comparison.

2. If a contiguous 6-hour window could not be acquired during the designated 24-hour period, then the day was reported as a down day.

3. A leak was reported if a two-hour segment of the 6-hour window shows a statistically significant variation from background at either of two thresholds:

a. if the calculated value exceeds a stable background value by $2 \%$

b. if the calculated value exceeds a stable background value by $5 \%$

4. A leak volume was calculated whenever a leak was detected.

5. A leak volume was calculated as long as the threshold was exceeded.

\section{C.3.6 Data Acquisition}

The electrical data were acquired as continuously as other operations allowed: (1) before any injections were made; (2) during the 110 day injection period; and (3) after the injections were completed. Data acquisition was completed during a single period from July $11^{\text {th }}$ through November $9^{\text {th }}, 2002$.

During the initial setup (background measurements) we tested a variety of hookups between the four steel-cased wells, fused-array ERT electrodes, surface electrodes, injection electrodes, the steel tank, and several instrument configurations to evaluate grounding problems. 
We minimized transmitting on the surface electrodes because of the limited surface area and the tendency for the transmitted electrical signal to consume the moisture surrounding the electrodes. Consequently, the surface electrodes were used as receiving points only and not as transmitter source points.

The system was programmed to acquire consecutive, repetitive data sets for a 24-hour period. The remote control allowed the sequence to be interrupted at any time to run ERT. The sequence was then restarted until the next interruption.

\section{C.3.7 Data Processing}

After the remote control computers and software were implemented, data were downloaded from the Mock Tank site to the local computer. Data were processed with hydroGEOPHYSICS' proprietary software either on-site, in the Richland area, or in the Tucson office. A large part of the processing to date consists of reformatting from the GDP-32-II file format into a format more readily imported into spreadsheets. This stage is referred to as data reduction. Data reduction incorporates:

1. manual editing of spurious data,

2. reformatting data into columnar tables,

3. referencing instrument channel number to sensor identification,

4. separating multiple sets into groups of times,

5. separating the four methods $(A, B, C, D)$ into separate spreadsheets,

6. and appending the spreadsheets into a cumulative database.

We emphasize the importance of distinguishing between two-electrode resistance measurements and four-electrode electric-field (e-field or transfer resistance) measurements. All data acquired for this study are electric-field measurements. The majority of data values presented are voltages normalized to current and have the units of resistance; i.e. volts divided by amps (V/I). However, they are not "true" resistances that would be measured by a two-electrode system (i.e. a standard voltmeter).

Note: Due to the proprietary nature of this topic, a separate Appendix $\mathbf{C}$ will contain a detailed description as provided for the PE Test. This appendix will only be made available to parties who have non-disclosure agreements with HGI.

Time Series graphical plots were generated using processed data using Golden Software's SURFER Grapher 3.0 software. Data were initially organized, edited, and partially processed using MicroSoft's EXCEL 2000 spreadsheet software. 


\section{C.4 Interpretation}

\section{C.4.1 Procedure for Leak Detection}

“Fused" ERT to "Fused" ERT Measurements (Method A)

"Fused" ERT to Surface Electrodes Measurements (Method B)

Overview of approach

Detection is performed by sensing a bulk change in soil moisture content that increases or decreases the potential measurement between sensors. Leak detection analysis is performed from measurements between the eight fused ERT arrays and surface electrodes. Methods A and B are used primarily for leak detection and both methods have no direct solution contact.

\section{C.4.1.1 Which Measurements Were Used}

Measurements between the "fused" ERT arrays were used to acquire data for leak detection; Method A. Measurements between the "fused" ERT arrays and surface electrodes were used to detect any changes in the potential field that surrounds the tank that could be caused by events other than the injected solution; Method B. It was hoped that Method B would aid in separating rainfall events from leak events.

Additionally, measurements between the injection system and steel casings were used for volume and rate determination. However, by definition, a calculated volume implies a detected leak.

\section{C.4.1.2 How the Data Were Processed}

For each day, three analysis periods were analyzed; 2 hour, 6 hour, and 24 hour. Each analysis period consists of multiple data sets each referenced to the starting time of the individual set. The potential data for each analysis window were then differenced to a specified earlier time. The potential difference is presented in terms of percent change and compared to the three predefined threshold values; $5 \%, 10 \%, 20 \%$. Daily leak detection analysis was performed using a fairly large data set. Lengthening the analysis period increases the statistical properties set and therefore increases the accuracy of detection.

\section{C.4.1.3 Algorithms applied to raw data to derive response curves}

Response curves, per se, were not derived for perturbation analysis. However, operational parameters were established that aided in the recognition of perturbations. Those parameters are discussed in Section 4.1.5. For a more detailed description of data processing algorithms, see Section 3.6 (Data Processing).

\section{C.4.1.4 How the Threshold Values Were Derived}

Threshold values are determined by system noise and, in the case of the mock tank test, diurnal thermal variations. When diurnal variations were inconsequential or processed out of the data, system noise proved to be approximately $\pm 0.1 \%$ of the nominal signal 
amplitude. Difference measurements were considered valid if they exceeded local background by $\pm 1 \%$.

\section{C.4.1.5 How the Calibration Factors Were Derived}

Calibration factors were not derived for leak detection. Leak detection requires a sharp change in system response (in the recorded time series) that is different from normal diurnal or other variations.

No calibration is necessary as the response is somewhat arbitrary. The change in system response related to the onset of a leak is sufficient to draw attention to the possibility of a leak being detected. Subsequent leak rate characteristics of the post-perturbation time series that differ from the pre-perturbation time series will confirm that a probable leak has been detected.

\section{C.4.1.6 Processing Time Required to Declare a Volume}

Ostensibly, a leak-related perturbation should be sufficient for detecting a leak. Such a perturbation may be identified within minutes of its occurrence, but, this is entirely dependent on the sampling rate of the system. The subsequent leak rate determines the slope of the time series. Without temperature correction, sufficient data must be acquired to confirm that the new slope of the post-perturbation time series is truly associated with a leak and is not due to system offsets or diurnal temperature effects. Additional confirmation must be acquired by reviewing other components of the system response.

The requisite time needed to confirm a detected leak depends, not only on the temporal characteristics of the system but also on the degree of completeness of the electrode configuration. Too much weight cannot be placed on a system with too few electrodes or grounding points. With the configuration used at the mock tank (without temperature compensation) approximately twenty-four hours was needed to confirm a detected leak. This time period however, is not true "processing" time, particularly when considering perturbation analysis. Perturbation analysis can be performed in real time, if the operator is viewing the data, or automatically with computer control. In either case, perturbation analysis only sets the flag to be followed with slope analysis. With real-time temperature compensation, the time window for leak detection (using both perturbation analysis and slope analysis) may be reduced to a few hours.

\section{C.4.2 Procedure for leak volume and leak rate determination Injection System Electrodes to Steel Casing Measurements (Method C) Injection System Electrodes to Surface Electrode Measurements (Method D)}

The procedure for detecting a leak is what HGI calls "perturbation analysis"; i.e. a rapid change in the system response relative to the preceding time series. "Rapid" means within a few sampling points regardless of the sampling interval. "Change" means a monotonic change of a few to several percent (to exceed the system noise level) within a few sampling intervals. For an example, see Figure C.9 below. 


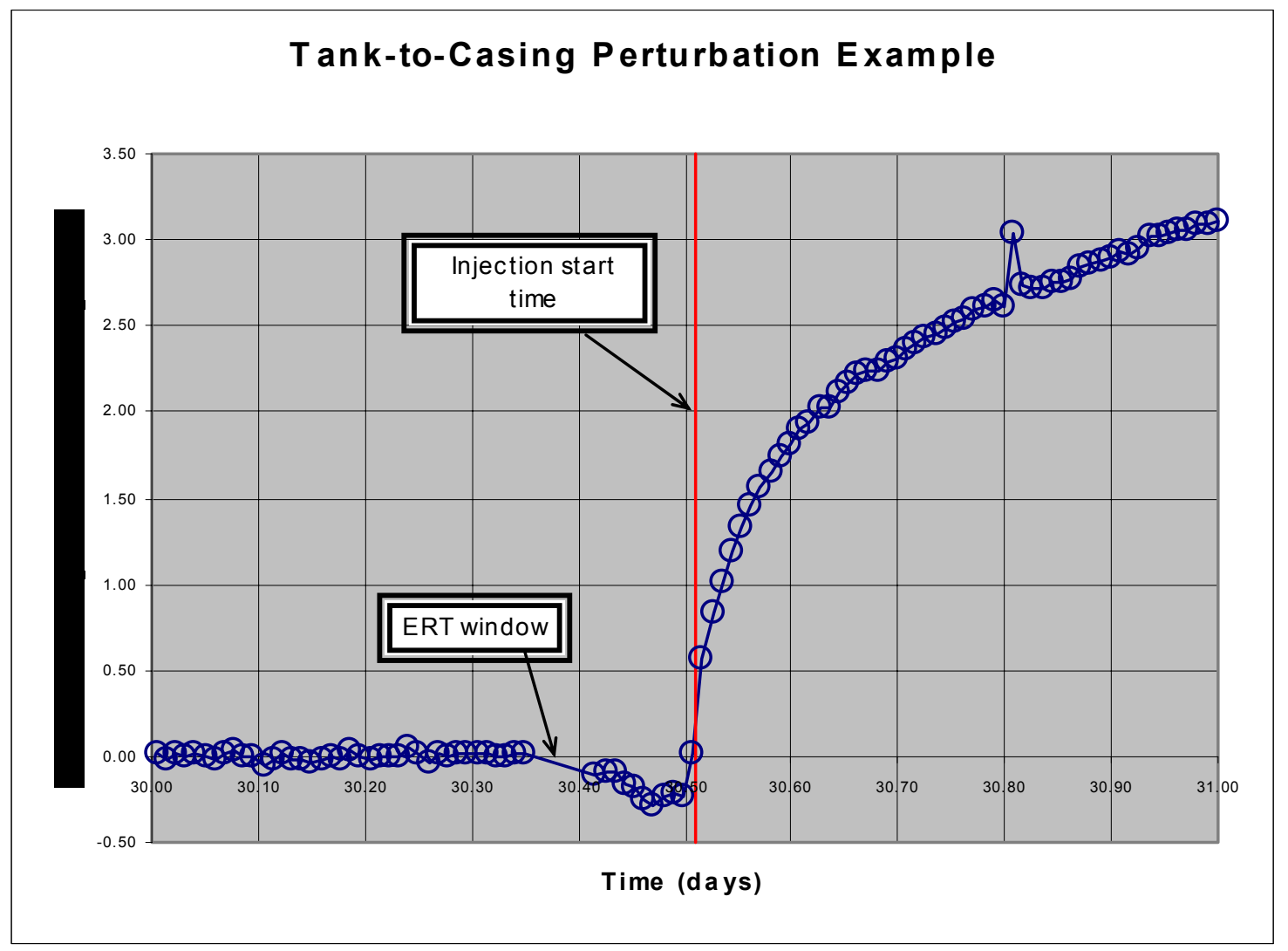

Figure C.9. An example of the Relative Change in Signal Level that Indicates a Perturbation Event upon the Start of a Leak

The data shown in Figure C.9 are unfiltered and minimally processed. Background in Figure C.9 example is equated to zero and the observed data are relative to background. Note that the typical or average noise envelope for the signal trace is substantially less than 1\% (approximately $\pm 0.1 \%)$. The gap in data indicated by "ERT window" is the time during which LLNL acquired their ERT data set for the day. Note that their data "snapshot" occurred prior to the start of the leak and would result in not detecting the leak on this day. The SCRT system response, however, is nearly instantaneous with the onset of the leak.

The monotonic change in the data persists for the remainder of the day. This is strongly indicative, but not necessarily absolutely indicative, of a leak. The objective of perturbation analysis is to alert the operator of a possible leak event.

The slight downward trend in the data shortly after the ERT window is the diurnal thermal effect seen in all data sets. 
During the PE test when the SCRT system was fully connected, perturbation analysis of the data showed rapid changes in nearly all time series observed. Perturbations were consistently significant and showed no degradation due to ground saturation. Indeed, upon termination of each leak event, there was a rapid response in the opposite direction to that of the leak onset. This tendency for the system response to return to previous levels is a good indicator of the progress of the leak in the ground. Although the leak itself has ceased the dynamics of the injected solution continue.

A rapid change in SCRT system response, by itself, cannot eliminate non-leak effects caused by other effects, e.g. altering the system configuration. The rapid change must be followed by a time series of a different and consistent slope than that of the time series preceding the perturbation. There are excellent examples of such changes in the PE test data, but time and budget constraints do not allow their analysis and presentation.

An unscheduled change in the PE test protocol was to inject solution into ports in the mock tank that were not instrumented. In such a situation the SCRT system is incomplete (out of test specifications) and there may or may not be a detectable perturbation associated with the leak. A good example of a non-instrumented port injection is leak " $\mathrm{R}$ " on PE test day 81. Figure C.10 illustrates the failure of the system to detect the onset of the leak.

The specific inter-electrode connections between the steel tank, sheet piling, solution, and injection ports, all of which comprise the injection system, were made to simulate a real tank as closely as possible. Unlike an actual tank, the injected solution is not in contact with the bulk of the tank structure, but rather is released into injection ports that are beneath the tank bottom. Injection port electrodes were installed to compensate for this difference and better simulate an actual tank. Injection into the non-instrumented ports may be interesting from an operational standpoint but deviate from the closest approximation to tank-farm conditions such that it is not representative of tank farm conditions. Such out-of-specification changes should not be incorporated into the performance statistics.

Figure C.10 also shows the relatively small noise envelope which in this case is approximately $\pm 0.2 \%$. A larger temperature variation during this time period offers a slightly larger diurnal thermal response which is approximately $\pm 0.3 \%$. Both of these noise sources are substantially less than the threshold values used for qualitative leak detection and quantitative leak rate estimations. 


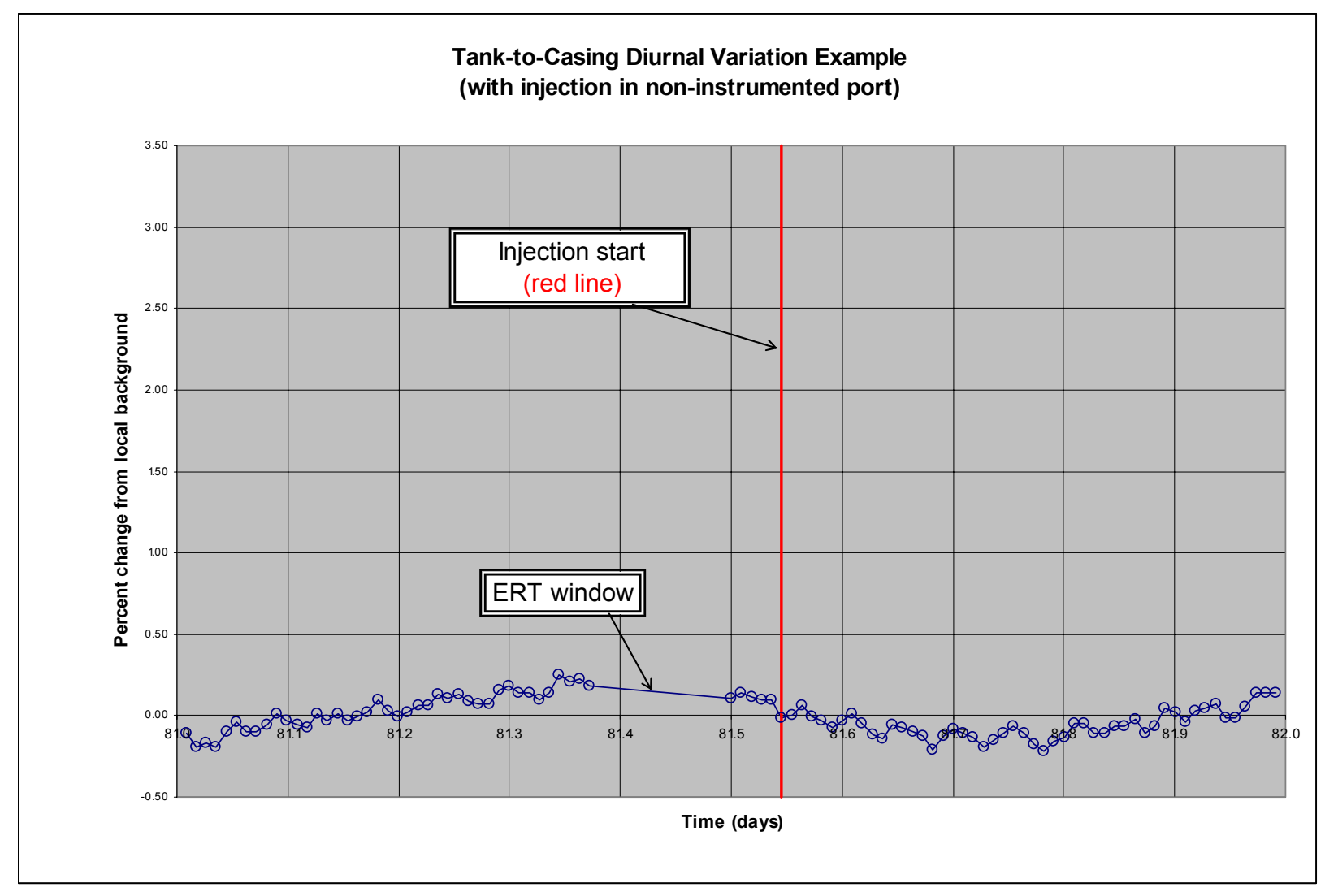

Figure C.10. An Example of the Relative Change in Signal Level that Does Not Indicate a Leak Because the Leak Port Was Not Instrumented. Diurnal variation is more apparent in this example.

\section{C.4.2.1 Overview of approach}

Leak detection is performed by sensing a change in electrical potential between the injection system and steel casings. Volume and leak detection methods use direct contact with the injection system or solution. Because the method has direct contact with the injected solution, it is almost entirely influenced by soil moisture changes caused by leak events.

Perturbations, or rapid changes in amplitude, in the SCRT system response can be due to several causes other than leak events. We observed perturbations caused by two artificial events; 1.) a simulated surface flood event, and 2.) the disconnection of features that comprise part of the grounding system. On the other hand, when the injections were moved to ports that were not part of the PE test protocol and were not instrumented, perturbations were so subdued as to render them undetectable.

Perturbation analysis is an excellent indicator of leaks providing the grounding system is satisfactorily designed, implemented, and maintained. It is not confirmatory. It does, 
however, provide the appropriate cautionary data to minimize the probability of a false alarm.

\section{C.4.2.2 Which Measurements Were Used}

For each method, the relevant time series were used for leak detection; e.g., for Methods $\mathrm{C}$ and $\mathrm{D}$, the injection system electrodes-to-steel casing data were used. Additionally, the injection system electrodes-to-surface data were included for Method D but only for quantitative comparison with the tank-to-casing data to confirm changes of similar magnitude. The tank-to-surface data aided in determining the influence of surface-related noise sources such as flooding and precipitation events.

\section{C.4.2.3 How the Data Were Processed}

Calculated volumes were determined using HGI's slope analysis method. In this process, one fits a linear trend to the potential data contained within each of the three analysis windows $(2,6,24$ hours $)$ and relates the slopes of the three trends to a calibration derived during the 2001 Mock Tank work. Unfortunately, the accuracy of results depend on what portion of the data is used to derive a slope. If a 24-hour analysis period is used and the leak only occurs at 18:00, then the 18 hours of no leak state will reduce the actual slope of the 6 hour portion of the leak. This problem is exacerbated by artificial or cultural events such as "flood" events, as illustrated in the example below (Figure C.11)

Slope analysis could be more accurate if adaptive analysis were incorporated to search for leak periods and then derive slopes from that more-relevant portion. The requirements of the PE test prevented such action but results of such a process can be viewed in Section 5.2.5 (Improved Methods - Time Series Analysis of Method C) and Section 5.6 (Comparison to Test Matrix).

\section{C.4.2.4 Algorithms applied to raw data to derive response curves}

Algorithms applied to raw data are described under Section 3.6, "Data Processing".

\section{C.4.2.5 How the Threshold Values Were Derived}

Threshold values are determined by system noise and, in the case of the mock tank test, diurnal thermal variations. When diurnal variations were inconsequential or processed out of the data, system noise proved to be approximately $\pm 0.1 \%$ of the nominal signal amplitude. Slope analysis trend lines were considered valid if they; 1.) exceeded local background by $\pm 1 \%$. 2.) were monotonic; 3.) had relatively steep slopes (delta $\Rightarrow$ $\pm 0.1 \% /$ minute), and 4 .) were followed by an asymptotic tendency of the new time series to a new slope. 


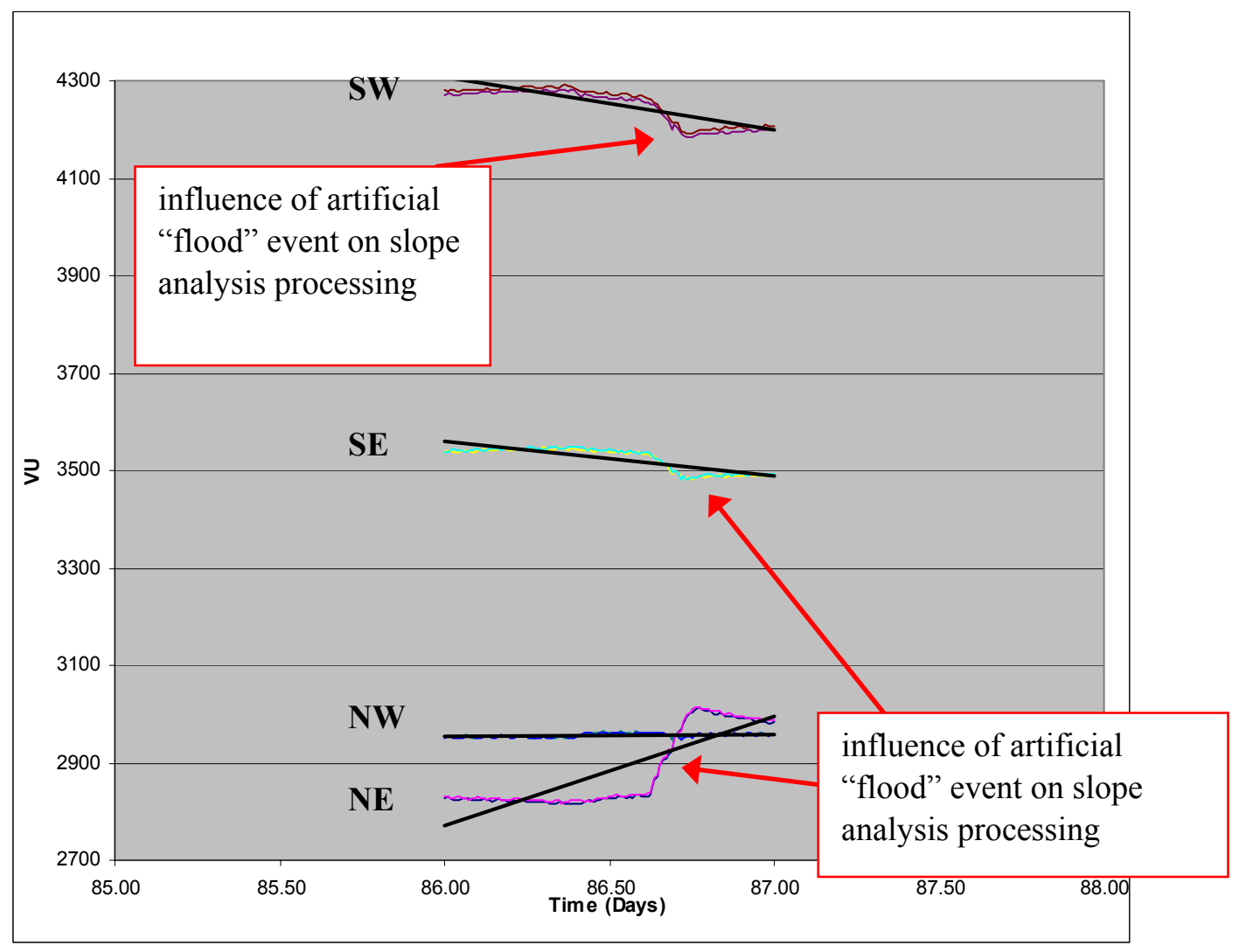

Figure C.11. Example Profile Illustrating the Influence of a Artificial "Flood" Event on HRRSCRT Slope Analysis Processing

\section{C.4.2.6 How the Calibration Factors Were Derived}

The algorithms used in this year's PE Test were modified during the 2001 Mock Tank work. The methodology behind this calibration algorithm was described in last year's report and the remainder of this section includes a copy of that description.

By relating the slope of the potential measurements to known flow volumes, and normalizing to observed time, we derived a linear relationship that appears to allow us to predict a flow rate for a given potential slope. It is interesting to note in Figure C.12 that we are plotting the rate of flow, a first derivative, versus the rate of change of potential, another first derivative. The linear fits to the potential data are a second derivative relating the two rates of changes. Although the flow is occurring in the unsaturated zone, the analogy between Darcy's Law and Ohm's Law is interesting.

The linear relationship is described by the equation:

Flow Rate $=f($ slope of potential measurements $)-$ constant 
With this equation, we were able to fit a line between any two times along our potential measurement curves. Putting this slope into the "flow rate" equation produces a "calibrated" flow rate for that particular time period based on minimally-processed efield data. This is similar to what we did at the Sisson and $\mathrm{Lu}$ site, although at Sisson and $\mathrm{Lu}$ we related estimated volume to potential.

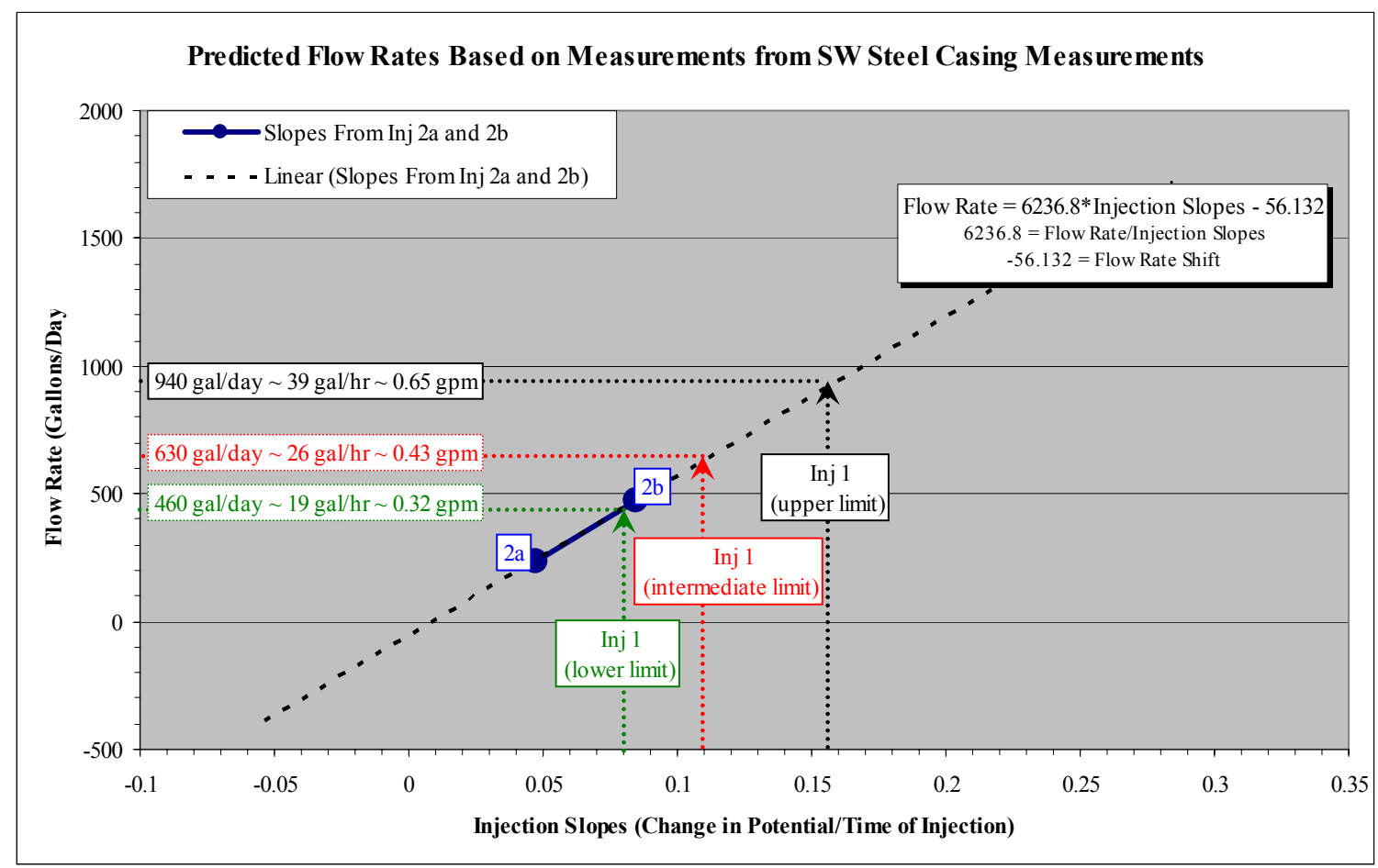

Figure C.12. Flow Rates vs. Injection Slopes

\section{C.4.2.7 Processing Time Required to Declare a Leak}

The analysis time periods used in the PE Test were defined as 2 hour, 6 hour and 24 hour. Processing for volume calculations can be completed in approximately 2 hours for all three analysis windows. Streamlining software could further reduce calculation time to near real-time. Work performed within an actual tank farm should use a real-time adaptive approach where slopes and therefore volume calculations are determined in near real-time and continually improved as the leak reaches various steady states.

\section{C.5 Results}

\section{C.5.1 Leak Detection Performance}

Almost without exception (with the in-specification configuration), every leak was detected. 


\section{C.5.1.1 Method A - "Fused" ERT Wells to "Fused" ERT Wells}

Method A produced the most noise and was the least diagnostic of the four methods. Method A has no direct contact with the injection system or solution. Detection is performed by sensing a bulk change in soil moisture content that increases or decreases the potential measurement between two "fused" ERT wells. It is likely that several of the ERT point electrodes that make up the "fused" wells were faulty. All potential data suffer from diurnal noise that we believe is caused by daily temperature variations. We were unable to correct this problem for the PE test, but in almost all cases, the magnitudes of the leaks were larger than diurnal noise and therefore did not affect leak detection.

The performance of the numeric leak detection for method A is currently under review by VET. Numeric results for Method A were submitted each day (in spreadsheet form) for the duration of the PE test. These results can be viewed in Appendix B.

The method did detect two rainfall events, a flood event, and the sheet piling disconnection and reconnection. It may prove more diagnostic in an actual tank farm implementation to install a digital rain gauge to help distinguish between rainfall and leak events.

Daily leak detection analysis is performed using a fairly large data set. Lengthening the analysis period increases the statistics and therefore increases the accuracy of detection.

\section{C.5.1.2 Method B - "Fused" ERT Wells to Surface Electrodes}

Method B produced unexpectedly clean and rather diagnostic results. Method B has no direct contact with the injection system or solution. Detection is performed by sensing a bulk change in soil moisture content that increases or decreases the potential measurement between a "fused" ERT well and a surface electrode. All potential data suffer from diurnal noise. We were unable to correct this problem for the PE test, but in almost all cases, the magnitude of the leaks were larger than diurnal noise and therefore did not affect leak detection.

The performance of the numeric leak detection for Method A is currently under review by VET. Numeric results for Method A were submitted each day (in spreadsheet form) for the duration of the PE. These results can be viewed in Appendix B.

The method did detect two rainfall events, a flood event, and the sheet piling disconnection and reconnection. Again, it may prove more diagnostic in an actual tank farm implementation to install a digital rain gauge to help distinguish between rainfall and leak events.

Daily leak detection analysis is performed using a fairly large data set. Lengthening the analysis period increases the statistics and therefore increases the accuracy of detection.

\section{C.5.1.3 Method C - Injection System to Steel Casings}

Method $\mathrm{C}$ has direct contact with the injection system or solution and therefore produced the cleanest data and most diagnostic and reliable results. Detection is performed by sensing a change in electrical potential between the injection system electrodes and four steel casings. Because the method has direct 
contact with the injected solution, it is almost entirely influenced by soil moisture changes caused by leak events. As a result Method $\mathrm{C}$ was the least sensitive to rainfall events.

All potential data suffered from diurnal noise that we believe was caused by diurnal temperature fluctuations. We were unable to correct this problem for the PE test, but in almost all cases, the magnitude of the leaks were larger than diurnal noise and therefore did not affect leak detection.

The performance of the numeric leak detection for Method $\mathrm{C}$ is currently under review by VET. Numeric results for Method A were submitted each day (in spreadsheet form) for the duration of the PE. These results can be viewed in Appendix B.

\section{C.5.1.4 Method D - Injection System to Surface Electrodes}

Method D also has direct contact with the injection system or solution and therefore also produced the cleanest data and most diagnostic and reliable results. Detection is performed by sensing a change in electrical potential between the injection system electrodes and surface electrodes. This method was primarily used to detect any changes to the potential field that surrounds the tank that could be caused by events other than the injected solution. It was hoped that Method D would aid in separating rainfall events from leak events. The method did detect two rainfall events, a flood event and the sheet piling disconnection and reconnection. We recommend in an actual tank farm implementation installing a digital rain gauge to help distinguish between rainfall and leak events.

All potential data suffered from diurnal noise. We were unable to correct this problem for the PE test, but in almost all cases, the magnitude of the leaks were larger than diurnal noise and therefore did not affect leak detection.

The performance of the numeric leak detection for Method D is currently under review by VET. Numeric results for Method D were submitted each day (in spreadsheet form) for the duration of the PE. These results can be viewed in Appendix B.

\section{C.5.1.5 Improved Methods}

\section{C.5.1.5.1 Time Series Analysis of Method A}

One can also perform a graphical analysis of the potential data by plotting a time series and visually separating areas of increased change. This method was not included in the PE statistical analysis because it was viewed by VET as subjective because it required interpretation by an individual. However, visual inspection proved to be an extremely useful tool providing accurate results in less time than numeric analysis. Visual analysis is strengthened by allowing the use of previous responses to leak events to enhance subsequent leak identification; a heuristic approach.

The performance of the graphical approach to Method A was quite favorable; detecting all but one leak event. The event that was not detected was a 187 gallon (1.8 gph) event between test day 92 and 96 that was leaked into in un-instrumented port. Two rainfall events, a flood event, and the sheet piling disconnection and reconnection were also detected. 
Figure C.13 shows a graphical time series of "Fused" ERT Well to "fused" ERT well potential data with colored rectangles that represent visually interpreted leak events.

\section{C.5.1.5.2 Time Series Analysis of Method B}

As with modified Method A, graphical analysis of Method B can also be evaluated. The performance of the graphical approach to Method B was quite favorable; detecting all but one leak event. The event that was not detected was a 187 gallons (1.8 gph) event between test day 92 and 96 that was leaked into in un-instrumented port. Two rainfall events, a flood event, and the sheet piling disconnection and reconnection were also detected.

Figure C.14 shows a graphical time series of "Fused" ERT Well to surface electrode potential data with colored rectangles that represent visually interpreted leak events.

\section{C.5.1.5.3 Time Series Analysis of Method C}

As with modified Method A, graphical analysis of Method C can also be evaluated. The performance of the graphical approach to Method $\mathrm{C}$ was extremely accurate; detecting all leaks that were released through ports that were instrumented. All leak events that were not detected were released into noninstrumented injection ports. A flood event and the sheet piling disconnection and reconnection were also detected.

Figure C.15 shows a graphical time series of the injection system to steel casing potential data with colored rectangles that represent visually interpreted leak events.

\section{C.5.1.5.4 Time Series Analysis of Method D}

As with modified Method A, graphical analysis of Method D can also be evaluated. The performance of the graphical approach to Method D was fairly accurate; detecting all leaks that were released through ports that were instrumented with electrodes. All leak events that were not detected were released into non-instrumented injection ports. A flood event and the sheet piling disconnection and reconnection were also detected.

Figure C.16 shows a graphical time series of the injection system to steel casing potential data with colored rectangles that represent visually interpreted leak events.

\section{C.5.1.6 Fused Arrays Versus Steel Casing Electrodes}

No attempt was made to quantitatively or qualitatively evaluate the performance difference between the "fused" ERT wells and steel casings during the 2002 LDMM PE Test. The data required to perform such an evaluation are on file should the need arise.

Of similar interest is the grounding difference between the steel casings and "fused" ERT wells. This topic was studied extensively during the 2001 Mock Tank work and is documented within that report. 
METHOD A - HRR-SCRT: Fused ERT Well to Fused ERT Well Measurements

hydroGEOPHYSICS, Inc.

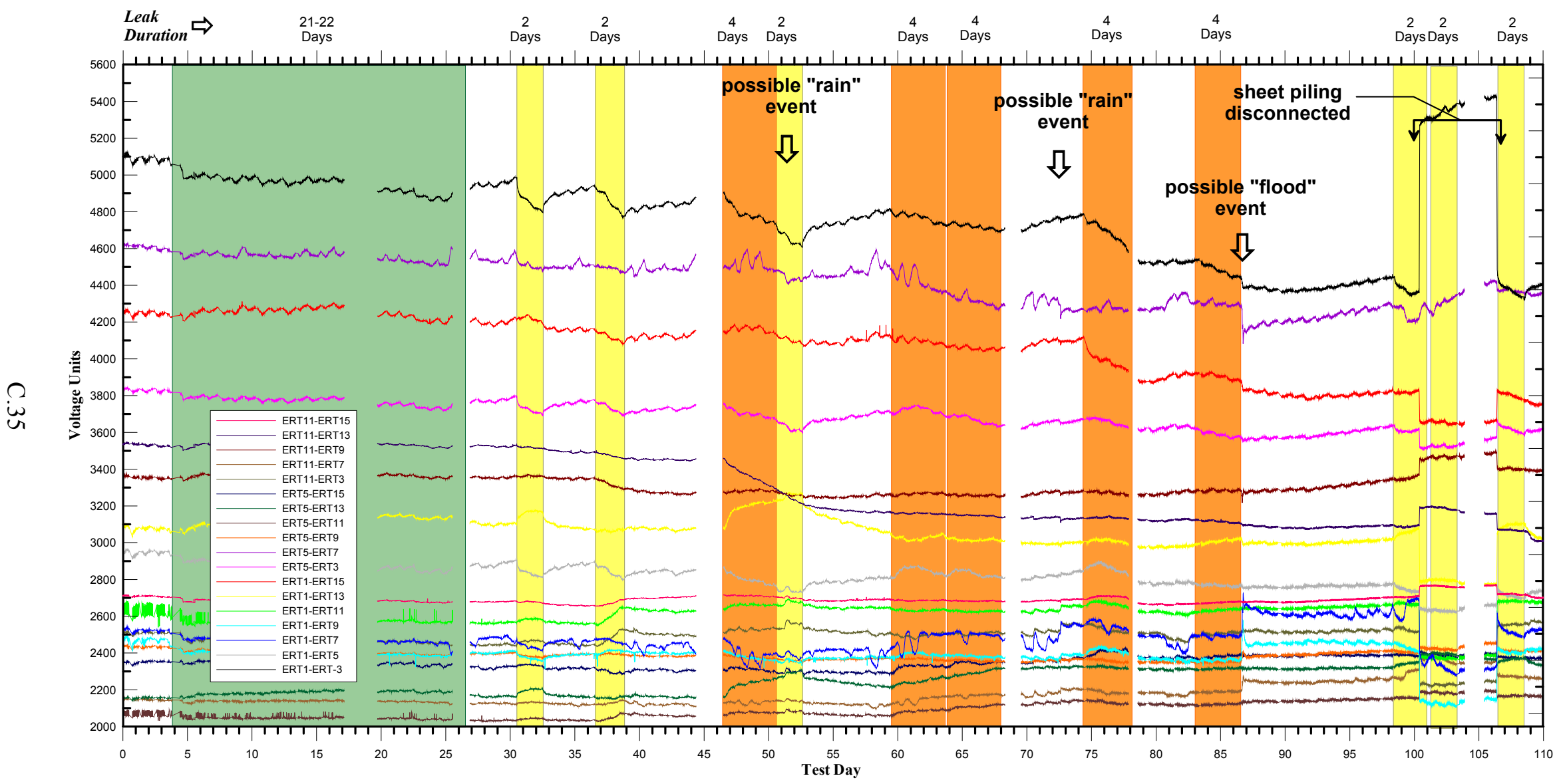

Figure C.13. Interpreted Leak Detection Time Series of "Fused" ERT Well to "Fused" ERT Well Potential Measurements 


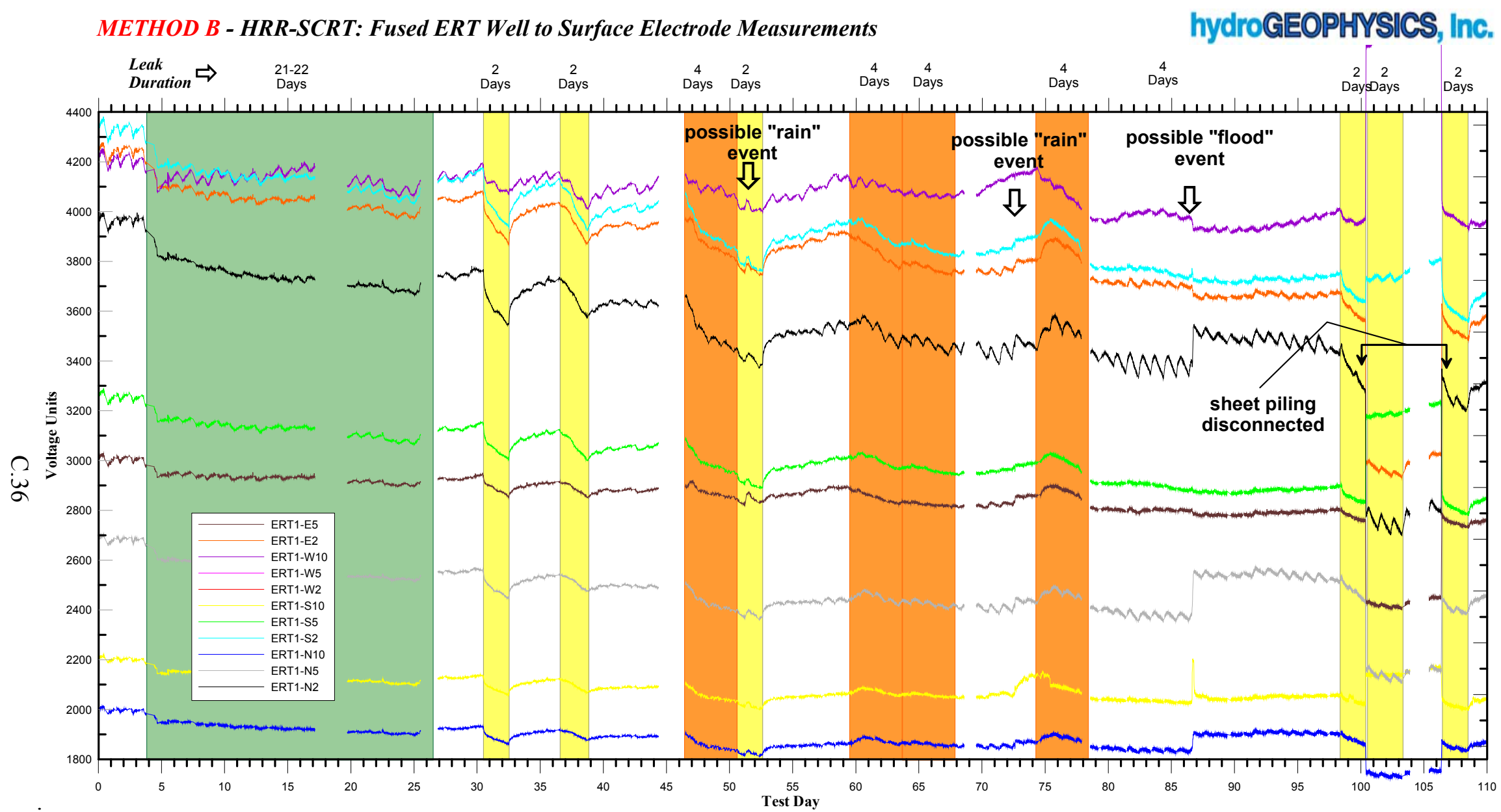

Figure C.14. Interpreted Leak Detection Time Series of "fused" ERT Well to Surface Potential Measurements 


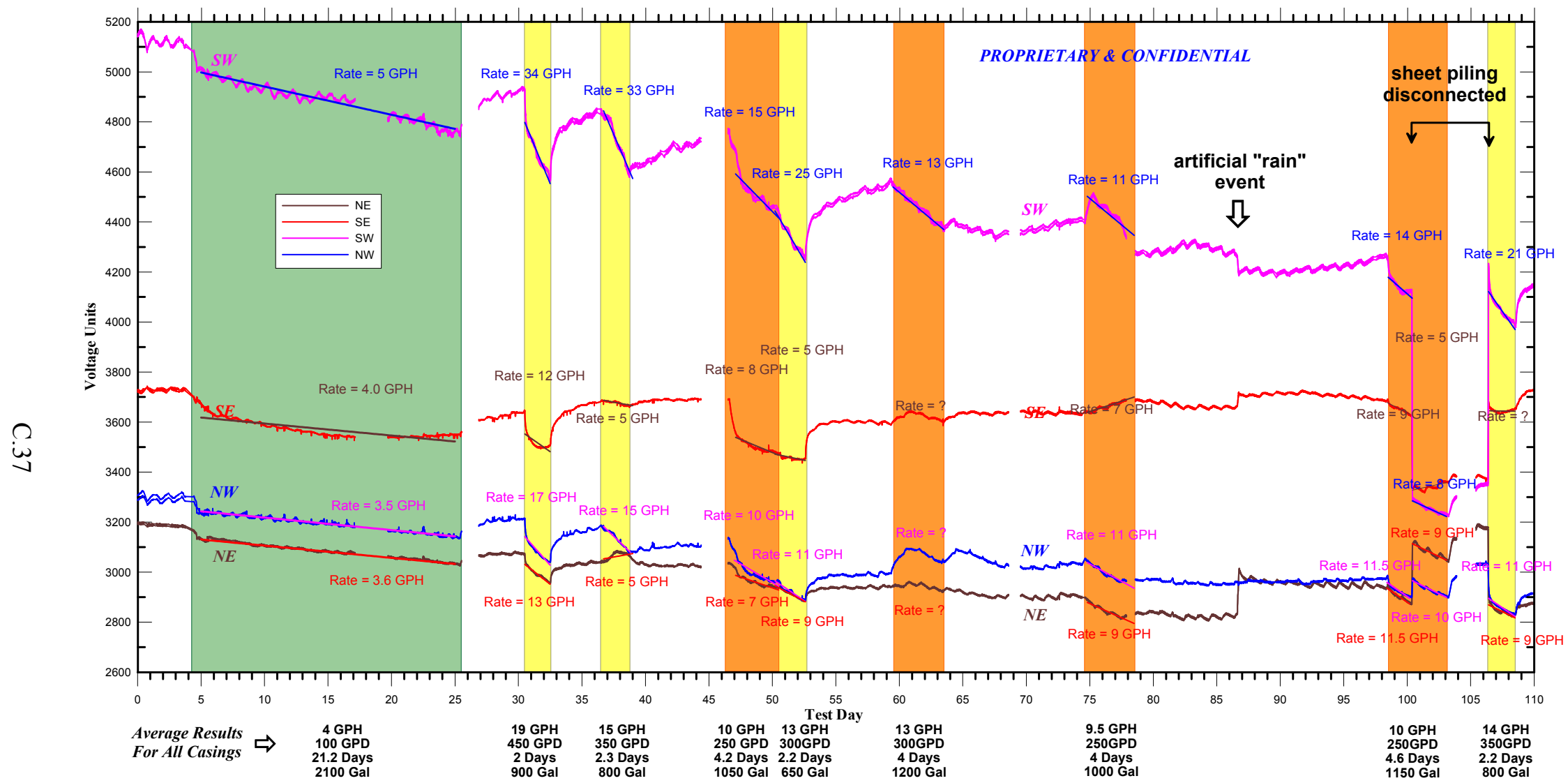

Figure C.15. Interpreted Leak Detection Time Series o Injection System Electrodes to Steel Casing Potential Measurements 
METHOD D - HRR-SCRT: Tank to Surface Electrode Measurements

hydroGEOPHYSICS, Inc.

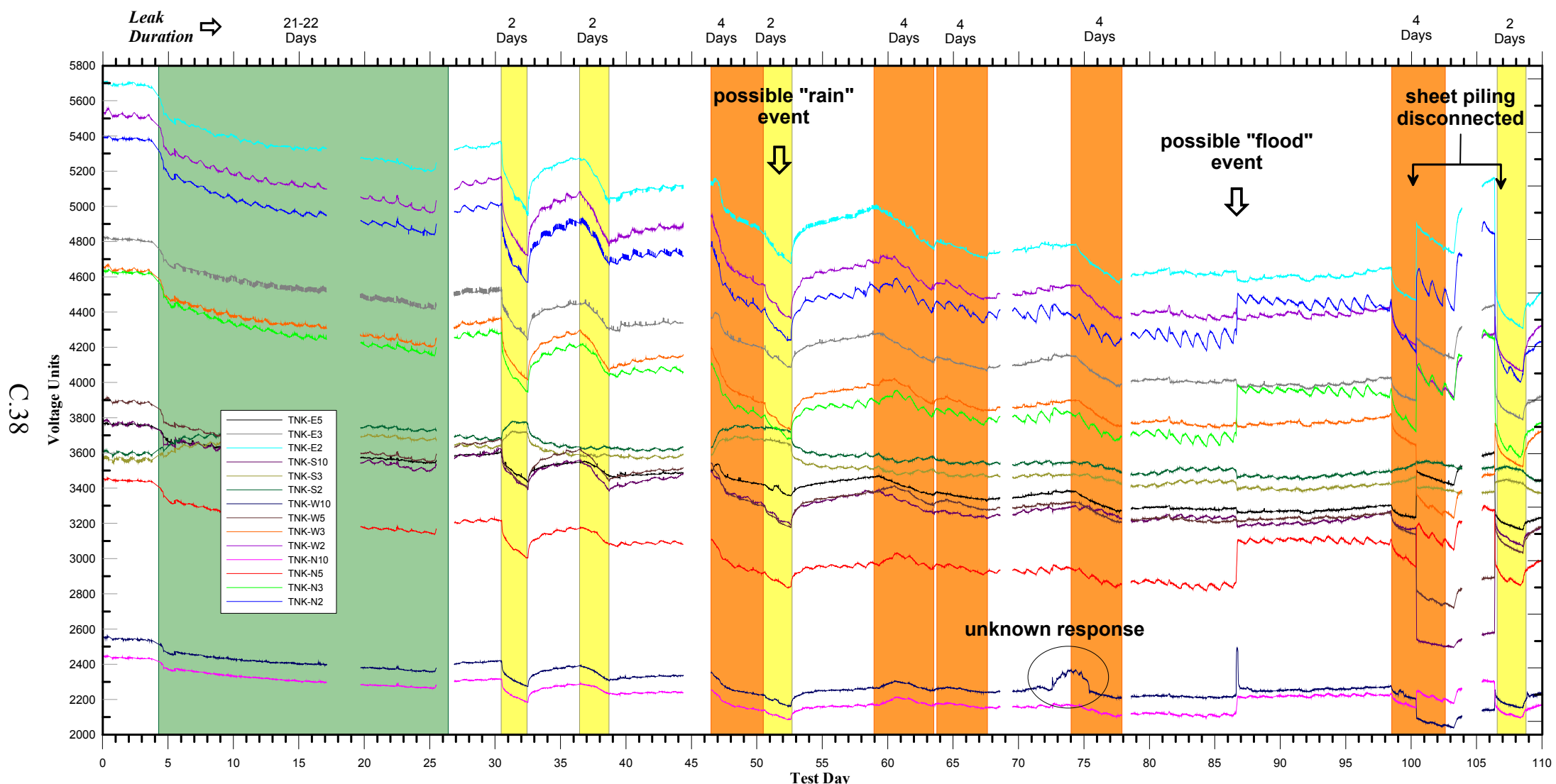

Figure C.16. Interpreted Leak Detection Time Series o Injection System Electrodes to Surface Electrode Potential Measurements 


\section{C.5.2 Volume Estimation Performance}

\section{C.5.2.1 Method A}

Method A does not use direct solution contact and was not used to perform volume calculations.

\section{C.5.2.2 Method B}

Method B does not use direct solution contact was not used to perform volume calculations.

\section{C.5.2.3 Method C}

Method $\mathrm{C}$ has direct contact with the injection system or solution and therefore produced the cleanest data and most diagnostic and reliable results. Because the method has direct contact with the injected solution, it is almost entirely influenced by soil moisture changes caused by leak events. As a result Method $\mathrm{C}$ was the least sensitive to rainfall events.

All potential data suffered from diurnal noise. We were unable to correct this problem for the PE test, but in almost all cases, the magnitudes of the leaks were larger than diurnal noise and therefore did not affect leak detection.

The performance of the volume calculations for method $\mathrm{C}$ is currently under review by VET. Numeric results for Method $\mathrm{C}$ were submitted each day (in spreadsheet form) for the duration of the PE. These results can be viewed in Appendix B.

\section{C.5.2.4 Method D}

Method D has direct contact with the injection system or solution and therefore produced the cleanest data and most diagnostic and reliable results. Detection is performed by sensing a change in electrical potential between the injection system electrodes and surface electrodes. This method was primarily used to detect any changes to the potential field that surrounds the tank that could be caused by events other than the injected solution. It was hoped that Method D would aid in separating rainfall events from leak events. The method did detect two rainfall events, a flood event and the sheet piling disconnection and reconnection. It may prove more diagnostic in an actual tank farm implementation to install a digital rain gauge to help distinguish between rainfall and leak events.

All potential data suffered from diurnal noise. We were unable to correct this problem at this time, but in almost all cases, the magnitude of the leaks were larger than diurnal noise and therefore did not affect leak detection.

Method D was used to detect any cultural distortions to the potential field that could be caused by artificial events. It was hoped that method $\mathrm{D}$ would adjust the results of Method $\mathrm{C}$ to accommodate for any occurrences. For the most part, the results of method $\mathrm{C}$ were not influenced by a cultural distortion to the field and therefore the results of Method D show no difference to that of Method C results. 
The performance of the volume calculations for Method D is currently under review by VET. Numeric results for Method D were submitted each day (in spreadsheet form) for the duration of the PE. These results can be viewed in Appendix B.

\section{C.5.2.5 Improved Methods - Time Series Volume Analysis of Method C}

A modification to Method C (Modified Method C) is more accurate than Method C because slopes were derived only from times of leak conditions. This adaptive approach produces the closest fit to the data and therefore the most descriptive slope. Volume is determined by inputting the slope into a calibration equation derived during the 2001 Mock Tank work.

Measurements between steel casings and the steel tank. The table listed below is a summary of rate and volume calculations based on HGI's "Perturbation" and "Slope Analysis" methods. Calculations are based on slopes derived from time windows that are limited to leak events and are therefore different from those originally defined in the LDMM Performance Evaluation test protocols.

\section{C.5.2.6 Fused Arrays Versus Steel Casing Electrodes}

No attempt was made to quantitatively or qualitatively evaluate the performance difference between the "fused" ERT wells and steel casings during the 2002 LDMM PE. Although the data need to perform such an evaluation are on file should the need arise.

Table C.2. Summary of Rate and Volume Calculations

\begin{tabular}{|c|c|c|c|c|c|c|}
\hline Event & $\begin{array}{l}\text { Start } \\
\text { Time }\end{array}$ & $\begin{array}{l}\text { End } \\
\text { Time }\end{array}$ & $\begin{array}{c}\text { Duration } \\
\text { (Days) }\end{array}$ & $\begin{array}{c}\text { Rate } \\
\text { (Gal/hour) }\end{array}$ & $\begin{array}{c}\text { Rate } \\
\text { (Gal/day) }\end{array}$ & $\begin{array}{c}\text { Volume } \\
\text { (Gal) }\end{array}$ \\
\hline Leak 1 & $\begin{array}{c}\text { Day } 4 \\
8 \text { am }\end{array}$ & $\begin{array}{l}\text { Day } 25 \\
12 \mathrm{pm}\end{array}$ & 21.2 & 4 & 100 & 2,100 \\
\hline Leak 2 & $\begin{array}{c}\text { Day } 30 \\
12 \mathrm{pm}\end{array}$ & $\begin{array}{l}\text { Day } 32 \\
12 \mathrm{pm}\end{array}$ & 2 & 19 & 450 & 900 \\
\hline Leak 3 & $\begin{array}{c}\text { Day } 36 \\
12 \mathrm{pm}\end{array}$ & $\begin{array}{c}\text { Day } 38 \\
7 \mathrm{pm}\end{array}$ & 2.3 & 15 & 350 & 800 \\
\hline Leak 4 & $\begin{array}{c}\text { Day } 46 \\
10 \text { am }\end{array}$ & $\begin{array}{c}\text { Day } 50 \\
2 \mathrm{pm}\end{array}$ & 4.2 & 10 & 250 & 1,050 \\
\hline Leak 5 & $\begin{array}{c}\text { Day } 50 \\
2 \mathrm{pm}\end{array}$ & $\begin{array}{c}\text { Day } 52 \\
7 \mathrm{pm}\end{array}$ & 2.2 & 13 & 300 & 650 \\
\hline Leak 6 & $\begin{array}{c}\text { Day } 59 \\
12 \mathrm{pm} \\
\end{array}$ & $\begin{array}{c}\text { Day } 63 \\
12 \mathrm{pm} \\
\end{array}$ & 4 & 13 & 300 & 1,200 \\
\hline Leak 7 & $\begin{array}{c}\text { Day } 74 \\
2 \text { pm }\end{array}$ & $\begin{array}{c}\text { Day } 78 \\
2 \mathrm{pm} \\
\end{array}$ & 4 & 9.5 & 250 & 1,000 \\
\hline $\begin{array}{l}\text { Rain } \\
\text { Event }\end{array}$ & $\begin{array}{c}\text { Day } 86 \\
2 \mathrm{pm}\end{array}$ & $?$ & $?$ & $\mathrm{n} / \mathrm{a}$ & $\mathrm{n} / \mathrm{a}$ & $\mathrm{n} / \mathrm{a}$ \\
\hline Leak 8 & $\begin{array}{c}\text { Day } 98 \\
12 \mathrm{pm} \\
\end{array}$ & $\begin{array}{c}\text { Day } 103 \\
2 \mathrm{am} \\
\end{array}$ & 4.6 & 10 & 250 & 1,150 \\
\hline $\begin{array}{c}\text { Sheet } \\
\text { Piling } \\
\text { Removed }\end{array}$ & $\begin{array}{c}\text { Day } 100 \\
10 \mathrm{am}\end{array}$ & $\begin{array}{c}\text { Day } 106 \\
9 \text { am }\end{array}$ & 6 & $\mathrm{n} / \mathrm{a}$ & $\mathrm{n} / \mathrm{a}$ & $\mathrm{n} / \mathrm{a}$ \\
\hline Leak 9 & $\begin{array}{c}\text { Day } 106 \\
10 \mathrm{am}\end{array}$ & $\begin{array}{c}\text { Day } 108 \\
2 \mathrm{pm}\end{array}$ & 2.2 & 14 & 350 & 800 \\
\hline & & & & & Tota & 9,650 \\
\hline
\end{tabular}


Of similar interest was the grounding difference between the steel casings and "fused" ERT wells. This topic was studied extensively during the 2001 Mock Tank work and is documented within that report.

\section{C.5.3 Changes in Sensitivity Over Time}

It is anticipated that SCRT sensitivity will decrease as a result of ground saturation within the detection volume. However, such saturation is extreme, temporary, and difficult to achieve.

All geophysical systems depend on a physical property contrast. In the case of electrical methods, the physical property contrast is the difference in electrical conductivity (or resistivity) between a target (in this case the leaking solution) and the background. Once sufficient solution has leaked and completely fills the volume of earth being investigated then the needed physical property contrast disappears. In the Hanford environment, the background medium is the vadose zone portion of the Hanford formation. Many geophysical tests performed in and on the Hanford formation show it to be relatively resistive (greater than $500 \mathrm{ohm}$-meters on average). Resistivity of the leak solution at the mock tank, which is intended to be representative of media found in the tanks in the tank farms, is less than one ohm-meter. Consequently, the physical property contrast between the background (unsaturated Hanford Fm.) and the target (leaking conductive solution) is extreme and highly desirable.

In the majority of tank farm environments any leaking solution will migrate downward past the sensing dry well casings. So, for a leak detection system deployed in the tank farms, even a long term leak would not pose a problem as far as saturation is concerned.

\section{C.5.4 Unexpected Responses}

Three unexpected responses were observed on days 86, 100, and 106.

The first unexpected response was related to the "flood" event on day 86. The responses observed during the flood event were simply offsets from the prior time series, but there was no sympathetic change in slope of the post-perturbation event.

The second unexpected response occurred on day 100 when the sheet piling was disconnected from the injection system during a leak event. The perturbation was the largest observed during the entire test. However, although the perturbation was large, it was obviously not a leak event. This was confirmed by the large magnitude changes in all observed responses followed by a consistent trend in slope of the subsequent time series. When the event occurred its cause was not known, but its effects were readily observed. This event was observed in all data sets.

The third unexpected response occurred on day 106 when the sheet piling was reconnected. Simultaneously, a leak was started. The return of all responses to near pre-day-100 levels confirmed the suspicions about the sheet piling. The subsequent change in slope confirmed the presence of a new leak. 
The importance of these unexpected events is that they clearly illustrate the diagnostic power of the method in discriminating leak events from non-leak events.

\section{C.5.5 Comparison to Test Matrix}

Daily numerical volumes for method $\mathrm{C}$ and $\mathrm{D}$ are currently being compared to the actual test matrix by VET and are therefore not discussed in this report. However, comparison of volume results generated from Modified Method C are presented below in Figure C.17 and Table C.2.

Analysis of this comparison show HRR-SCRT results to be well within the false trigger limits ( $>5 \%)$ and produced volume calculations within $20 \%$ of the actual injected volume.

The table below (Table C.2) is a summary comparison of calculated volumes from Modified Method $\mathrm{C}$ (perturbation analysis of injection system to steel casing time series) and actual leak totals. Rows highlighted in yellow, show days where leaks were released into ports that were not instrumented. The adjusted column (green) corrects for such occurrences by adding measured volumes to the HRR-SCRT daily totals.

The adjusted volume calculated from HRR-SCRT measurements was only 1900 gallons less than the actual total injected volume of 13571 gallons or $14 \%$ under. We are quite satisfied with this result and believe it may be possible to calculate possible Tank Farm leaks with in $20 \%$ of their volume.

\section{C.5.6 Discussion of Performance}

We used an analysis of the reciprocal readings as one quality control or performance evaluation tool. The table below (Table C.3) is a statistical summary of corresponding reciprocal injection system to steel casing measurements, in terms of percent difference.

The figure below (Figure C.18) shows a summary of percent difference reciprocal measurements recorded between the injection system and four steel casings. The first leak event occurred at approximately day 5 and one can clearly see a decrease in the total percent difference between reciprocal readings. Introduction of solution will reduce the ground to electrode contact resistance and therefore increase data reliability. Nevertheless, all reciprocal measurements are within $\pm 1 \%$.

\section{C.5.7 Volt-Ohm Meter Resistance Measurements}

A Simpson Volt-ohm meter was used to record resistance measurements between various Mock Tank infrastructure that included the injection system electrodes, steel casings, "fused" ERT wells, ERT point electrodes, surface electrodes and remote reference electrodes. Measurements were made by connecting one sensor to the positive lead of the VOM and another sensor to the negative lead. All readings were recorded in ohms, a partial display of these results can be viewed in Figure C.19. Measurements were performed during background measurements prior to the PE test and then again after the test was completed. The two measurements (before and after the test) are represented by the two resistance numbers listed on the figure below. The lines colored lines represent a resistance path between the two sensors. 

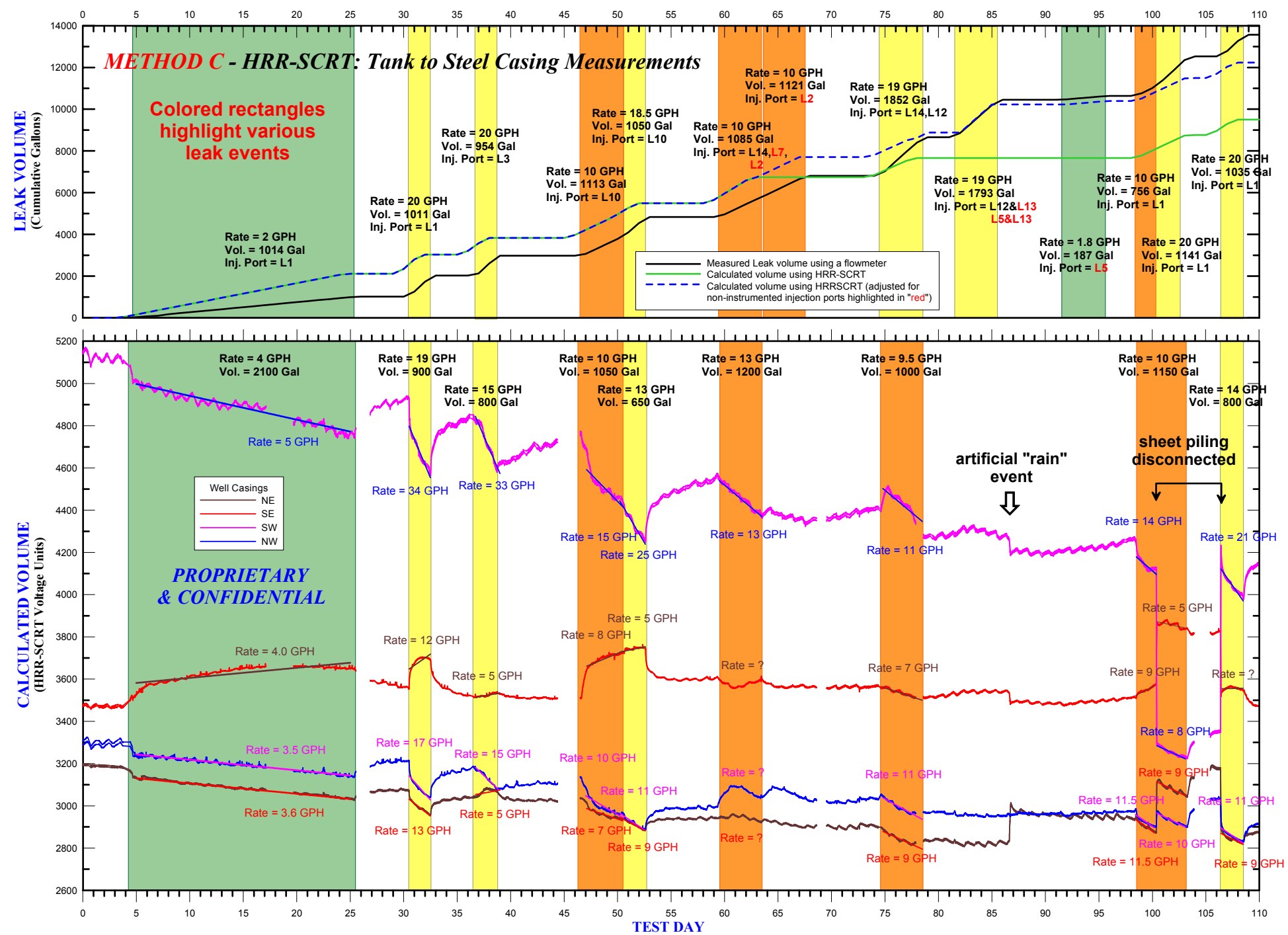

Figure C.17. Comparison of Modified Method C Time Series Volume Calculations to the Actual Test Matrix 
Table C.3. Comparison of Injection System to Steel Casing Results Produced from Perturbation Analysis of the Time Series Plot (Figure C.17)

\begin{tabular}{|c|c|c|c|c|c|c|c|c|}
\hline \multirow{2}{*}{$\begin{array}{l}\text { Test } \\
\text { Day }\end{array}$} & \multirow{2}{*}{$\begin{array}{l}\text { Injection } \\
\text { Port }\end{array}$} & \multirow{2}{*}{$\begin{array}{c}\text { Leak } \\
\text { ID }\end{array}$} & \multicolumn{2}{|c|}{ Actual Volume } & \multicolumn{2}{|c|}{$\begin{array}{l}\text { HRR-SCRT } \\
\text { Volume }\end{array}$} & \multicolumn{2}{|c|}{$\begin{array}{l}\text { Adj. HRR-SCRT } \\
\text { Volume }\end{array}$} \\
\hline & & & Cum. & Daily & Cum. & Daily & Cum. & Daily \\
\hline 4 & L3 & B & 30 & 30 & 60 & 60 & 60 & 60 \\
\hline 5 & L1 & B & 74 & 44 & 160 & 100 & 160 & 100 \\
\hline 6 & L1 & B & 95 & 21 & 260 & 100 & 260 & 100 \\
\hline 7 & L1 & B & 173 & 79 & 360 & 100 & 360 & 100 \\
\hline 8 & L1 & B & 222 & 48 & 460 & 100 & 460 & 100 \\
\hline 9 & L1 & B & 269 & 48 & 560 & 100 & 560 & 100 \\
\hline 10 & L1 & B & 318 & 48 & 660 & 100 & 660 & 100 \\
\hline 11 & L1 & B & 365 & 48 & 760 & 100 & 760 & 100 \\
\hline 12 & L1 & B & 413 & 48 & 860 & 100 & 860 & 100 \\
\hline 13 & L1 & B & 461 & 48 & 960 & 100 & 960 & 100 \\
\hline 14 & L1 & B & 509 & 48 & 1060 & 100 & 1060 & 100 \\
\hline 15 & L1 & B & 557 & 48 & 1160 & 100 & 1160 & 100 \\
\hline 16 & L1 & B & 605 & 48 & 1260 & 100 & 1260 & 100 \\
\hline 17 & L1 & B & 654 & 48 & 1360 & 100 & 1360 & 100 \\
\hline 18 & L1 & B & 702 & 48 & 1460 & 100 & 1460 & 100 \\
\hline 19 & L1 & B & 750 & 48 & 1560 & 100 & 1560 & 100 \\
\hline 20 & L1 & B & 799 & 48 & 1660 & 100 & 1660 & 100 \\
\hline 21 & L1 & B & 847 & 48 & 1760 & 100 & 1760 & 100 \\
\hline 22 & L1 & B & 893 & 46 & 1860 & 100 & 1860 & 100 \\
\hline 23 & L1 & B & 941 & 48 & 1960 & 100 & 1960 & 100 \\
\hline 24 & L1 & B & 990 & 48 & 2060 & 100 & 2060 & 100 \\
\hline 25 & L1 & B & 1014 & 24 & 2110 & 50 & 2110 & 50 \\
\hline 30 & L1 & D & 1252 & 238 & 2340 & 230 & 2340 & 230 \\
\hline 31 & L1 & D & 1735 & 483 & 2800 & 460 & 2800 & 460 \\
\hline 32 & L1 & D & 2025 & 290 & 3030 & 230 & 3030 & 230 \\
\hline 36 & L1 & $\mathrm{F}$ & 2124 & 100 & 3210 & 180 & 3210 & 180 \\
\hline 37 & L3 & $\mathrm{F}$ & 2609 & 484 & 3570 & 360 & 3570 & 360 \\
\hline 38 & L3 & $\mathrm{F}$ & 2979 & 370 & 3830 & 260 & 3830 & 260 \\
\hline 46 & L10 & I & 3063 & 84 & 3970 & 140 & 3970 & 140 \\
\hline 47 & L10 & I & 3304 & 241 & 4210 & 240 & 4210 & 240 \\
\hline 48 & L10 & I & 3544 & 240 & 4450 & 240 & 4450 & 240 \\
\hline 49 & L10 & I & 3784 & 240 & 4690 & 240 & 4690 & 240 \\
\hline 50 & L10 & $\mathrm{J}$ & 4092 & 308 & 4960 & 270 & 4960 & 270 \\
\hline 51 & L10 & $\mathrm{J}$ & 4542 & 450 & 5270 & 310 & 5270 & 310 \\
\hline 52 & L10 & $\mathrm{J}$ & 4834 & 292 & 5490 & 220 & 5490 & 220 \\
\hline 59 & L14 & $\mathrm{L}$ & 4960 & 126 & 5650 & 160 & 5650 & 160 \\
\hline 60 & L14 & $\mathrm{L}$ & 5201 & 241 & 5960 & 310 & 5960 & 310 \\
\hline 61 & L7 & $\mathrm{L}$ & 5445 & 244 & 6270 & 310 & 6270 & 310 \\
\hline 62 & L2 & $\mathrm{L}$ & 5686 & 241 & 6580 & 310 & 6580 & 310 \\
\hline 63 & L2 & M & 5919 & 232 & 6740 & 160 & 6740 & 160 \\
\hline 64 & L2 & M & 6164 & 245 & 6740 & 0 & 6990 & 250 \\
\hline 65 & L2 & M & 6409 & 245 & 6740 & 0 & 7230 & 250 \\
\hline 66 & L2 & M & 6653 & 244 & 6740 & 0 & 7470 & 240 \\
\hline 67 & L2 & M & 6807 & 154 & 6740 & 0 & 7630 & 150 \\
\hline 74 & L10 & $\mathrm{P}$ & 7026 & 219 & 6840 & 100 & 7730 & 100 \\
\hline
\end{tabular}


Table C.3 (Contd)

\begin{tabular}{|r|c|cr|rrr|rr|}
\hline \multirow{2}{*}{$\begin{array}{r}\text { Test } \\
\text { Day }\end{array}$} & Injection & Leak & \multicolumn{2}{|c|}{ Actual Volume } & \multicolumn{2}{|c|}{$\begin{array}{c}\text { HRR-SCRT } \\
\text { Volume }\end{array}$} & \multicolumn{2}{|c|}{$\begin{array}{c}\text { Adj. HRR-SCRT } \\
\text { Volume }\end{array}$} \\
\hline 75 & L14 & ID & Cum. & Daily & Cum. & Daily & Cum. & Daily \\
76 & L12 & P & 7505 & 479 & 7070 & 230 & 7960 & 230 \\
77 & L12 & P & 8408 & 455 & 7300 & 230 & 8190 & 230 \\
78 & L12 & P & 8659 & 251 & 7530 & 230 & 8420 & 230 \\
\hline 81 & L14 & R & 8846 & 187 & 7660 & 0 & 850 & 0 \\
82 & L12 \& L13 & R & 9289 & 443 & 7660 & 0 & 8550 & 0 \\
83 & L5 \& L13 & R & 9745 & 456 & 7660 & 0 & 9000 & 460 \\
84 & L5 \& L13 & R & 10197 & 452 & 7660 & 0 & 9460 & 450 \\
85 & L5 \& L13 & R & 10452 & 255 & 7660 & 0 & 9710 & 260 \\
\hline 91 & L12 & T & 10474 & 22 & 7660 & 0 & 9710 & 0 \\
92 & L12 & T & 10517 & 43 & 7660 & 0 & 9710 & 0 \\
93 & L5 & T & 10560 & 44 & 7660 & 0 & 9760 & 40 \\
94 & L5 & T & 10604 & 44 & 7660 & 0 & 9800 & 40 \\
95 & L5 & T & 10639 & 35 & 7660 & 0 & 9830 & 40 \\
\hline 98 & L5 & V & 10764 & 125 & 7780 & 120 & 9950 & 120 \\
99 & L3 & V & 11011 & 247 & 8020 & 240 & 10190 & 240 \\
100 & L1 & V & 11395 & 384 & 8260 & 240 & 10430 & 240 \\
\hline 101 & L1 & W & 11865 & 470 & 8500 & 240 & 10670 & 240 \\
102 & L1 & W & 12353 & 488 & 8740 & 240 & 10910 & 240 \\
103 & L1 & W & 12536 & 183 & 8760 & 20 & 10930 & 20 \\
\hline 106 & L1 & Y & 12788 & 253 & 8960 & 200 & 11130 & 200 \\
107 & L1 & Y & 13272 & 484 & 9300 & 340 & 11470 & 340 \\
108 & L1 & Y & 13571 & 299 & 9500 & 200 & 11670 & 200 \\
\hline
\end{tabular}

Table C.4. Statistical Summary of Percent Differences for Reciprocal Readings

\begin{tabular}{|l|rrrr|}
\hline Well & NE & SE & SW & NW \\
\hline Minimum & -0.3 & -0.7 & -0.6 & -0.3 \\
Average & -0.1 & 0.0 & 0.0 & 0.1 \\
Maximum & 0.1 & 0.5 & 0.5 & 0.8 \\
\hline
\end{tabular}




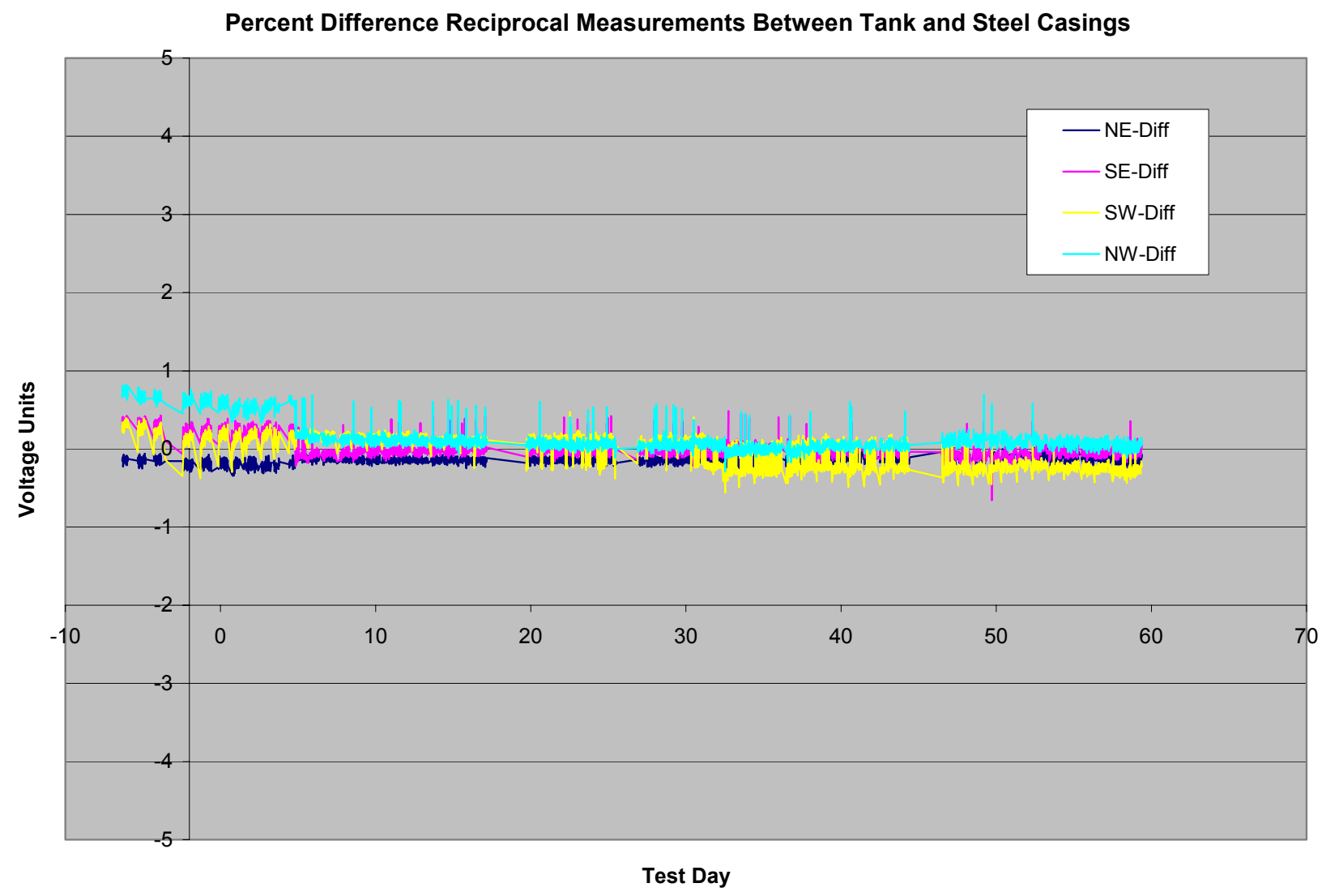

Figure C.18. Summary Plot of Tank-to-Steel-Casing Measurements, Showing the Distribution of Percent Difference Values for Reciprocal Readings 
No Sheet Piling

[before / after]
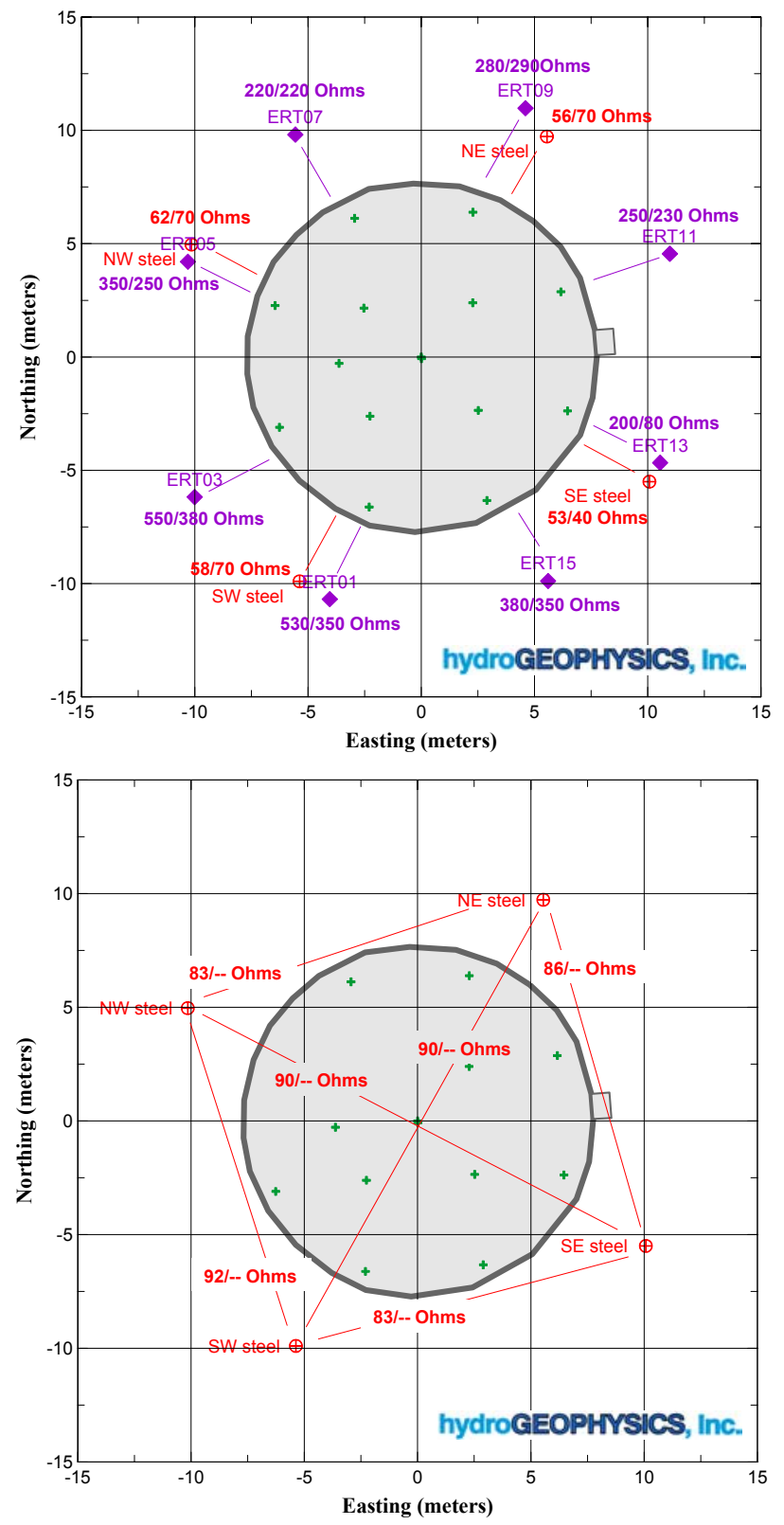

Sheet Piling

[before / after]
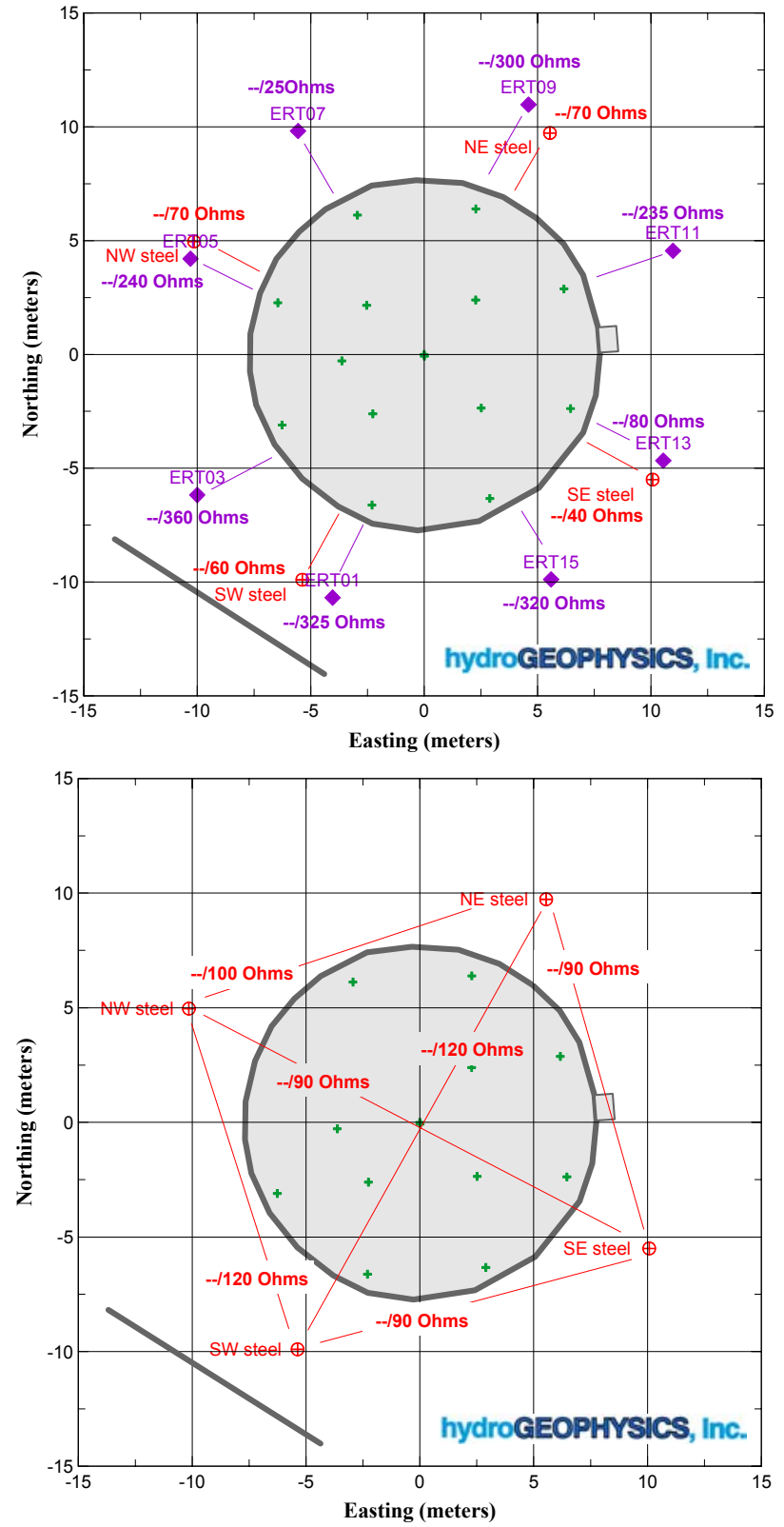

Figure C.19. VOM Resistance Measurements Before and After the PE Test 


\section{C.6 Conclusions and Recommendations}

Preliminary comparison of HRR-SCRT results to the Test Matrix show that first order volume approximations can be made based on existing knowledge of the local geology, environment and hydrology. HRR-SCRT can provide:

1. Accurate leak detection (>90\%)

2. Accurate leak duration (start \& end) - temporal data

3. Approximate leak rates - temporal data

4. Gross flow characteristics - spatial data

5. General leak location - spatial data

The test also demonstrates the effectiveness of a remote and autonomous internet-accessible data acquisition system. Remote operations provide a tremendous cost savings and increase the resolution and quality of the data.

This report is based on our best understanding of the electrical properties of earth materials and is limited to the areas where the surveys were performed and the conditions under which the measurements were made.

\section{C.6.1 Investigator Perspective on Test Outcome}

We are extremely pleased with the results of the 2002 LDMM PE Test because it provides us qualitative and quantitative statistical support that shows the effectiveness of direct solution contact electrical methods. HRR-SCRT's innovative use of existing infrastructure makes it cost effective while requiring no hazardous modification to future Tank Farm sites. Because of this we believe implementation of the existing methodology will prove a valuable tool for monitoring of Tank Farm remediation efforts. Although equipment and software refinement are still needed, almost all elements used in this test are directly transferable to actual Tank Farm LDMM.

Of particular importance is the fact that no drilling is required within the Tank Farms, and, to the best of our understanding, no other invasive efforts are required for the installation of a HRRSCRT system. Because PET will require installation of PET arrays, we believe that HRR-SCRT holds a big advantage over PET in deployment costs alone. HRR-SCRT data acquisition also includes the identical data sets obtained by LET. Consequently, in addition to slope and perturbation analysis, HRR-SCRT data also contain all the information needed for LET analysis. 


\section{C.6.2 Recommended Improvements to Methods}

\section{C.6.2.1 Software}

The most important improvement is to streamline the slope analysis process and eliminate the need for fixed evaluation periods. The results of this test clearly show the increased accuracy of the slope analysis method when one uses adaptive trend fitting to only leak portions of the time series. The PE test data should be used to determine a new SCRT system calibration. Such a calibration will bring the estimated leak rates closer to the actual rates and will decrease the error in total volume estimations. Recalibration efforts should be funded as soon as possible to make available more representative statistical results for further evaluation.

LET analysis should be performed on the HRR-SCRT datasets amenable to LET analysis to allow comparison of the dipole-dipole LET results to the pole-pole SCRT results.

\section{C.6.2.2 Hardware}

Although not an improvement to the Method, modifications to the equipment will be needed for implementation within actual Tank Farms. Air and ground temperature monitoring may be required.

\section{C.6.3 Adaptive Procedures for Tank Farm Deployment}

\section{C.6.3.1 Design Stage Implementation}

Our primary assumption is that CHG or a similar contractor would allow HGI to aid in the design phase of the tank farm retrieval efforts. This may include assisting and advising such a contractor as to the most advantageous implementation of an ex-tank geophysical monitoring system. Incorporation of a geophysical system at the design stage would:

- allow the seamless integration of the needed geophysical infrastructure to the planned remediation systems

- prevent any inadvertent problems to the remediation systems that could be caused by geophysical monitoring systems

- substantially reduce the cost by utilizing planned remediation systems infrastructure (such as trenches) for sensor installation

We believe that it would be advantageous to instrument the entire tank farm at one time. Not only would this allow for future remediation activities, but, it would present a "global" view of the entire tank farm at each instance of sampling such that any activity that might impact or influence leak detection and monitoring would be observed regardless of location within or near the tank farm. The 90-electrode multiplexers used at during the PE test demonstrated the ease and advantages of such spatial monitoring. 


\section{C.6.3.2 Sensor Installation}

One of the distinct advantages of the HRR-SCRT method comes from using remote reference electrodes. Compared to the dipole-dipole approach used for ERT, the amplitude of the driving (transmitting) signal can be much lower resulting in a decrease in safety concerns and an increase in signal to noise ratio. For these reasons, it would be particularly desirable to use distant, steelcased wells that have been completed to ground water as remote reference electrodes. This would ensure stable grounding characteristics and, in addition, may help alleviate some of the thermal problems. If such wells are not available then new wells away from the tank farms might be considered.

Shallow surface electrodes may be strategically placed within the tank farm to aid in distinguishing non-leak events from leak events. Strategic placement would depend on some knowledge of the location of existing buried conductive features.

Also, shallow surface electrodes may be placed within one foot of the ground surface which, although we do not know the requirements within the tank farm enclosures, may alleviate concerns about invasive installation.

Conceptually, connections to the dry wells are straightforward, but, the limited amount of available contact area of the casing at ground surface will require some effort to make the contacts good and enduring. This would also be required for LET. The inter-tank connections that are assumed to exist should be tested for continuity and possibly by-passed by new, specific connections. Such connections between tanks eliminate the possibility of sparking within the tanks.

\section{C.6.3.3 Geophysical Equipment}

There has been much discussion over the requirements of a geophysical system that could provide ex-tank leak detection monitoring for retrieval operations. Items topping the list are:

- Safety - making sure that such an instrument is strictly current and voltage limited so that there would be no possibility of a spark or shock potential. HGI could easily incorporate our Doubly Redundant Safety System (DRSS) which is fixed to each sensor to provide isolated protection against stray voltage and current transmission. This system will satisfy UL-913 requirements. Currently available off-the-shelf (OTS) geophysical systems are designed to maximize output voltage at any given current level. The demands of the tank farm are quite different and would require purpose-built systems.

- Backup Operation - making sure that such an instrument is completely backed up by either a redundant instrument or making sure that plug-and-play replacement parts are readily available.

Unfortunately, off-the-shelf, commercially available systems (like the system currently used in the LDMM Performance evaluation at the Mock Tank site) cannot provide such assurances without extensive modification. Both safety and backup operations will be necessary in tank farm implementation. 


\section{C.6.3.4 Daily Monitoring}

Retrieval monitoring would occur in a similar fashion to that of this PE Test, with continuous data acquisition and daily result presentation through remote network systems. Geophysically speaking, it makes little difference if one plans to remediate one tank vs. the entire tank farm. As long as we have equipment that can handle up to the planned maximum number of simultaneous retrievals. Streamlining of the processing software will reduce processing time required on each retrieval campaign and significantly reduce monitoring costs.

\section{C.6.4 S-112 Tank Data Analysis}

This topic is covered in Appendix A.

\section{C.6.5 Acknowledgments}

We wish to thank the many individuals without whom this project would not have been possible. Of special recognition is the Department of Energy who funded our efforts, PNNL for providing seamless management and logistical support, and LLNL who provided use of their resistivity equipment.

We would appreciate any feedback regarding the interpretation based on additional surveying or invasive characterization performed at the mock tank site. In particular, we would appreciate more insight into the makeup of the pipeline corridor immediately to the southeast of the southeast steel casing. We acknowledge and appreciate the support provided by CHG, LLNL, PNNL, and VET.

Respectfully submitted,

James B. Fink, Ph.D., P.E. (geophysical), R.L.S.

President

Marc T. Levitt

Project Engineer
Mr. Chris Baldyga

Geophysical Engineer 


\section{C.7 References}

Aichele, W.T. 1978. Report on Boeing Pipeline Leak Detection System. Rockwell Hanford Operations, Informal Report RHO-LD-61, 70 pp.

Barnett, D.B., G.W. Gee, and M.D. Sweeney. 2001. Test Plan for the Demonstration of Geophysical Techniques for Single-Shell Tank Leak Detection at the Hanford Mock Tank Site-Fiscal Year 2001. PNNL Report \# 13598, 94 pp.

Binley, A., W. Daily, and A. Ramirez. 1997. Detecting Leaks from Environmental Barriers using Electrical Current Imaging" JEEG, Vol. 2, No. 1, pp 11-19.

Deichelbohrer, P.R. 1978. Interim Evaluation Report of Boeing Leak Detection System. Rockwell Hanford Operations, Unclassified Report RHO-CD-265, 62 pp.

Dwight, H.B. 1936. Calculation of Resistances to Ground. Electrical Engineering, Vol. 55, pp 1319-1328.

Eaton, J.R. 1962. Grounding Electric Circuits Effectively. James G. Biddle Co., Bulletin 25T2, 19 pp.

Fink, J.B., M.T. Levitt, and C.A. Baldyga. 2002. Electrical HRR/SCRT Measurements Completed for the 2001 Leak Detection, Mitigation, \& Monitoring (LDMM) Study, Mock Tank Site, Hanford, WA, hydroGEOPHYSICS Report 2001-002, 51 pp.

Fink, J.B., M.T. Levitt, and C.A. Baldyga. 2002. Electrical Background Removal Tests at Sisson and Lu for the 2002 VZTF Study, Hanford Site, WA, hydroGEOPHYSICS Report 2002-005, 52 pp.

Freeman-Pollard, J.R. 1992. Work Plan for Drilling and Sampling Activities Near Single-Shell Tank 241-T-106 in Response to GAO/RCED-89-157. Westinghouse Hanford Company, Report \# WHC-SDEN-AP-078, $265 \mathrm{pp}$.

Gee, G.W. and A.L. Ward. 2001. Vadose Zone Transport Field Study: Status Report. PNNL Report \# 13679, 77 pp.

Key, K.T. 1975. Nuclear Waste Tank and Pipeline External Leak Detection Systems. Atlantic Richfield Hanford Company, Informal Report ARH-LD-120, 143 pp.

Key, K.T. 1977. A Technique of Analysis for an External Leak Detection System. Atlantic Richfield Hanford Company, Unclassified Report ARH-CD-973, 96 pp.

Last, G.V. and B.D. Horton. 2000. Review of Geophysical Characterization Methods Used at the Hanford Site. PNNL Report \# 13149, 111 pp.

Oliver, R.G. 1976. Leak Detection Sensitivity - Boeing Leak Detection System (CPFF-217. Atlantic Richfield Hanford Company, Internal memo, 3 pp. (RMIS Accession \#293-007174). 
Ramirez, A., W. Daily, A. Binley, D. LaBrecque, and D. Roelant. 1995. Detection of Leaks in Underground Storage Tanks Using Electrical Resistance Methods. LLNL Report \# UCRL-JC-122180, $25 \mathrm{pp}$.

Thompson, N.G., L.E. Vaaler, J.R. Divine, J.L. Nelson, J.H. Payer, and T.J. Barlo. 1981. Final Report on Analysis of Complex Corrosion Conditions: Project B-234. Battelle Pacific Northwest Laboratories, $116 \mathrm{pp}$.

Unknown author. 1944. Specifications for Construction of Composite Storage Tanks Bldg. No. 241, Hanford Engineer Works Project 9536, 20 pp. (RMIS Accession \#: D194035988)

Unknown author. 1990. Standard Test Procedures for Evaluating Leak Detection Methods: Volumetric tank Tightness Testing Methods. U.S.E.P.A. Report EPA/530/UST-90/004, 93 pp.

Unknown author. 1990. Standard Test Procedures for Evaluating Leak Detection Methods: Statistical Inventory Reconciliation Methods (SIR). U.S.E.P.A. Report EPA/530/UST-90/007, 65 pp.

Unknown author. 2002. GDP-32II Multifunction Receiver Operation Manual. Zonge Engineering and Research Organization equipment manual, 398 pp.

Unknown author and no title, Tank Farm Report Sections 1.0 thru 6.0, a Boeing Company report with all titles, numbers, and references removed. Estimated date: 1978, 131 pp. (RMIS Accession \#: D196873298).

Vickery, E.A. Miscellaneous memos and progress reports regarding the Boeing Leak Detection System, 1976-1977, Atlantic Richfield Hanford Company, 21 pp.

Ward, A.L. and G.W. Gee. 2000. Vadose Zone Transport Field Study: Detailed Test Plan. PNNL Report, Rev. 0 (pre-release), 98 pp.

Ward, A.L. and G.W. Gee. 2000. Vadose Zone Transport Field Study: Detailed Test Plan for Simulated Leak Tests. PNNL Report \# 13263, 90 pp.

Ward, A.L. and G.W. Gee. 2001. Vadose Zone Transport Field Study: FY 2001 Test Plan. PNNL Report \# 13451, Rev. 1, 75 pp.

Ward, A.L. and G.W. Gee. 2001. Vadose Zone Transport Field Study: FY 2002 Test Plan. PNNL Report \# 13857, 63 pp. 


\section{Appendix D}

\section{Detecting Leaks in Storage Tanks Using Electrical Resistance Tomography}




\title{
Detecting Leaks in Single Shell Tanks Using Electrical Resistance Tomography
}

\author{
by \\ William Daily ${ }^{\mathrm{a}}$, Abelardo Ramirez ${ }^{\mathrm{a}}$ and Andrew Binley \\ ${ }^{a}$ Lawrence Livermore National Laboratory \\ Livermore, CA 94550 \\ ${ }^{b}$ Lancaster University \\ Lancaster, UK \\ Submitted to: \\ Pacific Northwest National Laboratory \\ Richland, WA
}

Abstract - A series of field tests and numerical calculations were performed to evaluate the performance of electrical resistance tomography (ERT) to detect leaks and estimate the volume leaked from metal underground storage tanks. The field test was performed under conditions simulating those expected during actual remediation of a single shell tank located at the Hanford Reservation, Washington. Nearly fourteen thousand gallons of concentrated sodium thiosulfate (simulating tank waste) were episodically released from a steel tank mockup (simulating a single shell tank) in a blind test lasting 110 days (we had no knowledge of the release episodes during the course of the test). Each day during the test a leak or no-leak condition was declared blind-based solely on analysis of the electrical data. In addition, estimates of the volume released were made periodically based solely on the ERT tomographs. Four days out of 110 were excluded from the test because of equipment malfunctions. Of the 105 declared test days, the method correctly assigned 60 days and incorrectly assigned 45 days. Only one day was the tank declared leaking when it was not. Statistically, the correct declaration of leaks was better than random choice nearly $93 \%$ of the time. Estimates of leaked volumes were uniformly high, with the maximum estimate above 35,000 gal or more than twice the actual leakage volume.

Post-test analysis of the data suggested improvements for using the ERT data for both detecting a leak condition and calculating the leaked volume. Application of the revised method to the ERTLET test data (blind - as though done during the test) generated leak or no-leak declarations that were better than random choice more than $99 \%$ of the time. Volume estimates using ERT-PET were adjusted through a recalibration procedure such that volumes were consistently within 2,000-2500 gal of the actual volumes delivered..

This work was performed under the auspices of the U.S. Department of Energy by University of California Lawrence Livermore National Laboratory under contract No. W-7405-Eng-48. 


\section{Contents}

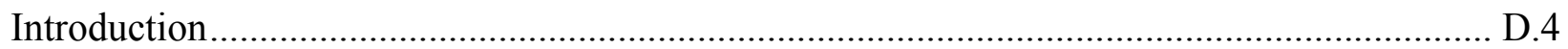

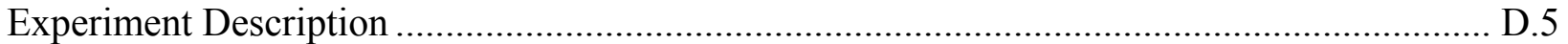

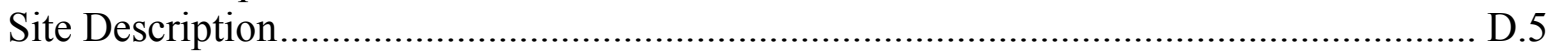

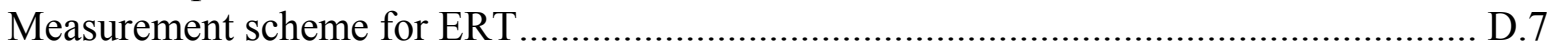

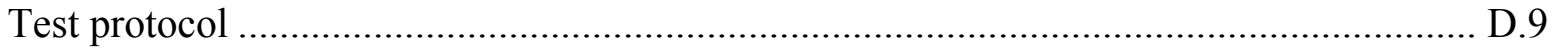

Measurement system used for ERT ….................................................................. D. 12

Data Analysis and Theory......................................................................................... D. 14

Reconstruction of resistivity images ............................................................... D. 14

Estimation of leak volumes............................................................................... D. 15

Results and Discussion ........................................................................................ D. 16

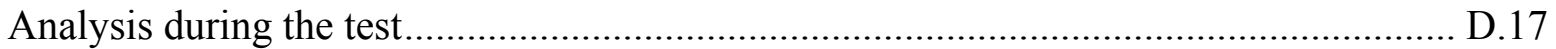

Declared leak status compared to actual release status................................................ D.17

Release B ..................................................................................................... D. 27

Releases B, D, I, L, M, T, Y ........................................................................ D. 27

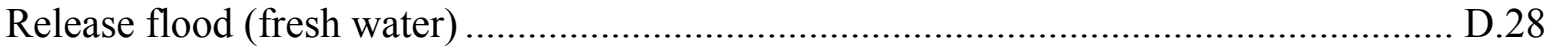

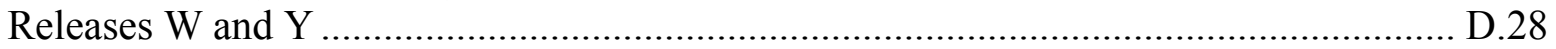

Leak volume estimates........................................................................................ D.29

What we learned after the test........................................................................... D.29

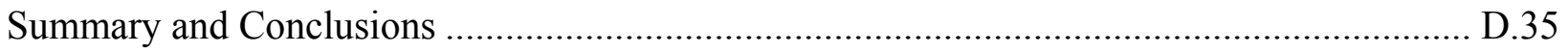

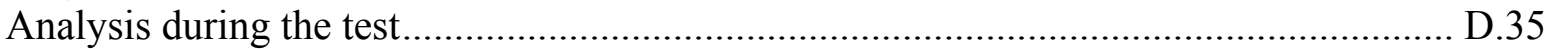

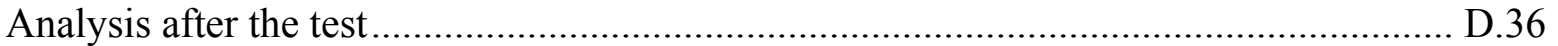

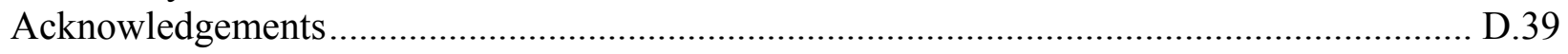

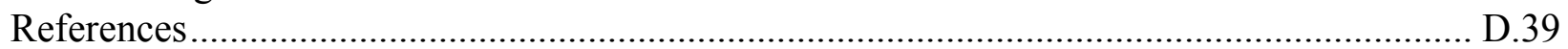




\section{Figures}

1. Schematic of the experimental set up for the mock tank

D.7

2. Block diagram of the principle components for the remotely operated data acquisition and control.

3. From a remote computer in California, or anywhere the internet was accessible, it was possible to control the data acquisition computer at the mock tank test site and move data files for processing.....

4. The apparent resistivity beneath the tank as measured from data on the eight point electrode arrays for each of the 110 days of the test (top) plotted with the actual release rates in gallons per hour (bottom)

5. The apparent resistivity beneath the tank as measured from data on the eight long electrodes for each of the 110 days of the test (top) plotted with the actual release rates in gallons per hour (bottom).

6. Two dimensional ERT of the volume beneath the mock tank for the month of September 2002 using long electrode data

7. Two dimensional ERT of the volume beneath the mock tank for the month of October 2002 using long electrode data. See the caption for 6.

8. ERT of the volume beneath the mock tank for the month of July 2002 ....................... D.22

9. ERT of the volume beneath the mock tank for the month of August........................... D.23

10. ERT of the volume beneath the mock tank for the month of September ..................... D.24

11. ERT of the volume beneath the mock tank for the month of October......................... D.25

12. ERT of the volume beneath the mock tank for the month of November...................... D.26

13. Comparison of apparent resistivity differences as measured using the point electrodes for each of the 110 days of the test (top) plotted with the actual release rates in gallons per hour (bottom)

14. The release volume calculated from equation (6) and using July 22 as a baseline is compared with the actual cumulative release volume.

15. ERT images in plan view of changes in resistivity at ten selected days from the test..... D.34

\section{Tables}

1. Test matrix showing volumes, times locations etc.

D.10

2. Statistical summary of ERT results compared to the test matrix

D. 21

3. The release volume calculations reported to the test director during the test.

D.30 


\section{Introduction}

One of the most difficult tasks for the US Department of Energy (DOE) is the clean up of environmental hazards left over from the cold war. An example of this is the very technically challenging remediation of the large underground tanks used to store both chemically toxic and radioactively dangerous byproducts of nuclear weapon production. Currently there are 177 of these tanks at Hanford in southeastern Washington and another 51 at Savannah River in western South Carolina. In addition, there are tanks at Idaho National Engineering Laboratory, Idaho and Oak Ridge, Tennessee. Cleanup plans for these tanks involves removing the contents and storing it in a long-term repository. This will be difficult and expensive and, at present, no experience exists for such an effort. The operation has a potentially high environmental impact, particularly as many of these tanks are located near large rivers (the Columbia River in Washington and the Savannah River in South Carolina) and thus a spill of high-level mixed waste could spread quickly and with serious consequences. However, inaction is not an option since some of the tanks have leaked in the past and are likely to leak in the future. The goal then is remediation of these storage tanks quickly and safely.

The purpose of the work is to demonstrate a geophysical technique to detect leaks from these tanks during their remediation. The task of detecting leaks from these tanks is a particularly challenging task because of the nature of the tank contents. Simple liquid level sensors are difficult to use because the waste varies in consistency from liquid to paste to solid - sometimes all mixed together in the same tank. Also, some water may be added to the tank to dissolve solid waste and then this dissolved waste is removed, making it necessary to measure liquid level and also track the volume of water added. All this is complicated by vapor loss and large temperature changes (some of the tanks are radiogenically heated) which will complicate using liquid level to determine tank inventory.

A leak detection method currently in use senses gamma rays from any radioactive contaminant plume as it forms outside the tank. Detectors are lowered into boreholes drilled for this purpose near some of the tanks. However, even the more energetic gamma rays travel only a few meters in soil so many boreholes are required to sample even one tank (typically $23 \mathrm{~m}$ in diameter) and it is particularly difficult using boreholes around the sides of a tank to detect leaks from the bottom of a tank. These same boreholes have been used to monitor fluid contents near boreholes using fast neutrons (Isaacson, 1982) but neutron logging is less sensitive than gamma logging since the sphere of influence (i.e., detection radius) for neutrons is typically less than $0.5 \mathrm{~m}$ from the borehole ( IAEA 1970).

The method of leak detection we report herein relies on detection of the plume from a leaking tank as the liquid waste changes the electrical conductivity of the soil. Electrical resistance tomography (ERT) is the technique that is used to map the spatial variations of electrical resistivity in the soil using an array of electrodes to inject current into the ground and measure the resulting electrical potentials (see for example, Ramirez et al. 1996) As the electrical conductivity of waste in all of the tanks is very high; even a small volume of fluid will create a measurable change in soil conductivity. Even more important, it is possible using ERT to detect 
this change using sensors located remote from any plume, so that measurements from around the periphery of the tank yield information about leaks under the center of the tank.

The principles of this method have already been demonstrated in a series of field experiments at Hanford and are reported by Ramirez et al. (1996). This earlier study proved a key element required for this method to work for leak detection - that electrical imaging adjacent to a highly conducting metal surface (the tank bottom) is possible. Prior to this work the concern was that so much electrical current flow would be through the steel tank as opposed to the more resistive soil, that there would be little sensitivity to the existence of conductivity changes adjacent to the tank.

The purpose of the work reported herein is to demonstrate the usefulness of ERT for detecting leaks from underground storage tanks under more rigorous conditions than previously studied. In this investigation a sequence of controlled leaks from an experimental ("mock")tank were generated over a period of 110-days s. By conducting ERT surveys on a daily basis, with no knowledge of the leak conditions or leak history, an assessment of the integrity of the tank each day was made. At the end of the experiment, the actual controlled leak history was made available and we are able to assess the success of the methodology and compare different ways in which ERT data may be used to determine the likelihood of leakage.

An additional and important aspect of the work is to demonstrate that the method can be made to work remotely; that is, ERT instrumentation operates unattended, for as long as necessary. The goal is operation without personal on site - that is, setting of operational parameters, initiation and termination of data acquisition, and moving data files to central computers for post processing.

\section{Experiment Description}

\section{Site Description}

The experiment was conducted at a tank mockup (Mock Tank 105A) located at the Hanford Reservation, 200 East Area. The site was chosen and the facility built to simulate, as closely as practical, conditions in a tank farm at Hanford. The strategy was to release a surrogate tank waste from the mock tank and use our candidate leak detection method to detect the release. This way it is possible to test performance under realistic conditions.

Site geology is similar to that at the Hanford tank farms - the site is only a few miles from them-and is described by Reidel et al., (1992). The near surface sediments were deposited during periods of Pleistocene cataclysmic flooding and Holocene eolian activity. The cataclysmic flooding occurred when ice dams in western Montana and northern Idaho were breached, allowing large volumes of water to spill across eastern and northern Idaho. The flood created a variety of deposits, including giant flood bars.

The site is underlain by the Hanford formation, which includes one of the cataclysmic flood bars. The Hanford formation consists of pebble size gravel to boulders, fine to coarse grained sand, and silt. This formation is thickest in the vicinity of the 200 West and 200 East Areas where it up to $65 \mathrm{~m}$ thick. The near surface sediments at the site consist primarily of fine to coarse- 
grained sand displaying plane lamination and bedding. Paleo-current indicators within the beds of plane-laminated sands are unidirectional, generally toward the south and east. Hydraulic conductivities for these sediments depend upon the silt content, which is variable. Electrical resistivity of the near surface sediments are fairly uniform to a depth of $20 \mathrm{~m}$ and are a few hundred Ohm-m.(Ramirez et al. 1996).

The electrical resistivity of the mock tank shell is similar to that of an in-service tank--the steel construction provides a highly conductive boundary directly below which the electrical resistivity must be mapped. The bottom of the mock tank is set only $1.5 \mathrm{~m}$ below ground level whereas in-service tanks are buried so that their bottoms are $15 \mathrm{~m}$ below ground surface. This is not an important difference and the mock tank construction does simplify the test. At $15.2 \mathrm{~m}$ diameter the mock tank is a reasonable test model for even the largest $23 \mathrm{~m}$ diameter tanks.

Several release points are built into the mock tank so that fluid can be released at a controlled rate into the soil. These release points were located near the edge, to simulate 'bathtub ring' corrosion holes, as well as points nearer the center to simulate corrosion holes in the bottom seams. A diagram of the mock tank is shown in Figure 1.

Not shown in the figure, a steel sheet pile wall $10 \mathrm{~m}$ long and $5 \mathrm{~m}$ deep, was installed $6 \mathrm{~m}$ south west of the tank to simulate the proximity of an adjacent tank wall. This was electrically connected to the mock tank since all tanks in a tank farm are electrically connected by plumbing that allows tank contents to be moved between tanks. The concern was that adjacent tanks could shunt electric current away from the volume under the mock tank and significantly reduce sensitivity of the method.

During earlier tests at this site (see Ramirez et al., 1996) an array of 64 electrodes were installed round the mock tank. (see Figure 1). From this array we were able to use ERT to map the two and three dimensional electrical resistivity distribution under the tank to a depth of $11.7 \mathrm{~m}$ (the deepest electrode). The diametrical distance between the electrode arrays was $20.7 \mathrm{~m}$. Although this arrangement of electrodes is not optimal for imaging the volume under the tank, it is a reasonable choice that can be installed near an actual tank given all the constraints that would be imposed working in a tank farm. Given this array, we needed to design the best scheme for detecting releases from the tank. It should be noted that such an array of electrodes would not be realistic in a existing tank farm because of drilling requirements, worker safety and expense issues. For this reason other alternatives including using the existing drywells as electrodes were considered and the ERT-LE (long electrode) method was chosen for testing as described below. 


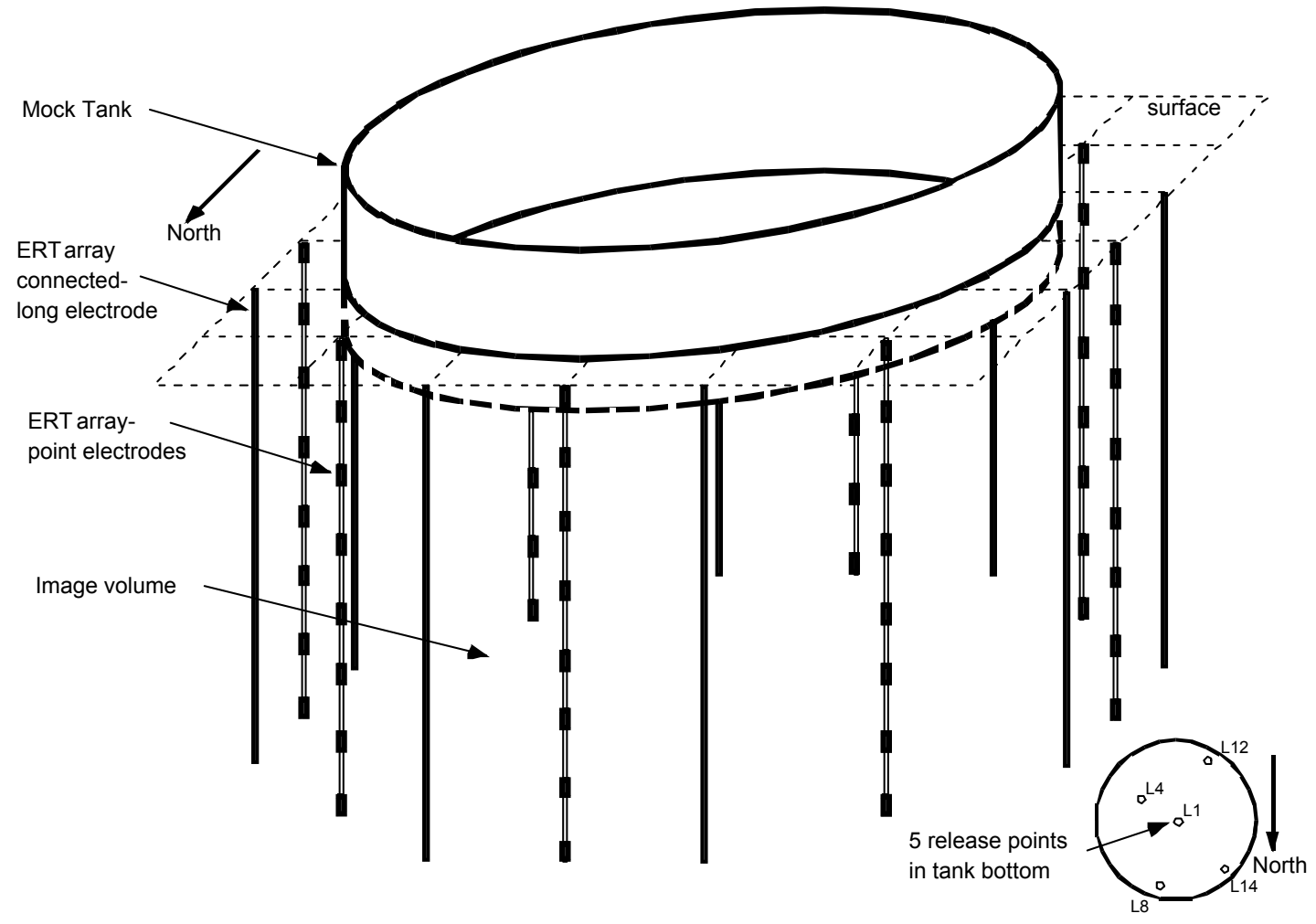

Figure 1. Schematic of the experimental set up for the mock tank. A 15 m diameter steel tank, the lower $1 \mathrm{~m}$ of which is buried, contains several built-in leak points shown in the lower right insert. Sixteen boreholes on an approximately $19 \mathrm{~m}$ diameter circle, each with 8 electrodes uniformly spaced between the surface and 35 feet depth, surround the tank. For every other electrode array the electrodes are connected together to approximate a continuous electrode 35 feet long.

Measurement scheme for ERT

The ideal test design will be much different from the one dictated by budget and time constraints. However, it is valuable to consider the ideal to guide the test design. Not surprisingly, the optimal design for obtaining the best leak-volume estimate would be to use as many electrodes as possible, uniformly spaced throughout the volume of interest or spaced uniformly on the surface of the volume of interest. The test was designed with that ideal in mind but also to be compatible with constraints of working within an operating tank farm.

Installing electrode arrays in a tank farm is expensive, therefore, we wanted to investigate the feasibility of using existing infrastructure as electrodes. Two options are available. First, there are a number of steel cased wells adjacent to many of the tanks which are used to monitor gamma ray activity resulting from any highly radioactive plumes. These boreholes could be used as 'long' electrodes to sense bulk resistivity changes beneath the tank as well as provide two dimensional images of horizontal (integrated over the casing length) resistivity variation. Second, the tank itself could be used as an electrode. This is attractive because the tank will be adjacent to any leak plume and it is known that the electrodes most sensitive to resistivity changes are those in closest proximity to those changes. In fact, Ramirez et al., (1996) reported that using the tank as an electrode significantly improved ERT images of a plume directly under the tank. They also reported successful results using 'long electrodes' to detect a leak. Binley et 
al.(1997) also report on successful attempts to detect leaks from the mock tank using the tank as an electrode.

With all of the above considerations, the following test design was used. Electrodes (except the surface electrodes) from the even numbered arrays in Figure 1, taken together provided 56 'point' electrodes, and were used to generate data 'set 1' (explained below). All the electrodes (including the surface electrode) in each odd numbered array were shorted together to approximate a 'long' electrode (a steel cased well used as an electrode) and these shorted arrays taken together provided 8 long electrodes used to generate data 'set 2'.

Even though using the tank itself as an electrode would improve the sensitivity of the data to the presence of a leak, the tank was not used as an electrode in any of the data acquisition schemes.

Data set 1 required about 110 minutes to acquire and was taken each day during the test. The 56 electrodes were sampled using 4-electrode measurements, the transmitter dipole spanning three electrodes and the receiver dipole spanning three electrodes. This resulted in a total of 1296 linearly independent measurements and the same number of (linearly dependent) reciprocal measurements (a reciprocal pair are generated by interchanging the transmitter and receiver dipoles). The reciprocal data were used to estimate data quality. Any reciprocal pair that differed by more than 5\% was not used in the analysis. Data set 1 was used to produce a 3 dimensional tomograph of the region under the mock tank to $11.6 \mathrm{~m}$ depth. Voxel by voxel differences between images on consecutive days were used to determine if a release occurred between the two days.

Data set 1 was also used to calculate various statistics in an effort to find a simple leak diagnostic that did not require the investment in computer time for tomographic inversion. Two different statistics were examined with the plan to evaluate their predictive capabilities after the test by comparing each with the actual test release schedule.

First, we calculated $\bar{\rho}$ the geometric mean apparent resistivity,

$$
\bar{\rho}=\left(\prod_{i=1}^{n} \rho_{i}\right)^{1 / n}
$$

where $\rho_{i}$ is the $i^{\text {th }}$ apparent resistivity and $n$ is the number of apparent resistivity values that pass the reciprocity test. Second, we calculated $R$ the average logarithm of the ratio of corresponding transfer resistance values (we will call this the 'mean log ratio') measured on consecutive days,

$$
R=\frac{1}{n} \sum_{i=1}^{n} \log \left(\frac{r_{i}^{t}}{r_{i}^{t-1}}\right)
$$

where $r_{i}^{t}$ and $r_{i}^{t-1}$ are the $i^{\text {th }}$ transfer resistances on day $t$ and $t-1$. 
Data set 2 required about 10 minutes to acquire and was also taken each day during the test. The 8 electrodes were sampled using 4-electrode measurements, the transmitter dipole and the receiver dipole both spanning one electrode. This resulted in a total of 20 linearly independent measurements and the same number of reciprocal measurements. Data set 2 was used to produce a 2 dimensional tomograph of the region under the mock tank which showed horizontal variations of the average resistivity between the tank and $11.6 \mathrm{~m}$ depth. Voxel by voxel differences between images on consecutive days was one diagnostic used to determine if a release occurred between the two days.

Data set 2 was also used to calculate the geometric mean apparent resistivity for the long electrode survey using equation (1). In addition, equation (2) was applied to data set 2 in order to assess changes in resistivity on a day to day basis.

\section{Test protocol}

To make the test as realistic as possible, the following protocol was followed:

(1) The test ran for 109consecutive days, corresponding to expected typical clean up campaigns for actual tanks.

(2) Periodically during the test, a sodium thiosulfate brine of controlled volume was released from one of the release points. The brine concentration was chosen to match as closely as practical the electrical resistivity, viscosity and density expected of actual tank contents. The fluid resistivity was $0.067 \mathrm{ohm} \mathrm{m}(15 \mathrm{~S} / \mathrm{m}$ - about 5 times more conductive than sea water) and about 3000 times more conductive that the subsurface sediment without the addition of the brine..

(3) The time of the release, the location and the volume of the release were not known to the authors until the end of the 109-day test. A summary of the released volumes is given in Table 1 .

(4) ERT data were collected each day and used to determine if there was a release of fluid since the previous data set. The leak-no leak decision was made only from the electrical data in the following way (determined before the test started):

(a) Data set 1 was used to calculate a bulk resistivity of the soil beneath the mock tank. The geometric mean of apparent resistivity using the point electrode data, $\bar{\rho}_{P}$, was used. 
Table 1. Table of test matrix showing volumes, times locations etc.

\begin{tabular}{|c|c|c|c|c|c|c|c|c|c|c|}
\hline \multicolumn{11}{|c|}{ Injection Schedule } \\
\hline \multirow[b]{2}{*}{ Date } & \multirow[b]{2}{*}{ Day } & \multirow[b]{2}{*}{ ID } & \multirow[b]{2}{*}{ Locale } & \multicolumn{6}{|c|}{ Actual Injection } & \multirow[b]{2}{*}{ Comments } \\
\hline & & & & Start Time & Stop Time & $\begin{array}{l}\text { Average } \\
\text { Rate gph } \\
\end{array}$ & \begin{tabular}{|c|} 
Average Rate \\
$2200-2400$ \\
gph
\end{tabular} & $\begin{array}{c}\text { Average Rate } \\
1800 \text { - } 2400 \\
\text { gph }\end{array}$ & $\begin{array}{l}\text { Volume } \\
@ 2300 \mathrm{hr} \\
\end{array}$ & \\
\hline 22-Jul & 0 & $\mathrm{~A}$ & L3 & $7 / 22 / 0214: 00$ & & & & & 0 & \\
\hline u23-Jul & 1 & A & L3 & & & & & & 0 & \\
\hline 24-Jul & 2 & A & L3 & & & & & & $\mathbf{0}$ & \\
\hline 25-Jul & 3 & A & L3 & & $7 / 26 / 0219: 30$ & & & & 0 & \\
\hline 26-Jul & 4 & $\mathrm{~B}$ & L1 & $7 / 26 / 0219: 36$ & & 2.00 & 1.995 & 1.995 & 30 & \\
\hline 27-Jul & 5 & $\mathrm{~B}$ & L1 & & & 2.00 & 1.950 & 1.992 & 74 & \\
\hline 28-Jul & 6 & $\mathrm{~B}$ & L1 & & & 2.00 & 1.954 & 1.963 & 95 & \\
\hline 29-Jul & 7 & $\mathrm{~B}$ & L1 & & & 2.00 & 2.015 & 2.016 & 173 & \\
\hline 30-Jul & 8 & $\mathrm{~B}$ & L1 & & & 2.00 & 1.981 & 1.997 & 222 & \\
\hline 31-Jul & 9 & $\mathrm{~B}$ & L1 & & & 2.00 & 1.981 & 2.008 & 269 & \\
\hline 1-Aug & 10 & $\mathrm{~B}$ & $\mathrm{~L} 1$ & & & 2.00 & 2.028 & 2.024 & 318 & \\
\hline 2-Aug & 11 & $\mathrm{~B}$ & L1 & & & 2.00 & 1.981 & 1.981 & 365 & \\
\hline 3-Aug & 12 & $\mathrm{~B}$ & L1 & & & 2.00 & 2.005 & 2.010 & 413 & \\
\hline 4-Aug & 13 & $\mathrm{~B}$ & L1 & & & 2.00 & 2.001 & 2.001 & 461 & \\
\hline 5-Aug & 14 & $\mathrm{~B}$ & L1 & & & 2.00 & 2.010 & 2.007 & 509 & \\
\hline 6-Aug & 15 & $\mathrm{~B}$ & L1 & & & 2.00 & 1.992 & 2.006 & 557 & \\
\hline 7-Aug & 16 & $\mathrm{~B}$ & L1 & & & 2.00 & 2.021 & 2.009 & 605 & \\
\hline 8-Aug & 17 & $\mathrm{~B}$ & L1 & & & 2.00 & 2.013 & 2.011 & 654 & \\
\hline 9-Aug & 18 & $\mathrm{~B}$ & L1 & & & 2.00 & 2.018 & 2.014 & 702 & \\
\hline 10-Aug & 19 & $\mathrm{~B}$ & L1 & & & 2.00 & 2.038 & 2.025 & 750 & \\
\hline 11-Aug & 20 & $\mathrm{~B}$ & L1 & & & 2.00 & 2.008 & 2.005 & 799 & \\
\hline 12-Aug & 21 & $\mathrm{~B}$ & L1 & & & 2.00 & 2.013 & 2.015 & 847 & \\
\hline 13-Aug & 22 & $\mathrm{~B}$ & L1 & & & 2.00 & 2.000 & 2.006 & 893 & \\
\hline 14-Aug & 23 & $\mathrm{~B}$ & L1 & & & 2.00 & 1.989 & 2.002 & 941 & \\
\hline 15-Aug & 24 & $\mathrm{~B}$ & L1 & & $8 / 16 / 02 \quad 10: 56$ & 2.00 & 2.026 & 2.068 & 990 & \\
\hline 16-Aug & 25 & $\mathrm{C}$ & L1 & $8 / 16 / 02$ 11:00 & & & & & 1014 & \\
\hline 17-Aug & 26 & $\mathrm{C}$ & L1 & & & & & & 1014 & \\
\hline 18-Aug & 27 & $\mathrm{C}$ & L1 & & & & & & 1014 & \\
\hline 19-Aug & 28 & $\mathrm{C}$ & L1 & & & & & & 1014 & \\
\hline 20-Aug & 29 & $\mathrm{C}$ & L1 & & $8 / 21 / 02 \quad 12: 00$ & & & & 1014 & \\
\hline 21-Aug & 30 & $\mathrm{D}$ & L1 & $8 / 21 / 02 \quad 12: 13$ & & 20.05 & 20.100 & 20.100 & 1252 & \\
\hline 22-Aug & 31 & $\mathrm{D}$ & L1 & & $8 / 23 / 0213: 35$ & 20.05 & 20.100 & 20.100 & 1735 & \\
\hline 23-Aug & 32 & $E$ & L1 & $8 / 23 / 0214: 00$ & & & & & 2025 & \\
\hline 24-Aug & 33 & $\mathrm{E}$ & L1 & & & & & & 2025 & \\
\hline 25-Aug & 34 & $\mathrm{E}$ & L1 & & & & & & 2025 & \\
\hline 26-Aug & 35 & $\mathrm{E}$ & L1 & & $8 / 27 / 02 \quad 17: 30$ & & & & 2025 & \\
\hline 27-Aug & 36 & $\mathrm{~F}$ & L3 & $8 / 27 / 02$ 18:00 & & 20.05 & 20.010 & 20.010 & 2124 & \\
\hline 28-Aug & 37 & $\mathrm{~F}$ & L3 & & $8 / 29 / 02 \quad 17: 36$ & 20.05 & 20.010 & 20.010 & 2609 & \\
\hline 29-Aug & 38 & $\mathrm{G}$ & L3 & $8 / 29 / 02 \quad 17: 45$ & & & & & 2979 & \\
\hline 30-Aug & 39 & $\mathrm{G}$ & L3 & & & & & & 2979 & \\
\hline 31-Aug & 40 & $\mathrm{G}$ & L3 & & & & & & 2979 & \\
\hline 1-Sep & 41 & $\mathrm{G}$ & L3 & & $9 / 2 / 02 \quad 13: 55$ & & & & 2979 & $\begin{array}{l}\text { Rain Event } 406 \text { gallons } \\
14: 00 \text { to } 14: 20\end{array}$ \\
\hline 2-Sep & 42 & $\mathrm{H}$ & L10 & $9 / 2 / 0214: 00$ & & & & & 2979 & \\
\hline 3-Sep & 43 & $\mathrm{H}$ & L10 & & & & & & 2979 & \\
\hline 4-Sep & 44 & $\mathrm{H}$ & $\mathrm{L} 10$ & & & & & & 2979 & \\
\hline 5-Sep & 45 & $\mathrm{H}$ & $\mathrm{L} 10$ & & $9 / 6 / 02 \quad 14: 30$ & & & & 2979 & \\
\hline 6-Sep & 46 & $\mathrm{I}$ & L10 & $9 / 6 / 0214: 34$ & & 10.01 & 10.041 & 10.043 & 3063 & \\
\hline 7-Sep & 47 & $\mathrm{I}$ & $\mathrm{L} 10$ & & & 10.01 & 9.997 & 10.004 & 3304 & \\
\hline 8-Sep & 48 & $\mathrm{I}$ & $\mathrm{L} 10$ & & & 10.01 & 9.994 & 9.989 & 3544 & \\
\hline
\end{tabular}


Table 1. (Contd)

\begin{tabular}{|c|c|c|c|c|c|c|c|c|c|c|}
\hline \multicolumn{11}{|c|}{ Injection Schedule } \\
\hline \multirow[b]{2}{*}{ Date } & \multirow[b]{2}{*}{ Day } & \multirow[b]{2}{*}{ ID } & \multirow[b]{2}{*}{ Locale } & \multicolumn{6}{|c|}{ Actual Injection } & \multirow[b]{2}{*}{ Comments } \\
\hline & & & & Start Time & Stop Time & $\begin{array}{l}\text { Average } \\
\text { Rate gph }\end{array}$ & \begin{tabular}{|c|} 
Average Rate \\
$2200-2400$ \\
gph
\end{tabular} & \begin{tabular}{|c|} 
Average Rate \\
$1800-2400$ \\
gph
\end{tabular} & $\begin{array}{c}\text { Volume } \\
@ 2300 \mathrm{hr}\end{array}$ & \\
\hline 9-Sep & 49 & $\bar{I}$ & $\overline{\mathrm{L} 10}$ & & \begin{tabular}{|l|l}
$9 / 10 / 02$ & $14: 35$ \\
\end{tabular} & 10.01 & 9.975 & 9.993 & 3784 & \\
\hline 10-Sep & 50 & $\mathrm{~J}$ & L10 & $9 / 10 / 0214: 45$ & & 18.63 & 18.602 & 18.567 & 4092 & \\
\hline 11-Sep & 51 & $\mathrm{~J}$ & L10 & & 9/12/02 $14: 44$ & 18.63 & 18.557 & 18.514 & 4542 & $\begin{array}{l}\text { Rain Event } 725 \text { gallons } \\
14: 00 \text { to } 14: 40\end{array}$ \\
\hline 12-Sep & 52 & $\mathrm{~K}$ & L14 & $9 / 12 / 02 \quad 15: 25$ & & & & & 4834 & \\
\hline 13-Sep & 53 & $\mathrm{~K}$ & L14 & & & & & & 4834 & \\
\hline 14-Sep & 54 & $\mathrm{~K}$ & L14 & & & & & & 4834 & \\
\hline 15-Sep & 55 & $\mathrm{~K}$ & L14 & & & & & & 4834 & \\
\hline 16-Sep & 56 & $\mathrm{~K}$ & L14 & & & & & & 4834 & \\
\hline 17-Sep & 57 & $\mathrm{~K}$ & L14 & & & & & & 4834 & \\
\hline 18-Sep & 58 & $\mathrm{~K}$ & L14 & & $9 / 19 / 029: 36$ & & & & 4834 & \\
\hline 19-Sep & 59 & $\mathrm{~L}$ & L14 & 9/19/02 10:28 & & 10.06 & 10.019 & 10.026 & 4960 & \\
\hline 20-Sep & 60 & $\mathrm{~L}$ & L7 & & & 10.06 & 10.143 & 10.127 & 5201 & \\
\hline 21-Sep & 61 & $\mathrm{~L}$ & $\mathrm{~L} 2$ & & & 10.06 & 10.025 & 10.034 & 5445 & \\
\hline 22-Sep & 62 & $\mathrm{~L}$ & $\mathrm{~L} 2$ & & 9/23/02 13:29 & 10.06 & 10.024 & 10.028 & 5686 & \\
\hline 23-Sep & 63 & $\mathrm{M}$ & $\mathrm{L} 2$ & $9 / 23 / 0214: 17$ & & 10.18 & 10.135 & 10.129 & 5919 & \\
\hline 24-Sep & 64 & $\mathrm{M}$ & L2 & & & 10.18 & 10.226 & 10.246 & 6164 & \\
\hline 25-Sep & 65 & $\mathrm{M}$ & $\mathrm{L} 2$ & & & 10.18 & 10.113 & 10.108 & 6409 & \\
\hline 26-Sep & 66 & $\mathrm{M}$ & L2 & & 9/27/02 14:13 & 10.18 & 10.222 & 10.213 & 6653 & Natural Rain, Trace \\
\hline 27-Sep & 67 & $\mathrm{~N}$ & L10 & $9 / 27 / 0214: 33$ & & & & & 6807 & \\
\hline 28-Sep & 68 & $\mathrm{~N}$ & L10 & & & & & & 6807 & \\
\hline 29-Sep & 69 & $\mathrm{~N}$ & L10 & & \begin{tabular}{|l|}
$9 / 30 / 02 ~ 11: 17$ \\
\end{tabular} & & & & 6807 & Natural Rain, Trace \\
\hline 30-Sep & 70 & $\mathrm{O}$ & L10 & $9 / 30 / 02 \quad 12: 39$ & & & & & 6807 & $\begin{array}{l}\text { Rain Event } 679 \text { gallons } \\
13: 00 \text { to } 13: 25\end{array}$ \\
\hline 1-Oct & 71 & $\mathrm{O}$ & L10 & & & & & & 6807 & \\
\hline 2-Oct & 72 & $\mathrm{O}$ & L10 & & & & & & 6807 & $\begin{array}{l}\text { Rain Event } 722 \text { gallons } \\
\text { 14:02 to } 15: 07\end{array}$ \\
\hline 3-Oct & 73 & $\mathrm{O}$ & L10 & & $10 / 3 / 0216: 33$ & & & & 6807 & Natural Rain, 0.08 inches \\
\hline 4-Oct & 74 & $\mathrm{P}$ & L14 & $10 / 4 / 02 \quad 12: 18$ & & 19.07 & 20.416 & 20.396 & 7026 & \\
\hline 5-Oct & 75 & $\mathrm{P}$ & L12 & & & 19.07 & 19.096 & 19.066 & 7505 & \\
\hline 6-Oct & 76 & $\mathrm{P}$ & L12 & & & 19.07 & 18.686 & 18.691 & 7960 & \\
\hline 7-Oct & 77 & $\mathrm{P}$ & L12 & & $10 / 8 / 0213: 16$ & 19.07 & 18.653 & 18.665 & 8408 & \\
\hline 8-Oct & 78 & $\mathrm{Q}$ & L5 & $10 / 8 / 0213: 33$ & & & & & 8659 & \\
\hline 9-Oct & 79 & Q & L14 & & & & & & 8659 & \\
\hline 10-Oct & 80 & Q & L14 & & 10/11/02 12:58 & & & & 8659 & \\
\hline 11-Oct & 81 & $\mathrm{R}$ & $\begin{array}{l}\mathrm{L} 12 \& \\
\mathrm{~L} 13\end{array}$ & 10/11/02 13:08 & & 18.79 & 18.691 & 18.675 & 8846 & \\
\hline 12-Oct & 82 & $\mathrm{R}$ & L5 \& L13 & & & 18.79 & 18.804 & 18.771 & 9289 & \\
\hline 13-Oct & 83 & $\mathrm{R}$ & L5 \& L13 & & & 18.79 & 18.809 & 18.783 & 9745 & \\
\hline 14-Oct & 84 & $\mathrm{R}$ & L5 \& L13 & & $10 / 15 / 02 \quad 12: 33$ & 18.79 & 18.813 & 18.785 & 10197 & \\
\hline 15-Oct & 85 & $\mathrm{~S}$ & L12 & $10 / 15 / 02 \quad 12: 43$ & & & & & 10452 & \\
\hline 16-Oct & 86 & $\mathrm{~S}$ & L12 & & & & & & 10452 & \begin{tabular}{|l} 
Flood Event, 2000 \\
gallons 13:30 to $16: 00$
\end{tabular} \\
\hline 17-Oct & 87 & $\mathrm{~S}$ & L12 & & & & & & 10452 & \\
\hline 18-Oct & 88 & $\mathrm{~S}$ & L12 & & & & & & 10452 & \\
\hline 19-Oct & 89 & $\mathrm{~S}$ & L12 & & & & & & 10452 & \\
\hline 20-Oct & 90 & $\mathrm{~S}$ & L12 & & 10/21/02 10:42 & & & & 10452 & \\
\hline 21-Oct & 91 & $\mathrm{~T}$ & L12 & $10 / 21 / 02 \quad 10: 54$ & & 1.82 & 1.833 & 1.833 & 10474 & \\
\hline 22-Oct & 92 & $\mathrm{~T}$ & L5 & & & 1.82 & 1.777 & 1.791 & 10517 & \\
\hline 23-Oct & 93 & $\mathrm{~T}$ & L5 & & & 1.82 & 1.826 & 1.828 & 10560 & \\
\hline 24-Oct & 94 & $\mathrm{~T}$ & L5 & & & 1.82 & 1.862 & 1.855 & 10604 & \\
\hline 25-Oct & 95 & $\mathrm{~T}$ & L5 & & 10/25/02 17:48 & 1.82 & & & 10639 & \\
\hline
\end{tabular}


Table 1. (Contd)

\begin{tabular}{|c|c|c|c|c|c|c|c|c|c|c|}
\hline \multicolumn{11}{|c|}{ Injection Schedule } \\
\hline \multirow[b]{2}{*}{ Date } & \multirow[b]{2}{*}{ Day } & \multirow[b]{2}{*}{ ID } & \multirow[b]{2}{*}{ Locale } & \multicolumn{6}{|c|}{ Actual Injection } & \multirow[b]{2}{*}{ Comments } \\
\hline & & & & Start Time & Stop Time & $\begin{array}{l}\text { Average } \\
\text { Rate gph }\end{array}$ & $\begin{array}{c}\text { Average Rate } \\
2200-2400 \\
\text { gph }\end{array}$ & $\begin{array}{c}\text { Average Rate } \\
1800-2400 \\
\text { gph }\end{array}$ & $\begin{array}{l}\text { Volume } \\
\text { @2300hr }\end{array}$ & \\
\hline 26-Oct & 96 & $\mathrm{U}$ & L5 & 10/25/02 18:06 & & & & & 10639 & \\
\hline 27-Oct & 97 & $\mathrm{U}$ & L5 & & $10 / 28 / 02 \quad 10: 30$ & & & & 10639 & \\
\hline 28-Oct & 98 & $\mathrm{~V}$ & L3 & 10/28/02 10:40 & & 9.53 & 10.247 & 10.237 & 10764 & Natural Rain, Trace \\
\hline 29-Oct & 99 & $\mathrm{~V}$ & L1 & & $10 / 30 / 028: 10$ & 9.53 & 10.335 & 10.309 & 11011 & Natural Rain, 0.04 inches \\
\hline 30-Oct & 100 & $\mathrm{~W}$ & L1 & $10 / 30 / 028: 15$ & & 19.95 & 19.320 & 19.340 & 11395 & $\begin{array}{l}\text { Sheet piling disconnected, } \\
7: 50\end{array}$ \\
\hline 31-Oct & 101 & W & L1 & & & 19.95 & 20.200 & 19.860 & 11865 & \\
\hline 1-Nov & 102 & $\mathrm{~W}$ & L1 & & $11 / 2 / 028: 09$ & 19.95 & 20.100 & 20.110 & 12353 & \\
\hline 2-Nov & 103 & $\mathrm{X}$ & L1 & $11 / 2 / 028: 30$ & & & & & 12536 & \\
\hline 3-Nov & 104 & $\mathrm{X}$ & L1 & & & & & & 12536 & \\
\hline 4-Nov & 105 & $\mathrm{X}$ & L1 & & $11 / 5 / 029: 13$ & & & & 12536 & \\
\hline 5-Nov & 106 & $\mathrm{Y}$ & L1 & $11 / 5 / 0210: 34$ & & 20.24 & 20.310 & 20.220 & 12788 & $\begin{array}{l}\text { Sheet piling reconnected, } \\
9: 40\end{array}$ \\
\hline 6-Nov & 107 & $\mathrm{Y}$ & L1 & & $11 / 7 / 02 \quad 13: 49$ & 20.24 & 20.250 & 20.250 & 13272 & \\
\hline 7-Nov & 108 & $\mathrm{Z}$ & L1 & $11 / 4 / 0214: 00$ & & & & & 13571 & Natural Rain, 0.13 inches \\
\hline 8-Nov & 109 & $\mathrm{Z}$ & L1 & & $11 / 8 / 0223: 59$ & & & & 13571 & Natural Rain, 0.03 inches \\
\hline
\end{tabular}

(b) In an analogous way, the long electrodes were used to calculate a geometric mean bulk resistivity $\bar{\rho}_{L}$ beneath the tank.

(c) When $\bar{\rho}_{P}$ decreased by more than $2 \%$ from its value on a baseline day, a leak flag $\left(F_{P}\right)$ was set. The baseline days were set by the person controlling the leak events.

(d) When $\bar{\rho}_{L}$ decreased by more than $6 \%$ from its value on the baseline day, a leak flag $\left(F_{L}\right)$ was set.

(e) If either $F_{P}$ or $F_{L}$ were set for a particular day then the 2-D and 3-D tomographs were examined to make the final decision if there had been a leak. Voxel by voxel percent differences between reconstructions from that day the previous day were used for the analysis. If these comparison images showed evidence of a conductive plume beneath the tank, a 'leak' condition was declared for that day. If they did not show convincing evidence of a plume, a 'no-leak' condition was declared for that day.

(f) if neither $F_{P}$ or $F_{L}$ were set for a particular day then a 'no leak' decision was reached 5-6 hours after data acquisition was complete.

Data acquisition required about 2 hours each day. Processing and interpretation required an additional 4 to 5 hours. For most days, the 'leak' or 'no-leak' condition was declared for a 24hour test period within the same day the test period ended.

\section{Measurement system used for ERT}

A commercial resistivity system (Zonge Engineering and Research Organization, GDP 32 receiver with MX 32 multiplexers) was used to acquire data. A desktop computer running 
system-specific control software automatically controlled the acquisition sequence. Each day 2592 measurements (which included reciprocals) of transfer resistance (ratio of voltage to current) were made on the 'point' electrodes with 40 measurements on the 'long' electrodes. Data were collected using an injection frequency of $0.5 \mathrm{~Hz}$ with 4 stacks.

To reduce operating costs during a long sluicing campaign we tested and ultimately used a remote measurement control and data acquisition system. The goal was to test a system that would allow frequent testing for leaks (e.g., daily or more often) over several months without the costs of on site personnel to set system parameters, initiate data acquisition, download files, process and interpret data. The system we tested allowed all of these functions to be performed from any remote computer that could access the internet.

The control computer at the 200 East Area at Hanford, Washington was controlled by a remote command computer located at LLNL in Livermore, California. Communication was via commercial software (Timbuktu) so that all the measurement system control parameters could be set remotely. The network used a virtual private network (VPN) to penetrate security 'firewalls' at both Lawrence Livermore National Laboratory (LLNL) and Pacific Northwest National Laboratory (PNNL). The remote system worked well using both high speed Ethernet connection or a lower speed dial-up modem connection for the remote command computer. The operator then had the flexibility to work from the office during the week or from anywhere there was a phone line (i.e., home and a low speed connection) on the weekends and holidays. A schematic of the network is shown in Figure 2, and pictures of the system are shown in Figure 3.

During the 110 days of continuous operating the remote system worked surprisingly well. On two occasions an amplifier battery required replacing and on two other occasions power supplies failed resulting in a total of only 4 days of lost data. Although there were minor problems with the network, they did not result in lost data.

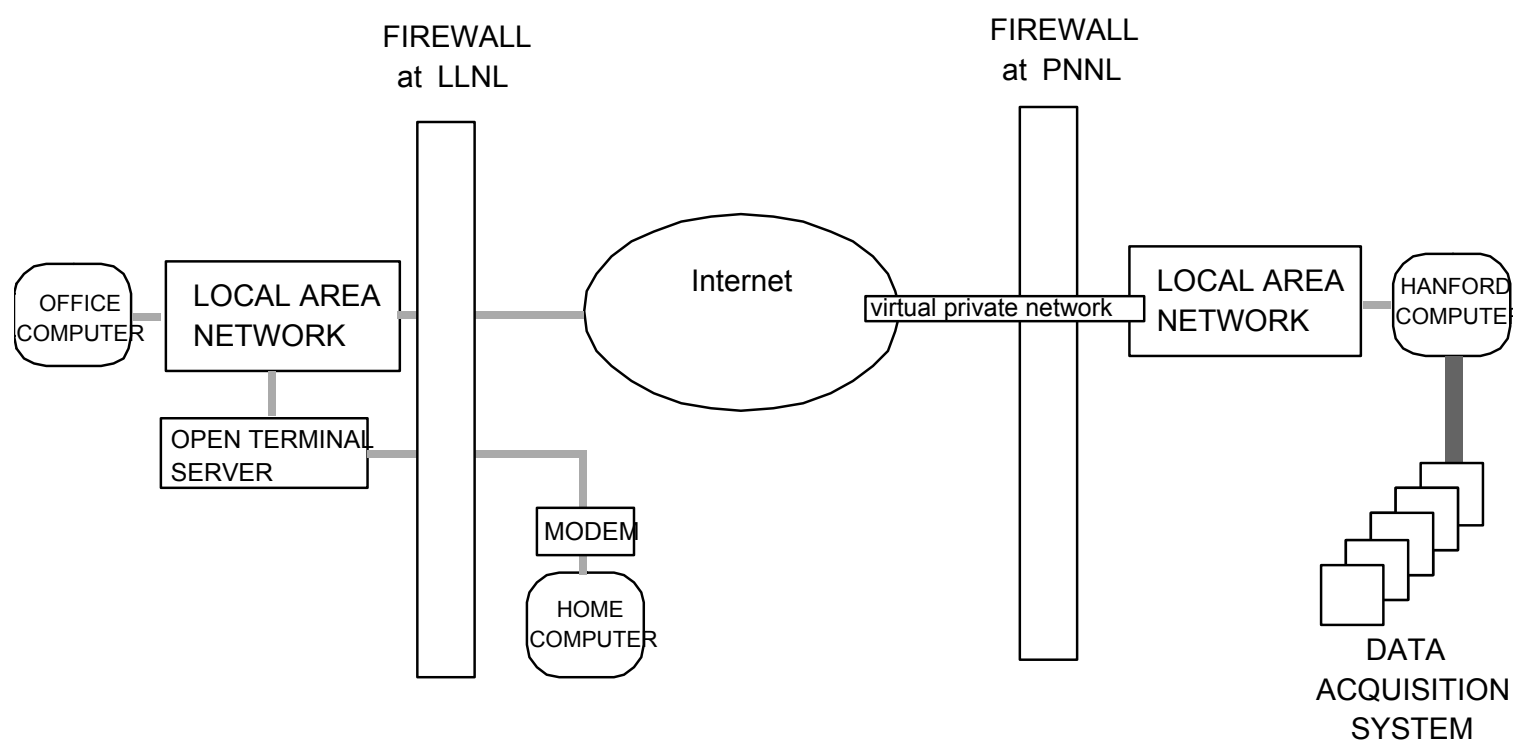

Figure 2. Block diagram of the principle components for the remotely operated data acquisition and control. 
We can run Zeta remotely from anywhere there is telephone or internet service

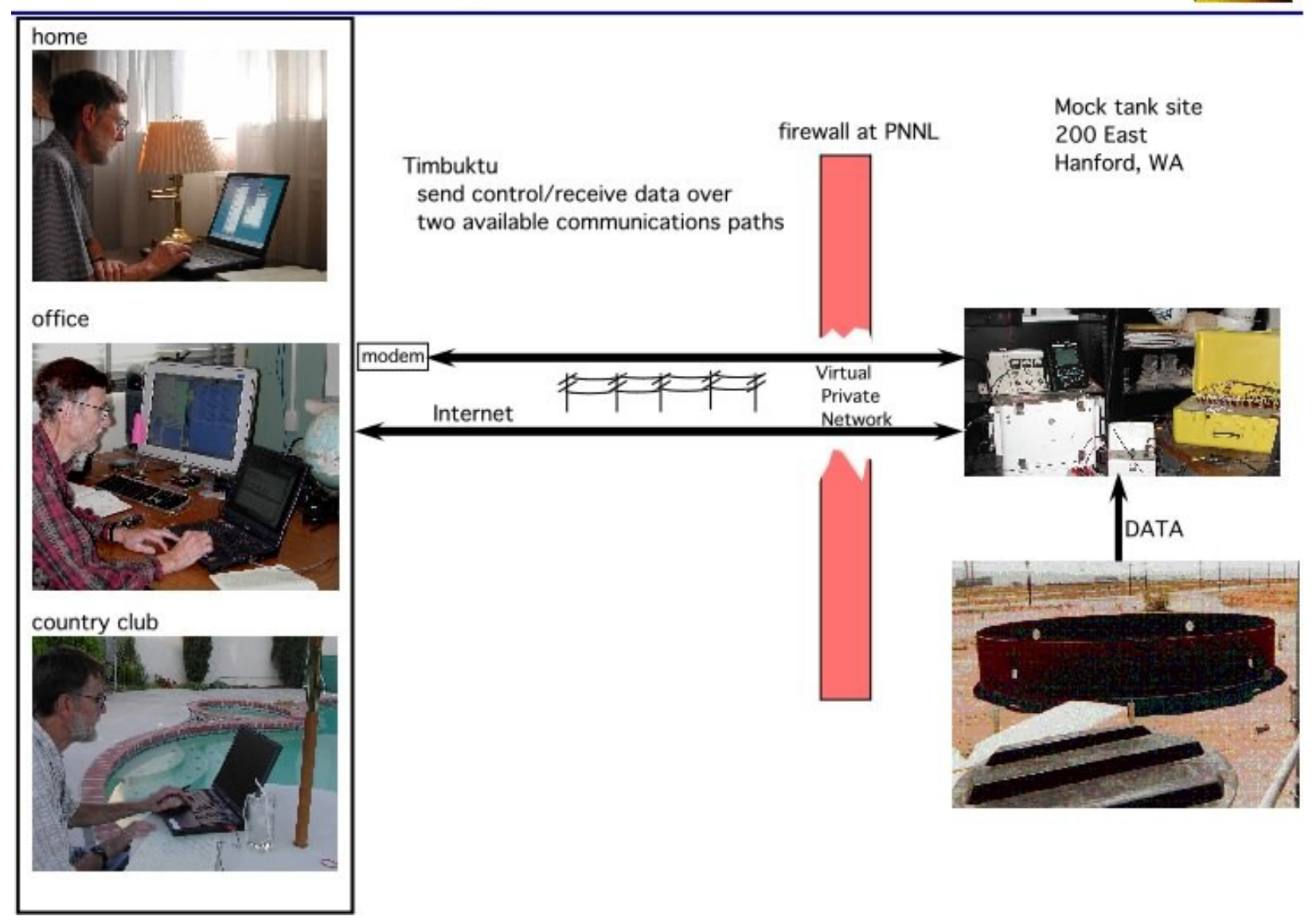

Figure 3. From a remote computer in California, or anywhere the internet was accessible, it was possible to control the data acquisition computer at the mock tank test site and move data files for processing.

\section{Data Analysis and Theory}

\section{Reconstruction of resistivity images}

In order to calculate a resistivity image from ERT data it is necessary to carry out an inversion that produces a model (that is, a spatially varying distribution of resistivity) that gives an 'acceptable' fit to the data and satisfies any other prescribed constraints. The numerical procedure requires three elements: a forward model which computes transfer resistance given a 2-D or 3-D distribution of resistivity; an objective function which states the model fitting criteria that will be adopted and a search algorithm which determines the way in which the 'optimum' resistivity model is found.

The objective function used here adopts the commonly used smoothness constraint and can be written as: 


$$
\Psi(\mathbf{m})=\left\|\mathbf{W}_{\mathrm{d}}[\mathbf{d}-\mathbf{f}(\mathbf{m})]\right\|^{2}+\alpha\left\|\mathbf{W}_{\mathrm{m}}(\mathbf{m})\right\|^{2}
$$

Where $\mathbf{d}$ is the data vector, $\mathbf{f}$ is the forward model operator, $\mathbf{W}_{\mathrm{d}}$ is a data weighting matrix, $\alpha$ is a regularization parameter, $\mathbf{W}_{\mathrm{m}}$ is a weight (or roughness) matrix that defines the spatial extent and nature of smoothing between each parameter and its neighbors and $\mathbf{m}$ is the parameter vector. Details of the inversion approach can be found in LaBrecque et al. (1995).

The objective of this work is to image the electrical properties of a conductive plume directly beneath a tank. The presence of the tank complicates this process because the metal walls and floor of the tank, approximately $10^{5} \mathrm{~S} / \mathrm{m}$, are in close proximity to the plume, approximately 1 $\mathrm{S} / \mathrm{m}$, and the native soil, about $0.01 \mathrm{~S} / \mathrm{m}$. The high conductivity of the tank produces two problems. First, much of the electrical current used for ERT is shunted through the tank, reducing the measurement sensitivity to the soil properties. Although we can do nothing about this problem, it is important to recognize that the tank affects the sensitivity of the measurements. In fact, an important goal of the work reported by Ramirez et al. (1996) was to demonstrate that even with this shunting effect of the tank walls, there was enough sensitivity to detect significant changes in soil conductivity. In the results reported herein we confirm this conclusion and better define the sensitivity limits. The second problem is that the discontinuity between the tank and soil conductivities is incompatible with the minimum-roughness stabilizing criterion; the algorithm can only find smooth solutions to match the data to the required tolerance. This we solved by removing the smoothness constraint in the finite element mesh along the tank-soil boundary. In other words, the region of the mesh representing the tank is decoupled from the rest of the mesh using appropriate alteration to the weight matrix $\mathbf{W}_{\mathrm{m}}$ in equation (3).

\section{Estimation of leak volumes}

Images of resistivity change were used to estimate leak volumes when a 'leak' flag had been set. During leakage of tank fluid, resistivity beneath the tank will change due to increases in fluid saturation and fluid conductivity. We wish to estimate the change in fluid saturation given estimates of the conductivity of the leaking fluid and the resultant changes of voxels in the region beneath the tank.

Archie's equation (see for example, Hearst et al., 2000) is a widely used empirical model that relates the soil's resistivity $\left(\rho_{s}\right)$ to the soil's saturation $(S)$, porosity $(\phi)$, and pore fluid conductivity $\left(\rho_{w}\right)$ as follows:

$$
\frac{\rho_{s}}{\rho_{w} \phi^{-m}}=S^{-n}
$$

The exponents $m$ and $n$ in equation (4) are empirically derived constants. Given that we are primarily interested in changes and that porosity is unlikely to change, we can derive the following equation: 


$$
\frac{S_{t}^{-n}}{S_{t-1}^{-n}}=\frac{\rho_{w, t-1}}{\rho_{w, t}} \frac{\rho_{s, t}}{\rho_{s, t-1}}
$$

The subscripts $t-1$ and $t$ indicate conditions before and after the soil's property change due to fluid invasion.

The ERT analysis will provide an estimate of $\left(\rho_{s, t} / \rho_{s, t-1}\right)$ for each voxel. Given an estimate of the change in fluid conductivity $\left(\rho_{w, t} / \rho_{w, t-1}\right)$ and the Archie exponent $n$, the change in saturation may be computed from equation (5). The change in pore water volume can then be calculated as follows:

$$
\Delta V_{w}=\left(\frac{S_{t}}{S_{t-1}}-1\right) S_{t-1} \phi V_{v},
$$

where $\Delta V_{w}$ is the change in the volume of water in each tomograph voxel and $V_{v}$ is the volume of the voxel.

Thus, in order to estimate the change in water volume between the times $t-1$ and $t$ the following are required:

1. The change in pore water conductivity due to the tank fluid - $\left(\rho_{w, t} / \rho_{w, t-1}\right)$. Analysis of previous ERT investigations of mock tank releases at the site suggests that a value in the range 1.09 to 1.11 is appropriate. This parameter may change during the experiment.

2. The Archie exponent $n$. Hearst et al.(2000) indicate that the exponent $n$ is typically $2.0 \pm$ 0.5 .

3. The saturation at time $t-1 S_{t-1}$. This will clearly change throughout the experiment. We anticipate that this value will lie in the range 0.2 to 0.3 .

4. The porosity $\phi$, which we estimate to lie in the range 0.2 to 0.4 .

Using these values we may produce an upper and lower bound estimate of $\Delta V_{w}$.

\section{Results and Discussion}

The test consisted of 13 separate releases, of various rates of release, separated by quiescent periods, over a period of 110 days. However, due to measurement system or computer network problems 5 surveys were not taken resulting in an effective test length of 105 days. A summary of the tank test conditions during the 110 days is in Table 1. Analysis and interpretation during the test was necessarily limited because of daily demands to declare a leak status and calculate a volume estimate. Without these demands and with the knowledge of the test parameters, posttest analysis of the data yielded improved methods for both leak detection and volume estimates 
as well as some insights into the hydraulic behavior of the released brine. Without these demands and with the knowledge of the test parameters, post-test analysis of the data yielded improved methods for both leak detection and volume estimates as well as some insights into the hydraulic behavior of the released brine. We first report results of analysis performed 'blind', during the test. Then we discuss lessons learned from post test analysis.

\section{Analysis during the test}

As stated earlier, from an analysis of the electrical data from two consecutive days, a leak condition or a no-leak condition was declared for each 24 hour period (the period between two consecutive surveys). In addition, if a leak was declared and a leak volume was calculated based on the size and resistivity change of the resulting plume. Both the declaration of leak status and the released volume were made 'blind' - with no knowledge of the actual test status. In presenting the results we first compare the declared leak status, determined using only the data and reconstructed images, with the actual leak status. Then we will compare the leak volume calculations with the actual released volumes.

\section{Declared leak status compared to actual release status}

An evaluation of the performance of the method to determine if a leak occurs requires considering four possible outcomes:

1. a leak occurred and a leak was declared-for convenience we call this "correct-leak".

2. a leak occurred but a leak was not declared-incorrect-leak

3. no leak occurred but a leak was declared-incorrect-no leak.

4. no leak occurred and no leak was declared - correct-no leak.

One of these conditions was chosen each of the 105 days using the algorithm described previously and the following data:

1. the daily change in the point electrode geometric mean apparent resistivity (see Figure 4),

2. the daily change in the long electrode geometric mean apparent resistivity (see Figure 5),

3. the pixel by pixel daily percentage difference in the long electrode ERT images and (see Figure 6 and 7),

4. the voxel by voxel daily percentage difference in the point electrode ERT images (see Figure $8-12)$.

Note that the long electrode ERT images were not all included in the figures. They were of little value in making the daily decisions so that only two months of these data are shown.

The daily declarations of leak or no-leak status as they compare to the actual test status are summarized in Table 2 and also shown in Figures 8 through 12. The figures also show the actual release status. 


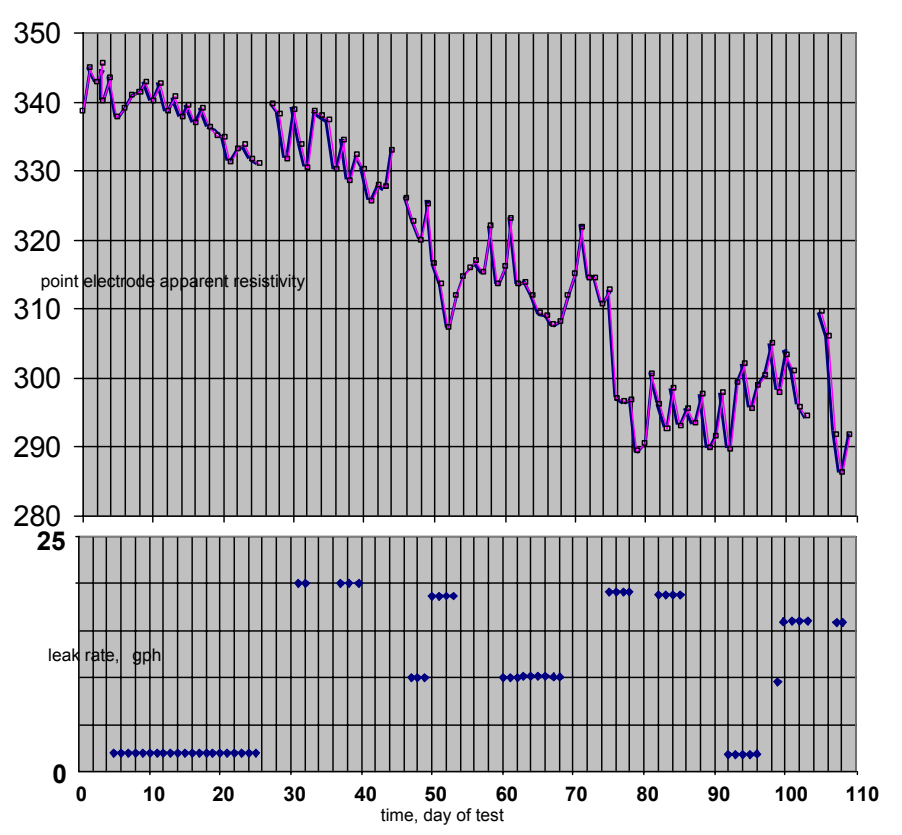

Figure 4. The apparent resistivity beneath the tank as measured from data on the eight point electrode arrays for each of the $\mathbf{1 1 0}$ days of the test (top) plotted with the actual release rates in gallons per hour (bottom)

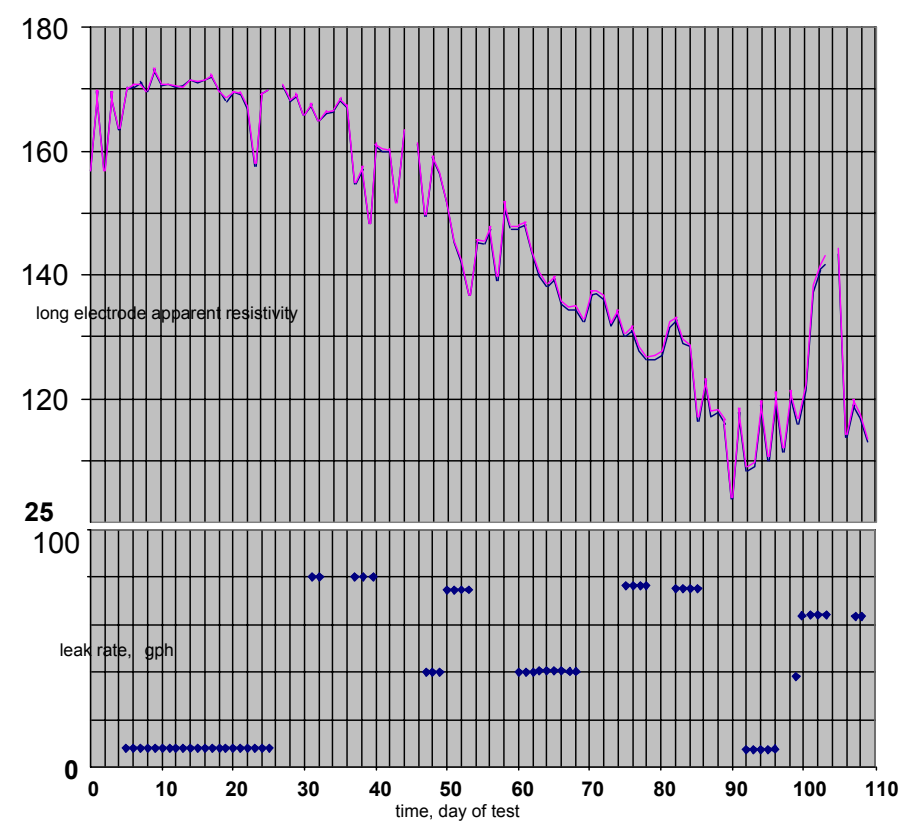

Figure 5. The apparent resistivity beneath the tank as measured from data on the eight long electrodes for each of the 110 days of the test (top) plotted with the actual release rates in gallons per hour (bottom). 


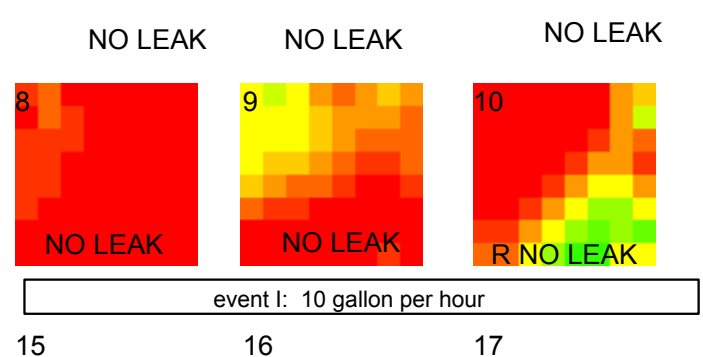

NO LEAK SYSTEM DOWN NO LEAK
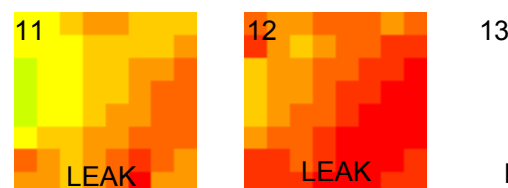

13

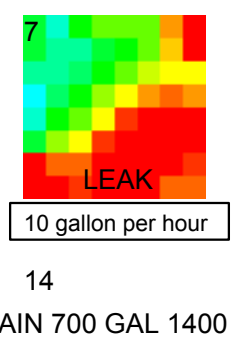

15

16
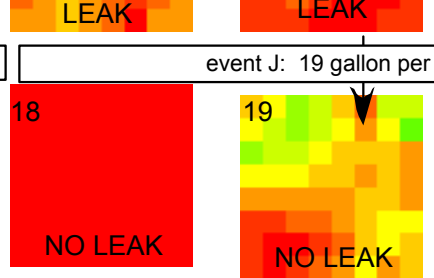

NO LEAK

NO LEAK

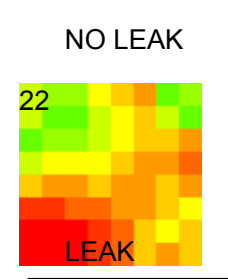

NO LEAK

NO LEAK

NO LEAK
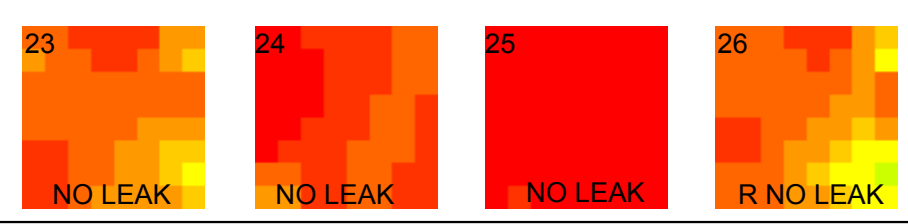

event $\mathrm{M}$ : 10 gallon per hour

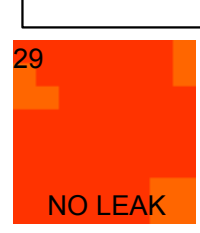

30

Figure 6. Two dimensional ERT of the volume beneath the mock tank for the month of September 2002 using long electrode data. The percent difference image shown for day $n$ is calculated using $100 \times\left(\rho_{i}{ }_{i}-\rho^{n-1} i\right) / \rho_{i}{ }_{i}$, where $\rho_{i}^{n}$ is the resistivity of the $i^{\text {th }}$ pixel. The color scale shows only voxels from $-30 \%$ to $0 \%$ (blue to green). Across the bottom of each image plane is the test state (leak or no leak) as declared during the blind test. Just below each image plane is the actual test state (left blank for no leak, otherwise the event designation and leak rate). 


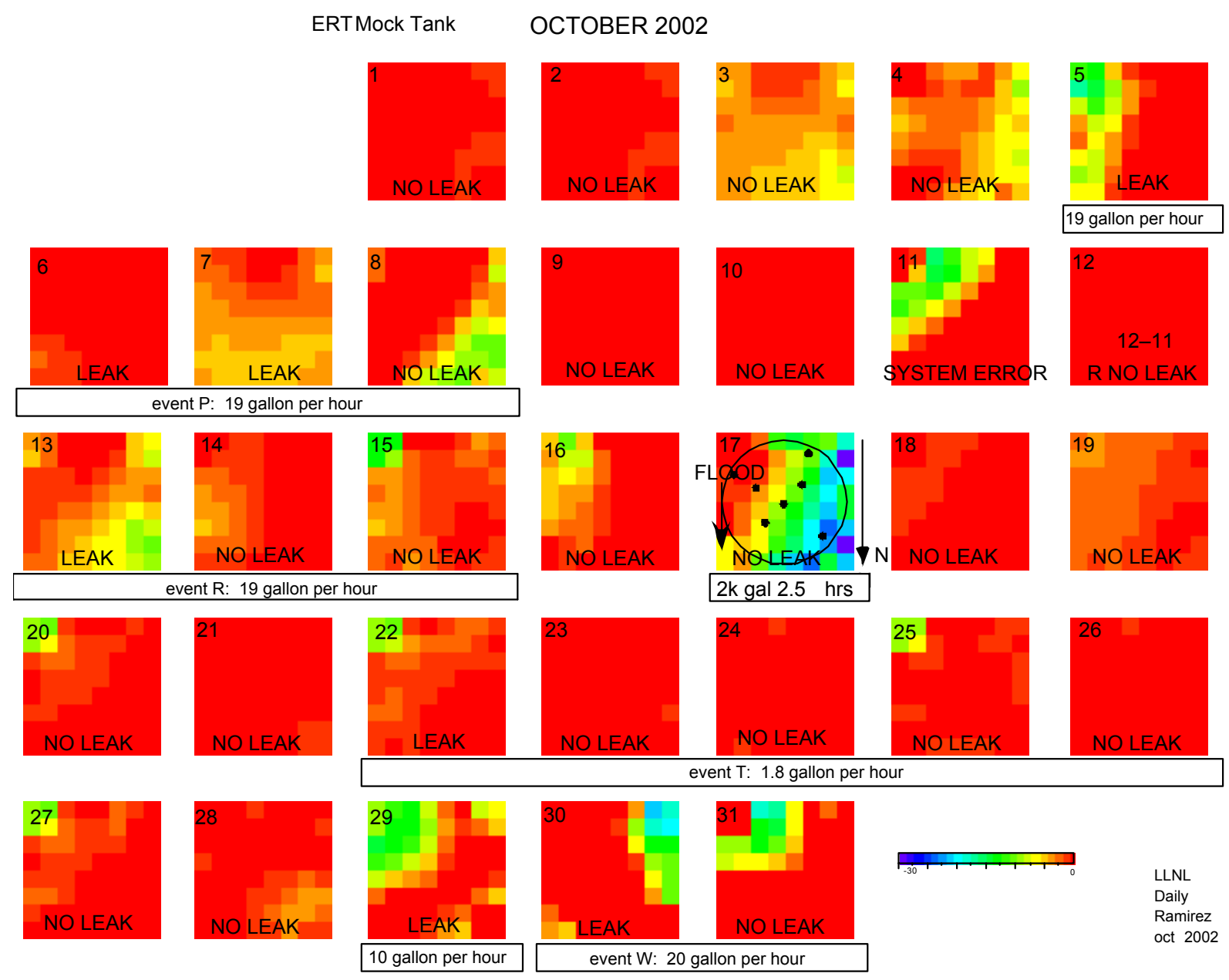

Figure 7. Two dimensional ERT of the volume beneath the mock tank for the month of October 2002 using long electrode data. See the caption for Figure 6. 
Table 2. Table of statistical summary of ERT results compared to the test matrix

\begin{tabular}{|c|c|c|c|c|c|c|c|c|c|c|}
\hline \multicolumn{11}{|c|}{$\begin{array}{l}\text { Pt electrode Images } \\
\text { summary of ert results }\end{array}$} \\
\hline $\begin{array}{c}\text { Event } \\
\text { ID } \\
\text { A }\end{array}$ & Leak Rate, Gph & $\begin{array}{l}\text { Release } \\
\text { location }\end{array}$ & $\begin{array}{c}\text { False- } \\
\text { leak } \\
0\end{array}$ & $\begin{array}{c}\text { True- } \\
\text { leak } \\
0\end{array}$ & $\begin{array}{c}\text { False- } \\
\text { no leak } \\
0\end{array}$ & $\begin{array}{c}\text { True- } \\
\text { no leak } \\
4\end{array}$ & $\begin{array}{l}\text { system } \\
\text { down }\end{array}$ & $\begin{array}{c}\text { total days } \\
5\end{array}$ & $\begin{array}{c}\text { CORRECT } \\
\text { CALLS } \\
4\end{array}$ & $\begin{array}{c}\text { INCORRECT } \\
\text { CALLS } \\
0\end{array}$ \\
\hline B & 2 & L1 & 19 & 2 & 0 & 0 & & 21 & 2 & 19 \\
\hline $\mathrm{C}$ & & & 0 & 0 & 0 & 4 & 1 & 5 & 4 & 0 \\
\hline $\mathrm{D}$ & 20.1 & L1 & 0 & 2 & 0 & 0 & & 2 & 2 & 0 \\
\hline $\mathrm{E}$ & & & 0 & 0 & 0 & 4 & & 4 & 4 & 0 \\
\hline $\mathrm{F}$ & 20 & L3 & 1 & 2 & 0 & 0 & & 3 & 2 & 1 \\
\hline $\mathrm{G}$ & & & 0 & 0 & 0 & 3 & & 3 & 3 & 0 \\
\hline $\mathrm{H}$ & & & 0 & 0 & 0 & 3 & 1 & 4 & 3 & 0 \\
\hline I & 10 & & 3 & 1 & 0 & 0 & & 4 & 1 & 3 \\
\hline $\mathrm{J}$ & 19 & & 1 & 2 & 0 & 0 & & 3 & 2 & 1 \\
\hline $\mathrm{K}$ & & & 0 & 0 & 0 & 6 & & 6 & 6 & 0 \\
\hline $\mathrm{L}$ & 10 & L14 & 2 & 2 & 0 & 0 & & 4 & 2 & 2 \\
\hline M & 10 & L14 & 5 & 0 & 0 & 0 & & 5 & 0 & 5 \\
\hline $\mathrm{N}$ & & & 0 & 0 & 0 & 3 & & 3 & 3 & 0 \\
\hline $\mathrm{O}$ & & & 0 & 0 & 0 & 3 & & 3 & 3 & 0 \\
\hline $\mathrm{P}$ & 19 & L12 & 1 & 3 & 0 & 0 & & 4 & 3 & 1 \\
\hline Q & & & 0 & 0 & 0 & 2 & 1 & 3 & 2 & 0 \\
\hline $\mathrm{R}$ & 18.8 & L12 & 3 & 1 & 0 & 0 & & 4 & 1 & 3 \\
\hline $\mathrm{S}$ & & & 0 & 0 & 0 & 1 & & 1 & 1 & 0 \\
\hline $\mathrm{S}$ & flood: 2000 gal $2.5 \mathrm{hrs}$ & & 1 & 0 & 0 & 0 & & 1 & 0 & 1 \\
\hline $\mathrm{S}$ & & & 0 & 0 & 0 & 4 & & 4 & 4 & 0 \\
\hline $\mathrm{T}$ & 1.8 & L5 & 4 & 1 & 0 & 0 & & 5 & 1 & 4 \\
\hline $\mathrm{U}$ & & & 0 & 0 & 0 & 2 & & 2 & 2 & 0 \\
\hline V & 10 & L1 & 0 & 1 & 0 & 0 & & 1 & 1 & 0 \\
\hline W & 16 & L1 & 3 & 1 & 0 & 0 & & 4 & 1 & 3 \\
\hline$X$ & & & 0 & 0 & 1 & 1 & 1 & 3 & 1 & 1 \\
\hline $\mathrm{Y}$ & 15.9 & L1 & 1 & 1 & 0 & 0 & & 2 & 1 & 1 \\
\hline \multirow[t]{2}{*}{$\mathrm{Z}$} & & & 0 & 0 & 0 & 1 & & 1 & 1 & 0 \\
\hline & & TOTALS & 44 & 19 & 1 & 41 & 4 & 110 & 60 & 45 \\
\hline
\end{tabular}



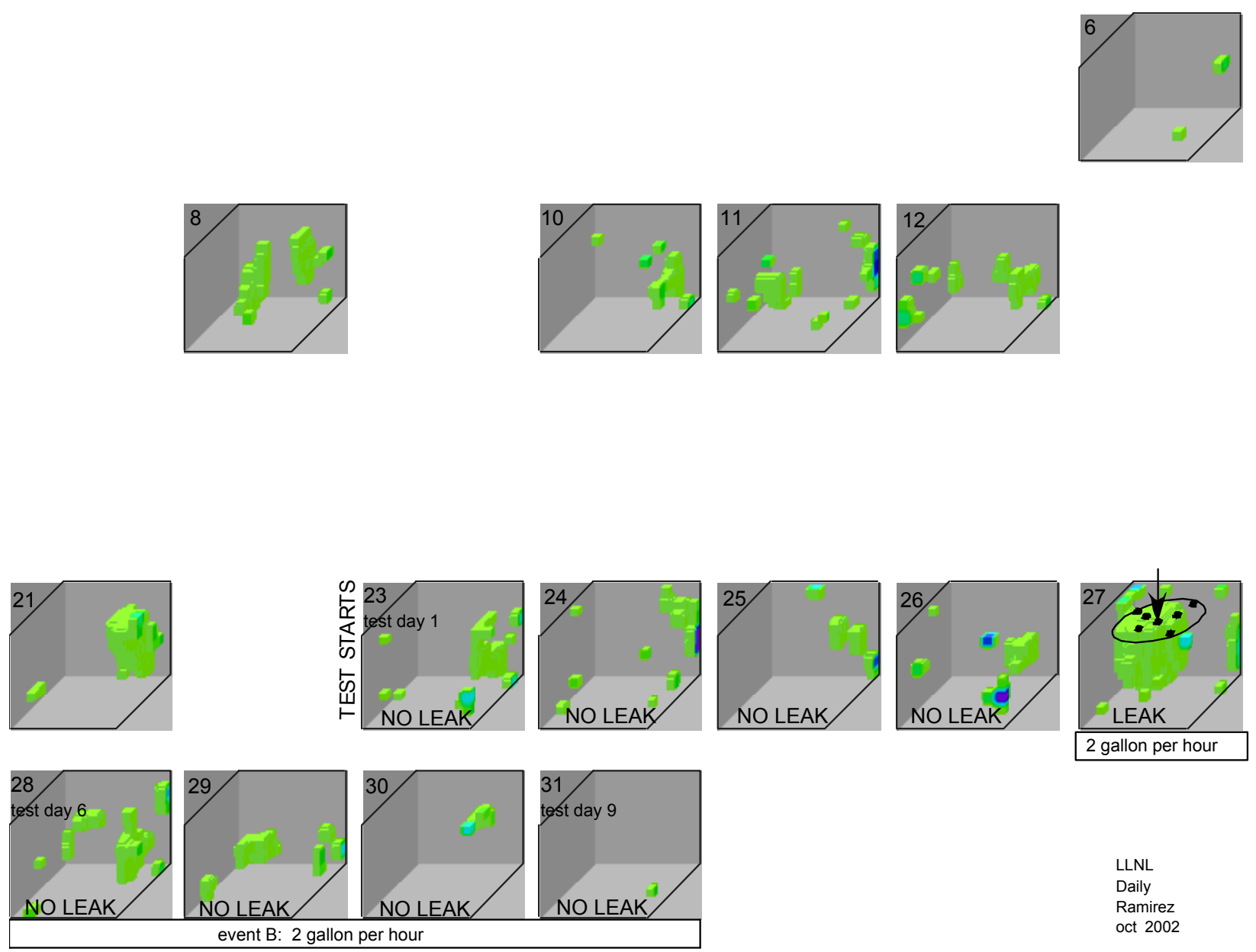

\section{2 gallon per hour}

Figure 8. ERT of the volume beneath the mock tank for the month of July 2002. The percent difference image shown for day $n$ is calculated using $100 \times\left(\rho^{n}{ }_{i}-\rho^{n-1}{ }_{i}\right) /$ $\rho^{n}{ }_{i}$, where $\rho_{i}{ }_{i}$ is the resistivity of the $i^{\text {th }}$ voxel. The color scale shows only voxels from $-\mathbf{3 0} \%$ to $-\mathbf{- 1 0 \%}$ (blue to green). All others are rendered transparent. Across the bottom of each image block is the test state (leak or no leak) as declared during the blind test. Just below each image block is the actual test state (left blank for no leak, otherwise the event designation and leak rate). 


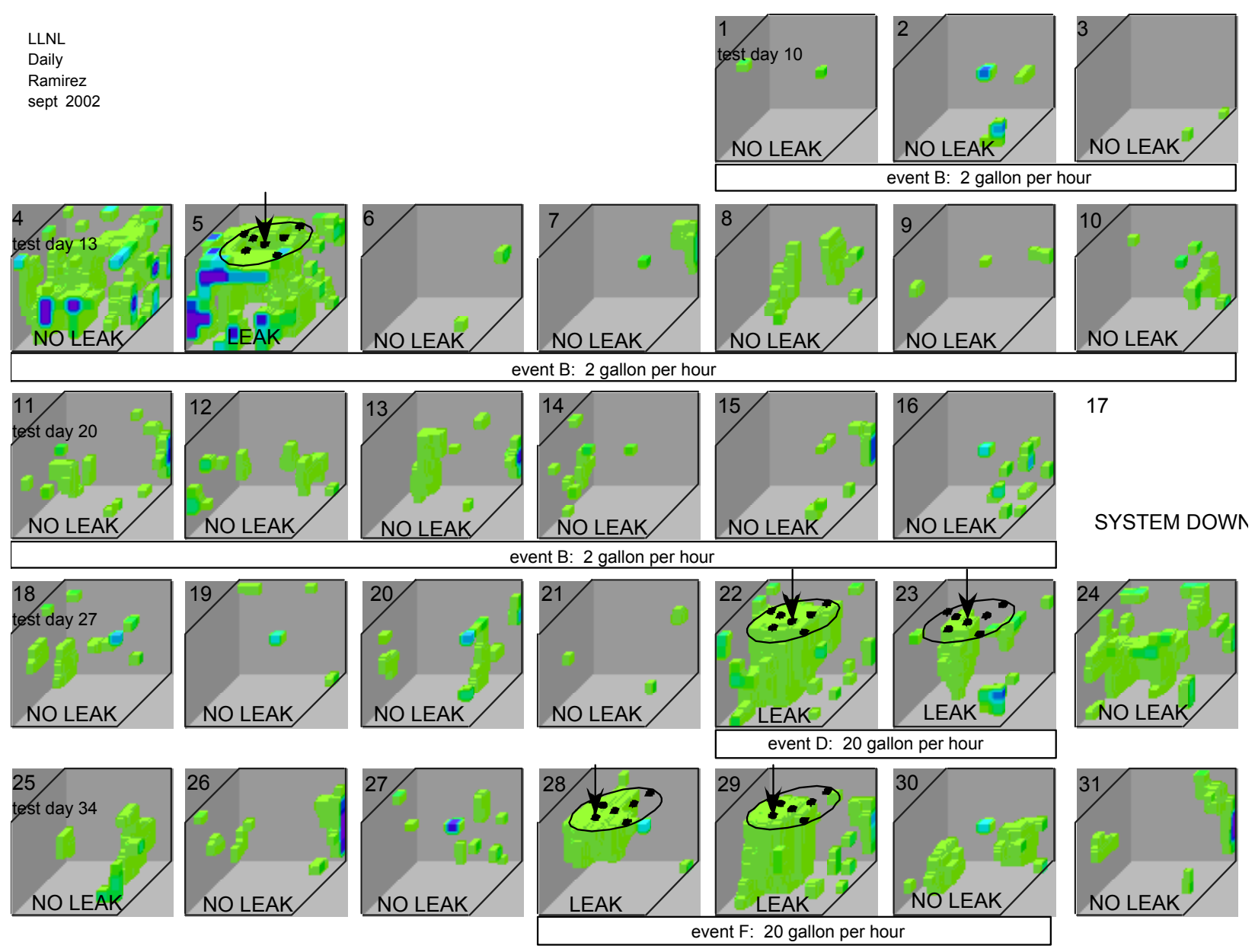

Figure 9. ERT of the volume beneath the mock tank for the month of August. See the caption for figure 8. 
ERTMock Tank
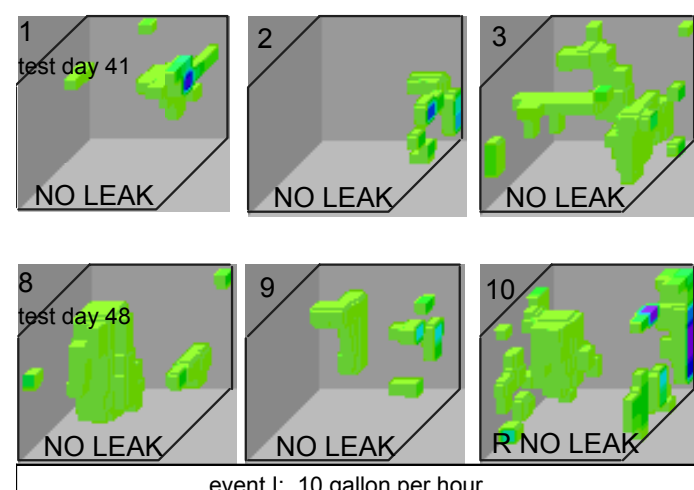

event I: 10 gallon per hour
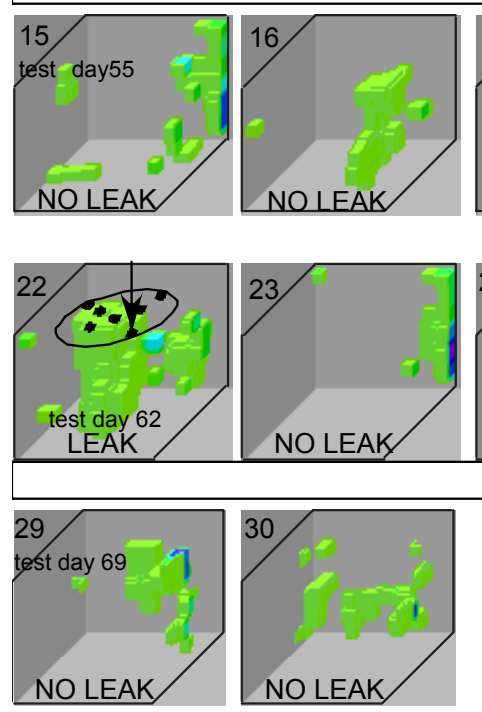

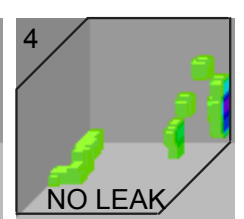

5

SYSTEM DOWN
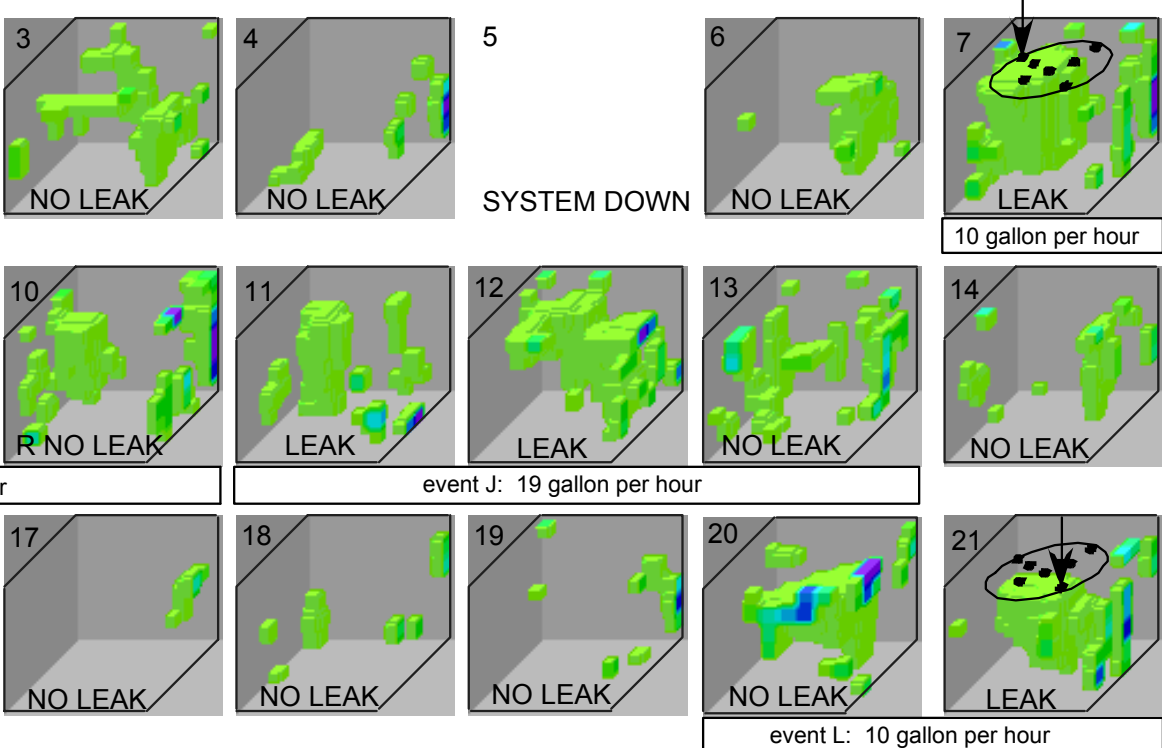

event L: 10 gallon per hour
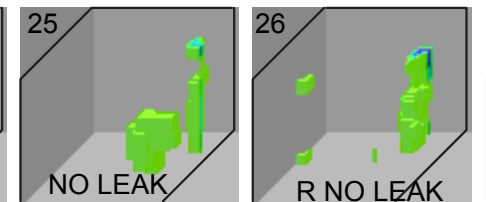

R NO LEAK

R NO LEAK

vent $\mathrm{M}: 10$ gallon per hour
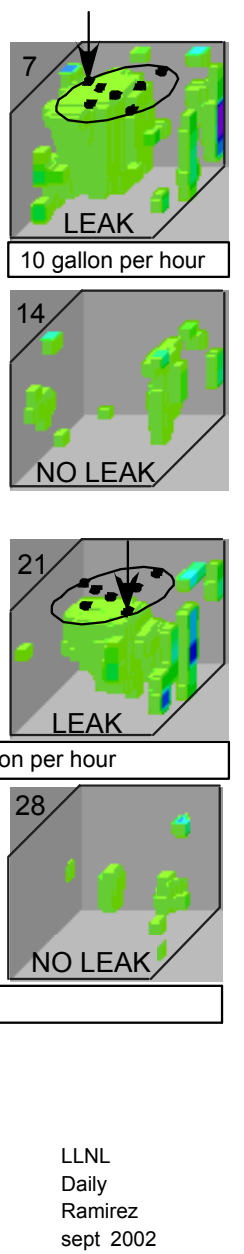

LLNL

Ramirez

sept 2002

Figure 10. ERT of the volume beneath the mock tank for the month of September. See the caption for figure 8. 


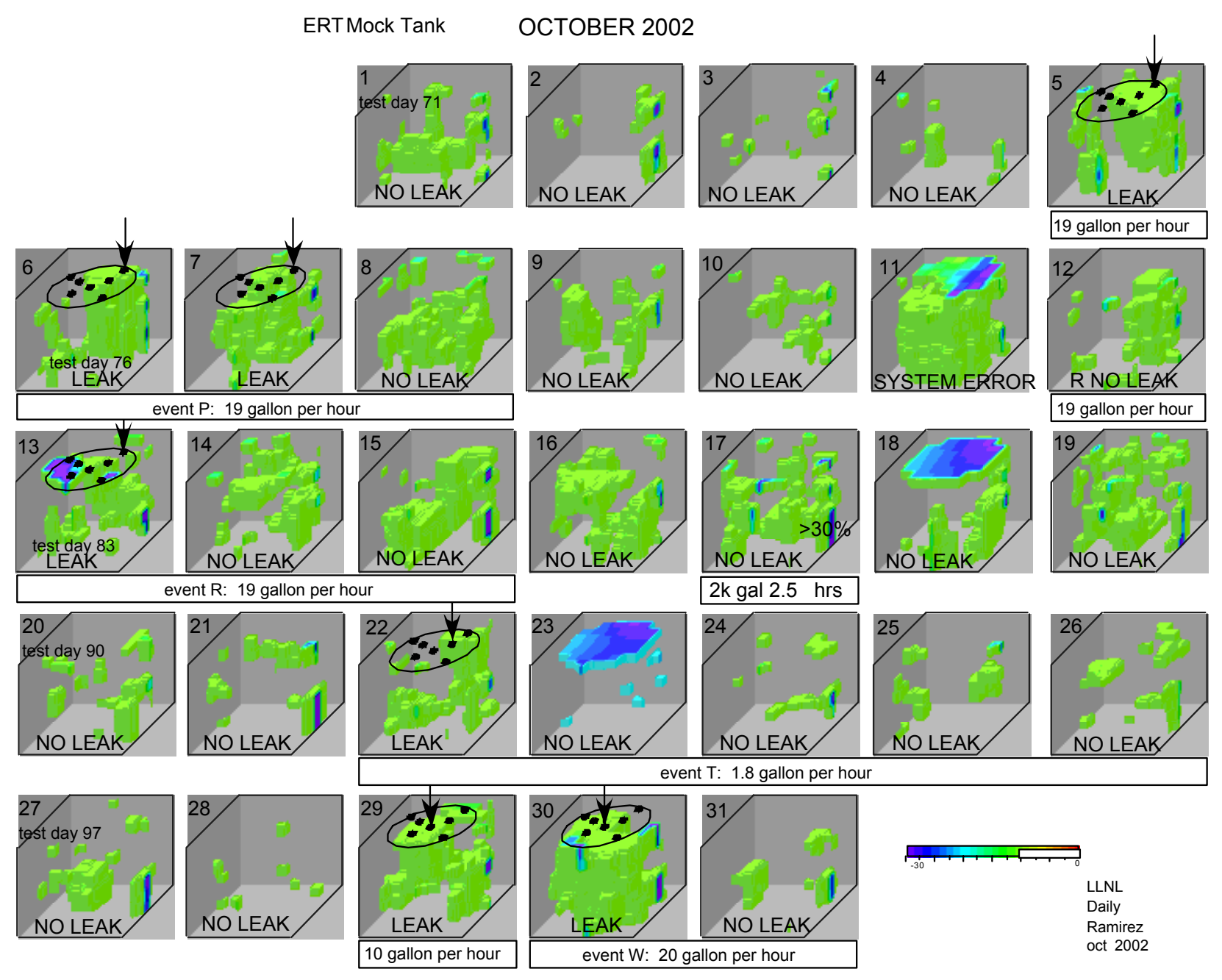

Figure 11. ERT of the volume beneath the mock tank for the month of October. See the caption for figure 8. 

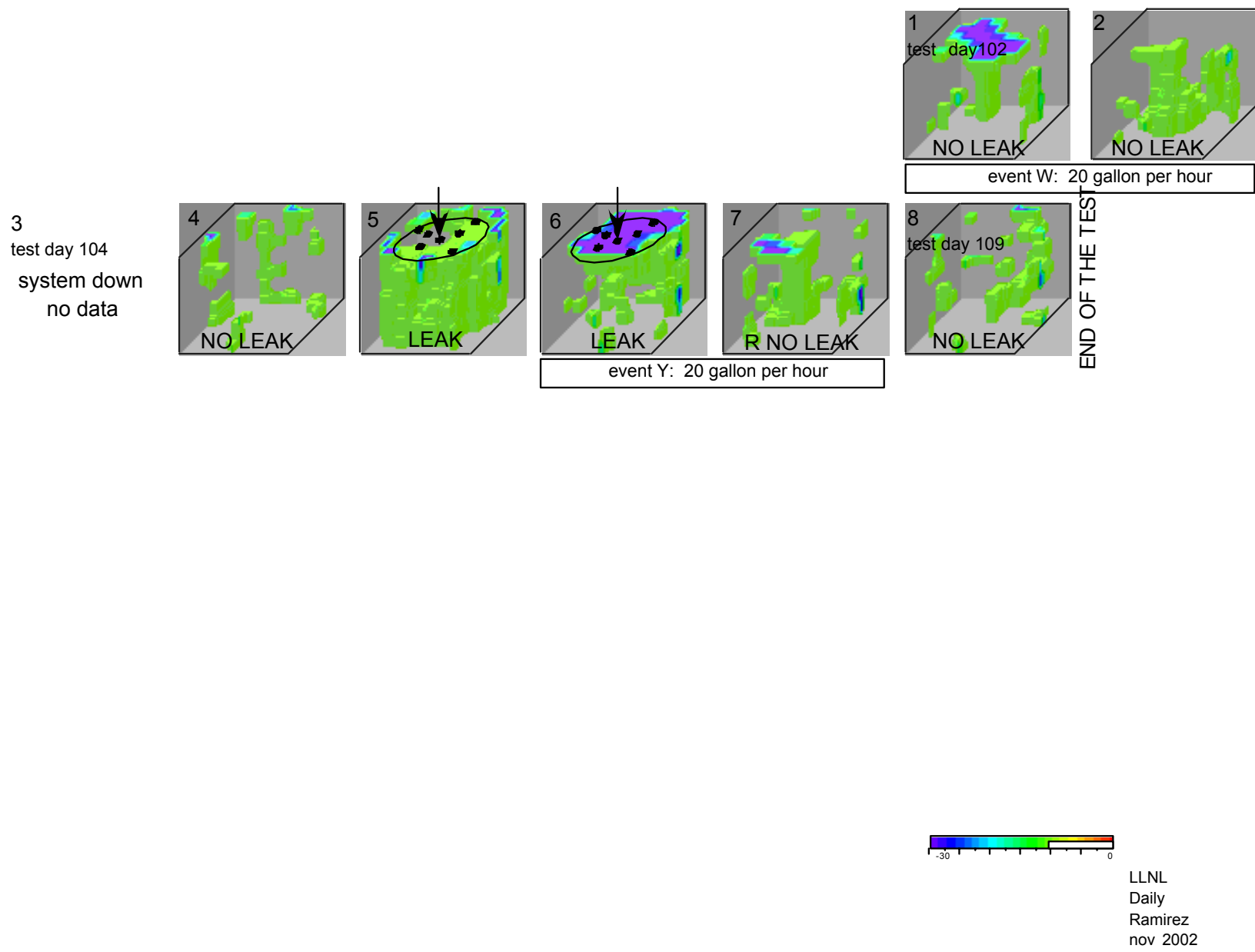

Figure 12. ERT of the volume beneath the mock tank for the month of November. See the caption for figure 8.

Of the 105 days there were 19 correct-leaks and 41 correct-no leaks. Therefore, 60 of the 105 test days $(57.14 \%$ of the time) the method detected the correct test condition. (These statistics include the flood release.) To determine if the leak status as determined from the ERT data was an improvement over random guesses we define the probability $\mathrm{p}$ that each estimate of the leak status is correct (conforms to the actual test status). The corresponding probability that it is incorrect is $\mathrm{q}$; hence $\mathrm{p}+\mathrm{q}=1$. There are $\mathrm{n}$ such estimates. The number of successes that will be obtained in the $\mathrm{n}$ trials is denoted by the letter $\mathrm{x}$. The problem then is to calculate the probabilities for the various possible values of the variable $\mathrm{x}$. This probability, denoted by $\mathrm{P}\{\mathrm{x}\}$ is the binomial distribution given by

$$
\mathrm{P}\{\mathrm{x}\}=[\mathrm{n} ! /(\mathrm{x} !(\mathrm{n}-\mathrm{x}) !)] \mathrm{p}^{\mathrm{x}} \mathrm{q}^{\mathrm{n}-\mathrm{x}}
$$

We know that the mean $\mu$ and standard deviation $\sigma$ of a binomial distribution are 


$$
\begin{aligned}
& \mu=n p \\
& \sigma=[\text { pqn }]^{1 / 2}
\end{aligned}
$$

(e.g., Hoel, 1997).

The probability of success is binary and $\mathrm{p}=\mathrm{q}=1 / 2$ and $\mathrm{n}=105$ so that for this test the mean is $\mu=52.5$ and the standard deviation $\sigma=5.1235$. To use this distribution we assume that each leak condition decision is independent. While this is mostly true since each is based on a daily difference, there is some dependence because the sensitivity to leak status does change as the test proceeds and the soil becomes progressively more conducting.

Random guessing of the test condition would have produced 52.5 (the mean) correct responses. To determine if the leak status as determined from the ERT data was an improvement over random guesses of leak status we can use the central limit approximation to get the test statistic $\mathrm{z}=1.4638$ so that the $\mathrm{p}$-value $=0.072$. Hence, at the 0.072 level of significance we conclude that the probability of success is significantly greater than $1 / 2$ and the detection methodology works significantly better than random selection. The probability of making a proper leak detection using ERT-LET is $92.8 \%$ better that making a random selection.

Some comments are needed about specific events:

\section{Release B}

The first release of only 2 gph began on July 27 and lasted for 21 days for a total volume of 1000 gallons yet only on July 27 and August 5 was a leak declared. On the first day of the release a strong conductive anomaly is clearly imaged from the release point to approximately 20 feet depth. We conclude from this result that the onset of this event is detectable using ERT. However, even though the release continues for the next 7 days, the daily difference images show almost no changes greater than $10 \%$. In other words, the plume disappears after the first day. We don't know the reason for a re-emergence of a strong conductive anomaly on August 4 and 5. Our conceptual model for hydrology of brine beneath the tank is a rapid movement of brine and early establishment of a stable flow conduit through the image block. This model would yield an early conductive anomaly (the conduit) followed by no resistivity changes (stable flow in the conduit). The only explanation we have for the ERT anomalies on August 4 and 5 is the establishment of new flow conduits. If this is so, these conduits remain stable flow paths for the next 11 days because there is little evidence of them in the remaining difference images through the end of the release. See Appendix B for further discussion and supporting evidence for this conceptual model.

\section{Releases $B, D, I, L, M, T, Y$}

Most of the leaks lasted for a few days (3-6 days). It is noteworthy that most of the declared leaks for these events were at the beginning of each event but did not detect a leak at the end of the event. This behavior is consistent with the preceding conceptual model of the rapid formation of a conduit or channel of flow from the release point through the image volume. Establishment of the flow channel would create a conductive anomaly and trigger a leak declaration. Once established in a steady state condition, brine would continue to move through the image block but its presence would disappear from the daily difference images. There are 
several examples of this behavior; that is, early formation of a conduit followed by its weakening or disappearance later in the release (July 27 and the days following, August 22-23, September 7 and days following, September 21 and 22 with the days following, October 22 and 29, November 5 and the days following in Figures 8-12).

\section{Release flood (fresh water)}

A surface discharge that did not interfere with leak-detection (no leak condition was declared during the release) was labeled a flood (simulated water-line leak) because 2000 gallons of water was released within a 2.5 hour period. However, this release was unlike any of the others for two other important reasons. First, the water was not the brine but was fresh water from the Columbia River with a conductivity of about $1.50 \times 10^{-2} \mathrm{~S} / \mathrm{m}$ or one hundred times less than the brine used for the rest of the releases. Second, instead of being released from one of the points inside the tank shell it was released outside the tank shell on the northeast side where it ponded there for several hours.

The flood began 3 hours after our ERT data collection on day 86 (October 16) and ended 16.5 hours before our data collection on day 87 . The plume should have been detected on the day 87 (October 17) difference (see Figure 11). The long electrode 2D image (figure 7) shows a strong conductive anomaly on the west side of the tank. Although the point electrode image shows a rather strong conductive anomaly in the same general area (some voxels changing more than $30 \%$ from the previous day), a no leak condition was declared because the anomaly did not have the expected shape. Notice also that the apparent resistivity did not indicated an abnormally large increase in bulk conductivity under the tank on day 87 (see figure 4). Even though the image showed some isolated regions of increased conductivity under the tank the indicators of bulk conductivity point to no significant change.

This event happened after a cumulative volume of 10,000 gallons of very conductive brine had already been released during the test. We might, therefore, expect before the flood at least some regions where pore water is very conductive. Introduction of this lower conductivity water would cause a decrease in electrical conductivity but in the leak detection analysis we only considered the increases in conductivity (the color scales for figures 8-12 were truncated above $0 \%$ resistivity difference). Re-examination of the October 17 reveals an increase in resistivity between 20 and 35 feed depth along ERT vertical array \#8 on the north side of the tank.

Although the above observations could be interpreted other ways, they are consistent with the idea that the flood water had a comparatively small effect on the bulk resistivity of the soil. The plume that did form moved toward the north end of the tank but most of its volume was outside of the ERT image block. These ideas are consistent with the ERT results which lead to a decision to declare a no leak condition for October 17.

\section{Releases $W$ and $Y$}

During most of the test a large sheet pile near the mock tank and on the southwest edge of the image block was electrically connected to the mock tank. Its purpose was to determine the effect of nearby tanks, as would be present in a tank farm, on electrical leak detection. On October 30 the sheet piling was disconnected electrically from the mock tank and then on November 6 it was reconnected coinciding with releases $\mathrm{W}$ and $\mathrm{Y}$ respectively. Changing the configuration of the 
sheet pile changed the allowed paths for electrical currents used for ERT, adversely affecting the difference images on those two days. However, the influence on the images was not large enough to affect the correct declaration of leak status. Notice also that neither the mean apparent resistivity nor the mean log difference register a significant change in bulk resistivity beneath the tank when the sheet pile is disconnected. When the sheet pile was reconnected on November 5 these parameters registered large changes, perhaps because the reconnection took place during the 2 hour period when the ERT data were collected on that day.

\section{Natural and artificial rain events}

Natural rainfall, with daily amounts between a trace and 0.13 inches, occurred on 7 days of the test. There were 4 simulated rain events occurring on September 1, 11 and 30 and October 2. The first event was about 400 gallons and the other three were about 700 gallons. Surface sprinklers irrigated the entire site (approximately $4 \times 10^{4} \mathrm{ft}^{2}$ ) during each event of one hour or less. Equivalent to about $0.7 \mathrm{~mm}$ of rain, even a 700 gallon event clearly may change only the surface resistivity slightly. The point electrodes were all 1 meter or deeper. The long electrodes extended from 35 feet depth to the surface. There was little evidence of these natural or simulated rain events in any of the ERT data.

\section{Leak volume estimates}

During the test we used equation 6 to calculate, for selected periods, the released water volume. For each calculation, the test director specified the time span over which the released volume was calculated. Results of these calculations were reported during the test and are summarized in Table 3. The model parameters and actual released volumes are also presented. Notice that each calculation is expressed as a range of values. Because of our uncertainty in some of the parameters used in the model a range spanning the likely value for each was specified resulting in a corresponding range in the result.

The calculated volumes are systematically larger than the actual volumes. This is a direct result of our uncertainty in the model parameters, especially the initial saturation and change in pore water resistivity, to which the result is especially sensitive. For many cases the range is so large that it is of little value. In fact, we believe that these calculations give little more than a very rough estimate of the leak volume. These calculated volumes are not quantitatively useful.

\section{What we learned after the test}

After the test ended and time allowed for additional data analysis, additional analyses were conducted to improve and extend the methods used during the test. This work led to significant improvements in the leak detection results and a calibration of parameters used in the volume calculation. We also gained some new insights into the transport and fate of the released water beneath the mock tank. 
Table 3. Table of the release volume calculations reported to the test director during the test.

\begin{tabular}{|c|c|c|c|c|c|c|c|}
\hline Date & $\begin{array}{l}\text { Baseline } \\
\text { Date }\end{array}$ & $\begin{array}{l}\text { Volume } \\
\text { Calculated, } \\
\text { Gallons }\end{array}$ & $\begin{array}{c}\text { Actual Released } \\
\text { Volume, Gallons }\end{array}$ & $\begin{array}{c}\text { Parameters Used } \\
\text { for the Calculation } \\
\text { Pore Water } \\
\text { Resistivity Ratio }\end{array}$ & $\begin{array}{l}\text { Archie's } \\
\text { Index }\end{array}$ & Saturation & Porosity \\
\hline 5-Aug & 3-Aug & $0-72$ & 78 & $1.0-1.12$ & 1.8 & 0.25 & 0.4 \\
\hline 5-Aug & 21-Jul & $0-7247$ & 509 & $1.0-1.12$ & $1.5-2.0$ & $0.2-0.3$ & $0.2-0.4$ \\
\hline 27-Jul & 21-Jul & $0-3178$ & 74 & $1.0-1.12$ & 1.8 & $0.2-0.3$ & $0.2-0.4$ \\
\hline 4-Aug & 21-Jul & $0-4793$ & 461 & $1.0-1.12$ & 1.8 & $0.2-0.3$ & $0.2-0.4$ \\
\hline 8-Aug & 21-Jul & $0-6021$ & 654 & $1.0-1.12$ & 1.8 & $0.2-0.3$ & $0.2-0.4$ \\
\hline 9-Aug & 21-Jul & $0-6076$ & 702 & $1.0-1.12$ & 1.8 & $0.2-0.3$ & $0.2-0.4$ \\
\hline 10-Aug & 21-Jul & $0-6558$ & 750 & $1.0-1.12$ & 1.8 & $0.2-0.3$ & $0.2-0.4$ \\
\hline 11-Aug & 21-Jul & $0-7444$ & 796 & $1.0-1.12$ & 1.8 & $0.2-0.3$ & $0.2-0.4$ \\
\hline 13-Aug & 21-Jul & $0-8076$ & 893 & $1.0-1.12$ & 1.8 & $0.2-0.3$ & $0.2-0.4$ \\
\hline $22-\mathrm{Aug}$ & 21-Jul & $0-11184$ & 1704 & $1.0-1.12$ & 1.8 & $0.2-0.3$ & $0.2-0.4$ \\
\hline 7-Sep & 6-Sep & $0-4170$ & 241 & $1.0-1.12$ & 1.8 & $0.2-0.3$ & $0.2-0.4$ \\
\hline 10-Sep & 6-Sep & $0-7794$ & 1029 & $1.0-1.12$ & 1.8 & $0.2-0.3$ & $0.2-0.4$ \\
\hline 11-Sep & 6-Sep & $0-8854$ & 1479 & $1.0-1.12$ & 1.8 & $0.2-0.3$ & $0.2-0.4$ \\
\hline 12-Sep & 6-Sep & $691-11283$ & 1771 & $1.0-1.12$ & 1.8 & $0.2-0.3$ & $0.2-0.4$ \\
\hline 13-Sep & 6-Sep & $0-8973$ & 1771 & $1.0-1.12$ & 1.8 & $0.2-0.3$ & $0.2-0.4$ \\
\hline 6-Sep & 21-Jul & $1383-10542$ & 3063 & $1.0-1.12$ & 1.8 & $0.2-0.3$ & $0.2-0.4$ \\
\hline 21-Sep & 6-Sep & $557-7901$ & 2382 & $1.0-1.12$ & 1.8 & $0.2-0.3$ & $0.2-0.4$ \\
\hline 22-Sep & 6-Sep & $1184-9906$ & 2623 & $1.0-1.12$ & 1.8 & $0.2-0.3$ & $0.2-0.4$ \\
\hline 26-Sep & 6-Sep & $2141-12963$ & 3590 & $1.0-1.12$ & 1.8 & $0.2-0.3$ & $0.2-0.4$ \\
\hline 27-Sep & 6-Sep & $2328-13563$ & 3744 & $1.0-1.12$ & 1.8 & $0.2-0.3$ & $0.2-0.4$ \\
\hline 5 -Oct & 6-Sep & $3308-166931$ & 4442 & $1.0-1.12$ & 1.8 & $0.2-0.3$ & $0.2-0.4$ \\
\hline 6-Oct & 6-Sep & $6324-26330$ & 4897 & $1.0-1.12$ & 1.8 & $0.2-0.3$ & $0.2-0.4$ \\
\hline 7-Oct & 6-Sep & $8848-34394$ & 5345 & $1.0-1.12$ & 1.8 & $0.2-0.3$ & $0.2-0.4$ \\
\hline 12-Oct & 6-Sep & 7533-30192 & 6226 & $1.0-1.12$ & 1.8 & $0.2-0.3$ & $0.2-0.4$ \\
\hline $13-O c t$ & 6-Sep & $5772-24563$ & 6682 & $1.0-1.12$ & 1.8 & $0.2-0.3$ & $0.2-0.4$ \\
\hline 22-Oct & 6-Sep & $7408-29791$ & 7454 & $1.0-1.12$ & 1.8 & $0.2-0.3$ & $0.2-0.4$ \\
\hline 29-Oct & 6-Sep & $7490-30053$ & 7948 & $1.0-1.12$ & 1.8 & $0.2-0.3$ & $0.2-0.4$ \\
\hline $30-O c t$ & 6-Sep & $9489-36443$ & 8332 & $1.0-1.12$ & 1.8 & $0.2-0.3$ & $0.2-0.4$ \\
\hline $5-\mathrm{Nov}$ & 6-Sep & $10091-38361$ & 9725 & $1.0-1.12$ & 1.8 & $0.2-0.3$ & $0.2-0.4$ \\
\hline 6-Nov & 6-Sep & $10746-40453$ & 10209 & $1.0-1.12$ & 1.8 & $0.2-0.3$ & $0.2-0.4$ \\
\hline 7-Nov & 6-Sep & $9115-35246$ & 10508 & $1.0-1.12$ & 1.8 & $0.2-0.3$ & $0.2-0.4$ \\
\hline
\end{tabular}

\section{Leak detection}

The leak detection criteria, selected prior to the start of the experiment, are based on the assumption that any fluid leaking from the tank will decrease the resistivity of the soil beneath the tank. Since it was expected that the resistivity would change as the experiment progressed (due to multiple leaks and natural inputs) it was decided that a comparison of daily changes in resistivity would be the most appropriate indicator of a leak. Such an indicator proved successful in detecting the onset of most leaks. For the 13 leak events, the start of 10 events were successfully detected and announced, 2 other events ( $\mathrm{L}$ and R on Sept 20 and Oct 12, respectively) were detected one day late and only one event (the flood event on Oct 17) was not detected. Thus, for all tank brine leaks that onset of each event was detected within 24 hours.

As stated earlier, the presumed hydrological response of the system is that more or less steady state conditions are achieved within a day or two of each leak event. Therefore, in hindsight, monitoring daily changes is unlikely to be successful in detecting continuous leaks of several days. 
If we compare the ERT data on each day with a baseline data set at the start of the experiment the full extent of each leak event is more obvious. Figure 13 shows the mean log difference (equation (2)) computed using the ERT data on the July 22 as a reference. The impact of all release events on the ERT data is evident except the 1.8 gph event L between Oct 22 and Oct 26.

This figure also suggests a strategy for detecting leaks different from the one we used during the test. Therefore, we applied a new algorithm for declaring a leak using equation 2 with $r_{i}^{t-1}=r_{i}^{22}$ July: if $\mathrm{R}^{\mathrm{t}}>\left(\mathrm{R}^{\mathrm{t}-1}+\mathrm{R}^{\mathrm{t}-2}+\mathrm{R}^{\mathrm{t}-3}\right) / 3$ then a leak condition is declared, otherwise a no-leak condition is declared. This simple algorithm is designed to identify any significant decreases in the bulk resistivity due to a leak condition; all other are identified as a no-leak conditions.

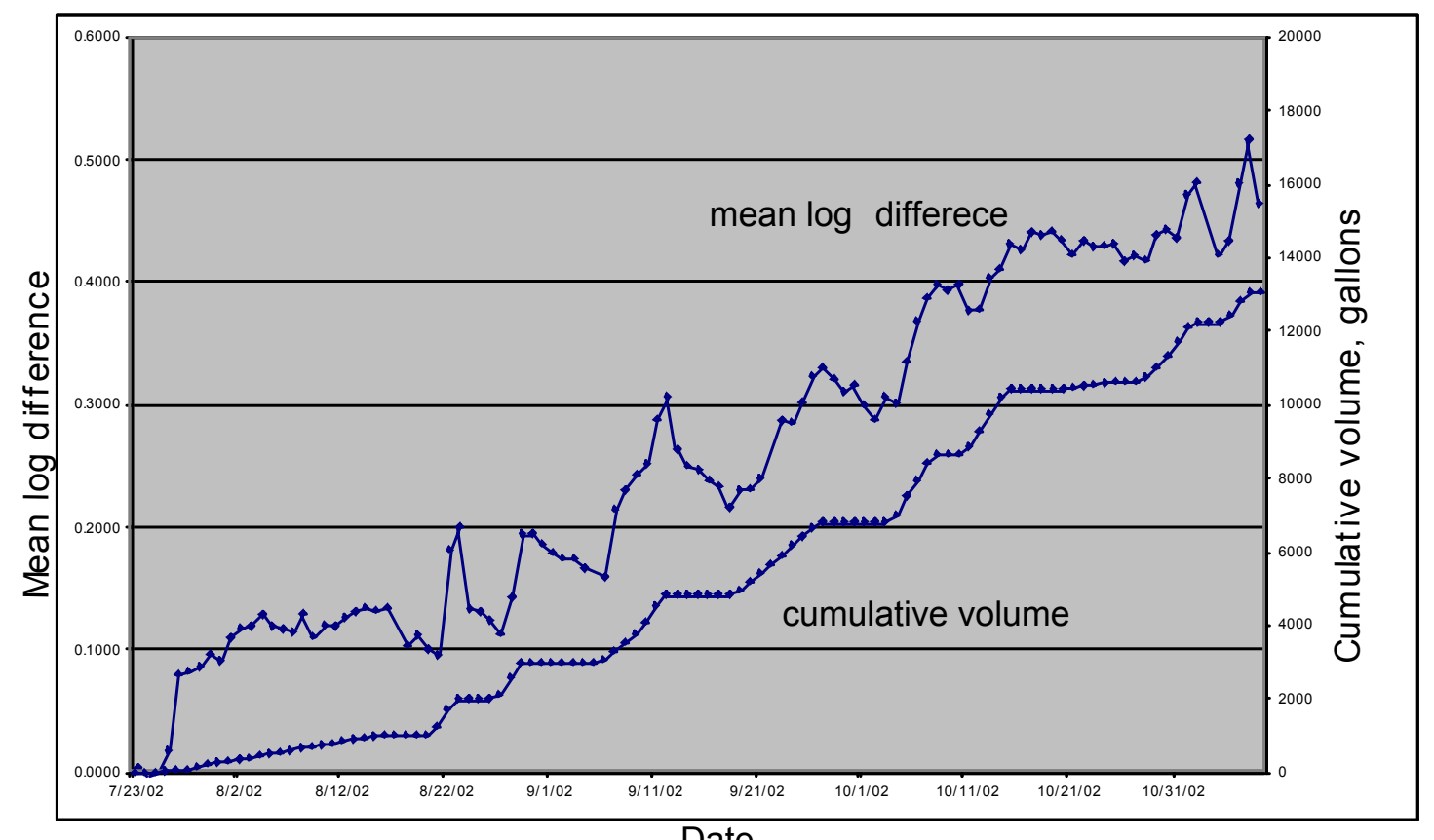

Figure 13. Comparison of apparent resistivity differences as measured using the point electrodes for each of the $\mathbf{1 1 0}$ days of the test (top) plotted with the actual release rates in gallons per hour (bottom). The apparent resistivity on day a is $\left.\mathbf{R}^{\mathrm{a}}=\sum_{\mathrm{l}=1}{ }^{\mathrm{n}}\left(\log \mathbf{t}_{\mathbf{j}}{ }^{\mathrm{a}}-\log \mathbf{t}_{\mathbf{j}}^{\mathrm{a}-1}\right)\right) / \mathbf{n}$ where $\mathbf{t}_{\mathbf{j}}^{\mathrm{a}}$ is the $\mathbf{j}^{\text {th }}$ transfer resistance on day a.

When this algorithm is used with the point electrode data, the number of days of correctly identified test status is dramatically increased. During the test, using the original method, 60 leak declarations were made. Using this new algorithm 86 leak conditions are correct. On the other hand, only 1 false alarm was declared during the test and this new method yields 11 false alarms; incorrect no-leak conditions. In addition, during the test 44 incorrect declarations were made whereas this method detects only 11 . Using this new approach the 86 successful declarations are 6.4 standard deviations from the mean so that there is a $99.9 \%$ probability of doing as good or better that random selection. However there are more false positives (false alarms) than in the blind test. 
During the test we concluded that the mean apparent resistivities calculated from the long electrode data were of little value in identifying a leak or no-leak condition. However, the same analysis described above for the point electrode data can be done with the mean log difference of long electrode data and the releases are clearly evident there also. Taking all available data this method produces 62 days of correct declarations and 38 days of incorrect declarations. The correct prediction is expected to occur $99 \%$ of the time.

Clearly, the connection between the sheet pile and mock tank affect the long electrode data more than it did the point electrode data (compare figures 4 and 5). Since changing this part of the test configuration would not be part of tank farm operation, it is reasonable to repeat the above analysis after removing data affected by the disconnection of the sheet pile near the end of the test. For this case, there are 62 days of correct and 32 days of incorrect leak conditions. Random choices are likely to produce this result or better only $0.25 \%$ of the time.

\section{Leak volume estimates}

Calculations of leak volume during the test give little more than very rough estimates that are not very useful. However, let us consider these calculated volumes for each day of the test using a single baseline at the beginning of the test. Figure 14 shows the volume for each day of the test calculated using a baseline of July 22 . The model parameters were adjusted so that the calculated cumulative volume correlated well with the actual cumulative volume. Although the correlation was not formally maximized, the model parameters were adjusted within the range of expected values (we actually used $\mathrm{n}=2.0, \mathrm{~S}_{0}=0.1, \phi=0.4$ and $\rho_{\mathrm{w}} / \rho_{\mathrm{w}, 0}=1.06$ ) to produce a good agreement. Close examination of Figure 14 shows that the calculations are qualitatively consistent with the actual released volumes and with our conceptual model for the hydraulic behavior of the system.

The test history is a series of releases separated by several days of no release. Typically at the beginning of each release, the calculated volume begins to increase not usually the first day but rather on the second day (this is just a problem with the date alignment again). The calculated volume continues to increase throughout the release period but at the end of the release, the volume begins to decline. The decline continues until the next release begins. This cycle is repeated with surprising fidelity throughout most of the test.

The rise in calculated volume during the release is consistent with an expected increase in pore volume brine. When the release ends, brine drains out of the system faster than being added so the calculated volume decreases as expected. Drainage continues and the calculated volume decreases until the next release adds brine to the system faster than drainage depletes it and the volume calculates begin another increase. This is the cycle that is repeated throughout the test. We believe that this qualitative behavior could be used as a diagnostic in any future applications to indicate the onset and duration of a leak event. 


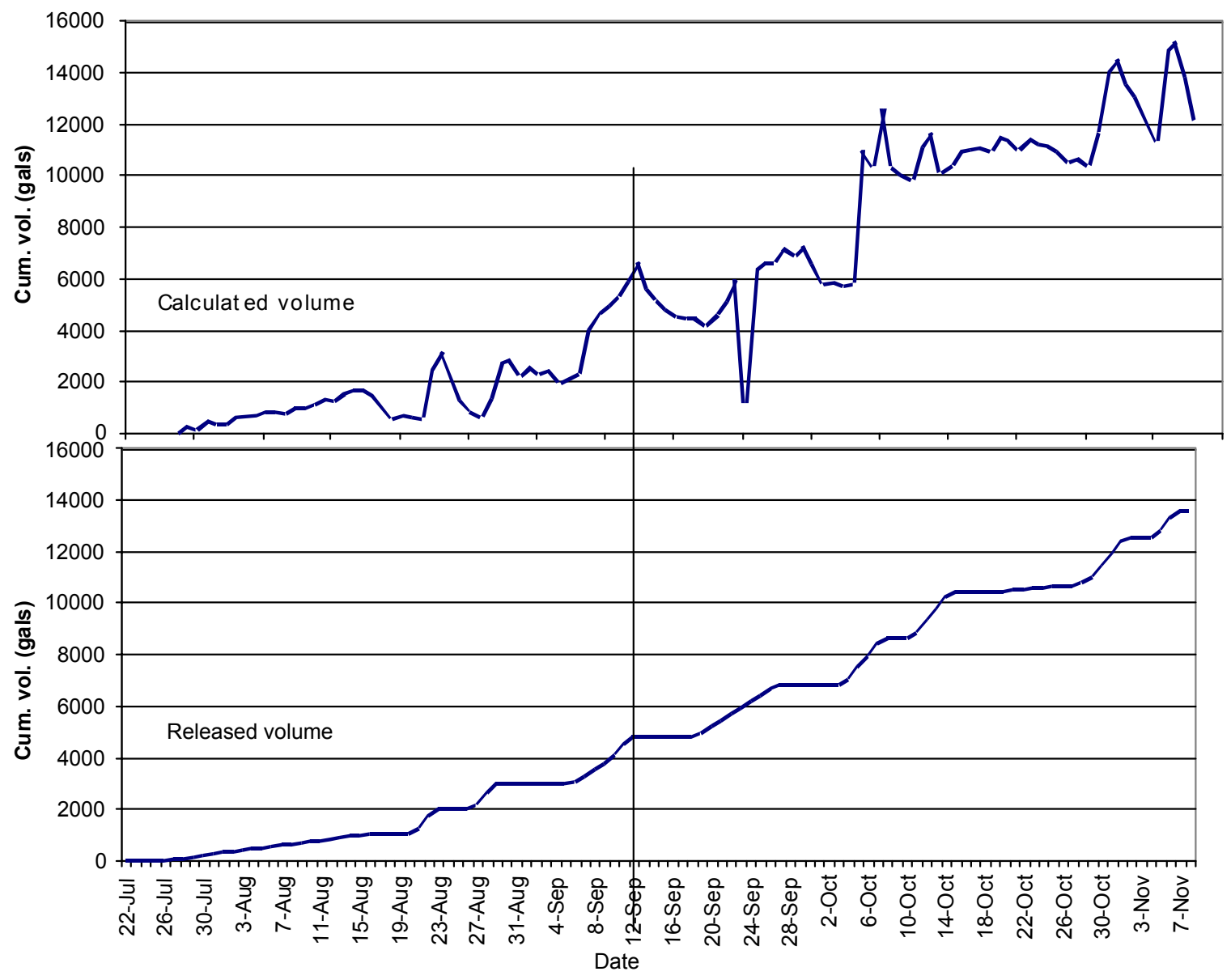

Figure 14. The release volume calculated from equation (6) and using July 22 as a baseline is compared with the actual cumulative release volume.

After the test we might use the known released volumes to calibrate our model - that is, to determine a set of hydraulic parameters that are consistent with the actual release data. Then future use of the method, if carried out with a similar test protocol and with similar geologic conditions, may result in much more reliable volume calculations. Figure 14 demonstrates how this might work. The volume for each day of the test is calculated with the baseline of July 22 . The model parameters are adjusted so that the results correlate well with the actual released volume as in Figure 14. Then these model parameters are used in future calculations of volume when the actual volumes are unknown.

We point out that this method of 'calibration' is heuristic. We cannot use it to determine the actual values of the hydraulic parameters or to determine the veracity of the model. There are many models with four parameters could be made to approximate the volume release data. However, this calibration should still be useful, with similar geologic and experimental conditions, for obtaining reasonable estimates of release volume in a tank farm.

\section{Leak location}

Using the ERT image of the conducting plume it is sometimes possible to determine the approximate location of the leak as well as information about the formation and movement of the 
released water. Figure 15 shows ERT images (similar to those in Figures 8-12) of the daily changes in resistivity selected to represent leak events throughout the test. They are oriented to viewed the plume from the top with the tank removed but showing its footprint and leak locations. Each reconstruction is represented using a different color scale, chosen in each case to show just the core of the plume - the most conductive central part.

The first six examples (through 5 October) each show a compact plumes that is clearly associated with the location of the release point. For these examples, choosing the center of the plume image adjacent to the tank bottom would yield a leak location within about $4 \mathrm{~m}$ of the actual location. Such accuracy certainly does not estimate the location well enough that might be useful for a repair. However, this accuracy might be useful for guiding in-tank retrieval efforts so as to minimize leakage during tank remediation.
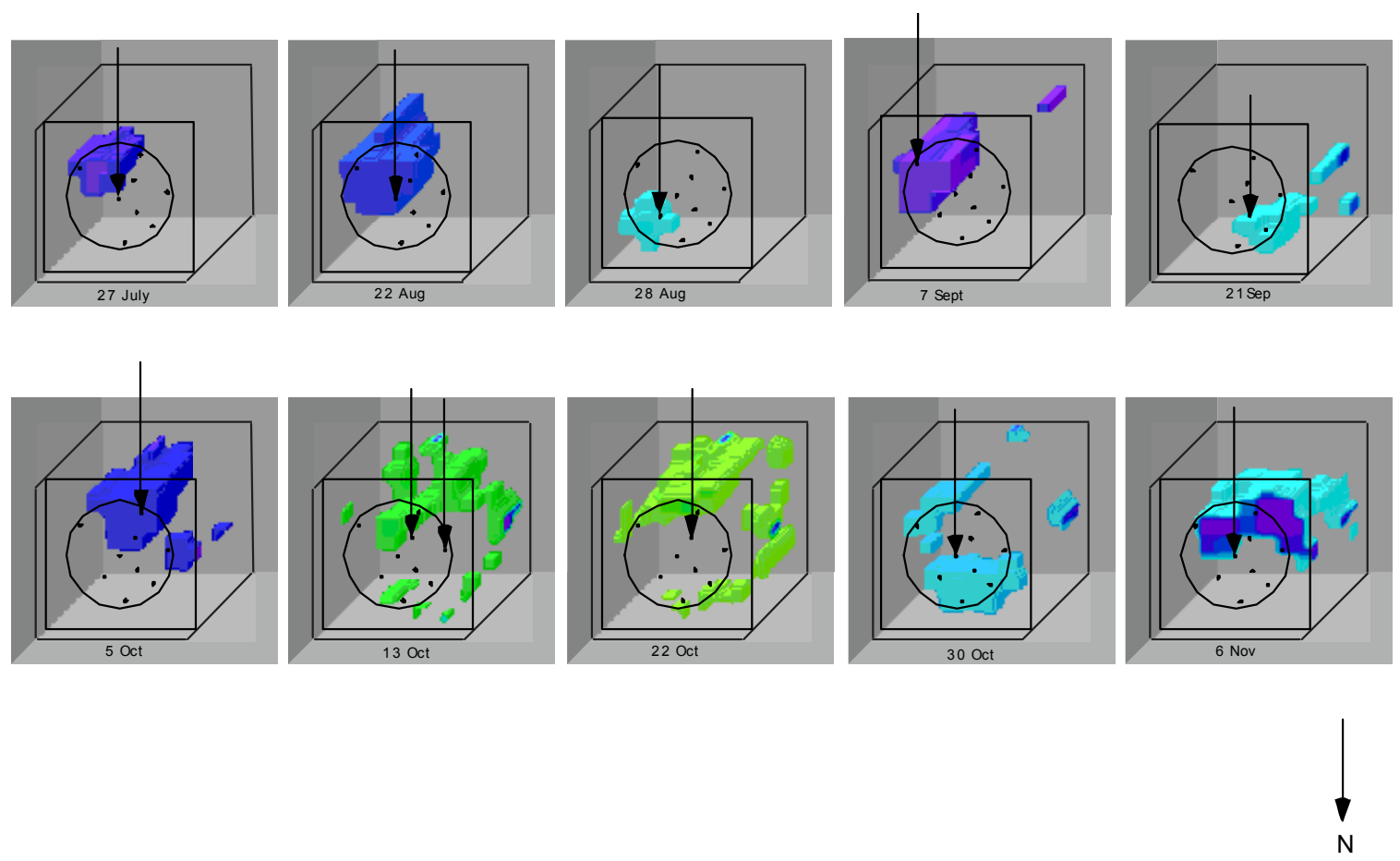

Figure 15. ERT images in plan view of changes in resistivity at ten selected days from the test. The color scales vary but are unimportant as the purpose is to define the center of each plume at the tank-soil boundary for comparison to the leak location which is denoted by the arrow pointing to a leak point. Two release points were used on 13 Oct since L13 (the one closest to the edge) would accept only a very slow flow rate.

The last four examples (13 October through 6 November) show a clearly different characteristic form for the plume image. No single leak point is suggested from these data. However, these results do suggest a different response of the system later in the test and we believe this likely results from changes in the subsurface due to the 10,000 gallons of brine had already been released. Approximately 6500 gallons of this 10,000 gallons of injectate was release near the center of the tank and these last four examples are all for leaks near the center. There are several 
possible explanations for the different character in these last four examples. One possibility is that much of that early injected remained in the formation near the center of the tank, held in the sands by capillarity. If 6500 gallons of injectate were held by capillarity in a volume 20 feet in diameter and 30 feet deep around the center of the tank, the drained porosity would change from 0.1 (typical value for undisturbed sands at the site) to about 0.2 (typical maximum for welldrained soil at the site). The additional saturation might then reduce the relative permeability to liquid, forcing injectate later in the test to move along paths that are preferentially around the central region.

Another possibility is that the central porosity was plugged by precipitate from early releases. Precipitation is reasonable because during the summer months the injectate will cool as it enters the formation, forcing some precipitation from the super saturated solution. Analysis of a few soil samples from beneath the tank would be of help. Of course, there are other possible explanations for the different response suggested by the last four images but more data are required before we could select any one of them as most likely correct.

\section{Summary and Conclusions}

\section{Analysis during the test}

1. Remote operation of the data acquisition system was highly successful. It saved time and money. We estimate approximately $\$ 63 \mathrm{~K}$ savings in travel and salary costs during this experiment. The remote acquisition system was also very convenient, allowing the investigators to acquire and process data from almost any convenient location during weekdays, weekends and holidays (see Figure 3).. During more than 110 days of operation there was no lost data from computer networking problems and only 4 days of lost data from equipment battery failures. If there is utility power at a site, there is no practical limit to the time which this remote system could operate unattended. We believe that the remotely operated system proved itself as the key to future long term ERT monitoring and will be the only way that electrical methods should be used at the Tank Farms for leak detection purposes.

2. The ERT method using the point electrode 3D images and mean apparent resistivity was successful in detecting leaks during the test. The probability of doing as good or better than ERT at declaring a leak condition using random guessing is $7.2 \%$. The tendency was, however, to detect the early part of the release and not the latter part. This we believe is a result of the early establishment of a stable preferential flow path which would tend to disappear in comparisons of images from consecutive days.

3. Because we did not have accurate values for the hydraulic properties of the soil, the release volume estimates calculated from the point electrode images yielded volumes that were consistently large compared to the actual released volumes.

4. The long electrode data were not very helpful during the test in detecting leaks and were not useful for estimating released volume.

5. We saw no evidence of natural or man made rain events in either the long or point electrode data. 
Analysis after the test

After the test ended and time allowed for additional data analysis, much was learned about the utility of the data for detecting leaks and estimating release volumes. It was even necessary to change some of the conclusions that were formed during the test.

1. The point electrode mean log differences were very successful in detecting leaks without any subjective expert evaluation of the data as was used with the mean apparent resistivity method used during the test. This new method did not require examination of the 3D images but only used a comparison of a single number statistic for a given day and the average of that statistic from the previous 3 days. The results are 6.4 standard deviations better than a normal distribution. The false alarm rate was higher but could be reduced by including an examination of the daily difference 3D ERT images.

2. The long electrode mean log differences were also successful in detecting leaks, again without any subjective expert evaluation. This method did not require examination of the 2D ERT images but only used a comparison of a single number statistic for a given day and the average of that statistic from the previous 3 days. The results are 2.4 standard deviations from the mean so that the probability of doing as good or better using random guessing is $0.82 \%$. The significance of this result is that it suggests an accurate and inexpensive method for use in a tank farm. Using the dry wells around a tank as long electrodes obviates the need for intrusive and expensive point electrode installation.

3. Using the actual released volumes, we calibrated the calculated volume estimates by choosing a set of model parameters that was consistent with the release data. The calculated total cumulative volumes are in reasonable agreement with actual cumulative volumes and are even consistent with the release history, but day to day variations are often missed and have significant uncertainty. This heuristic approach does not verify the model or the parameters but should be useful for obtaining reasonable volume estimates from actual tank farm data if used in the same geologic environment and under the same experimental conditions.

4. Using the ERT image of the conducting plume obtained by point electrode methods is sometimes possible to determine the approximate location of the leak as well as information about plume formation and movement of the released water.

5. Examination of the 3D ERT images provides evidence for a conceptual flow model for the released brine. This model is for flow primarily through a preferred channel (or channels) which is stable for periods of several days and which partially drains when the source is cut off. 


\begin{abstract}
Attachment A
Our conceptual model for the hydraulics of the brine injectate is mentioned several places. We believe that as the brine is released it moves rapidly to form a preferential path or channel. Rapidly means that for even the slow release rates of 2 gph a distinctive path is established on the ERT images within 24 hours. Even at this early stage the conductive anomaly in the reconstructions can be well defined and compact (especially noticeable in the first half of the test). Once established, the channel is stable even though water continues to flow through it and out of the image volume. Evidence for this is clearly seen in event B where the ERT image of the channel appears as it is being established but then disappears from the daily differences (see figures 8 and 9). It would not disappear if it wandered around the image block. In fact, it reappears during that leak event only once, on 5 August, and then disappears again. Once the brine source is terminated, the channel drains. However, drainage is not complete so that the channel remains more conductive than before the release.
\end{abstract}

A summary of ERT evidence for this model is shown in Figure A1 which focuses on the first release, event B. The first ERT image shows the changes during the first day of the releaseformation of the channel. The width is exaggerated by the smoothing parameter $\mathbf{W}_{\mathrm{m}}$ in equation (3) but this is the image of the approximately vertical channel through the image block originating from L1 on the tank bottom. Figures 8 and 9 show subsequent daily differences and this channel is absent because the resistivity is not changing. Although brine continues to flow through the channel, the brine has already reached a steady state saturation and the channel resistivity remains mostly constant (notice that the color scale is slightly different for figure A1 than for figure 8 and 9).

The center ERT image in Figure A1 shows the change in resistivity at the end of event Bdraining of the channel. (Notice that the difference spans 2 days because of the data gap on 17 Aug.) The channel has actually become more resistive relative to the condition when brine was flowing through it. However, the channel resistivity has not returned to pre-event B values. The rightmost image in Figure B1 is a comparison of resistivity distribution before the leak began to after it ended. Clearly, the channel remains more conductive than before the release because not all of the brine has drained away. 


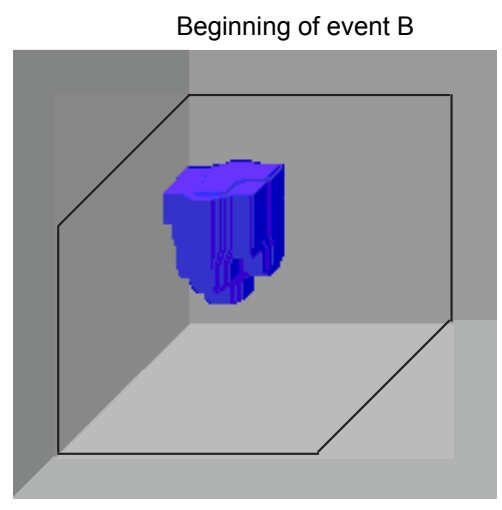

0727_0726
End of event B

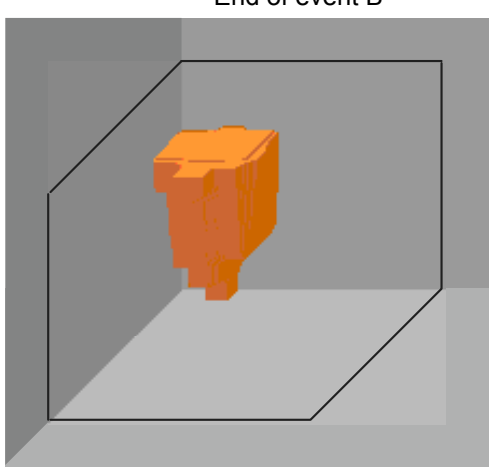

0818_0816
All of event B

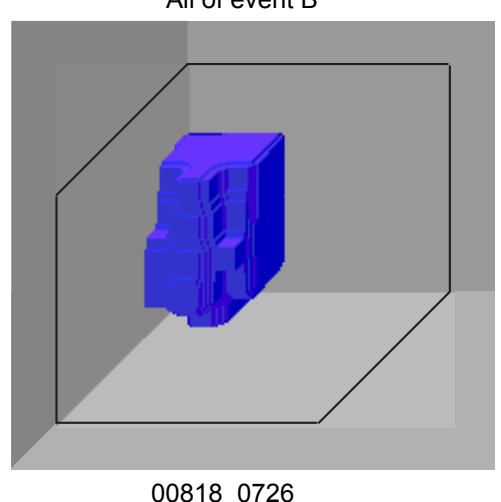

Resistivity change, percent

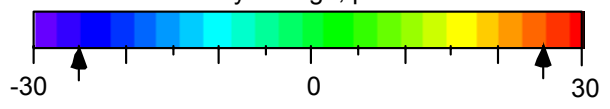

Figure A.1. Percent change in resistivity distribution for event B. Below each image are the dates (month and day) of the 'after' minus the 'before' difference used. In the left and the right image all volxels greater than $-\mathbf{2 5 \%}$ are rendered transparent. In the center image all voxels less than $+25 \%$ are rendered transparent. The north side of the mock tank is facing forward. 


\section{Acknowledgements}

The authors wish to acknowledge the assistance of Brent Barnett, Mike Johnson, Glendon Gee, Mark Sweeney, Pacific Northwest National Laboratory; Wes Bratton, Vista Engineering; Dan Beatty, CH2MHILL Hanford Group Inc.; Fred Reich, Cogema Inc.; Pete Gibbons, Numatec Hanford Corp. for their help and support during the long field test, its preparation and its conclusion. Bill Hanley from Lawrence Livermore National Laboratory made helpful suggestions on data analysis. Jim Fink and Mark Levitt, Hydrogeophysics Inc. were very helpful during the field test.

This work was supported by the Department of Energy, Office of River Protection, and Fred Reich program manager. This work was performed under the auspices of the U.S. Department of Energy by University of California Lawrence Livermore National Laboratory under contract No. W-7405-Eng-48.

\section{References}

Binley, A., W. Daily and A. Ramirez, 1997, Detecting Leaks from Environmental Barriers using Electrical Current Imaging, J. Env. and Eng. Geophysics, 2.(1), p11-19.

Hoel, P. G., 1997, Elementary statistics, John Wiley and Sons, New York.

IAEA. 1970. Neutron Moisture Gauges. Tech. Rept Ser. 112. International Atomic Energy Agency, Vienna, Austria.

Isaacson, R. E. 1982. Supporting Information for the Scientific Basis for Establishing Dry-Well Monitoring Frequencies. RHO-RE-EV-4, Rockwell Hanford Operations, Richland, Washington.

Keller, G. V. ad F. C. Frischknecht, 1966, Electrical methods in geophysics, Electromagnetic Waves, vol., 10, eds: A. L. Cullen, V. A. Fock and J. R. Wait, Pergamon Press, Oxford.

LaBrecque, D. J., Morelli, G., Ramirez, A., Daily, W., and Lundegard, P., 1995, Occam's inversion of 3D ERT data: Proceedings of the International Symposium on Three-Dimensional Electromagnetics 1995, Ridgefield, CT, 471 - 477.

Ramirez, A., W. Daily, A. Binley, D. LaBrecque and D. Roelant, 1996, Detection of leaks in underground storage tanks using electrical resistance methods, J. Environ. and Eng. Geophs., Vol. 1, 189-203.

Reidel, S. P., K. A. Lindsey and K. R. Fecht, 1992, Field trip guide to the Hanford Site, WHCMR-0391, Westinghouse Hanford Corp., Richland, WA. 
PNNL-14192

\section{Distribution}

No. of

Copies

OFFSITE

3 Vista Engineering Technologies

8203 W. Quinault

Kennewick, WA 99336

Attn: J. W. Maresca

W. C. Dickerson

W. L. Bratton

3 HydroGEOPHYSICS, Inc. 2302 N. Forbes Blvd.

Tucson, AZ 85745

Attn: Dr. J. B. Fink

M. T. Levitt

C. Baldyga

2 Lawrence Livermore National Laboratory

L-130

Livermore, CA 94550

Attn: Dr. A. Ramirez

Dr. W. D. Daily

1 Lancaster University, UK

Dr. A. Binley

c/o W. D. Daily

L-130

Livermore, CA 94550
No. of

Copies

\section{ONSITE}

14 CH2M Hill Hanford Group

R. M. Boger S7-12

J. W. Cammann H6-22

R. D. Wojtasek R2-39

J. G. Kristofzski R2-58

W. T. Thompson $\quad$ S7-90

A. J. Knepp E6-35

V.J. Rohay E6-35

F.M. Mann E6-35

D.A. Myers E6-35

D. W. Crass $\quad$ S7-90

B. E. Brendel S7-90

K. E. Carpenter $\quad$ S7-90

D. G. Baide $\quad$ S7-90

C. D. Wittreich H9-03

2 Cogema

F. R. Reich (2) S7-12

2 U.S. Department of Energy-Office of River Protection

R. M. Yasek H6-60

R.W. Lober H6-60

$5 \quad$ U.S. Department of Energy-Richland

Operations

B. L. Foley

A6-38

R. D. Hildebrand

A5-13

K. A. Kapsi

A5-13

J. G. Morse

A6-38

K. M. Thompson

A6-38

Distr. 1 


\section{Distribution (contd)}

No. of

Copies

ONSITE

5 Numatec

P. W. Gibbons (5)

7 Fluor Hanford, Inc.

M. Byrnes

E6-35

R. J. Fabre

B. H. Ford

R. Jackson

R. Khaleel

R. T. Wilde

T. W. Fogwell

5 Washington Department of Ecology

R. W. Bond

J. Caggiano

D. Goswami

A. Huckaby

N. H. Uziemblo
No. of

Copies

\section{ONSITE}

53 Pacific Northwest National Laboratory

D. B. Barnett (15) K6-81

W. F. Bonner K9-14

J. W. Brothers K7-15

J. G. Bush K6-96-

R. E. Clayton P8-37

D. D. Dauble K6-84

M. J. Fayer K9-33

M. D. Freshley K9-33

G. W. Gee (10) K9-33

M. D. Johnson K6-96

J. M. Keller K9-33

W. J. Martin K6-81

V.F. Medina K6-96

D.P. Mendoza K6-81

P. D. Meyer K9-33

M. L. Rockhold K9-33

P. D. Meyer K9-33

M. L. Rockhold K9-33

S. M. Narbutovskih K6-96

C,E, Strickland K9-33

M. D. Sweeney (5) K6-81

A. L. Ward K9-33

S. B. Yabusaki K9-33

Z. F. Zhang K9-33

Technical Report Files (2)

Distr. 2 